\title{
APORTACIONES A LA GESTIÓN DE LOS SISTEMAS DE MEDICIÓN DE CAUDAL EN REDES DE DISTRIBUCIÓN DE AGUA A PRESIÓN
}

Carmen Virginia Palau Estevan 


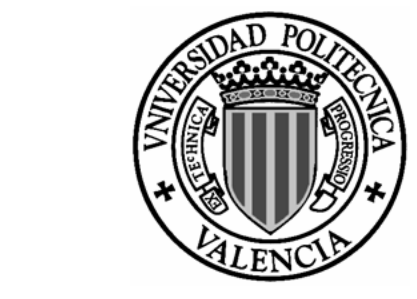

UNIVERSIDAD POUTÉC NICA

DE VALENCIA

DEPARTAMENTO DE INGENIERÍA HIDRÁULICA

Y MEDIO AMBIENTE

\section{Aportaciones a la gestión de los sistemas de medición de caudal en redes de distribución de agua a presión}

\section{TESIS DOCTORAL}

Presentada por:

Carmen Virginia Palau Estevan

DIRECTOR DE TESIS

Dr. Francisco Arregui de la Cruz

Valencia, Abril 2005 


\section{Esta editorial es miembro de la UNE, lo que garantiza la difusión y comercialización de sus publicaciones a nivel

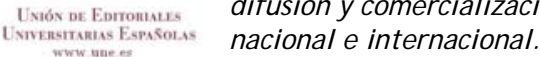

(c) Carmen Virginia Palau Estevan, 2011

Primera edición, 2011

(c) de la presente edición:

Editorial Universitat Politècnica de València

www.editorial.upv.es

ISBN: $-978-84-694-9718-0$

Ref. editorial: 5509

Queda prohibida la reproducción, distribución, comercialización, transformación, y en general, cualquier otra forma de explotación, por cualquier procedimiento, de todo o parte de los contenidos de esta obra sin autorización expresa y por escrito de sus autores. 


\section{RESUMEN}

Uno de los puntos esenciales en una gestión del agua adecuada corresponde a la medición de los caudales circulantes por las tuberías y los consumos de los usuarios. Solamente, a partir de estas mediciones es posible evaluar la calidad y cantidad disponible y utilizada de este recurso y trazar las diferentes estrategias de mejora en una red de distribución de agua.

La Tesis doctoral presentada pretende aportar diversas experiencias y técnicas que permitan optimizar y profundizar en el conocimiento que se tiene del funcionamiento de los sistemas de medición utilizados en los abastecimientos de agua, tanto urbana como agrícola. El motivo no es otro que mostrar que una correcta medición del caudal y de los consumos de los usuarios puede mejorar significativamente la gestión técnica de los abastecimientos de agua y reducir las pérdidas en la red. Un buen control desde las tomas de agua hasta los puntos finales de consumo depende de las mediciones que se lleven a cabo en la red.

Durante el desarrollo de la Tesis se ha comprobado que uno de los problemas más graves en los sistemas de medición es la incorrecta instalación de los aparatos. Otra fuente de error es la derivada de una inadecuada selección del instrumento, tanto en cuanto al tipo de tecnología como a su calibre, dimensionado. Por último, se ha advertido que las empresas gestoras ignoran frecuentemente el mantenimiento en estos sistemas, recurriendo únicamente a la sustitución de los medidores cuando la obsolescencia de los aparatos resulta obvia y en aquellos casos en los que dejan de funcionar de manera definitiva.

Las empresas, en ocasiones, infravaloran las ventajas que supone tener unos datos fiables de caudal o de consumo y admiten posibles errores en los mismos aduciendo el bajo coste del agua. Mejorar el control de la red comienza por medir con cierto grado de fiabilidad los caudales inyectados mediante un seguimiento de los instrumentos en los puntos de inyección. Posteriormente, un buen control del sistema de medición permitirá discriminar de forma acertada entre pérdidas en la red y los volúmenes incontrolados debido a errores de medición.

En este contexto, la presente Tesis doctoral aporta diversas experiencias encaminadas a ampliar el conocimiento de las diferentes tecnologías de medición de caudal en conductos cerrados, tanto en abastecimientos urbanos como en redes agrícolas, así como técnicas que permitan mejorar la utilización de estos sistemas, minimizando el efecto de las fuentes de error mencionadas.

Inicialmente, se realiza una breve revisión de los principios de funcionamiento de los principales instrumentos de medida de caudal y contadores de agua utilizados en los sistemas de distribución y de las diferentes fuentes de error que pueden influir en la medición del caudal o de los consumos de agua, con el objetivo de saber de qué forma se puede reducir la magnitud de los errores cometidos.

Tras la descripción de cada uno de los aparatos y de los conceptos previos relativos a la medida de caudal, se presenta un detallado estudio en laboratorio del comportamiento de diversos tipos de contadores de agua (pequeño y gran calibre) frente a diversas variables En primer lugar se ha cuantificado la influencia de la posición de instalación (horizontal, vertical o inclinada) en la curva de error de los micromedidores, en su mayoría contadores de agua domésticos. Por otro lado se ha comprobado cómo el desgaste de los elementos mecánicos del contador altera el momento resistente de la turbina acusándose dicha variación principalmente en el rango inferior de caudales. Otro punto clave es la determinación de la evolución de la curva de error en el tiempo de los contadores de pequeño calibre en abastecimientos urbanos. Para ello, se han llevado a cabo multitud de ensayos de 
contadores de diferentes edades valorando así su deterioro en el tiempo y estimando entre otras cosas el error promedio de parque de contadores y su frecuencia de renovación óptima.

Respecto al estudio de los contadores de mediano y gran calibre, la presente Tesis propone un seguimiento individualizado de los mismos. Los parámetros que pueden afectar a las características de su curva de error son, fundamentalmente, la distorsión en el perfil de velocidades a la entrada del instrumento, el dimensionado inadecuado y la calidad del agua cuando pueda afectar, en el tiempo, a las características dimensionales de los aparatos.

Profundizando en el primer parámetro, se realizaron una serie de ensayos en laboratorio con diferentes elementos perturbadores del flujo de agua, cuantificando su incidencia sobre diversas tecnologías. Posteriormente, se ha desarrolla un método de análisis numérico, basado en técnicas de Computational Fluid Dynamics, que evalúa cualitativamente, sin necesidad de ensayos en laboratorio, cómo afectan a la curva de error estas distorsiones en el flujo. En particular se simula el funcionamiento de tres instrumentos, un contador Woltman de eje horizontal, que se compara con los resultados experimentales, un caudalímetro electromagnético y uno de ultrasonidos de tiempo de tránsito instalados a diferentes distancias aguas abajo del elemento perturbador. El procedimiento analítico presentado permite contrastar las recomendaciones facilitadas por los fabricantes sobre la necesidad de determinadas longitudes de tramos rectos para cada uno de los instrumentos analizados.

La segunda parte de la Tesis doctoral aborda aspectos que ayudan a mejorar la gestión global de estos sistemas. Entre las principales estrategias de mejora de los sistemas de medición, particularmente en abastecimientos urbanos, se encuentra el cálculo del error global de medición de un parque de contadores. De las diferentes metodologías propuestas anteriormente en la bibliografía se proponen ciertas mejoras que reducen la incertidumbre en la estimación de dicho error global. Conocer este error global de medición, por una parte, permite a la empresa gestora maximizar los ingresos obtenidos del consumo de agua y reducir los costes que supone mantener el sistema de medición funcionando. Por otra parte, estima el volumen de agua atribuido a subcontaje de los instrumentos durante el cálculo del rendimiento hidráulico de una red.

A su vez, se propone una guía práctica de diferentes estrategias que pueden aplicarse para gestionar correctamente los micromedidores y los macromedidodres de una red de distribución y aumentar tanto su eficacia como su eficiencia. Herramientas como el control estadístico de calidad a la recepción de contadores nuevos o el análisis de los costes que supone el uso de medidores de agua calculando su periodo óptimo de renovación permiten mejorar el control de los mismo optimizando su funcionamiento.

Finalmente, se reconoce la necesidad de convertir las mediciones en información verdaderamente útil y fácilmente interpretable para el control del agua. En este sentido, existen diferentes técnicas capaces de manejar estos datos y extraer conclusiones que ayuden en la toma de decisiones. Este trabajo presenta una técnica estadística novedosa en este campo, el análisis por componentes principales, que maneja las medidas de caudal de los macromedidores de control de sectores y redes llegadas a un telemando. La metodología estadística presentada crea modelos de funcionamiento habitual de la red que establecen márgenes de variabilidad y permiten detectar de forma rápida cualquier incidencia o perturbación producida en al red que no responda a las condiciones operativas normales del sistema. 


\section{RESUM}

Un dels punts essencials en una gestió de l'aigua adequada correspon al mesurament dels cabals circulants per les canonades i els consums dels usuaris. Només, a partir d'estos mesuraments és possibles avaluar la qualitat $\mathrm{i}$ quantitat disponible i utilitzada d' aquest recurs i traçar les diferents estratègies de millora en una xarxa de distribució d'aigua.

La Tesi doctoral presentada pretén aportar diverses experiències i tècniques que permeten optimitzar i aprofundir en el coneixement que es té del funcionament dels sistemes de mesurament utilitzat en els abastiments d'aigua, tant urbana com agrícola. El motiu no és un altre que mostrar que un correcte mesurament del cabal i dels consums dels usuaris pot millorar significativament la gestió tècnica dels abastiments d'aigua i reduir les pèrdues en la xarxa. Un bon control des de les preses d'aigua fins als punts finals de consum depèn dels mesuraments que es facin a terme en la xarxa.

Durant el desenvolupament de la Tesi s'ha comprovat que un dels problemes més greus en els sistemes de mesurament és la incorrecta instal.lació dels aparells. Una altra font d'error és la derivada d'una inadequada selecció de l'instrument, tant quant al tipus de tecnologia com al seu calibre. Finalment, s'ha advertit que les empreses gestores ignoren sovint el manteniment en estos sistemes, recorrent únicament a la substitució dels mesuradors quan l' obsolèscencia dels aparells resulta òbvia i en aquells casos en què deixen de funcionar de manera definitiva.

Les empreses, a vegades, infravaloren els avantatges que suposa tenir unes dades fiables de cabal o de consum $\mathrm{i}$ admeten possibles errors en els mateixos adduint el baix cost de l'aigua. Millorar el control de la xarxa comença per mesurar amb cert grau de fiabilitat els cabals injectats per mitjà d'un seguiment dels instruments en els punts d'injecció. Posteriorment, un bon control del sistema de mesurament permetrà discriminar de forma encertada entre pèrdues en la xarxa i els volums incontrolats a causa d'errors de mesurament.

En aquest context, la present Tesi doctoral aporta diverses experiències encaminades a ampliar el coneixement de les diferents tecnologies de mesurament de cabal en conductes tancats, tant en abastiments urbans com en xarxes agrícoles, així com tècniques que permeten millorar la utilització d'estos sistemes, minimitzant l'efecte de les fonts d'error mencionades.

Inicialment, es realitza una breu revisió dels principis de funcionament dels principals instruments de mesura de cabal i comptadors d'aigua utilitzats en els sistemes de distribució i de les diferents fonts d'error que poden influir en el mesurament del cabal o dels consums d'aigua, amb l'objectiu de saber de quina forma es pot reduir la magnitud dels errors comesos.

Després de la descripció de cada un dels aparells i dels conceptes previs relatius a la mesura de cabal, es presenta un detallat estudi en laboratori del comportament de diversos tipus de comptadors d'aigua (menuts i de gran calibre) enfront de diverses variables En primer lloc s'ha quantificat la influència de la posició d'instal.lació (horitzontal, vertical o inclinada) en la corba d'error dels micromesuradors, en la majoria comptadors d'aigua domèstics. Per un altre costat s'ha comprovat com el desgast dels elements mecànics del comptador altera el moment resistent de la turbina acusant-se la dita variació principalment en el rang inferior de cabals. Un altre punt clau és la determinació de l'evolució de la corba d'error en el temps dels comptadors de menor calibre en abastiments urbans. Per això, s'han dut a terme multitud d' assajos de comptadors de diferents edats valorant així el seu deteriorament en el temps i estimant, entre altres coses, l'error mitjana del parc de comptadors i la freqüència de renovació òptima. 
Respecte a l'estudi dels comptadors de mitjà i gran calibre, la present Tesi proposa un seguiment individualitzat dels mateixos. Els paràmetres que poden afectar les característiques de la corba d'error són, fonamentalment, la distorsió en el perfil de velocitats a l'entrada de l'instrument, el dimensionat inadequat i la qualitat de l'aigua quan puga afectar, en el temps, a les característiques dimensionals dels aparells.

Aprofundint en el primer paràmetre, es van realitzar una sèrie d'assajos en laboratori amb diferents elements pertorbadors del flux d'aigua, quantificant la incidència sobre diverses tecnologies. Posteriorment, s'ha desenvolupa un mètode d'anàlisi numèrica, basat en tècniques de Computational Flü̈u Dynamics, que avalua qualitativament, sense necessitat assajos en laboratori, com afecten la corba d'error estes distorsions en el flux. En particular se simula el funcionament de tres instruments, un comptador Woltman d'eix horitzontal, que es compara amb els resultats experimentals, un cabalímetre electromagnètic $i$ un d'ultrasons de temps de trànsit instal-lats a diferents distàncies aigües avall de l'element pertorbador. El procediment analític presentat permet contrastar les recomanacions facilitades pels fabricants sobre la necessitat determinades longituds de trams rectes per a cada un dels instruments analitzats.

La segona part de la Tesi doctoral aborda aspectes que ajuden a millorar la gestió global d'estos sistemes. Entre les principals estratègies de millora dels sistemes de mesurament, particularment en abastiments urbans, es troba el càlcul de l'error global de mesurament d'un parc de comptadors. De les diferents metodologies proposades anteriorment en la bibliografia es proposen certes millores que reduïxen la incertesa en l'estimació de tal error global. Conéixer este error global de mesurament, d'una banda, permet a l'empresa gestora maximitzar els ingressos obtinguts del consum d'aigua i reduir els costos que suposa mantindre el sistema de mesurament funcionant. D'altra banda, estima el volum d'aigua atribuït a subregistre dels instruments durant el càlcul del rendiment hidràulic d'una xarxa.

Al seu torn, es proposa una guia pràctica de diferents estratègies que poden aplicar-se per a gestionar correctament els micromesuradors i els macromesuradors d'una xarxa de distribució i augmentar tant la seua eficàcia com la seua eficiència. Ferramentes com el control estadístic de qualitat a la recepció de comptadors nous o l'anàlisi dels costos que suposa l'ús de mesuradors d'aigua calculant el seu període òptim de renovació permeten millorar el control dels mateix optimitzant el seu funcionament.

Finalment, es reconeix la necessitat convertir els mesuraments en informació verdaderament útil $\mathrm{i}$ fàcilment interpretable per al control de l'aigua. En este sentit, hi ha diferents tècniques capaces de manejar estes dades $\mathrm{i}$ extraure conclusions que ajuden en la presa de decisions. Este treball presenta una tècnica estadística nova en este camp, l'anàlisi per components principals, que es maneja les mesures de cabal dels macromesuradors de control de sectors i xarxes arribades a un telecomandament. La metodologia estadística presentada crega models de funcionament habitual de la xarxa que establixen marges de variabilitat i permeten detectar de forma ràpida qualsevol incidència o pertorbació produïda en al xarxa que no responga a les condicions operatives normals del sistema. 


\section{SUMMARY}

An adequate water management requires an accurate measurement of water flows and consumptions. Only this information makes possible the analysis of the available quality and quantity of the water sources and allows the outlining of different strategies designed to improve the efficiency of the water distribution system.

This Thesis pretends to summarize different experiences and techniques that enhance the available knowledge related to the utilization of flow measurement devices and water meters. It has been demonstrated that an accurate flow and water consumption measurement can drastically reduce water losses and improve the technical management of the utility. The water control in the network, from the injection to the consumption points, strongly relies on the measurements performance.

One of the most common problems found in water systems is that the instrumentation is not installed and used properly and, consequently, the metrological performance of the meters considerably decreases. Another source of inaccuracies in the measurements is the inappropriate selection of the water meters and flowmeters. Some times the working principle and the size of the meter is not the most adequate given the specific conditions of the water network. Finally, it has been notice that some companies ignore the maintenance of the measuring systems. The meters are only replaced when they are completely obsolete or when a critical failure is detected.

Some utilities do not pay attention to the relevance of accurate information about injected flows and water consumptions and justify the obsolescence of their measurement systems with the low selling price of water. However, improving network efficiency starts, in first place, with an accurate and reliable measure of injected flows. Later, an adequate data processing will make possible to discriminate water losses, due to leaks in pipes, from uncontrolled water due to inaccuracies in the water meters.

This doctoral Thesis contributes with diverse experiences to extend the knowledge of various flow measuring technologies used in both urban and irrigation networks. It describes methods designed to enhance the performance of such instruments minimising the effect of the different sources of error that can appear during their utilisation.

In first place, a review of the working principles of most common flowmeters and water meters is presented which include a detailed description of possible sources of error. The aim is to identify, quantify and reduce when possible the effect of these variables on the metrological performance of the various instruments studied.

The research includes a detailed study in laboratory of the performance water meters, domestic and industrial size, under different working conditions. One of the parameters studied is the impact of the installation orientation on the accuracy curve of different commercial models and the wear of the mechanical parts, which mainly affects the accuracy at low flows. In any case, for any utility, the most important parameter is the accuracy rate of decay. In order to obtain typical values for the accuracy rate of decay of the accuracy curve of more than a thousand domestic meters, of different ages and cities, has been obtained in the laboratory. This information allows calculating the average accuracy of the water meters and the optimum replacement frequency.

Regarding the study of medium and bigger water meters, this Thesis proposes to follow-up individually each particular case. Mainly, the variables that influence the accuracy curve in this sort of instruments are velocity profiles distortions at the instrument entrance, incorrect instrument sizing and the effect of water quality over the time.

The first parameter has been analyzed in laboratory, quantifying the influence on several commercial meters of different flow distortion elements. Afterwards, a three-dimensional numerical simulation using computational fluid 
dynamics techniques (CFD) is used to qualitatively calculate the accuracy curve after the alteration of the velocity profile by upstream fittings. Particularly, the operating principle of three different instruments has been simulated, a Woltman water meter which is compared with experimental results, an electromagnetical flowmeter and transit-time ultrasonic flowmeter installed in different distances downstream the flow distorting element. The analytical procedure permits to verify the straight distances recommended by manufacturers in each case.

Second part this Thesis discuss some issues related with the management of water measurement systems. One of the main strategies to improve these systems, principally in an urban water supply, is to evaluate the weighted accuracy error of the whole water meter system. In this sense, there are several proposals in the bibliography. This work contributes to improve the methodology to estimate this parameter reducing uncertainty. Weighted accuracy error provides some important information to the water company to maximise incomes obtained from water consumption and reduce measurement systems costs. In the other hand, unmetered water volume can be estimated from this methodology.

As well, a practical guide of different strategies can be applied to manage correctly the measurement systems of a distribution network to increase their effectiveness and efficiency. Tools like the statistical quality control of new water meters or an economical analysis of the costs of water measurement to estimate the optimal renewal period, allows improving the control of operation.

Finally, convert the measurements in useful and easily information to control the whole water system is the aim of this matter. In this sense, there are several techniques able to handle these data and to draw conclusions that help in the decision making. For the first time in flow measurement, a new statistical technique is used, principal component analysis. This methodology creates models to simulate usual network behaviour. This model establishes variability margins that allow detecting incidences produced in the distribution network that does not respond to the normal operative conditions of the system. 


\section{Índice de la tesis}

1.INTRODUCCIÓN .............................................................................................................................................

1.1.JUSTIFICACOON DE LA TESIS .....................................................................................................................................

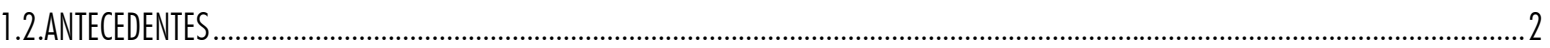

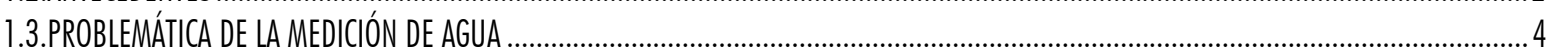

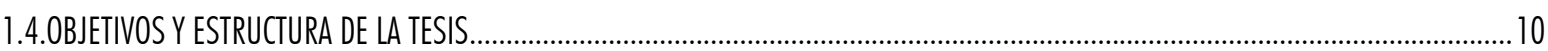

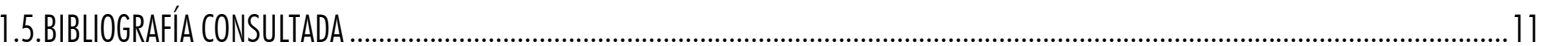

2.DESCRIPCIÓN DE LOS INSTRUMENTOS DE MEDIDA DE CAUDAL Y CONTADORES DE AGUA ........................... 13

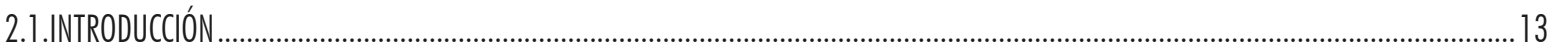

2.2. CONCEPTOS BÁSICOS SOBRE MEDICIÓN DE CAUDAL ................................................................................................... 14

2.2.1 . Comportamiento del flujo dentro de un conducto circular a presión .................................................................................... 14

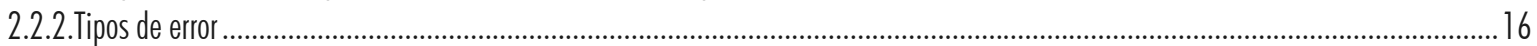

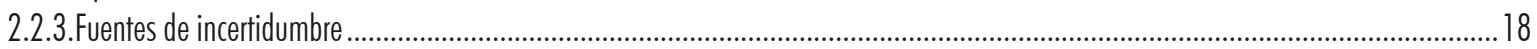

2.3.NORMATIVA RELATIVA A INSTRUMENTOS DE MEDIDA DE CAUDAL_...................................................................................21

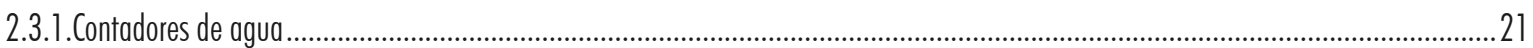

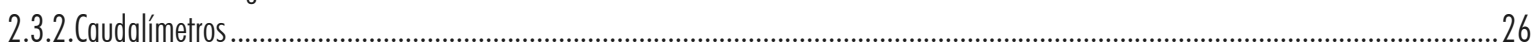

2.4.CLASIFICACIÓN DE LOS INSTRUMENTOS DE MEDIDA DE CAUDAL EN CONDUCTOS CERRADOS …………......................................2

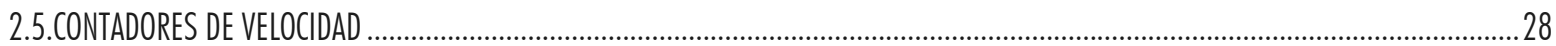

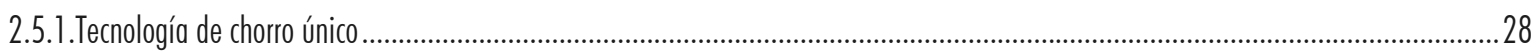

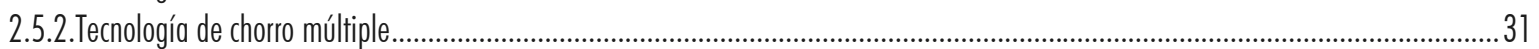

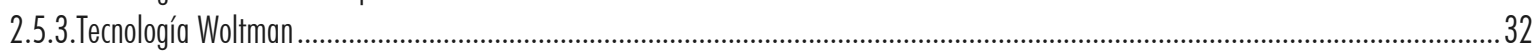

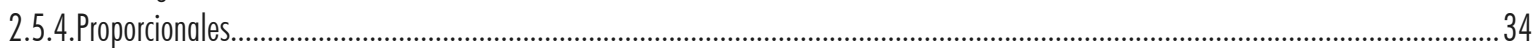

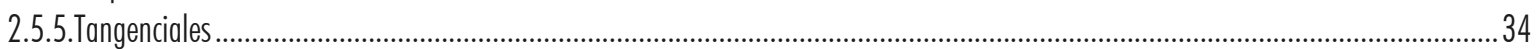

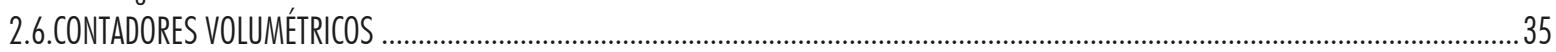

2.6.1.Tecnología de pistón rotativo ........................................................................................................................................3

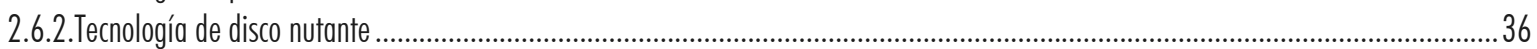

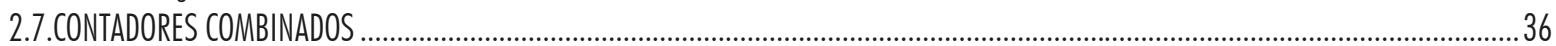

2.8.CAUDALÍMETROS DE PRESIÓN DIFERENCIAL ............................................................................................................. 37

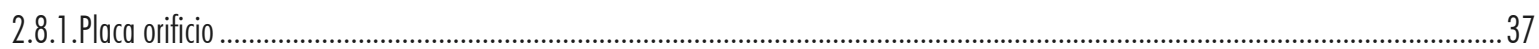

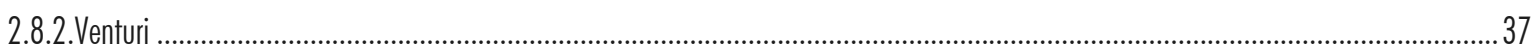

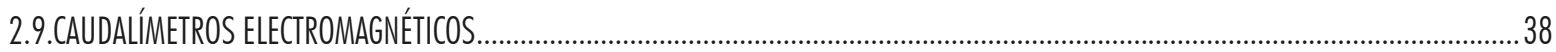

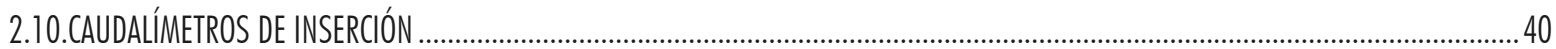

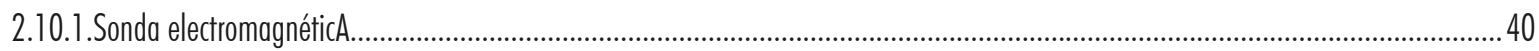

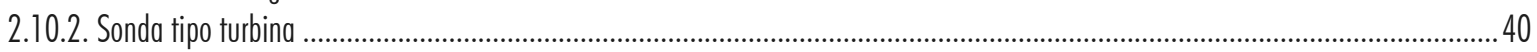

2.10.3.Métodos de medida de caudal con caudalímetros de inserción...................................................................................... 41

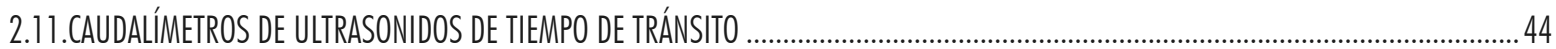

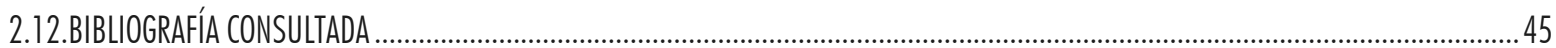




\section{ESTUDIO EN LABORATORIO DEL COMPORTAMIENTO METROLÓGICO DE CONTADORES DE AGUA} 47

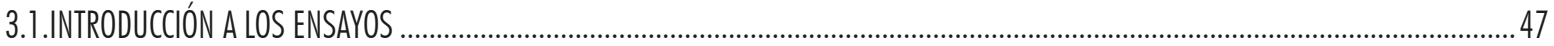

3.2.ENSAYOS DE ERROR A CONTADORES DE PEQUEÑNO CALIBRE DE USO DOMÉSTICO

3.2.1.Variables que afectan a la medición micromedidores .......................................................................................................... 49

3.2.2.Ensayos detallados de la curva de error de contadores de chorro único .............................................................................

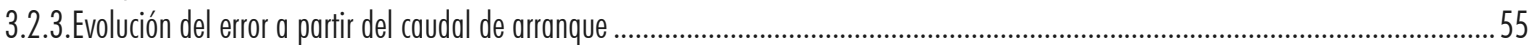

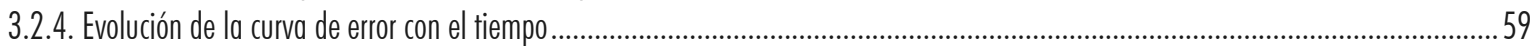

3.3.ENSAYOS DE LA CURVA DE ERROR A CONTADORES DE USO NO DOMÉSTICO

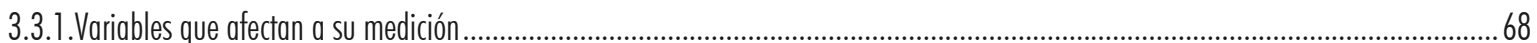

3.3.2.Ensayos de error a contadores nuevos de uso no doméstico .....................................................................................................

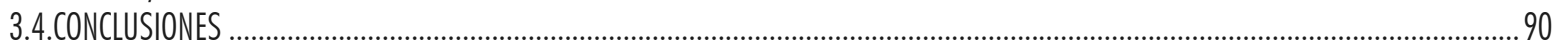

3.5.BIBLIOGRAFÍA CONSULTADA …………………………………………………………………………………………....

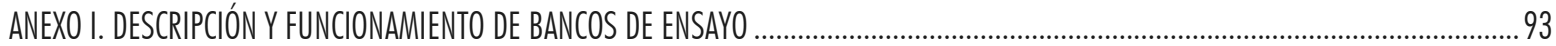

\section{INFLUENCIA DE LAS PERTURBACIONES DEL FLUJO EN LA MEDICIÓN DE AGUA...............................................97}

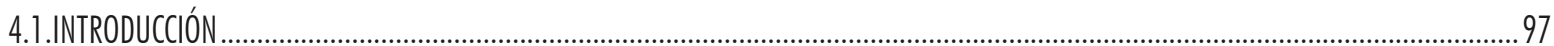

4.2.INFLUENCIA DE LAS DISTORSIONES DEL FLUJO EN LA MEDICIÓN DE CAUDAL ……............................................................98

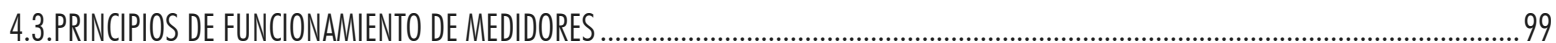

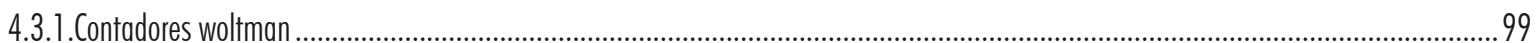

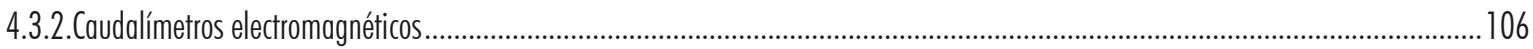

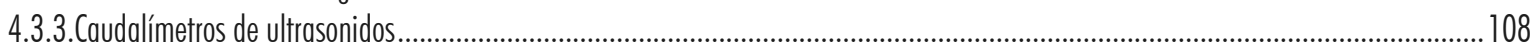

4.4.ANÁLISIS NUMÉRICO DEL COMPORTAMIENTO DEL FLUJO ……......................................................................110

4.5.ESTUDIO DE LA INFLUENCIA DE LAS DISTORSIONES EN EL PERFIL DE VELOCIDADES SOBRE CADA TECNOLOGÍA DE MEDICIÓN............... 120

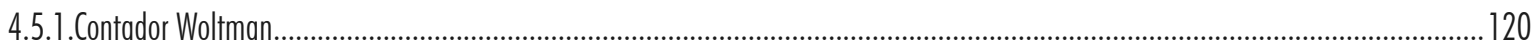

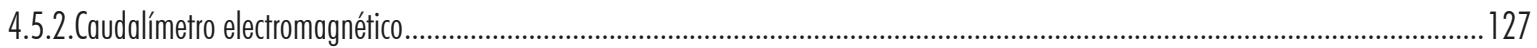

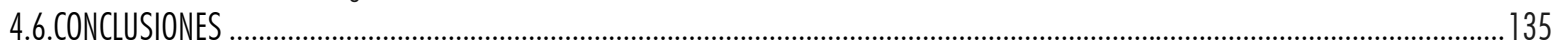

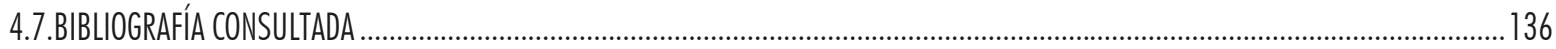

5.CÁLCULO DEL ERROR GLOBAL DE UN CONTADOR DE AGUA......................................................................... 139

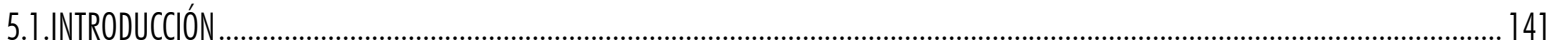

5.2.CURVA DE ERROR.

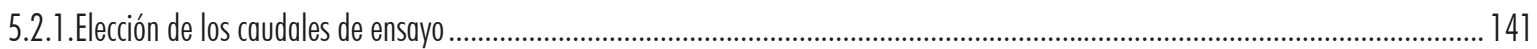

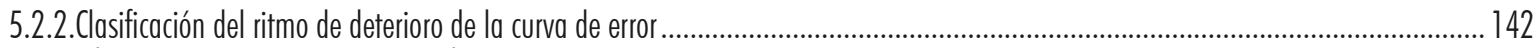

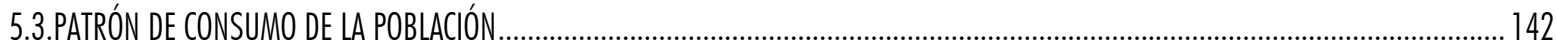

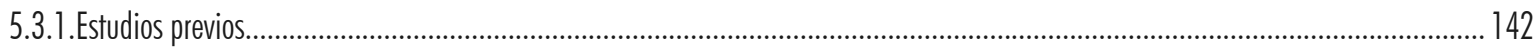

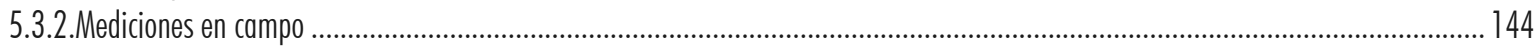

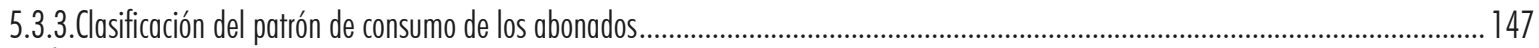

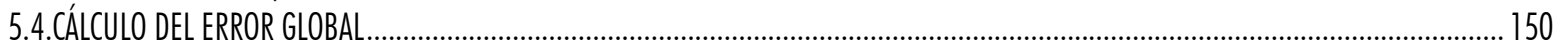

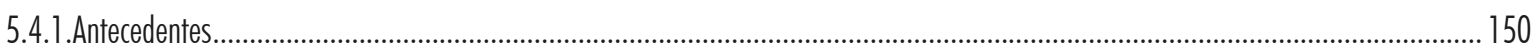

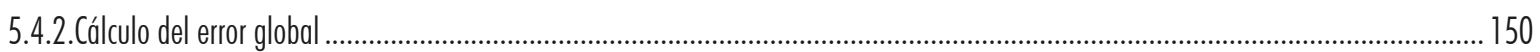

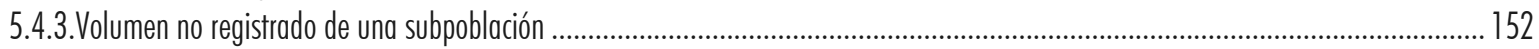

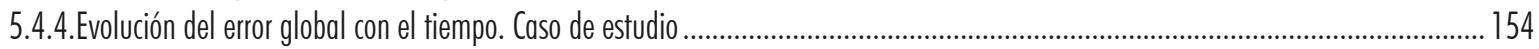

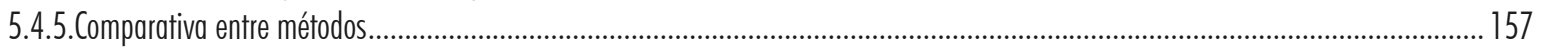

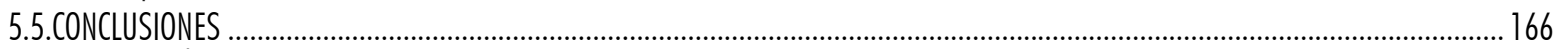

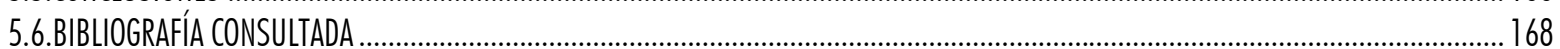




\section{GESTIÓN DE LOS SISTEMAS DE MEDICIÓN EN REDES HIDRÁULICAS A PRESIÓN} 171

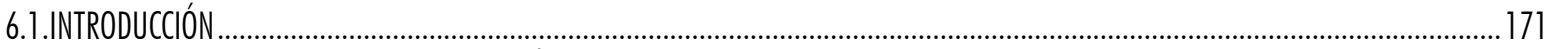

6.2.CONTROL DE CALIDAD DE CONTADORES DOMÉSTICOS _...................................................................................

6.2.1.Visión general y problemática ............................................................................................................................ 174

6.2.2. Consideraciones sobre la calidad de los instrumentos .............................................................................................. 175

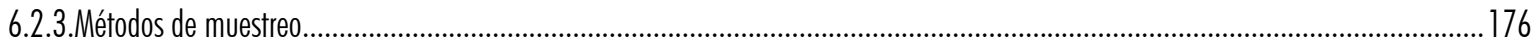

6.2.4.Mvestreo de Aceptación por variables..................................................................................................................... 177

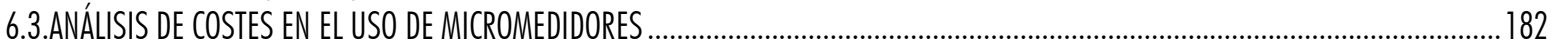

6.3.1.Formulación matemática del problema ......................................................................................................... 182

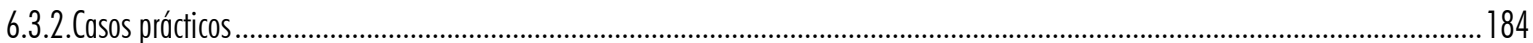

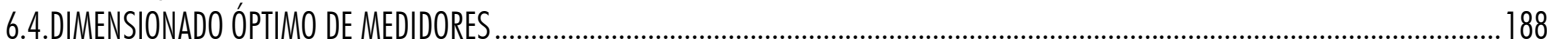

6.4.1.Problemática del dimensionado ................................................................................................................... 188

6.4.2.Métodos y consideraciones sobre el dimensionado de medidores.................................................................................190

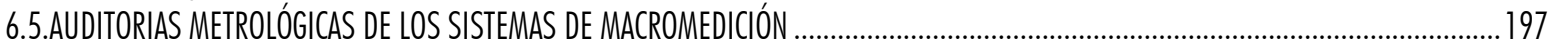

6.5.1. Introducción ...................................................................................................................................197

6.5.2.Una primera inspección del sistema de medicón ......................................................................................................... 198

6.5.3. Verificación in situ de instrumentos de medición de caudal .................................................................................... 199

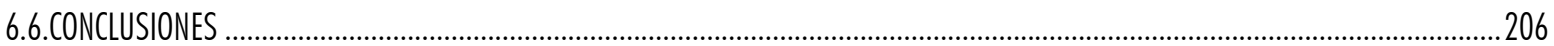

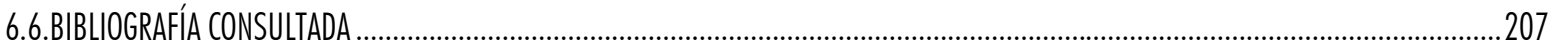

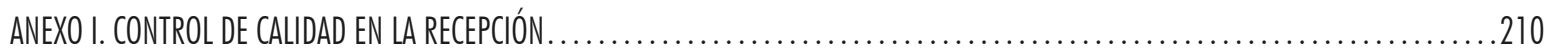

\section{CONTROL ESTADÍSTICO DE LOS CAUDALES MEDIDOS.....................................................................................213}

7.1.INTRODUCCIÓN ....................................................................................................................................................213

7.2. ANÁLISIS POR COMPONENTES PRINCIPALES.................................................................................................214

7.2.1.0bjetivos del andilisis de componentes principales (ACP) ........................................................................................2214

7.2.2. Generalidades sobre la metodología del análisis.................................................................................................22

7.23. Definición matemática de ACP...........................................................................................................................217

7.3.ANÁlLIS ESTADÍSTICO POR COMPONENTES PRINCIPALES DE LOS CAUDALES INYECTADOS A UNA RED..........................................229

7.3.1.0bjetivos del estudio ...................................................................................................................................231

7.3.2. Elaboración de los modelos de referencia ...........................................................................................................233

7.3.3.Consideraciones sobre el nivel de significación del modelo..................................................................................................233

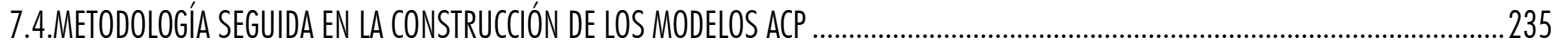

7.4.1.Validación del modelo: detección de anomalía en la red..................................................................................237

7.5.1.Modelo nocturno de referencia ..............................................................................................................................241

7.5.2. Modelo de referencia de mañana $(7-16$ horas)......................................................................................................248

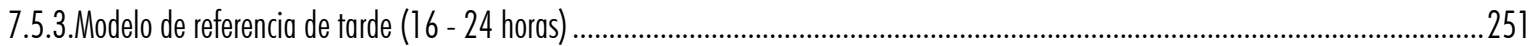

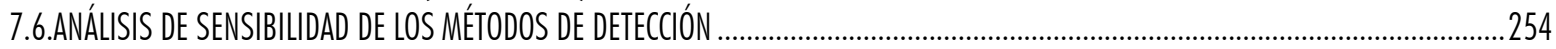

7.6.1. Simulación de cauddes inyectados en un sector con fugas ..................................................................................224

7.6.2.Análisis de sensibilidad $\mathrm{T}^{2} \mathrm{H}$ Hotelling...........................................................................................................256

7.6.3.Análisis de sensibilidad mediante la DMOD .......................................................................................................262

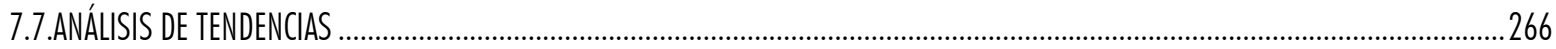

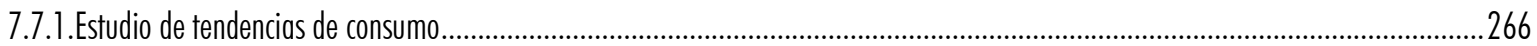

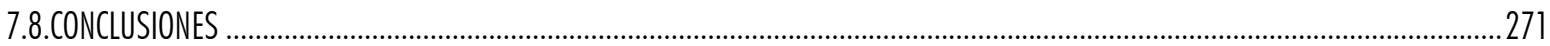

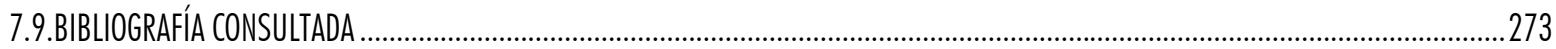

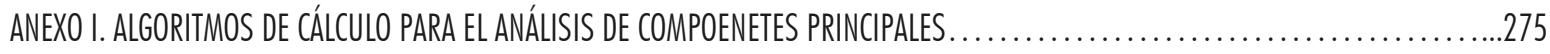

ANEXO II. CASO PRÁCTICO. MATRICES DE DATOS ORIGINALES 
8.CONCLUSIÓN

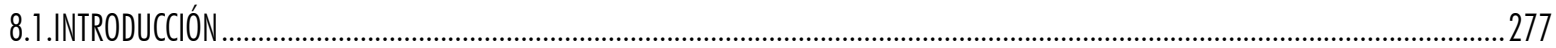

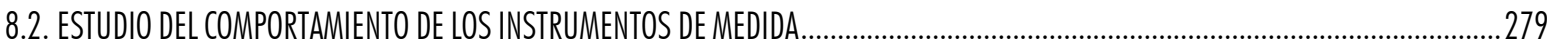

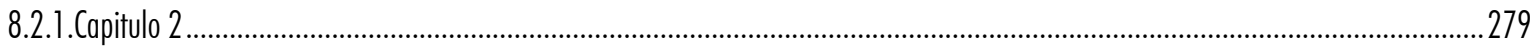

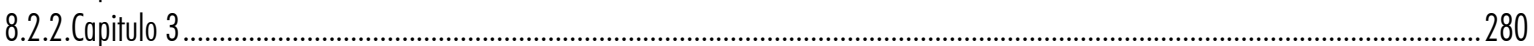

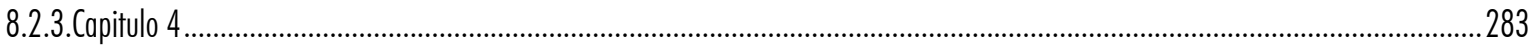

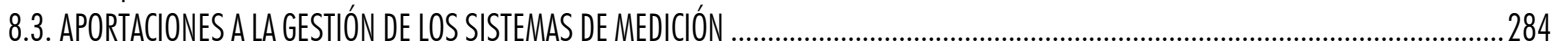

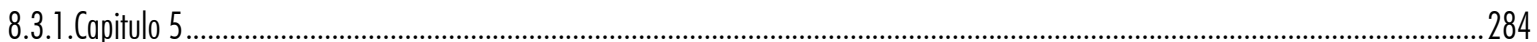

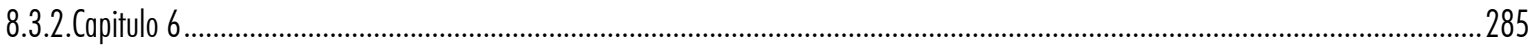

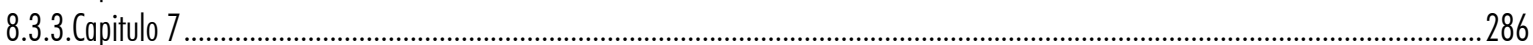

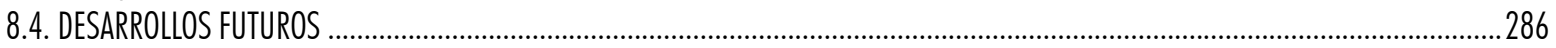




\section{CAPÍTULO 1}

INTRODUCCIÓN 


\section{INTRODUCCIÓN}

\subsection{JUSTIFICACIÓN DE LA TESIS}

El agua es un recurso natural que ha adoptado a lo largo de la historia un papel fundamental en el desarrollo de las civilizaciones. Las innovaciones técnicas en el almacenamiento y transporte del recurso desde los puntos de captación hasta los de consumo se han ido sucediendo continuamente, siempre con el fin garantizar de la manera más fiable posible la disponibilidad de agua, tanto para consumo humano como para uso agrícola o industrial. Estudiar el funcionamiento de los sistemas de distribución de agua, cómo circula y en qué cantidad, ha sido siempre una inquietud importante en el campo de la Hidráulica.

Recientemente, como se lee con frecuencia en los periódicos, la preocupación sobre la cantidad y calidad del agua disponible se hace más patente. Cada día existen mayores necesidades de agua y menor cantidad de recursos disponibles de la calidad deseada. El desequilibrio entre oferta y demanda se acentúa paulatinamente, haciéndose necesarias nuevas soluciones que resuelvan dicho desequilibrio. La falta de disponibilidad es especialmente grave en la cuenca del Mediterráneo, donde la propuesta del Plan Hidrológico Nacional (PHN), formulada en la Ley 10/2001 del 5 de Julio y, derogada por el gobierno socialista durante junio de 2004, se planteaba como una posible solución al problema a corto plazo. Este plan esencialmente promovía el aumento de la oferta disponible mediante la construcción de embalses y canales desde la cuenca hidrográfica del Ebro hasta el litoral sur del Mediterráneo. Con dichas obras se esperaba trasvasar hasta mil hectómetros cúbicos por año, suficiente para satisfacer las demandas de agua de la cuenca mediterránea.

Teniendo en cuenta los inconvenientes que todo trasvase supone, el actual gobierno ha planteado una serie de proyectos alternativos para satisfacer las necesidades hídricas de estas regiones. En este caso también se plantea aumentar la oferta del recurso, no a través de un trasvase, sino mediante la construcción y puesta en funcionamiento de desaladoras. Una vez más la solución planteada por los gobernantes pasa por aumentar la oferta.

No obstante, a día de hoy, no está disponible información precisa sobre cómo se utiliza el agua, tanto en agricultura como en abastecimiento urbano. Surgen inmediatamente una serie de cuestiones. ¿Es posible, hoy en día, una reducción apreciable en la demanda de agua sin sacrificar usos?. ¿Podrían resolverse los desequilibrios existentes de otro modo que 
no fuese, como siempre, aumentando la disponibilidad de recursos?. En caso de que solamente con una mayor oferta se resolviese el problema, ¿cuántos recursos son realmente necesarios?

Todas estas preguntas solamente pueden contestarse sabiendo exactamente cómo se utiliza el agua, y esto es posible únicamente implantando unos sistemas de medición adecuados que permitan conocer con exactitud cuánto agua se inyecta y se consume en cada red de distribución.

Precisamente la Tesis está enfocada a mejorar la gestión de los sistemas de medición a través del mejor conocimiento de los instrumentos de medida, tanto de los caudales circulantes como de los consumos de agua.

No obstante, todas las propuestas planteadas reflejan una idea fundamental, el uso racional del agua. Este uso racional comienza por incrementar los rendimientos hidráulicos de las redes de distribución tanto urbanas como agrícolas, reduciendo las pérdidas que en redes urbanas llegan, en ocasiones, hasta el 50\%. En regadío, como comenta el catedrático Losada "el volumen de recursos que escapan del control de los sistemas de riego, sin llegar a beneficiar a los cultivos, supera los $10.000 \mathrm{Hm} 3 / a n ̃ o$. Aunque parte retorna..., unos 5000 Hm³/año no son recuperables". Fomentando el empleo de técnicas de riego más eficientes y la reutilización de aguas residuales depuradas, se apunta hacia un desarrollo sostenible. Cualquiera de estas técnicas racionales pasa por un adecuado control del recurso desde su captación hasta su consumo. Es prioritario conocer los caudales de entrada y salida, es decir, los consumos y las pérdidas de agua, y los volúmenes destinados a cada uso, urbano, industrial o agrícola.

El arduo debate surgido sobre política del agua de los últimos años constata un baile de cifras referente a consumos, rendimientos y volúmenes de agua ${ }^{1}$. Discriminar y gestionar los caudales de este recurso natural es imposible sin un adecuado sistema de medición de caudales, tanto en grandes canales como en instalaciones domésticas de agua. Los sistemas de macro y micromedición de caudal son una de las partes fundamentales en las redes de suministro de agua. Conocer los caudales que circulan por cada conducto aporta al ingeniero, 0 al técnico encargado, información esencial para la correcta gestión de la red, tanto durante el diseño de nuevos tramos y elementos como desde el punto de vista de operación del sistema.

La presente Tesis doctoral pretende revisar las tecnologías de medición, poco investigadas, y ampliamente utilizadas por las empresas y comunidades que suministran el agua. Hacer hincapié en las ventajas e inconvenientes que presentan en cada situación. $Y$ desde un punto de vista metrológico, observar aquellos aspectos que pueden afectar a la medición, tanto porque actúan directamente sobre el propio mecanismo como porque esas circunstancias aceleran el natural deterioro del mismo. En suma, invita a gestionar de forma más eficiente los sistemas de medición de caudal en redes a presión.

\subsection{ANTECEDENTES}

El interés por la medida del caudal de agua viene desde los antiguos moradores del Tigris y el Eufrates, aproximadamente 5000 a. C, que necesitaban medir el agua para distribuirla de forma justa a cada una de las comunidades que poblaban esas tierras.

Siglos después, científicos griegos explicaban el comportamiento de líquidos y gases en movimiento. Durante la época romana, el comisario encargado del suministro de agua Sextus Julius Frontinus en su libro De Aquis Urbis Romae traducido al inglés por Clemens Herschel bajo el título The water supply of the city of Rome, comentaba la evolución hidráulica sufrida

\footnotetext{
${ }^{1}$ Como escribe Cabrera Jr. E, en su tesis doctoral Diseño de un sistema para la evaluación de la gestión de abastecimientos urbanos, " consumos rendimientos y volúmenes suelen estimarse con mejor voluntad que certeza....salvo las empresas que necesitan obtener beneficios de la gestión de recursos, se mide poco y mal".
} 
en la Roma del momento debido al rápido aumento de la población. Después de describir en detalle la construcción de nueve acueductos dentro del Gran Imperio, su inquietud fue dirigida al conocimiento de la cantidad de agua que transportaría cada uno de ellos.¿Qué cantidad sería suministrada a las ciudades? ¿Cuanto volumen iría a parar a las fuentes públicas?.¿Y a los consumidores privados?

En los textos de Frontinus aparecen antiguas unidades de medida como la quinariae o la centenariae que permitían contabilizar un volumen de agua en un recipiente de sección conocida. El principal problema residía en que se ignoraba por completo la medida de la velocidad del agua, simplemente, medía el flujo de agua mediante el área de su sección de paso tanto en conductos cerrados como en canal abierto.

A partir de los libros del romano, el ingeniero griego Heron de Alejandría, durante el primer siglo antes de Cristo, tuvo en cuenta para conocer la cantidad de agua de una corriente, su velocidad de circulación. Este fue el punto de inicio de la medida de caudal de agua. A partir de entonces, comenzaron a desarrollarse artilugios y utensilios para averiguar la velocidad de circulación del fluido.

En el siglo XVII y XVIII d.C, aparecieron los primeros instrumentos de medida de caudal en conductos cerrados. En 1730, Henri Pitot utilizó lo que posteriormente se conocería como tubo Pitot. Este ingeniero francés realizó ensayos en el río Sena con un tubo hueco de cristal en ángulo recto y dirigido hacia la corriente de agua. De esta forma, fue capaz de relacionar la altura del agua en el tubo, es decir su energía de presión, con la velocidad del flujo, concluyendo que la altura era proporcional al cuadrado de la velocidad.

En 1790, el alemán Reinhard Woltman diseñó un medidor tipo turbina para controlar el caudal circulante por un conducto. A partir de este prototipo, H. Meinecke en 1897, introdujo en el mercado un caudalímetro de turbina. Ese mismo año, esta compañía alemana patenta su principio de funcionamiento como contador, es decir, totaliza el volumen de agua trasegado en el tiempo, lo que actualmente se conoce como contador Woltman. A la par, Siemens en Inglaterra diseñó un medidor con los mismos principios de funcionamiento obteniendo resultados bastante apurados. El grave problema que se encontraron fue la corrosión. Los materiales, fundamentalmente bronce y hierro fundido, se deterioraban con el agua y las piezas internas del instrumento aumentaban su rozamiento afectando a la medición.

Los medidores tipo Woltman fueron el comienzo de posteriores diseños de instrumentos basados en la medida de la velocidad, como tecnologías de chorro único o múltiple, contadores tangenciales o incluso combinaciones de dos tecnologías en un mismo instrumento.

Como puede leerse en AWWA (1986), la mayor contribución a la medición de caudal mediante diferencia de presión la realizó el físico e inventor italiano Giovanni Battista Venturi (1.746-1.822) cuando diseñó el tubo Venturi. Este medidor consiste en una tubería corta, cuello o garganta, entre dos tramos cónicos que origina una diferencia de presión al pasar por él un fluido con cierta velocidad. En esencia, la presión varía en la proximidad de la sección estrecha, de esta forma, al colocar un manómetro diferencial entre la garganta y la entrada o la salida se puede medir la caída de presión y calcular el caudal instantáneo. Una ventaja fundamental del Venturi es que no consta de partes móviles en el interior de la tubería, además, sólo pierde de manera permanente un 10-20\% de la diferencia de presión entre la entrada y la garganta debido al cono divergente que desacelera la corriente.

Otro tipo de tecnología de medición tradicional es la placa orificio. Su dispositivo de medición consta de un disco con un agujero central que se inserta concéntricamente en el interior de la tubería. Esta placa produce una disminución en la presión ocasionada por la pérdida de carga al atravesar la sección de paso reducida. La disminución de presión en la placa orificio es proporcional al cuadrado del caudal circulante.

Los contadores volumétricos o los de disco nutante fueron adaptados mediante modificaciones de bombas. El número de ciclos para un volumen de agua determinado se contabilizaba para determinar el consumo. El primer medidor de este tipo fue diseñado por William Sewell e introducido en el mercado en Estados Unidos por Henry Worthington. Este prototipo 
constaba de dos cilindros con sus respectivos pistones, y mientras el agua entraba en un cilindro, en el otro, el pistón estaba desalojándola. De esta manera, se contabilizaban los pulsos de volumen en cada cilindro llenado.

En el siglo XX aparecieron los primeros caudalímetros electrónicos. El principio de medición de los electromagnéticos, basados en la Ley de Faraday, fue concebido en 1831. Pero no fue hasta un siglo después que dicha teoría fue aplicada a la medida de caudal. Así, en 1930 Williams referenció el primer caudalímetro electromagnético.

Tal y como comentan Baker (2000), Thompsom (1978), la primera propuesta de utilizar el sonido como variable de medida de caudal fue en una patente alemana que data de 1928. No obstante, hasta 1945 la idea no fue acogida por los ingenieros del momento. La aparición de transductores piezoeléctricos potenció el desarrollo de estos aparatos, y durante 1959 Fischbacker hizo una revisión de los principales instrumentos aparecidos con estos principios de funcionamiento.

En la actualidad, el diseño de estas tecnologías de medición ha evolucionado en muchos aspectos. En primer lugar, los materiales utilizados son mucho más resistentes y refinados que los de antaño. El uso de plásticos y de metales no corrosivos permite obtener instrumentos mucho más precisos. Además, los nuevos diseños de contadores y caudalímetros van encaminados a disminuir al máximo la fricción producida en los engranajes de los contadores, a fabricar y diseñar nuevas bobinas capaces de generar campos electromagnéticos más uniformes que no estén condicionados por el perfil de velocidades del flujo o instrumentos con el mínimo número de partes móviles en el interior de la tubería.

Además, las nuevas tecnologías van más allá de la simple medición de caudal desarrollando prototipos electrónicos con capacidad de almacenamiento de datos que aportan información relevante sobre caudales y consumos producidos por el usuario o la red de distribución.

La evolución tecnológica sufrida por estos instrumentos es incuestionable. El problema aparece cuando una vez instalados, en primer lugar, no se extrae toda la información posible de ellos y, en segundo, el mantenimiento y ubicación de cada una de las tecnologías no es adecuada, lo que genera graves perjuicios tanto sobre el aparato como sobre la medición. Todos estos puntos hacen pensar en la necesidad de abordar este tema con mayor empeño, ya que como se comenta en el siguiente epígrafe, en ocasiones los sistemas de medición son un diamante en bruto sin pulir.

\subsection{PROBLEMÁTICA DE LA MEDICIÓN DE AGUA}

La presente Tesis doctoral tiene como principal objetivo promover la mejora de la gestión de los abastecimientos de agua a través de una mejor medición del agua en las redes de distribución. Como ya se ha comentado, un adecuado control del sistema únicamente es posible mediante una medición exhaustiva de las variables hidráulicas, en este caso los caudales circulantes por las tuberías y los consumos de agua de los usuarios. Solamente si se dispone de esta información es posible implantar, o poner en práctica, diferentes técnicas de mejora en la gestión de la red, algunas de las cuales se comentan a lo largo del trabajo. Por ello, es necesario recalcar que la medición de agua constituye un aspecto fundamental en la gestión de la empresa de abastecimiento. La información derivada de los instrumentos se puede utilizar en múltiples áreas, internamente dentro de la compañía o, externamente, por parte de las autoridades competentes que demandan estadísticas fiables de consumos o los valores reales de los rendimientos hidráulicos conseguidos.

Consecuentemente, resulta esencial conocer perfectamente el grado de fiabilidad real de los instrumentos utilizados y disponer de un orden de magnitud de la incertidumbre en las medidas que facilitan. Esta última idea se debe tener en todo momento muy presente puesto que en realidad la calidad de las medidas no sólo depende de la calidad del instrumento sino, además, de su entorno, es decir, sus condiciones de funcionamiento e instalación.

La realidad muestra un panorama bastante negativo, totalmente inesperado, teniendo en cuenta las ventajas que aporta a los gestores un buen sistema de medición. Muchas empresas carecen de técnicos cualificados capaces de garantizar una correcta medición de los caudales inyectados y de los consumos de agua de los usuarios, seleccionando, instalando y 
manteniendo inadecuadamente los instrumentos. Es frecuente encontrar en muchos abastecimientos equipos completamente obsoletos, de más de treinta años de antigüedad, con unas características no adecuadas para las condiciones de funcionamiento y que, además, se encuentran mal dimensionados.

Aún así, en los foros de debate sobre gestión de redes de distribución de agua se advierte una evidente preocupación por parte de los técnicos sobre la fiabilidad de estos sistemas. Sin embargo, las buenas intenciones mostradas en estos foros caen en muchas ocasiones en el olvido. Los compromisos diarios, de un personal con una carga laboral excesiva, absorben completamente la jornada laboral y muchas de las actuaciones proyectadas para la mejora de los sistemas de medición no pueden llevarse finalmente a cabo, quedándose en meros proyectos. Unas veces por falta de tiempo y otras de presupuesto.

Actualmente son muy pocas las empresas que puedan afirmar que disponen de un procedimiento programado para la selección, instalación, verificación y calibración de los aparatos de medida. En multitud de ocasiones, los caudalímetros instalados en las tuberías de distribución son abandonados, y su mantenimiento y verificación metrológica es prácticamente inexistente, lo que, evidentemente, afecta a la incertidumbre de las medidas efectuadas por dichos instrumentos y a la efectividad de las técnicas que se pongan en práctica a partir de dichas medidas.

Algo parecido sucede con los contadores de agua, tanto domésticos como de carácter industrial. Estos instrumentos sirven a la empresa como herramienta de facturación del agua consumida por los diferentes usuarios. Sus ingresos dependen directamente de la capacidad de los contadores para registrar el consumo. Es evidente que llevar un buen inventario y control del funcionamiento en campo de estos aparatos permite mejorar la gestión del sistema y garantizar los ingresos de manera equitativa entre todos los abonados en función de su consumo. Sin embargo, en la práctica, incluso el inventario de los contadores, algo que debería estar perfectamente actualizado y mantenido puesto que se utiliza para gestionar los cobros, está frecuentemente desactualizado. Es fácil encontrar contadores cuya lectura en la base de datos no concuerda con la lectura real, el modelo de contador anotado no corresponde con el realmente instalado, la longitud y diámetro de la conexión no se encuentran disponibles, etc.

Profundizando sobre las anteriores consideraciones se enumeran a continuación los diversos factores que actualmente afectan a la calidad de la medición del agua, especialmente aquellos que se refieren al consumo de los usuarios.

A primera vista, uno de los defectos más importantes encontrados ha sido el espacio disponible para los instrumentos. Éste en muchas instalaciones interiores es mínimo, lo que obliga a colocarlos de manera incorrecta por lo que la lectura de los mismos resulta en ocasiones prácticamente imposible. Este problema no se limita únicamente a viviendas antiguas, muchas edificaciones de nueva construcción no acondicionan lugares adecuados para los contadores de agua. Sirva como ejemplo la fotografía presentada en la Figura 1.

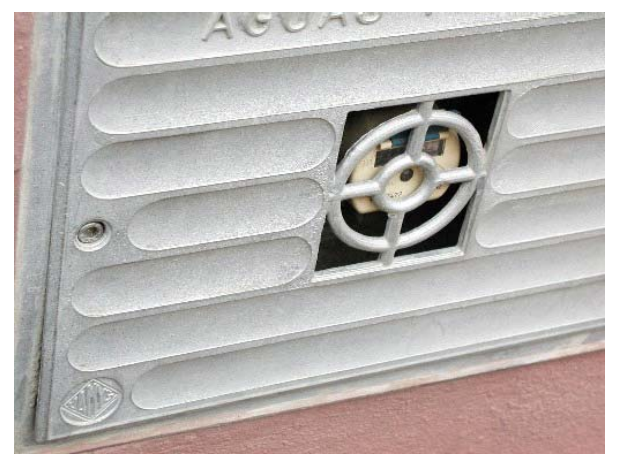

FIGURA 1. INSTALACIÓN INAPROPIADA DE CONTADORES EN PARED Y BATERÍA

$\mathrm{Ni}$ las empresas constructoras ni los fabricantes de contadores ayudan a resolver el problema. Los constructores no tienen en cuenta la correcta instalación de los instrumentos que irán dentro del armario, simplemente "hacen que quepan". Por otro lado, los fabricantes continúan diseñando totalizadores excesivamente voluminosos y de difícil lectura, y son muy pocos los 
que se han decantado por modelos que resolviesen el problema de la lectura en armarios con poco espacio. Solo algunos han sacado al mercado modelos con un visor en 45, tal y como muestra la Figura 2.

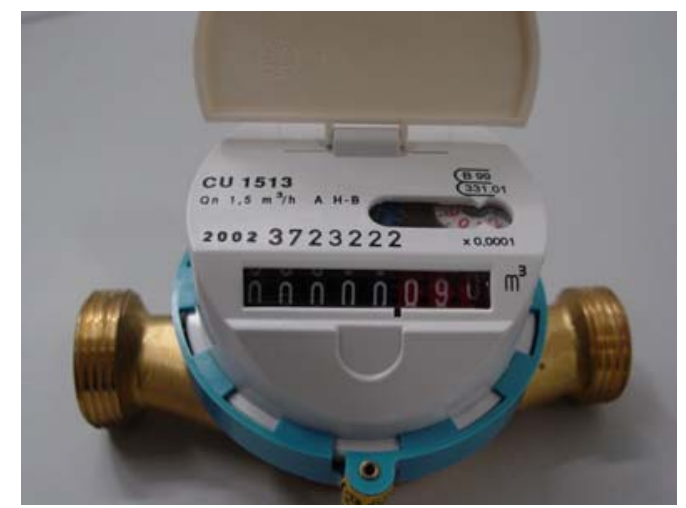

FIGURA 2.DISEÑO ALTERNATIVO DEL TOTALIZADOR PARA FACILITAR LA LECTURA DEL CONTADOR

Como se ha dicho, una reducida capacidad de lectura obliga frecuentemente a los operarios a inclinar los contadores. El principal problema que aparece cuando los contadores se instalan inclinados, y no están diseñados para funcionar en esta posición, es que la turbina no asienta correctamente en el eje 0 en los apoyos, provocándose holguras que a medio plazo, a caudales bajos, reducen la capacidad de medición del instrumento por la mayor fricción generada. Sin embargo, según el diseño, la instalación en posición inclinada puede perjudicar más gravemente a unos modelos que a otros.

Teniendo en cuenta las diferencias de comportamiento detectadas entre distintos modelos, se recomienda que en aquellos abastecimientos en los que un número importante de contadores estén instalados con cierta inclinación, se elijan modelos en los que la inclinación del contador no afecte en exceso a su curva de error, es decir su clase metrológica sea independientemente de su posición de instalación.

Otro parámetro importante en la medición del caudal es la calidad del agua. La curva de error de la mayoría de contadores, independientemente de la tecnología que utilicen, puede verse seriamente afectada por la calidad del agua circulante. En el caso concreto de los contadores de chorro único, la metrología está íntimamente ligada a las tolerancias dimensionales internas del mismo. Además, muchos contadores de chorro único y chorro múltiple disponen de un sistema de ajuste de la curva de error que consiste en un circuito en derivación que impide que parte del caudal de agua no impacte sobre la turbina. En estos casos, el error depende directamente del porcentaje de agua que se desvía por el circuito de regulación. Por ello, una reducción de la sección de paso libre en la cámara de la turbina o en la tobera de entrada a la misma puede dar lugar a errores de sobrecontaje.

En otros casos, una acumulación excesiva de sedimentos entorpece el giro de la turbina provocando el efecto contrario, errores de subcontaje, o incluso el bloqueo de la misma. Por fortuna, normalmente aparecen señales de alerta, la facturación decae progresivamente, antes de que la turbina se bloquee completamente (Figura 3). 

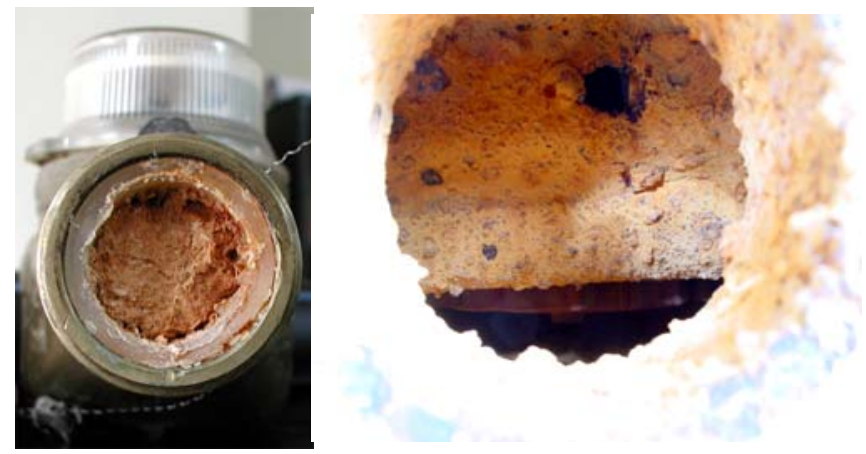

FIGURA 3. DEPOSICIONES CALCÁREAS EN EL INTERIOR DE DOS CONTADORES.

Por otro lado, la condensación en los totalizadores afecta principalmente a los contadores instalados en regiones húmedas en arquetas a nivel de suelo y dificulta e impide la lectura de los mismos aumentando los costes de esta operación. Además, aumenta la probabilidad de que surjan conflictos con los usuarios al tomarse lecturas erróneas que en algunos casos conduzcan a facturaciones claramente excesivas. En teoría, el uso de totalizadores extrasecos resuelve este problema. Pero en la práctica, se demuestra que incluso los contadores más modernos se empañan al cabo de cierto tiempo.

Otro problema frecuente es la manipulación de los contadores que genera frecuentemente problemas en la medición de los consumos. Son numerosas las técnicas empleadas para perjudicar la precisión de los aparatos. Como ocurre en cualquier ámbito, a medida que se desarrollan sistemas antifraude surgen nuevos métodos para neutralizarlos. La Figura 4 muestra un ejemplo de manipulación ineficaz de un contador, en el que se demostró que la curva de error no se alteró significativamente. La manipulación consistía en el taponamiento parcial de la salida del contador con la presunta intención de reducir la velocidad de giro de la turbina.

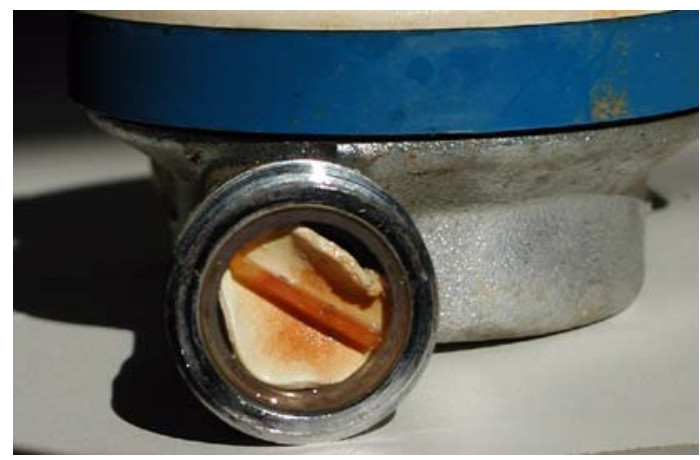

FIGURA 4. INTENTO DE MANIPULACIÓN INFRUCTUOSA: OBTURACIÓN DE LA TOBERA DE SALIDA.

El dimensionado de los instrumentos de medida de caudal es fundamental para garantizar una adecuada medición. La relación existente entre los caudales circulantes y la curva de error de un contador de un calibre determinado, muestran la eficacia de una adecuada elección del calibre.

Aunque en los contadores de pequeño calibre este aspecto no cobra demasiada importancia, salvo en aquellas viviendas con jardín y piscina propia, en los contadores de mediano y gran calibre el dimensionado del instrumento es un factor crucial. Una parte importante de los errores de medida que se producen en los usuarios importantes es debido, principalmente, al mal dimensionado de los contadores. Por un lado, si el contador trabaja a caudales excesivamente bajos, 
los errores de subcontaje, por la falta de sensibilidad del instrumento en este rango, serán apreciables. Por el contrario, si el contador trabaja frecuentemente a caudales demasiado elevados, el deterioro de la curva de error puede acelerarse significativamente, conduciendo a graves errores de medida al poco tiempo de su instalación.

Para dimensionar correctamente los instrumentos, se puede recurrir a tres métodos:

- En caso de suministrar principalmente a usuarios particulares, es posible calcular el caudal punta de la instalación a partir del caudal instalado. Este método es el que habitualmente se utiliza en el cálculo de los caudales punta en las instalaciones interiores de edificios. Tiene en cuenta el número de aparatos de consumo y la posible simultaneidad de uso de los mismos.

o Otro método de dimensionado habitual utiliza el volumen mensual registrado para seleccionar el caudal nominal del contador. A pesar de que esta aproximación no es tan directa como la anterior (caudal instalado) es muy utilizada por ser los datos del consumo mucho más fáciles de obtener, a partir de la lectura periódica de los medidores, que informaciones fiables en cuanto a las instalaciones internas de los consumidores. Es un método recomendado por algunos fabricantes de contadores, en la medida que permite estimar por la lectura acumulada y tiempo de uso si el medidor estaba sujeto a caudales mayores o menores que los recomendados que, como se ha dicho, es una de las circunstancias que lleva al subregistro de consumos.

- Finalmente, el método más preciso se basa en el levantamiento de un perfil de caudales para conocer realmente los caudales circulantes por la conducción. Solamente se debe tener la precaución de corregir las mediciones con el posible sesgo que pueda introducir el caudalímetro o contador empleado en el levantamiento del perfil.Por ejemplo, si se utiliza un contador Woltmann ya instalado para verificar si es adecuado o no, dados los caudales circulantes, puede suceder que el contador esté deteriorado y no proporcione una imagen real de lo que realmente circula por la conducción. No registrar consumos a caudales bajos no necesariamente implica que no los haya. Puede ser que el medidor no los registre por no tener suficiente sensibilidad o estar averiado.

Otro inconveniente encontrado es la instalación junto a los medidores de otros elementos hidráulicos que perturban el flujo de agua sin mantener una distancia de tubería suficiente para estabilizar el flujo de agua (Figura 5).

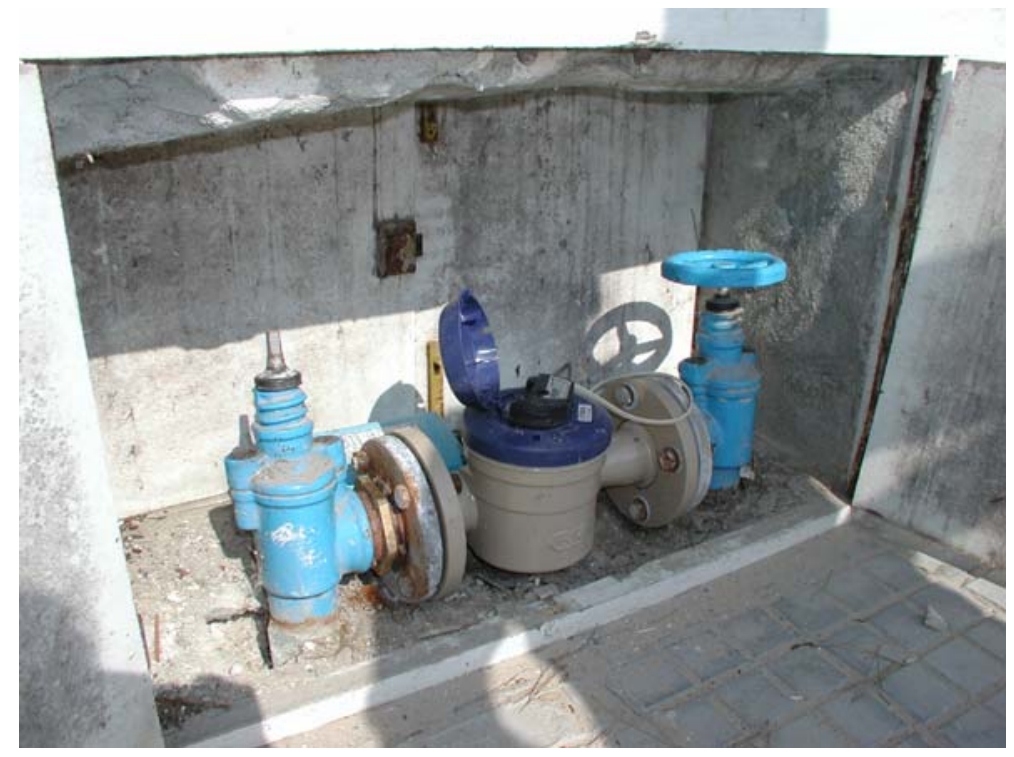

FIGURA 5. INSTALACIÓN DE UNA CONTADOR DE CHORRO ÚNICO JUNTO CON UNA VÁLVULA DE COMPUERTA AGUAS ARRIBA SIN MANTENER TRAMOS RECTOS DE TUBERÍA. 
Como se verá en numerosas secciones durante el presente trabajo, los instrumentos de medida de caudal y los contadores de agua requieren que el perfil de velocidades en la sección de medición no se encuentre distorsionado y su forma corresponda con el que se tendría en un flujo turbulento plenamente desarrollado. La instalación de accesorios y válvulas aguas arriba de los instrumentos provocan distorsiones en el flujo que deterioran la calidad de medición de los aparatos. En el uso de cada tecnología de medición se deben cumplir unos requerimientos en cuanto a los tramos de estabilización necesarios entre el elemento perturbador y el instrumento. En general, se puede afirmar que aquellos caudalímetros y contadores que tomen menos información del flujo, por ejemplo realizando una medición puntual de la velocidad, son más sensibles a posibles distorsiones en el perfil de velocidades. Por el contrario, los que tomen medidas en zonas más amplias de la sección, por ejemplo un caudalímetro electromagnético, se verán a priori menos afectados por las perturbaciones en el flujo.

En general, los ingenieros proyectistas no tienen en cuenta los requerimientos de los instrumentos de medida. Las instalaciones interiores de agua donde se ubican los instrumentos, los armarios 0 arquetas y los accesorios colindantes perturbadores del flujo de agua producen que los instrumentos trabajen en condiciones de funcionamiento no óptimas para su correcta medición.

En España, aún hoy, es común encontrar abastecimientos de agua que, en épocas de escasez, cortan el suministro de agua a los abonados durante varias horas al día. Para proteger a los abonados de estos cortes de suministro se han incorporado a las instalaciones interiores depósitos de almacenamiento individuales. Además, otro motivo por el que ciertos abastecimientos promueven el uso de tales elementos y en los que no se dan cortes de suministro, tiene que ver con el insuficiente dimensionado de las redes de distribución.

Al margen de otras consideraciones, que en absoluto aconsejan el uso de estos depósitos de almacenamiento, el perjuicio económico que causan a la empresa suministradora es considerable. En Arregui et al. (2003), se demostró que los caudales de consumo circulantes en este tipo de instalaciones interiores se reducían notablemente, alcanzándose errores de medición de los contadores instalados cercanos al -20\%. En este sentido, hay que tener en cuenta que un consumo típico disminuye el nivel del agua en el tanque mínimamente, por lo que la válvula de boya proporcional que habitualmente se instala, rellena el depósito a un caudal muy bajo. La solución a este problema pasa por el uso, en lugar de las válvulas proporcionales, de válvulas de entrada todo-nada.

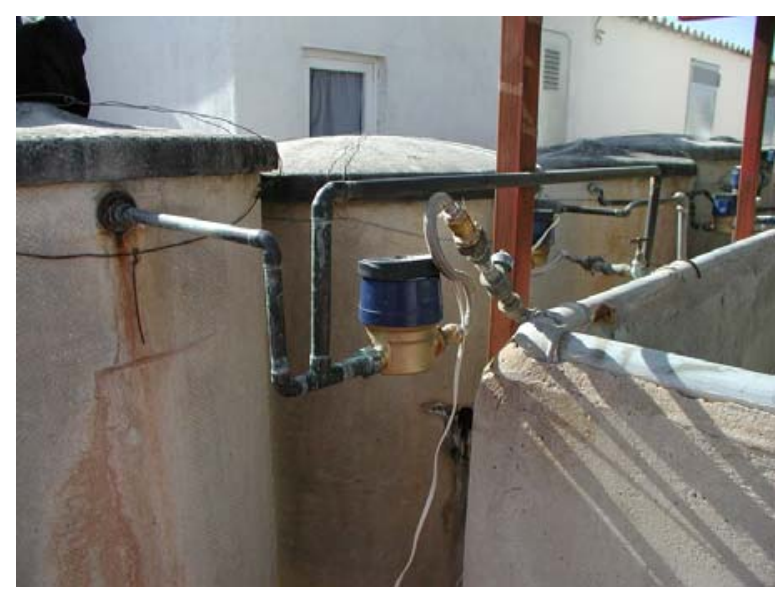

FIGURA 6. PRESENCIA DE DEPÓSITOS DE ALMACENAMIENTO EN LAS INSTALACIONES INTERIORES

Resolver todos estos problemas no es factible de un día para el otro, pero un punto de partida puede ser la concienciación en la necesidad de medir correctamente, y en particular de la importancia de la gestión de instrumentos de medida para el control del agua de los sistemas de agua. 


\subsection{OBJETIVOS Y ESTRUCTURA DE LA TESIS}

Como se ha dicho, la calidad de medición de los caudalímetros y contadores puede verse afectada por multitud de parámetros. Conocer como se deteriora efectivamente esta capacidad para registrar adecuadamente en el tiempo los consumos y los caudales circulantes resulta completamente necesario para garantizar un buen control del sistema de distribución de agua.

Actualmente existe un marcado desconocimiento sobre la evolución de la metrología de este de tipo de instrumentos. No existen estudios publicados que cubran de manera amplia esta temática. Puntualmente se llevan a cabo trabajos, normalmente de carácter confidencial, desarrollados por algunas empresas de abastecimiento, que muchas veces carecen del obligado rigor técnico. Esta laguna de información ha sido uno de los principales motores de la presente línea de investigación. En este sentido, los numerosos ensayos en laboratorio realizados durante el periodo de investigación de contadores domésticos, de diferentes edades, posibilitan evaluar cómo evoluciona capacidad metrológica en función de los parámetros más influyentes.

La presente Tesis doctoral se encuentra dividida en dos partes bien diferenciadas. Una primera, describe el comportamiento de los medidores de caudal mediante una amplia revisión bibliográfica en catálogos comerciales y artículos científicos de los aparatos existentes en el mercado que con mayor frecuencia se instalan en las redes de abastecimiento. A su vez, como resultado de los ensayos en laboratorio de contadores retirados de las instalaciones de los usuarios, se obtiene la evolución metrológica de los instrumentos de medida en el tiempo y la influencia que ejercen elementos externos sobre la capacidad medición de los mismos. Dichos ensayos para obtener las curvas de error frente al caudal se han llevado a cabo tanto para contadores domésticos como para tecnologías de medición típicas de instrumentos de mayor calibre. En concreto, se ha estudiado el comportamiento de contadores de chorro único, chorro múltiple, Woltman de eje horizontal y vertical, contadores tangenciales, proporcionales e hidrantes.

Asimismo, esta primera parte, apunta aquellos factores que afectan a la medición de caudal. La calidad del agua, la posición de instalación o el perfil de velocidades aguas arriba del instrumento son factores que pueden tener influencia sobre este tipo de tecnologías. En particular, profundiza en el efecto que producen elementos perturbadores del flujo sobre la medición de caudal.

En el caso concreto del contador Woltman de eje horizontal se ha llevado a cabo un análisis numérico de su comportamiento bajo la influencia de diversas perturbaciones. Para ello se ha modelado el flujo de agua incidente, en diferentes configuraciones, sobre la turbina mediante el programa FLUENT, y se ha estimando el par motriz resultante. Las variaciones de dicho par motriz, con respecto al que se obtiene para un perfil de velocidades plenamente desarrollado proporciona una estimación de los posibles errores de medida. Los resultados numéricos han sido contrastados con los empíricos realizados en laboratorio.

Paralelamente, se ha llevado a cabo un análisis numérico similar para estimar el error que provocaría, a un caudalímetro electromagnético y uno de ultrasonidos, la instalación de una válvula a varias distancias aguas arriba del instrumento.

La segunda parte de la Tesis doctoral ahonda en los aspectos más importantes de la gestión de sistemas de medición. El cálculo del error global del parque de contadores domésticos se aborda en profundidad en el Capítulo 5. La Tesis doctoral de Arregui (1999) comenzó está línea de investigación, proponiendo una metodología para evaluar el agua potable que dejaba de registrarse por errores de medición. Este trabajo aprovecha el avance realizado en este sentido, para mostrar nuevos ensayos y mediciones que amplían el conocimiento sobre el cálculo de este error, proponiendo ciertas mejoras a su metodología.

El Capítulo 6 es un compendio de temas relacionados con la gestión de los sistemas de medición, tanto de micromedidores como de macromedidores. En él, se exponen de forma práctica algunas de las estrategias básicas que se deben seguir 
para llevar un buen control de los medidores. Por ejemplo, en lo que respecta al sistema de contadores domésticos se presentan técnicas de muestreo para controlar la calidad de los contadores nuevos llegados de fábrica donde se establecen límites coherentes de rechazo o aceptabilidad de lotes de instrumentos. El tiempo que deben permanecer los contadores domésticos instalados en las casas puede ser también una piedra de toque en su gestión. Cuando el objetivo del gestor es optimizar económicamente estos instrumentos conviene realizar un análisis económico donde se tiene en cuenta los costes iniciales, fundamentalmente de instalación y compra, y los costes variables que contemplan el volumen de agua que deja de registrarse a medida que pasa el tiempo y el instrumento se deteriora. La revisión de todos estos costes permite estimar la frecuencia de renovación óptima de cada red, teniendo en cuenta que el ritmo de deterioro en cada parque puede ser diferente dependiendo de su entorno y condiciones de funcionamiento, como se explica, reiteradamente, durante toda la Tesis doctoral.

La segunda parte de este Capítulo 6, aborda aspectos del dimensionado de contadores de gran calibre, y propone y revisa las prácticas de verificación in situ de los instrumentos de medición de caudal más comunes. Dimensionar de forma adecuada un instrumento de medida a priori es difícil. Comúnmente, se tiende a instalar el mismo calibre de la tubería ocasionando, la mayoría de las veces, un sobredimensionado del instrumento ya que por él circulará un rango de caudales muy inferior a su capacidad real.

Por último, las medidas de caudal obtenidas de estos equipos de medición deben ser aprovechadas al máximo por los ingenieros encargados de la gestión de la red. Existen diversas técnicas que utilizan los caudales medidos tanto en sectores hidrométricos como en instalaciones interiores con el objetivo común de conocer la circulación del agua por la tubería. En este sentido, el Capítulo 7 propone una metodología novedosa en el campo de la Hidráulica para detectar comportamientos anormales de los caudales que habitualmente circulan por una conducción o sector. Esta técnica basada en el análisis estadístico multivariante es capaz de detectar fugas en un sector hidrométrico en un tiempo relativamente corto que permite al gestor mejorar el tiempo de reacción de las cuadrillas.

\subsection{BIBLIOGRAFÍA CONSULTADA}

Arregui F.J, Palau C.V, Gascón L, Peris O. (2003). Evaluating domestic water meter accuracy. A case study. PEDS Pumps, electromechanical devices and systems. Applied to urban water management. Balkema. Vol. 1. pp. 343-352.

Arregui F.J. (1999). Propuesta de una metodología para el análisis y gestión del parque de contadores de agua. Tesis doctoral. Universidad Politécnica de Valencia.

AWWA (1986). M6 Water meters-Selection, installation, testing and maintenance. Manual of Water supply practices. ED. American Water Works Association.

Baker R.C. (2000) Flow measurement handbook. Ed. Cambridge University Press.

Cabrera E. Jr. (2001). Diseño de un sistema para la evaluación de la gestión de abastecimientos urbanos. Tesis doctoral. Universidad Politécnica de Valencia.

Losada A. (1994) Eficiencia técnica en la utilización del agua de riego. Revista Estudios Agro-Sociales, №. 167, pp. 131154.

Thompson E.J. (1978). Two beam ultrasonic flow measurement. Ph. D. Thesis, University of London.

Ley 10/2001, de 5 julio, del Plan Hidrológico Nacional. Ministerio de Medio Ambiente. 


\section{DESCRIPCIÓN DE LOS INSTRUMENTOS DE MEDIDA DE CAUDAL Y CONTADORES DE AGUA}

\subsection{INTRODUCCIÓN}

Este segundo capítulo describe las características y los principios de funcionamiento de los principales instrumentos de medida de caudal utilizados en las redes de abastecimiento para el control del agua circulante por las conducciones y los consumos de los usuarios.

Como es sabido, existe gran cantidad de instrumentos para la medida de caudal, pero la dificultad estriba en encontrar un aparato que combine una buena precisión en un amplio rango de medida con un coste económico bajo, y que además, sea fácilmente instalable, no requiera mantenimiento y sufra el menor desgaste posible. Se podría afirmar que encontrar el instrumento de medida ideal que sirva en cualquier circunstancia es pura ficción. Crucial es adaptar la selección de la tecnología a emplear con el entorno donde se ubicará el aparato y las condiciones de funcionamiento específicas de la instalación.

La característica metrológica de un instrumento es la capacidad que tiene para registrar de manera precisa la variable observada. Para ello, se deben tener en cuenta aquellos parámetros que puedan afectar de alguna forma a la calidad de la medida. Por ejemplo, si se trata de medir el caudal, una adecuada selección del rango de funcionamiento es un parámetro fundamental en este sentido. Elegir un contador o caudalímetro cuyo rango de medida efectivo se ajuste al máximo a los caudales que circularán por la conducción mejorará su rendimiento y limitará el deterioro que pueda sufrir a largo plazo. Otros parámetros a tener en cuenta a la hora de elegir un aparato de medida de caudal son la sensibilidad a los posibles elementos perturbadores o la influencia que la calidad del agua pueda ejercer en el comportamiento del instrumento. En ocasiones la disponibilidad física donde se pretende instalar el instrumento o el tipo de agua restringe la elección del tipo de tecnología.

La presente tesis doctoral investiga algunos de estos aparatos aportando al lector un conocimiento más amplio de sus ventajas e inconvenientes, de la evolución en el tiempo de sus características metrológicas o de los parámetros más importantes que conviene tener en cuenta para su adecuado manejo. En resumen, elegir el instrumento que mejor se adapte a cada aplicación o instalación. 


\subsection{CONCEPTOS BÁSICOS SOBRE MEDICIÓN DE CAUDAL}

De forma breve, a continuación se presentan una serie de conceptos generales relacionados con la obtención del caudal, las fuentes de error y las incertidumbres asociadas a la medida.

Por regla general, la mayoría de caudalímetros de agua, diseñados para funcionar en conductos cerrados a presión, recurren a la medición local de la velocidad del flujo para estimar un valor de velocidad media axial en la sección y, a partir del área de paso, obtener un valor del caudal circulante (Ecuación 1).

Caudal $=$ Velocidad media axial $\cdot$ Sección

Cada instrumento dispone de un principio de funcionamiento diferente que permite obtener la velocidad local y relacionar la velocidad medida con la velocidad media en la conducción. Por ejemplo, un caudalímetro de inserción mide la velocidad del fluido en una zona muy reducida en las inmediaciones del sensor. A partir de este dato es posible estimar, en función de la forma de parábola achatada que adopta el perfil de velocidades en flujo turbulento, la velocidad media de circulación en la sección. Otros instrumentos como los caudalímetros de ultrasonidos miden la velocidad en una cuerda de la conducción mediante la medición del tiempo de tránsito de las ondas sonoras emitidas por los transductores. La relación entre este tiempo, la velocidad de propagación del sonido y la separación entre emisor-receptor permite deducir la velocidad media en dicha cuerda, y posteriormente estimar la velocidad media axial necesaria para la obtención del caudal.

\subsubsection{COMPORTAMIENTO DEL FLUJO DENTRO DE UN CONDUCTO CIRCULAR A PRESIÓN}

La relación entre las velocidades medidas y la velocidad media axial se puede obtener habida cuenta de que en un flujo turbulento plenamente desarrollado es decir, sin distorsión, se conoce la distribución de velocidades en la tubería. Por ello, otro aspecto fundamental en la medida de caudal es el comportamiento del flujo de agua en el interior de la conducción, puesto que si varía respecto al conocido, las relaciones anteriores entre velocidades se rompen.

Idealmente el perfil de velocidades en una conducción de agua, con un flujo plenamente desarrollado, tiene una simetría axial y dependiendo del tipo de flujo adquiere una forma más o menos parabólica. Con números de Reynolds menores de 2000 (Ecuación 2), el flujo se considera laminar y su perfil es parabólico. En cambio, un flujo pasa a turbulento cuando el número de Reynolds es mayor de 2000, entonces el perfil de velocidades se achata en la zona central (Figura 1). En la mayor parte de los casos, el flujo de agua en las redes de distribución urbanas es turbulento.

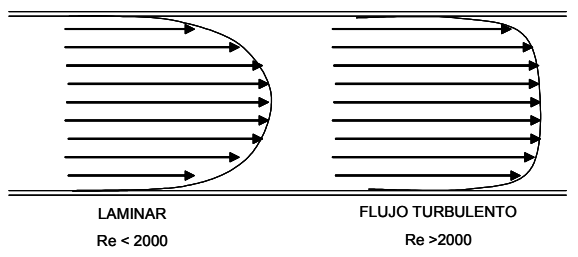

FIGURA 1. PERFILES DE VELOCIDAD EN FLUJO LAMINAR Y TURBULENTO.

$$
\operatorname{Re}=\frac{\rho \cdot V \cdot D}{\mu}
$$


Cuando el flujo es laminar, las ecuaciones que describen el comportamiento del perfil de velocidades dentro de un conducto circular a presión son:

$$
\frac{V}{V_{\max }}=\left(1-\left(\frac{r}{R}\right)^{2}\right)
$$

En este caso, donde el perfil de velocidades tiene forma de parábola, la velocidad media en el conducto corresponderá a la mitad de la velocidad máxima, tal y como se expresa en la Ecuación 4.

$$
\mathrm{V}_{\mathrm{m}}=\frac{\mathrm{V}_{\mathrm{max}}}{2}
$$

siendo $\mathrm{V}_{\mathrm{m}}$ la velocidad media en el conducto, $\mathrm{V}_{\max }$ la máxima y $\mathrm{V}$ la velocidad en un punto situado en un radio de corona $\mathrm{r}$.

El flujo de agua pasa de laminar a turbulento con números de Reynolds superiores a 2000, en estos casos, la curva que más se aproxima al perfil sigue la expresión 5.

$$
\frac{V}{V_{\max }}=\left(1-\frac{r}{R}\right)^{1 / n}
$$

donde $n$ es el coeficiente de Von Kármán que depende del número de Reynolds. En la Tabla 1 se facilitan valores de n para diferentes números de Reynolds.

TABLA 1. COEFICIENTE dE VON KÁRMÁN N, FUnCIÓN DEL NÚMERO DE RE (BAKER, 2000)

\begin{tabular}{cccccc}
\hline $\operatorname{Re}$ & $4 \cdot 10^{3}$ & $2,3 \cdot 10^{4}$ & $1,1 \cdot 10^{5}$ & $1,1 \cdot 10^{6}$ & $210^{6}$ a $3,2 \cdot 10^{6}$ \\
\hline $\mathrm{n}$ & 6,0 & 6,6 & 7,0 & 8,8 & 10 \\
\hline $\mathrm{V} / \mathrm{V}_{\mathrm{m}}$ (a 0,75R) & 1,003 & 1,004 & 1,004 & 1,005 & 1,005 \\
\hline
\end{tabular}

En general, cuando el perfil de velocidades se encuentra plenamente desarrollado, la velocidad media se calcula integrando la expresión de la velocidad en todo el área y dividiendo el resultado por la sección de la conducción. Con un flujo turbulento se integrará la expresión anterior en toda el área (Ecuación 6). El caudal se calculará a partir de dicha velocidad media por el área de dicha sección (Ecuación 7).

$$
V_{m}=\frac{\int_{0}^{R} V_{\max }\left(1-\frac{r}{R}\right)^{1 / n} \cdot r \cdot d r}{A}
$$




$$
\mathrm{Q}=\mathrm{V}_{\mathrm{m}} \cdot \text { area }
$$

El problema reside en que ningún caudalímetro es capaz de integrar la velocidad considerando todos los puntos de la sección y únicamente estiman la velocidad promedio a partir de la medición en uno o varios puntos, en una cuerda, una zona, etcétera. Por ello, cuando el perfil de velocidades varía su forma, se altera la relación existente entre la velocidad medida y la media, cometiéndose graves errores en la medición de caudal. En el informe del National Engineering Laboratory (2002) se manifiesta la importancia que tienen los perfiles de velocidad sobre la medición de caudal.

Durante el Capítulo 4 se profundiza en la influencia sobre la medición de flujos distorsionados. Los instrumentos de medida de caudal toman la medida de velocidad en uno o varios puntos dependiendo del tipo de tecnología. A partir de esta velocidad medida, cuando el flujo se encuentra equilibrado, es posible relacionarla con la velocidad media en la conducción para estimar el caudal circulante. La relación entre la velocidad medida a $3 / 4$ de radio desde el eje y la velocidad media de la conducción es aproximadamente la unidad.

Así pues, en un flujo turbulento la velocidad media se relaciona con la velocidad máxima del fluido dentro de la conducción mediante la expresión 8. Esta expresión deriva de resolver la Ecuación 6.

$$
\frac{V_{m}}{V_{\max }}=\frac{2 n^{2}}{(n+1) \cdot(2 n+1)}
$$

Cuando la velocidad se mide con un instrumento en cualquier punto de la sección de medición esta relación actúa como factor de calibración, vinculando la velocidad medida y la máxima según la Ecuación 9 que se extrae de relacionar las expresiones 5 y 8 (Baker, 2000).

$$
\frac{V}{V_{m}}=\frac{(n+1) \cdot(2 n+1)}{2 n^{2}}\left(1-\frac{r}{R}\right)^{1 / n}
$$

siendo $\mathrm{V}$ la medida por el instrumento.

Por tanto, a partir de la medición de la velocidad en uno o varios puntos de la sección es posible conocer el valor de la velocidad media, y con ello, el caudal circulado por el conducto.

\subsubsection{TIPOS DE ERROR}

En condiciones reales de funcionamiento los sistemas de medición no se comportan como idealmente se espera. Existen multitud de factores que pueden afectarles originándose ciertas discrepancias entre el valor real de la variable observada y la lectura de los instrumentos. Por ello, en la práctica, cualquier lectura de un aparato de medida difiere en mayor o menor grado del verdadero valor de la variable monitorizada. En consecuencia, siempre se debe hablar de un intervalo de confianza, donde se espera, con una determinada probabilidad, se encuentre dicho valor verdadero. Precisamente la Real Academia de la Lengua define error como la "diferencia entre el valor medido o calculado y el real".

Entre los factores que afectan al error de medida cabe distinguir dos tipos, los que causan errores sistemáticos y los que originan errores aleatorios. Los errores son sistemáticos, para unas determinadas condiciones del sistema, cuando ocurren 
siempre en el mismo sentido y son de una magnitud más o menos constante. Por ejemplo, el desplazamiento de la curva de error en un contador debido a la sedimentación de cal en el interior del cuerpo del instrumento siempre provoca que el registro del consumo a un determinado caudal se produzca, aproximadamente, con el mismo error. Es decir, cada vez que se repitiese la medida del consumo a un determinado caudal, éste se registraría con errores similares. Otro ejemplo de error sistemático en la medida es el causado por la mala calibración de un instrumento o por un sensor en mal estado.

TABLA 2. VARIABLES QUE AFECTAN A LA MEDICIÓN DEL CAUDAL DE AGUA.

\begin{tabular}{l}
\hline VARIABLES QUE AFECTAN A LA MEDICIÓN DEL CAUDAL \\
\hline Perfil de velocidades distorsionado \\
Mal funcionamiento del sensor \\
Rango de funcionamiento inadecuado \\
Mala instalación, posición del instrumento \\
Calidad del agua \\
Ruido eléctrico \\
Variación en la sección nominal de la conducción \\
\hline
\end{tabular}

Por las características comentadas, los errores sistemáticos se pueden eliminar mediante la calibración de los instrumentos. Esta calibración debe llevarse a cabo en campo si se sospecha que el origen del error sistemático es la propia instalación o en laboratorio, en caso de tener cierta seguridad de que el causante de los errores es el instrumento en sí.

En la práctica aparecen otros factores que originan otro tipo de errores llamados aleatorios. Éstos, como su nombre indica, ocurren de forma circunstancial, cada vez en un sentido y con diferente magnitud, sin seguir un patrón fijo. Estas desviaciones del valor real son causadas por variables, generalmente temporales, que influyen en la medición con intensidad variable. Un ejemplo de este tipo de error son las interferencias producidas por el ruido eléctrico generado por la línea de alimentación de una bomba que discurra paralela a la línea de transmisión de la señal de un caudalímetro electromagnético.

El único modo de paliar o reducir estos errores aleatorios es tomando un número elevado de medidas de la magnitud observada. Dado que estos errores oscilan de modo aleatorio sobre el valor real, es de esperar que los errores de unas medidas compensen los de otras, siempre y cuando las condiciones de la medición no varíen en el tiempo. Por ello, calculando el valor promedio de las mediciones se obtiene, con mayor probabilidad, un valor más próximo al real.

Profundizando más en esta cuestión considérese $n$ medidas $-x_{1}, x_{2}, \ldots, x_{n}$ - tomadas de un instrumento en unas condiciones estables. El conjunto de estas medidas constituyen una variable aleatoria cuyo valor medio, $\bar{x}$ es un estimador del verdadero valor de la magnitud que se trata de determinar, $x_{r}$. Evidentemente, el valor de cada medida es distinto y diferente a $x_{r}$. Las fluctuaciones sobre éste valor, suponiendo eliminado cualquier error sistemático, están causadas por los errores aleatorios. Por ello, para estimar el orden de magnitud de estos errores se recurre a un parámetro que sirva de estimador de esta dispersión de las medidas sobre el verdadero valor observado. En este caso la desviación típica muestral, s, del conjunto de medidas tomadas.

$$
\bar{x}=\frac{1}{n}\left(x_{1}+x_{2}+\ldots+x_{n}\right)=\frac{1}{n_{i}=1} \sum_{i}^{n} x_{i} \quad s= \pm \sqrt{\frac{\sum_{i=1}^{n}\left(\bar{x}-x_{i}\right)^{2}}{(n-1)}}
$$


En la práctica, interesa conocer cómo de acertada es la estimación del valor medio $\bar{x}$, respecto a $\mathrm{x}_{\mathrm{r}}$, verdadero valor de la magnitud. Para ello es importante tener en cuenta que dicha media $\bar{x}$, no es una constante, sino una variable aleatoria. Es decir, cada vez que se tomasen $n$ muestras en las mismas condiciones el valor resultante sería diferente. Intuitivamente, es posible relacionar la dispersión, estimada a través de la desviación típica muestral s, con el orden de magnitud de la incertidumbre en la estimación de $\mathrm{x}_{\mathrm{r}}$. Mayor dispersión de las medidas necesariamente llevará asociada una elevada incertidumbre en la estimación. Por otro lado, y como se ha dicho anteriormente, al compensarse los errores aleatorios un número mayor de medidas conducirá a una reducción en la incertidumbre.

Formalmente, la incertidumbre se expresa mediante la definición de un intervalo de confianza, que facilita información sobre el rango de valores en el cuál se espera, con una determinada probabilidad, se encuentre el verdadero valor observado, $x_{r}$. Dicho intervalo de confianza se calculará aplicando la expresión 11, donde z es el factor de fiabilidad que depende del grado de confianza con que se quiera calcular el intervalo. Mayor grado de confianza necesariamente lleva asociado, para una misma dispersión de las medidas, un rango más amplio. Típicamente, para intervalos de confianza del 90 y $95 \%$, z adopta valores de 1.68 y 1.96. En la Ecuación 11 también se puede apreciar el efecto del tamaño de muestra, n.

$$
\text { Estimación de } x_{r}=\bar{x} \pm \Delta x=\bar{x} \pm z \frac{s}{\sqrt{n}}
$$

\subsubsection{FUENTES DE INCERTIDUMBRE}

Como se ha explicado, lograr cierto grado de fiabilidad en la medida de caudal está condicionado por las incertidumbres asociadas a las magnitudes físicas que entran en juego durante la medición (Figura 2). Las fuentes de incertidumbre están presentes en toda la cadena, comenzando por la capacidad del propio instrumento de medir correctamente la velocidad local. De esta forma, por ejemplo, un caudalímetro de inserción tipo turbina que mide puntualmente la velocidad del fluido nunca tendrá la misma precisión que un contador de velocidad cuya turbina gira en función de la incidencia del flujo en toda la sección de entrada. El primero, por su propio principio de funcionamiento, está sujeto a mayores incertidumbres, como una mala alineación y colocación del sensor, un aumento de la fricción en el eje de giro, etcétera. Cada aparato que sale de fábrica tiene una precisión condicionada por las limitaciones de su principio de funcionamiento y por las tolerancias de fabricación que se impongan. Esta fuente de incertidumbre está asociada al instrumento y genera errores sistemáticos que pueden evaluarse comparándolo con otro más preciso o mediante alguna técnica de calibración en laboratorio que permita cuantificar la desviación respecto al caudal real.

Una segunda fuente de error aparece durante el cálculo o estimación de la velocidad media axial a partir de las velocidades locales medidas. Este método indirecto de obtención de la velocidad media axial, estimada en cada caso mediante diferentes técnicas, puede generar errores fundamentalmente cuando el perfil de velocidades está distorsionado. En estos casos, la relación entre la velocidad medida por el instrumento y la velocidad media axial cambia produciéndose importantes desviaciones en la estimación del caudal. Durante el Capítulo 4 de la presente Tesis se aborda específicamente este aspecto, observando la influencia sobre la medición de un perfil irregular.

Por último, el diámetro interior de la tubería siempre es una incógnita que produce incertidumbres durante el cálculo de la sección útil de paso del agua. Las incrustaciones y deposiciones calcáreas que reducen éste área y provocan cierta ovalidad respecto a la sección ideal condicionan directamente la estimación de la medida de caudal. 


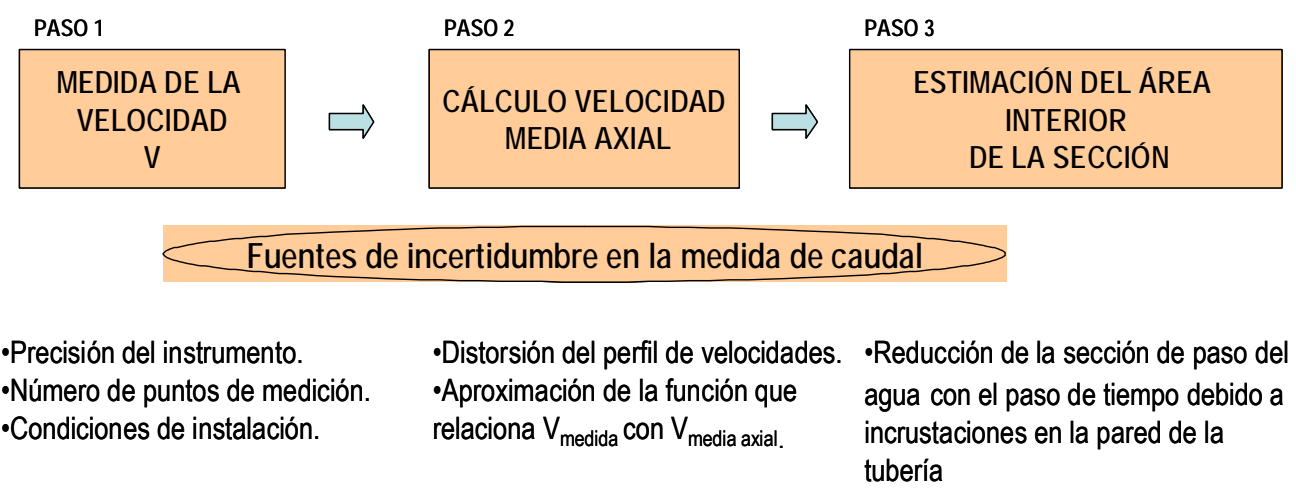

FIGURA 2. ESQUEMA DE LAS FUENTES DE INCERTIDUMBRE EN LA MEDIDA DEL CAUDAL.

Para cuantificar las incertidumbres asociadas a la medida de caudal, como en el caso de la medición de cualquier otra variable, se deberá realizar un análisis de la incertidumbre que indique el intervalo en el que oscilará el verdadero valor de la medida. Es decir, el valor de caudal obtenido del instrumento irá siempre asociado a un intervalo de incertidumbre 0 desviación esperada sobre el valor real de estas medidas. El cálculo de este intervalo requiere necesariamente analizar toda la cadena de medición, desde el elemento primario hasta la señal de salida.

\subsubsection{Transmisión de errores}

Hasta ahora, se han comentado los tipos de errores posibles, aleatorios y sistemáticos, durante el proceso de medición de una determinada variable, por ejemplo el caudal, y las fuentes de incertidumbre que generan dichos errores. En la práctica, para determinar el grado de incertidumbre final en la estimación de una variable, conviene analizar la cadena de medición al completo. Hay que tener en cuenta que la mayoría de las variables se obtiene de forma indirecta. Por ejemplo, el caudal, tal y como se muestra en la Figura 2, se calcula a partir de otras variables que, a su vez, se determinan mediante medición directa o estimación, como el diámetro, la velocidad del fluido, etcétera. Dependiendo del principio de funcionamiento del instrumento, los errores en la estimación de dichas variables auxiliares tendrá un mayor o menor impacto en el resultado final. Precisamente, para conocer el efecto de posibles errores en estas magnitudes en el resultado final de la medida caudal, es necesario emplear la teoría de transmisión de errores. En este sentido, y con el fin de ilustrar mejor los conceptos presentados se aplicará directamente la teoría de transmisión de errores a la medida del caudal.

El cálculo teórico del caudal que circula a través de una superficie se realiza mediante la integración extendida a dicha superficie del producto escalar de la velocidad y diferencial de área. En el caso particular de una conducción circular, interesa conocer el flujo volumétrico que atraviesa una sección perpendicular al eje de la tubería. En este caso particular la Ecuación 12.a se podría simplificar a la Ecuación 12.b. Por comodidad, muchas veces se trabaja con velocidades medias, llegándose a la conocida expresión 13 , que relaciona diámetro, caudal y velocidad media axial.

$$
\begin{gathered}
Q=\oint \vec{V} \cdot d \vec{A} \\
Q=\int_{0}^{2 \pi} \int_{0}^{R} V_{\text {axial }}(r, \varphi) d r d \varphi \\
Q=\frac{\pi \cdot D^{2}}{4} \bar{V}_{\text {axial }}
\end{gathered}
$$


A la hora de analizar la cadena de medición de un determinado caudalímetro hay que plantearse como se obtienen las diferentes variables implicadas en la Ecuación 13. Es decir, el valor del diámetro o de la velocidad media axial se puede obtener mediante medición directa o estimación a través de otras variables. Normalmente será a partir de otras variables 0 magnitudes. Por ejemplo, un caudalímetro de inserción tipo turbina estimará la velocidad media axial a partir de la medición de la velocidad en determinado punto de la sección, un caudalímetro de ultrasonidos la estimará a partir de una velocidad calculada por una diferencia de tiempos, etcétera. Profundizando en el caso del caudalímetro de inserción habría que preguntarse cómo se obtiene la velocidad del fluido en la zona de medición. En este caso la respuesta sería a partir de la velocidad de rotación de la turbina, que a su vez se estima a partir de la frecuencia de oscilación de un campo electromagnético. Por tanto, si hubiese un error en la medición de dicha frecuencia, éste se trasladaría al valor de la velocidad local del fluido y posteriormente a la estimación de la velocidad media axial.

Por tanto, cuando intervienen diversas variables en la medida del caudal y se conoce la incertidumbre con que se determinan estas variables $(x, y, z)$, la incertidumbre máxima, $\Delta Q_{\max }$, se calcula mediante la expresión (14). Esta incertidumbre es una función de la sensibilidad de la medida del caudal a cada una de las variables y el error relativo cometido en la estimación de las mismas $(\Delta \mathrm{x}, \Delta \mathrm{y}, \Delta \mathrm{z})$. En estos casos, el error máximo absoluto cometido en la medida indirecta viene de las derivadas parciales de las diferentes medidas directas (Ecuación 14).

$$
\Delta Q=\left(\left|\frac{\partial Q}{\partial x}\right| \Delta x+\left|\frac{\partial Q}{\partial y}\right| \Delta y+\left|\frac{\partial Q}{\partial z}\right| \Delta z+\ldots\right)
$$

Particularmente, el error relativo en la determinación del caudal, conocidas las incertidumbres en la estimación de la velocidad media axial y el diámetro (expresión 13), se obtiene del siguiente cálculo:

$$
\text { Error relativo } \mathrm{Q}=\frac{\Delta \mathrm{Q}}{\mathrm{Q}}=\frac{\left|\frac{\partial \mathrm{Q}}{\partial \mathrm{V}}\right| \Delta \mathrm{V}+\left|\frac{\partial \mathrm{Q}}{\partial \mathrm{D}}\right| \Delta \mathrm{D}}{\mathrm{K} \cdot \mathrm{D}^{2} \cdot \mathrm{V}}=\frac{\mathrm{K} \cdot \mathrm{D}^{2} \cdot \Delta \mathrm{V}+2 \cdot \mathrm{K} \cdot \mathrm{D} \cdot \mathrm{V} \cdot \Delta \mathrm{D}}{\mathrm{K} \cdot \mathrm{D}^{2} \cdot \mathrm{V}}=\frac{\Delta \mathrm{V}}{\mathrm{V}}+2 \cdot \frac{\Delta \mathrm{D}}{\mathrm{D}}
$$

Es importante comprobar, según la Ecuación 15, que un error relativo del 1\% en la estimación del diámetro tiene un impacto del $2 \%$ en el error relativo de la medida del caudal. Este impacto podría aumentar o disminuir en función de las relaciones que pudiese haber entre las medidas de la velocidad media axial y el diámetro (por ejemplo en un caudalímetro de ultrasonidos).

Teniendo en cuenta que los errores de las diferentes magnitudes pueden compensarse, la mayoría de las veces no se trabaja con los errores máximos, sino con el error cuadrático medio (Ecuación 16). De esta manera, para el caso particular comentado, el error cuadrático medio se calcula de la siguiente forma:

$$
\frac{\Delta Q}{Q}=\frac{\sqrt{\left(\frac{\partial Q}{\partial V} \Delta V\right)^{2}+\left(\frac{\partial Q}{\partial D} \Delta D\right)^{2}}}{K \cdot D^{2} \cdot V}=\frac{K \cdot \sqrt{D^{4} \cdot \Delta V^{2}+4 \cdot D^{2} \cdot V^{2} \cdot \Delta D^{2}}}{K \cdot D^{2} \cdot V}=\sqrt{\frac{\Delta V^{2}}{V^{2}}+\frac{4 \cdot \Delta D^{2}}{D^{2}}}
$$


En términos relativos el error cuadrático medio es siempre inferior en magnitud que el error máximo, al compensarse los errores. En conclusión, se ha visto que es importante considerar la influencia de todas las variables implicada en la cadena de medición, puesto que al final tienen un impacto directo en el cálculo del caudal. El estudio de las incertidumbres asociadas a cada tipo de caudalímetro se desarrolla en detalle en el Capítulo 6 (apartado 5.3.4).

\subsection{NORMATIVA RELATIVA A INSTRUMENTOS DE MEDIDA DE CAUDAL}

Durante el año 2004 se aprobó una nueva Directiva europea 2004/22/CEE relativa a instrumentos de medida en general para sustituir a la Directiva 71/316/CEE. Ambas normativas contemplan de forma general los requerimientos técnicos y metrológicos esenciales de diversos instrumentos. Además, contemplan todos los instrumentos existentes para cualquier aplicación. Normativas específicas actualizadas están en proyecto para armonizar los estándares de todos los países de la Unión Europea. A continuación, se comentan las principales normas relativas a contadores de agua y caudalímetros.

\subsubsection{CONTADORES DE AGUA}

\subsubsection{Normativa actual}

En la actualidad, la normativa europea referente a contadores de agua data de diciembre de 1974 para contadores de agua fría recogida en la Directiva europea 75/33/CEE y la Directiva 79/830/CEE de septiembre de 1979 para agua caliente. Posteriormente, en el año 1993, se redacta una norma internacional ISO 4064 que establece las características metrológicas y modo de empleo de este tipo de instrumentos.

Según esta norma, los caudales que definen las características metrológicas de los contadores de agua y que establecen los márgenes de precisión del instrumento y las clases metrológicas que los agrupan son los siguientes:

- Caudal mínimo ( $\left.Q_{\min }\right)$ : Por encima de este caudal, el error de medida no puede ser superior al $\pm 5 \%$ del caudal realmente trasegado.

- Caudal de transición $\left(Q_{t}\right)$ : Por encima de este caudal el error de medida no puede ser superior al $\pm 2 \%$ del caudal realmente trasegado.

- Caudal máximo $\left(Q_{\operatorname{máx}}\right)$ : Define el límite superior del rango de medida. Por encima de estos caudales el contador no debe funcionar, salvo en periodos limitados, dado que en caso contrario sufriría un deterioro importante.

- Caudal nominal $\left(Q_{n}\right)$ : Es la mitad del caudal máximo y es el que se emplea usualmente para designar al contador. El fabricante garantiza que el instrumento de medida puede trabajar ininterrumpidamente a este caudal sin sufrir deterioro.

Tradicionalmente, los contadores se clasifican en cuatro clases (A, B, C y D), siendo la clase A la de rango de medida más estrecho y la $D$ la de mayor amplitud de rango según la norma internacional ISO 4064. Sin embargo, la directiva 75/33/CEE solo establece las clases A, B y C que son las más comercializadas dentro del sector del agua. Los límites de precisión de todas las clases son los mismos, variando solo el rango de caudales en los que se exige al contador mantener una determinada precisión (Figura 3). 


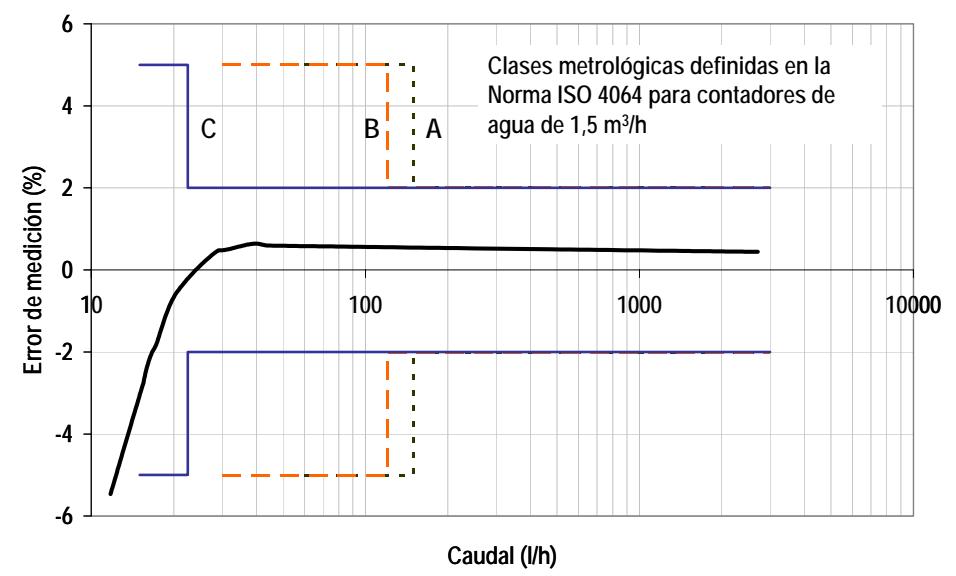

FIGURA 3. EJEMPLO DE LA CURVA DE ERROR DE UN CONTADOR DE AGUA (QN=1,5 M3/H) Y CLASES METROLÓGICAS SEGÚN ISO 4064.

Cuando se ensaya el comportamiento de un contador es posible obtener la curva de error que facilita información sobre el error de medición del contador a cada caudal. En la Figura 3 puede verse un ejemplo de una curva de error típica de un contador de agua y los límites de error definidos por la norma ISO 4064:1999. Se observa en este gráfico que los errores a caudales bajos son mayores debido a que las fuerzas motrices del agua en este rango son inferiores y deben vencer la resistencia ofrecida por el rozamiento de la turbina del contador.

Además, en dicha norma internacional ISO 4064 se recogen los valores del caudal mínimo y de transición para las diferentes clases metrológicas, expresados en función del caudal nominal (Tabla 3).

TABLA 3. CARACTERISTICAS METROLÓGICAS ESTABLECIDAS EN LA NORMATIVA.

\begin{tabular}{llll}
\hline & \multicolumn{3}{c}{ Caudal nominal } \\
\hline Clase metrológica & Caudal & $<15 \mathrm{~m}^{3} / \mathrm{hora}$ & $\geq 15 \mathrm{~m}^{3} /$ hora \\
\hline \multirow{2}{*}{ (CEE/ISO) } & Mínimo & $0.04 \cdot \mathrm{Q}_{\mathrm{n}}$ & $0.08 \cdot \mathrm{Q}_{\mathrm{n}}$ \\
& Transición & $0.10 \cdot \mathrm{Q}_{\mathrm{n}}$ & $0.30 \cdot \mathrm{Q}_{\mathrm{n}}$ \\
B (CEE/ISO) & Mínimo & $0.02 \cdot \mathrm{Q}_{\mathrm{n}}$ & $0.03 \cdot \mathrm{Q}_{\mathrm{n}}$ \\
& Transición & $0.08 \cdot \mathrm{Q}_{\mathrm{n}}$ & $0.20 \cdot \mathrm{Q}_{\mathrm{n}}$ \\
$\mathrm{C}$ (CEE/ISO) & Mínimo & $0.01 \cdot \mathrm{Q}_{\mathrm{n}}$ & $0.006 \cdot \mathrm{Q}_{\mathrm{n}}$ \\
& Transición & $0.015 \cdot \mathrm{Q}_{\mathrm{n}}$ & $0.015 \cdot \mathrm{Q}_{\mathrm{n}}$ \\
\hline
\end{tabular}

La clase metrológica A se encuentra prácticamente en desuso en los abastecimientos urbanos. No obstante, todavía es posible encontrarla en redes de riego por su bajo coste de inversión. Esta clase es la que posee menor amplitud en el rango de caudales de trabajo lo que la hace menos precisa a caudales bajos, y poco atractiva para cierto tipo de usos.

La clase B, puede decirse que es la más extendida en la actualidad por su relación calidad-precio, aunque se están realizando esfuerzos importantes por parte de los fabricantes para sacar al mercado instrumentos más precisos a un coste asequible. La curva de error de estos instrumentos se encuentra desplazada hacia la derecha en comparación con los contadores de clase $\mathrm{C}$, ya que su diseño y fabricación no está sometido a controles tan estrictos, lo que le resta precisión a caudales bajos.

Los contadores de agua más precisos son de la clase metrológica $\mathrm{C}$, que por su peculiar diseño tienen una resistencia mínima a las fuerzas de rozamiento introducidas por las partes móviles del contador, lo cual permite obtener una alta sensibilidad a caudales bajos. Esta baja resistencia se consigue mediante un diseño adecuado de los puntos de apoyo de la turbina y un bajo rozamiento de los engranajes de totalizador. 
En cualquier caso, estas exigencias de precisión impuestas en la normativa vigente sólo rigen para contadores nuevos. Cuando el medidor se encuentra en servicio un periodo de tiempo largo esta precisión mengua provocando errores importantes en el registro de agua. Actualmente, no existe ninguna legislación clara al respecto sobre cuál es el error máximo admisible de los contadores en uso.

\subsubsection{Nueva normativa europea relativa a instrumentos de medida}

El 30 de Abril de 2004 se aprobó la nueva Directiva europea 2004/22/CEE sobre instrumentos de medida que convivirá durante dos años con las normas europeas todavía vigentes recogidas en la Directiva 75/33/CEE para contadores de agua fría y en la 79/830/CEE para agua caliente, citadas anteriormente, tal y como expone Navarro (2003).

En España la legislación actual sobre contadores de agua se encuentra recogida en la orden Ministerial del 28 de Diciembre de 1988, aunque nuevas normas europeas específicas y armonizadas para toda Europa están en proyecto (prEN 14.154 de contadores de agua limpia y prEN 14.268 para contadores de agua de riego). Estos proyectos de norma están basados en las recomendaciones dadas por la Organización Internacional de Metrología en sus documentos OIML R49-1, OIML R49-2 y OIML R49-3, y una de las diferencias más importantes respecto de la anterior se encuentra en la definición de las características metrológicas, no en cuanto a requisitos de los errores máximos permitidos, que son los mismos, sino en lo referente a la nomenclatura utilizada para definir las calidades metrológicas. En este proyecto de norma, los caudales característicos establecidos en las nuevas recomendaciones que clasifican metrológicamente a los instrumentos, son los siguientes:

- Caudal mínimo $\left(Q_{1}\right)$ es el caudal más bajo al cual se exige que el contador funcione dentro del error máximo permisible.

- Caudal permanente $\left(Q_{3}\right)$, caudal más alto en condiciones normales de funcionamiento, al cual se exige que el contador funcione satisfactoriamente dentro del error máximo permisible. Los caudales admitidos en el proyecto de norma se concretan en la Tabla 4.

- Caudal de transición $\left(Q_{2}\right)$ es un caudal entre el mínimo y el permanente que divide el rango de caudales en dos zonas con márgenes de precisión diferentes.

- Caudal de sobrecarga $\left(Q_{4}\right)$ se define como el caudal más alto al cual el contador puede trabajar durante un periodo corto de tiempo, dentro de su error permisible, manteniendo su rendimiento metrológico a posteriori.

Las nuevas normas europeas utilizan otra clasificación metrológica basada en ratios de caudal que definen los límites de error. De esta forma, se determinan tres ratios $\left(Q_{3} / Q_{1}, Q_{2} / Q_{1}, Q_{4} / Q_{3}\right)$ estableciendo como base de cálculo el caudal permanente que puede oscilar entre 1 y $6300 \mathrm{~m}^{3} / \mathrm{h}$ (Tabla 4). De esta forma, según prEN 14.154, los valores que pueden ser elegidos en el ratio $Q_{3} / Q_{1}$ están indicados en la Tabla 5.

TABLA 4. CAUDAL PERMANENTE Q3 (M3/H) SEGÚN PREN14154-1:2004.

\begin{tabular}{lllll}
\hline \multicolumn{5}{c}{ Q3 } \\
\hline $1,5^{*}$ & $3,5^{\star}$ & $6^{*}$ & $15^{*}$ & $20^{\star}$ \\
1 & 1,6 & 2,5 & 4 & 6,3 \\
10 & 16 & 25 & 40 & 63 \\
100 & 160 & 250 & 400 & 630 \\
1000 & 1600 & 2500 & 4000 & 6300 \\
\hline
\end{tabular}

TABLA 5. RATIO Q3/Q1 SEGÚN PREN 14154-1:2004.

\begin{tabular}{llllllllll}
\hline \multicolumn{10}{c}{ Q3/Q1 } \\
\hline $15^{*}$ & $35^{*}$ & $60^{*}$ & $212^{*}$ & & & & & \\
10 & 12,5 & 16 & 20 & 25 & 31,5 & 40 & 50 & 63 & 80 \\
100 & 125 & 160 & 200 & 250 & 315 & 400 & 500 & 630 & 800 \\
\hline & *Valores admitidos durante un periodo de transición de 5 años desde la \\
publicación oficial de la Norma.
\end{tabular}


La relación entre el caudal máximo y el permanente será siempre la misma de 1,25, mientras que el ratio entre el caudal de transición y el mínimo será constante e igual a 1,6. De esta manera, cualquier variación del ratio $Q_{3} / Q_{1}$ modificará también el caudal de transición. Así pues, la Figura 4 muestra la variación de los límites de error de un contador con $\mathrm{Q}_{3} 2,5 \mathrm{~m}^{3} / \mathrm{h}$ cuando se aumenta el ratio $Q_{3} / Q_{1}$ (nombrado como $R$ ).

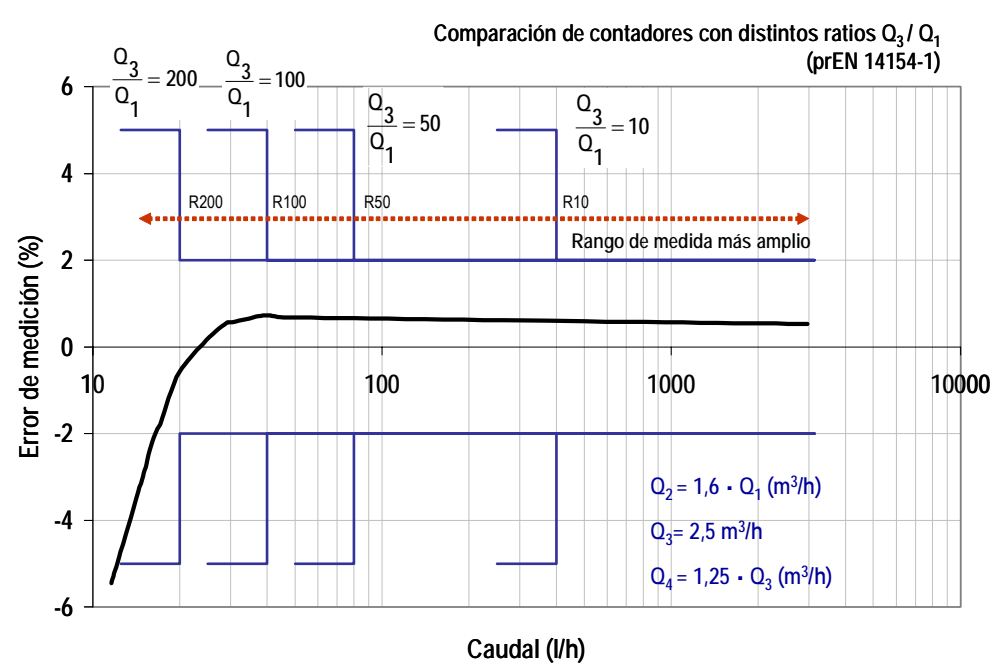

FIGURA 4. CLASIFICACIÓN METROLÓGICA SEGÚN PR 14154 (2004)

Valores más altos del ratio $Q_{3} / Q_{1}$ señalan un rango de medida más amplio. Además, al haber más valores admisibles para este ratio, existe multitud de clase metrológicas que permiten diferenciar las calidades de los instrumentos. Por ejemplo, la Figura 5 muestra una comparativa entre los límites exigidos por la norma vigente y el proyecto de norma prEN14154. Un ratio $Q_{3} / Q_{1}$ de 200 en un contador de $2,5 \mathrm{~m}^{3} / \mathrm{h}$ equivaldría a un caudal mínimo de $12,5 \mathrm{l} / \mathrm{h}$ y un caudal de transición de $20 \mathrm{l} / \mathrm{h}$ frente a los 22,5 y $15 \mathrm{l} / \mathrm{h}$, respectivamente, que supondría un contador de clase metrológica $\mathrm{C}$ con capacidad similar (caudal máximo aproximadamente $3 \mathrm{~m} 3 / \mathrm{h}$ ) en la norma ISO 4064. A su vez, el proyecto de norma admitiría contadores de peor calidad cuando el ratio $Q_{3} / Q_{1}$ fuera inferior (p.e $R=10$ ).

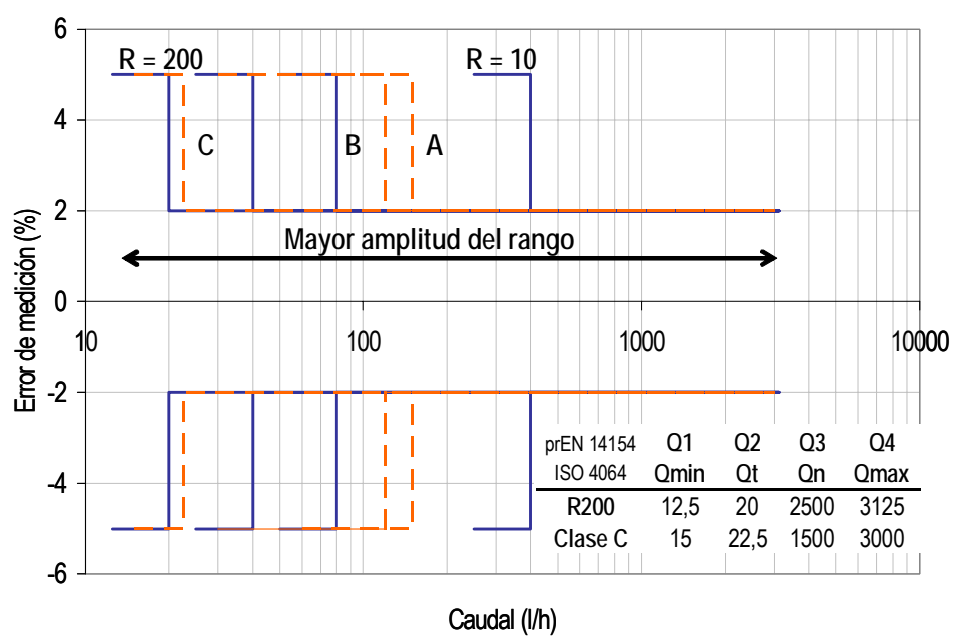

FIGURA 5. COMPARATIVA DE LAS CARACTERÍSTICAS METROLÓGICAS EXIGIDAS EN EL PROYECTO DE NORMA PREN $14154-1$ CON RESPECTO DE LA ISO 4064. 
La equivalencia entre la clase metrológica $B$ para un contador de caudal nominal $1,5 \mathrm{~m} 3 / \mathrm{h}$, común en las instalaciones interiores, y la nueva de la norma europea citada sería un contador con caudal permanente $Q_{3}$ de 2,5 con un ratio $Q_{3} / Q_{1}$ de 80, lo que representa un caudal mínimo de $31,25 \mathrm{l} / \mathrm{h}$ y un máximo de $3.125 \mathrm{l} / \mathrm{h}$. Es decir, la designación en esta nueva normativa sería para un contador de las características descritas en el ejemplo, fabricado en el año 2004 para un funcionamiento en posición horizontal $Q_{3} 2,5 ; R 80 ; H ; n^{0}$ contador; 04; nombre del fabricante.

Además, existen otras clasificaciones descritas en la prEN 14154 que atienden, por ejemplo, a la presión máxima admisible por el instrumento que vienen referenciadas por la MAP (maximum admissible pressure); MAP 6, MAP 10, MAP16, MAP25 y MAP40, 0 a la máxima pérdida de carga admisible al caudal máximo; $\triangle \mathrm{P} 63, \Delta \mathrm{P} 40, \Delta \mathrm{P} 25, \Delta \mathrm{P} 16$ y $\Delta \mathrm{P} 10$. La presión mínima admisible (mPA, minimum admissible pressure) para la cual debe estar diseñado el contador de agua es de 0,3 bar.

Otra clasificación considera el rango de temperaturas máximas o mínimas $\left(e{ }^{\circ} \mathrm{C}\right.$ ) que puede soportar el aparato; $\mathrm{T} 30, \mathrm{~T} 50$, T70, T90, T130, T180, T30/70, T30/90, T30/130 y T30/180.

Por último, se introduce una clasificación que diferencia la sensibilidad de cada instrumento salido de fábrica a las irregularidades en el perfil de velocidades. Así, se llevan a cabo ensayos en laboratorio con diversos elementos perturbadores del flujo y se evalúa el comportamiento del medidor y la necesidad de incorporar tramos rectos 0 estabilizadores de flujo en la instalación donde se coloque el mismo. Las clases se asignan con una $\mathrm{U}$ cuando se designa la influencia aguas arriba del elemento y con D para las exigencias aguas abajo.

TABLA 6. CLASES Y CONDICIONES EN TRAMOS RECTOS AGUAS ARRIBA REQUERIDAS EN CONTADORES DE AGUA SEGÚN PREN14154.

\begin{tabular}{ccc}
\hline Clase & $\begin{array}{c}\text { Longitud en } \\
\text { tramos rectos } \\
\text { requerida }\end{array}$ & $\begin{array}{c}\text { Necesidad de } \\
\text { estabilizador del } \\
\text { flujo }\end{array}$ \\
\hline U0 & 0 & NO \\
U3 & 3 & NO \\
U5 & 5 & NO \\
U10 & 10 & NO \\
U15 & 15 & NO \\
U0S & 0 & SI \\
U3S & 3 & SI \\
U5S & 5 & SI \\
U10S & 10 & SI \\
\hline
\end{tabular}

TABLA 7.CLASES Y CONDICIONES EN TRAMOS RECTOS AGUAS ARRIBA REQUERIDAS EN CONTADORES DE AGUA SEGÚN PREN14154.

\begin{tabular}{ccc}
\hline Clase & $\begin{array}{c}\text { Longitud en } \\
\text { tramos rectos } \\
\text { requerida }\end{array}$ & $\begin{array}{c}\text { Necesidad de } \\
\text { estabilizador } \\
\text { del flujo }\end{array}$ \\
\hline D0 & 0 & NO \\
D3 & 3 & NO \\
D5 & 5 & NO \\
D0S & 0 & SI \\
D3S & 3 & $\mathrm{SI}$ \\
\hline
\end{tabular}

El proyecto de norma prEN 14154-3 introduce nuevos ensayos de durabilidad, resistencia mecánica y inmunidad electromagnética. De esta forma, los contadores de agua se someten a pruebas de durabilidad según el procedimiento resumido en la Tabla 8. 
TABLA 8. ENSAYOS DE DURABILIDAD EN CONTADORES DE AGUA. PREN 14154.

\begin{tabular}{|c|c|c|c|c|c|c|c|c|}
\hline $\begin{array}{l}\text { Clasificación } \\
\text { por } \\
\text { Temperatura }\end{array}$ & $\begin{array}{c}\text { Caudal } \\
\text { permanente } \\
\left(Q_{3}\right)\end{array}$ & $\begin{array}{l}\text { Caudal } \\
\text { ensayo }\end{array}$ & $\begin{array}{l}\text { Temperatura de } \\
\text { ensayo } \pm 5^{\circ} \mathrm{C}\end{array}$ & $\begin{array}{l}\text { Tipo de } \\
\text { ensayo }\end{array}$ & $\begin{array}{c}\mathrm{N}^{0} \text { de } \\
\text { interrupciones }\end{array}$ & $\begin{array}{c}\text { Duración } \\
\text { pausas }\end{array}$ & $\begin{array}{l}\text { Periodo } \\
\text { de la } \\
\text { prueba }\end{array}$ & $\begin{array}{l}\text { Tiempo de } \\
\text { arranque }\end{array}$ \\
\hline \multirow{4}{*}{ T30 y T50 } & \multirow[t]{2}{*}{$Q_{3} \leq 16 \mathrm{~m}^{3} / \mathrm{h}$} & $Q_{3}$ & $20^{\circ} \mathrm{C}$ & Discontinuo & 100.000 & $15 \mathrm{~s}$ & $15 \mathrm{~s}$ & $\begin{array}{c}0,15\left[Q_{3}\right] \mathrm{s} \\
\text { con un } \\
\text { mínimo de } \\
\text { 1s. }\end{array}$ \\
\hline & & $Q_{4}$ & $20^{\circ} \mathrm{C}$ & Continuo & - & - & $100 \mathrm{~h}$ & - \\
\hline & \multirow{2}{*}{$\mathrm{Q}_{3}>16 \mathrm{~m} 3 / \mathrm{h}$} & $Q_{3}$ & $20^{\circ} \mathrm{C}$ & Continuo & - & - & $800 \mathrm{~h}$ & - \\
\hline & & $Q_{4}$ & $20^{\circ} \mathrm{C}$ & Continuo & - & - & $200 \mathrm{~h}$ & - \\
\hline $\begin{array}{l}\text { Contadores } \\
\text { combinados }\end{array}$ & $\mathrm{Q}_{3}>16 \mathrm{~m} 3 / \mathrm{h}$ & $Q \geq 2 x Q_{x}$ & $20^{\circ} \mathrm{C}$ & Discontinuo & 50.000 & $15 \mathrm{~s}$ & $15 \mathrm{~s}$ & $3 a 6 s$ \\
\hline \multirow{4}{*}{ Otras clases } & \multirow[t]{2}{*}{$Q_{3} \leq 16 \mathrm{~m}^{3} / \mathrm{h}$} & $Q_{3}$ & $50^{\circ} \mathrm{C}$ & Discontinuo & 100.000 & $15 \mathrm{~s}$ & $15 \mathrm{~s}$ & $\begin{array}{c}0,15\left[Q_{3}\right] \mathrm{s} \\
\text { con un } \\
\text { mínimo de } \\
\text { 1s. }\end{array}$ \\
\hline & & $\mathrm{Q}_{4}$ & $0,9 \cdot \mathrm{MAT}$ & Continuo & - & - & $100 \mathrm{~h}$ & - \\
\hline & \multirow{2}{*}{$\mathrm{Q}_{3}>16 \mathrm{~m} 3 / \mathrm{h}$} & $Q_{3}$ & $50^{\circ} \mathrm{C}$ & Continuo & - & - & $800 \mathrm{~h}$ & - \\
\hline & & $\mathrm{Q}_{4}$ & $0,9 \cdot \mathrm{MAT}$ & Continuo & - & - & $200 \mathrm{~h}$ & - \\
\hline
\end{tabular}

Tras estos ensayos de durabilidad los instrumentos deben someterse a nuevas pruebas metrológicas admitiendo variaciones sobre la curva de error del instrumento nuevo de $3 \%$ para caudales en la zona baja del rango $\left(Q_{1}<Q<Q_{2}\right)$ y de $1,5 \%$ en la zona alta $\left(Q_{2}<Q<Q_{4}\right)$. Además, los errores de medida no deben superar $\pm 6 \%$ en esta zona baja y $\pm 2,5 \% 0 \pm 3 \%$ en la zona alta para contadores de agua fría o caliente, respectivamente.

También, la citada norma introduce controles metrológicos estableciendo el tamaño de muestra y el número de elementos que se deben ensayar durante la aprobación del modelo. Posteriormente, una vez aprobado el diseño de contador se somete cada instrumento a una verificación inicial donde se realizan ensayos de error antes de salir de fábrica a tres caudales entre $Q_{1}$ y $1,1 Q_{1}, Q_{2}$ y $1,1 Q_{2}$ y $0,9 Q_{3}$ y $Q_{3}$ exigiendo al instrumento no superar los errores máximos permitidos para cada caudal.

\subsubsection{CAUDALÍMETROS}

En contraste con los contadores de agua, los caudalímetros no tienen legalmente unas exigencias metrológicas iniciales. Antes de salir de fábrica se someten a una serie de ensayos de calibración que les confieren un mínimo de calidad descrito en las especificaciones técnicas de cada a aparato, pero sin ser sometidos a una certificación metrológica legal por parte de las autoridades. No obstante, existen o están en elaboración estándares específicos para los tipos de caudalímetros más comunes.

Por ejemplo, la norma internacional EN ISO 6817: 1992 describe el principio de funcionamiento, la instalación, prestaciones y adecuada calibración de los caudalímetros electromagnéticos. La norma ISO 9104 (EN 29104) evalúa el funcionamiento de estos instrumentos y las variables que afectan a su medición.

De igual forma, la norma internacional ISO 5167-1 especifica la forma y el modo de empleo de instrumentos de medida de caudal basados en la medida de la presión diferencial, como diafragmas, toberas y tubos Venturi insertados en una tubería de sección circular en carga. Esta norma, al igual que la anterior para caudalímetros electromagnéticos, cubre las informaciones necesarias para el cálculo del caudal y de su incertidumbre asociada, además de sus requisitos constructivos. 


\subsection{CLASIFICACIÓN DE LOS INSTRUMENTOS DE MEDIDA DE CAUDAL EN CONDUCTOS CERRADOS}

En la actualidad existe en el mercado gran cantidad de caudalímetros y contadores de agua con multitud de principios de funcionamiento de acuerdo a los requerimientos de cada sistema. Generalmente, como se comenta en el epígrafe anterior, a un instrumento de medida de caudal se le exige precisión, robustez, durabilidad, versatilidad en diferentes condiciones del flujo, etcétera. Muchos de los principios de funcionamiento han quedado obsoletos y han sido superados ampliamente por otros, por ello, en la presente Tesis doctoral se abordan únicamente los instrumentos más comunes, hoy en día, en las redes de distribución urbana y agrícola.

La clasificación realizada de los instrumentos de medida de caudal en este trabajo atiende a su principio de funcionamiento. Apartados posteriores abordarán con más detalle cada una de estas tecnologías.

En primera instancia definiremos la diferencia entre un contador y un caudalímetro. Los contadores totalizan el volumen de agua que circula por su interior mediante la integración del caudal a lo largo del tiempo. Los caudalímetros, en cambio, proporcionan el caudal instantáneo circulante en el instante de observación. En la práctica ${ }^{1}$ es fácil confundirlos. En numerosas ocasiones, los contadores vienen adaptados con convertidores que proporcionan el caudal instantáneo en el mismo visor, o el caso contrario, existen caudalímetros capaces de acumular el volumen circulado, y que actúan como contador. La nueva directiva atenuará, aún más si cabe, la frontera entre ambos términos.

Teniendo en cuenta las anteriores consideraciones se puede proceder a realizar la clasificación por tecnologías. Así pues dentro de los contadores, existe una primera categoría con una característica común por la que pueden agruparse juntos. El elemento primario del instrumento se mueve proporcionalmente a la velocidad de paso del agua. A este tipo de contadores se les denomina comúnmente de velocidad. Una segunda categoría comprendería los contadores volumétricos que miden el agua contabilizando el número de veces que se llena y vacía una cámara interna de volumen conocido. Dentro de la clasificación de contador puede existir combinaciones de dos tipos de tecnología, por ejemplo un contador Woltman con uno de chorro único en el mismo aparato. La ventaja fundamental de este tipo de instrumento es que amplían el rango de caudales de funcionamiento, ya que permite que circule por el contador de pequeño calibre los caudales más bajos y por el de mayor calibre los más altos, logrando mayor rango de medición.

Por último, existen principalmente dos tipos de caudalímetros comunes en los servicios de agua. Los caudalímetros electromagnéticos crean un campo electromagnético que induce una fuerza electromotriz medible proporcional a la velocidad de circulación del fluido. Los caudalímetros de ultrasonidos de tiempo de tránsito aprovechan la velocidad de propagación del sonido a través de un medio transmisor como el agua para registrar el tiempo transcurrido desde que las ondas sonoras generadas desde el punto emisor llegan al punto receptor.

Existen otros caudalímetros utilizados por las empresas de abastecimiento de agua. El primer tipo son los de presión diferencial, como el tubo Venturi o la placa orificio, donde el paso del agua por el aparato origina una presión diferencial entre la entrada y la salida que puede relacionarse con el caudal circulante. Los caudalímetros de área variable o rotámetros miden el caudal mediante la relación existente entre la posición de un flotador dentro de un tubo vertical de sección variable que se encuentra inmerso en la corriente de fluido.

A continuación, en la Tabla 9, se exponen las principales características y la clasificación de los instrumentos de medida de caudal.

\footnotetext{
${ }^{1}$ Numerosos técnicos confunden ambos términos, llamando a los caudalímetros contadores, y viceversa.
} 
TABLA 9. PRINCIPALES CARACTERISTICAS DE LOS INSTRUMENTOS DE MEDIDA DE CAUDAL.

\begin{tabular}{|c|c|c|c|c|c|c|c|c|}
\hline INSTRUMENTO & TIPO & TECNOLOGÍA & USOS EN AGUA & $\begin{array}{c}\text { RANGO DE } \\
\text { CAUDALES } \\
\left(\mathrm{m}^{3} / \mathrm{h}\right)\end{array}$ & $\begin{array}{c}\text { CALIBRES } \\
(\mathrm{mm})\end{array}$ & PRECISIÓN & $\begin{array}{l}\text { PÉRDIDA DE } \\
\text { CARGA a Q } \\
\text { (bar) }\end{array}$ & COSTE \\
\hline \multirow{8}{*}{ CONTADOR } & \multirow{5}{*}{ DE VELOCIDAD } & Chorro único & Doméstico/ndustrial & $0,6-50$ & $7-100$ & •• & 0,9 & Medio \\
\hline & & Chorro mútiple & Doméstico/lndustrial/ Riego & $1,5-15$ & $15-50$ & •• & 0,9 & Medio \\
\hline & & Woltman & Industrial / Gestión red & $20-2500$ & $50-500$ & $\bullet$ & $0,2-0,4$ & Medio \\
\hline & & Proporcional & Riego & $80-500$ & $65-150$ & - & 0,5 (a Qmax) & Bajo \\
\hline & & Tangencial & Riego & $15-600$ & $50-300$ & - & 0,1 & Bajo \\
\hline & \multirow{2}{*}{ VOLUMÉTRICOS } & Pistón rotativo & Doméstico & $1-36$ & $15-100$ & $\cdots$ & $<1$ & Medio \\
\hline & & Disco nutante & Doméstico & - & - & •• & $<1$ & Medio \\
\hline & COMBINADOS & & Industrial & $20-2500$ & $50-500$ & •.• & 0,4 & Medio \\
\hline \multirow{7}{*}{ CAUDALÍMETRO } & \multirow{2}{*}{$\begin{array}{l}\text { DE PRESIÓN } \\
\text { DIFERENCIAL }\end{array}$} & Placa orificio & Industrial & $1-3 \cdot 10^{5}$ & 50-1000 & $\bullet$ & Alta & Medio \\
\hline & & Tubo Venturi & Industrial & $30-7000$ & 50-1200 & •• & Media & Medio/Bajo \\
\hline & \multirow[b]{2}{*}{ DE INSERCIÓN } & Electromagnético & Industriall Gestión red & \multirow{2}{*}{$\begin{array}{l}\text { Fon del grado } \\
\text { de inserción }\end{array}$} & $200-8000$ & - & Baja & Medio/Bajo \\
\hline & & Tipo turbina & Industriall Gestión red & & & - & Baja & Bajo \\
\hline & $\begin{array}{l}\text { CON TENSIÓN } \\
\text { INDUCIDA }\end{array}$ & Electromagnético & Industrial / Gestión red & $0,02-10^{5}$ & $2-3000$ & $\bullet \bullet$ & Baja & Medio/Alto \\
\hline & \multirow{2}{*}{ ULTRASONIDOS } & $\begin{array}{l}\text { Ultrasonidos de tiempo } \\
\text { de tránsito }\end{array}$ & Industria // Gestión/Verificación red & $3-10^{5}$ & 10-2000 & $\bullet \bullet$ & Baja & Medio/Alto \\
\hline & & $\begin{array}{l}\text { Ultrasonidos de efecto } \\
\text { Doppler }\end{array}$ & Industria & 3-10 55 & $200-1000$ & • & Baja & Medio/Alto \\
\hline
\end{tabular}

\subsection{CONTADORES DE VELOCIDAD}

\subsubsection{TECNOLOGÍA DE CHORRO ÚNICO}

\subsubsection{Principio de funcionamiento}

Los contadores de chorro único son los instrumentos más comunes utilizados en los domicilios españoles para la medición del agua consumida por los abonados. Los más habituales son los de pequeño calibre de $15 \mathrm{~mm}$ con un caudal nominal de $1,5 \mathrm{~m}^{3} / \mathrm{h}$, aunque es posible encontrar calibre superiores en industrias o en establecimientos con mayor consumo de agua.

Como se ha comentado anteriormente, estos instrumentos contabilizan el consumo de agua totalizando el número de vueltas de la turbina cuando el agua incide sobre ella. La velocidad de giro de la turbina depende del caudal de agua circulante en cada momento. En esta construcción, a diferencia de otros contadores, el flujo incide sobre un único punto de la periferia de la turbina.

En principio, estos contadores están pensados para funcionar en posición horizontal, con el eje de la turbina totalmente vertical. No obstante, existen modelos homologados para funcionar en cualquier posición, aunque en ocasiones en detrimento de su precisión. 
Las características dimensionales del instrumento adquieren un papel esencial en la metrología del mismo. Así pues, los sólidos en suspensión y las sedimentaciones calcáreas pueden dar lugar a sobrecontaje, cambiando la relación entre el caudal y la velocidad de giro de la turbina al depositarse en el cuerpo del contador. También, las fibras y sólidos en suspensión alteran el correcto funcionamiento de estos contadores, bloqueando o dificultando el giro de la turbina, lo que evidentemente provoca subcontaje.

Los perfiles de velocidad distorsionados no suelen afectar gravemente a la calidad de medición, es decir, no aumentan el error de registro del contador. Esto es debido a su diseño, en el que normalmente la entrada tiene forma de tobera convergente que regulariza los perfiles de velocidad distorsionados, manteniendo constante la relación entre la velocidad de giro de la turbina y el caudal. Por ello, en general, no se requiere de la disposición de tramos rectos de tubería aguas arriba del contador.

Las pérdidas de carga admisibles para este tipo de instrumentos es de 1 bar al caudal máximo, siendo generalmente del orden de 0,2-0,25 bar a caudales nominales.

\subsubsection{Características constructivas}

Estos instrumentos están compuestos por un totalizador de consumo unido por unos engranajes o un acoplamiento mecánico a la turbina. De esta forma, cada vuelta efectuada será transmitida por los engranajes al totalizador que se moverá en función de la resolución del contador. Para cada instrumento, el número de vueltas de la hélice se asocia a un volumen marcado en el totalizador mediante una relación de desmultiplicación constante. Por ejemplo, un litro de agua circulado puede corresponder a 25 vueltas de la turbina. De esta forma, se computa el volumen total consumido por el usuario.

Por tanto, los contadores de chorro único clásicos se componen del totalizador con unos engranajes magnéticos y un visor de lectura, una tapa de la carcasa que aísla la zona de paso del agua del resto del instrumento y que en algunos casos sirve como elemento de regulación de la curva de error, una turbina giratoria y una caja o cuerpo de latón (Figura 6).

En la actualidad el diseño de esta tecnología ha mejorado cualitativamente. Los fabricantes han puesto hincapié en mejorar los acabados de la caja del contador introduciendo modelos de plástico en los que las tolerancias de fabricación son más estrictas. Además, evalúan el número de paletas más adecuado de la turbina en función de su geometría. Menor número de paletas supone menos inercia de la turbina y consecuentemente caudales de arranque más bajos, aumentando el rango de medición. Por contra, es más susceptible a oscilaciones y desequilibrios que deterioren la turbina prematuramente.

La transmisión mecánica desde la turbina hasta el totalizador se sustituye por un acoplamiento magnético, protegido de cualquier interferencia. Todos estos adelantos depuran y hacen más robustos a los contadores de chorro único conservando mejor en el tiempo sus características metrológicas.

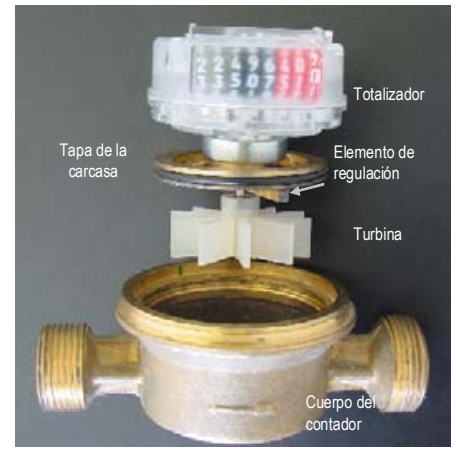

FIGURA 6. DESPIECE DE UN CONTADOR DE CHORRO ÚNICO.

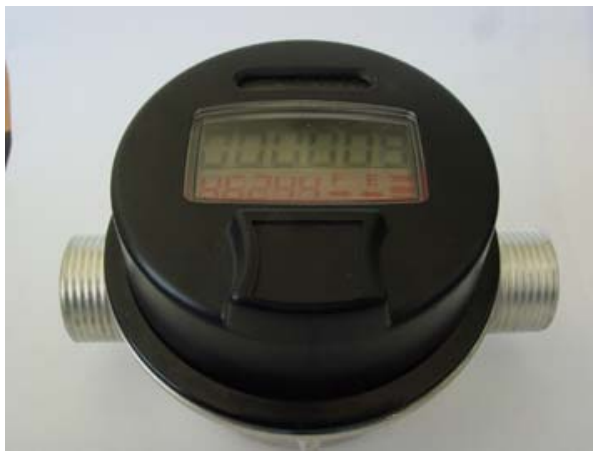

FIGURA 7. CONTADOR DE CHORRO ÚNICO CON TECNOLOGÍA ELECTRÓNICA. 
En cualquier caso, el desarrollo tecnológico de los contadores de agua se encamina hacia instrumentos más precisos con mayores prestaciones. Actualmente, se están sustituyendo los totalizadores mecánicos por totalizadores electrónicos que incorporan características que los hacen atractivos en el mercado del agua (Figura 7). En la tabla siguiente se comparan las ventajas aportadas por este tipo de tecnología frente a la tradicional.

TABLA 10. COMPARATIVA ENTRE CONTADORES TRADICIONALES Y ELECTRÓNICOS

\begin{tabular}{|c|c|}
\hline CONTADOR MECÁNICO & CONTADOR ELECTRÓNICO \\
\hline $\begin{array}{l}\text {-Solo admite lectura remota con emisores de impulsos. } \\
\text {-Pueden alcanzar, Clase } \mathrm{C} \text { en horizontal, pero son clase B en posición } \\
\text { vertical (salvo excepciones). } \\
\text { - Caudal de arranque } 5-8 \mathrm{l} / \mathrm{h} \text {. } \\
\text { - Transmisión mecánica o magnética. Fricción en engranajes del totalizador. } \\
\text { - No admite ajuste del comportamiento metrológico por software.. }\end{array}$ & $\begin{array}{l}\text { - Lectura automática mediante bus. } \\
\text { - Capacidad de almacenamiento de datos y análisis de } \\
\text { información. } \\
\text { - Clase } \mathrm{C} \text { en cualquier posición. } \\
\text { - Caudal de arranque } 2-3 \mathrm{l} / \mathrm{h} \text {. } \\
\text { - Un único elemento móvil, la turbina. No existe fricción mecánica } \\
\text { en los engranajes. } \\
\text {-Posible regulación metrológica mediante sofware. }\end{array}$ \\
\hline
\end{tabular}

El atractivo principal de estos instrumentos es la capacidad de almacenamiento y análisis de los datos de consumo de agua. El software permite detectar aquellos consumos que estadísticamente se encuentran fuera de la normalidad, como una situación de fuga. También aporta información sobre los hábitos de consumo del usuario, extrayendo los patrones de consumo sin necesidad de instalar un datalogger con un emisor de impulsos. Evidentemente, detalla el consumo mensual registrado por el usuario y lo almacena para un posterior análisis de la evolución de las facturaciones en los sucesivos periodos (Figura 8).

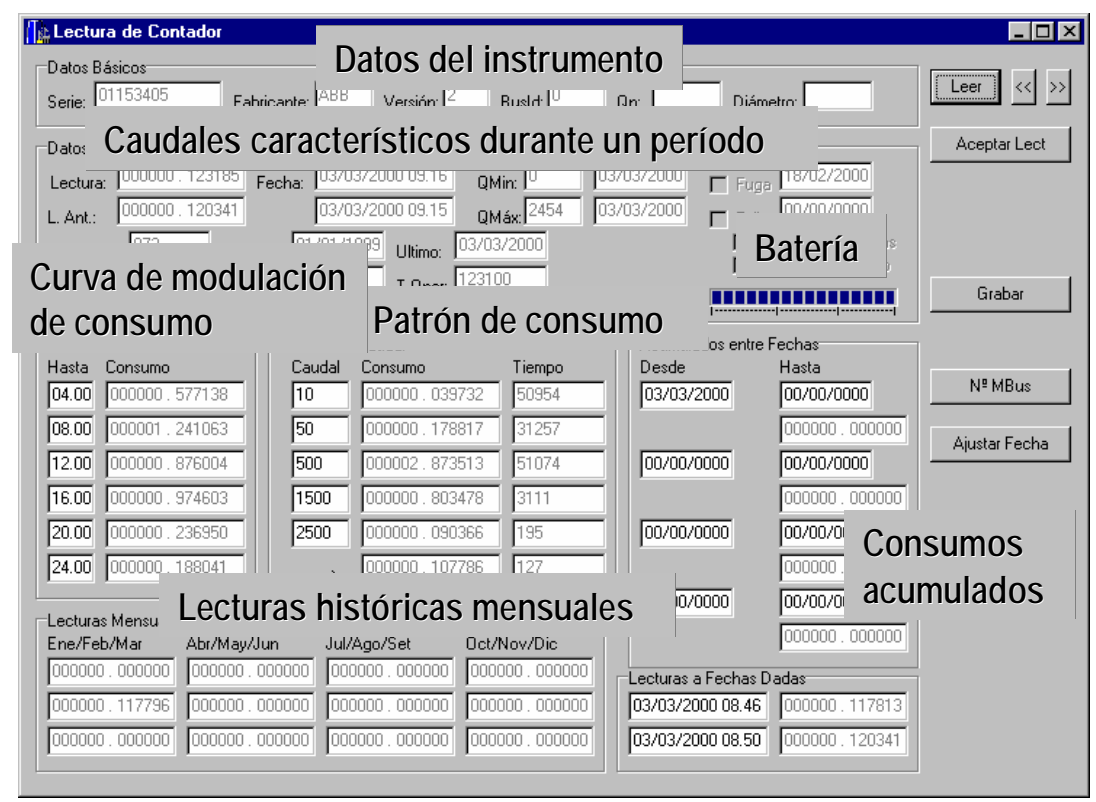

FIGURA 8. SOFTWARE DE ANÁLISIS. 


\subsubsection{TECNOLOGÍA DE CHORRO MÚLTIPLE}

\subsubsection{Principio de funcionamiento}

Los contadores de chorro múltiple se incluyen al igual que los de chorro único en el grupo de los contadores de velocidad. Este tipo de contadores son muy utilizados en redes de riego, generalmente, en tuberías terciarias y en establecimientos e industrias donde el consumo de agua es superior al de un domicilio y se requiere el uso de instrumentos mecánicamente más robustos. Los calibres oscilan entre 15 y $50 \mathrm{~mm}$, es decir, hasta un caudal nominal de $15 \mathrm{~m}^{3} / \mathrm{h}$. Las tablas siguientes detallan las principales características metrológicas mostradas en un catálogo comercial, además de una comparativa entre clases para una misma tecnología. Habitualmente, en este caso la clase metrológica más precisa abarca solo calibres hasta $20 \mathrm{~mm}$ (Tabla 12).

TABLA 11. CARACTERÍSTICAS METROLÓGICAS CONTADOR DE CHORRO MÚLTIPLE. CLASE B.

\begin{tabular}{|c|c|c|c|c|c|c|}
\hline CARACTERÍSTICA & & $\mathrm{CL}$ & E ME & OLÓ & CA B & \\
\hline Diámetro $(\mathrm{mm})$ & 15 & 20 & 25 & 30 & 40 & 50 \\
\hline$Q_{N}\left(m^{3} / h\right)$ & 1,5 & 2,5 & 3,5 & 5 & 10 & 15 \\
\hline$Q_{\max }\left(m^{3} / h\right)$ & 3 & 5 & 7 & 10 & 20 & 30 \\
\hline Qtransición $(I / h)( \pm 2 \%)$ & 120 & 200 & 280 & 400 & 800 & 3000 \\
\hline$Q_{\min }(1 / h)( \pm 5 \%)$ & 30 & 50 & 70 & 100 & 200 & 450 \\
\hline Pérdida de carga a $Q_{N}$ & \multicolumn{6}{|c|}{0,25} \\
\hline Caudal de arranque (l/h) & 10 & 13 & 25 & 25 & 70 & 90 \\
\hline
\end{tabular}

TABLA 12. CARACTERÍSTICAS METROLÓGICAS CONTADOR DE CHORRO MÚLTIPLE. CLASE C.

\begin{tabular}{lll}
\hline CARACTERÍSTICA & \multicolumn{2}{l}{ CLASE METROLÓGICA C } \\
\hline Diámetro $(\mathrm{mm})$ & 15 & 20 \\
$\mathrm{Q}_{\mathrm{N}}\left(\mathrm{m}^{3} / \mathrm{h}\right)$ & 1,5 & 2,5 \\
$\mathrm{Q}_{\max }\left(\mathrm{m}^{3} / \mathrm{h}\right)$ & 3 & 5 \\
$\mathrm{Q}_{\text {transición }}(\mathrm{I} / \mathrm{h})( \pm 2 \%)$ & 22,5 & 37,5 \\
$\mathrm{Q}_{\min }(\mathrm{l} / \mathrm{h})( \pm 5 \%)$ & 15 & 25 \\
Pérdida de carga a $\mathrm{Q}_{\mathrm{N}}(\mathrm{bar})$ & 0,25 & \\
Caudal de arranque $(\mathrm{l} / \mathrm{h})$ & 10 & 13 \\
\hline
\end{tabular}

Al igual que ocurre con los contadores del apartado anterior, la velocidad de giro de la turbina depende de la velocidad de impacto del agua sobre la misma. Por ello, cualquier modificación en la relación entre el caudal y la velocidad a la cual debe entrar el agua en la cámara de la turbina implica una alteración en la curva de error. La diferencia de funcionamiento con respecto a los contadores de chorro único está en cómo incide el agua en la turbina. En los contadores de chorro múltiple el agua golpea en el elemento giratorio en toda la periferia de la cámara. Con esta característica se consigue un funcionamiento más equilibrado de la turbina y, en teoría, mayor durabilidad del contador.

Al igual que los contadores de chorro único, estos contadores no requieren tramos rectos de tubería aguas arriba. Una instalación inclinada o en vertical es muy habitual, si bien suele reducir su vida útil y la sensibilidad del contador a caudales bajos. Sin embargo, cuando se trabaja en torno a su caudal nominal, caudales medios y altos, la curva de error no se ve afectada.

La sedimentación de partículas disueltas en el agua es un fenómeno común en las redes de riego debido a su funcionamiento discontinuo (programado) y a las oscilaciones de temperatura en las tuberías de distribución, y resulta un inconveniente ya que favorece la obturación tanto del circuito de regulación como de la tobera de entrada del contador, produciendo en ocasiones el paro total del instrumento de medida.

Las pérdidas de carga, generalmente están próximas a 1 bar al caudal máximo de funcionamiento.

\subsubsection{Características constructivas}

Como en el instrumento anterior, los elementos principales de los que consta un contador de chorro múltiple son un totalizador y una turbina. Además, en este caso, la turbina se encuentra alojada dentro de una cámara de distribución plástica con diversas aperturas por donde entra el agua. Esta cámara se protege de sólidos en suspensión y sedimentos con un filtro, tal y como se muestra en la Figura 9. 
En los contadores de chorro múltiple, la regulación de la curva de error se logra gracias a la presencia de un circuito en paralelo que ajusta el porcentaje de flujo incidente sobre la turbina dentro de unos márgenes adecuados. Para evitar la obturación de este circuito, el instrumento dispone de un segundo filtro a la entrada. No obstante, en caso de taponarse este by-pass, a causa de fibras o sólidos en suspensión de cierto tamaño, la velocidad de circulación del agua por la turbina será superior a la esperada para un determinado caudal, por lo que la turbina girará a mayor velocidad. Es decir, en estos casos, los errores de contaje se volverán positivos.

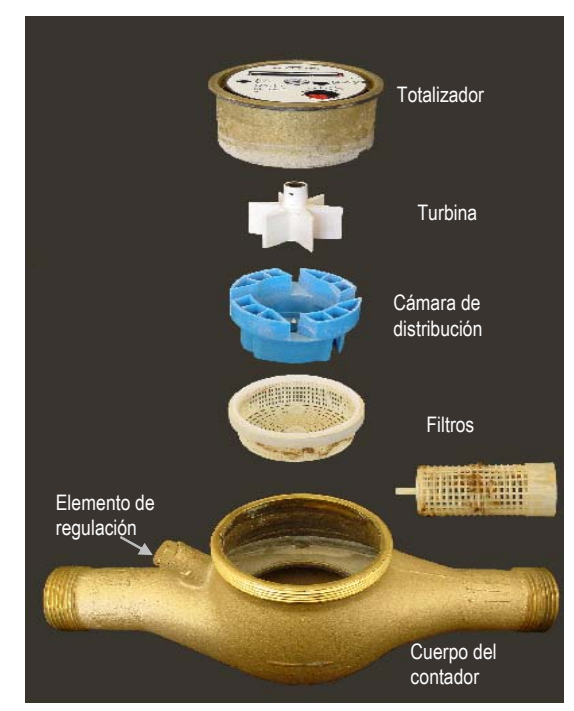

FIGURA 9. DESPIECE DE UN CONTADOR DE CHORRO MÚLTIPLE.

\subsubsection{TECNOLOGÍA WOLTMAN}

\subsubsection{Principio de funcionamiento}

Se denominaron Woltman a este tipo de contadores de agua en homenaje a su inventor Reinhard Woltman que diseñó en 1790 el primer medidor de caudal tipo turbina. Este tipo de instrumentos de mayor calibre son utilizados comúnmente en instalaciones de agua donde los caudales circulantes son elevados. Su elemento primario, como en todos los contadores de velocidad, es una hélice sobre la que incide, en dirección axial, el flujo de agua (Figura 10). La velocidad de giro de la misma es función tanto del caudal como de las características constructivas de la hélice, y del ángulo de ataque del agua sobre sus álabes. En el Capítulo 4, se estudia en detalle la incidencia del agua sobre este elemento y la influencia que llegan a ejercer otros accesorios sobre el flujo y consecuentemente sobre su capacidad de medición.

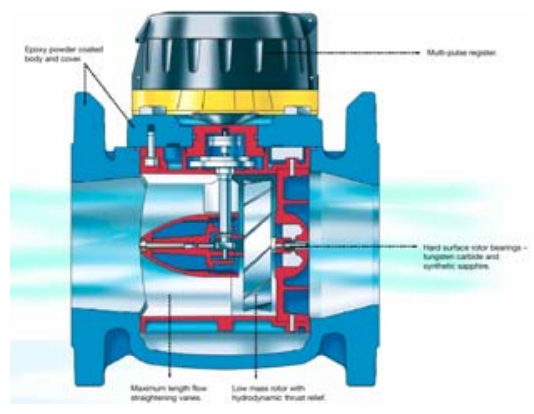

FIgURA 10. CORTE TRANSVERSAL DE UN CONTADOR WOLTMAN DE EJE HORIZONTAL (ABB)

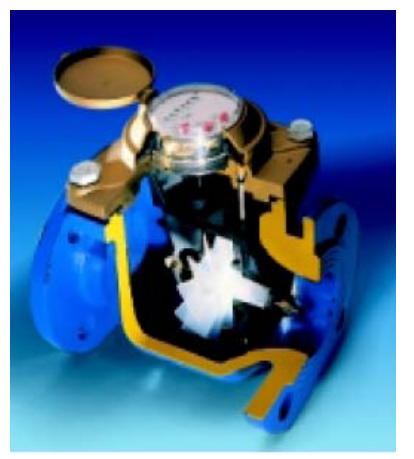

FIGURA 11. INTERIOR DE LA CÁMARA DE MEDICIÓN DE UN WOLTMAN DE EJE HORIZONTAL. 
Existen tres tipos de contador Woltman en función de sus características constructivas y del eje de rotación de la turbina los de eje horizontal, los de eje vertical y los Woltman en codo. En los contadores Woltman de eje horizontal (Figura 11) la dirección del flujo de agua coincide con el eje de giro de la turbina, en cambio, los de eje vertical el avance del fluido se produce perpendicularmente al eje de giro. La tecnología en codo es poco habitual y se utiliza para la medición del agua en pozos (Figura 12).

En los contadores Woltman de eje horizontal, es lógico pensar que el perfil de velocidades a la entrada juega un papel importante en la metrología del mismo. Estudios realizados en torno a este aspecto muestran la necesidad de establecer cierta longitud de tubería recta para regularizar de nuevo un perfil previamente distorsionado por otro elemento hidráulico.
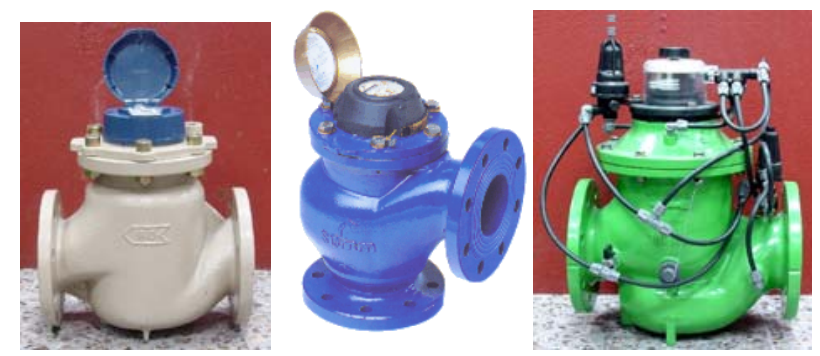

FIGURA 12. CONTADORES WOLTMAN. TECNOLOGÍA EJE VERTICAL, EN CODO Y VÁLVULA-CONTADOR.

En ocasiones, fundamentalmente en redes de riego, es posible encontrar una variante de los contadores de eje vertical a la que se le añade una válvula de control o regulación. Esta válvula actúa cuando por el contador ha circulado un determinado volumen de agua o simplemente para limitar el caudal, la presión o ambos parámetros. A estos contadores se les denomina comúnmente válvulas-contador, válvulas volumétricas, o hidrómetros.

Los calibres de los contadores Woltman oscilan entre $50 \mathrm{~mm}$ y $800 \mathrm{~mm}$ en función del diseño del instrumento, aunque es difícil encontrar instrumentos de diámetro superior a $500 \mathrm{~mm}$. Los Woltman de eje horizontal tienen mayor capacidad de caudal para un mismo diámetro que los de eje vertical y en codo. Sin embargo, su sensibilidad a caudales bajos con respecto a los contadores de eje vertical es inferior, como se puede ver en el resumen extraído de diferentes catálogos comerciales para calibres de 50 a $150 \mathrm{~mm}$ (Tabla 13 y Tabla 14).

TABLA 13. CARACTERISTICAS DE FUNCIONAMIENTO DE UN WOLTMAN HORIZONTAL.

\begin{tabular}{|c|c|c|c|c|c|c|}
\hline Diámetro & $\mathrm{mm}$ & 50 & 65 & 80 & 100 & 150 \\
\hline Caudal nominal & $\mathrm{m} 3 / \mathrm{h}$ & 25 & 40 & 60 & 100 & 250 \\
\hline Caudal máximo & $\mathrm{m} 3 / \mathrm{h}$ & 50 & 80 & 120 & 200 & 500 \\
\hline Caudal de transición $( \pm 2 \%)$ & $\mathrm{m} 3 / \mathrm{h}$ & 5 & 8 & 12 & 20 & 50 \\
\hline Caudal mínimo $( \pm 5 \%)$ & $\mathrm{m} 3 / \mathrm{h}$ & 0.75 & 1.2 & 1.8 & 3 & 7.5 \\
\hline Caudal de arranque & $\mathrm{l} / \mathrm{h}$ & 200 & 250 & 300 & 400 & 1400 \\
\hline Caudal excepcional (pocos minutos) & $\mathrm{m} 3 / \mathrm{h}$ & 90 & 200 & 250 & 300 & 700 \\
\hline Pérdida de carga a $Q \max$ & bar & 0.3 & 0.6 & 0.6 & 0.3 & 0.3 \\
\hline
\end{tabular}

TABLA 14. CARACTERÍSTICAS DE FUNCIONAMIENTO DE UN WOLTMAN VERTICAL.

\begin{tabular}{|c|c|c|c|c|c|c|}
\hline Diámetro & $\mathrm{mm}$ & 50 & 65 & 80 & 100 & 150 \\
\hline Caudal nominal (ISO 4064) & $\mathrm{m} 3 / \mathrm{h}$ & 15 & 25 & 40 & 60 & 150 \\
\hline Caudal máximo (ISO 4064) & $\mathrm{m} 3 / \mathrm{h}$ & 30 & 50 & 80 & 120 & 300 \\
\hline Caudal de transición (ISO 4064) & $\mathrm{m} 3 / \mathrm{h}$ & 3 & 5 & 8 & 12 & 30 \\
\hline Caudal mínimo (ISO 4064) & $\mathrm{m} 3 / \mathrm{h}$ & 0.45 & 0.75 & 1.20 & 1.80 & 4.5 \\
\hline Caudal de arranque & $\mathrm{l} / \mathrm{h}$ & 0.05 & 0.07 & 0.10 & 0.11 & 0.50 \\
\hline Caudal excepcional(pocos minutos) & $\mathrm{m} 3 / \mathrm{h}$ & 35 & 70 & 110 & 180 & 350 \\
\hline Pérdida de carga a Q maximo & bar & 0,23 & 0,27 & 0,38 & 0,28 & 0,58 \\
\hline
\end{tabular}


En estos casos, un Woltman de calibre, por ejemplo, $80 \mathrm{~mm}$ tiene un caudal nominal de $60 \mathrm{~m}^{3} / \mathrm{h}$ frente a los $40 \mathrm{~m}^{3} / \mathrm{h}$ de uno de eje vertical, siendo el caudal máximo en ambos instrumentos el doble.

\subsubsection{PROPORCIONALES}

\subsubsection{Principio de funcionamiento}

El particular diseño de los contadores proporcionales (Figura 13) les permite ser poco sensibles, al menos en teoría, a la calidad del agua. Están, por tanto, indicados para la contabilización de aguas no filtradas extraídas de pozos y cargadas con partículas sólidas. No obstante, prácticamente ningún modelo de este tipo de tecnología está aprobada dentro del marco de la Directiva europea 75/33/CEE debido a su baja precisión y estrecho rango de medida.

Este tipo de medidor incorpora dos circuitos en paralelo por donde circula el fluido. Caracterizando los circuitos principal y secundario se conoce la relación entre el caudal total que circula por el contador proporcional y el que registra el contador del circuito secundario (Ecuación 17). Normalmente el contador empleado en el secundario puede ser un contador de chorro único o de chorro múltiple de pequeño calibre, donde el flujo de agua es menor, mientras que en el primario se monta una tobera convergente-divergente, que no supone impedimento al libre paso del agua, y por donde pasa la mayor parte del caudal. En la Figura 14 se muestra el esquema de funcionamiento.
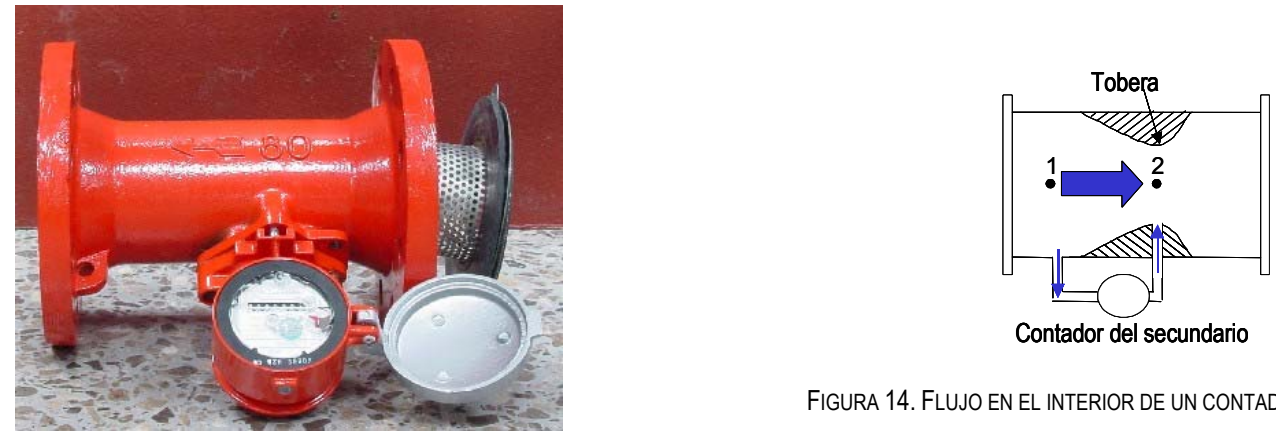

FIGURA 13. CONTADOR PROPORCIONAL.

FIGURA 14. FLUJO EN EL INTERIOR DE UN CONTADOR PROPORCIONAL.

La relación de caudales entre ambos circuitos y el caudal total trasegado se extrae del siguiente cálculo.

$$
\begin{array}{ll}
\text { Primario } & h_{1-2}=K_{1} \cdot Q_{1}{ }^{2} \\
\text { Secundario } & h_{1-2}=K_{2} \cdot Q_{2}{ }^{2} \text { despejando el caudal circulado total } Q_{T}=\left[\sqrt{\frac{K_{2}}{K_{1}}}+1\right] \cdot Q_{2} \\
& Q_{1}+Q_{2}=Q_{T}
\end{array}
$$

\subsubsection{TANGENCIALES}

\subsubsection{Principio de funcionamiento}

Este tipo de contador, al igual que los proporcionales, está diseñado especialmente para riego. Su funcionamiento como en cualquier contador de velocidad se basa en el movimiento de una turbina situada en la parte superior de la conducción. Este elemento móvil gira proporcionalmente a la velocidad del agua en esa zona. Este hecho puede producir graves imprecisiones en la medida cuando el perfil de velocidades llega a la turbina distorsionado. El Capítulo 3 presenta ensayos en laboratorio de la influencia que puede ejercer sobre esta tecnología diferentes elementos perturbadores del flujo. En la Figura 15 se muestra el instrumento visto desde la sección de entrada del agua. 
Sin embargo, a pesar de estos inconvenientes tiene ciertas ventajas que los hacen atractivos en el mercado. La primera es que el propio diseño del contador permite que se utilice en todo tipo de aguas ya que internamente no presenta impedimentos al paso de sólidos en suspensión. Además, la perdida de carga producida en este caso será mucho menor en comparación con otras tecnologías de velocidad. Por último, pero no menos importante, es su coste de adquisición comparativamente más bajo que otros modelos.

En este caso es posible encontrar modelos mecánicos aprobados para clase metrológica A para calibres de 50 a $125 \mathrm{~mm}$, mientras calibres superiores hasta $300 \mathrm{~mm}$ están en fase de aprobación. Más recientemente, se ha aprobado algún modelo para clase metrológica B con totalizador electrónico. Un ejemplo de los datos de caudal en este tipo de tecnología se presenta en la Tabla 15.

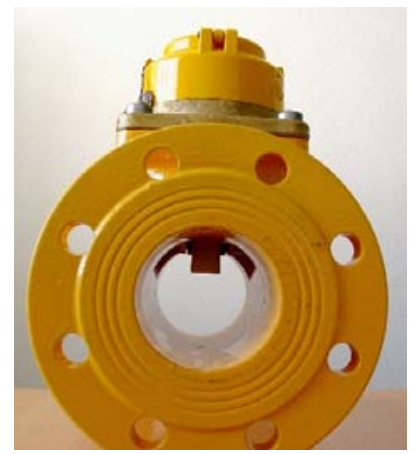

TABLA 15. ESPECIFICACIONES TÉCNICAS DE UN CONTADOR TANGENCIAL.

FIGURA 15. CONTADOR TANGENCIAL.

\begin{tabular}{|c|c|c|c|c|c|}
\hline CALIBRE & DN 50 & DN 65 & DN 80 & DN 100 & DN 125 \\
\hline Caudal nominal (m³/h) & 15 & 25 & 40 & 60 & 100 \\
\hline Caudal máximo (m³/h) & 30 & 50 & 80 & 120 & 200 \\
\hline Caudal de transición $\left(\mathrm{m}^{3} / \mathrm{h}\right)$ & 4,5 & 7,5 & 12 & 18 & 30 \\
\hline Caudal mínimo (m³/h) & 1,2 & 2 & 3,2 & 4,8 & 8 \\
\hline Presión máxima (bar) & 16 & & & & \\
\hline Totalización máxima (m³) & $10^{7}$ & & & & \\
\hline
\end{tabular}

\subsection{CONTADORES VOLUMÉTRICOS}

Los contadores volumétricos basan su principio de funcionamiento, a diferencia de los contadores de velocidad, en el conteo del número de llenados y vaciados de una o dos cámaras de volumen conocido. Existen dos tecnologías, los de pistón rotativo, que suelen ser más comunes, y los de disco nutante. La diferencia entre ellos se encuentra en el elemento móvil, los primeros poseen un pistón rotativo que gira excéntricamente mientras que el movimiento en los segundos lo realiza un disco giratorio.

\subsubsection{TECNOLOGía DE PISTÓN ROTATIVO}

Esta tecnología consta del cuerpo de medición donde se encuentra alojada la cámara de volumen calibrado, el pistón rotativo y el plato de división. Generalmente, se fabrica en plástico de alta densidad aunque modelos antiguos todavía se pueden encontrar en latón o bronce. Otro elemento fundamental en este instrumento es el filtro dispuesto aguas arriba de la cámara de medición. Este elemento protege al pistón rotativo de impurezas o partículas de arena que puedan impedir su rotación. El agua se acumula mediante totalizadores de transmisión magnética o mecánica.

El funcionamiento del instrumento se inicia cuando entra el agua dentro de la cámara. Debido a la mayor presión aguas arriba, el pistón tiende a girar excéntricamente cambiando el agua de cada compartimiento. De este modo, se produce el llenado por un lado y, al mismo tiempo, el vaciado por otro. Cada rotación implica el desplazamiento de un volumen de agua conocido.

En particular, este tipo de tecnología de medición ha sido utilizado durante los ensayos en campo de la presente Tesis doctoral por sus buenas características metrológicas. Estos instrumentos, de clase metrológica $\mathrm{C}$, con caudales de arranque de hasta $1 / / h$, son capaces de registrar un amplio rango de caudales que los hacen interesantes a la hora de describir los caudales de consumo de un usuario. 
No obstante, presentan inconvenientes que conviene conocer. Por ejemplo, tienen una alta tendencia a obturarse siendo muy sensibles a las impurezas o partículas sólidas del agua que se introducen en los huecos y holguras del interior de la cámara provocando su paro. A su vez, estas partículas pueden colmatar el filtro de entrada al instrumento, normalmente mucho más fino que en otras tecnologías, aumentando su pérdida de carga y reduciendo la sección de paso del agua y el caudal circulante.

\subsubsection{TECNOLOGÍA DE DISCO NUTANTE}

La tecnología de disco mutante no es muy habitual en Europa. Su elemento móvil es un disco que gira alrededor a un eje con un movimiento similar al de una peonza. De igual forma, el agua se traslada por el interior del compartimiento de una parte a otra girando excéntricamente en torno al vástago y reconduciendo al agua desde el punto de entrada hasta la salida. De nuevo, en cada rotación del disco se trasiega desde la entrada a la salida el mismo volumen de agua (Figura 16). Las ventajas e inconvenientes son prácticamente similares a las de pistón rotativo.

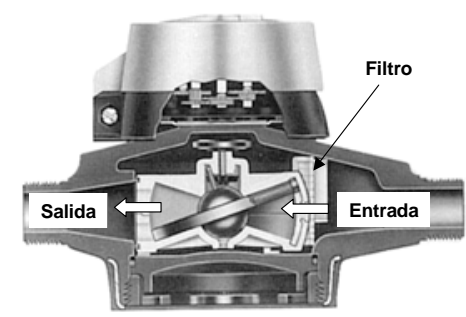

FIGURA 16. CORTE TRANSVERSAL DE UN CONTADOR VOLUMÉTRICO DE DISCO MUTANTE.

\subsection{CONTADORES COMBINADOS}

Esta tecnología de medición, como su nombre indica, combina dos instrumentos de velocidad de diversos diámetros y capacidades en un mismo aparato. Por ejemplo, un contador Woltman asociado con uno de chorro múltiple. Ambos instrumentos pueden estar conectados en serie o en paralelo como el caso de la Figura 17.

La ventaja de este diseño frente a un único contador es que amplía el rango de funcionamiento, ya que permite medir caudales en rangos altos, a través del contador principal, y bajos, gracias al secundario de pequeño calibre con una buena precisión.

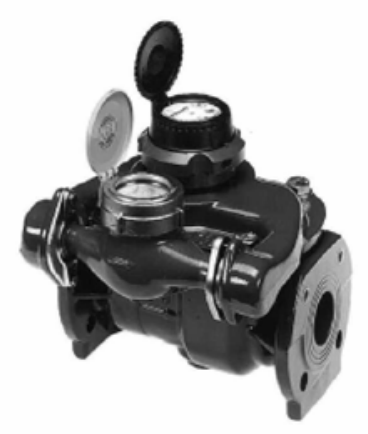

FIGURA 17. CONTADOR COMBINADO.

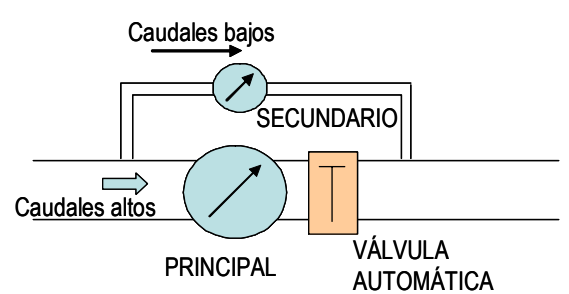

FIGURA 18. PRINCIPIO DE FUNCIONAMIENTO DE UN CONTADOR COMBINADO EN PARALELO. 
Habitualmente, esta tecnología se instala en lugares donde existe una diferencia elevada entre los caudales máximos y mínimos que se demandan. Por ejemplo, un colegio donde durante ciertas horas el consumo de agua es muy alto y cuando los alumnos están en clase los fines de semana, disminuye de forma brusca, o en un hospital, con grandes diferencias entre el consumo diario y el nocturno.

La derivación del caudal por un circuito u otro se realiza mediante una válvula automática instalada aguas abajo del contador principal. Cuando el caudal es bajo, la válvula está cerrada y el agua circula por el contador secundario. A medida que aumenta el caudal la pérdida de carga en el contador de menor calibre aumentará provocando la apertura de la válvula de regulación y la circulación del fluido por ambos instrumentos (Figura 18).

Existen también combinaciones en serie aunque no son tan habituales. En estos casos, la válvula automática desvía el agua por uno de los dos circuitos en función del caudal. Cuando el caudal es bajo cierra la salida del circuito principal haciendo pasar el agua por el secundario, al contrario, en el caso de caudales altos donde inhabilita el la salida del contador más pequeño.

\subsection{CAUDALIMETROS DE PRESIÓN DIFERENCIAL}

\subsubsection{PLACA ORIFICIO}

La placa orificio es un instrumento capaz de medir el caudal en base a la presión diferencial entre dos puntos. A partir de la diferencia de alturas de presión en la entrada y la salida de este dispositivo se calcula el caudal circulante por la conducción mediante la aplicación del teorema de Bernouilli y la ecuación de continuidad.

$$
\mathrm{Q}=\mathrm{k} \sqrt{\frac{\Delta \mathrm{P}}{\rho}} \quad \mathrm{k}=\frac{2 \cdot \mathrm{C} \cdot \mathrm{A} 2}{\sqrt{1-\left(\beta^{4}\right)}} \text { siendo } \beta=\frac{\mathrm{d}}{\mathrm{D}}
$$

Donde $\Delta \mathrm{P}$ es la diferencia de presión del fluido entre la entrada y la salida, $\rho$ la densidad del fluido que para el caso del agua será $1000 \mathrm{Kg} / \mathrm{m}^{3} \mathrm{y}$ k es una constante que depende del área de paso de la placa orificio, y de la relación de diámetros placa orificio-conducción ( $\beta$ ). El coeficiente de descarga $C$ viene dado por la ecuación de Reader-Harris/Gallagher que es función de $\beta$, el número de Re y la localización de las tomas en carga ( $L$ y L/2), según la Norma UNE-EN ISO 5167 en su primera modificación de 1998. La colocación de las tomas de presión está perfectamente definida en dicha Norma donde se establecen detalladamente las características y modo de empleo de este tipo de tecnología.

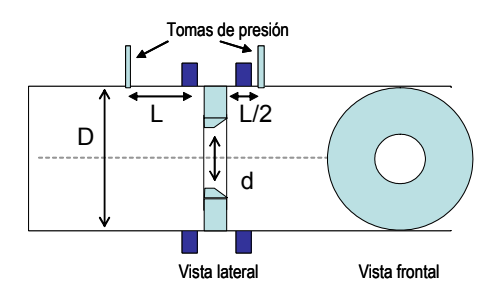

FIGURA 19. PRINCIPIO DE FUNCIONAMIENTO DE UNA PLACA ORIFICIO.

\subsubsection{VENTURI}

Esta tecnología de medición fue creada por el físico e inventor italiano Giovanni Battista Venturi (1.746 - 1.822). Su principio de funcionamiento es similar al de una placa orificio. Un tubo Venturi está constituido por un convergente, un cuello y un difusor que retorna gradualmente la sección de paso a la original. Este dispositivo mide el gasto de un fluido, es decir, la 
cantidad de flujo por unidad de tiempo, a partir de una diferencia de presión entre dos secciones, una a la entrada y otra la de menor área de paso.

Los parámetros geométricos del tubo de Venturi para medición de caudales, tal como las estableció Clemens Herschel, son los establecidos en la norma ISO 5167-1. Por lo general, la forma clásica de un tubo Venturi y los parámetros internos más importantes se muestran en la Figura 20. La entrada es una tubería corta recta del mismo diámetro que la tubería a la cual va unida. El cono de entrada, que forma el ángulo a1, conduce por una curva suave a la garganta de diámetro d1. Un largo cono divergente, que tiene un ángulo a2, restaura la presión y hace expansionar el fluido al pleno diámetro de la tubería. La ecuación que permite la estimación del caudal depende de la geometría del instrumento y de la diferencia de presión obtenida.

Cuando el fluido entra por el convergente, aumenta progresivamente la velocidad a medida que se estrecha la sección, consecuentemente el término cinético. Este hecho origina una caída de presión en el cuello del Venturi. A partir de la diferencia de presión entre la entrada y el cuello, es posible obtener la velocidad de circulación en cualquiera de las dos secciones y relacionarlas con el caudal circulante mediante la expresión 19.

A diferencia de las placas de orificio, la perdida de carga permanente en este caso es menor ya que el convergente de entrada redondeado distorsiona menos las partículas del fluido que el acabado afilado de la placa de orificio. La altura piezométrica del flujo se recupera, en parte, tras su paso por el Venturi.

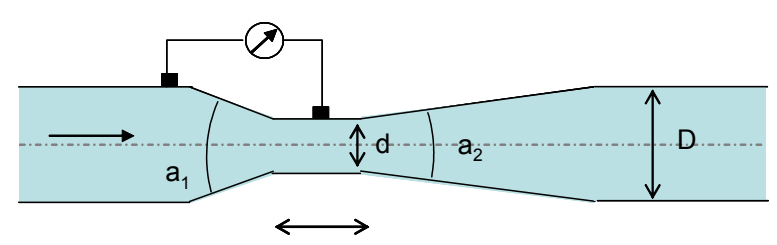

FIGURA 20. CARACTERISTICAS DIMENSIONALES DE UN TUBO VENTURI.

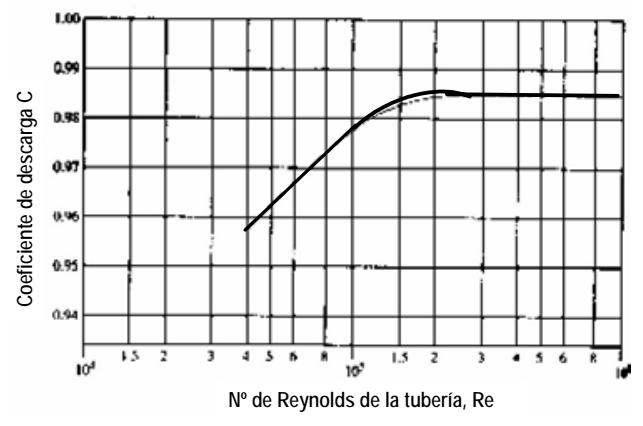

FIGURA 21. RELACIÓN ENTRE EL COEFICIENTE DE DESCARGA C Y EL N RE.

$$
Q=C \cdot A_{2} \sqrt{\frac{2 g\left(p_{1}-p_{2}\right) / \gamma}{1-\left(A_{2} / A_{1}\right)^{2}}}
$$

El valor del coeficiente $\mathrm{C}$ depende del número de Reynolds del flujo y de la geometría real del medidor. La Figura 21 muestra una curva típica de $\mathrm{C}$ frente al número de Reynolds en la tubería principal.

\subsection{CAUDALLIMETROS ELECTROMAGNÉTICOS}

El principio de funcionamiento de un caudalímetro electromagnético está basado en la ley enunciada por Faraday en 1832 , según la cual entre los extremos de cualquier conductor que atraviese un campo electromagnético se induce una fuerza electromotriz E perpendicular al campo y a la dirección de circulación del líquido que actúa como conductor. Esta fuerza 
electromotriz es proporcional a velocidad del conductor $V$, a la longitud del mismo $L$ y a la intensidad del campo magnético $B$ que atraviesa, atendiendo a la siguiente expresión:

$$
E=k \cdot B \cdot L \cdot V
$$

La constante k es un factor de calibración que se determina en la práctica por vía húmeda (ISO 9104).

A partir de esta medida de la tensión eléctrica puede calcularse la velocidad media del líquido y, en consecuencia, el caudal circulante por la conducción, tal y como se detalla en la norma ISO 6817:1995, sobre medida de caudal en líquidos conductores en conductos cerrados mediante caudalímetros electromagnéticos.

$$
\begin{gathered}
V=\frac{\mathrm{E}}{\mathrm{k} \cdot \mathrm{B} \cdot \mathrm{L}} \\
Q=\text { Área } \cdot V=\frac{\pi \cdot D^{2}}{4 \cdot k \cdot L}\left(\frac{E}{B}\right)=K \cdot\left(\frac{E}{B}\right)
\end{gathered}
$$

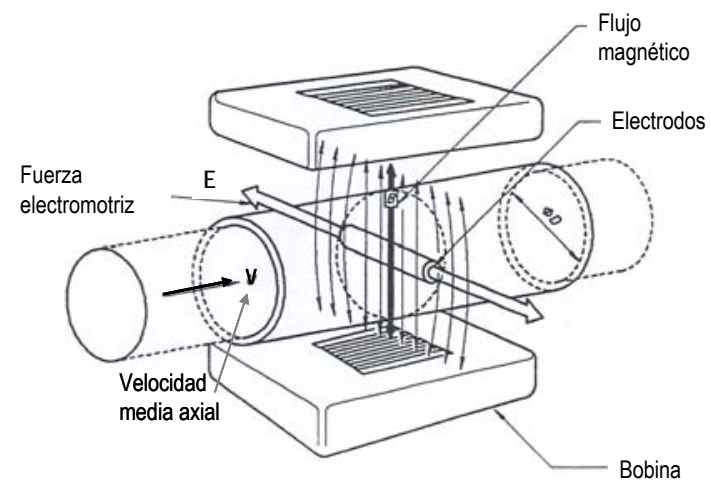

FIGURA 22. PRINCIPIO DE FUNCIONAMIENTO DE UN CAUDALIMETRO ELECTROMAGNÉTICO. IMAGEN EXTRAÍDA DE LA NORMA ISO 6817.

En la práctica, la fuerza electromotriz generada por el flujo de agua no es proporcional a la velocidad media del fluido calculada ponderando uniformemente los diferentes puntos de la sección, sino que es fruto de una ponderación en la que el peso de las distintas zonas es variable. En la bibliografía se han desarrollado diferentes funciones de ponderación que asignan los pesos de las velocidades en la sección con el fin de estimar una velocidad media ponderada que se asimilará como velocidad media. Existen propuestas, como la realizada por Shercliff en 1962 o por Al-Rabeh y Baker en 1979 donde se ensayan diferentes materiales, formas de bobinas inductoras y condiciones del flujo magnético que desarrollan funciones de ponderación teóricas para la estimación del caudal circulante.

En cuanto a su construcción, este instrumento está constituido por dos partes bien diferenciadas, un elemento primario por el que circula el fluido y que proporciona como salida una señal alterna de baja intensidad proveniente de los electrodos situados en la conducción (Figura 23), y otro secundario integrado por componentes electrónicos, que amplifican y transforman esa señal en una salida eléctrica normalizada. 


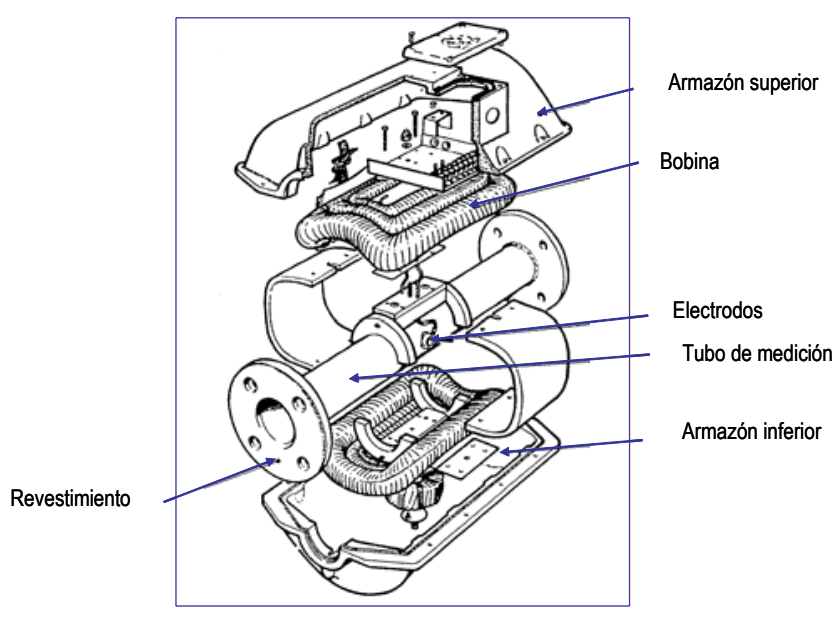

FIGURA 23. COMPONENTES DE UN CAUDALIMETRO ELECTROMAGNÉTICO.

Con el avance de esta tecnología de medición los fabricantes han diseñado y probado otro tipo de materiales y construcciones para inducir un flujo magnético tal que se homogenice el peso de todos los puntos de la sección de medida. El objetivo es obtener funciones de ponderación lo más uniformemente posible. De esta forma, como se comprueba durante el Capítulo 4, se minimizaría la influencia de perfiles de velocidad distorsionados sobre la medida de caudal.

\subsection{CAUDALLIMETROS DE INSERCIÓN}

\subsubsection{SONDA ELECTROMAGNÉTICA}

Este tipo de sonda obtiene la velocidad local del fluido, en las proximidades del cabezal, por el mismo principio físico que los caudalímetros electromagnéticos, la Ley de Faraday. La propia sonda incorpora unas bobinas que generan un campo magnético. El agua al circular con cierta velocidad alrededor de la sonda, genera una diferencia de potencial en los electrodos que resulta proporcional a su velocidad en esta zona (Figura 24). El caudal se obtiene ponderando las velocidades medidas con el área de la conducción y ciertos parámetros correctores (Aquaprobe, ABB-Kent).

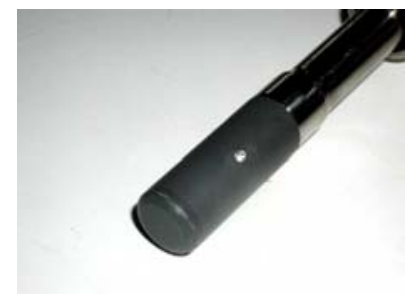

FIGURA 24. SONDA DE INSERCIÓN ELECTROMAGNÉTICA.

\subsubsection{SONDA TIPO TURBINA}

Son caudalímetros autónomos donde la velocidad local del fluido se obtiene a partir de la velocidad de rotación de una turbina (Figura 25). El eje de giro de la misma es transversal al eje de la conducción y debe estar perpendicular al flujo de agua para obtener mediciones fiables. La velocidad de giro de la turbina se recoge mediante sensores magnéticos que detectan cada paso de los alabes. 


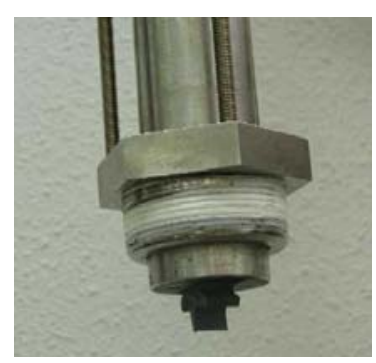

FIGURA 25. SONDA DE INSERCIÓN DE TURBINA

\subsubsection{MÉTODOS DE MEDIDA DE CAUDAL CON CAUDALÍMETROS DE INSERCIÓN}

Los caudalímetros de inserción calculan el caudal de agua mediante la medición puntual de la velocidad del flujo. La localización de los puntos de medida cobra especial importancia ya que la relación entre la velocidad medida y la velocidad media en la sección difiere dependiendo de la situación del sensor.

Idealmente el perfil de velocidades en una conducción de agua, con un flujo plenamente desarrollado, tiene una simetría axial y dependiendo del tipo de flujo adquiere una forma más o menos parabólica (Figura 26). En la mayor parte de los casos, el flujo de agua en las redes de distribución urbanas es turbulento. Básicamente las técnicas para la obtención del caudal mediante sondas de inserción podrían agruparse en tres modalidades descritas a continuación.
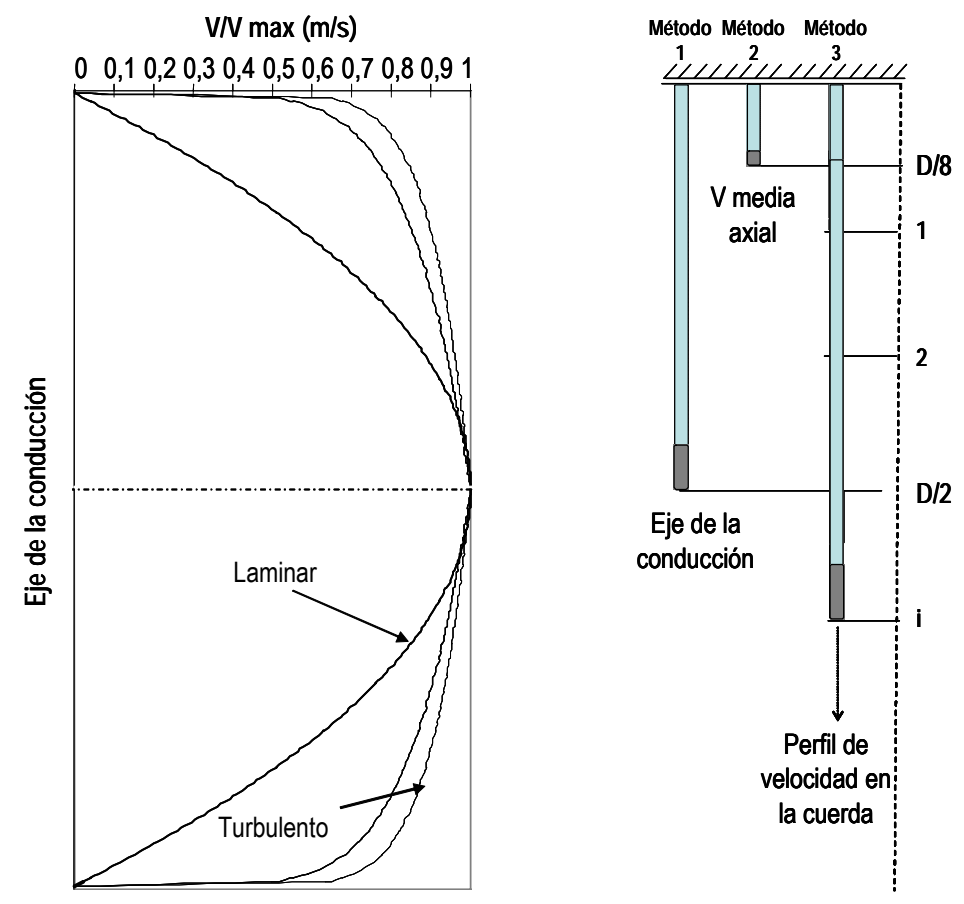

FIGURA 26. PERFILES DE VELOCIDAD EN FLUJO LAMINAR Y TURBULENTO. TÉCNICAS DE INSERCIÓN DE SONDAS

\subsubsection{Método 1. Medición de la velocidad en el eje de la conducción}

Como se explicó durante apartado 2.2, en régimen turbulento y con un flujo plenamente desarrollado, la relación entre la velocidad máxima y la velocidad en cualquier punto de la sección de la conducción circular a presión se calcula mediante la 
fórmula teórica 23. Luego, a partir de la medición de la velocidad en el eje, es posible estimar la velocidad en cualquier punto en estas condiciones de flujo.

$$
V_{i}=\left(1-\frac{r}{R}\right)^{1 / n} \cdot V_{\max }
$$

donde $\mathrm{n}$ es el coeficiente de Von Karman, parámetro que depende del número de Reynolds.

Matemáticamente, la velocidad media en un conducto se calcula integrando la expresión de la velocidad en cualquier punto y dividiendo el resultado por el área de la sección. Consecuentemente, la relación entre la velocidad media y la máxima se obtendría mediante la siguiente expresión (NEL, 2002).

$$
V_{\text {med }}=\frac{2 \cdot n^{2} \cdot V_{\max }}{(1+2 \cdot n) \cdot(1+n)}=K_{1} \cdot V_{\max }
$$

Dicha relación, $K_{1}$, no es constante y depende del caudal circulante, a través del coeficiente de Von Karman, $\mathrm{n}$. El coeficiente $\mathrm{K}_{1}$, que relaciona ambas velocidades, oscila entre 0,79 para un número de Reynolds de 10.000 y 0,875 para un número de Reynolds de $10^{7}$.

Finalmente, en este método, el caudal se puede obtener mediante la siguiente expresión:

$$
\mathrm{Q}=\mathrm{K}_{1} \mathrm{~F}_{\mathrm{i}} \cdot \text { Area } \cdot \mathrm{V}_{\max }
$$

donde $V_{\max }$ corresponde a la velocidad máxima en el eje de la conducción; $K_{1}$ al factor de perfil de velocidad; $F_{i}$ al factor de inserción que tiene en cuenta la distorsión en el perfil de velocidades y la obstrucción del área de paso ocupada por la propia sonda.

\subsubsection{Método 2. Medición de la velocidad a una profundidad de inserción de $1 / 8 \mathrm{D} 0$ 3/4 desde el eje de la tubería.}

En un flujo de agua turbulento perfectamente desarrollado se puede demostrar que la velocidad en un anillo de radio $3 / 4 \cdot R$ siendo $\mathrm{R}$ el radio de la conducción, o lo es que lo mismo, un grado de inserción de 1/8D o 7/8 D, prácticamente coincide con la velocidad media en la sección independientemente del número de Reynolds. Aprovechando esta propiedad el factor de perfil se puede considerar constante e igual a 1,005 por lo que el cálculo del caudal se realizaría con la ecuación:

$$
Q=1.005 \cdot F_{i} \cdot \text { Area } \cdot V_{3 / 4 R}
$$

donde los factores $\mathrm{F}$ son de nuevo los que consideran la influencia de la introducción de la sonda en el flujo y la obstrucción generada por ella.

La Figura 27 muestra la relación entre la velocidad a $3 / 4$ de radio y la velocidad media en la sección en función del número de $\operatorname{Re}$. 


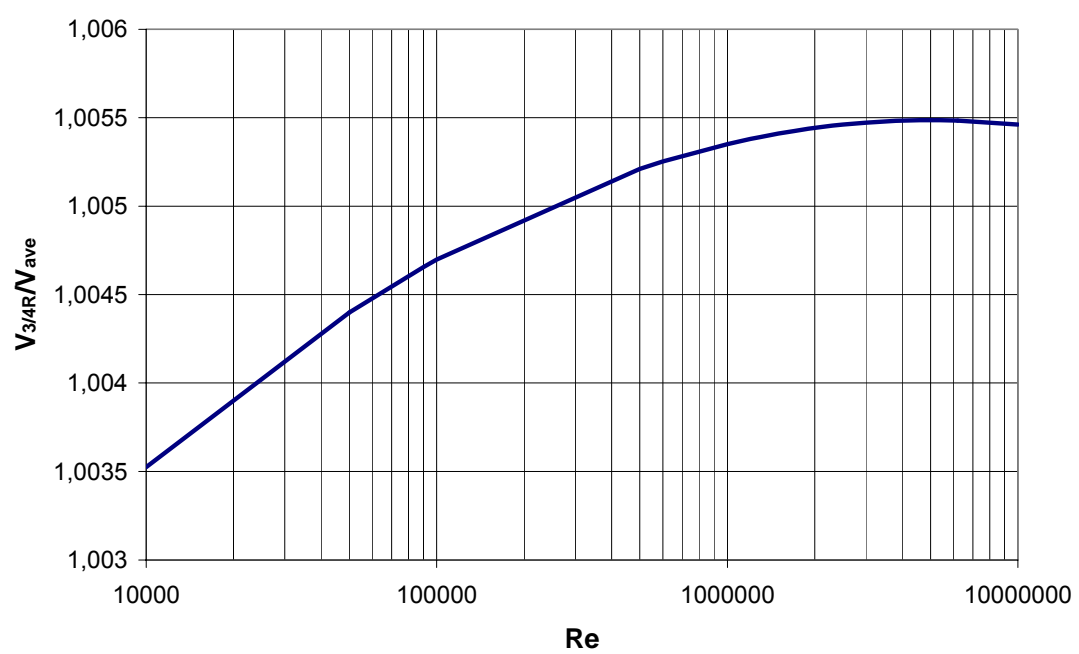

FIGURA 27. RELACIÓN ENTRE LA VELOCIDAD EN UN ANILLO DE RADIO 3/4R Y LA VELOCIDAD MEDIA EN LA SECCIÓN.

\subsubsection{Medición del perfil de velocidad en la cuerda diametral.}

Para garantizar una buena medición en campo es importante conocer la velocidad de circulación del fluido en varios puntos que resultan menos sensibles a las alteraciones del flujo, reduciendo la incertidumbre asociada a una sola medida.

Para estimar el perfil de velocidades dentro de la conducción, los puntos de medida deben seleccionarse adecuadamente dentro de una cuerda diametral.

Existen diferentes métodos de integración de la velocidad como el método de los centroides de áreas iguales o el método de los cubos (NEL, 2002). El primer procedimiento localiza los puntos de medida dentro de la cuerda diametral obteniendo varias velocidades locales que permiten estimar la velocidad media. La Tabla 16 indica la relación entre la distancia de inserción y el radio de la conducción en función del número de puntos de medida, tal y como se muestra en la Figura 28 para el caso de 6 puntos.

TABLA 16. MÉTODO DE LOS CENTROIDES DE ÁREAS IGUALES.

\begin{tabular}{clllllll}
\hline $\begin{array}{c}\text { No Puntos de } \\
\text { medida }\end{array}$ & \multicolumn{6}{c}{ Distancia del punto al eje (r/R) } \\
\hline 6 & 0,408 & 0,706 & 0,914 & & & \\
8 & 0,354 & 0,612 & 0,79 & 0,936 & & \\
10 & 0,316 & 0,548 & 0,708 & 0,836 & 0,948 & \\
\hline 12 & 0,288 & 0,5 & 0,646 & 0,764 & 0,866 & 0,958 \\
\hline
\end{tabular}

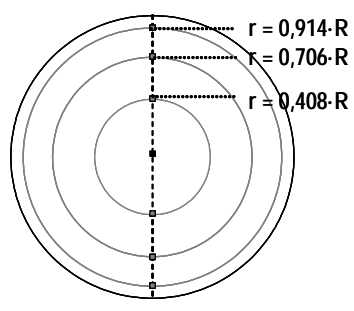

FIGURA 28. INSERCIÓN DE 6 PUNTOS DE MEDIDA DENTRO DE UNA CONDUCCIÓN CIRCULAR.

A partir de las medidas de velocidad locales de estos puntos es posible calcular la velocidad media en la sección como su media ponderada. De este modo el caudal se obtendría mediante la siguiente expresión.

$$
\begin{aligned}
& V_{\text {med }}=\frac{1}{n} \sum_{i=1}^{n} V_{i} \\
& Q=\text { Area } \cdot V_{\text {med }}
\end{aligned}
$$


El método de los cubos estima mediante la Ecuación 29 la velocidad media en función de las i medidas a ri/R:

$$
\begin{aligned}
V_{\text {med }} & =V_{0}\left[\frac{5}{12} \cdot r_{1}^{2}-\frac{1}{12} r_{2}^{2}+\frac{1}{12} \frac{r_{1}^{3}}{r_{2}}\right]+V_{1}\left[\frac{1}{6} r_{1}^{2}+\frac{2}{3} r_{2}^{2}-\frac{1}{12} r_{3}^{2}\right]-V_{2}\left[\frac{1}{12} \frac{r_{1}^{3}}{r_{2}}\right]+\sum_{i=2}^{i=n-2} V_{i}\left[-\frac{1}{12} r_{i+2}^{2}+\frac{2}{3} r_{i+1}{ }^{2}-\frac{2}{3} r_{i-1}^{2}+\frac{1}{12} r_{i-2}^{2}\right] \\
& +V_{n-i}\left[\frac{1}{2} r_{n}^{2}+\frac{1}{12} r_{n-1}^{2}-\frac{2}{3} r_{n-2}{ }^{2}+\frac{1}{12} r_{n-3}{ }^{2}\right]+V_{n}\left[\frac{n}{n+1}\left(1-r_{n}{ }^{2}\right)+\frac{1}{12} \frac{\left(r_{n}^{2}-r_{n-1}{ }^{2}\right)^{2}}{n\left(1-r_{n}^{2}\right)}+\frac{7}{12} r_{n}^{2}-\frac{2}{3} r_{n-1}{ }^{2}+\frac{1}{12} r_{n-2}{ }^{2}\right]
\end{aligned}
$$

donde $V_{0}, V_{1}, V_{2}, \ldots V_{n}$ son las velocidades locales medidas en el centro de la tubería a distancias $r_{i} / R$ y $n$ es el coeficiente de Von Karman.

\subsection{CAUDALÍMETROS DE ULTRASONIDOS DE TIEMPO DE TRÁNSITO}

Los caudalímetros de ultrasonidos de tiempo de tránsito obtienen una estimación de la velocidad de circulación del agua a partir de la velocidad de propagación del sonido en un medio en movimiento. Este instrumento registra el tiempo transcurrido desde que las ondas sonoras generadas desde el punto emisor llegan al punto receptor en un medio transmisor como el para relacionarlo con el caudal circulante por la tubería. Este tiempo de tránsito depende de múltiples factores como la velocidad de propagación del sonido en el medio, de la dirección del flujo, de la instalación y las características geométricas del instrumento, etcétera.

En general, este tipo de tecnología consta de dos transductores piezoeléctricos cerámicos que actúan indistintamente como receptores y como emisores de ondas sonoras. Como emisores se excitan mediante pulsos eléctricos que seguidamente convierten en una señal acústica, y como receptores el proceso es justamente el contrario, captan las variaciones de presión debidas a las ondas sonoras creadas por el emisor transformándolas en impulsos eléctricos.

Existen diferentes tipos de transductores, los que están en contacto directo con el medio transmisor, denominados wetted transducers (Figura 30), que son más precisos, y los que se instalan exteriormente, clamp-on tranducers, que generalmente se utilizan como caudalímetros portátiles.

Los caudalímetros de tiempo de tránsito sitúan estos focos de emisión y recepción a cierta distancia en línea recta de la tubería formando un ángulo a entre el eje de la conducción y la línea ficticia de ondas sonoras. De ésta disposición se tiene, una longitud $L$ entre transductores, un ángulo a y el diámetro $D$ de la tubería que forman un triángulo, base para el cálculo del tiempo de tránsito del tren de ondas sonoras (Figura 29).

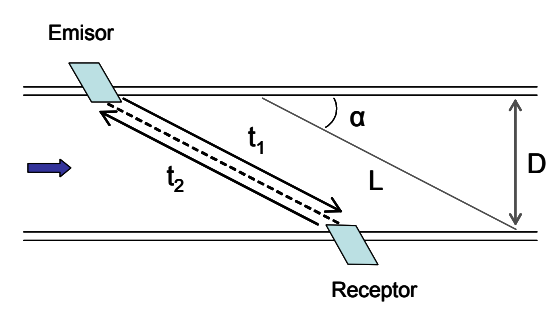

FIGURA 29. PRINCIPIO DE FUNCIONAMIENTO DE UN CAUDALÍMETRO DE TIEMPO DE TRÁNSITO.

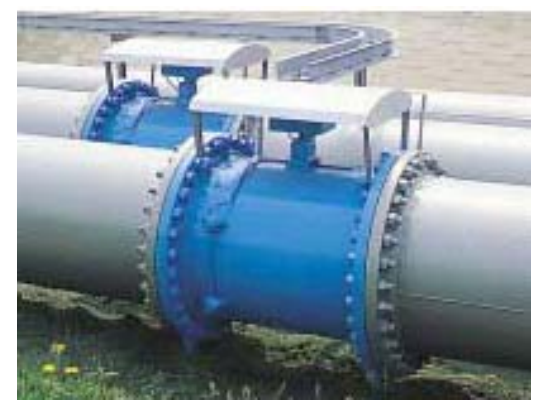

Figura 30. CAUdALÍMETRO dE ULTRASONIDOS EN LíNEA. KROHNE, 2002

El transductor situado aguas arriba manda una señal que tarda un tiempo $t_{1}$ en llegar al transductor aguas abajo que, en este caso, actúa como receptor y que invierte el proceso emitiendo ondas sonoras que tardan un tiempo t 2 en alcanzar el transductor aguas arriba. 
Cuando la velocidad de circulación del fluido es nula, ambos tiempos son iguales, pero cuando el fluido se encuentra en movimiento estos tiempos se ven influenciados por la velocidad del agua. Es decir, el perfil de velocidades de la cuerda entre transductores provocará que las ondas sonoras viajen a mayor o menor velocidad, y en consecuencia, el tiempo de tránsito disminuya o aumente. Las ondas de presión que se transmiten en el sentido del flujo tendrán un tiempo de tránsito menor $\left(t_{1}\right)$ que aquellas que viajan en sentido contrario al flujo de agua $\left(t_{2}\right)$.

Así pues a partir de la disposición de los transductores y el diámetro de la conducción es posible calcular la diferencia de tiempos de tránsito de las ondas sonoras (Ecuación 30 y 31).

$$
\begin{array}{ll}
t_{1}=\frac{L}{c+V \cdot \cos \alpha} \quad t_{2}=\frac{L}{c-V \cdot \cos \alpha} \\
t_{2}-t_{1}=\Delta t=\frac{2 \cdot L \cdot V \cdot \cos \alpha}{c^{2}-V^{2} \cdot \cos ^{2} \alpha}
\end{array}
$$

siendo c la velocidad de propagación del sonido que en el agua a una temperatura de $20^{\circ} \mathrm{C}$ es de $1482 \mathrm{~m} / \mathrm{s}$, y V la velocidad media del fluido en la conducción.

Teniendo en cuenta que la velocidad del sonido es elevada se puede despreciar el término $\mathrm{V}^{2} \cdot \cos ^{2} a$ frente a c, con lo que despejando se obtiene la velocidad del fluido y posteriormente el caudal circulante.

$$
\begin{gathered}
V=\frac{\Delta t \cdot c^{2}}{2 \cdot L \cdot \cos \alpha} \\
Q=A \cdot V=\frac{\pi \cdot D^{2}}{4} \cdot \frac{\Delta t \cdot c^{2}}{2 \cdot L \cdot \cos \alpha}
\end{gathered}
$$

\subsection{BIBLIOGRAFÍA CONSULTADA}

Aquaprobe. ABB-Kent-Taylor. Manual de instalación Medidor electromagnético.

Arregui F.J. (1999). Propuesta de una metodología para el análisis y gestión del parque de contadores de agua. Tesis doctoral. Universidad Politécnica de Valencia.

Arregui F, Palau C.V, García-Serra J, Gascón L. (2003). Evaluating domestic water meter accuracy. A case study. PEDS Pumps, electromechanical devices and systems. Applied to urban water management. Balkema. Vol. 1. pp. 343-352.

Arregui F, Palau C.V, García-Serra J, Herrero M. (2004). Contadores de agua para riego. Medición y recomendaciones prácticas. Riegos y drenajes XXI. Vol.134. pp.36-42.

Baker R.C. (2000). Flow measurement handbook. Industrial designs, operating principles, performance, and applications. Ed. Cambridge University Press.

Cabrera E, Espert V, García -Serra J, Martínez F. (1996). Ingeniería hidráulica aplicada a sistemas de distribución de agua. Universidad Politécnica de Valencia-Aguas de Valencia.

Directiva europea 2004/22/CEE del parlamento europeo y del consejo de 31 de marzo de 2004 relativa a los instrumentos de medida. 
Environmental Agency (2003). Continuous water monitoring equipment. Part 3: Performance standards for water flowmeters. MCERTs. United Kingdom.

Flow programme (2002). Best practices guide calibration of flowmeters. NEL. United Kingdom.

Instituto Tecnológico del Agua (2001). La medición en sistemas de distribución de agua. Primera parte. Documento interno. Curso de la Universidad Politécnica de Valencia.

ISO 4064-1:1993. Medición del caudal de agua en conductos cerrados. Parte 1. Especificaciones.

ISO 4064-2:1978. Medición del caudal de agua en conductos cerrados. Parte 2. Condiciones de instalación..

ISO 4064-3:1983. Medición del caudal de agua en conductos cerrados. Parte 3. Métodos y materiales de ensayo.

ISO 6817-3:1995. Measurement of conductive liquid flow in closed conduits -- Method using electromagnetic flowmeters

ISO 6158:1978. Medida de caudal de fluidos en conductos cerrados. Cálculo de la incertidumbre.

ISO 5167-1:1996 Medición de caudal de fluidos mediante aparatos de presión diferencial. Parte 1: Diafragmas, toberas y tubos Venturi intercalados en conducciones en carga de sección circular.

ISO 5167-1/A1 (1998). Medición de caudal de fluidos mediante aparatos de presión diferencial. Parte 1: Diafragmas, toberas y tubos Venturi intercalados en conducciones en carga de sección circular.

ISO 9104 (1991). Medida de caudal de fluidos en conductos cerrados. Método para la evaluación del funcionamiento de caudalímetros electromagnéticos para líquidos.

ITA (2001). Curso de medición en sistemas de distribución de agua. Primera parte. Universidad Politécnica de Valencia.

Krohne (2002). Measuring instruemnts for water and waste water management. Documentación fabricante.

Navarro I. (2003). La futura normativa relativa a contadores de agua. Tecnología del agua. Vol.240. pp.48-55.

National Engineering Laboratory (2002). Auditing water flowmetering systems. Flow center. Nacional Engineering Laboratory. United Kingdom.

Orden ministerial 28 de diciembre de 1988 por la que se regulan los contadores de agua fria (BOE num.5, de 6 de marzo de 1989).

OIML R-49-1:2000. Waters meters intended for the metering of cold potable water. Part 1: Metrological and technical requirements.

PrEN 14.154: 2004. Water meters.

PrEN 14.268:2004. Contadores de agua de riego

Especificaciones técnicas de cada instrumento. Catálogos comerciales 2000-2003. ACTARIS, URALITA, ELSTER, SIBERLINE, PANAMETRICS, DANFOSS INSTRUMENTATION, CONTAZARA, REGABER, ZENNER, SAPPEL, WEHRLE, ETC. 


\section{CAPÍTULO 3}

ESTUDIO EN LABORATORIO DEL COMPORTAMIENTO METROLÓGICO DE CONTADORES DE AGUA 


\section{ESTUDIO EN LABORATORIO DEL COMPORTAMIENTO METROLÓGICO DE CONTADORES DE AGUA}

\subsection{INTRODUCCIÓN A LOS ENSAYOS}

Este capítulo expone una serie de resultados referentes al comportamiento metrológico de los sistemas de medición de agua tanto en contadores de chorro único, comúnmente utilizados en viviendas, como de contadores de gran calibre tipo Woltman, tangencial, proporcional, etcétera.

Para ello, inicialmente es importante definir la forma en que se calcula el error de medición de un contador de agua. Los contadores, a diferencia de los caudalímetros que proporcionan el caudal instantáneo, totalizan el agua circulada mediante la integración del caudal a lo largo del tiempo (Arregui, 2001). Consecuentemente, la correcta totalización del volumen de agua dependerá del error a los diferentes caudales de consumo del usuario.

Por ello, el ensayo de estos instrumentos tiene como objetivo trazar la curva de error característica de cada contador de agua que relaciona el error de medición con el caudal realmente trasegado por la conducción (Figura 3, Capítulo 2). De esta forma, se conoce la desviación del volumen real a cada caudal.

Ensayar estos instrumentos de medición a un número elevado de caudales permitiría trazar dicha curva de error de forma detallada. Claro está, el ensayo de un número elevado de puntos de la curva supone un mayor coste económico. Consecuentemente, como se expone durante el Capítulo 5, el ensayo se realiza a caudales característicos que permiten definir correctamente la curva de error. Esta curva asigna un error a cada caudal ensayado, y posteriormente, se interpola linealmente a todo el rango de funcionamiento. No obstante, en ocasiones, cuando los caudales de ensayo no son los adecuados puede ocurrir que estas interpolaciones lineales del error no reflejen correctamente el funcionamiento del medidor.

El error de medición a un caudal establecido y el caudal medio circulante en cada ensayo se determinan mediante las ecuaciones siguientes:

$$
\varepsilon_{Q}(\%)=\frac{\text { Volumen acumulado }- \text { Volumen real circulado }}{\text { Volumen real circulado }} \cdot 100
$$




$$
Q(I / h)=\frac{\text { Volumen real circulado (litros) }}{\text { Tiempo (horas) }}
$$

Durante el Capítulo 2 se describieron las características metrológicas que se exigen a contadores de agua fría y caliente, tanto en la normativa vigente ISO 4064 (Orden Ministerial del 28 de diciembre de 1988) como en el proyecto de norma prEN 14154. En la presente Tesis doctoral, los ensayos en laboratorio se contrastaran con las exigencias legales impuestas en esta orden.

Estos instrumentos pueden ensayarse por diferentes métodos perfectamente definidos en diversas normas de medida del caudal de agua circulante por un conducto cerrado. Uno de los métodos de ensayo para la medida del caudal de agua se basa en el control de aforo por pesada, descrito en la norma europea EN 24185:1993 (ISO 4185:1980). El procedimiento mide la masa de líquido vertida en un tanque de pesada durante un intervalo de tiempo. Esta prueba puede realizarse tanto en dinámico, a contador lanzado utilizando un desviador de flujo, es decir el ensayo comienza partiendo de un flujo estacionario, como en estático desde un caudal nulo. Esta técnica, en las condiciones especificadas en la norma, sólo necesita medidas de masa y de tiempo, por lo que puede considerarse muy precisa como método de calibración.

Otra técnica de ensayo es la descrita en la norma internacional UNE-EN ISO 8316, método por recogida de líquido en un tanque volumétrico, que determina el volumen de agua recogido en un tanque volumétrico de dimensiones calibradas en un intervalo de tiempo conocido. Estos ensayos también pueden ser en dinámico desviando el flujo al final de la prueba, o en estático donde la calibración se realiza partiendo de un caudal cero.

La presente Tesis doctoral utiliza esta técnica para ensayar los contadores de pequeño calibre o micromedidores (hasta $40 \mathrm{~mm})$, como se describe en el Anexo I de este capítulo.

Por último, el error de medición del instrumento también puede evaluarse mediante la comparación con otro instrumento más preciso, como se realiza para instrumentos de mayor calibre en las pruebas descritas en el apartado 3.2. Al instrumento patrón se le exige, según la norma ISO 4064, que para la verificación primitiva, su precisión sea 1/10 de la del instrumento de medida que se pretende calibrar.

En este capítulo se presentan los resultados de laboratorio más relevantes, tanto de micromedidores como de contadores de mayor calibre. En él se han realizado multitud de pruebas para analizar el funcionamiento de estos instrumentos en diferentes condiciones, en posición horizontal, en vertical, ensayos de la curva de error en detalle, pruebas con otros elementos hidráulicos, ensayos de repetibilidad, del caudal de arranque, pruebas a contadores de cierta edad, etcétera. Asimismo, en el caso del estudio presentado referido a un parque de medidores, se ha realizado un análisis de la incertidumbre en los resultados de las pruebas realizadas.

\subsection{ENSAYOS DE ERROR A CONTADORES DE PEQUEÑO CALIBRE DE USO DOMÉSTICO}

Este apartado tiene por objeto describir el comportamiento metrológico de los contadores de agua de pequeño calibre más comunes en los abastecimientos urbanos y en las redes agrícolas. Generalmente, los abastecimientos urbanos españoles utilizan, en su mayoría, la tecnología de chorro único, calibre $13 / 15 \mathrm{~mm}$, para el registro de agua en domicilios.

Por ello, este capítulo realiza un análisis en profundidad de las características metrológicas de este tipo de contadores. También describe qué variables afectan a la medición del agua consumida por los abonados. Posteriormente, se realiza una comparativa entre diferentes marcas de un parque de medidores y su evolución en el tiempo, discerniendo aquellas marcas que tienen un comportamiento más estable. 


\subsubsection{VARIABLES QUE AFECTAN A LA MEDICIÓN MICROMEDIDORES}

Durante el desarrollo de la presente Tesis doctoral se han observado en campo multitud de parámetros que pueden afectar al correcto funcionamiento de los contadores de agua. Estos instrumentos, habitualmente, se encuentran instalados en cuartos especiales 0 en arquetas, con condiciones no siempre óptimas para su funcionamiento. A continuación se presenta brevemente una descripción de la incidencia de diversos parámetros sobre la medición del agua.

\subsubsection{Posición de instalación}

La mayor parte de los contadores de agua son homologados para su funcionamiento en posición horizontal. Sin embargo, normalmente por dificultades en la lectura del totalizador, los operarios tienden a girar los contadores (Figura 1).

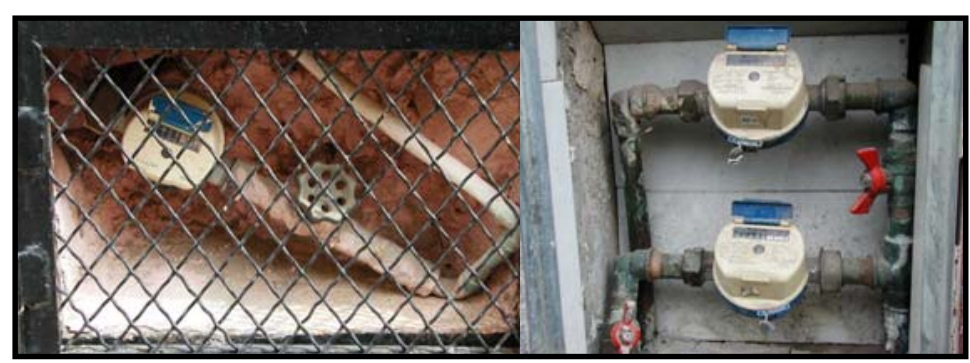

FIGURA 1. INSTALACIÓN INCLINADA DE LOS CONTADORES DE AGUA.

En otras ocasiones, como en riego localizado, el principal motivo que justifica este tipo de montaje es la disponibilidad de espacio en la arqueta. Los contadores instalados en posición horizontal ocupan más espacio y la caseta debe proyectarse de mayor tamaño, aumentando los costes (Figura 2). Además, el riego de frutales suele ser interrumpido, con lo que la tubería y el propio instrumento pasa largos periodos de tiempo vacía, sedimentando con mayor facilidad los sólidos en suspensión cuando su posición es en horizontal.

En la actualidad, todavía es posible encontrar baterías de contadores domésticos en condiciones de instalación pésimas que no cumplen las normas básicas de instalaciones de suministro de agua (Orden del 9 de diciembre de 1975), en lo referente a su posición de instalación (Figura 3).

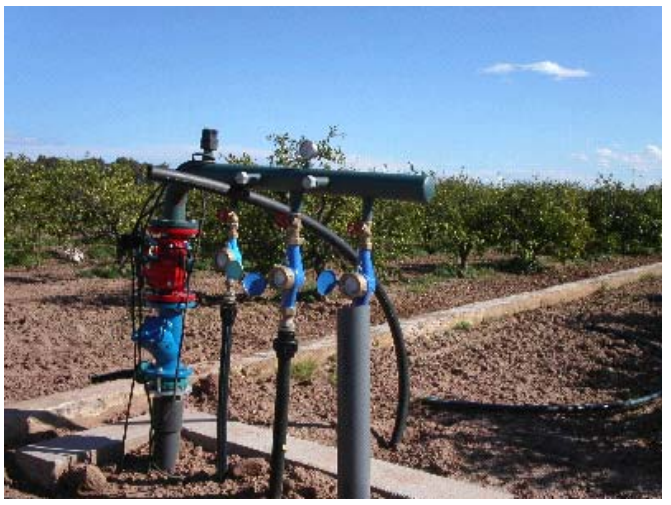

FIGURA 2. INSTALACIÓN TÍPICA DE UN HIDRANTE DE RIEGO.

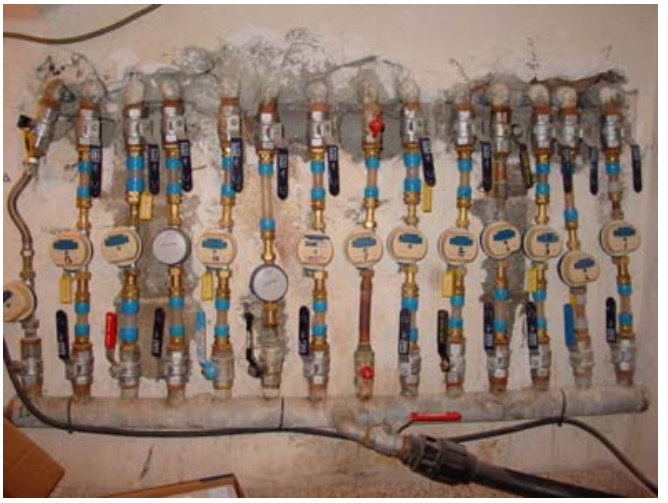

FIGURA 3. BATERÍA DE CONTADORES DOMÉSTICOS INSTALADOS EN POSICIÓN VERTICAL.

Esta inadecuada instalación de los contadores se refleja en el deterioro de la curva de error, principalmente, a caudales bajos debido al incremento en el rozamiento de la turbina, mientras que a caudales medios y altos el error de medición no sufre tanta variación respecto de su posición. 
Además de estos efectos inmediatos sobre la curva de error provocados por la posición de instalación, a medio/largo plazo pueden aparecer otras secuelas no deseadas, como un desgaste prematuro de la superficie interior de la turbina. La Tabla 1 muestra los resultados del ensayo de 35 contadores del mismo modelo instalados en dos posiciones, horizontal e inclinado $45^{\circ}$ sobre la horizontal. En ella, se observa claramente que los contadores se encuentran bastante deteriorados en todos los caudales para ambas posiciones de instalación. No obstante, se aprecia un mayor desgaste en el rango bajo de caudales donde en posición inclinada el error llega a ser superior a -70\%.

TABLA 1. INFLUENCIA DE LA POSICIÓN DE INSTALACIÓN SOBRE LA CURVA DE ERROR.

\begin{tabular}{ccc}
\hline & \multicolumn{2}{c}{ Error de medición (\%) } \\
\hline Caudal $(\mathrm{I} / \mathrm{h})$ & Horizontal & Inclinado $\mathbf{4 5}^{\circ}$ \\
\hline 30 & $-58,5$ & $-71,1$ \\
120 & $-15,8$ & $-15,5$ \\
750 & $-5,6$ & $-5,4$ \\
1500 & $-4,6$ & $-3,6$ \\
\hline
\end{tabular}

\subsubsection{Incrustaciones de cal.}

La calidad del agua de la red es otro factor determinante en el deterioro de los instrumentos. Las deposiciones calcáreas modifican gravemente la curva de error de los contadores, tanto de chorro único como volumétricos. En los primeros, inicialmente la reducción del área de paso en el interior del contador provoca que, a un caudal dado, la turbina gire más rápidamente de lo que debiera, dando lugar a sobrecontaje (Figura 4). Posteriormente, las deposiciones pueden ser de tal magnitud que lleguen incluso a bloquear el movimiento de la turbina (Figura 5).

Otras veces, los sólidos en suspensión arrastrados taponan gradualmente el filtro de entrada hasta impedir prácticamente el paso del agua (Figura 6). Si los caudales circulantes son excesivamente bajos se originará una situación equivalente a la provocada por un contador parado. Esta circunstancia es especialmente grave, desde el punto de vista de la medición, en aquellos abastecimientos en los que entre el abonado y la red se intercala un depósito de almacenamiento ya que, frecuentemente, el usuario no advierte la gran pérdida de carga originada y no avisa a la empresa de abastecimiento.

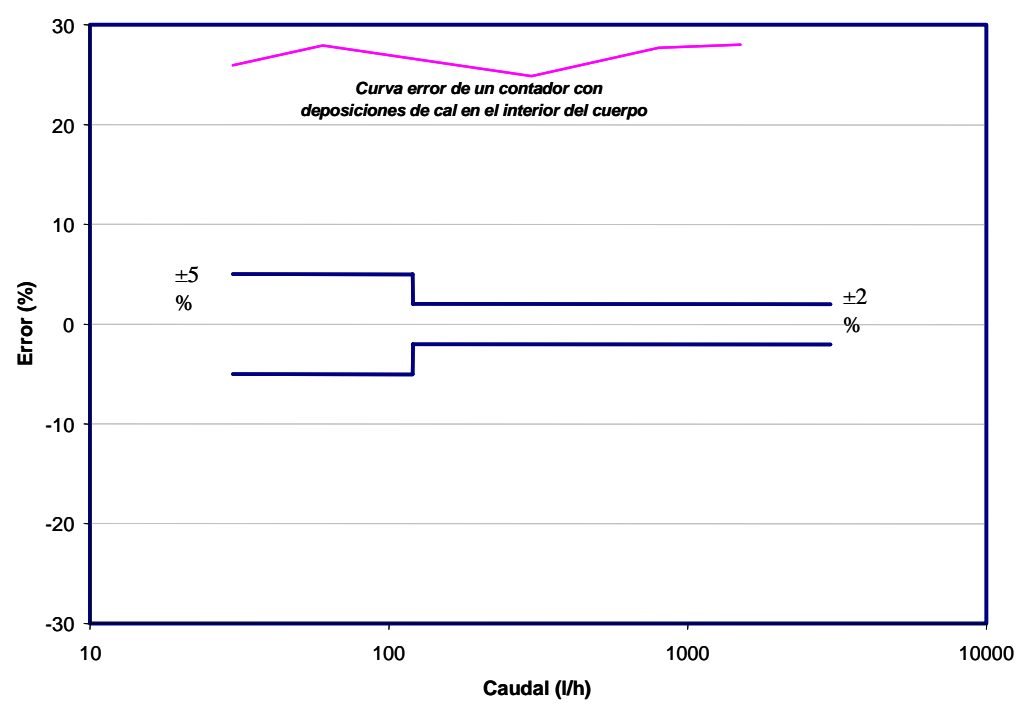

FIGURA 4. EFECTO DE LAS DEPOSICIONES CALCÁREAS SOBRE LA CURVA DE ERROR DE UN CONTADOR CHORRO ÚNICO. 


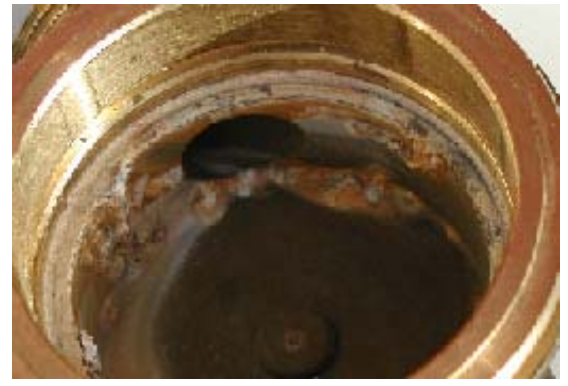

FIGURA 5. DEPOSICIONES CALCÁREAS EN EL CUERPO DEL CONTADOR DE AGUA.

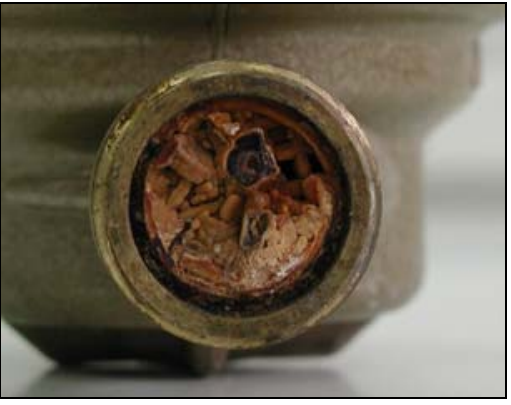

FIGURA 6. FILTRO DE ENTRADA OBSTRUIDO.

\subsubsection{Desgaste de los elementos mecánicos.}

Los contadores de agua como cualquier otro instrumento mecánico se desgastan a lo largo de su vida en servicio. En consecuencia, la curva de error de un contador no es la misma cuando se acaba de montar que cuando ha estado 15 años instalado.

En principio, el parámetro más utilizado para definir la edad de un contador es el tiempo que ha transcurrido desde su instalación. En la práctica, este parámetro es difícil de obtener, ya que el año de fabricación no siempre coincide con el año de instalación, y cuando se introduce en la base de datos de la empresa se incurre en error, ya que se supone más edad de la que realmente ha acumulado en servicio.

Por ello, en diversos trabajos se ha optado por cuantificar la edad de los contadores mediante el volumen acumulado, por ser este parámetro más accesible y certero a la hora de realizar estudios.

La influencia del factor tiempo debe cuantificarse para cada tecnología de medición mediante muestreos estadísticos de la población de contadores de agua, como se verá en el apartado 3.2.4. Estos muestreos aleatorios del parque de medidores estimarán el ritmo de deterioro sufrido con la edad y permitirán hacer comparativas entre modelos y tecnologías de medición.

\subsubsection{Aire}

Otra variable que afecta a la medición de agua es el aire que entra dentro de las instalaciones. Este factor influye negativamente contabilizando aire en lugar de agua consumida. En otras ocasiones, cuando los contadores tienen totalizadores semisecos el aire tiende a acumularse en la parte superior del medidor. Este inconveniente produce que no se lubriquen adecuadamente los engranajes del totalizador, generando mayor fricción a caudales bajos y, consecuentemente, mayor error de medición. La acumulación de aire en el totalizador puede hacer que un contador de Clase C pase a Clase B. Además, el aire durante largos periodos de tiempo en el interior del contador favorece que se depositen y solidifiquen los sólidos en suspensión empeorando su funcionamiento.

\subsubsection{ENSAYOS DETALLADOS DE LA CURVA DE ERROR DE CONTADORES DE CHORRO ÚNICO}

Los ensayos para obtener de forma detallada la curva de error se realizaron para dos clases metrológicas distintas, descritas en la norma ISO 4064, donde se garantiza una precisión de $\pm 2 \%$ para caudales entre el mínimo y el de transición, y del $\pm 5 \%$ para caudales entre el de transición y el máximo.

En este apartado se prueban contadores nuevos y usados de chorro único descritos en el capítulo anterior. Los ensayos en detalle a estos instrumentos se realizaron a aproximadamente 20 caudales diferentes, aforando en el depósito de 10 litros hasta $120 \mathrm{l} / \mathrm{h}$, y a partir de este caudal en el depósito de 200 litros (Anexo I). Los instrumentos de medición corresponden a modelos de diversas casas comerciales. 


\subsubsection{Contadores de chorro único clase B}

La Figura 7 muestra los resultados obtenidos en las pruebas a contadores nuevos de clase metrológica B. Las exigencias de la norma para esta clase metrológica se ven cumplidas en cuatro de los modelos probados ya que las curvas entran dentro de los límites de error de $\pm 2 \%$ y $\pm 5 \%$ a los caudales específicados. Sin embargo, se aprecia que el modelo $\mathrm{E}$ al caudal mínimo, $30 \mathrm{l} / \mathrm{h}$ para este calibre de contador, no cumple los requisitos establecidos.

Además, es importante advertir que las discrepancias más importantes entre los modelos ensayados se encuentran a caudales bajos menores de $30 \mathrm{l} / \mathrm{h}$, a partir de este caudal los resultados en contadores nuevos son muy similares.

La franja de caudales entre el caudal de arranque y aproximadamente $30 \mathrm{l} / \mathrm{h}$ es crítica a la hora de diseñar un contador de velocidad. Mucha de la investigación de nuevos prototipos en las empresas de fabricación va encaminada hacia la mejora de su comportamiento a caudales bajos. Por ejemplo, es habitual que el conjunto de engranajes del totalizador se comunique con la turbina mediante una transmisión magnética en lugar de la mecánica. Este tipo de transmisión tiene mayor fiabilidad y robustez frente a la mecánica al no introducirse nada entre los engranajes del totalizador. En cambio, la turbina presenta mayor inercia causada por los imanes del totalizador que provoca un aumento de los caudales de arranque. Es por ello, que hasta hace poco no existían en el mercado contadores de clase $\mathrm{C}$ con este tipo de totalizador.

Conjuntamente, los ensayos de laboratorio realizados a caudales bajos deben ser muy rigurosos ya que una ligera variación durante la regulación del caudal de la prueba puede dar errores que no caractericen correctamente la precisión del instrumento a este caudal. Por ejemplo, cuando se ajusta el caudal de ensayo a $15 \mathrm{l} / \mathrm{h}$, este debe mantenerse sin oscilaciones durante toda la prueba. El laboratorio de ensayo donde se realizaron las pruebas dispone de un calderín aguas arriba del banco de ensayo que sirve como punto de alimentación, asegurándose de este modo la máxima repetibilidad y estabilidad en los caudales de ensayo.

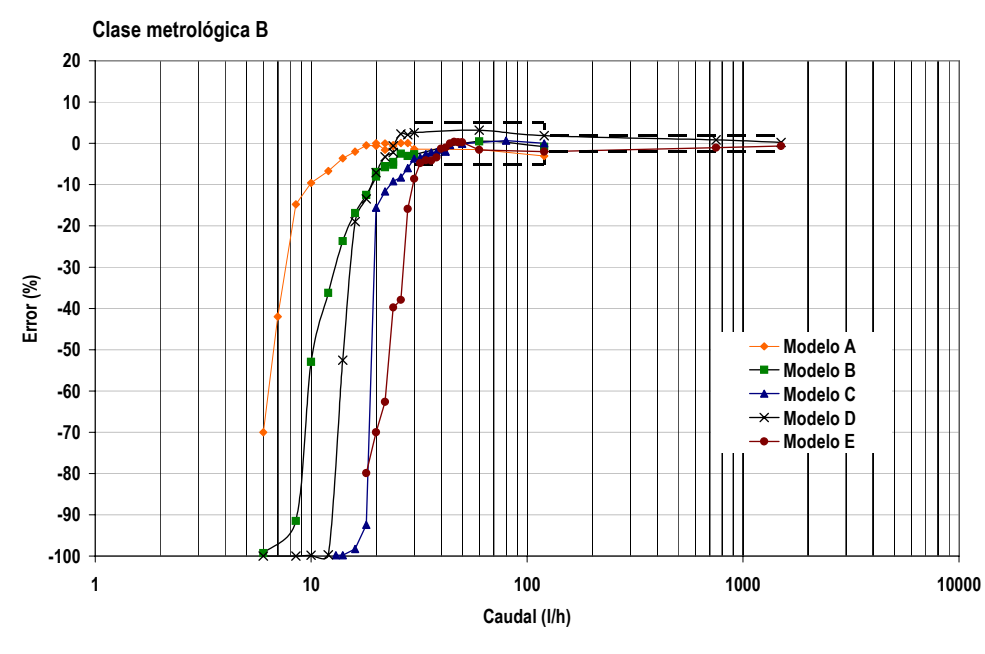

FigURA 7. CURVAS DE ERROR DE CONTADORES DE CHORRO ÚNICO CLASE B (QN=1,5 M3/H CLASE B).

Cuando se analiza por separado cada una de las curvas (Figura 7) se descubre, por un lado, que el caudal de arranque de cada uno de los instrumentos es variable. Este caudal, como se explica en el siguiente epígrafe, se considera aquel en el cual la turbina del contador pasa de encontrarse en movimiento a parada, es decir, de registrar consumo con un determinado error de medición a no registrar agua, aun consumiendo el usuario. Estrictamente la denominación correcta sería caudal de paro. 
A su vez, se advierte que a medida que la curva está situada más hacia la izquierda el volumen de consumo no contabilizado por el instrumento será menor. Por ejemplo, si se observa la Figura 7, el modelo A será capaz de registrar agua a un caudal de $6 \mathrm{l} / \mathrm{h}$ mientras que a ese mismo caudal cualquier otro modelo estaría parado. De igual manera, conseguir un error de medición de $-10 \%$ en el modelo $A$ es posible a un caudal de $12 \mathrm{l} / \mathrm{h}$, mientras que en el modelo $\mathrm{C}$ que respeta también los límites de la norma ese error se logra a $24 \mathrm{l} / \mathrm{h}$. En consecuencia, aun teniendo la misma clase metrológica la amplitud del rango en el modelo A es superior, siendo capaz de registrar los volúmenes consumidos a caudales más bajos.

Estas discrepancias son reflejo de la calidad del diseño y los materiales utilizados por los fabricantes de contadores. En el Capítulo 6 de la presente Tesis doctoral se propone una metodología para el control de las partidas de contadores que salen de fábrica realizando chequeos que garanticen su calidad metrológica.

Además, es importante considerar la capacidad metrológica a la hora de elegir este tipo de instrumentos, ya que como se verá más adelante, el contador en su proceso natural de deterioro tiende a desplazar la curva hacia la derecha, registrando los consumos más deficientemente a medida que pasa el tiempo. Si se parte de un contador con una curva de error muy ajustada a los márgenes de error establecidos se saldrán rápidamente de estos, dejando de contar parte del consumo de agua. En el Capítulo 5, se detalla la metodología para ponderar el error de medición con el perfil de consumo particular de cada usuario con el fin de estimar qué porcentaje del agua no se registra.

El desgaste que el instrumento sufre con el tiempo se refleja, claramente, en su curva de error. La Figura 8 ilustra el desplazamiento que sufre esta curva tras un cierto volumen trasegado en dos modelos diferentes de contador de chorro único. El deterioro o la acumulación de sólidos en la parte del instrumento en contacto con el líquido perturba el giro de la turbina que ofrece mayor resistencia. Este fenómeno se acusa sobre todo a caudales bajos donde las fuerzas motrices del agua son menores y la mayor fricción causada por el desgaste de las piezas internas es más apreciable en su precisión.

A medida que trasiega mayor volumen de agua, el deterioro puede generalizarse a caudales más altos, como en el caso del modelo $C$, que tras un volumen acumulado de $1385 \mathrm{~m}^{3}$ su curva de error sale completamente de los límites establecidos en la norma.

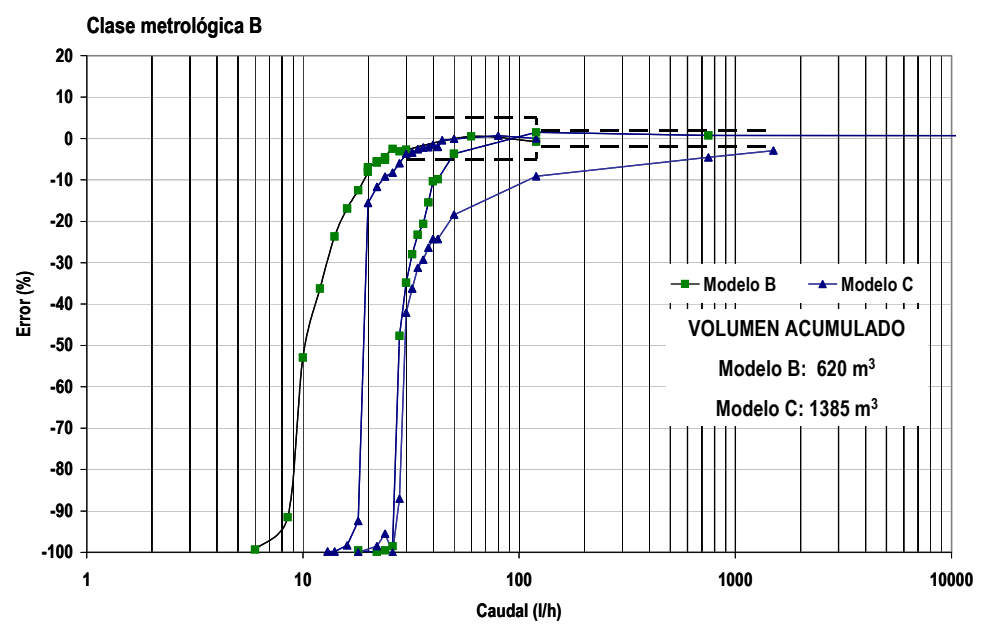

FIGURA 8. COMPARATIVA ENTRE UNA CURVA DE ERROR DE UN CONTADOR NUEVO Y USADO.

\subsubsection{Contadores de chorro único clase metrológica C}

Los contadores de clase metrológica $\mathrm{C}$ deben cumplir unas exigencias en precisión superiores. Por ejemplo, un contador instalado en una vivienda media, de $Q_{n}=1,5 \mathrm{~m}^{3} / \mathrm{h}$, siendo de clase $C$ debe alcanzar una precisión de $\pm 5 \%$ a un caudal de $15 \mathrm{l} / \mathrm{h}$, mientras que en clase metrológica $B$ esta exigencia sería a $30 \mathrm{l} / \mathrm{h}$. 
Para ello, generalmente el diseño y fabricación de estos instrumentos es más riguroso utilizando materiales mejor acabados que encarecen el coste del instrumento. Además, durante el proceso de fabricación los márgenes de tolerancia admisibles de cada pieza son mucho más estrechos llevando un control estricto de la producción.

En la Figura 9 aparecen los resultados de error obtenidos para esta clase metrológica. Los modelos ensayados son todos del mismo calibre y tecnología, chorro único. El modelo $E$ posee un display electrónico y los modelos $F$ y $G$ visualizan el consumo mediante un visor tradicional.

Las pruebas son satisfactorias para los tres modelos de contador. Aunque de nuevo, se observa cierta variabilidad en los errores entre los diferentes contadores a caudales bajos condicionada por los diseños de cada uno. En cada modelo hay que vencer un determinado momento inicial que no necesariamente es de la misma magnitud. En el instante en que el par motriz supera dicho momento resistente la turbina comienza a moverse, considerándose este punto, como se verá en el siguiente epígrafe, como caudal de arranque. En la Figura 7 y Figura 9 puede observarse cómo los caudales de arranque varían de un modelo a otro, desplazando en consecuencia la curva de error en sentido horizontal.

La diferencia más importante en diseño del modelo $E$ frente a los otros es que no emplea un totalizador clásico, es decir, suple la transmisión magnética utilizada en los otros modelos por un sistema de detección del movimiento de la turbina mediante células de efecto Hall que muestrean el número de vueltas de la turbina totalizando el consumo de agua. Además, este modelo añade un totalizador super-seco donde sólo la turbina del contador se encuentra en contacto con el agua, con lo que el desgaste provocado por agua duras es mínimo.

Todas estas características disminuyen la fricción mecánica logrando que el movimiento de la turbina se obtenga a caudales mucho menores, del orden de 3-4 I/h. La figura muestra claramente que el modelo $\mathrm{E}$ es más sensible a caudales bajos desplazándose la curva de error hacia la izquierda donde para un mismo caudal la precisión mejora.

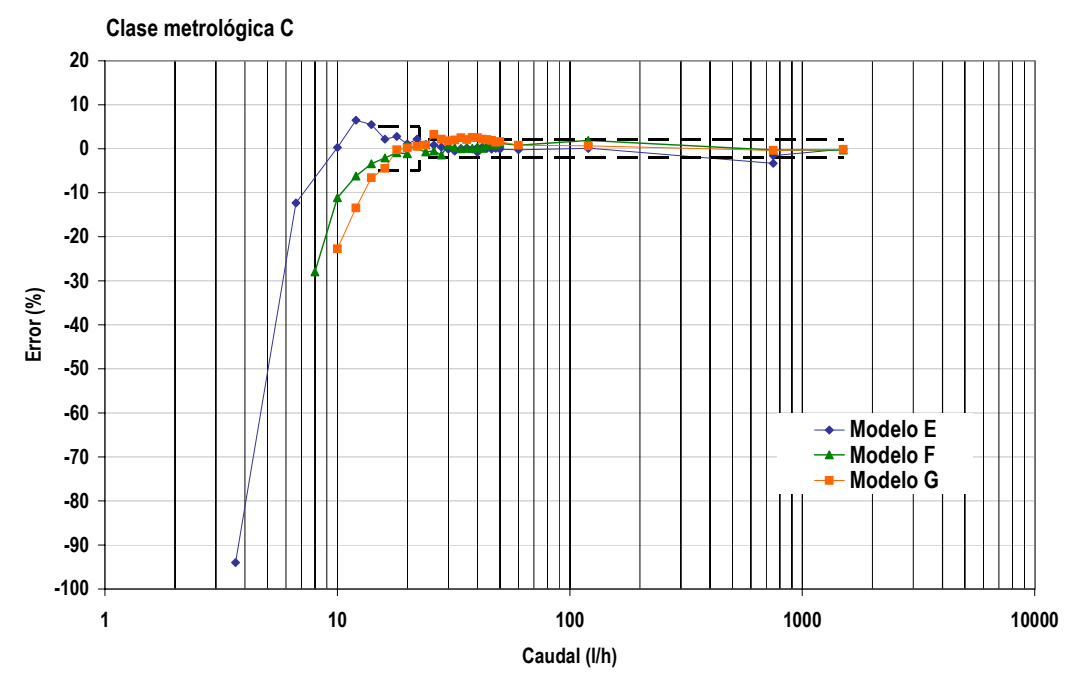

FIGURA 9. ENSAYOS A CONTADORES DOMÉSTICOS DE CHORRO ÚNICO CLASE C (QN=1,5 M³/H CLASE C).

\subsubsection{Conclusiones}

Cuando se analizan en conjunto los resultados obtenidos para ambas clases metrológicas es posible apreciar como en clase $\mathrm{C}$ el error decrece rápidamente al aumentar el caudal. En aproximadamente $6 \mathrm{l} / \mathrm{h}$, pasa de un error, por ejemplo para el modelo $\mathrm{E}$, de $-93 \%$ a $4 \mathrm{l} / \mathrm{h}$ a $0,3 \%$ a $10 \mathrm{l} / \mathrm{h}$. 
Por el contrario, la curva de error para clase metrológica B no mejora tan subitamente como en clase C. En este caso, la franja de caudal entre la que oscilan los errores es más amplia, aproximadamente de $10 \mathrm{l} / \mathrm{h}$, desde un caudal de arranque con un error cercano a $-70 \%$ hasta que la curva entra dentro de los límites establecidos por la norma.

En ambas clases la forma de esta curva es similar aunque depende de las características constructivas de cada modelo. La única diferencia es el caudal de arranque y funcionamiento. En el caso de contadores más precisos, esta curva se desplaza hacia la izquierda, o lo que es lo mismo, contabiliza volúmen de agua a caudales más bajos debido a su diseño y acabado. Los contadores menos precisos desplazan la curva hacia la derecha no siendo capaces de registrar rangos de caudal inferiores.

Evidentemente, a medida que la curva de error se encuentre más desplazada hacia la izquierda, para un mismo ritmo de deterioro, las condiciones metrológicas de este instumento serán mejores que un contador con la curva más desplazada hacia la derecha.

Por último, comentar que la variabilidad obtenida a caudales bajos en cualquier clase metrológica es debido al juego de fuerzas internas dentro del instrumento, fuerzas de resistencia al movimiento de la turbina frente a las fuerzas del fluido.

\subsubsection{EVOLUCIÓN DEL ERROR A PARTIR DEL CAUDAL DE ARRANQUE}

El caudal de arranque, como se verá, juega un papel muy importante en la determinación del porcentaje de agua registrado por el contador.

Frecuentemente, los contadores disponen de un indicador del flujo de agua que permite detectar el giro de la turbina 0 pistón. De esta forma, el caudal de arranque puede estimarse de dos modos, estando el contador parado y observando cuando comienza a moverse la turbina, o por el contrario, desde un estado en movimiento hasta que la turbina para.

Habitualmente, la gran mayoría de los consumos en viviendas a estos caudales se dan desde un estado en que la turbina del instrumento se encuentra en movimiento hasta que las fuerzas del agua no son suficientes para moverla. Como ejemplo se muestra el llenado de una cisterna que, en ocasiones, representa cerca del $30 \%$ del volumen total consumido por un usuario (Arregui, 2000). El patrón de llenado de una cisterna con una válvula de boya muestra inicialmente un caudal aproximado de $350 \mathrm{l} / \mathrm{h}$ que va disminuyendo a medida que sube la boya y hasta que finalmente cierra. En este caso, la turbina inicialmente se encuentra en movimiento y reduce progresivamente el caudal hasta llegar al caudal de arranque momento en que para (Figura 10).

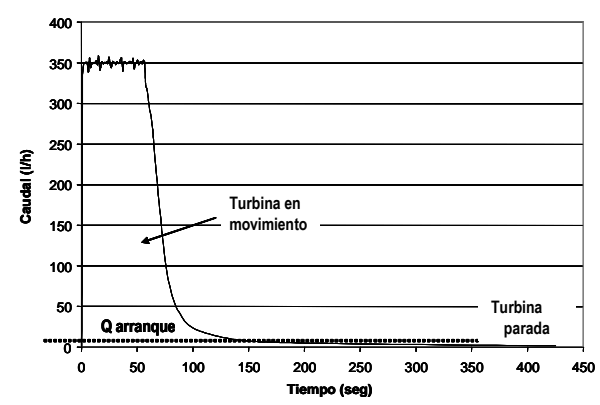

FIGURA 10. PATRÓN DE CONSUMO TÍPICO DE UNA CISTERNA.

Consecuentemente, conviene realizar este ensayo en dinámico regulando el caudal hasta observar en el indicador de flujo que la turbina comienza a tener dificultades en su movimiento, determinando este punto como el caudal de arranque.

La determinación del caudal de arranque es clave en la ponderación correcta del patrón de consumo y la curva de error en el tramo de caudales bajos. El ajuste de la precisión del contador a caudales bajos es difícil ya que dependiendo de las 
circunstancias y características del instrumento la curva de error se encuentra más o menos desplazada hacia caudales superiores. Asimismo, en la zona de caudales bajos la variabilidad encontrada en los ensayos de error es mucho mayor con lo que la incertidumbre en esta zona aumenta.

Conocer el caudal de arranque, punto crítico donde la turbina comienza a detenerse o moverse, es fundamental para estimar el error global de medición de un contador. Este caudal separa el intervalo del patrón de consumo en dos partes diferenciadas. Una parte, antes del caudal de arranque $\left(Q_{a}\right)$, donde el contador no se mueve, es decir, no registra consumo, y un segundo tramo, donde el consumo registrado en ese subintervalo dependería del error asociado al caudal medio del mismo, calculado según la linealización de la curva de error ${ }^{1}$ entre los diferentes caudales a los que se ha ensayado el instrumento.

Como se ha comentado, tal y como se demostró en estudios previos (Arregui, 1999), no incluir el caudal de arranque repercute negativamente en el cálculo correcto del error global, al no considerar como no registrado el porcentaje de volumen consumido a caudales por debajo del mismo. No obstante, determinar el caudal de arranque supone en muchos casos un tiempo de ensayo elevado y una paciencia considerable por parte del técnico de laboratorio.

Otra de las incógnitas, ocasionada por la gran dispersión encontrada incluso para un mismo contador, es el error que debe asignarse a este caudal, ya que como se explicó a esos caudales las fuerzas presentes tienen una magnitud muy pequeña por lo que cualquier alteración en las mismas cambia significativamente el punto de equilibrio. Uno de los supuestos al respecto parte de la propuesta presentada por Arregui para ponderar el error global de medición, que considera el error al caudal de arranque cercano al $-70 \%$. Esta afirmación se corrobora con los ensayos realizados en la presente Tesis doctoral (Figura 11).

De las pruebas en detalle realizadas con diferentes contadores de agua, es fácil observar aproximadamente en qué momento cesa el movimiento. Estos ensayos del caudal de arranque se inician a caudales donde la turbina tiene un movimiento estable y continuo, disminuyéndose en $2 \mathrm{l} / \mathrm{h}$, hasta llegar a un caudal donde la turbina deja de moverse y su error es de $-100 \%$, es decir el instrumento no contabiliza consumo de agua.

En esta prueba tras varios ensayos de error a caudales bajos la turbina cesa su movimiento. Entre los caudales de ensayo, uno en movimiento y otro prácticamente parado, se sitúa el caudal de arranque y su error de medición. Es decir, un punto sería el caudal al cual el error es más elevado, lo que significa que el contador se ha movido en algún momento del ensayo pero que posteriormente se ha parado. $Y$ otro en el ensayo al caudal superior, donde la turbina del contador lleva un movimiento lento pero continuo.

Luego, para determinar con cierto nivel de confianza el error al caudal de arranque se calcula el punto intermedio entre los caudales descritos. De esta forma, en la Tabla 2 se especifican los resultados obtenidos de los ensayos en laboratorio para estos caudales, y el punto medio calculado. En la Figura 11, se ilustran estos mismos valores en un gráfico donde se extrae la recta intermedia entre el conjunto de puntos anteriores y posteriores.

\footnotetext{
1 La linealización de la curva de error es el método propuesto por Arregui (2001), como se verá durante el Capítulo 5, donde se profundiza en los métodos de cálculo del error global.
} 
TABLA 2. ENSAYOS REALIZADOS PARA LA ESTIMACIÓN DEL ERROR AL CAUDAL DE ARRANQUE.

\begin{tabular}{|c|c|c|c|c|c|c|c|}
\hline CONTADOR & $\begin{array}{l}\text { Caudal anterior al } \\
\text { de arranque }(\mathrm{l} / \mathrm{h})\end{array}$ & $\begin{array}{l}\text { Error } \\
(\%)\end{array}$ & $\begin{array}{l}\text { Caudal posterior } \\
\text { al de arranque(l/h) }\end{array}$ & $\begin{array}{l}\text { Error } \\
(\%)\end{array}$ & $\begin{array}{l}\text { Caudal medio } \\
(\mathrm{l} / \mathrm{h})\end{array}$ & $\begin{array}{c}\text { Error medio } \\
(\%)\end{array}$ & $\begin{array}{c}\text { Volumen } \\
\text { acumulado por el } \\
\text { contador }\left(\mathrm{m}^{3}\right)\end{array}$ \\
\hline 1 & 10 & $-95,1$ & 11 & $-37,1$ & 10,5 & $-66,1$ & 8,68 \\
\hline 2 & 12 & $-99,7$ & 14 & $-52,6$ & 13 & $-76,1$ & 9,8 \\
\hline 3 & 12 & $-99,9$ & 14 & $-62,6$ & 13 & $-81,3$ & 12,4 \\
\hline 4 & 8,5 & $-91,5$ & 10 & $-53,0$ & 9,25 & $-72,2$ & 8 \\
\hline 5 & 18 & $-92,4$ & 20 & $-15,6$ & 19 & $-54,0$ & 0,4 \\
\hline 6 & 26 & $-98,5$ & 28 & $-47,7$ & 27 & $-73,1$ & 620 \\
\hline 7 & 28 & $-87,0$ & 30 & $-42,1$ & 29 & $-64,6$ & 1385 \\
\hline 8 & 28 & $-98,0$ & 30 & $-72,0$ & 29 & $-85,0$ & 530 \\
\hline 9 & 22 & $-84,8$ & 24 & $-39,5$ & 23 & $-62,2$ & 322 \\
\hline \multirow[t]{2}{*}{10} & 13 & $-78,0$ & 14 & $-52,1$ & 13,5 & $-65,0$ & 2 \\
\hline & & & & \multicolumn{2}{|c|}{ Caudal de arranque } & $-70,0$ & \\
\hline
\end{tabular}

Como puede comprobarse en la Figura 11, los contadores con un caudal de arranque mayor corresponden a instrumentos retirados de campo después de su uso, mientras los contadores con menor volumen acumulado se sitúan a la izquierda del gráfico con un caudal de arranque menor.

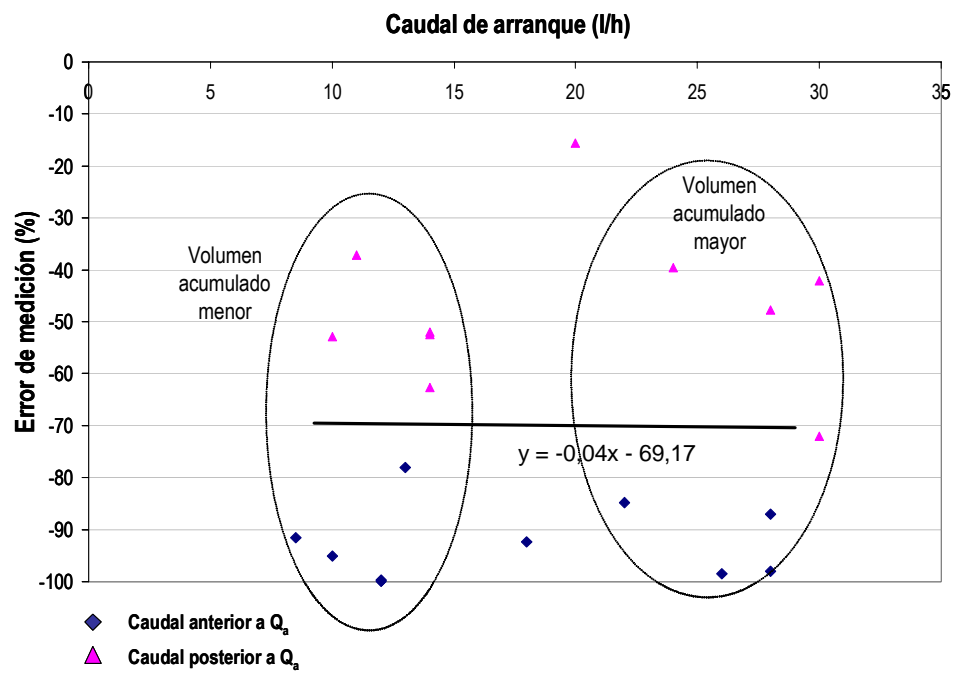

FIGURA 11. RESULTADOS DEL ERROR DE MEDICIÓN AL CAUDAL DE ARRANQUE.

Así pues, los resultados del error medio al caudal de arranque se estimarán en - 70\%, tal como se supone en la metodología de ponderación presentada por Arregui (2001).

No obstante, determinar el caudal de arranque implica en muchos casos un tiempo de ensayo elevado y una paciencia considerable por parte del técnico de laboratorio. Por ello, en ocasiones es conveniente intentar simplificar este trabajo investigando métodos que permitan eliminar este proceso. En este sentido se ha estudiado la relación entre el caudal de arranque y el error de medición a $30 \mathrm{l} / \mathrm{h}$ de un modelo de contador de chorro único agrupando el error de medición a $30 \mathrm{l} / \mathrm{h}$ por franjas, constatándose una alta correlación entre ambos (Figura 12).

En la Tabla 3 se presenta una clasificación por intervalos de error realizada con el fin de relacionar estos dos parámetros $\left(Q_{a}-\varepsilon_{30}\right.$ In $)$, y con ello simplificar la aproximación a la curva de error. Asimismo, se muestra que la incertidumbre obtenida en la medida del $Q_{a}$, en general, no sobrepasa los $\pm 2 / / h$.

TABLA 3. CLASIFICACIÓN EN INTERVALOS DE ERROR A 30 L/H PARA OBTENER CAUDALES DE ARRANQUE 


\begin{tabular}{|c|c|c|c|c|c|}
\hline Intervalo \& (30 I/h) & $\begin{array}{c}\varepsilon_{\text {medio }} \\
(30 / / h)\end{array}$ & $\begin{array}{l}\text { Qa medio } \\
(\mathrm{l} / \mathrm{h})\end{array}$ & $\begin{array}{c}\sigma(\mathrm{Qa}) \\
(\mathrm{l} / \mathrm{h})\end{array}$ & Tamaño muestra & $\begin{array}{c}\text { Incertidumbre }(90 \% \\
\text { confianza) }\end{array}$ \\
\hline de $-50 \%$ a $-40 \%$ & $-45,02$ & 23,56 & 2,12 & 9 & 1,19 \\
\hline de $-40 \%$ a $-30 \%$ & $-33,85$ & 21,78 & 2,71 & 18 & 1,07 \\
\hline de $-30 \%$ a $-20 \%$ & $-24,59$ & 19,54 & 3,27 & 27 & 1,06 \\
\hline de $-20 \%$ a $-10 \%$ & $-14,81$ & 18,51 & 2,48 & 46 & 0,61 \\
\hline de $-10 \%$ a $-5 \%$ & $-7,91$ & 16,38 & 2,06 & 34 & 0,59 \\
\hline de $-5 \%$ a $0 \%$ & $-2,63$ & 13,91 & 1,93 & 29 & 0,60 \\
\hline$>0 \%$ & 1,22 & 14,49 & 2,94 & 9 & 1,65 \\
\hline
\end{tabular}

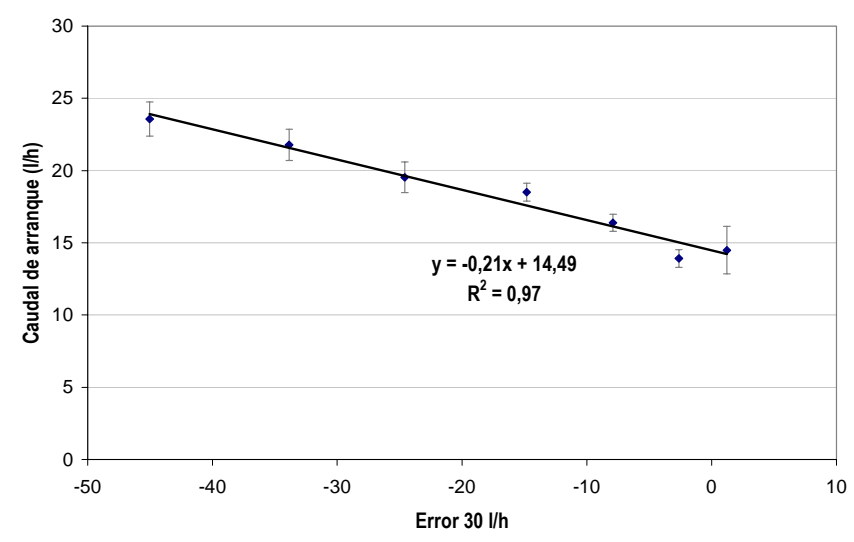

FIGURA 12. RELACIÓN ENTRE EL CAUDAL DE ARRANQUE Y EL ERROR A 30 L/H.

De esta forma, por ejemplo, si el resultado de un ensayo a $30 \mathrm{l} / \mathrm{h}$ de un contador de chorro único es de $-24 \%$, según el ajuste lineal obtenido, se estimaría un caudal de arranque de 19,5 l/h. Así pues, un solo ensayo es capaz de determinar con cierto margen de confianza el caudal de arranque del contador, al que se le asignaría como se ha justificado, un error de medición de $-70 \%$.

Otra relación interesante puede ser la existente entre el caudal de arranque y el error a $120 \mathrm{l} / \mathrm{h}$ donde se han excluido aquellos aparatos que se encuentran parados (Figura 13). En ella se puede observar que existe una acumulación de puntos con un error prácticamente nulo a un caudal de $120 \mathrm{l} / \mathrm{h}$. Esta nube de puntos se corresponde con aquellos contadores más nuevos que poseen un caudal de arranque menor.

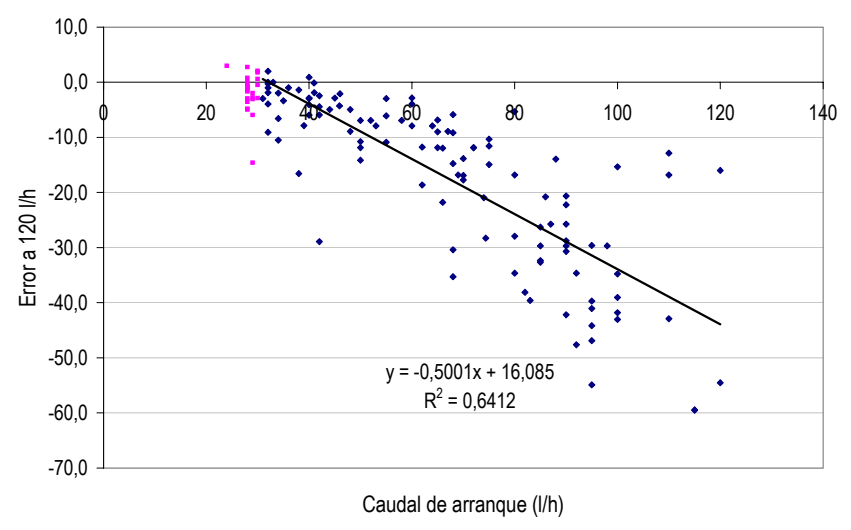

FIGURA 13. RELACIÓN ENTRE EL CAUDAL DE ARRANQUE Y EL ERROR A 120 L/H.

La justificación a este fenómeno es que un contador en buen estado mantiene mejor los límites de error a caudales altos que bajos. El deterioro de un contador comienza por los caudales más bajos de su curva de error. Luego aquellos 
contadores con menores caudales de arranque se encontrarán en mejores condiciones a caudales altos. Se demuestra también que una vez sobrepasados los límites de error del $\pm 5 \%$ existe cierta linealidad entre ambas variables. Es decir, a medida que el error a $120 \mathrm{l} / \mathrm{h}$ se hace más negativo, el caudal de arranque aumenta.

Esta correlación no es tan fuerte como la anterior y lo único que demuestra este gráfico es lo que se viene comentando durante toda la Tesis, primero, que los contadores de velocidad se deterioran más con el paso del tiempo a caudales bajos, y segundo, que a partir de un caudal aproximadamente de $100 \mathrm{l} / \mathrm{h}$ el error de la muestra ensayada es mucho menor.

\subsubsection{EVOLUCIÓN DE LA CURVA DE ERROR CON EL TIEMPO}

\subsubsection{Descripción de los contadores de agua muestreados}

Los contadores de agua ensayados en el laboratorio, que han estado en servicio en diferentes abastecimientos, corresponden a instrumentos con la misma tecnología de medición, chorro único, muy común en las empresas de agua españolas, al contrario que en otros países como EEUU donde la tecnología más común es la de disco nutante o pistón rotativo.

El parque de contadores de cada uno de los abastecimientos analizados es, en general, similar en cuanto a clase metrológica inicial de los contadores de agua, tecnología de medición, etcétera. Las diferencias se encuentran en las características de su entorno. Factores como la calidad del agua, la forma y posición de instalación, la propia tipología de la vivienda o el periodo que permanecen en servicio son variables que afectan en mayor o menor medida a su deterioro.

En este apartado se efectúa un análisis estadístico del parque de contadores de 6 abastecimientos diferentes, donde se han ensayado muestras de cada uno llegando a un total de, aproximadamente, 800 contadores. De estos ensayos en laboratorio es posible conocer la evolución que han sufrido estos instrumentos en cada uno de los abastecimientos.

Los abastecimientos analizados se numeran del 1 al 6 , y los diferentes modelos de contadores ensayados con letras en minúsculas, llevando en todo este epígrafe, siempre que se haga referencia a ellos esta misma numeración.

El tamaño de la muestra ensayada y el número de modelos de cada abastecimiento no es siempre representativo del número de abonados total. Consecuentemente, a la hora de extraer conclusiones se recurrirá a aquellos modelos que sean más representativos. La Tabla 4 resume de forma global el número total de contadores ensayados durante esta etapa.

TABLA 4. DESCRIPCIÓN DE LAS MUESTRAS DE CONTADORES EN SERVICIO.

\begin{tabular}{cccccccc}
\hline Modelo de & \multicolumn{7}{c}{ Abastecimiento de agua } \\
\cline { 2 - 8 } contador & $\mathbf{1}$ & $\mathbf{2}$ & $\mathbf{3}$ & $\mathbf{4}$ & $\mathbf{5}$ & $\mathbf{6}$ & Total \\
\hline $\mathbf{a}$ & 81 & - & 5 & 35 & & 272 & 393 \\
$\mathbf{b}$ & - & - & - & - & 66 & 66 \\
$\mathbf{c}$ & - & 17 & - & 40 & & 11 & 68 \\
$\mathbf{d}$ & 3 & - & 11 & 39 & & 3 & 56 \\
$\mathbf{e}$ & 12 & - & - & 11 & & 1 & 24 \\
$\mathbf{f}$ & 34 & - & 20 & - & & - & 54 \\
$\mathbf{g}$ & - & 4 & - & - & 110 & 7 & 121 \\
$\mathbf{h}$ & - & 1 & - & - & & 2 & 3 \\
$\mathbf{i}$ & - & - & 1 & - & & 22 & 23 \\
\hline Total & 130 & 22 & 37 & 125 & 110 & 384 & 808 \\
\hline No abonados & 5500 & 750 & 4000 & 200000 & 4500 & 7500 & \\
aproximado & & & & & & & \\
\hline
\end{tabular}

Cuando se examina la tabla anterior, no es difícil comprobar que el trabajo de campo fue más intenso en unos casos que en otros. En concreto, el abastecimiento número 6, fue el que se estudió con mayor grado de detalle. En este caso la muestras es más representativa que el resto. 
El procedimiento adoptado para ensayar estos contadores fue en todos los casos el mismo, descrito en el epígrafe anterior, con la salvedad que se realizaron 4 pruebas a caudales de ensayo de 30,120, 750 y $1500 \mathrm{l} / \mathrm{h}$. Una vez ensayados en laboratorio los micromedidores, se llevó a cabo un análisis de la incertidumbre de la medida por abastecimientos y por modelo de contador posibilitando la comparativa entre los sistemas de medición estudiados.

\subsubsection{Resultados de los ensayos por abastecimiento}

En este apartado se exponen los resultados de los ensayos a medidores de agua por abastecimientos, calculando la incertidumbre asociada en la estimación del error de medición a cada caudal. Estos intervalos de confianza, con un nivel de fiabilidad del $95 \%$, acotan el error promedio obtenido de la muestra de contadores ensayada. De esta forma, se establece el intervalo de error en el que oscila el verdadero valor del error del modelo probado (Daniel y Terriel, 1994). Tamaños de muestra inferiores a 10 contadores no son representativos con lo que no se ha calculado su incertidumbre.

A su vez, como supuestos importantes se considera un contador parado cuando presenta a todos los caudales de ensayo un error de medición de $-100 \%$, mientras que estará deteriorado cuando no contabiliza agua a $120 \mathrm{l} / \mathrm{h}$. Los errores medios se estiman sin tener en cuenta estos dos tipos de contadores. Es decir, considerando sólo aquellos instrumentos que, teóricamente, se encuentran en mejor estado.

De esta forma, los errores promedio de las muestras extraídas en cada una de las poblaciones se exponen en las siguientes tablas. Inicialmente, se presentan los resultados del abastecimiento 1 (Tabla 5).

TABLA 5. RESULtADOS DE LOS ENSAYOS REALIZADOS EN EL ABASTECIMIENTO 1.

\begin{tabular}{|c|c|c|c|c|c|c|c|c|}
\hline MODELO & $\begin{array}{l}\mathrm{N}^{0} \text { contadores } \\
\text { ensayados }\end{array}$ & $\begin{array}{c}\text { Volumen } \\
\text { acumulado } \\
\mathrm{m}^{3}\end{array}$ & $\begin{array}{c}\text { Error a } \\
30 \mathrm{l} / \mathrm{h}(\%)\end{array}$ & $\begin{array}{c}\text { Error a } \\
120 \mathrm{l} / \mathrm{h}(\%)\end{array}$ & $\begin{array}{c}\text { Error a } \\
750 \mathrm{l} / \mathrm{h}(\%)\end{array}$ & $\begin{array}{c}\text { Error a } \\
1500 \mathrm{l} / \mathrm{h}(\%)\end{array}$ & $\begin{array}{c}\mathrm{N}^{\circ} \\
\text { PARADOS }\end{array}$ & $\begin{array}{c}\mathbf{N}^{0} \\
\text { DETERIORADOS }\end{array}$ \\
\hline \multirow[t]{2}{*}{ a } & 70 & 1308,4 & $-42,7$ & -3 & $-0,9$ & $-0,4$ & 2 & 8 \\
\hline & Incertidumbre (\%) & & $\pm 10,1$ & $\pm 2,7$ & $\pm 0,9$ & $\pm 0,8$ & & \\
\hline d & 3 & 2007,5 & $-34,5$ & $-5,2$ & $-3,1$ & $-2,7$ & 0 & 0 \\
\hline \multirow[t]{2}{*}{ e } & 11 & 3396,2 & $-14,2$ & $-2,9$ & $-3,1$ & $-2,6$ & 0 & 1 \\
\hline & Incertidumbre (\%) & & $\pm-9,2$ & $\pm 2,6$ & $\pm 1,6$ & \pm 2 & & \\
\hline \multirow[t]{2}{*}{$f$} & 26 & 3164,6 & -43 & $-4,9$ & $-3,9$ & $-3,1$ & 4 & 11 \\
\hline & Incertidumbre (\%) & & $\pm 15,2$ & $\pm 1,7$ & $\pm 2,2$ & $\pm 0,8$ & & \\
\hline
\end{tabular}

En este abastecimiento 1 se ensayaron un total de 130 medidores, los cuales se encontraban bastante deteriorados. Como se ha comentado, el deterioro de los contadores se acusa principalmente a caudales bajos. En la Tabla 5, los modelos a y $f$, bastante comunes en esta red, muestran errores de $-43 \%$ a $30 \mathrm{l} / \mathrm{h}$, e incluso a caudales más altos el comportamiento de este último modelo puede producir importantes errores de subregistro de agua.

El deterioro a caudales altos es más evidente para la empresa de agua, ya que cuando el error es elevado en esta franja, en general se deja de registrar mayor cantidad de agua debido a que el groso del volumen consumido se produce en ese rango.

En la muestra se han encontrado un número excesivo de contadores parados y deteriorados. Se observa que, además, los instrumentos tienen volumen acumulado promedio de cerca de $2100 \mathrm{~m}^{3}$, lo que hace pensar que la muestra se encuentra en cierto modo sesgada. Esto puede ser debido a que la muestra fue seleccionada por la empresa de abastecimiento, con lo que es posible que gran parte de estos instrumentos hayan sido retirados por tener sospecha de encontrarse en mal estado. 
Por ello, es importante extraer una muestra de medidores al azar entre toda la población del parque. En este tipo de estudio es fundamental la colaboración de la empresa de suministro de agua que es la encargada de tomar la muestra. En ocasiones, ésta no se extrae al azar y los contadores retirados de los domicilios no son los más representativos de la población, sesgando normalmente los resultados hacia errores más desfavorables.

Los resultados obtenidos en los abastecimientos 2,3 y 4 se presentan a continuación.

TABLa 6. Resultados de los ensayos en el ABAstecimiento 2.

\begin{tabular}{|c|c|c|c|c|c|c|c|c|}
\hline MODELO & $\begin{array}{l}\mathrm{N}^{0} \text { contadores } \\
\text { ensayados }\end{array}$ & $\begin{array}{c}\text { Volumen } \\
\text { acumulado } \\
\left(\mathrm{m}^{3}\right)\end{array}$ & $\begin{array}{c}\text { Error a } \\
30 \mathrm{l} / \mathrm{h}(\%)\end{array}$ & $\begin{array}{c}\text { Error a } \\
120 \mathrm{l} / \mathrm{h}(\%)\end{array}$ & $\begin{array}{c}\text { Error a } \\
750 \mathrm{l} / \mathrm{h}(\%)\end{array}$ & $\begin{array}{c}\text { Error a } \\
1500 \mathrm{l} / \mathrm{h}(\%)\end{array}$ & $\begin{array}{c}\mathrm{N}^{\circ} \\
\text { PARADOS }\end{array}$ & $\begin{array}{c}\mathbf{N}^{\circ} \\
\text { DETERIORADOS }\end{array}$ \\
\hline \multirow[t]{2}{*}{ c } & 17 & 222,9 & $-24,3$ & $-1,3$ & $-0,8$ & $-0,7$ & 0 & 0 \\
\hline & Incertidumbre (\%) & & $\pm 18,2$ & $\pm 1,7$ & $\pm 0,5$ & $\pm 0,4$ & & \\
\hline g & 3 & 1456,7 & $-42,5$ & $-4,3$ & 0,5 & $-0,7$ & 0 & 1 \\
\hline $\mathrm{h}$ & 1 & 95,2 & $-8,4$ & $-0,9$ & 0,7 & $-1,8$ & 0 & 0 \\
\hline
\end{tabular}

TABLA 7. RESUltados de LOS ENSAYOS EN EL ABASTECIMIENTO 3.

\begin{tabular}{|c|c|c|c|c|c|c|c|c|}
\hline MODELO & $\begin{array}{l}\mathrm{N}^{0} \text { contadores } \\
\text { ensayados }\end{array}$ & $\begin{array}{c}\text { Volumen } \\
\text { acumulado } \\
\left(\mathrm{m}^{3}\right)\end{array}$ & $\begin{array}{c}\text { Error a } \\
30 \mathrm{l} / \mathrm{h}(\%)\end{array}$ & $\begin{array}{c}\text { Error a } \\
120 \mathrm{l} / \mathrm{h}(\%)\end{array}$ & $\begin{array}{c}\text { Error a } \\
750 \mathrm{l} / \mathrm{h}(\%)\end{array}$ & $\begin{array}{c}\text { Error a } \\
1500 \mathrm{l} / \mathrm{h}(\%)\end{array}$ & No PARADOS & $\begin{array}{c}\mathbf{N}^{0} \\
\text { DETERIORADOS }\end{array}$ \\
\hline a & 4 & 1022,3 & $-57,0$ & $-0,5$ & 0,2 & 0,3 & 1 & 0 \\
\hline \multirow[t]{2}{*}{ d } & 11 & 1420,6 & $-30,3$ & 1,3 & 0,6 & 2,0 & 0 & 0 \\
\hline & Incertidumbre (\%) & & $\pm 26,6$ & $\pm 3,2$ & $\pm 2,1$ & $\pm 2,2$ & & \\
\hline$f$ & 6 & 2121,4 & $-74,2$ & $-7,9$ & $-5,5$ & $-6,0$ & 12 & 2 \\
\hline i & 1 & 1601,6 & $-100,0$ & 1,4 & $-9,4$ & $-8,3$ & 0 & 0 \\
\hline
\end{tabular}

TABLA 8. RESULTADOS ABASTECIMIENTO 4.

\begin{tabular}{|c|c|c|c|c|c|c|c|c|}
\hline MODELO & $\begin{array}{l}\mathrm{N}^{0} \text { contadores } \\
\text { ensayados }\end{array}$ & $\begin{array}{c}\text { Volumen } \\
\text { acumulado } \\
\left(\mathrm{m}^{3}\right)\end{array}$ & $\begin{array}{c}\text { Error a } \\
30 \mathrm{l} / \mathrm{h}(\%)\end{array}$ & $\begin{array}{c}\text { Error a } \\
120 \mathrm{l} / \mathrm{h}(\%)\end{array}$ & $\begin{array}{c}\text { Error a } \\
750 \mathrm{l} / \mathrm{h}(\%)\end{array}$ & $\begin{array}{c}\text { Error a } \\
1500 \mathrm{l} / \mathrm{h}(\%)\end{array}$ & $\mathrm{N}^{0}$ PARADOS & $\begin{array}{c}\mathbf{N}^{\circ} \\
\text { DETERIORADOS }\end{array}$ \\
\hline \multirow[t]{2}{*}{ a } & 32 & - & $-19,8$ & 0,0 & $-0,6$ & $-0,2$ & 0 & 3 \\
\hline & Incertidumbre (\%) & & $\pm 11,9$ & $\pm 0,9$ & $\pm 0,7$ & $\pm 0,8$ & & \\
\hline \multirow[t]{2}{*}{ c } & 40 & - & $-17,3$ & 0,9 & 1,2 & 1,3 & 0 & 0 \\
\hline & Incertidumbre (\%) & & $\pm 10,1$ & $\pm 1,6$ & $\pm 1,6$ & $\pm 1,6$ & & \\
\hline \multirow[t]{2}{*}{ d } & 39 & - & $-5,3$ & $-0,7$ & $-0,2$ & 0,3 & 0 & 0 \\
\hline & Incertidumbre (\%) & & \pm 5 & $\pm 0,4$ & $\pm 0,4$ & $\pm 0,4$ & & \\
\hline \multirow[t]{2}{*}{ e } & 10 & - & $-62,5$ & 3,0 & 4,9 & 5,0 & 0 & 1 \\
\hline & Incertidumbre (\% & & $\pm 21,5$ & $\pm 2,4$ & $\pm 2,4$ & $\pm 2,3$ & & \\
\hline
\end{tabular}

El tamaño de muestra extraída de los abastecimientos 2, 3 y 4 no puede considerarse representativo de la población de instrumentos del municipio, con lo que estos resultados sólo serán válidos para estudiar el comportamiento de cada modelo de contador con el tiempo pero no para sacar conclusiones sobre el estado metrológico del parque de contadores de estas localidades o para determinar si en un abastecimiento el deterioro sufrido es mayor o menor. 
La Tabla 9 del abastecimiento 5, muestra solo los resultados de un modelo de contador. Se aprecia que el porcentaje de contadores parados es de cerca de 35 lo que puede evidenciar dos cosas, que se ha instalado una partida defectuosa, no excesivamente antigua, que está generando importantes pérdidas económicas para la empresa de suministro y un ineficiente control del consumo de agua de la población. O que la muestra no refleja adecuadamente el comportamiento real de los medidores y que corresponde a un grupo sobre el cual tenía sospechas la empresa de suministro.

TABLA 9. RESULTADOS DE LOS ENSAYOS EN EL ABASTECIMIENTO 5.

\begin{tabular}{ccccccccc}
\hline MODELO & $\begin{array}{c}\mathbf{N}^{\circ} \text { contadores } \\
\text { ensayados }\end{array}$ & $\begin{array}{c}\text { Volumen } \\
\text { acumulado } \\
\left(\mathbf{m}^{3}\right)\end{array}$ & $\begin{array}{c}\text { Error a } 30 \\
\mathrm{l} / \mathrm{h}(\%)\end{array}$ & $\begin{array}{c}\text { Error a } \\
\mathbf{1 2 0} \mathrm{l} / \mathrm{h}(\%)\end{array}$ & $\begin{array}{c}\text { Error a } \\
\mathbf{7 5 0} \mathrm{l} / \mathrm{h}(\%)\end{array}$ & $\begin{array}{c}\text { Error a } \\
1500 \mathrm{l} / \mathrm{h} \\
(\%)\end{array}$ & $\begin{array}{c}\mathbf{N}^{\circ} \\
\text { PARADOS }\end{array}$ & $\begin{array}{c}\mathbf{N}^{\circ} \\
\text { DETERIORADOS }\end{array}$ \\
\hline $\mathbf{g}$ & 64 & 892,9 & $-14,8$ & $-2,1$ & $-0,1$ & $\mathbf{0 , 9}$ & 34 & 1 \\
& Incertidumbre (\%) & & $\pm 6,5$ & $\pm 1,4$ & $\pm 0,7$ & $\pm 0,4$ & & \\
\hline
\end{tabular}

TABLA 10. RESULtAdOS DE LOS ENSAYOS EN EL ABASTECIMIENTO 6.

\begin{tabular}{|c|c|c|c|c|c|c|c|c|}
\hline MODELO & $\begin{array}{l}\mathrm{N}^{0} \text { contadores } \\
\text { ensayados }\end{array}$ & $\begin{array}{c}\text { Volumen } \\
\text { acumulado } \\
\left(\mathrm{m}^{3}\right)\end{array}$ & $\begin{array}{l}\text { Error a } 30 \\
\quad \text { I/h (\%) }\end{array}$ & $\begin{array}{c}\text { Error a } \\
120 \mathrm{l} / \mathrm{h}(\%)\end{array}$ & $\begin{array}{c}\text { Error a } \\
750 \mathrm{l} / \mathrm{h}(\%)\end{array}$ & $\begin{array}{c}\text { Error a } \\
1500 \mathrm{l} / \mathrm{h} \\
(\%)\end{array}$ & $\begin{array}{c}\mathrm{N}^{\circ} \\
\text { PARADOS }\end{array}$ & $\begin{array}{c}\mathbf{N}^{\circ} \\
\text { DETERIORADOS }\end{array}$ \\
\hline \multirow[t]{2}{*}{ a } & 253 & 893,3 & $-52,5$ & $-6,8$ & $-1,8$ & $-1,1$ & 4 & 13 \\
\hline & Incertidumbre (\%) & & $\pm 5,1$ & $\pm 1,6$ & $\pm 0,3$ & $\pm 0,3$ & & \\
\hline \multirow[t]{2}{*}{ b } & 62 & 1737.6 & $-11,0$ & 0,0 & $-0,2$ & 2,4 & 2 & 1 \\
\hline & Incertidumbre (\%) & & $\pm 8,9$ & $\pm 1,3$ & $\pm 1,7$ & $\pm 1,6$ & & \\
\hline \multirow[t]{2}{*}{ c } & 11 & 352,8 & $-29,8$ & $-0,2$ & $-1,4$ & $-0,9$ & 0 & 0 \\
\hline & Incertidumbre (\%) & & $\pm 22,6$ & $\pm 0,9$ & $\pm 1,1$ & $\pm 0,4$ & & \\
\hline d & 3 & 1110,1 & $-20,7$ & $-2,2$ & $-1,6$ & $-1,8$ & 0 & 0 \\
\hline e & 1 & 485,6 & $-100,0$ & $-1,3$ & 0,8 & 1,2 & 0 & 0 \\
\hline g & 7 & 3588,3 & $-0,5$ & $-0,9$ & $-1,2$ & $-0,6$ & 0 & 0 \\
\hline $\mathrm{h}$ & 2 & 237 & $-1,0$ & 0,7 & $-1,4$ & $-0,8$ & 0 & 0 \\
\hline \multirow[t]{2}{*}{ i } & 22 & 2152,5 & $-60,2$ & $-3,5$ & $-1,2$ & $-1,6$ & 0 & 0 \\
\hline & Incertidumbre (\%) & & $\pm 19,0$ & $\pm 3,5$ & $\pm 1,8$ & $\pm 1,9$ & & \\
\hline
\end{tabular}

El abastecimiento 6 (Tabla 10), donde la muestra sí se considera representativa del parque de contadores, permite realizar un estudio en profundidad de la evolución de los errores de medición, comparando los modelos en servicio y señalando qué posibles variables afectan a su medición

Arregui et al.(2003), llevó a cabo un estudio económico del error global del parque de medidores de este municipio extrayendo conclusiones sobre su ritmo de deterioro y el periodo óptimo de sustitución de cada modelo en función de su comportamiento metrológico a lo largo del tiempo.

De los resultados, es posible apreciar que la curva de error de los contadores retirados del modelo a se encuentra muy deteriorada. En ella, los errores promedio de los contadores ensayados salen fuera de los límites establecidos en la norma ISO 4064 para caudales de 30 y $120 \mathrm{l} / \mathrm{h}$ (Figura 14). Además, un alto porcentaje de ellos no consigue arrancar a $30 \mathrm{l} / \mathrm{h}$ (aproximadamente un 6\%) o lo hace con errores de subcontaje superiores al $50 \%$ del volumen trasegado.

En este caso, un parámetro que puede haber tenido influencia en el rápido deterioro de todos los modelos es la inclinación con que muchos de ellos se instalan en este abastecimiento, lo que repercute a corto plazo en la facturación de la empresa de suministro y a medio-largo plazo en el estado físico de los mismos.

Los contadores del modelo b presentan un desgaste muy inferior (Figura 14). Asimismo, se advierte que este modelo tiene ligeros errores de sobrecontaje para caudales de ensayo próximos al caudal nominal. Esto puede ser atribuido al sistema de 
regulación de la curva de error que tiene forma de circuito en by-pass. Este circuito, con el tiempo, puede llegar a obturarse haciendo que la velocidad de impacto del agua sobre la turbina a un determinado caudal sea más alta, girando a mayor velocidad, provocando dicho sobrecontaje.

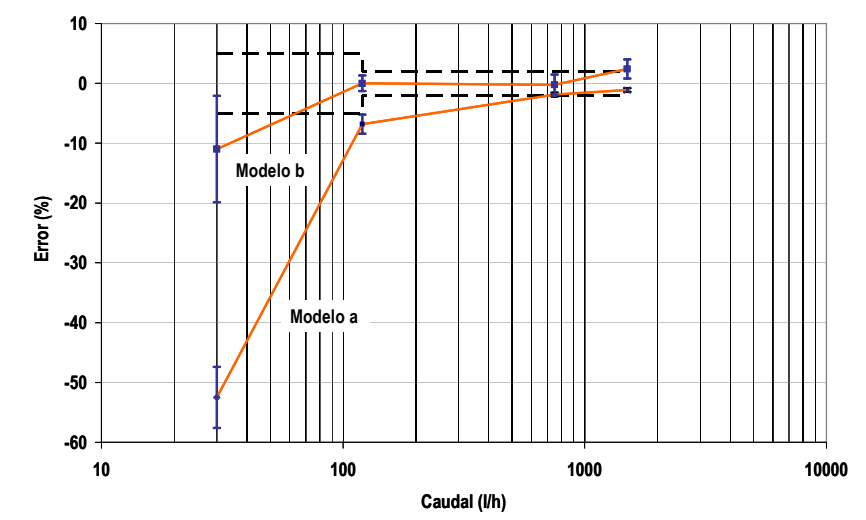

FIGURA 14. CURVA DE ERROR DE LOS MODELOS A Y B INSTALADOS EN EL ABASTECIMIENTO 5.

\subsubsection{Comparativa por modelo de contador}

Si se comparan los errores obtenidos para cada modelo en cada uno de los abastecimientos se aprecia que, en general, el comportamiento en cada uno de los municipios ha sido bastante similar, y se advierte que la variable edad es el parámetro que más condiciona su deterioro.

Como se comenta en el apartado 3.2.1, existen otros factores que aceleran el proceso de deterioro de los contadores de chorro único, como la calidad del agua o la posición de instalación. Estos factores afectan a su ritmo de deterioro aportando cierta variabilidad en los errores de medición entre un abastecimiento y otro. No obstante, es difícil cuantificar su grado de influencia sobre la población de medidores de agua.

Los resultados obtenidos sobre los modelos de contador más representativos se muestran en las siguientes tablas.

TABLA 11. MODELO A

\begin{tabular}{|c|c|c|c|c|c|c|}
\hline ABASTECIMIENTO & $\mathbf{N}^{0}$ & $\begin{array}{c}\text { Edad } \\
\text { promedio } \\
\text { (años) }\end{array}$ & $\begin{array}{c}\text { Error a } \\
30 \mathrm{l} / \mathrm{h}(\%)\end{array}$ & $\begin{array}{c}\text { Error a } \\
120 \mathrm{l} / \mathrm{h}(\%)\end{array}$ & $\begin{array}{c}\text { Error a } \\
750 \mathrm{l} / \mathrm{h}(\%)\end{array}$ & $\begin{array}{c}\text { Error a } \\
1500 \mathrm{l} / \mathrm{h}(\%)\end{array}$ \\
\hline 1 & 70 & 8,2 & $-42,7$ & $-3,0$ & $-0,9$ & $-0,4$ \\
\hline Incertidumbre (\%) & & & $\pm 10,12$ & $\pm 2,7$ & $\pm 0,9$ & $\pm 0,8$ \\
\hline 3 & 7 & 10,1 & $-62,8$ & $-0,6$ & 0,3 & 0,3 \\
\hline 4 & 35 & 7,2 & $-26,8$ & $-0,4$ & $-0,8$ & $-0,3$ \\
\hline Incertidumbre (\%) & & & $\pm 13,2$ & $\pm 0,9$ & $\pm 0,8$ & $\pm 0,8$ \\
\hline 6 & 251 & 9,8 & $-52,2$ & $-6,9$ & $-1,9$ & $-1,1$ \\
\hline Incertidumbre (\%) & & & $\pm 5,1$ & $\pm 1,6$ & $\pm 0,3$ & $\pm 0,3$ \\
\hline \multicolumn{2}{|l|}{ PROMEDIO } & 9,3 & $-48,3$ & $-5,4$ & $-1,8$ & $-0,9$ \\
\hline \multicolumn{2}{|c|}{ Incertidumbre (95\%) } & & $\pm 4,3$ & $\pm 1,2$ & $\pm 0,6$ & $\pm 0,3$ \\
\hline
\end{tabular}

El modelo a, con un total de 363 contadores ensayados, demuestra que el deterioro sufrido en todos los abastecimientos es similar encontrando cierta variabilidad entre ellos causada por su entorno. Por ejemplo, la muestra de medidores ensayados en el abastecimiento 6 posee ciertas características que favorecen su deterioro respecto del 4, como la posición inclinada de instalación de la mayoría de muestra. 
Asimismo, en estas condiciones se puede concluir que a los 10 años el estado metrológico de este modelo se encuentra en pésimas condiciones en comparación, por ejemplo, con el modelo $d$ (Tabla 13) que tiene la misma edad promedio y su precisión no ha empeorado de manera tan brusca.

TABLA 12. MODELO C.

\begin{tabular}{|c|c|c|c|c|c|c|}
\hline ABASTECIMIENTO & $\mathrm{N}^{0}$ & $\begin{array}{c}\text { Edad } \\
\text { promedio } \\
\text { (años) }\end{array}$ & $\begin{array}{c}\text { Error a } \\
30 \mathrm{l} / \mathrm{h}(\%)\end{array}$ & $\begin{array}{c}\text { Error a } \\
120 \text { l/h (\%) }\end{array}$ & $\begin{array}{c}\text { Error a } \\
750 \mathrm{l} / \mathrm{h}(\%)\end{array}$ & $\begin{array}{c}\text { Error a } \\
1500 \mathrm{l} / \mathrm{h}(\%)\end{array}$ \\
\hline 2 & 17 & 3,9 & $-24,3$ & $-1,3$ & $-0,9$ & $-0,7$ \\
\hline Incertidumbre (\%) & & & $\pm 18,2$ & $\pm 1,7$ & $\pm 0,5$ & $\pm 0,4$ \\
\hline 4 & 40 & 3,7 & $-17,3$ & $-0,8$ & $-1,2$ & 1,3 \\
\hline Incertidumbre (\%) & & & $\pm 10,1$ & $\pm 1,6$ & $\pm 1,6$ & $\pm 1,6$ \\
\hline 6 & 11 & 5,8 & $-29,8$ & $-0,5$ & $-1,4$ & $-0,9$ \\
\hline Incertidumbre (\%) & & & $\pm 22,6$ & $\pm 1,1$ & $\pm 1,1$ & $\pm 0,4$ \\
\hline PROMEDIO & & 4,1 & $-21,1$ & 0,1 & 0,3 & 0,4 \\
\hline Incertidumbre (95\%) & & & $\pm 8,3$ & \pm 1 & \pm 1 & \pm 1 \\
\hline
\end{tabular}

Observando las tablas del modelo c y $d$, claramente se aprecia que el entorno del abastecimiento 4 en ambos casos es más favorable que cuando se instala en el 2 o en el 1 para aproximadamente el mismo periodo de servicio de cerca de 4 y 7 años, respectivamente.

TABLA 13. MODELO D.

\begin{tabular}{ccccccc}
\hline ABASTECIMIENTO & No & $\begin{array}{c}\text { Edad } \\
\text { promedio } \\
\text { (años) }\end{array}$ & $\begin{array}{c}\text { Error a } \\
\mathbf{3 0 ~ I / h ~ ( \% ) ~}\end{array}$ & $\begin{array}{c}\text { Error a } \\
120 \mathrm{llh}(\%)\end{array}$ & $\begin{array}{c}\text { Error a } \\
750 \mathrm{llh}(\%)\end{array}$ & $\begin{array}{c}\text { Error a } \\
1500 \mathrm{l} / \mathrm{h}(\%)\end{array}$ \\
\hline 1 & 3 & 7 & $-34,4$ & $-5,2$ & $-3,1$ & $-2,7$ \\
3 & 11 & 16,4 & $-30,3$ & 1,3 & 0,6 & 1,9 \\
Incertidumbre (\%) & & & $\pm 26,6$ & $\pm 3,2$ & $\pm 2,1$ & $\pm 2,2$ \\
4 & 39 & 6,8 & $-5,3$ & $-0,6$ & $-0,2$ & 0,3 \\
Incertidumbre (\%) & & & \pm 5 & $\pm 0,4$ & $\pm 0,4$ & $\pm 0,4$ \\
6 & 3 & 13 & $-20,7$ & $\mathbf{2 , 2}$ & $-1,6$ & $-1,8$ \\
\hline PROMEDIO & & 9,1 & $-12,6$ & $-0,6$ & $-0,3$ & 0,3 \\
Incertidumbre (95\%) & & & $\pm 6,8$ & $\pm 0,8$ & $\pm 0,5$ & $\pm 0,6$ \\
\hline
\end{tabular}

TABLA 14. MODELO G

\begin{tabular}{ccccccc}
\hline ABASTECIMIENTO & $\mathbf{N}$ & $\begin{array}{c}\text { Edad } \\
\text { promedio } \\
\text { (años) }\end{array}$ & $\begin{array}{c}\text { Error a } \\
30 \mathrm{llh}(\%)\end{array}$ & $\begin{array}{c}\text { Error a } \\
120 \mathrm{llh}(\%)\end{array}$ & $\begin{array}{c}\text { Error a } \\
750 \mathrm{llh}(\%)\end{array}$ & $\begin{array}{c}\text { Error a } \\
1500 \mathrm{l} / \mathrm{h} \\
(\%)\end{array}$ \\
\hline 2 & 3 & 5,3 & $-42,5$ & $-4,4$ & $-0,5$ & $-0,7$ \\
5 & 64 & 4,7 & $-14,8$ & $-2,1$ & $-0,1$ & 1 \\
Incertidumbre (\%) & 7 & 8,4 & $-30,3$ & $-1,4$ & $\pm 0,7$ & $\pm 0,4$ \\
6 & 5 & $-14,6$ & $-2,1$ & $-0,2$ & 0,8 \\
PROMEDIO & & & $\pm 6,2$ & $\pm 1,3$ & $\pm 0,7$ & $\pm 0,4$ \\
\hline Incertidumbre (95\%) & & & & & & \\
\hline
\end{tabular}

Frecuentemente, los departamentos de gestión de abonados utilizan la fecha de fabricación o el volumen acumulado promedio para catalogar el estado de sus instrumentos de medida. Las siguientes figuras agrupan todos los contadores de un mismo modelo por grupos de edad obteniendo la evolución del error con el tiempo para cada uno de los caudales de 
ensayo. De esta forma, se puede estimar el error de medición aproximado que tendrá este modelo a medida que pasa el tiempo a cada caudal.

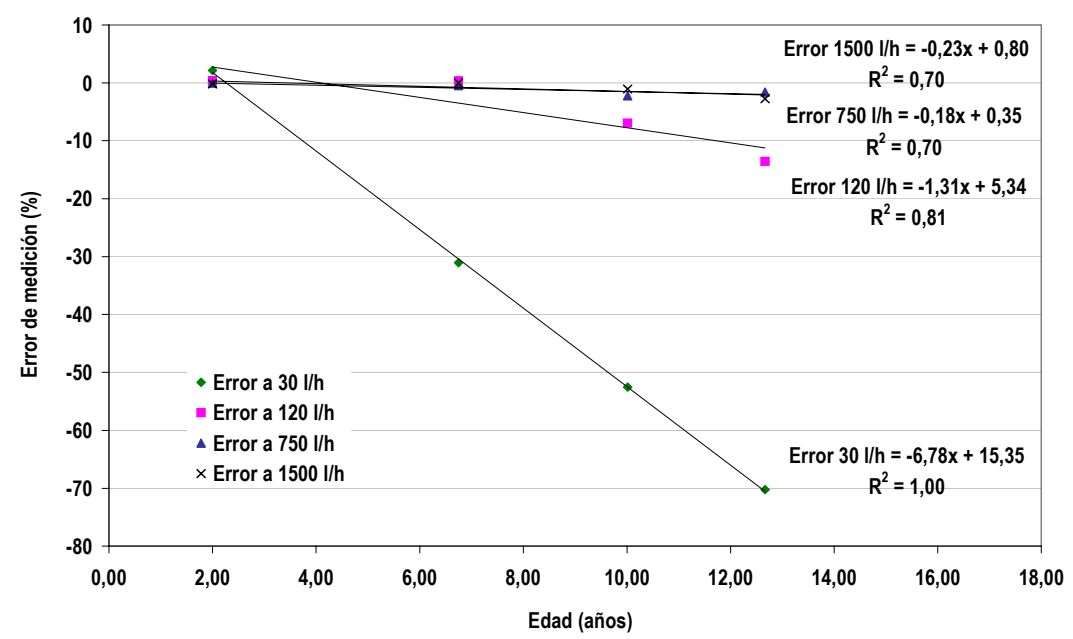

FIGURA 15. EVOLUCIÓN DEL ERROR CON LA EDAD MODELO A.

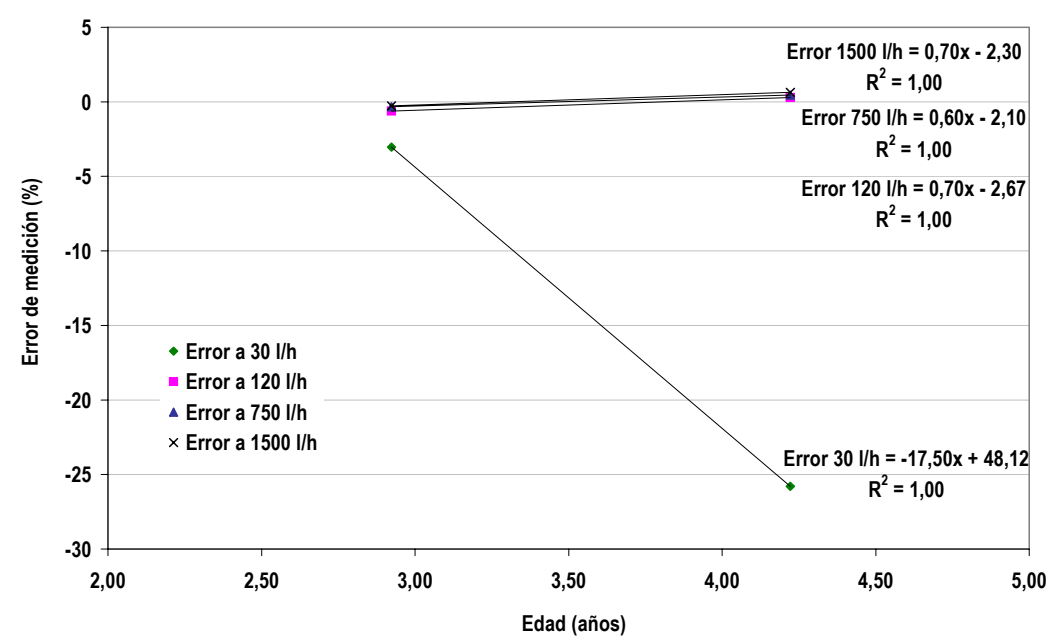

FIGURA 16. EVOLUCIÓN DEL ERROR CON LA EDAD MODELO C.

En general a caudales altos, superiores a $120 \mathrm{l} / \mathrm{h}$, los ritmos de deterioro de estos instrumentos no son muy elevados

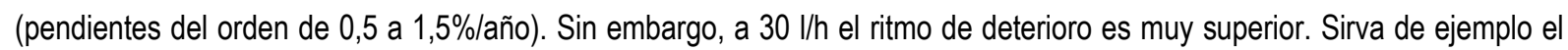
caso de los modelos a y $c$, ya que para una edad de 4 años el modelo a alcanzaba un error de $-12 \%$ mientras que el $c$ sobrepasaba el -22\%.

El estudio de las poblaciones de contadores agrupadas por franjas de volumen acumulado puede ayudar, también, a determinar el estado de cada modelo y conocer qué instrumentos precisan ser renovados con antelación, de forma más fiable que el parámetro edad, que en ocasiones no se ajusta realmente al tiempo que el contador ha estado en servicio. 
La Figura 17 ilustra el ritmo de deterioro del modelo a de chorro único para cada caudal en función del volumen acumulado.

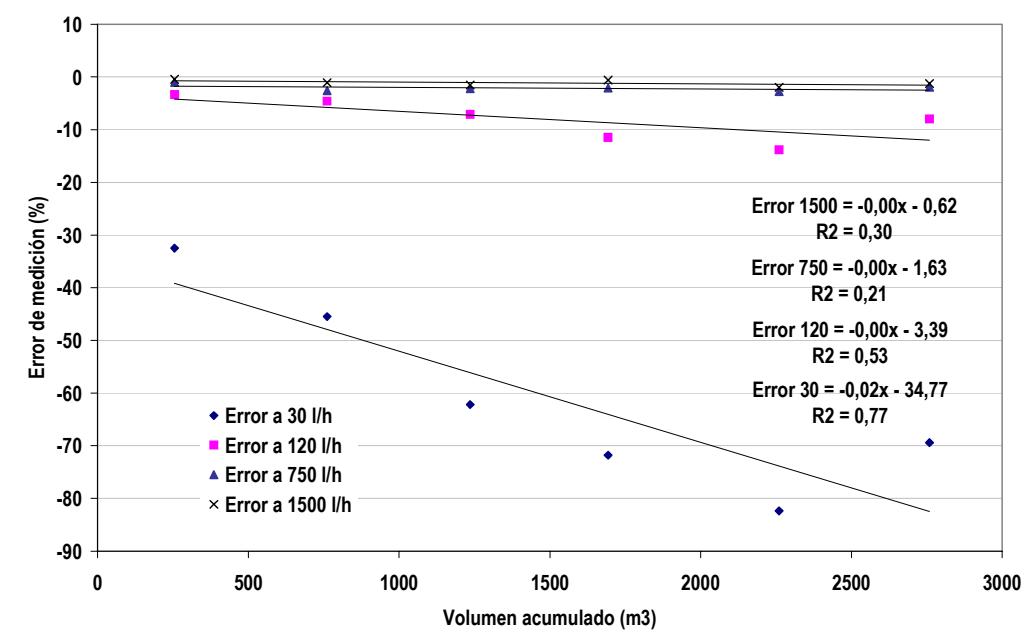

FIGURA 17. EVOLUCIÓN DEL ERROR DE MEDICIÓN CON EL VOLUMEN ACUMULADO PROMEDIO DE LA MUESTRA DEL MODELO A..

Otras tecnologías de medición muestran tendencias diferentes, como las extraídas del estudio llevado a cabo en una ciudad sudamericana por Arregui (2000), donde se ensayaron 365 contadores volumétricos y 262 contadores de chorro múltiple, todos ellos de caudal nominal $1,5 \mathrm{~m}^{3} / \mathrm{h}$.

Los caudales de ensayo de este estudio fueron de 30,60,120,500, 1500 y $3000 \mathrm{l} / \mathrm{h}$ y se constataron trayectorias del error decrecientes para todos los caudales en contadores volumétricos de pistón rotativo (Figura 18). Este tipo de contador, por su principio de funcionamiento no puede ver alterada su curva de error hacia valores positivos, al contrario de lo que puede ocurrir con los contadores de velocidad. Como se describe en el Capítulo 2, esta tecnología se basa en la acumulación de llenados y vaciados de una cámara de volumen conocido. A medida que pasa el tiempo, las partes móviles del instrumento tienden a desgastarse holgando el movimiento de giro del pistón y provocando errores de medición siempre negativos provocado por las fugas entre el pistón y la pared.

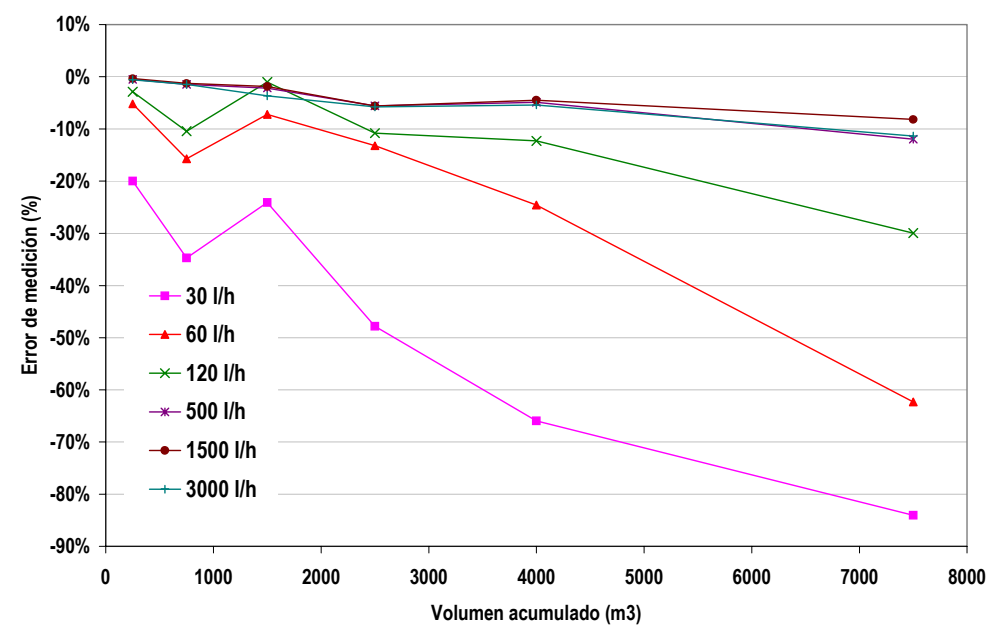

FIGURA 18. RITMO DE DETERIORO EN CONTADORES VOLUMÉTRICOS (ARREGUI, 2000). 
Los resultados de este mismo estudio referentes a los contadores de chorro múltiple muestran ciertas particularidades comparándolos con el resto de tecnologías. Los errores a caudales de $30 \mathrm{l} / \mathrm{h}$ presentan tendencias decrecientes, pero a caudales superiores a $120 \mathrm{l} / \mathrm{h}$ su comportamiento cambia hacia errores positivos, tanto mayores cuanto mayor es el caudal y el volumen acumulado por el contador.

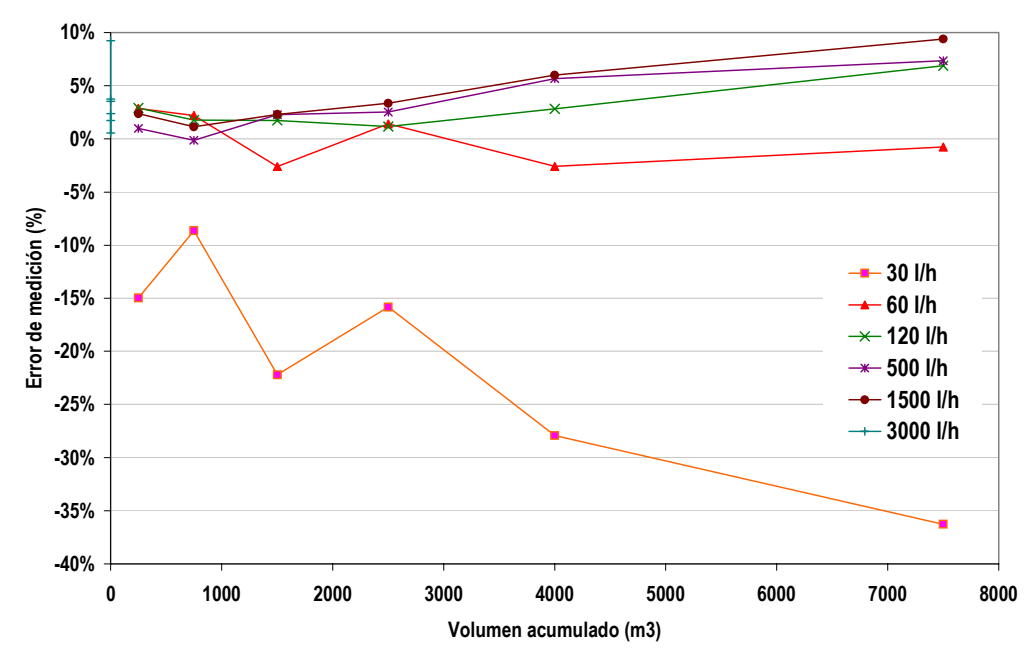

FIGURA 19. RITMO DE DETERIORO DE CONTADORES DE CHORRO MÚLTIPLE (ARREGUI, 2000).

\subsection{ENSAYOS DE LA CURVA DE ERROR A CONTADORES DE USO NO DOMÉSTICO}

Realmente, definir qué calibre de contadores son considerados como macromedidores y qué otros como micromedidores suele ser difícil. Una posible clasificación se basa en el caudal nominal de los medidores, donde aquellos instrumentos con $\mathrm{Q}_{n}<15 \mathrm{~m}^{3} / \mathrm{h}$ pueden ser considerados como micromedidores y los que superan este valor como macromedidores. El problema se encuentra en que con esta clasificación son considerados como micromedidores instrumentos que requeririan un control más exhaustivo de su funcionamiento ya que su consumo de agua es considerablemente elevado. La clasificación por calibre es otra posibilidad similar a la anterior, en la que se define un calibre límite que separa ambos sistemas.

La presente Tesis doctoral opta por definir como sistema de macromedición a aquellos instrumentos usados para la medición del caudal de usuarios no domésticos que consumen un elevado volumen de agua, por lo que es recomendable un seguimiento individualizado de su funcionamiento. Esto es impracticable con el sistema de micromedición, ya que por una parte el número de usuarios domésticos es muy elevado y requiere un tratamiento estadístico por muestreos de la población y, por otra, los volúmenes consumidos en este caso son irrisorios para ser evaluados individualmente.

Particularmente, en este apartado se estudia el comportamiento metrológico de los contadores destinados a uso no doméstico, como industrias, sectores de una red de distribución, parcelas de riego, etcétera. Conviene indicar que todos estos usos suponen un porcentaje elevado del consumo de agua lo que hace más importante la correcta medición del caudal a la hora de auditar las redes de distribución de agua mediante balances hídricos.

Las pruebas de error a estos calibres de contador se realizaron en un banco de ensayo de válvulas, tal y como se describe en el Anexo I para macromedidores. 


\subsubsection{VARIABLES QUE AFECTAN A SU MEDICIÓN}

Las tecnologías de medición más habituales utilizadas en grandes consumidores en el ámbito urbano son los contadores de chorro único o múltiple y los contadores Woltman. Los parámetros expuestos en el apartado 3.2.1 afectaban al sistema de micromedidores en su mayoría de chorro único. A continuación se describen diversas variables que influyen en la medición de los macromedidores más comunes.

\subsubsection{Elementos perturbadores del flujo de agua}

La influencia que ejerce sobre la medición del caudal las distorsiones del flujo de agua provocadas por accesorios hidráulicos instalados cerca del instrumento es un factor importante ampliamente estudiado durante toda la Tesis doctoral. Su influencia se evalúa con dos enfoques, uno basado en experimentos de laboratorio donde se ensaya el comportamiento metrológico de los instrumentos ante diferentes configuraciones de la instalación, y otro analítico, que abarca un capítulo completo, y donde se combinan simulaciones numéricas del flujo de diferentes tipologías de instalación con los principios de funcionamiento de cada medidor.

Así pues, elementos hidráulicos como bombas, válvulas y codos, alteran el correcto funcionamiento del instrumento siendo necesaria la instalación de tramos rectos de tubería o de estabilizadores que equilibren el flujo de agua.

Los fabricantes de contadores de agua en algunos casos, recomiendan de forma general la instalación de 8 a 10 diámetros de tramos rectos de tubería. En otras ocasiones, la instalación de estabilizadores de flujo modera estas distorsiones mejorando la medición del caudal y reduciendo estos requisitos de tubería recta.

Sin embargo, en la actualidad no existe ningún tipo de reglamentación al respecto sobre los estándares que deben seguirse durante la instalación de medidores de agua. West en 1961 consideró que el estudio de la distribución de velocidades dentro de la conducción ayudaría a entender su influencia sobre la medición.

Autores como Withers et al. (1971), demostraron que los caudalímetros tipo turbina, efectivamente, eran sensibles a las condiciones del flujo, a la temperatura o al caudal de funcionamiento. Baker (1993) comprobó la efectividad de la instalación de tramos rectos aguas arriba y aguas abajo de un caudalimetro tipo turbina. Así, a partir de las recomendaciones ANSI/API (American Nacional Standards Institut / American Petrolium Institute) señala que 20D de tubería recta aguas arriba y 5D aguas abajo ayudarían enormemente a la estabilización del flujo.

Hanson y Schwankl (1998) llevaron a cabo un estudio sobre el error de medición de caudalímetros de diferentes tecnologías con uso principalmente agrícola. De esta manera, se investigó el comportamiento metrológico en todo el rango de funcionamiento de los medidores ante condiciones de funcionamiento no óptimas como la medición junto a un codo, 0 junto a una válvula de compuerta o de mariposa parcialmente abierta. Se concluía que medidores tipo turbina no se veían excesivamente afectados en estas circunstancias, mientras que otros basados en la medición en un solo punto de la conducción no eran, en absoluto, fiables.

En este capitulo y en el siguiente se aborda este tema, exponiendo nuevos resultados y procedimientos que ayuden a establecer ciertas recomendaciones prácticas a la hora de instalar instrumentos de medida de caudal.

\subsubsection{Dimensionado inadecuado}

Habitualmente, el dimensionado de contadores de agua se efectúa teniendo en cuenta su caudal nominal, que es aquel para el cual el contador puede funcionar de manera continua sin deterioro (ISO 4064). Este caudal nominal no es único, en diámetros medianos y grandes. Para cada diámetro puede variar dependiendo del diseño del fabricante. No obstante, en ocasiones, se tiende a instalar un medidor de iguales dimensiones que la conducción sin tener en cuenta los caudales a los cuales consume el usuario, lo que puede provocar que el instrumento trabaje en un rango no deseable, por ser excesivamente alto o bajo. 
Una adecuada elección de la capacidad de caudal del contador es fundamental en cualquier aparato de medida ya que hace que aumente su durabilidad, es decir su vida útil, y garantiza una correcta medición de los consumos. En el caso de los contadores de agua, un infradimensionado implica que por el instrumento circulan caudales excesivamente altos lo que daña en un periodo corto de tiempo sus elementos internos deteriorando su curva de error. Por el contrario, un contador sobredimensionado trabaja en la zona inferior del rango de medida donde los errores de medición son más elevados.

Por tanto, para dimensionar correctamente un macromedidor se deben conocer primero los caudales de agua que trasiega y, segundo, el tiempo durante el cual circularán estos caudales. El Capítulo 6 profundiza en la metodología para establecer los porcentajes de agua que se consumen en cada rango de caudales extraídos de las mediciones realizadas en campo.

Con un tiempo de uso largo conviene elegir un contador que ajuste su caudal nominal a los caudales circulantes. En cambio, si los periodos de uso del instrumento son más cortos y separados en el tiempo, es admisible el uso de contadores de calibres más pequeños, siempre y cuando los caudales circulantes no superen el caudal máximo del mismo y las pérdidas de carga que originen estén dentro de los valores admisibles por la instalación.

\subsubsection{Calidad del agua}

Otro de los problemas que pueden influir en la medición es la calidad del agua. Las diferentes tecnologías de medición del caudal en un conducto cerrado a presión se ven afectados por la calidad del agua de manera desigual. Existen instrumentos huecos, como los caudalímetros electromagnéticos o de los de ultrasonidos, que no presentan ninguna obstrucción al flujo de agua y son más robustos y apropiados para aguas cargadas. Otros en cambio, están constituidos por partes móviles en contacto con el agua que están expuestas a desgaste y a un mayor riesgo de obstrucción cuando el agua contiene fibras o transporta sólidos.

Las fibras se enredan en las turbinas de los contadores impidiendo su movimiento. Los sólidos, como piedras y arenilla, rompen y desgastan estos elementos internos deteriorando de manera acelerada su funcionamiento, y consecuentemente disminuyendo su vida útil.

Generalmente, los contadores de velocidad se protegen con filtros para impedir que estos sólidos lleguen a las hélices. En esos casos, con el tiempo, estos filtros se colmatan y es necesario un mantenimiento periódico del instrumento que raramente se realiza. Las obturaciones parciales del filtro pueden producir alteraciones en el perfil de velocidades que afectan seriamente a la medición (Figura 20).

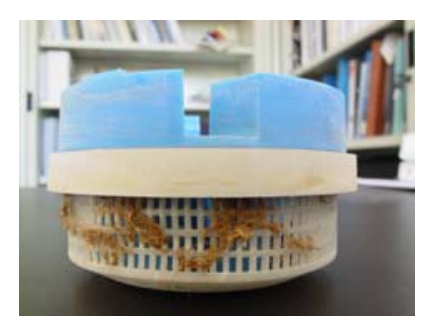

FIGURA 20. FILTRO DE UN CONTADOR DE CHORRO MÚLTIPLE CON FIBRAS.

En este aspecto, los medidores que controlan el agua de riego son más sensibles, ya que por estas conducciones, sobre todo las de mayor calibre, suelen circular gran cantidad de impurezas. Los cabezales en riego localizado poseen filtros de anillas y de mallas que mejoran la calidad del agua con el fin de no obturar los goteros lo que beneficia a los medidores instalados aguas abajo. No obstante, como se ha comentado, los sólidos en suspensión cuando sedimentan impiden, también, el giro de la turbina siendo uno de los motivos de su instalación en posición vertical (ver Figura 2). 


\subsubsection{Desgaste de elementos móviles}

El envejecimiento es un factor intrínseco a cualquier instrumento mecánico. La evolución de la curva de error en contadores de gran calibre requiere un amplio estudio, similar al desarrollado en el punto 3.2.4, donde las condiciones de funcionamiento de cada aparato, su volumen acumulado y las mediciones en campo de los patrones de consumo permitirán conocer su comportamiento metrológico y estimar su vida útil.

Esta Tesis doctoral simplemente ha efectuado pruebas a un número reducido de instrumentos retirados del servicio, pero sin llegar a conclusiones definitivas. Por ello, con la colaboración de las empresas de suministro de agua, se deja una puerta abierta para futuras investigaciones en torno a este aspecto.

Una muestra de contadores de chorro único de mayor calibre $(20 \mathrm{~mm})$ evidencia que el deterioro también se sufre con mayor intensidad a caudales bajos.

TABLA 15. RESULTADOS DE LAS PRUEBAS A CONTADORES DE 20 MM.

\begin{tabular}{|c|c|c|c|c|c|c|c|}
\hline CLASE & Calibre & $\begin{array}{c}\text { Q.arranque } \\
(\mathrm{I} / \mathrm{h})\end{array}$ & Año de instalación & \%Error(Q.MAX) & $\%$ Error $\left(Q_{n}\right)$ & $\%$ Error $\left(Q_{t}\right)$ & $\% \operatorname{Error}\left(Q_{\text {MIN }}\right)$ \\
\hline B & $20 \mathrm{~mm}$ & 55 & 1996 & 11,60 & 6,53 & $-0,79$ & $-60,08$ \\
\hline \multirow[t]{7}{*}{ Ch. único } & & 190 & 1993 & $-0,36$ & 8,50 & $-40,48$ & $-100,00$ \\
\hline & & 75 & 1994 & 4,62 & 4,56 & $-9,72$ & $-100,00$ \\
\hline & & 20 & 1999 & 3,53 & 2,19 & 0,69 & $-5,94$ \\
\hline & & 62 & 1994 & $-2,65$ & $-2,74$ & $-2,03$ & $-100,00$ \\
\hline & & 75 & 1994 & $-1,75$ & $-3,24$ & $-18,40$ & $-100,00$ \\
\hline & & 32 & 1994 & $-0,76$ & $-2,15$ & $-2,20$ & $-19,41$ \\
\hline & & 72,7 & 1994 & 2,03 & 1,95 & $-10,42$ & $-69,35$ \\
\hline
\end{tabular}

Además, se ensayaron 4 contadores de chorro único, clase metrológica $C$, de calibre $50 \mathrm{~mm}$ con edades comprendidas entre 2 y 5 años. La Figura 21 muestra sus curvas de error, donde los contadores de mayor edad, claramente, salen fuera de los límites establecidos en la normativa para esta clase. El resto de contadores, con tan solo 2 años en funcionamiento, mantienen una precisión satisfactoria.

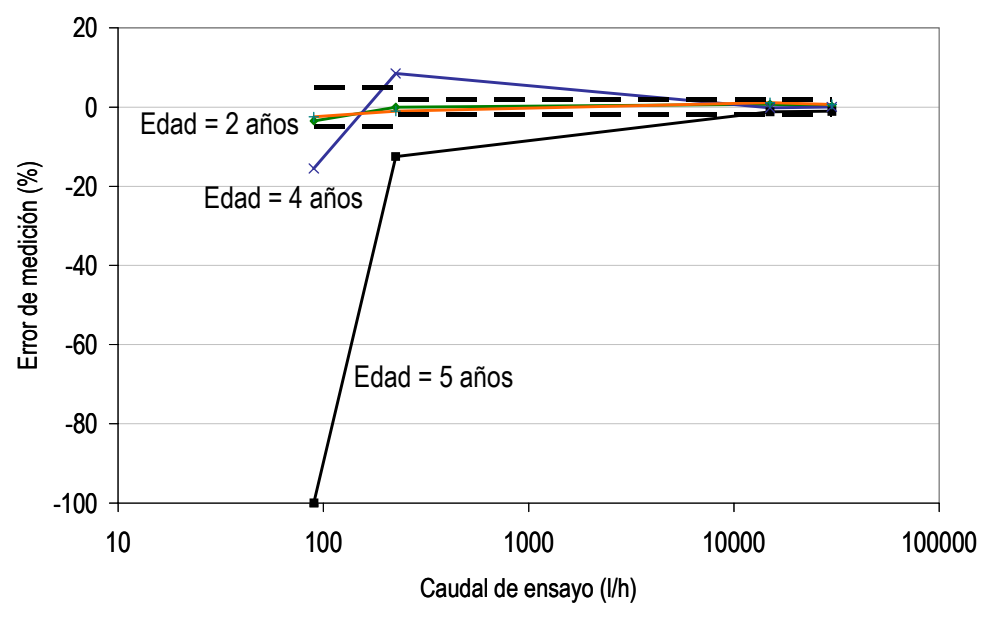

FIGURA 21. CURVAS DE ERROR DE CONTADORES DE CHORRO MÚLTIPLE RETIRADOS DEL SERVICIO. 


\subsubsection{ENSAYOS DE ERROR A CONTADORES NUEVOS DE USO NO DOMÉSTICO}

El esquema seguido durante el desarrollo de los ensayos en laboratorio se describe en este apartado. Como se ha comentado el objetivo primordial de estas pruebas es conocer de manera fiable cómo se comportan y de qué forma influyen en la curva de error de los contadores de agua diversos tipos de perturbaciones en el flujo. Los elementos hidráulicos que habitualmente pueden encontrarse junto a medidores son válvulas de obturación o de corte, tipo mariposa o compuerta, 0 válvulas de regulación como reductoras o mantenedoras de presión o caudal o, incluso, codos y tes. Todos estos elementos perturban de manera diferente el flujo de agua, fenómeno que puede revertir de forma directa sobre su medición.

Consecuentemente, en esta fase, se expone el diseño de los experimentos programados, es decir, la gama de posibles configuraciones que pueden observarse comúnmente en estaciones de bombeo, redes de distribución de agua y sectores hidráulicos, cabezales de riego, etc. En todos los casos se ha comparado el comportamiento del medidor con un ensayo establecido como referencia metrológica en el que el funcionamiento del instrumento se encuentra bajo unas condiciones de flujo idóneas, es decir, cuando se respetan los tramos rectos recomendados por fabricantes aguas arriba y aguas abajo del aparato.

El conjunto de configuraciones elemento-medidor se resume a continuación, teniendo como posibles factores influyentes en su comportamiento, primero, el tipo de elemento hidráulico ya que cada uno de ellos perturba el flujo de forma diferente y, segundo, el grado de apertura de estos elementos y la distancia entre el medidor y el elemento hidráulico. Cotejando estas variables, las diferentes configuraciones adoptadas durante los ensayos de laboratorio han sido prácticamente para todas las tecnologías probadas las siguientes:

- Ensayo de referencia: Contador con suficientes TRAMOS RECTOS de tubería.

- Ensayo con VÁLVULA DE COMPUERTA aguas arriba.

Distancias: 0,3 y 6 diámetros (0D, 3D y 6D)Cierre: 0\%, 25\%, 50\% Y 75\%.

- Ensayo con VÁLVULA DE MARIPOSA aguas arriba.

Distancias: 0,3 y 6 diámetros (OD, 3D y 6D).Cierre: Abierta o $30^{\circ}$ cerrada.

- Ensayo en SENTIDO INVERSO.

- Ensayo con VÁLVULA REDUCTORA aguas abajo.

- Ensayos con el CONTADOR GIRADO $90^{\circ}$ sobre la horizontal.

- Ensayos con TES y CODOS.

Las diferentes tecnologías probadas son todas del mismo calibre $80 \mathrm{~mm}$, a excepción de la válvula volumétrica que es de $100 \mathrm{~mm}$, y sus características metrológicas más importantes se describen a continuación:

Tecnología de medición Woltmann de eje horizontal:

Modelo WH1

- $\quad$ Clase metrológica $B$

- $Q_{n}=60 \mathrm{~m}^{3} / \mathrm{h} \quad Q_{\max }=120 \mathrm{~m}^{3} / \mathrm{h} \quad Q_{\min }=1,8 \mathrm{~m}^{3} / \mathrm{h} \quad Q_{\mathrm{r}}=12 \mathrm{~m}^{3} / \mathrm{h}$

- Pérdida de carga máxima 0,6 bar.

- Caudal de arranque en $300 \mathrm{l} / \mathrm{h}$.

Modelo WH2:

- Clase metrológica $B$

- $Q_{n}=120 \mathrm{~m}^{3} / \mathrm{h} \quad Q_{\max }=200 \mathrm{~m}^{3} / \mathrm{h} \quad Q_{\min }=0,5 \mathrm{~m}^{3} / \mathrm{h} \quad Q_{\mathrm{t}}=2 \mathrm{~m}^{3} / \mathrm{h}$

- Pérdida de carga máxima 0,27 bar.

- Caudal de arranque en $220 \mathrm{l} / \mathrm{h}$. 
Tecnología de medición Woltmann de eje vertical:

- Clase metrológica B.

- $Q_{n}=40 \mathrm{~m}^{3} / \mathrm{h} \quad Q_{\max }=80 \mathrm{~m}^{3} / \mathrm{h} \quad Q_{\min }=1,2 \mathrm{~m}^{3} / \mathrm{h} \quad Q_{\mathrm{t}}=8 \mathrm{~m}^{3} / \mathrm{h}$.

- Capacidad de funcionamiento durante $24 \mathrm{~h}$ a $Q=50 \mathrm{~m} 3 / \mathrm{h}$.

- Pérdida de carga máxima 0,6 bar.

- Caudal de arranque en $100 \mathrm{l} / \mathrm{h}$.

Tecnología de medición Chorro único:

- Clase metrológica $\mathrm{C}$.

- $Q_{n}=30 \mathrm{~m}^{3 / h} \quad Q_{\max }=60 \mathrm{~m}^{3} / \mathrm{h} \quad Q_{\min }=0,180 \mathrm{~m}^{3 / h} \quad Q_{\mathrm{t}}=0,45 \mathrm{~m}^{3 / h}$

- Pérdida de carga máxima 1,45 bar.

Tecnología de medición Tangencial:

- Clase metrológica A

- $Q_{n}=40 \mathrm{~m}^{3} / \mathrm{h} \quad Q_{\max }=80 \mathrm{~m}^{3} / \mathrm{h} \quad Q_{\min }=3,2 \mathrm{~m}^{3} / \mathrm{h} \quad Q_{\mathrm{i}}=12 \mathrm{~m}^{3 / h}$

- Pérdida de carga mínima.

Tecnología de medición Proporcional:

- Precisión $\pm 5 \%$ (sin aprobación metrológica).

- Qpermanente máximo $=120 \mathrm{~m}^{3} / \mathrm{h} \quad Q_{\max \text { excepcional }}=120 \mathrm{~m}^{3} / \mathrm{h} \quad Q_{\min }=4,8 \mathrm{~m}^{3} / \mathrm{h}$

- Pérdida de carga máxima 0,44 bar.

- Caudal de arranque en $1800 \mathrm{l} / \mathrm{h}$.

Medición con Válvula volumétrica (UNE 68-074-86):

- Medidor Woltman de eje vertical con válvula de control accionada por diafragma y con una válvula auxiliar de cierre para aplicaciones de dosificación.

- Cumple con la norma ISO 4064 Clase A.

- $Q_{n}=110 \mathrm{~m}^{3} / \mathrm{h} \quad Q_{\max }=180 \mathrm{~m}^{3} / \mathrm{h} \quad Q_{\min }=4,8 \mathrm{~m}^{3} / \mathrm{h} \quad Q_{\mathrm{l}}=18 \mathrm{~m}^{3} / \mathrm{h}$.

\subsubsection{Resultados de los ensayos a un contador tipo Woltman}

\section{WOLTMAN DE EJE HORIZONTAL}

Las pruebas metrológicas efectuadas a los contadores Woltman de eje horizontal muestran la influencia de las distorsiones en cada una de las tipologías instaladas.

Inicialmente, se extrae como referencia la curva de error de cada contador probado cuando los perfiles de velocidad no se encuentran distorsionados, es decir, instalando tramos rectos de tubería aguas arriba y abajo del instrumento, tal y como se muestra en la Figura 22 a. Posteriormente, se añadirán diversos accesorios hidráulicos simulando condiciones reales de funcionamiento para comprobar cómo varía la precisión del instrumento en cada situación. 
(a)

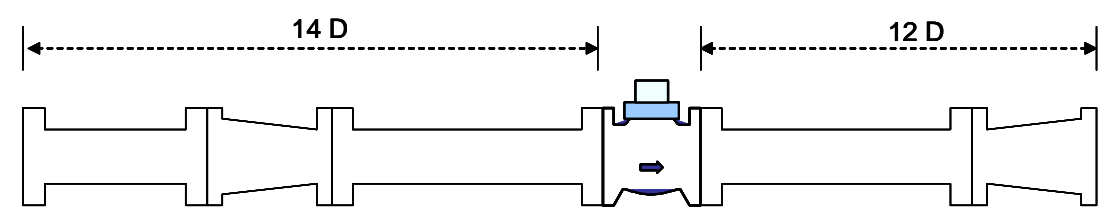

(b)
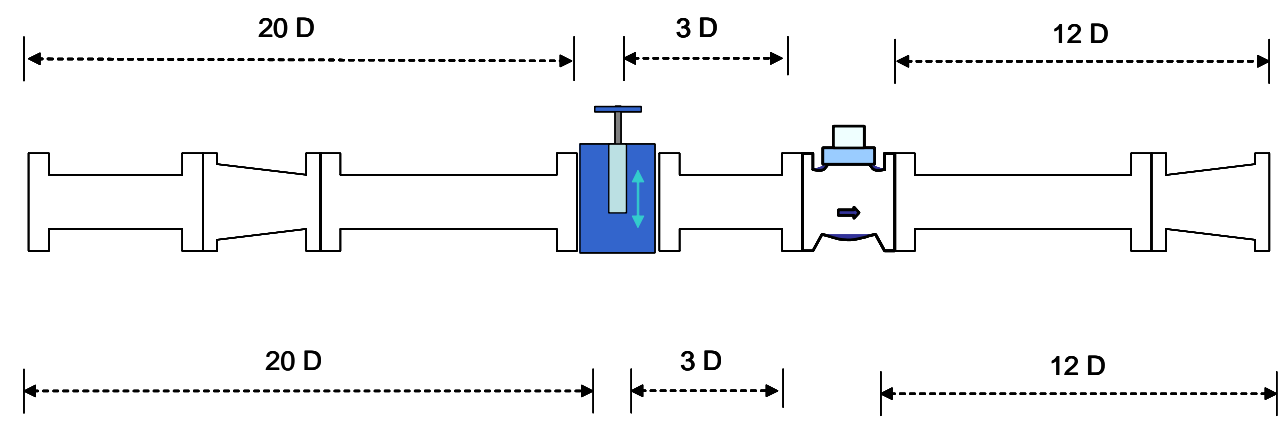

(c)

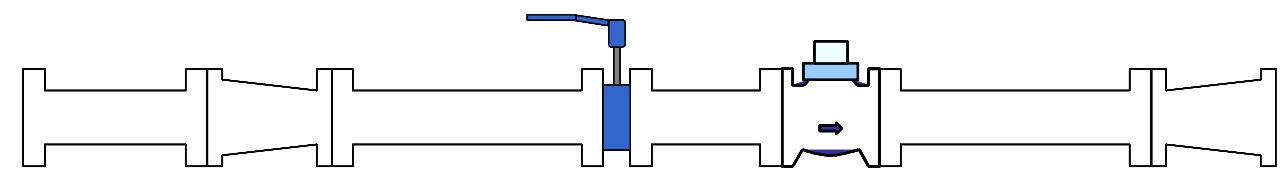

FIGURA 22. CONFIGURACIONES DE LA INSTALACIÓN DEL LABORATORIO.

Como es bastante común en arquetas de redes hidráulicas reales, en la siguiente configuración se instala una válvula de compuerta aguas arriba del instrumento, primero sin mantener tramos rectos (OD) y posteriormente guardando una distancia entre elementos de 3D (Figura 22b). Si la válvula se encuentra junto al contador (OD) totalmente abierta los resultados de laboratorio no muestran imprecisiones significativas. El problema aparece a medida que la válvula se cierra. Entonces, el contador comienza a percibir las distorsiones en el flujo de agua aumentando su imprecisión hacia errores positivos, llegando a salir de los límites establecidos para clase metrológica B en el caso de un cierre de la compuerta al $75 \%$ (Figura 23 y Figura 24).

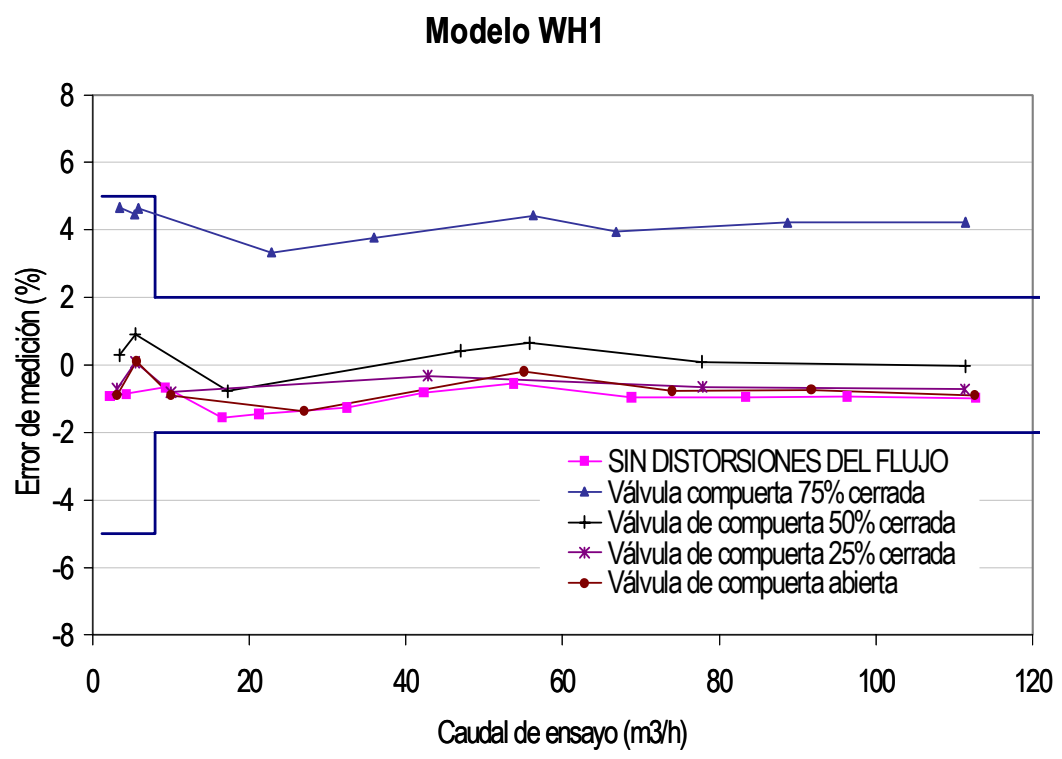

FIGURA 23. VÁlVULA DE COMPUERTA AGUAS ARRIBA DE UN WOLTMAN WH1 DE EJE HORIZONTAL A OD. 


\section{Modelo WH2}

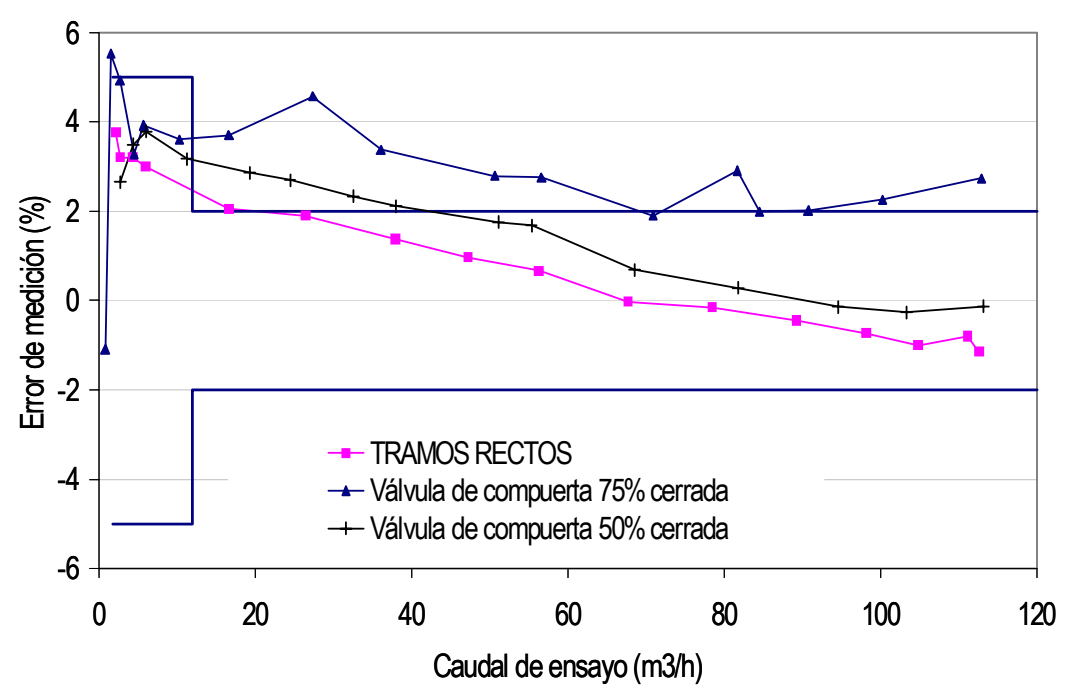

FIGURA 24. VÁLVULA DE COMPUERTA AGUAS ARRIBA DE UN WOLTMAN WH2 DE EJE HORIZONTAL A OD.

La justificación a estos resultados, como se verá en el capítulo siguiente, es que el perfil de velocidades se distorsiona incrementando bruscamente su magnitud en la zona inferior de la conducción. Estas velocidades elevadas del flujo generan mayor par motriz aumentando la velocidad de rotación de la turbina, y consecuentemente dando errores positivos.

Lógicamente, cuando el perfil llega menos deformado a los álabes del Woltman, bien porque el grado de cierre de la válvula es menor, bien porque se mantienen 3D de tubería recta aguas arriba del contador, la medición se ve menos afectada en ambos modelos (Figura 25). Según los resultados experimentales obtenidos, una distancia recta mínima de 3D sería suficiente, en este caso, para moderar la distorsión en el flujo, y conseguir una precisión aceptable.

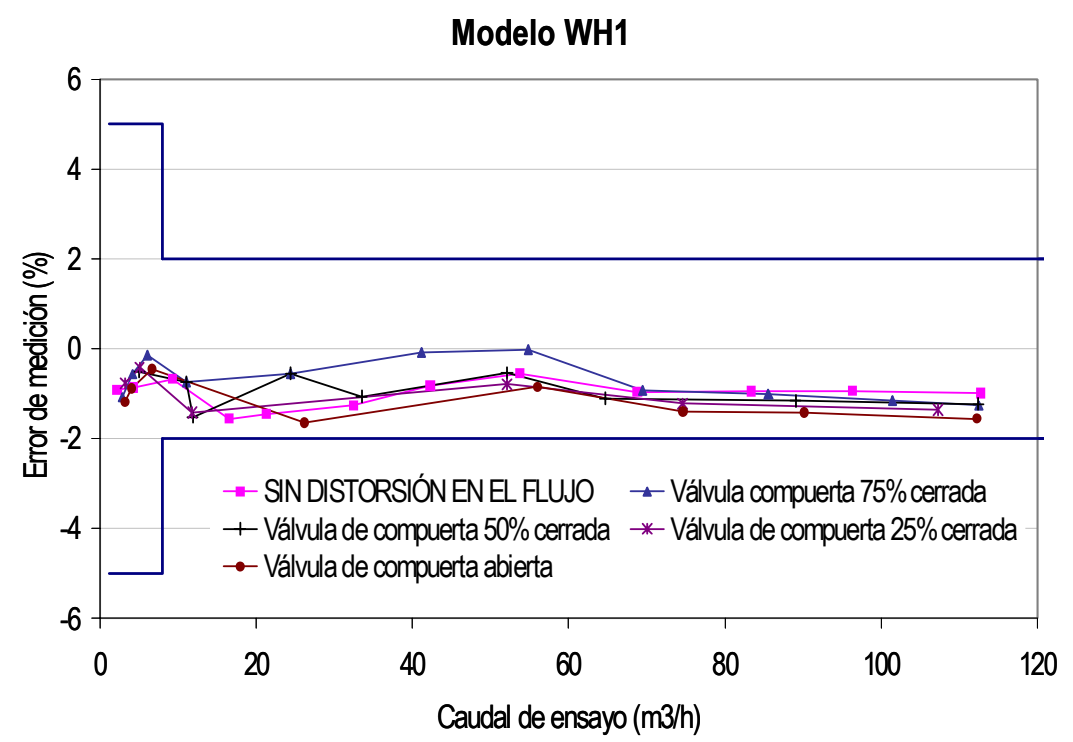

FIGURA 25. VÁLVULA DE COMPUERTA AGUAS ARRIBA DEL WOLTMAN HORIZONTAL WH1 A UNA DISTANCIA DE 3D. 


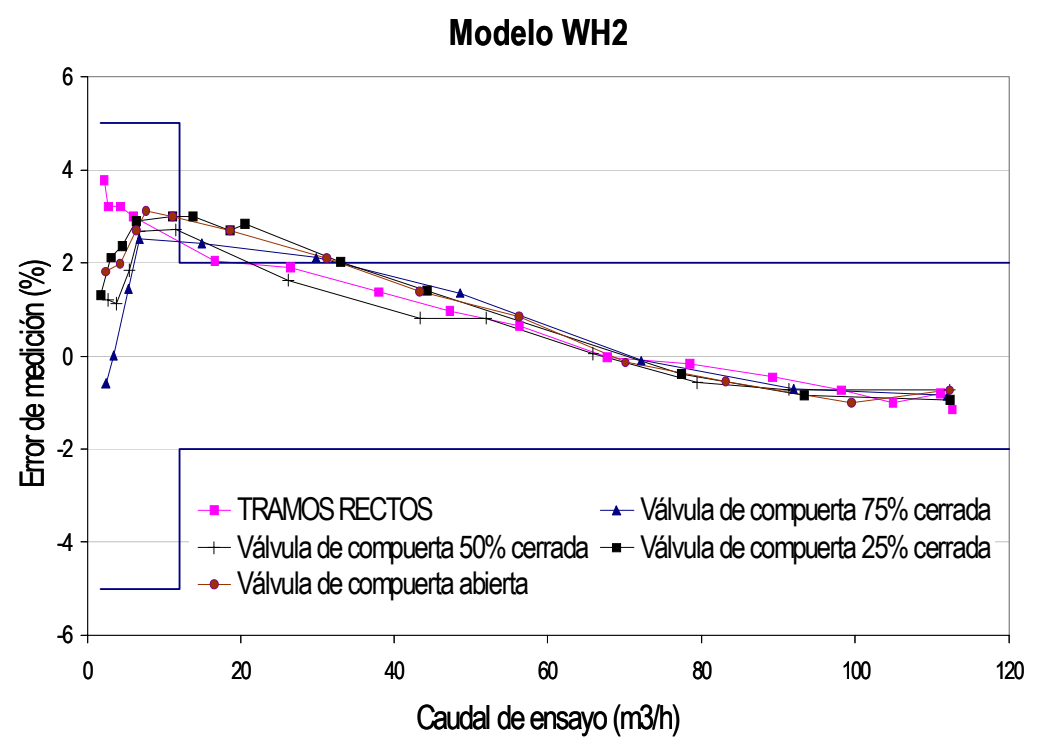

FIGURA 26. VÁLVULA DE COMPUERTA AGUAS ARRIBA DEL WOLTMAN HORIZONTAL WH2 A UNA DISTANCIA DE 3D.

Para comprobar la influencia de las distorsiones sobre el medidor Woltman se ensayaron diferentes grados de apertura de la válvula de compuerta, instalada junto al contador (OD), apreciándose en la Figura 27 que hasta un grado de cierre de aproximadamente $90 \%$ el error de medición no podía considerarse significativo.

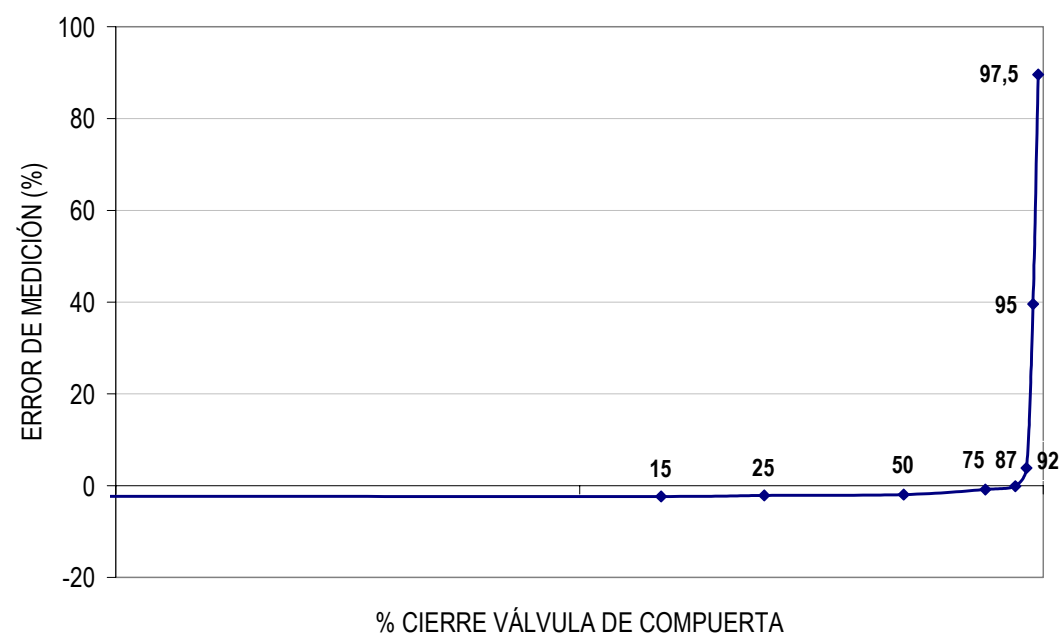

FIGURA 27. RELACIÓN ENTRE EL ERROR DE MEDICIÓN Y EL GRADO DE APERTURA DE UNA VÁLVULA DE COMPUERTA INSTALADA A OD.

Contrastando estos resultados con los ensayos proporcionados por el fabricante de uno de los contadores Woltman horizontal se observa que los requerimientos de longitud recta antes del medidor son similares. Los resultados muestran una clara influencia sobre la medición cuando se instala una válvula de compuerta prácticamente cerrada aguas arriba a 3D y OD, respectivamente (Figura 28 y Figura 29). 


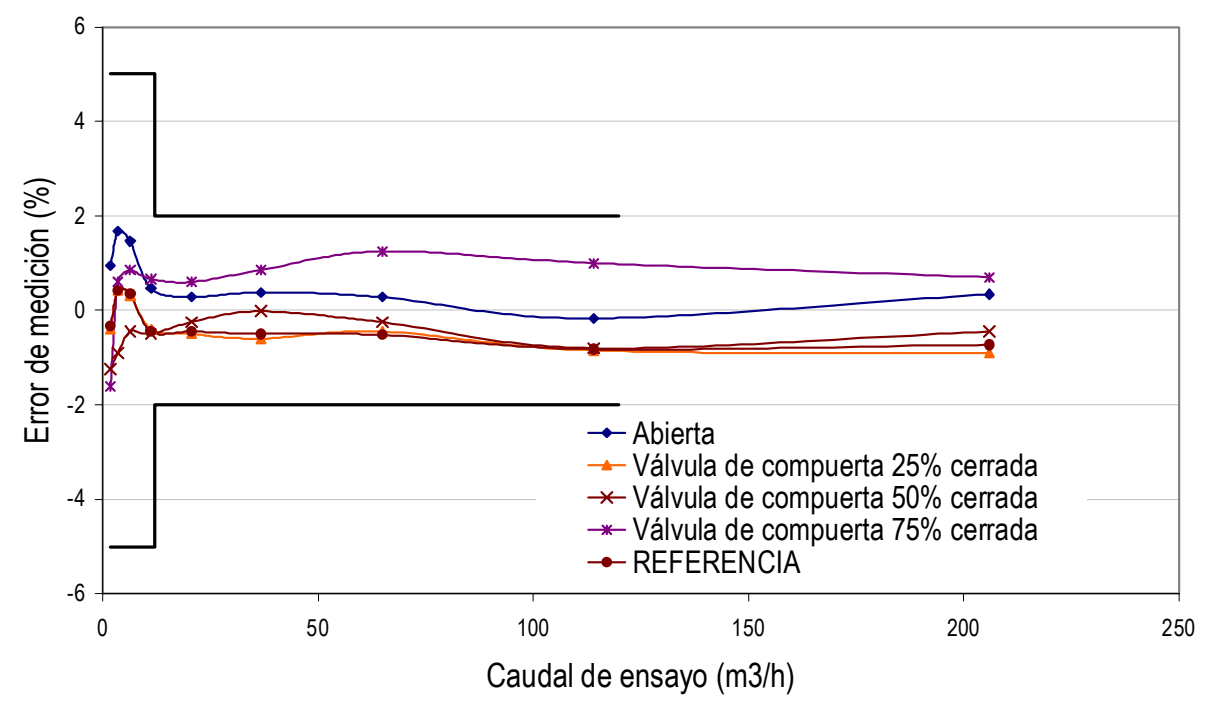

FIGURA 28. ENSAYOS PROPORCIONADOS POR EL FABRICANTE ACTARIS A 3D.

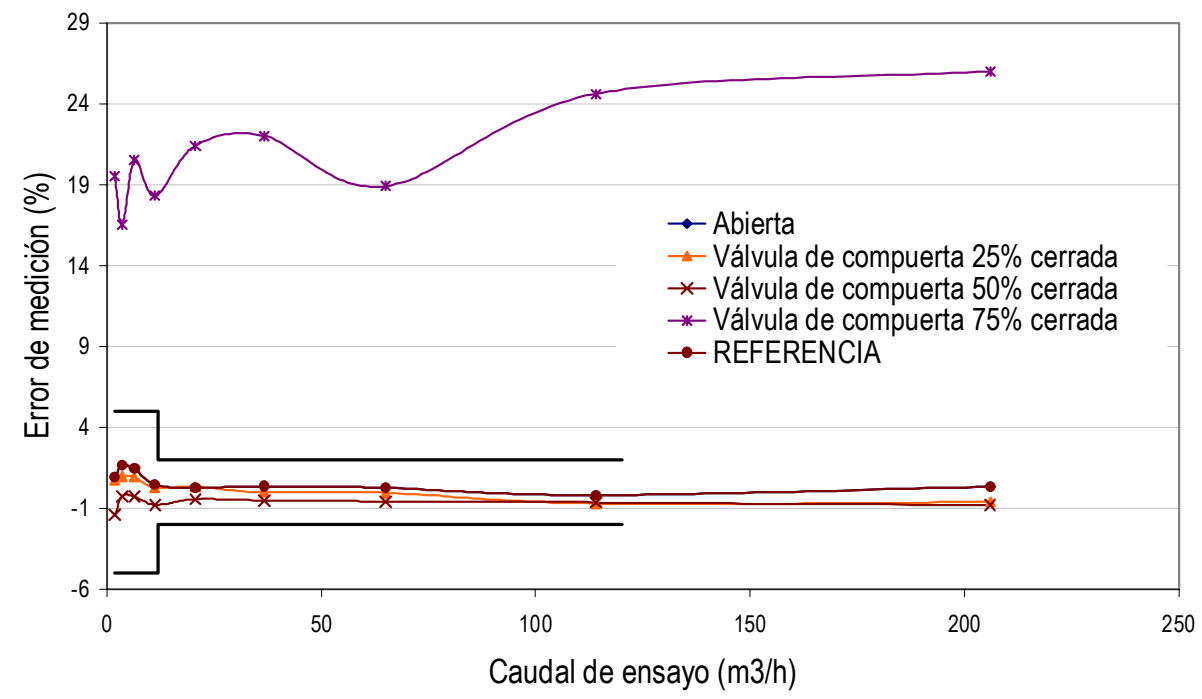

FIGURA 29. ENSAYOS PROPORCIONADOS POR EL FABRICANTE ACTARIS A OD.

La instalación de una válvula de mariposa no afectó de forma tan marcada a la precisión del contador Woltman (Figura 30). En este caso, la válvula abierta situada a 3D (no es posible su instalación a 0D), no genera errores significativos. 


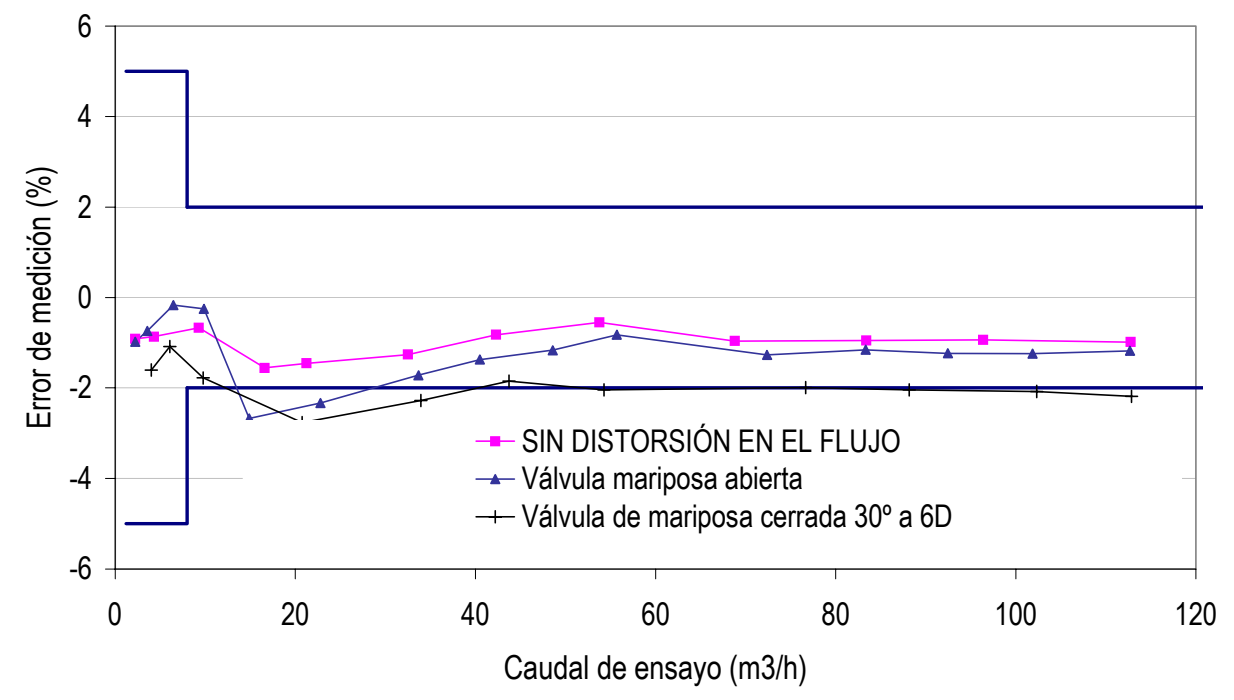

FIGURA 30. ENSAYOS DE LA CURVA DE ERROR CON UNA VÁLVULA DE MARIPOSA.

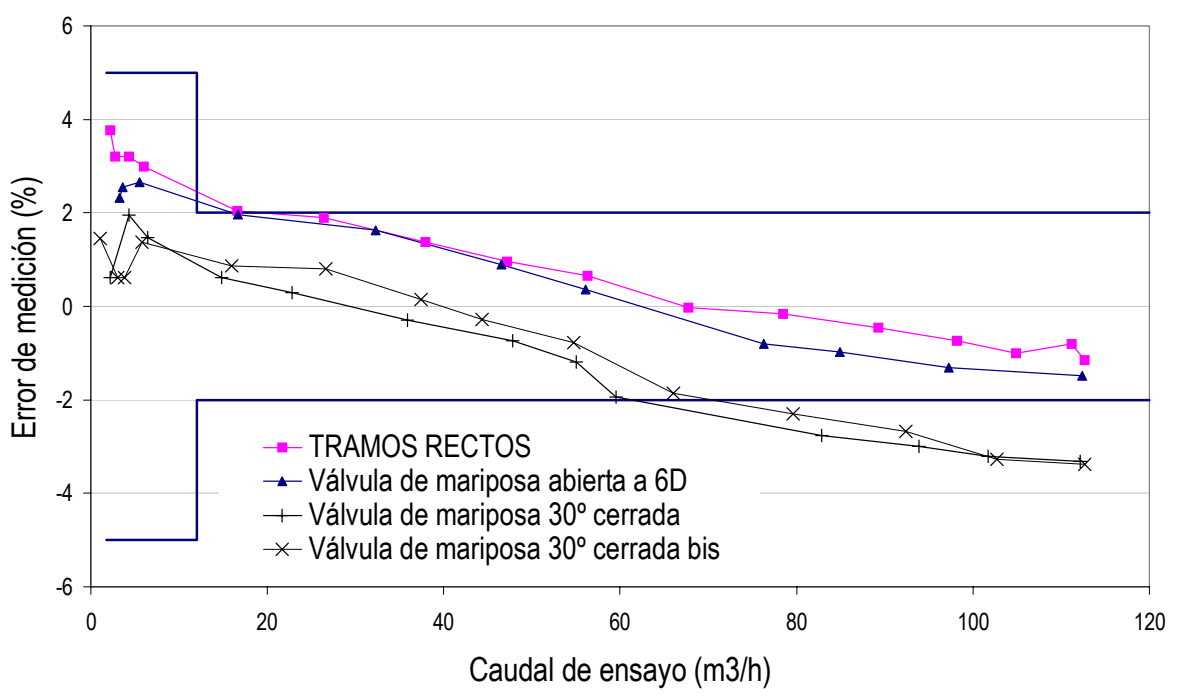

FIGURA 31. ENSAYOS DE LA CURVA DE ERROR CON UNA VÁLVULA DE MARIPOSA PARCIALMENTE CERRADA.

Sólo cuando la válvula se cierra $30^{\circ}$ se observan ligeros errores de subcontaje (Figura 31). A su vez, los ensayos de repetibilidad dieron resultados muy aceptables.

Otro de los ensayos realizados a este tipo de tecnología de medición consistió en girar la válvula de mariposa hacia un lado $u$ otro, con el fin de simular un flujo directo semejante sobre la parte superior o inferior del contador Woltman. La diferencia se encuentra en que en uno de los supuestos, la lenteja de la válvula $30^{\circ}$ cerrada cambia la dirección del flujo incidiendo sobre la zona superior donde se encuentra la paleta reguladora de caudal. Esta paleta, como se describe en el capítulo anterior, sirve para ajustar la curva de error del contador dentro de los límites fijados en la norma (Figura 32). 
En la Figura 34 se aprecia la influencia que ejerce sobre la medición cada uno de los casos. Cuando el flujo choca directamente sobre la paleta de calibración con velocidades elevadas en esa zona, cambia el ángulo de incidencia sobre la turbina disminuyendo su velocidad y produciendo mayor subcontaje.
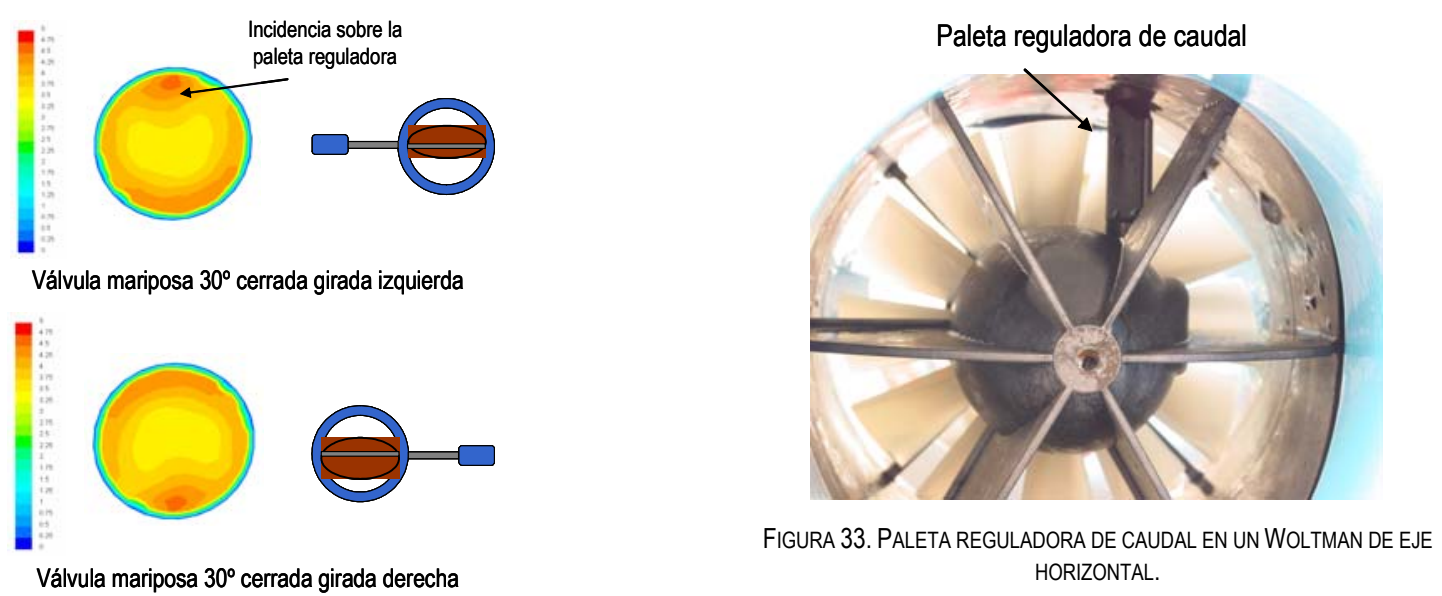

FIGURA 32. COMPORTAMIENTO DEL FLUJO CON VÁLVULA DE MARIPOSA $30^{\circ}$ CERRADA.

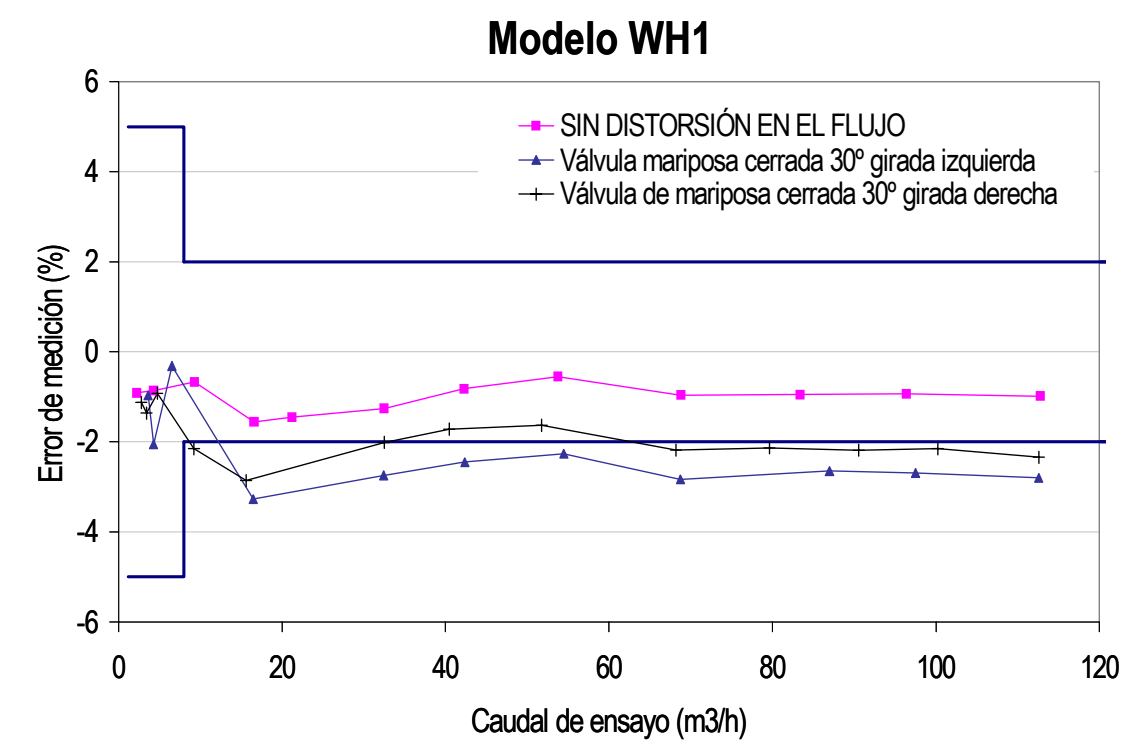

FIGURA 34. VÁLVULA DE MARIPOSA GIRADA EN DIFERENTES POSICIONES CON CIERRE DE $30^{\circ}$.

Es muy común encontrar contadores Woltman junto a válvulas reductoras en las instalaciones de riego localizado (Figura 35). Estas válvulas reductoras, instaladas aguas abajo del contador, regulan la presión hasta el valor tarado. La influencia que ejercen sobre la medición no se considera significativa, como se aprecia en la Figura 36, o en todo caso tienen una ligera tendencia hacia errores negativos. 


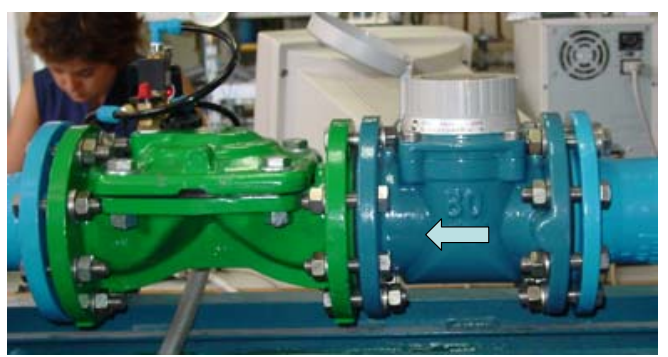

FIGURA 35. INSTALACIÓN TIPICA DE UN HIDRANTE DE RIEGO.

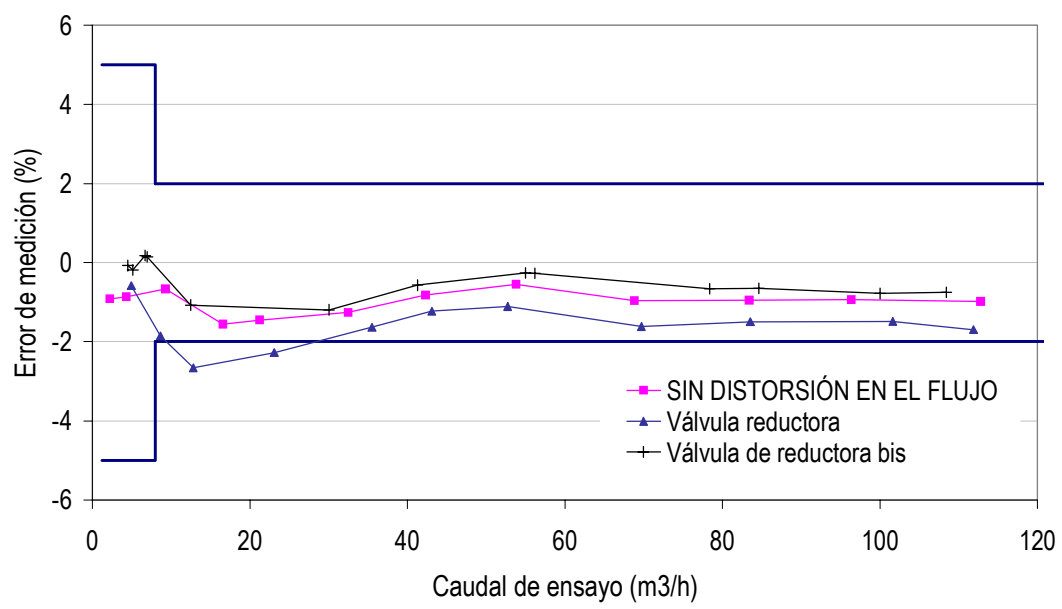

FIGURA 36. ERROR DE MEDICIÓN DEL WOLTMAN HORIZONTAL JUNTO A UNA VÁLVULA REDUCTORA.

Por último, se ensayaron dos modelos de Woltman horizontal obteniéndose resultados, en algunos casos, desiguales atribuidos principalmente al diseño de cada uno. Por ejemplo, cuando el contador se instala en sentido inverso cada uno responde de forma diferente, el modelo WH1 como se aprecia en la Figura 37 registra menor volumen, aproximadamente $-10 \%$, al contrario que el modelo WH2 que sobre registra en torno a $+10 \%$ del volumen real (Figura 38 ). Esta discrepancia de comportamiento se atribuye al diseño de los álabes y del pivote central, que alteran la velocidad y ángulo de impacto del agua en función del sentido de circulación del agua.

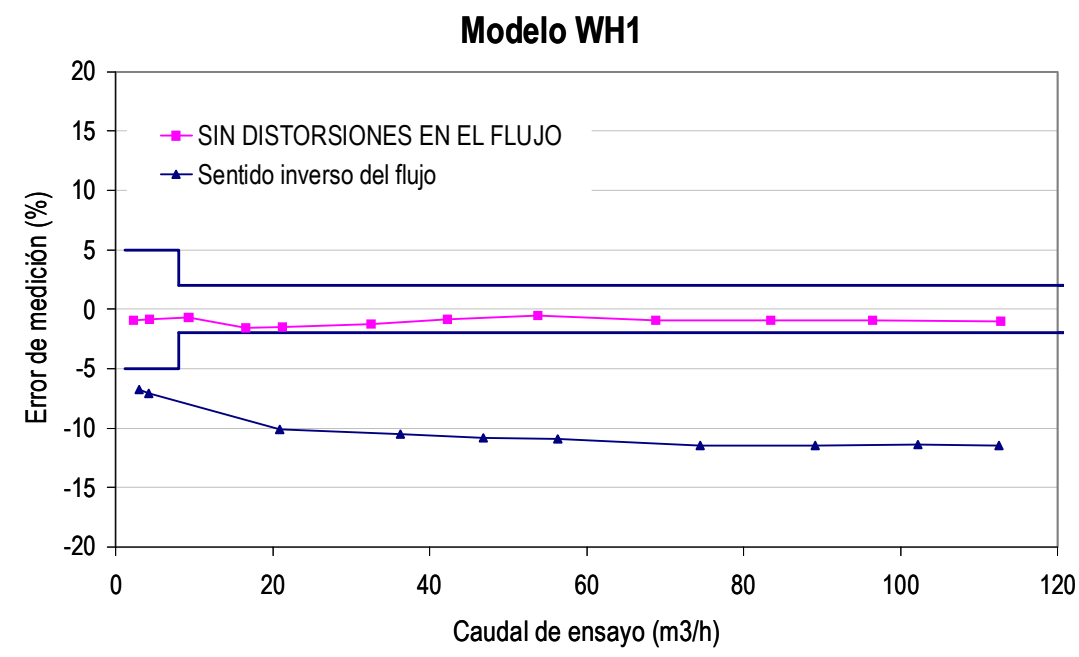

FIGURA 37. ENSAYO DE WOLTMAN HORIZONTALES CON SENTIDO DEL FLUJO INVERSO. 


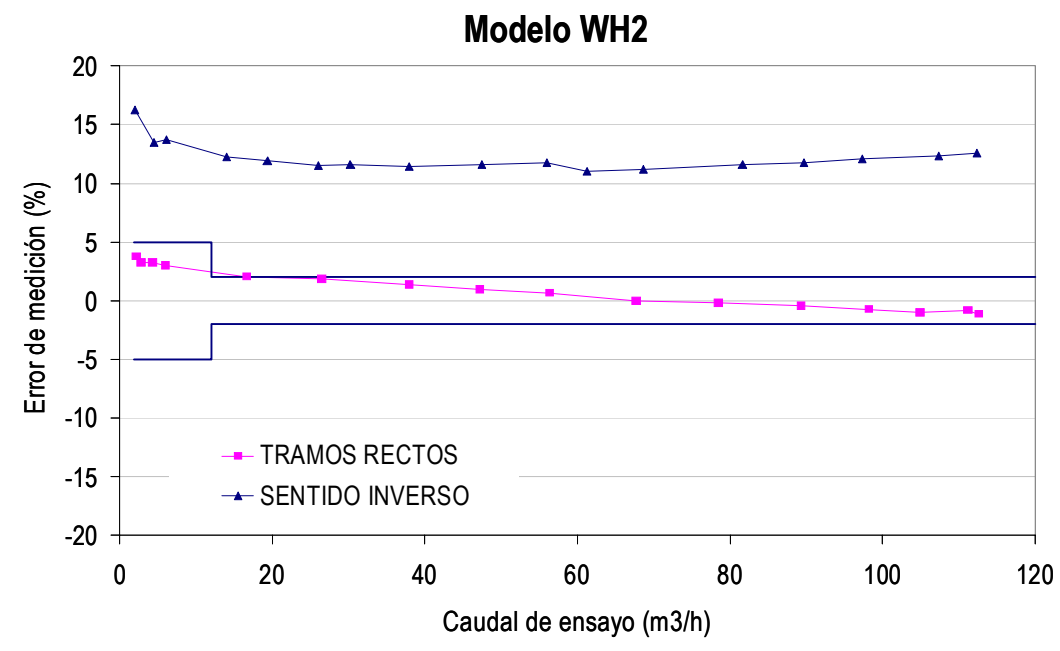

FIGURA 38. ENSAYO WOLTMAN HORIZONTAL EN SENTIDO DEL FLUJO INVERSO

Consecuentemente, la instalación de estos medidores sin dispositivos antirretorno puede ocasionar errores de medida importantes. Por otro lado, si se pretende utilizarlos como caudalimetros en la red debe asegurarse que el sentido de circulación del agua es único o que el fabricante garantice los errores en ambos sentidos. 


\section{WOLTMAN DE EJE VERTICAL}

En el diseño de este tipo de tecnología, como se ha explicado con anterioridad, el flujo de agua entra en la cámara del aparato en dirección axial sufriendo un giro de $90^{\circ}$ dentro del mismo receptáculo que conduce el agua hacia la turbina del instrumento dispuesta en la misma dirección que los ejes del totalizador. En otras palabras, el eje de la turbina es perpendicular al de la tubería. Esta configuración interna genera por sí misma turbulencias en el fluido, lo que implica que cualquier otra alteración previa del flujo no influye de manera directa sobre la turbina del Woltman de eje vertical.

De los resultados en laboratorio se extrae una serie de conclusiones:

- Cuando el contador se instala en sentido inverso al flujo los errores ocasionados durante la medición son del orden de $+6 \%$, además presenta buena repetibilidad en los ensayos (Figura 39).

- Este tipo de tecnología de medición no se ve excesivamente afectada en términos metrológicos por la instalación de una válvula de compuerta aguas arriba del contador con diversos grados de apertura (Figura 40). Los resultados pueden explicarse teniendo en cuenta que un perfil distorsionado no incide directamente sobre la turbina sino que sufre cambios de dirección en el interior del cuerpo hasta que llega al elemento móvil de medición.

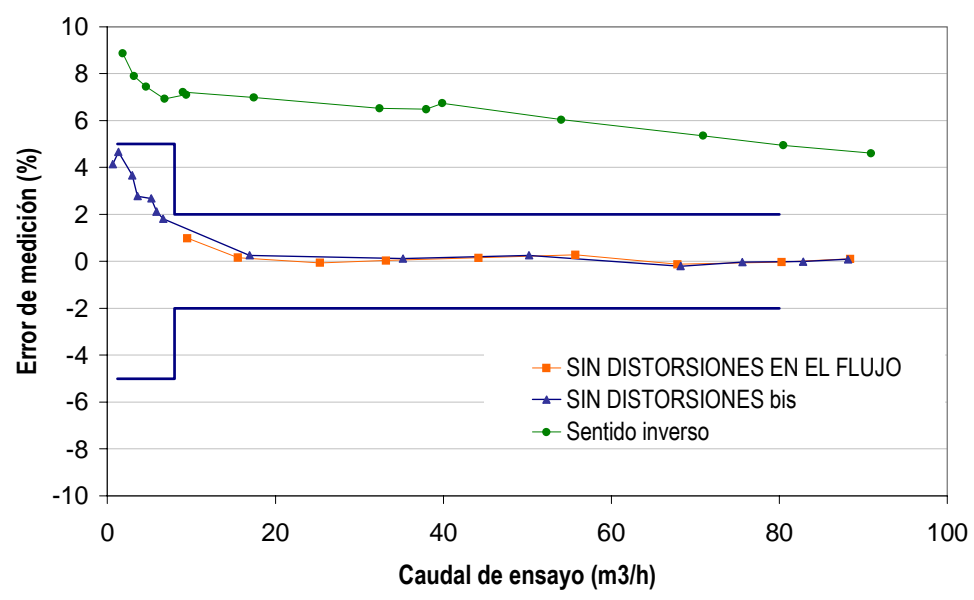

Figura 39. PRUEBAS A LA TECNOLOGÍA WOLTMAN DE EJE VERTICAL.

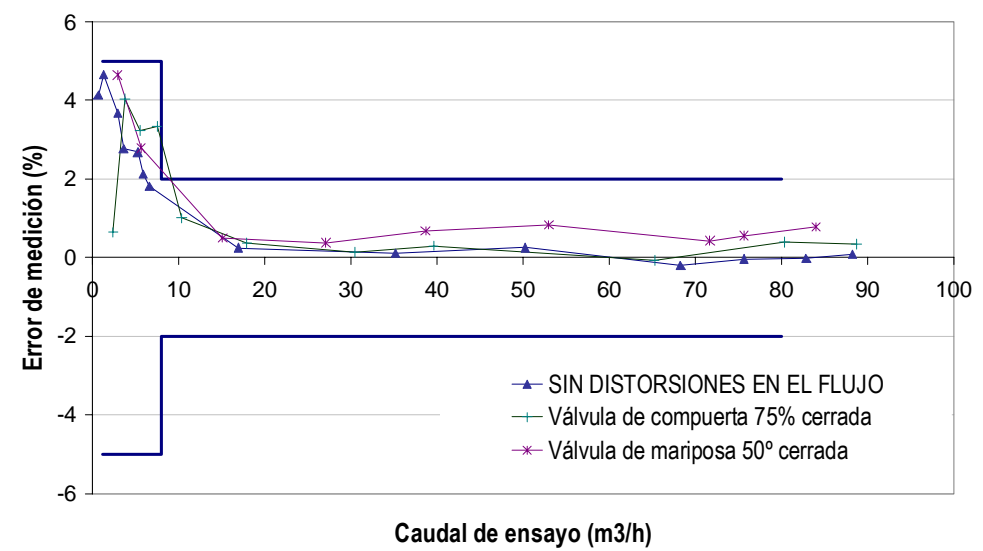

FIGURA 40. RESULTADOS DE LOS ENSAYOS A Un WOLTMAN DE EJE VERTICAL A OD. 


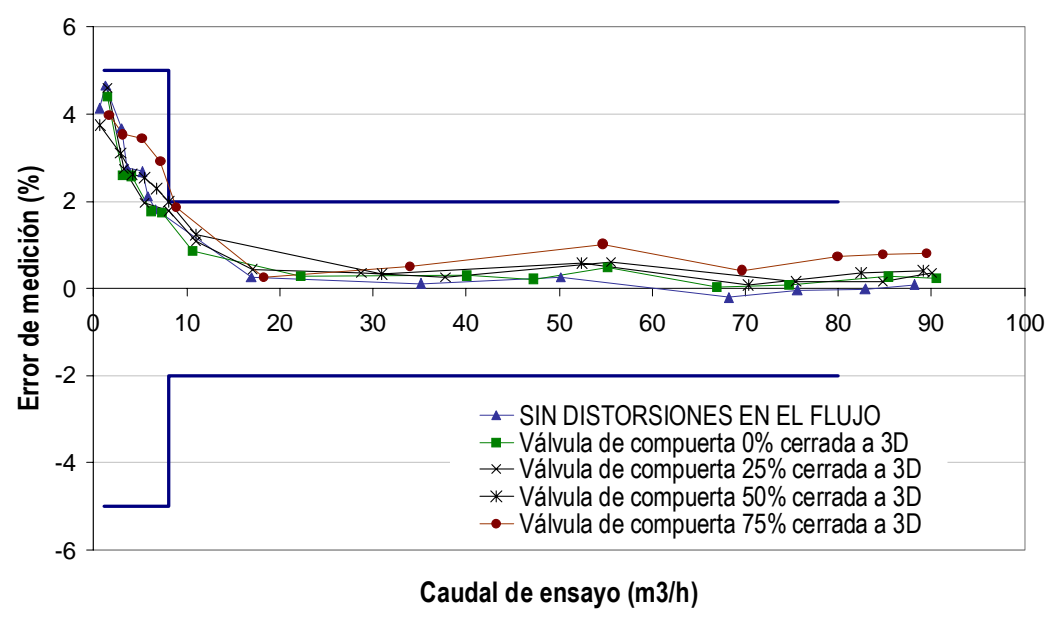

Figura 41. Resultados de LOS eNSAYOS A un WoltMAN DE EJe VeRTicAL A 3D.

Cuando la válvula se instala a 3D, la influencia observada sobre el caudal es insignificante con lo que se puede concluir que, efectivamente, loa elementos perturbadores no afectan a la medición en el caso de un Woltman de eje vertical.

\subsubsection{Resultados de los ensayos a contador de chorro único}

Los resultados de los ensayos de la curva de error a contadores de chorro único son muy favorables. El principio de funcionamiento y su construcción, con un tramo convergente a la entrada, lo hacen prácticamente insensible al perfil de velocidades.

De esta forma, cuando se obstruye el flujo con una válvula de compuerta $75 \%$ cerrada, el comportamiento del instrumento es prácticamente el mismo que ante un flujo sin distorsiones. La instalación de 3D de tubería recta no supone ningún beneficio sustancial (Figura 42 y Figura 43). Estos ensayos están corroborados con las pruebas efectuadas por el fabricante (Figura 44).

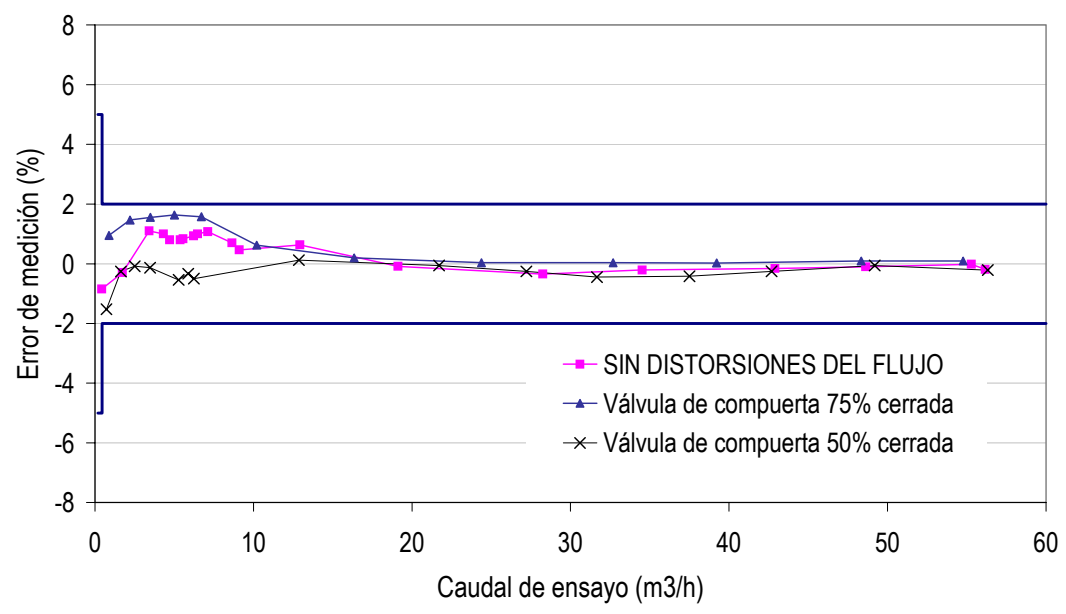

FIGURA 42. RESULTADOS DE ERROR DE LA TECNOLOGÍA DE CHORRO ÚNICO A OD. 


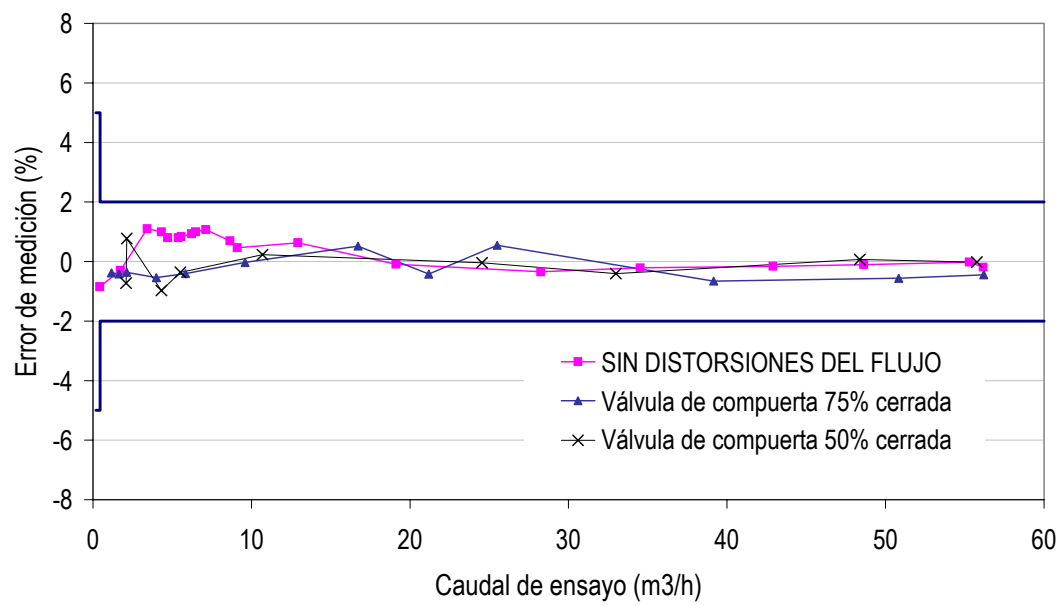

FIGURA 43. RESULTADOS DE ERROR DE LA TECNOLOGÍA DE CHORRO ÚNICO A 3D.

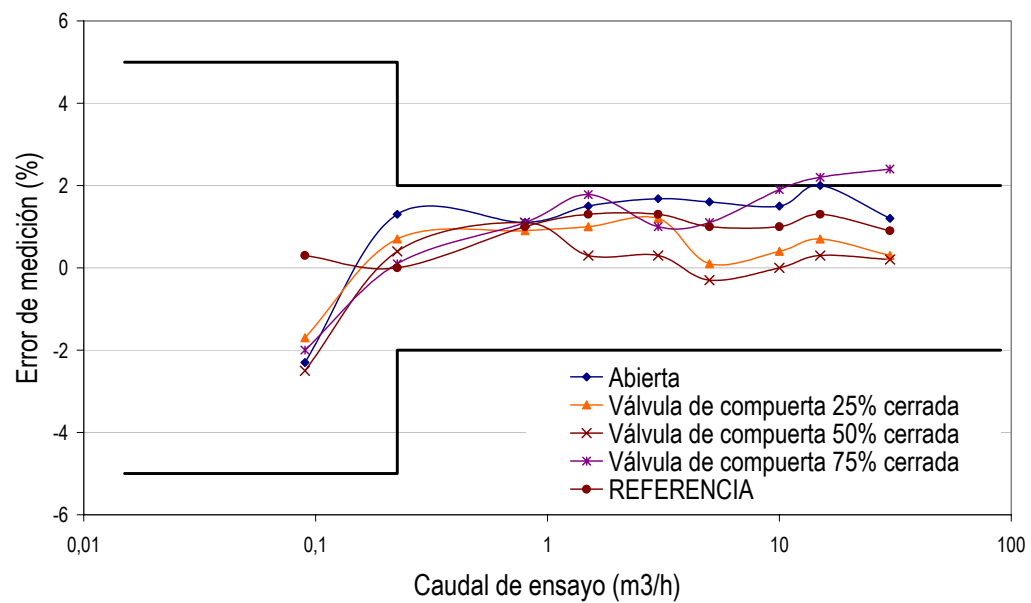

FIGURA 44. RESULTADOS DE LA CURVA DE ERROR DE UN CONTADOR DE CHORRO ÚNICO 50MM PROPORCIONADO POR ACTARIS.

Sorprendentemente, cuando se llevó a cabo la prueba para evaluar su comportamiento en sentido inverso se advirtió que no contabilizaba agua a ningún caudal (turbina parada).

\subsubsection{Resultados de los ensayos a un contador tangencial}

El principio de medición empleado por los contadores tangenciales es teóricamente uno de los más sensibles al perfil de velocidades. Es más, hasta hace pocos años, ningún modelo estaba aprobado. No obstante, últimamente existen modelos que han conseguido la homologación europea y la aprobación española para clase metrológica A. En este epígrafe se presentan los resultados de los ensayos en laboratorio con los límites especificados para un calibre de $80 \mathrm{~mm}$.

El primer ensayo describe el comportamiento del contador con tramos rectos aguas arriba y abajo. Se realizó una segunda prueba para comprobar su repetibilidad, logrando excelentes resultados tanto en precisión como en repetibilidad (Figura 45). 


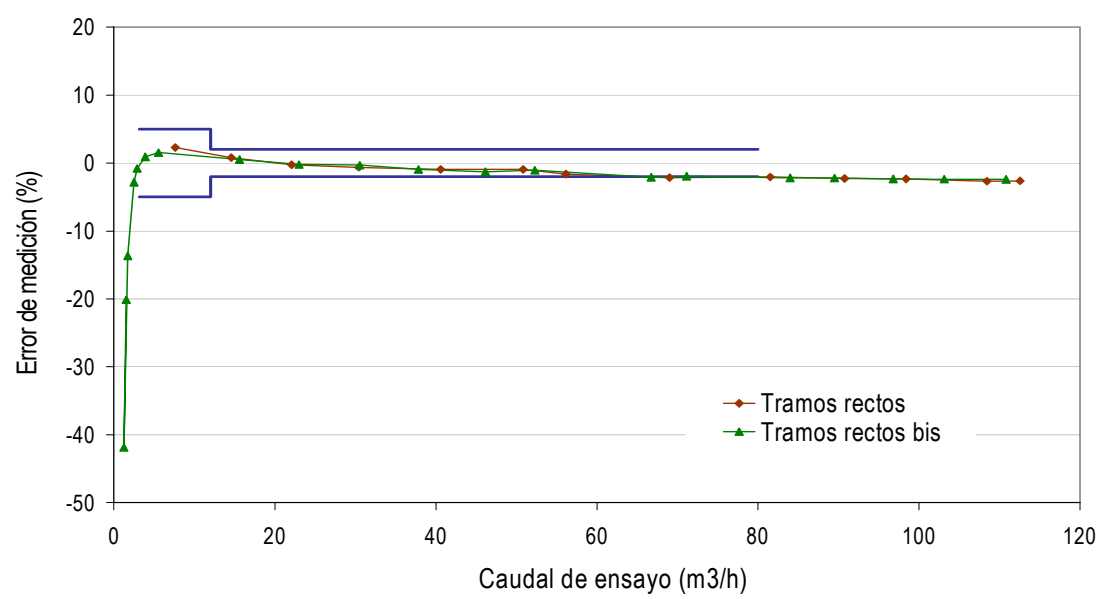

FIGURA 45. RESULTADOS DE ERROR DE UN CONTADOR TANGENCIAL CON TRAMOS RECTOS AGUAS ARRIBA Y ABAJO.

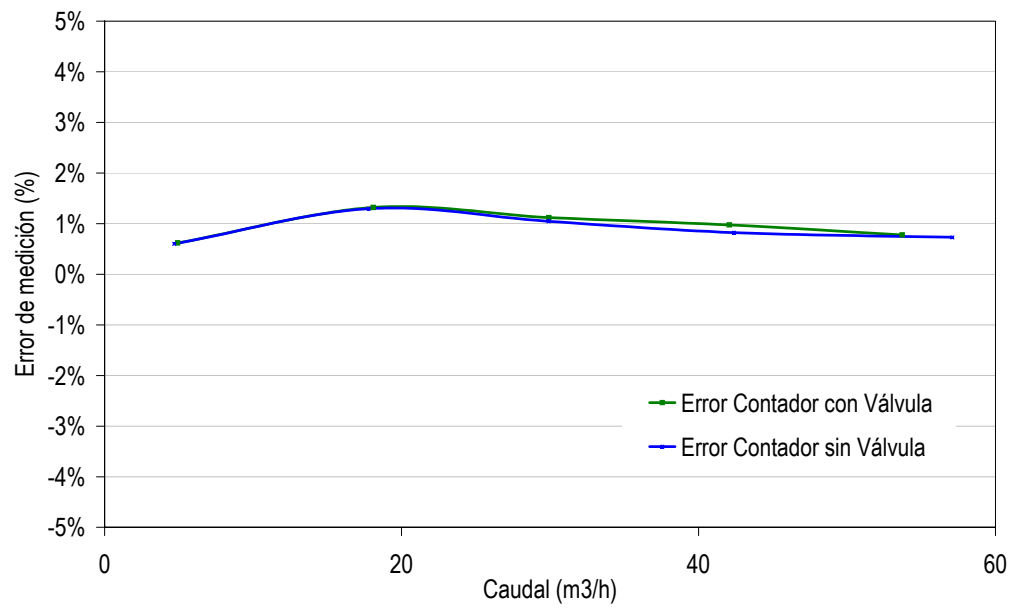

FIGURA 46. VÁlVULA REDUCTORA AGUAS ABAJO DE UN CONTADOR TANGENCIAL.

Una configuración habitual en este tipo de instalaciones, sobretodo en cabezales de riego, consiste en un contador tangencial junto a una válvula reductora que regula la presión aguas abajo del mismo. Al igual que se probó para contadores Woltman de eje horizontal (Figura 36), esta configuración apenas afecta a la medición del instrumento como se aprecia en al Figura 46.

No obstante, es muy importante tener en cuenta que la disposición de la turbina de medición en la zona superior de la conducción ocasiona graves errores ante perfiles de velocidad alterados. Así pues, cuando el cierre de la válvula de compuerta es del $75 \%$ a una distancia del contador de $0 \mathrm{D}$, en esta zona superior donde se localiza la turbina se producen velocidades muy bajas e, incluso, es posible apreciar flujos inversos que generan subcontajes de hasta $-30 \%$ del volumen real trasegado (Figura 47).

La mejora producida cuando se instalan entre elementos 3D de tubería recta es evidente, disminuyendo en aproximadamente un $15 \%$ el error de subcontaje (Figura 48). Así, para una válvula de compuerta cerrada un $75 \%$ el error típico de $-30 \%$ a $0 \mathrm{D}$ al $-15 \%$ a $3 \mathrm{D}$. 


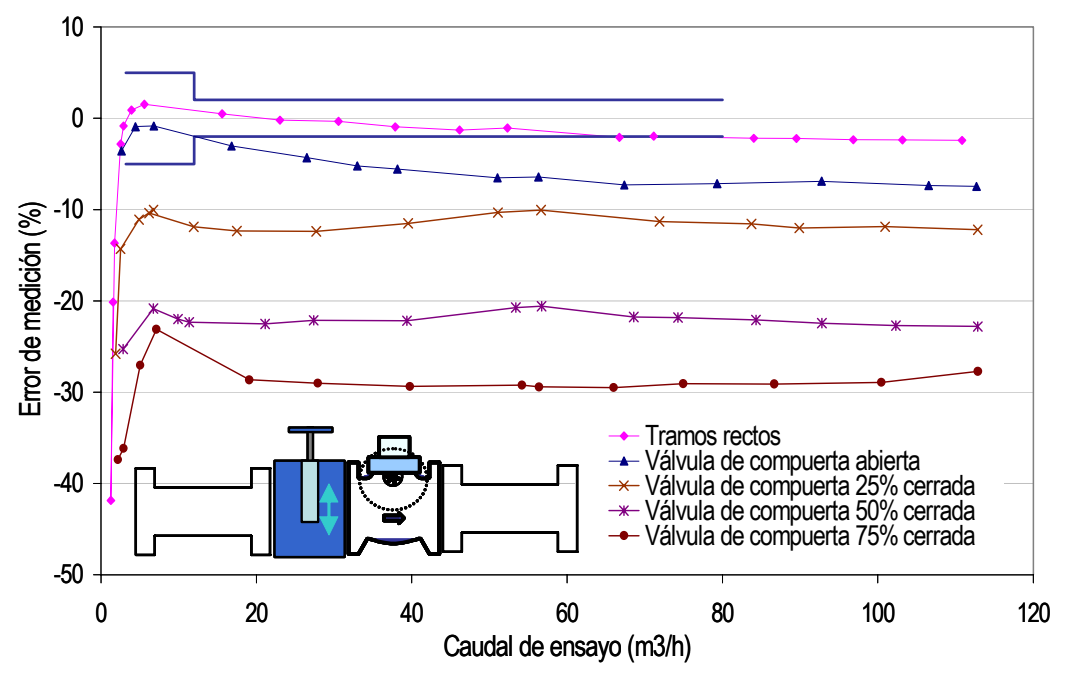

FIGURA 47. RESULTADOS DE ERROR DEL CONTADOR TANGENCIAL JUNTO CON UNA VÁLVULA DE COMPUERTA A OD.

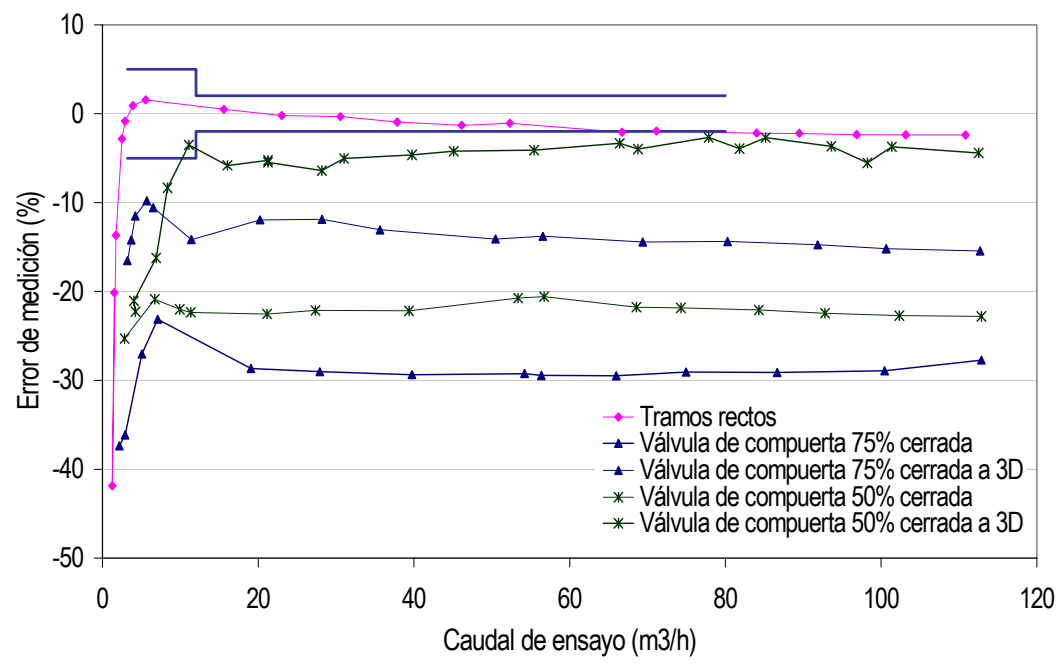

FIGURA 48. TANGENCIAL JUNTO CON UNA VÁLVULA DE COMPUERTA A DIFERENTES DISTANCIAS Y CIERRES.

El ensayo de esta tecnología de medición junto con una válvula de mariposa con el eje de la lenteja vertical no ocasionó un error de medición tan acusado como en el caso de una válvula de compuerta. Así, la válvula de mariposa totalmente abierta a una distancia de $3 \mathrm{D}$ aguas arriba no provocó alteración de la curva, mientras que cuando se cerraba $30^{\circ}$ la curva se desplazaba aproximadamente un -10\%. Este desplazamiento se subsanaba estableciendo entre el instrumento y la válvula $6 \mathrm{D}$ de tramo recto (Figura 49).

De igual forma que en el apartado 3. 3.3.2, se giró la válvula de mariposa a fin de cambiar la dirección del flujo de agua (ver Figura 32). En este caso, velocidades elevadas en la zona superior muestran errores de sobrecontaje de $+5 \%$ aproximadamente, mientras que cuando el flujo no se enfoca directamente sobre la turbina, los errores son similares (cerca de $-10 \%$ ) en cualquier otra posición de la válvula (Figura 50). 


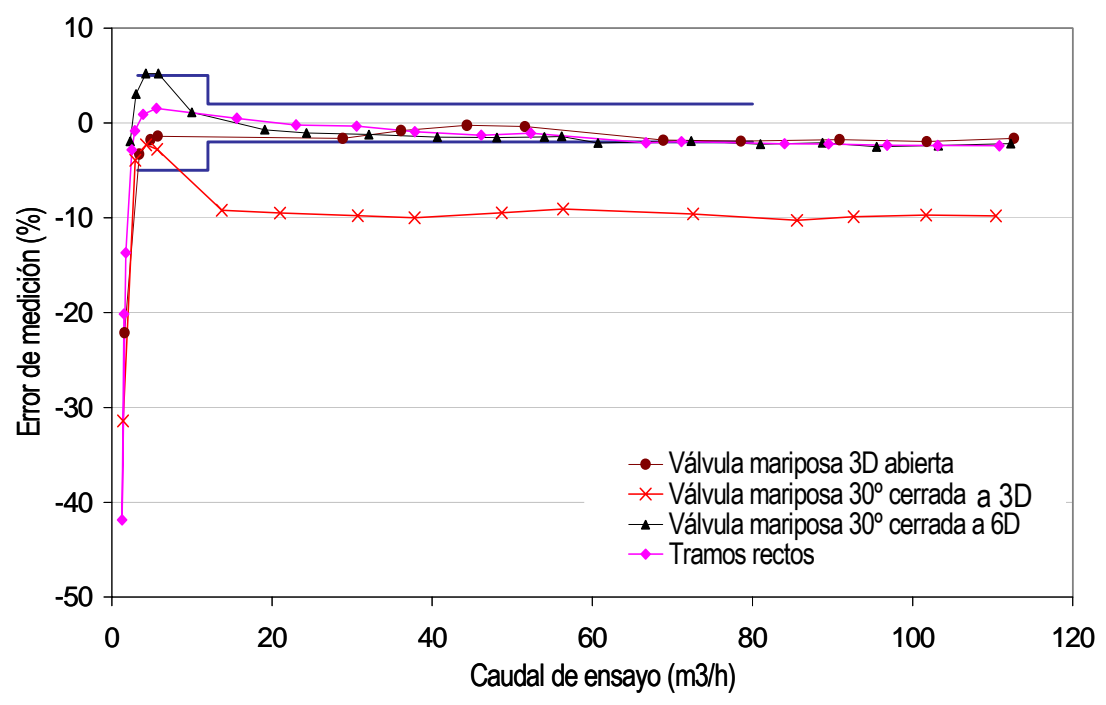

FIGURA 49. RESULTADOS DE ERROR DE UNA VÁLVULA DE MARIPOSA JUNTO AL INSTRUMENTO O 3D.

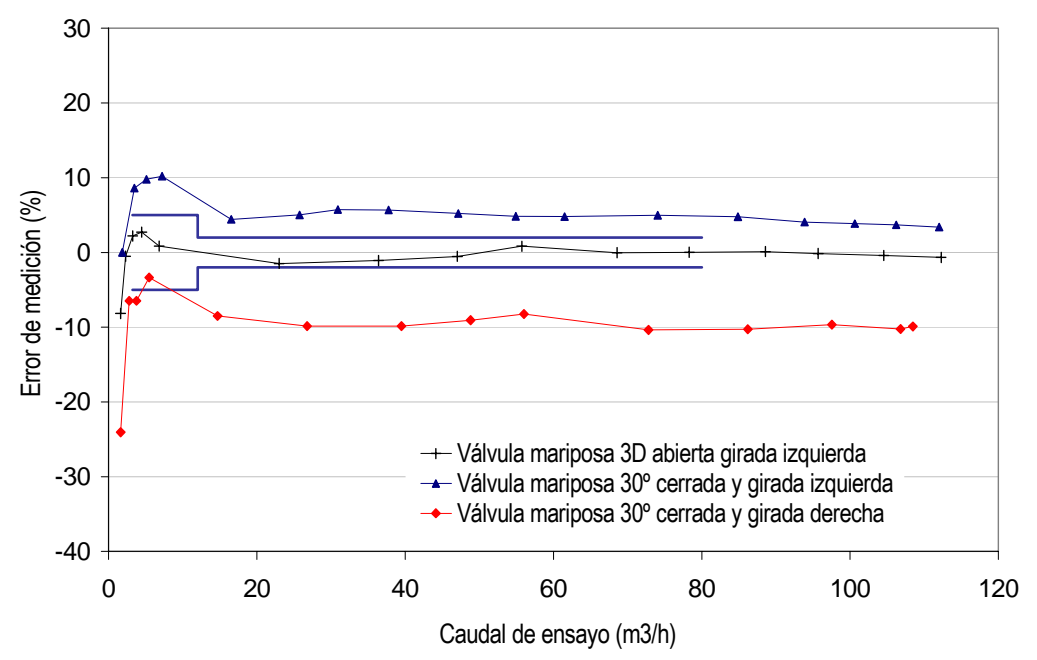

FIGURA 50. PRUEBAS DEL CONTADOR TANGENCIAL CON UNA VÁLVULA DE MARIPOSA A 3D.

Por último, con esta tecnología de medición más sensible se llevaron a cabo otra serie de pruebas con el contador tangencial girado $90^{\circ}$ (la turbina se encuentra entonces en un lateral de la conducción), en sentido inverso del flujo de agua e instalado junto a un codo, una te y una reducción (Figura 51). El objetivo del ensayo era determinar la distancia en tramos rectos en que la curva de error se aproxime a la de referencia.

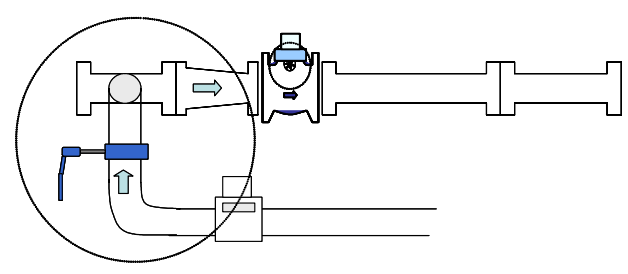

FIGURA 51. CONFIGURACIÓN DE UN CONTADOR TANGENCIAL CON VÁLVULA DE MARIPOSA, CODO, TE Y REDUCCIÓN A DIFERENTES DISTANCIAS. 


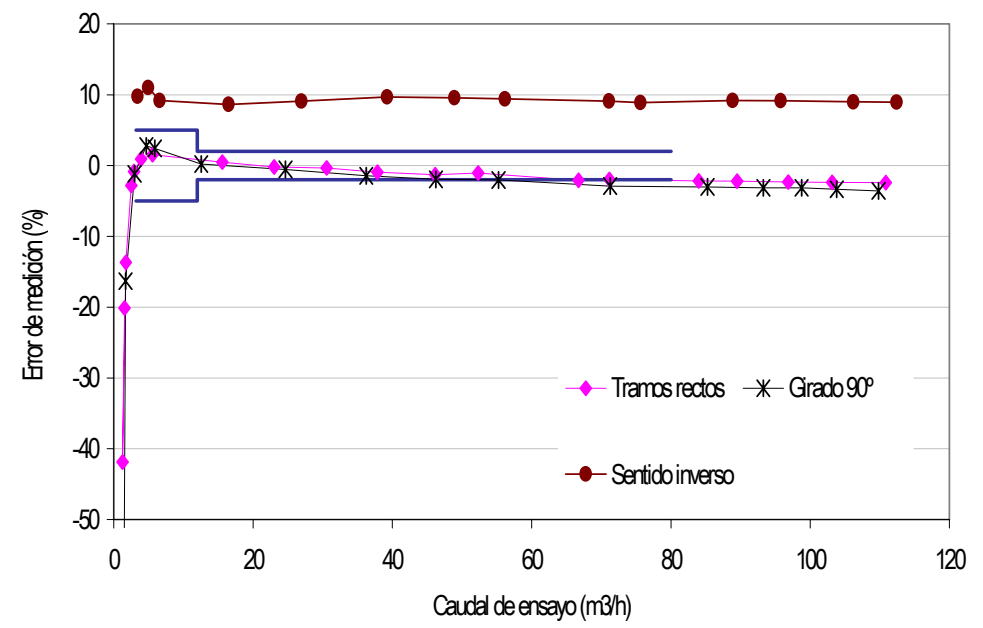

FIGURA 52. OTROS ENSAYOS DE LA CURVA DE ERROR.

De estas últimas pruebas, se obtuvieron errores positivos de $+10 \%$ con la instalación del instrumento en sentido inverso del flujo. Aún siendo más susceptible al perfil de velocidades, esta tecnología presenta resultados muy satisfactorios en posiciones de instalación no habituales, como inclinadas $90^{\circ}$ (Figura 52).

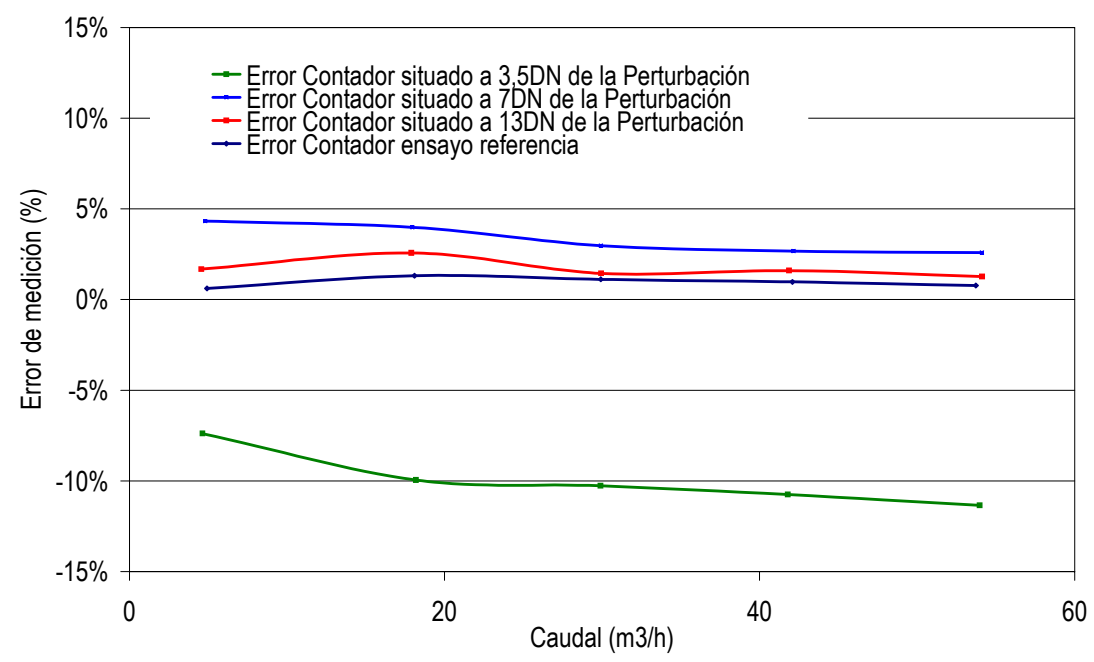

FIGURA 53. INFLUENCIA DE UN CODO+T+REDUCCIÓN SOBRE UN TANGENCIAL A DIFERENTES DISTANCIAS.

Por ultimo, se aprecia claramente que la instalación de tramos rectos de tubería entre en instrumento y la perturbación beneficia la medición del caudal significativamente obteniéndose valores de hasta $-10 \%$ de error cuando el instrumento se encuentra a 3,5 D de la perturbación.

\subsubsection{Resultados de los ensayos a un contador proporcional}

El contador proporcional, descrito en el capítulo anterior, contabiliza el volumen de agua trasegado mediante la relación establecida entre dos circuitos en paralelo de diferente capacidad. Totaliza el caudal de uno de los circuitos, el de menor 
capacidad, y estima el volumen circulado gracias a la relación conocida entre ambos (Figura 54). Comúnmente, el contador instalado en el secundario suele ser de tecnología de chorro único o múltiple.

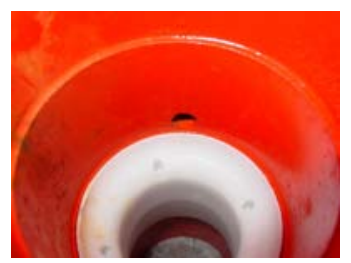

FIGURA 54. PARTE INTERNA DEL CONTADOR PROPORCIONAL. CIRCUITO PRIMARIO CON TOBERA Y ENTRADA DEL CIRCUITO SECUNDARIO.

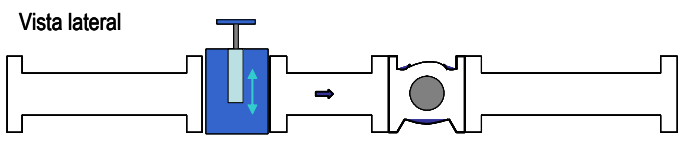

Vista superior

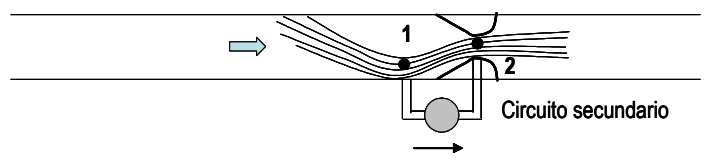

FIGURA 55. ESQUEMA DEL COMPORTAMIENTO DE UN CONTADOR PROPORCIOANLA ANTE UN FLUJO PERTURBADO.

Sin embargo, las características resistentes del circuito secundario pueden variar cuando localmente la velocidad en la entrada a este circuito es más elevada debido al efecto que produce un elemento perturbador sobre el flujo. Así pues, el término cinético aumenta produciendo menores diferencia de presión entre el punto 1 y 2, y trasegando menor caudal por el circuito secundario (Figura 55).

Consecuentemente, alteraciones en el flujo con velocidades elevadas a la entrada del contador pueden ocasionar errores de medición negativos, como es el caso del ensayo con una válvula de compuerta cerrada (Figura 56).

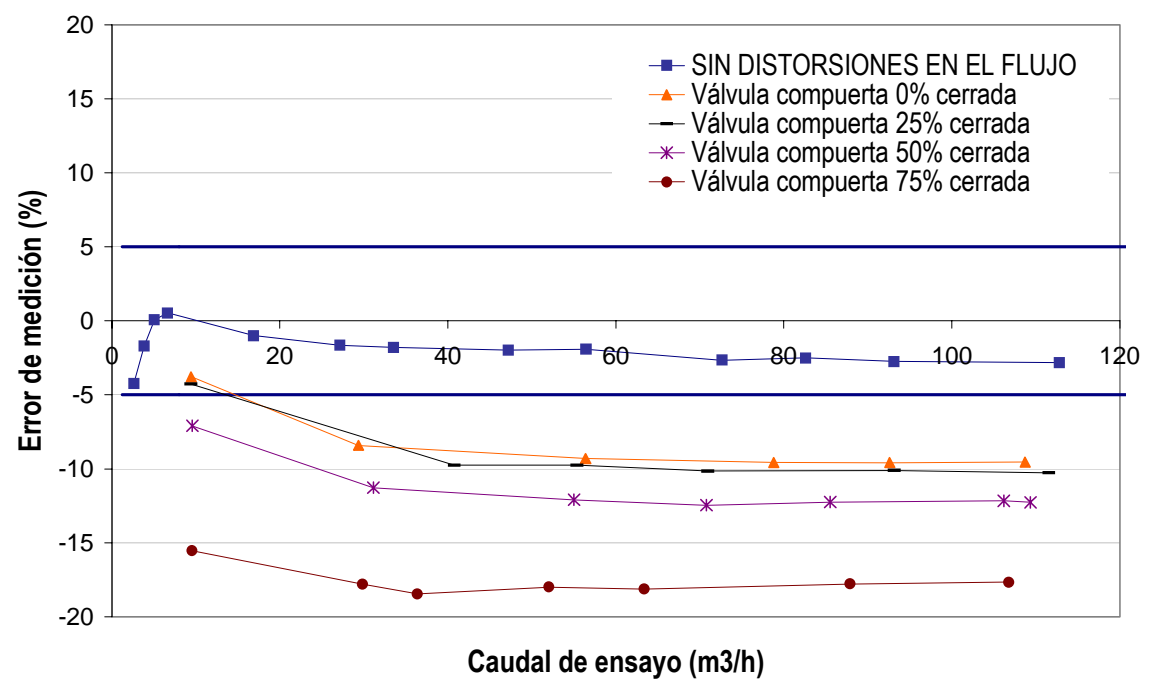

FIGURA 56.ENSAYOS PARA EVALUAR LA INFLUENCIA DE UNA VÁLVULA DE COMPUERTA SOBRE UN CONTADOR PROPORCIONAL. 
Además, esta tecnología tiene un inconveniente importante. Su instalación debe ser extremadamente cuidadosa, ya que una incorrecta colocación del filtro de malla que protege la entrada al circuito secundario puede producir errores muy graves al cambiar la relación entre las características resistentes de ambos circuitos.

De hecho, durante las pruebas, de forma involuntaria se instaló el contador en sucesivas ocasiones con el filtro mal colocado. Este suceso produjo que los resultados obtenidos cuando se evaluó el efecto de una válvula de compuerta a 3D fueran muy aleatorios y poco concluyentes (Figura 57).

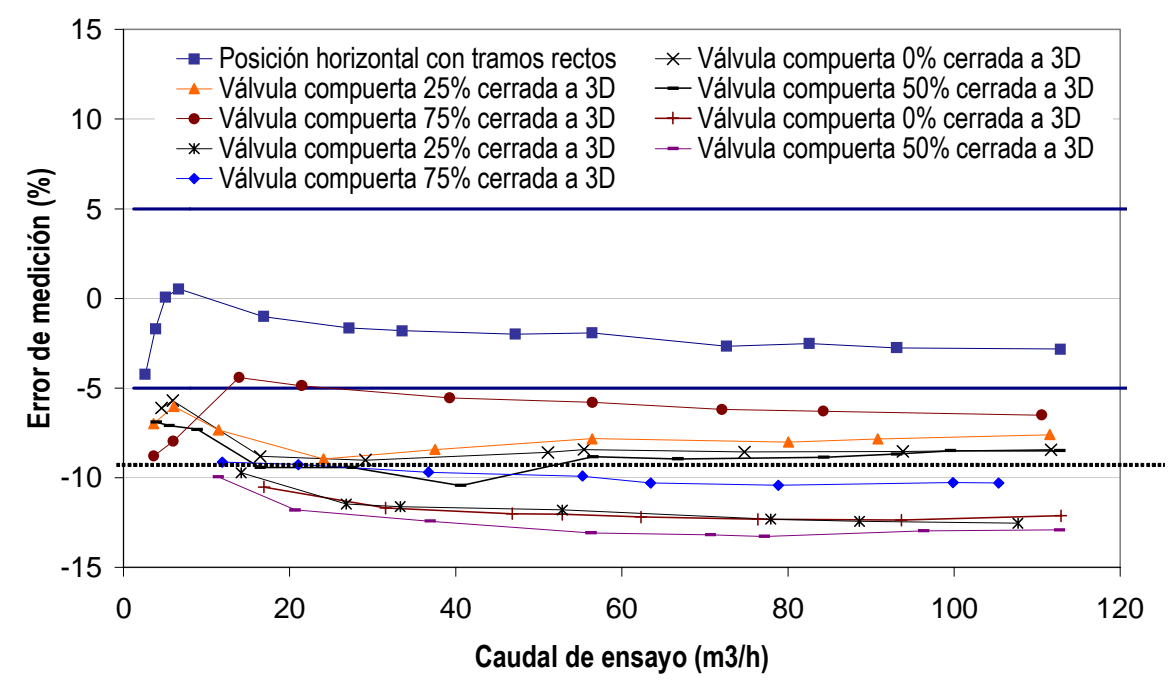

FIGURA 57. ENSAYOS PARA EVALUAR LA INFLUENCIA DE UNA VÁLVULA DE COMPUERTA SOBRE UN CONTADOR PROPORCIONAL.

Los resultados extraídos de los ensayos muestran que una válvula de mariposa con diferentes grados de apertura no altera la curva de error del contador.

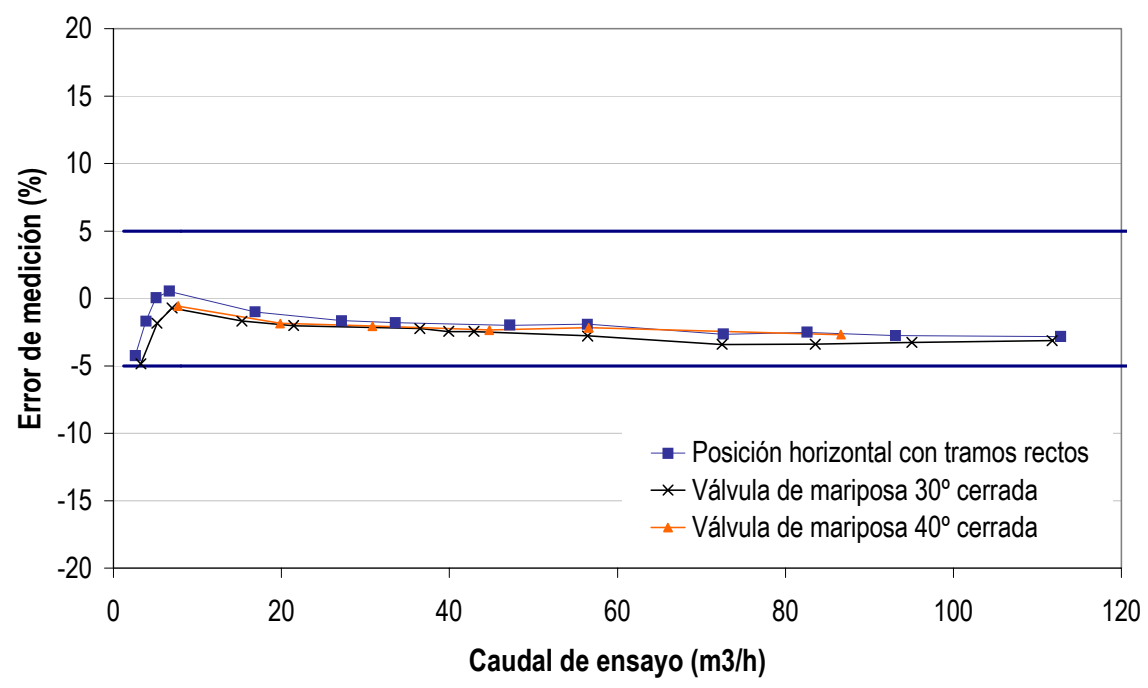

FIGURA 58. PRUEBAS DE ERROR DE UN CONTADOR PROPORCIONAL CON UNA VÁLVULA DE MARIPOSA. 


\subsubsection{Resultados de la válvula-contador}

Las válvulas volumétricas son instrumentos que combinan las funciones de un medidor de agua y de una válvula hidráulica. Las funciones de medición son las típicas de control del consumo y de dosificación volumétrica del agua. Como válvula de regulación puede tener varias funciones, como limitadora de caudal o reductora de presión.

En este caso simplemente se obtuvo la curva de error de este aparato cuando la válvula se encuentra limitando el caudal concluyendo que satisfactoriamente entra dentro de los límites de la norma para clase $\mathrm{A}$, como muestra la siguiente figura.

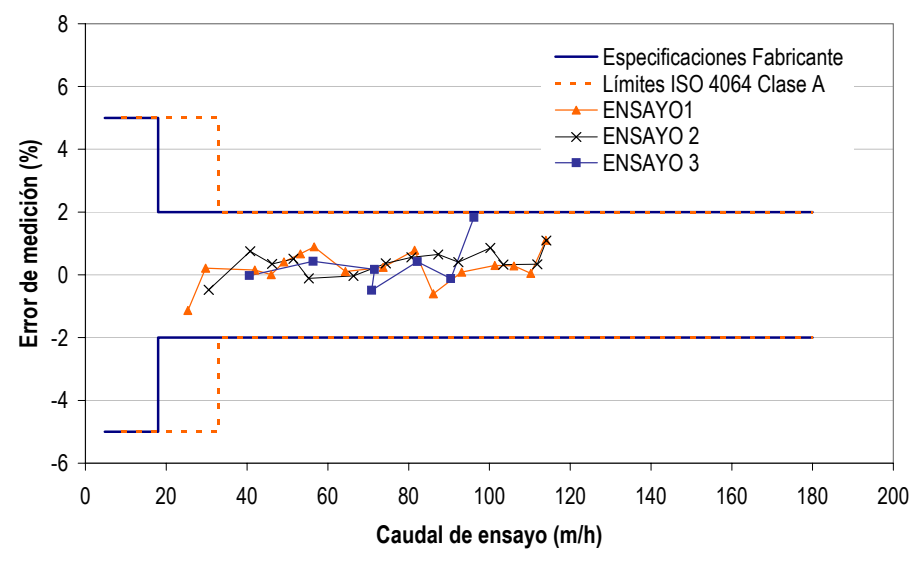

FIGURA 59. RESULTADOS DE LA CURVA DE ERROR A UNA VÁLVULA-CONTADOR CALIBRE 100MM.

\subsection{CONCLUSIONES}

El agua es un bien preciado que debe ser medido y su consumo controlado de forma adecuada. En la actualidad, existe un vacío en la bibliografía técnica en lo que se refiere al estudio de los sistemas de medición de redes hidráulicas. Los abastecimientos de agua, salvo raras excepciones no desarrolla trabajos en los que se analice el comportamiento de los instrumentos y, sencillamente, confía en las prestaciones de los mismos sin conocer sus verdaderas fortalezas ni sus debilidades.

Este capítulo describe los resultados de laboratorio respecto al comportamiento metrológico de medidores de agua, en su mayoría contadores de velocidad, llevados a cabo durante toda la etapa doctoral.

En lo referente al sistema de micromedición, una de las carencias fundamentales es el desconocimiento de la evolución metrológica de los contadores de pequeño calibre con el tiempo. Esto, por una parte, tiene implicaciones en la gestión del agua ya que los balances hídricos de entradas y salidas de caudal no cuadran si se desconoce el error con que se miden los consumos de los usuarios domésticos, que representan aproximadamente el $70 \%$ del total. En segundo lugar, el usuario no recibe información fiable sobre su consumo de agua. $Y$ por último, pueden producirse pérdidas económicas importantes debido al volumen de agua que deja de registrarse con el tiempo.

Por ello, es fundamental potenciar la investigación en torno al ritmo de deterioro de cada tecnología de medición, detallando qué variables tienen más influencia en la evolución de la curva de error. Como se ha visto, parámetros como la calidad del agua y la posición de instalación en contadores de pequeño calibre pueden acelerar su deterioro natural.

El control del sistema de macromedidores mejora la gestión de redes hidráulicas posibilitando extraer datos de gran utilidad para el diseño de nuevos sectores, la dosificación de volúmenes de agua de riego, el control de fugas en redes urbanas, etcétera. 
Consecuentemente, de la misma forma, se evalúa la metrología de diferentes tecnologías de medición y la influencia que ejercen sobre ella elementos perturbadores del flujo. Las exigencias de la nueva normativa europea sobre ensayos a contadores de agua introducen pruebas de homologación del instrumento frente a diferentes perturbaciones indicando la distancia requerida por cada contador salido de fábrica. Otros parámetros relacionados con la calidad del agua y las características de la instalación. Estos últimos aspectos son sobre los que se debe incidir en el futuro, ya que en la actualidad todavía queda mucho por investigar.

\subsection{BIBLIOGRAFÍA CONSULTADA}

Arregui F.J. (1999). Propuesta de una metodología para el análisis y gestión del parque de contadores de agua. Tesis doctoral. Universidad Politécnica de Valencia.

Arregui F.J. (2000). Cálculo del patrón de consumo y la vida útil de los contadores de Santa Fé de Bogotá. Documento interno. Instituto Tecnológico del Agua. Universidad Politécnica de Valencia.

Arregui F.J. (2000). Evaluación de la precisión de diversos contadores durante el llenado de cisternas. Documento interno. Instituto Tecnológico del Agua. Universidad Politécnica de Valencia.

Arregui F.J. (2001). Algunas consideraciones sobre la elección del tipo de contador doméstico y el cálculo de su vida útil. Jornadas técnicas Baleares 2015: La Gestión del Agua.

Arregui F, Palau C.V, Garcia-Serra J, Gascón L. (2003). Evaluating domestic water meter accuracy. A case study. PEDS Pumps, electromechanical devices and systems. Applied to urban water management. Balkema. Vol. 1. pp. 343-352.

Arregui F.J., Palau C.V., García-Serra J., Herrero M. (2004). Contadores de agua para riego. Medición y recomendaciones prácticas. Riegos y drenajes XXI. Vol.134. pp.36-42.

Baker, R.C. (1993). Turbina flowmeters. Part II. Theoretical and published information. J. Flow measurement and Instrumentation. Vol.4 pp. 123-144.

Environmental Agency (2003). Continuous water monitoring equipment. Part 3: Performance standards for water flowmeters. MCERTs. United Kingdom.

Flow programme (2002). Best practices guide calibration of flowmeters. NEL. United Kingdom.

Hanson B.R. and Schwankl L.J. (1998). Error analysis of flowmeter measurements. Journal of Irrigation and Dranaige Engineering. pp.248-256.

Instituto Tecnológico del Agua (2001). La medición en sistemas de distribución de agua. Primera parte. Documento interno. Curso de la Universidad Politécnica de Valencia.

ISO 4064-1:1993. Medición del caudal de agua en conductos cerrados. Parte 1. Especificaciones.

ISO 4064-2:1978. Medición del caudal de agua en conductos cerrados. Parte 2. Condiciones de instalación.

ISO 4064-3:1983. Medición del caudal de agua en conductos cerrados. Parte 3. Métodos y materiales de ensayo.

ISO 4185: 1980. Measurement of liquid flow in closed conduits -- Weighing method.

ISO UNE 8316: 1987. Measurement of liquid flow in closed conduits -- Method by collection of the liquid in a volumetric tank Navarro I. (2003). La futura normativa relativa a contadores de agua. Tecnología del agua. Vol.240. pp.48-55.

Mello E.J. (1997). Hidrômetro sem ângulo para leitura. XXIV Assemblea nacional da Aséame. Brasilia. Brasil. 
Orden ministerial 28 de diciembre de 1988 por la que se regulan los contadores de agua fria (BOE num.5, de 6 de marzo de 1989).

OIML R-49-1:2000. Waters meters entended for the metering of cold potable water. Part 1: Metrological and technical requirements.

Pr EN 14.154: 2004. Water meters.

PrEN 14.268:2004. Contadores de agua de riego

RAC 2200/I. Especificaciones técnicas del banco de ensayo de contadores domésticos. Actaris.

Terriel J.C., Daniel W.W.(1994). Business statistics for management and economics. Ed. Houghton Mifflin Company. Boston.

Withers, V.R., Strang, W., y Allnutt, G. (1996). Flow characteristics of turbine flowmeters. Proc. Int. Conf. On Flor measurement. Harwell Conference Publication vol. 10. pp. 305-320.

Especificaciones técnicas de cada instrumento. Catálogos comerciales 2000-2003.

Calibración del caudalímetro electromagnético. Danfoss instrumentation. 


\section{ANEXO I. DESCRIPCIÓN Y FUNCIONAMIENTO DE BANCOS DE ENSAYO}

\section{MICROMEDIDORES}

El método de ensayo utilizado para este tipo de instrumentos de menor calibre es el de recogida de líquido en un tanque volumétrico descrito en la norma UNE-EN ISO 8316.

Este banco de ensayo es capaz de verificar la calidad metrológica de contadores de agua de calibre 13 a $40 \mathrm{~mm}$ y está compuesto por tres líneas independientes de caudal que trabajan en función del rango de caudales que se desee ensayar.

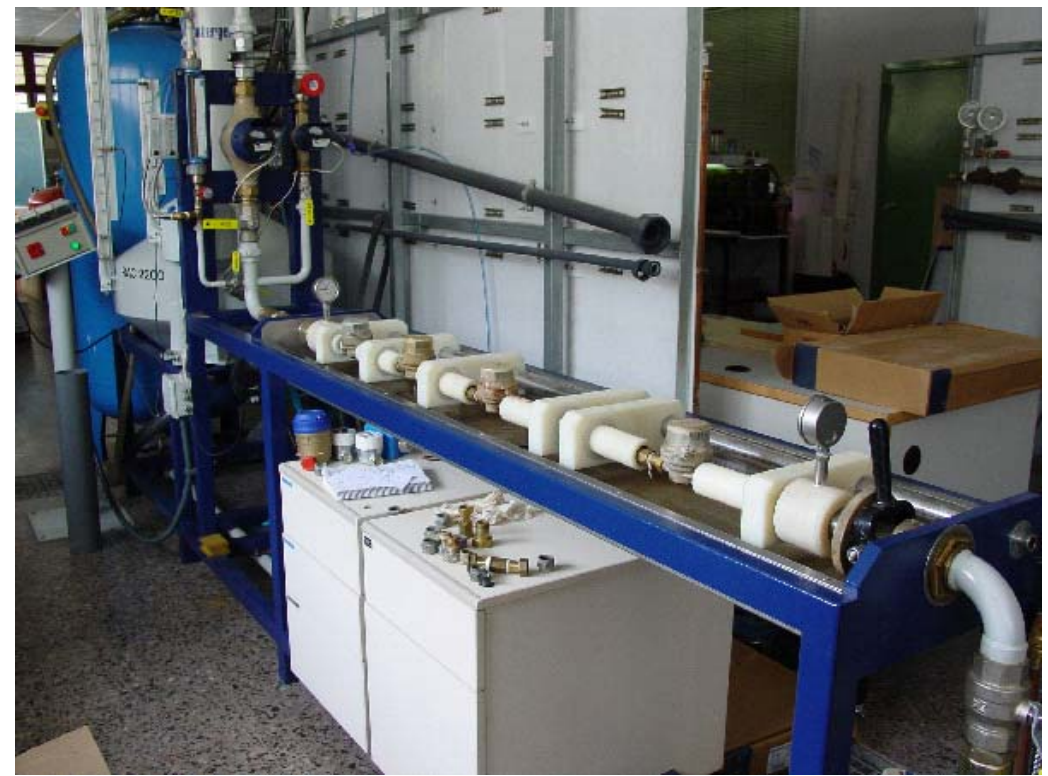

FIGURA 1. VISTA GENERAL DEL BANCO DE ENSAYO DE CONTADORES DE PEQUEÑO CALIBRE (<40MM).

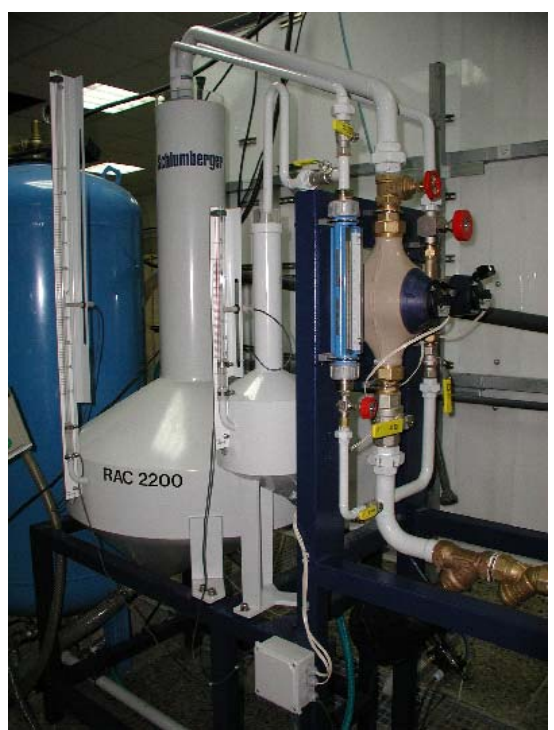

(a)

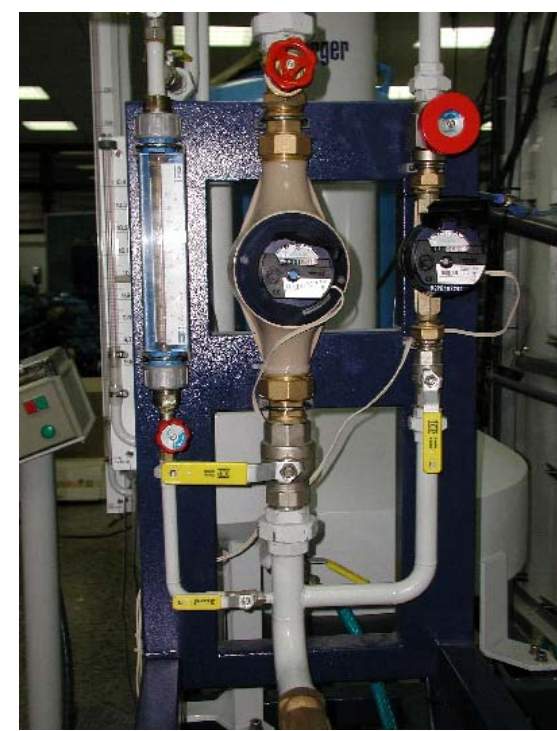

(b)

FIGURA 2. BANCO DE ENSAYO DE MICROMEDIDORES 
Además, el equipo dispone de dos probetas o depósitos graduados, de 10 y 200 litros, construidos en acero con forma tronco cónica para asegurar un correcto vaciado tras cada ensayo. En ellos se afora el volumen de agua de cada prueba (Figura 2a).

Dos de las líneas, las de mayor calibre, están provistas de contadores volumétricos de gran precisión con emisores de pulsos, uno de $20 \mathrm{~mm}$ (emisor de $0,1 \mathrm{l} / \mathrm{pulso}$ ) y otro de $40 \mathrm{~mm}$ (emisor de 1//pulso). La frecuencia de estos pulsos es recibida por un convertidor que junto a la medida del tiempo hace posible regular el caudal de ensayo indicándolo en un display digital. La tercera línea de ensayo dispone de un caudalímetro de área variable o rotámetro que permite el ajuste de caudales entre 10 y $100 \mathrm{l} / \mathrm{h}$ (Figura 2b).

El rango de medida de caudal en este equipo es de $0,01 \mathrm{~m} 3 / \mathrm{h}$ a $20 \mathrm{~m} 3 / \mathrm{h}$ y regulando con válvulas de aguja se llega a conseguir una precisión del $2 \%$ sobre la medida para caudales hasta $0,1 \mathrm{~m} 3 / \mathrm{h}$ y de $5 \%$ para el resto del rango. La capacidad, resolución y precisión de las probetas calibradas se indica en la siguiente tabla.

TABLA 1. CARACTERISTICAS DE LOS DEPÓSITOS DE AFORO

\begin{tabular}{cccc}
\hline & Capacidad nominal (I) & $\begin{array}{c}\text { Resolución de lectura } \\
\text { (I en la zona de medida) }\end{array}$ & $\begin{array}{c}\text { Precisión } \\
\text { (\%sobre la capacidad máxima) }\end{array}$ \\
\hline Depósito de 10 litros & $10 \pm 5 \%$ & 0,01 & $>0,2 \%$ \\
\hline Depósito de 200 litros & $200 \pm 5 \%$ & 0,2 & $0,2 \%$ \\
\hline
\end{tabular}

Cada depósito está equipado con un interruptor de nivel capacitivo que corta el flujo de agua cuando el volumen nominal se alcanza. Una vez parada la circulación de agua se lee en una regla calibrada la medida exacta del volumen aforado.

El procedimiento de ensayo se basa en la comparación del volumen del depósito calibrado y el volumen medido por los contadores dispuestos en el banco a ese caudal de ensayo (diferencia en las lecturas del totalizador del instrumento antes y después del ensayo).

El error de medida del instrumento vendrá calculado por la diferencia de volúmenes, mediante la ecuación 1 expuesta en el apartado 1 de este capítulo.

\section{MACROMEDIDORES}

El método de ensayo utilizado para estos contadores de mayor calibre es el de contraste con otro aparato de medición más preciso. La norma ISO-4064 en su punto 5.4, especifica las características de precisión del dispositivo de comparación las cuales no deben exceder 1/10 de la precisión máxima del instrumento ensayado.

Las pruebas se realizaron en un banco con capacidad de ensayo de válvulas de calibre 50 hasta $100 \mathrm{~mm}$ en el Instituto Tecnológico del Agua (Universidad Politécnica de Valencia) donde es posible examinar, también, diferentes tecnologías de medición de agua. Las características del banco son bastante sencillas, y consta de los siguientes equipos:

Dos bombas de $18,5 \mathrm{~kW}$, una de velocidad fija y otra con variador de frecuencia.

- 4 líneas independientes que permiten el estudio de diferentes calibres de válvulas y contadores de agua, con la carretería apropiada para cada uno de ellos (Figura 6).

- Un circuito en by-pass, cuya línea principal contiene un caudalímetro electromagnético utilizado como referencia, y una secundaria cuyos caudales se contrastan con contador volumétrico de precisión. El conjunto del circuito hidráulico permite medir un amplio rango de caudales (Figura 3).

- Un equipo de adquisición de datos, programado específicamente en Labview, para el manejo y análisis de toda la información recogida. 


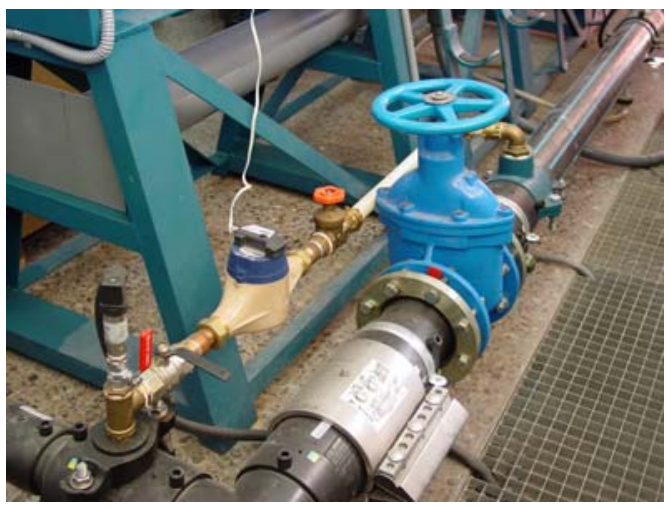

FIGURA 3. CIRCUITO EN BY-PASS PARA CAUDALES BAJOS CON CONTADOR VOLUMÉTRICO DE PRECISIÓN.

Los ensayos en las diferentes configuraciones comienzan desde caudales más bajos aumentando progresivamente hasta caudales más elevados. De este modo, las lecturas del contador objeto de ensayo se contrastarán con las de un caudalímetro electromagnético de caudal máximo $2500 \mathrm{~m} 3 / \mathrm{h}$ y con las de un contador volumétrico de precisión en el circuito by-pass para la franja de caudales donde el caudalímetro no es capaz de medir.

Este caudalímetro tiene una precisión teórica del $0,5 \%$ sobre la lectura lo que sobrepasa las exigencias de precisión de la norma. No obstante, la recta de calibración del aparato indica valores inferiores de error lo que resulta más admisible como dispositivo de referencia (Figura 4).

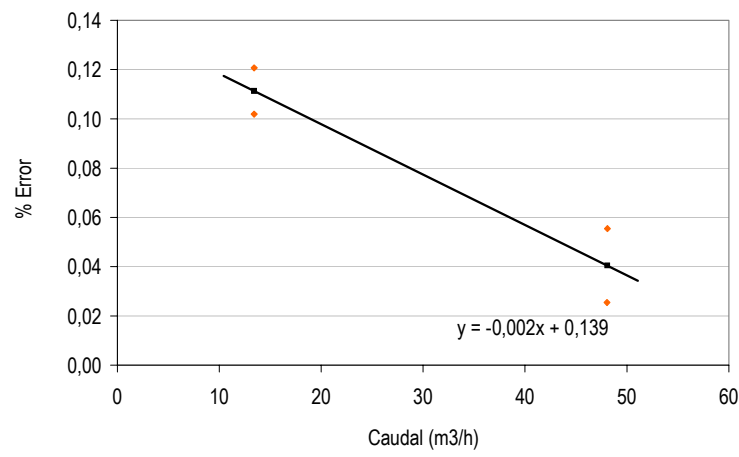

FIGURA 4. RECTA DE CALIBRACIÓN DEL CAUDALÍMETRO ELECTROMAGNÉTICO ENSAYADA EN FÁBRICA.

Este instrumento dispone de dos salidas, una en frecuencia (digital de 0-5 V) en la que se controlará el número de flancos de subida por unidad de tiempo producidos en función del caudal que circula por la tubería, y otra en intensidad (analógica de 4-20 mA).

Durante el ensayo los datos del caudalímetro son transferidos al ordenador mediante esta última señal de 4-20 mA, que con una resistencia de $249 \Omega$, pasa a voltaje la señal de intensidad asignando el máximo caudal a $5 \mathrm{~V}$. Los contadores ensayados se comunican con el ordenador central mediante emisores de pulsos inductivos 0 tipo REED que envían una señal digital en forma de pulso (apertura y cierre de un interruptor) cada cierto volumen de agua trasegado (Figura 7). 


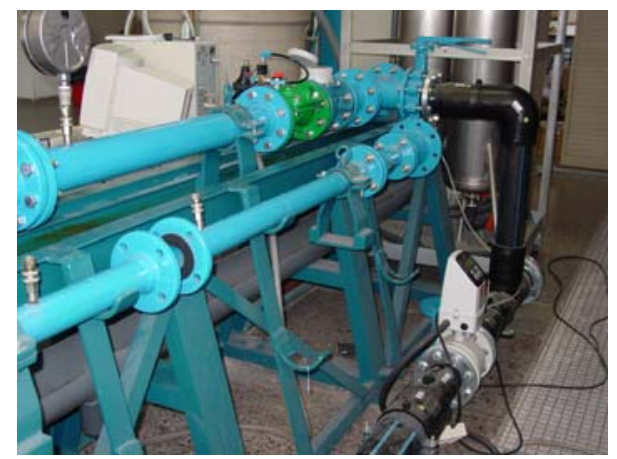

FigURA 6. VISTA DEL BANCO DE ENSAYO dE VÁLVULAS. CAUDALÍMETRO DE REFERENCIA Y CONTADOR ENSAYADO.

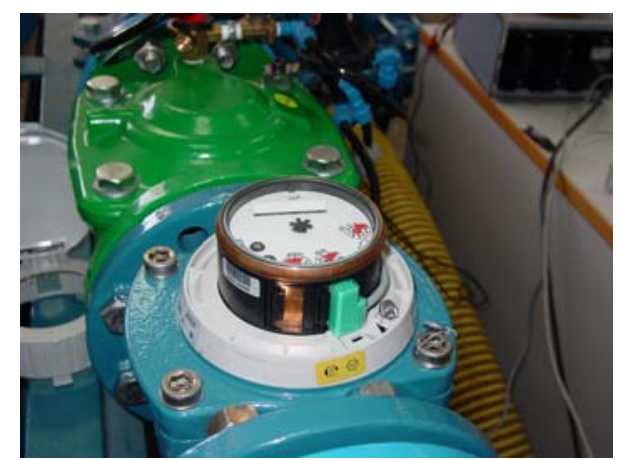

FIGURA 7. EMISOR DE PULSOS TIPO REED.

La regulación del caudal para cada prueba se realiza mediante válvulas de asiento montadas al final de la línea, justamente antes de la descarga al depósito (Figura 8).

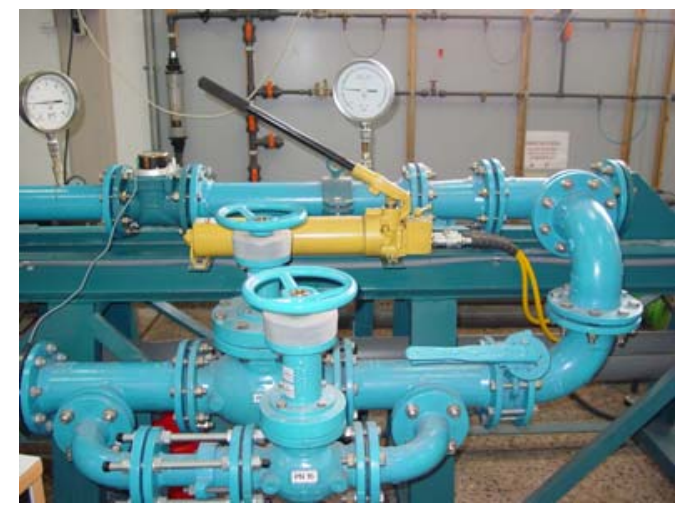

FIGURA 8. VÁLVULAS DE REGULACIÓN DE LOS CAUDALES DE ENSAYO.

Por tanto, las variables físicas tomadas durante las pruebas mediante una tarjeta de adquisición de datos son fundamentalmente, la presión antes y después del elemento perturbador, los caudales de referencia del caudalímetro electromagnético y del contador volumétrico descritos anteriormente, y las propias lecturas del instrumento estudiado.

\section{RESUMEN DE LA INSTRUMENTACIÓN Y AUTOMATISMOS DEL BANCO DE ENSAYO}

- Caudalímetro electromagnético de referencia de $80 \mathrm{~mm}$ (Qmax= $2500 \mathrm{m3} / \mathrm{h}$ ). Magflo (DANFOSS). Precisión teórica $0.5 \%$ del caudal real

- Contador volumétrico de precisión (2-5\% sobre el caudal circulado).

- Ordenador personal y sistema de adquisición de datos.

- Válvula de mariposa para aislamiento del circuito. DN $100 \mathrm{~mm}$.

- Válvula de asiento para regular el caudal circulante. DN 50 y $100 \mathrm{~mm}$

- Válvula de compuerta para el aislamiento del circuito primario.

- Transductor de presión (16 bar). Precisión $0.28 \%$ sobre el fondo de escala.

- Manómetros tipo Bourdon. 16 bares. Precisión de $\pm 0.5 \%$ sobre el fondo de escala.

- Variador de frecuencia.

- Dos bombas conectables en paralelo (18,5 kW).

- Carretería de 50/80/100 mm. 


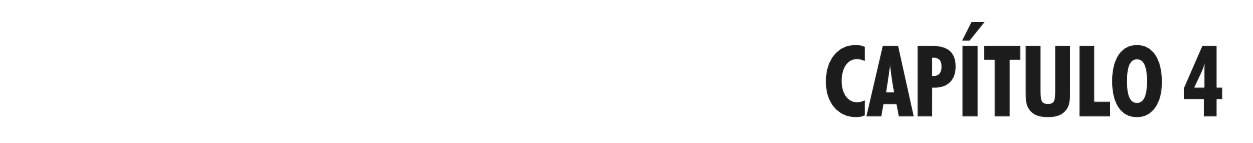

INFLUENCIA DE LAS PERTURBACIONES DEL FLUJO EN LA MEDICIÓN DE AGUA 


\section{INFLUENCIA DE LAS PERTURBACIONES DEL FLUJO EN LA MEDICIÓN DE AGUA}

\subsection{INTRODUCCIÓN}

Como se ha comentado, actualmente están disponibles una gran cantidad de tecnologías para la medición del caudal que circula a través de una tubería a presión. La mayoría recurre a la medición de variables físicas auxiliares que permiten estimar la velocidad del fluido ya sea localmente 0 en toda la sección. Ejemplos de estas variables son la diferencia de presión entre dos puntos, la tensión inducida entre dos electrodos, la diferencia en tiempo de tránsito de un pulso sonoro, etcétera.

En cualquier caso, la mayoría de la instrumentación utilizada para el control de los caudales que circulan en tuberías a presión mide la velocidad del flujo, infiriendo seguidamente el valor del caudal.

Los contadores de agua van un paso por delante, ya que integran esta señal de caudal en el tiempo obteniendo el volumen trasegado en un intervalo temporal. Luego, aparatos como los contadores de turbina parten de la medida de la velocidad para obtener el volumen total circulado. En ellos, la calidad de esta medida está condicionada por las fuerzas del agua incidentes sobre la turbina que varían en función de la forma del perfil de velocidades a la entrada del contador.

Otras tecnologías como los caudalímetros de ultrasonidos o los de inserción también relacionan la medida de la velocidad en una cuerda o varias de la sección con el caudal circulante. Otros caudalímetros, como los electromagnéticos, que basan su tecnología en la medición de la tensión inducida, obtienen el caudal ponderando las velocidades en diferentes zonas de la sección.

En todos estos casos, el conocimiento del comportamiento del flujo de agua, particularmente el perfil de velocidades dentro de la tubería, es determinante para la correcta medición del caudal.

En este capítulo se presenta un estudio numérico en profundidad, sobre cómo afectan diversas alteraciones del flujo de agua en la medición del caudal. Inicialmente se presenta, de forma teórica, la influencia sobre tres tecnologías bien diferentes, un contador tipo turbina, particularizando en el caso de un contador Woltman de eje horizontal, un caudalímetro electromagnético y uno de ultrasonidos. Posteriormente, se realiza un estudio de las perturbaciones del flujo causadas por elementos hidráulicos mediante simulaciones numéricas relacionándolas con el principio de medición de cada tecnología. Finalmente, este punto se ilustra con casos reales resueltos numéricamente mediante simulaciones posteriormente contrastados con los ensayos de laboratorio expuestos en el capítulo anterior. 


\subsection{INFLUENCIA DE LAS DISTORSIONES DEL FLUJO EN LA MEDICIÓN DE CAUDAL}

Una de las incógnitas más importantes en la instrumentación para la medida del agua es el orden de magnitud de la influencia que ejercen otros elementos hidráulicos, como válvulas, codos, reducciones, etc. sobre el error de medición. Como se ha comentado, muchas de las tecnologías estiman el caudal circulante a partir de la evaluación de la velocidad del flujo en una zona de la sección, en un punto o en una cuerda, siendo siempre más sensibles a las distorsiones en el flujo aquellos instrumentos que basan su medición en un número menor de medidas, como los caudalímetros de inserción.

Por lo tanto, es conveniente tener siempre presente que en prácticamente todos los caudalímetros, cuando algún elemento hidráulico altera el perfil de velocidades, el resultado final de la medida de caudal puede diferir de manera significativa respecto al valor real.

No obstante, hay que tener en cuenta que cada accesorio hidráulico perturba de forma diferente el flujo de agua. Por ejemplo, una válvula de compuerta parcialmente cerrada genera velocidades elevadas en la parte inferior de la conducción e importantes turbulencias en el flujo tras su paso por este elemento. En contraste, una válvula de mariposa semicerrada obstruye el flujo de agua en un plano diferente a la de compuerta, distorsionando el perfil de velocidades de forma asimétrica respecto del eje de giro de la válvula (Figura 1). Asimismo, un codo puede producir un flujo rotacional, debido a la diferencia de velocidades entre su zona exterior e interior. Finalmente, la combinación de varios elementos puede provocar lo que en terminología anglosajona se denomina swirl que consiste en una mezcla de movimientos longitudinales y rotacionales alrededor del eje de la conducción. Este tipo de distorsión es extremadamente perjudicial para la medición del caudal y se atenúa muy lentamente, por lo que requiere unos tramos de estabilización muy largos.

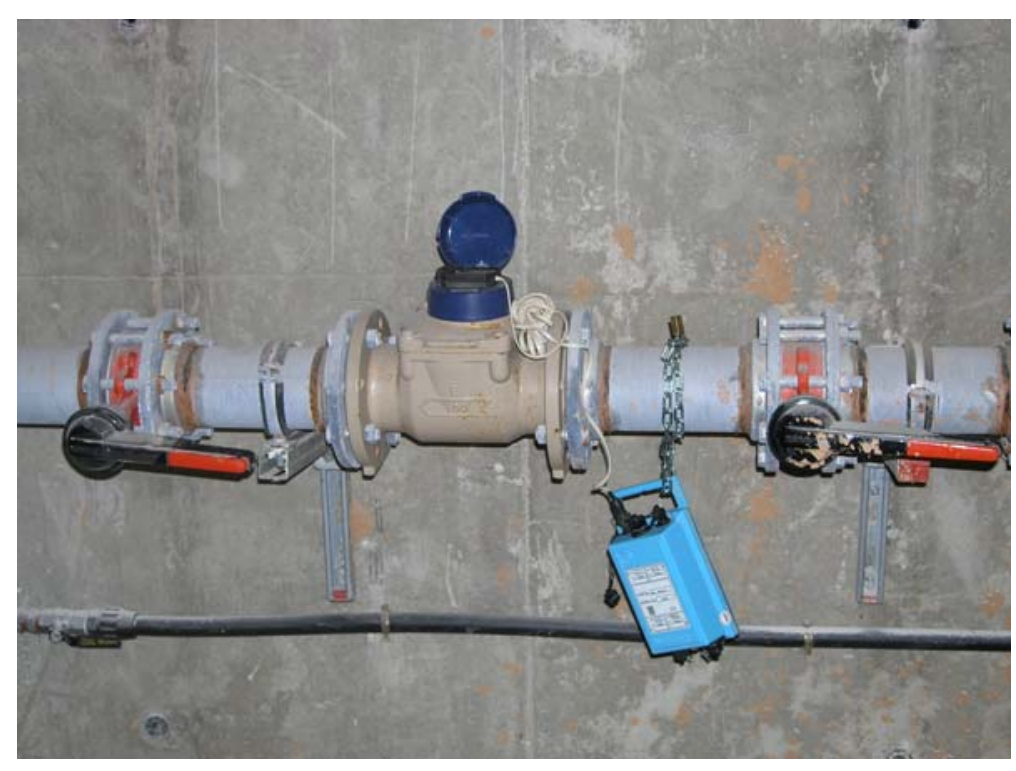

FIGURA 1. INSTALACIÓN DE UNA CONTADOR WOLTMAN JUNTO A UNA VÁLVULA DE MARIPOSA.

Por ello, y con el fin de garantizar una mínima calidad del perfil de velocidades entrante al instrumento, los fabricantes recomiendan la instalación de cierta longitud de tubería recta aguas arriba del mismo. Estos requisitos varían en función del tipo de elemento hidráulico que produce la perturbación, de la presencia de estabilizadores de flujo, y de la tecnología de medición de caudalímetro a contador (Figura 2). 


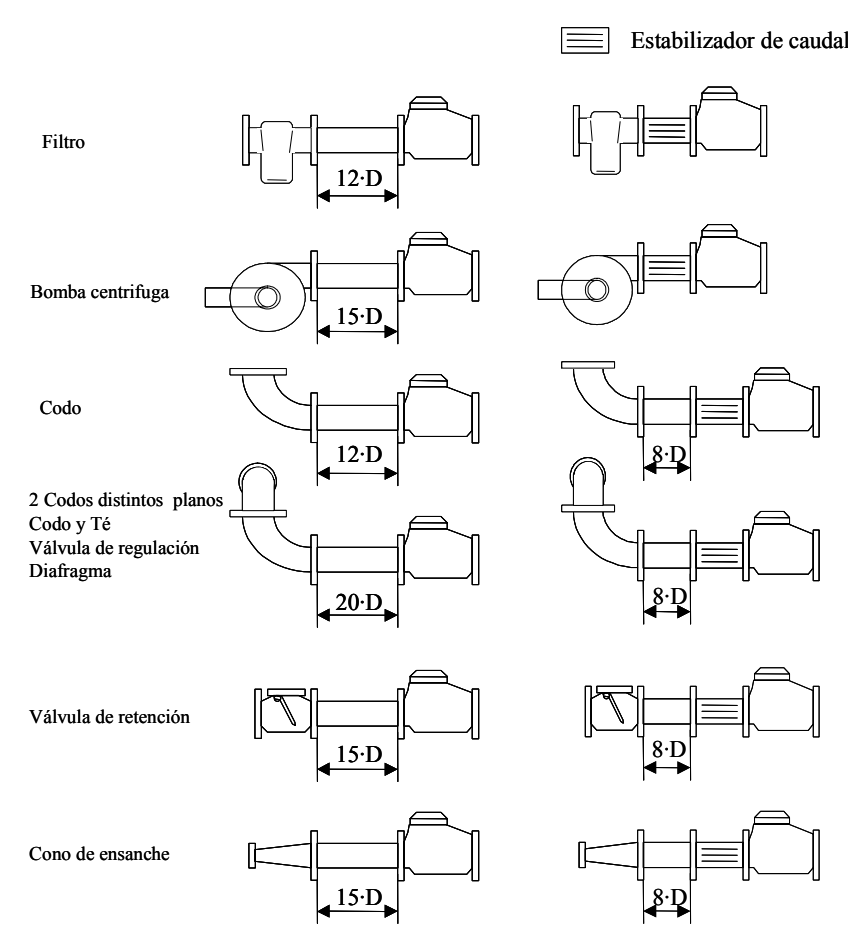

FIGURA 2. RECOMENDACIONES DE FABRICANTES PARA LA INSTALACIÓN DE CONTADORES DES TIPO WOLTMAN.

El presente capítulo pretende verificar de forma analítica estas exigencias en tramos rectos en tres tecnologías de medición muy comunes en las redes de distribución de agua a presión, combinando un análisis numérico que describe el comportamiento del flujo en estas situaciones y el principio de funcionamiento de cada aparato.

\subsection{PRINCIPIOS DE FUNCIONAMIENTO DE MEDIDORES}

En este apartado y antes de comenzar el análisis numérico, se describe en profundidad el funcionamiento de tres tecnologías de medición con el objetivo de conocer de qué modo pueden verse influenciadas por elementos externos instalados en la conducción.

\subsubsection{CONTADORES WOLTMAN}

\subsubsection{Principio de funcionamiento}

Para entender mejor el comportamiento de los contadores de velocidad tipo Woltman ante perturbaciones en el flujo, se desarrolla un estudio de las fuerzas que se ejercen sobre el elemento móvil del instrumento. De este modo es posible obtener la influencia que ciertas perturbaciones ejercen sobre el error de medición.

El elemento principal de este contador de velocidad es la turbina o hélice cuya velocidad de giro es función del caudal circulante por la conducción. Este elemento, enlazado con los engranajes del totalizador, gira más o menos rápido dependiendo de la velocidad del agua y de cómo incide ésta sobre sus álabes.

Para cada contador, el número de vueltas de la hélice se asocia a un volumen marcado en el totalizador mediante una relación de desmultiplicación constante. En la práctica existen diversas variables, unas intrínsecas al instrumento y otras 
relacionadas con el entorno donde se encuentra funcionando, que alteran esta relación, es decir, provocan un desequilibrio entre el volumen realmente circulado y el contabilizado por el instrumento.

Para totalizar correctamente el volumen circulado, durante la calibración en fábrica del instrumento, se ajusta la relación entre el volumen circulado y el número de vueltas de la hélice. Lógicamente, esta operación se realiza en condiciones normales de funcionamiento, es decir, cuando el flujo de agua se encuentra plenamente desarrollado.

En el caso de los contadores Woltman, la calibración del instrumento de medida se realiza adecuando la inclinación de la paleta de regulación (Figura 16). Esta paleta permite variar la relación entre la velocidad de rotación y el caudal circulante, y ajustar la curva de error dentro de los márgenes de error establecidos en la norma ISO 4064 para caudales de ensayo entre el mínimo y el máximo (Figura 3).

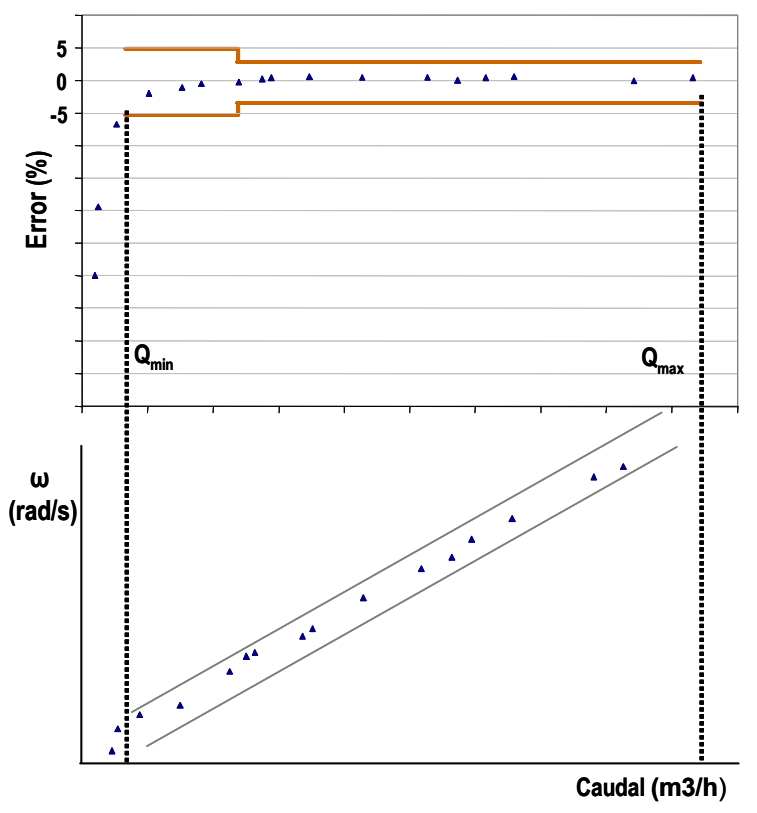

FIGURA 3.RELACIÓN LINEAL VELOCIDAD DE ROTACIÓN-CAUDAL CIRCULANTE.

A un determinado caudal, cuando el perfil de velocidades se encuentra alterado, el par motriz que actúa sobre la turbina puede diferir considerablemente de aquel que se consigue con un perfil plenamente desarrollado, afectando así, a la medición del agua. Aunque, en régimen permanente se produce siempre un equilibrio entre pares, dependiendo de cómo sea al perfil, este equilibrio se alcanzará a una velocidad de rotación u otra.

$$
M_{\text {motriz en el eje }}=M_{\text {resistente de la hélice }}
$$

La fiabilidad en la medición del instrumento se pierde cuando se desconoce cómo varía el par motriz del chorro de agua incidente con un perfil de velocidades alterado. En este caso, se debe estimar la velocidad de rotación que difiere de la obtenida con un perfil plenamente desarrollado. Como ejemplo para aclarar este fenómeno se muestra la Figura 4, donde se observan dos perfiles de velocidad, uno sin distorsión y otro alterado por algún tipo de elemento hidráulico. En la figura superior, la incidencia del flujo del agua es semejante en toda la sección de entrada a la turbina del contador Woltman. El caso contrario ocurre en la inferior, donde el par ejercido en la zona más baja de la turbina por las fuerzas impulsoras del agua es mayor, generando una variación positiva de la velocidad de rotación, mientras que en la zona superior la menor velocidad del agua puede, incluso, provocar un par negativo. 

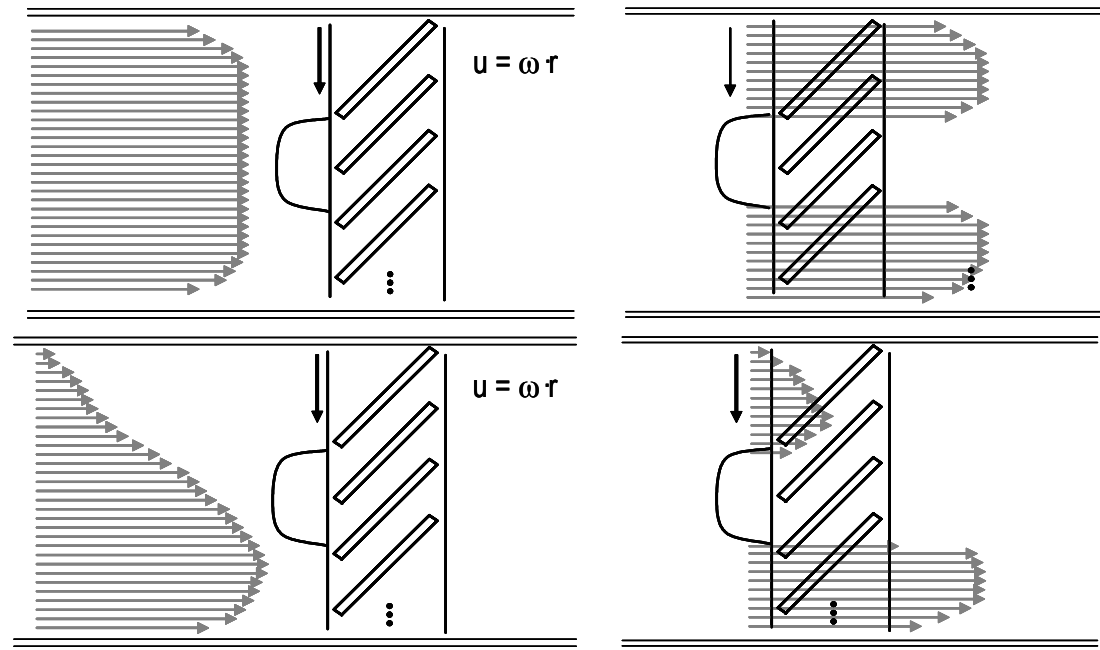

FIGURA 4. CORTE LONGITUDINAL DE UNA CONDUCCIÓN.

PERFIL PLENAMENTE DESARROLLADO Y PERFIL DISTORSIONADO.

Profundizando más en este aspecto, y tal y como proponen diversos autores, la velocidad de rotación de una turbina y los esfuerzos que se ejercen sobre ella, pueden ser calculados mediante la aplicación de la ecuación de la conservación del momento cinético con un análisis de los esfuerzos del chorro de agua incidente o mediante teoría de álabes (Wadlow, 1998). Baker (2000) demuestra que ambos enfoques son equivalentes.

Precisamente debido a la dificultad planteada para hallar la variación en la velocidad de giro de la turbina cuando los perfiles llegan alterados al contador Woltman, en la presente Tesis doctoral, se ha utilizado un procedimiento basado en la teoría de álabes para conocer la forma en que afectan estas distorsiones a la medición del instrumento y cuantificar, de manera aproximada, su error de medición.

\subsubsection{Cálculo del par motriz}

El estudio de las fuerzas ejercidas por un flujo de agua sobre la hélice de un contador Woltman requiere un análisis numérico que haga posible conocer los esfuerzos motores que se ejercen sobre el perfil hidrodinámico del instrumento que provocan su movimiento.

En primer lugar, para analizar la incidencia de los diferentes flujos de agua sobre la turbina, conviene realizar un estudio diferencial de la hélice del instrumento suponiendo un corte cilíndrico de radio $r$ y espesor $\Delta r$, considerando que se encuentra en el seno de un fluido en movimiento (Figura 5).

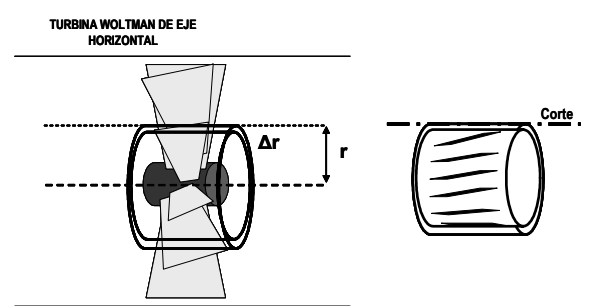

FIGURA 5.TURBINA DE UN CONTADOR WOLTMAN Y CORTE DIFERENCIAL.

Cuando se extrae este cilindro e hipotéticamente se despliega bidimensionando los álabes de la turbina se pueden considerar las fuerzas que actúan sobre este elemento en toda la sección de la tubería. 
Sobre cada uno de estos cilindros incidirá un anillo de flujo, de espesor $\Delta r$ y radio $r$, que representará los vectores de velocidad a la entrada del contador. Consecuentemente, los diversos perfiles de velocidad que abarcan toda la superficie de entrada del contador también se descompondrán en círculos concéntricos con una velocidad media en cada uno de ellos (Figura 6).

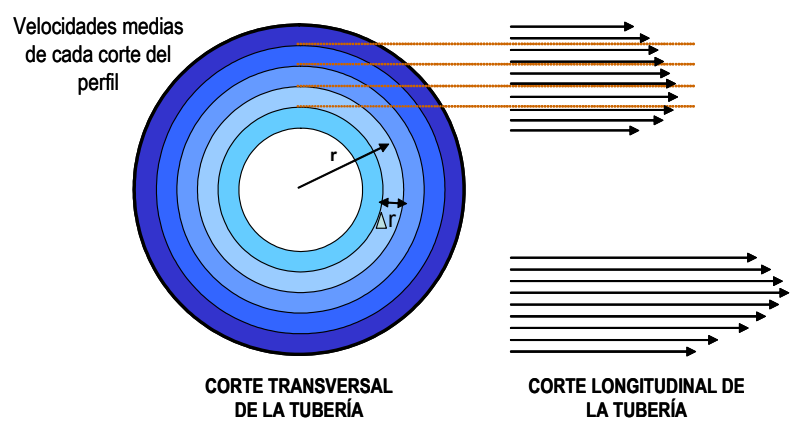

FIGURA 6.CORTES DEL PERFIL DE VELOCIDADES DE UN FLUJO DE AGUA.

De esta forma, en régimen dinámico se pueden diferenciar dos fuerzas que actúan sobre la turbina como consecuencia de la incidencia del flujo de agua. Una en la misma dirección del flujo incidente denominada esfuerzo de arrastre, $\vec{F}_{x}$, y otra, perpendicular a la misma, llamada esfuerzo de sustentación $\overrightarrow{F_{z}}$. Ambas son función de la velocidad incidente del agua respecto del álabe (Figura 7).

Estos esfuerzos son provocados por la velocidad relativa del fluido incidiendo sobre el álabe $(\vec{W})$ que depende tanto de la velocidad axial del fluido $(\vec{V})$ en el corte diferencial, como de la velocidad tangencial $(\vec{U})$ de la hélice en movimiento. Esta velocidad axial estará condicionada por el perfil de velocidades que llegue al contador, mientras que la tangencial es proporcional a la velocidad rotacional $\omega$ que depende a su vez de $\vec{v}, y$ de su radio de giro $r$.

$$
\vec{W}=\vec{V}-\vec{U}
$$

siendo $\vec{U}=\omega \cdot r$ y $\vec{V}$ la velocidad media del fluido en cada elemento diferencial.

Por tanto, la velocidad incidente variará en función del perfil de velocidades en la sección de entrada al contador y del caudal circulante en ese momento.

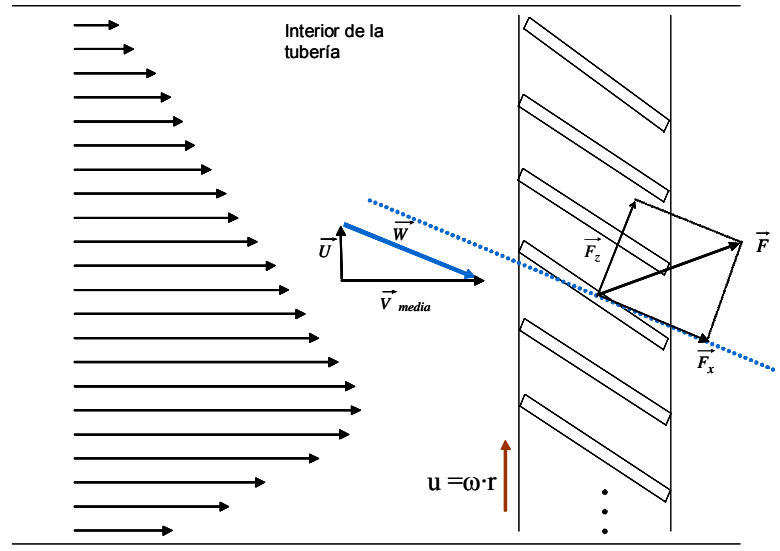

FIGURA 7.FLUJO INCIDENTE SOBRE UNA TURBINA WOLTMAN. 
En concreto, conociendo la geometría de la turbina y las velocidades descritas anteriormente es posible deducir los esfuerzos diferenciales que se ejercen sobre el álabe mediante las siguientes expresiones (Espert, 2001).

$$
\begin{aligned}
\Delta \mathrm{F}_{\mathrm{x}} & =\frac{1}{2} \rho \cdot \Delta \mathrm{A} \cdot \mathrm{W}^{2} \cdot \mathrm{C}_{\mathrm{x}} \\
\Delta \mathrm{F}_{\mathrm{z}} & =\frac{1}{2} \rho \cdot \Delta \mathrm{A} \cdot \mathrm{W}^{2} \cdot \mathrm{C}_{\mathrm{z}}
\end{aligned}
$$

siendo $\Delta A$ el diferencial de área $L_{c} \cdot \Delta r$, $\rho$ la densidad del fluido $\left(\mathrm{Kg} / \mathrm{m}^{3}\right)$, W la velocidad incidente y, $C_{x}$ y $C_{z}$ los coeficientes de arrastre y sustentación, respectivamente, función del ángulo de incidencia, del diseño de la hélice y de la viscosidad cinemática del fluido.

En la presente Tesis se consideran, para los casos estudiados, álabes planos debido a que sus características geométricas son difíciles de ajustar a cualquier perfil caracterizado. Wallis (1961) aproxima el coeficiente de sustentación para álabes planos, función de su ángulo de incidencia, a la expresión $C_{z}=2 \pi \cdot$ seni/2. El coeficiente de arrastre se simplifica a $\mathrm{C}_{\mathrm{x}} \approx 0$ considerando el fluido ideal (viscosidad cinemática nula).

Así pues, cada fragmento del perfil de velocidades tendrá una velocidad incidente y un ángulo i variable, que será el que forme dicha velocidad incidente $\vec{W}$ con la longitud transversal de la pala o cuerda del álabe $L_{c}$. A su vez, el ángulo $\alpha$ será el que forma la pala con la vertical y dependerá de la geometría del álabe que varía en función del radio de corte. De esta forma, el ángulo I será la suma de estos ángulos para cada sección diferencial (Figura 8).

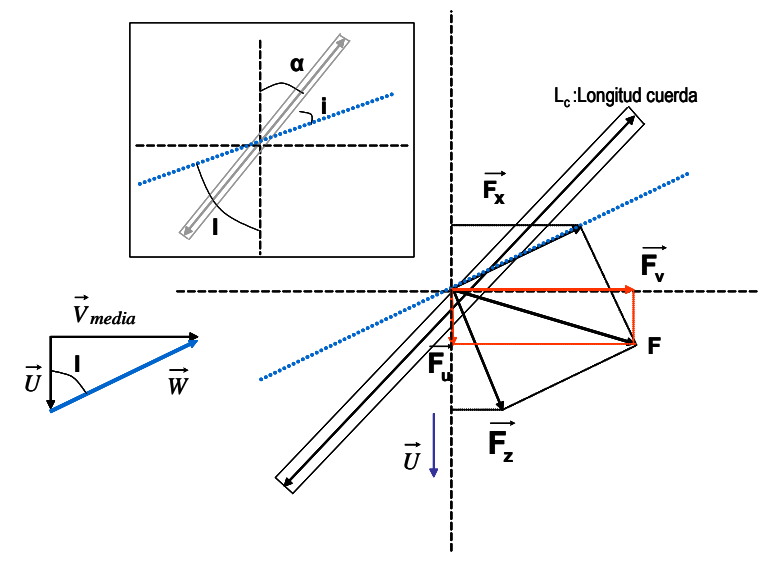

FIGURA 8. FUERZAS QUE ACTÚAN SOBRE EL ÁLABE DEL CONTADOR WOLTMAN.

Proyectando el esfuerzo resultante $\overrightarrow{\mathrm{F}}_{\text {resul tante }}$ en las direcciones del flujo de agua y del giro de la hélice se tienen los valores de $\overrightarrow{F_{v}}$ y $\overrightarrow{F_{u}}$ que corresponden al empuje axial sobre la hélice y a la fuerza motora que genera un par de giro, respectivamente.

$$
\begin{aligned}
& \Delta \mathrm{F}_{\mathrm{V}}=\frac{1}{2} \rho \cdot \Delta \mathrm{A} \cdot \mathrm{W}^{2} \cdot\left(\mathrm{C}_{\mathrm{Z}} \cos \mathrm{I}+\mathrm{C}_{\mathrm{X}} \operatorname{sen} \mathrm{l}\right) \\
& \Delta \mathrm{F}_{\mathrm{U}}=\frac{1}{2} \rho \cdot \Delta \mathrm{A} \cdot \mathrm{W}^{2} \cdot\left(\mathrm{C}_{\mathrm{Z}} \operatorname{sen} \mathrm{l}-\mathrm{C}_{\mathrm{X}} \cos \mathrm{l}\right)
\end{aligned}
$$


De esta forma, el par motriz para cada corte diferencial $r$ transmitido al eje de la hélice por el esfuerzo $\Delta \mathrm{F}_{\mathrm{u}}$ se calcula mediante la expresión:

$$
\Delta \mathrm{M}_{\text {álabe }}=\mathrm{r} \cdot \Delta \mathrm{F}_{\mathrm{u}}
$$

Consecuentemente, el par motriz total generado por el flujo de agua se obtendrá mediante el sumatorio de todos los esfuerzos motores obtenidos en cada porción de filete concéntrico de vectores de velocidad por el número de álabes de la turbina Woltman, según la expresiones 8 y 9.

$$
\begin{gathered}
M_{\text {eje }}=\sum_{i=r} \sum_{z=n^{0} \text { deálabes }}\left(\Delta \boldsymbol{F}_{u}\right)_{z} \cdot r_{i} \\
M_{\text {eje }}=\frac{1}{2} \iint \rho \cdot L_{c} \cdot W^{2} \cdot\left(C_{z} \operatorname{sen}(I)-C_{X} \cos (I)\right) \cdot r \cdot d r
\end{gathered}
$$

\subsubsection{Procedimiento de cálculo del error de medición generado por perturbaciones del flujo}

En este apartado se detalla el procedimiento numérico utilizado para estimar error de medición en contadores Woltman cuando un elemento hidráulico cercano perturba el flujo de agua.

Las fuerzas resistentes, intrínsecas al instrumento de medida son función de su geometría y diseño. Cada contador Woltman tendrá un comportamiento ante el flujo de agua diferente. Por ello, el primer paso es conocer el par resistente de la turbina a partir de la expresión (1) que iguala el par motriz en el eje con el resistente en el rango de caudales de funcionamiento en régimen estacionario y con un perfil de velocidades plenamente desarrollado.

Se parte de una velocidad de rotación $\omega_{0}$ asociada a un determinado caudal mediante la relación de desmultiplicación $\omega-Q$ característica del instrumento. El flujo de agua a dicho caudal $Q_{o}$, cuando el perfil se encuentra plenamente desarrollado, ejerce un par motriz calculado mediante el procedimiento numérico expuesto en el apartado anterior. En estas condiciones, y en régimen estacionario, este par motriz coincide con el par resistente de la hélice lo que hace posible obtener una curva que relacione el caudal con el momento resistente de la turbina (Figura 9).

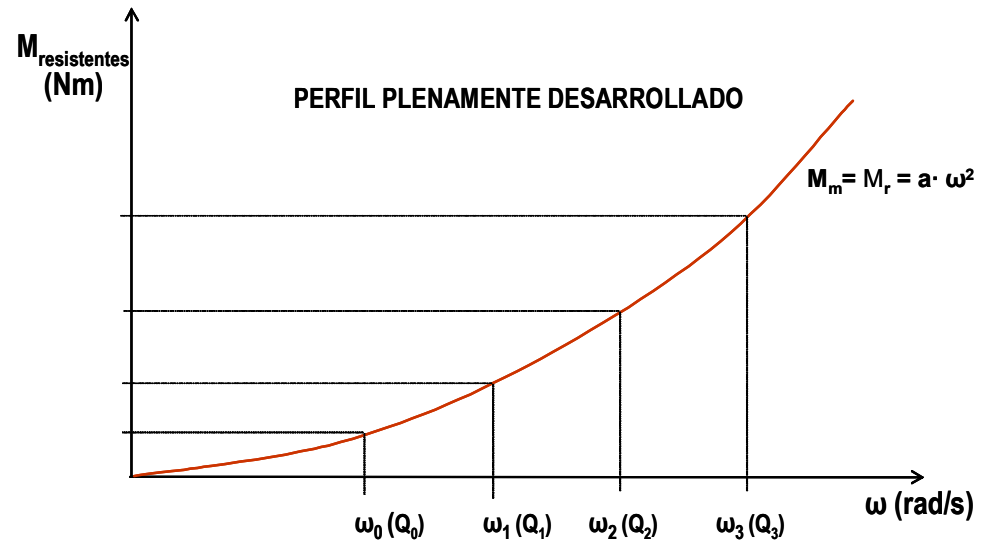

FIGURA 9. MOMENTO RESISTENTE PARA UN PERFIL PLENAMENTE DESARROLLADO. 
Cuando el flujo de agua se distorsiona por algún tipo de elemento hidráulico el momento motriz sobre la turbina varía, provocando una velocidad de rotación diferente a la que se produciría con un flujo plenamente desarrollado. Estas discrepancias son debidas a que el momento motriz provocado por un perfil distorsionado difiere del obtenido con uno plenamente desarrollado. El equilibrio de pares se rompe y se alcanza a una velocidad de rotación diferente, lo que genera errores de medición.

Esta variación en la velocidad de rotación puede estimarse mediante un procedimiento de cálculo iterativo (Figura 10). En primera instancia, se parte de una caudal $Q_{0}$ que permite deducir el par motriz mediante las ecuaciones planteadas en el apartado anterior (Figura 10). Como se ha comentado, este par motriz para un flujo distorsionado, diferirá del par resistente del instrumento hallado mediante la ecuación $M_{m}=a \cdot \omega^{2}$ para ese caudal. Comparando ambos pares se extraerá una velocidad de rotación aproximada con la que se repetirán los cálculos hasta encontrar la velocidad de rotación wo que iguale las funciones de par resistente y par motriz, y proporcione la nueva velocidad de giro de la hélice (Figura 10).

Este procedimiento se realizará para varios caudales hasta cubrir todo el rango de funcionamiento del aparato (Figura 11).

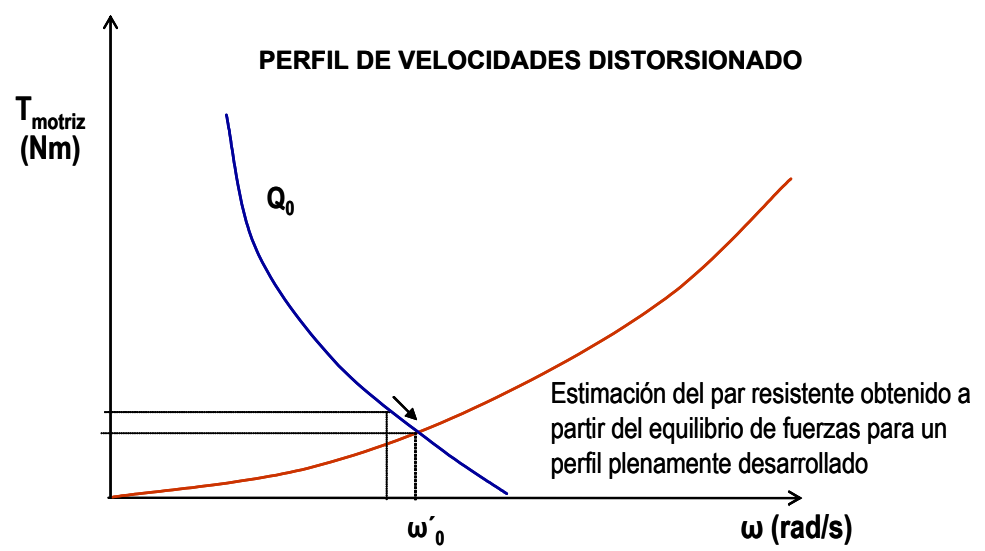

FIGURA 10. PUNTO INICIAL PARA ESTIMAR EL ERROR PRODUCIDO POR UN PERFIL DE VELOCIDADES DISTORSIONADO..

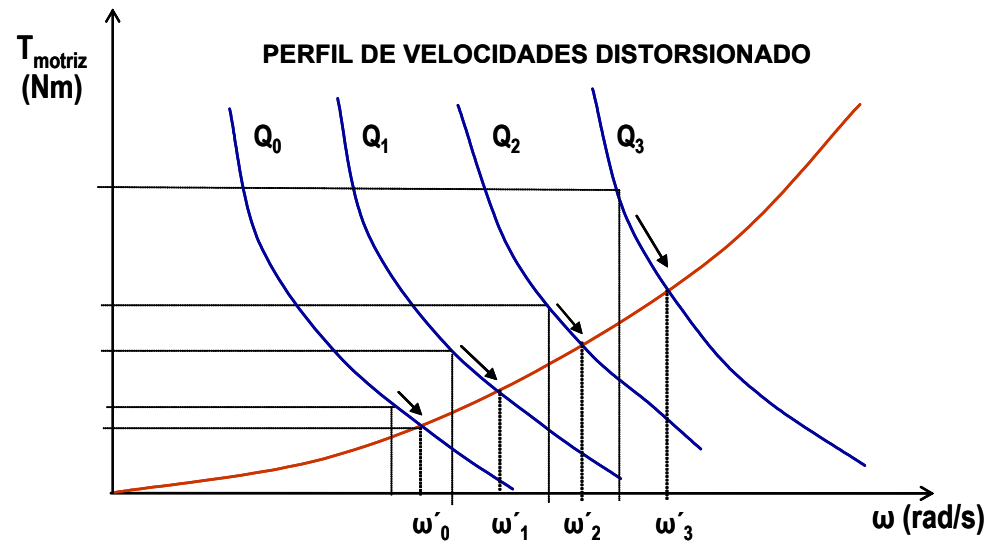

FIGURA 11. PROCEDIMIENTO ITERATIVO PARA LA ESTIMACIÓN DE $\Omega$ DISTORSIÓN.

Las velocidades de rotación estimadas para cada caudal pueden compararse con las halladas en un flujo sin distorsiones con el objetivo de conocer el error que ha producido la instalación de elementos hidráulicos aguas arriba del contador Woltman (Ecuación 10).

$$
\varepsilon_{Q}=\frac{\omega_{\text {distorsionado }}-\omega_{\text {plenamente desarrollado }}}{\omega_{\text {plenamente desarrollado }}}
$$




\subsubsection{CAUDALÍMETROS ELECTROMAGNÉtICOS}

\subsubsection{Principio de funcionamiento}

Como se explicó durante el Capítulo 2, el principio de funcionamiento de un caudalímetro electromagnético está basado en la ley enunciada por Faraday en 1832, según la cual entre los extremos de cualquier conductor que atraviese un campo electromagnético se induce una fuerza electromotriz $\mathbf{E}$ proporcional a su velocidad $\mathbf{V}$, a la longitud del mismo $\mathbf{L}$ y a la intensidad del campo magnético B que atraviesa, atendiendo a la siguiente expresión:

$$
E=K \cdot B \cdot L \cdot V
$$

En el caso de redes de agua, el fluido conductor es el agua que circula entre dos electrodos separados una longitud $L$, que generalmente se corresponde con el diámetro de la conducción. La intensidad del campo magnético $\mathrm{B}$, está sujeta a los cambios en la tensión de alimentación de la bobina y de la conductividad del fluido. La constante de proporcionalidad es proporcional a cada instrumento, y por último, la diferencia de voltaje en la señal de salida que dependerá de la velocidad media ponderada del agua que atraviesa la sección en la que están situados los electrodos.

Es decir, la fuerza electromotriz generada por el flujo de agua no es proporcional a la velocidad media real del fluido en toda la sección, sino que es fruto de una ponderación de las velocidades en la sección de medición.

Shercliff en 1962 obtuvo, con el fin de predecir el efecto de las perturbaciones del flujo de agua, una función de ponderación teórica suponiendo una intensidad de flujo magnético constante y un caudalímetro de electrodos redondos y puntuales. Esta función indica la contribución de la velocidad de cada zona de la sección entre electrodos en el cálculo del caudal circulante (Figura 12).

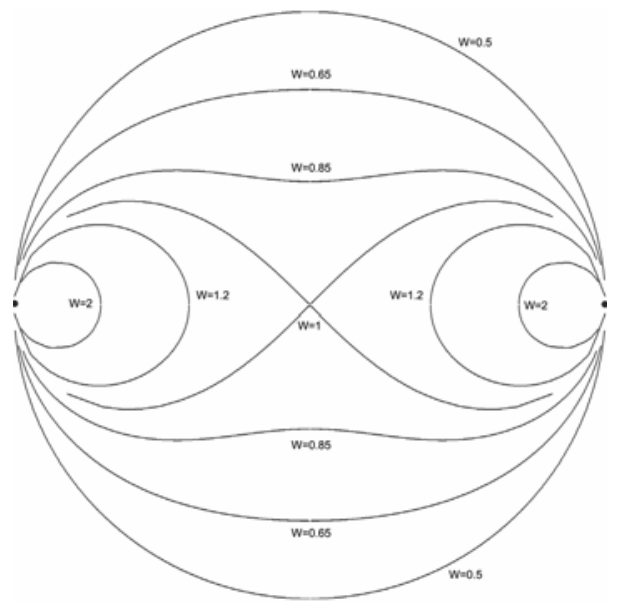

FIGURA 12. FUNCIÓN DE PONDERACIÓN DE SHERCLIFF (1962)

Es decir, a partir de esta función teórica es posible predecir la lectura de caudal proporcionada por el instrumento, independientemente de las posibles perturbaciones en el flujo, ya que se conoce la contribución de cada zona a la misma.

En este caso, la diferencia de voltaje entre los electrodos del caudalímetro, proporcional a la velocidad del fluido, podrá calcularse mediante la siguiente ecuación que incorpora la función de ponderación planteada por Shercliff o cualquier otra que pueda hallarse empíricamente. 


$$
\Delta \mathrm{U}_{\mathrm{EE}}=\iint_{\substack{\text { Secciónde } \\ \text { medición }}} \overrightarrow{\mathrm{W}}(\mathrm{r}, \theta) \times \overrightarrow{\mathrm{B}}(\theta) \times \overrightarrow{\mathrm{v}}(\mathrm{r}, \theta) \mathrm{dr} \mathrm{d} \theta
$$

El caudal circulante se calcula mediante la Ecuación 13 que en coordenadas polares, depende del radio $r$ donde se encuentre el punto en la sección de medida y del ángulo $\theta$ cuyo origen es paralelo a la dirección de la intensidad del flujo magnético, es decir, perpendicular a la cuerda entre electrodos (Baker, 2000).

$$
Q=\iint_{\substack{\text { Seccionde } \\ \text { medicion }}} \frac{a^{4}+2 a^{2} r^{2} \cos 2 \theta}{a^{2} r^{2} \cos 2 \theta+r^{4}} \cdot V_{x}(r, \theta) \cdot r \cdot d r d \theta
$$

Con el avance de esta tecnología de medición se han diseñado y probado otro tipo de materiales y construcciones para inducir un flujo magnético tal que se homogenice el peso de todos los puntos de la sección de medida. Por ejemplo, existen otras propuestas, como la realizada por Al-Rabeh y Baker (1979), donde se ensayan diferentes materiales y formas de bobinas inductoras. Los resultados proporcionan otras funciones, con coeficientes de ponderación de la señal, más cercanos a la unidad en toda la sección que la propuesta realizada por Shercliff.

En consecuencia, el diseño de nuevos caudalímetros va dirigido hacia la búsqueda de una función de ponderación cuyos coeficientes de ponderación sean más homogéneos y cercanos a la unidad en toda la sección de paso, con el fin de insensibilizar la respuesta del caudalímetro a posibles distorsiones en el perfil de velocidades.

\subsubsection{Procedimiento de cálculo del error de medida}

Al igual que los contadores Woltman, expuestos en el epígrafe anterior, la calidad de la medida de estos instrumentos también depende de las condiciones en las que han sido instalados y del perfil de velocidades entrante. El procedimiento utilizado en la presente Tesis para estimar la influencia que ejercen ciertas distorsiones sobre un caudalímetro electromagnético de electrodos redondos se basa en la función propuesta por Shercliff en 1962 y las simulaciones numéricas expuestas en el apartado 3.

Inicialmente, los perfiles de velocidad extraídos del análisis numérico están representados en coordenadas cartesianas. Estos se transforman a coordenadas polares para el cálculo de los pesos $w$ en cada punto de la sección de medición y del caudal mediante la Ecuación 13, tal y como muestra el ejemplo de la Tabla 1.

La Figura 13 muestra el mapa de vectores de velocidad en la sección de medición de la conducción que han sido sacados en cada simulación (el supuesto planteado en este caso es simétrico). Estos vectores se ponderarán según el peso atribuido a esa zona $(w)$.

TABLA 1. CÁlculo del CAUdal en Un PUNTO de LA SECCIÓN.

\begin{tabular}{rrrrrrrrrr}
\hline \multicolumn{10}{c}{ Datos Fluent 6.1} \\
\hline Punto & $\mathrm{x}$ & $\mathrm{y}$ & $\mathrm{z}$ & Velocidad axial & $\mathrm{r}$ & $\theta$ & $\mathrm{w}$ & $\mathrm{w}^{*}$ Vaxial & $\mathrm{dQ}$ \\
\hline $\mathrm{X}$ & 1,165 & 0,039 & 0,005 & 0,814 & 0,039 & 7,5 & 0,506 & 0,412 & 0,031 \\
\hline
\end{tabular}

Como resultado, la integral en toda la superficie de estos vectores de velocidad ponderados dará el caudal circulante por la conducción. 


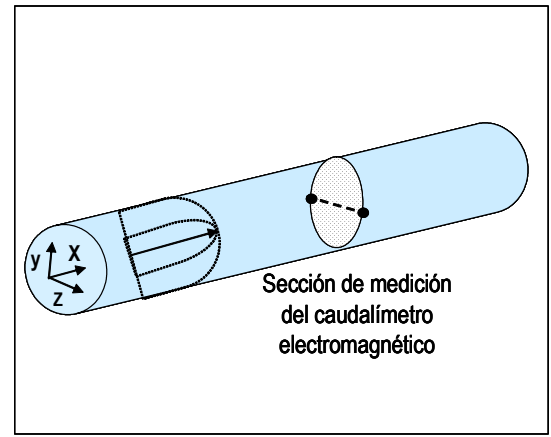

(a)

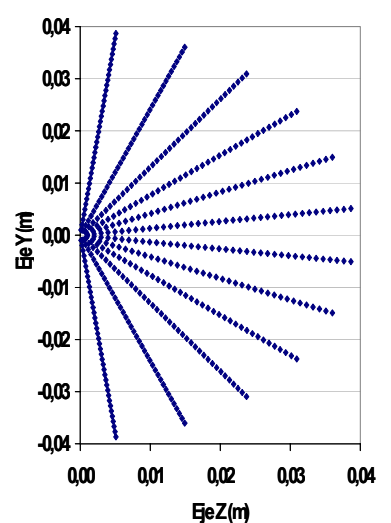

(b)

FIGURA 13. SECCIÓN DE MEDICIÓN DE UN CAUDALIMETRO ELECTROMAGNÉTICO DE ELECTRODOS REDONDOS.

De nuevo, la comparativa entre un sistema de medición en condiciones de funcionamiento normales, y otro en el que se ha instalado elementos que pueden afectar la medición del instrumento, indicará el error provocado por éstos.

\subsubsection{CAUDALÍMETROS DE ULTRASONIDOS}

\subsubsection{Principio de funcionamiento}

Como se explicó durante el Capítulo 2, este instrumento aprovecha la velocidad de propagación del sonido a través de un medio transmisor como el agua para registrar el tiempo transcurrido desde que las ondas sonoras generadas desde el punto emisor llegan al punto receptor. Este tiempo de tránsito depende del medio por el que se transmiten las ondas, de la temperatura, y sobre todo, del perfil de velocidades en la cuerda por donde discurre el sonido.

A partir del ángulo a formado entre el eje de la conducción y la línea ficticia de ondas sonoras, la longitud $L$ entre transductores y el diámetro $\mathrm{D}$ de la tubería se obtiene el tiempo de tránsito, y consecuentemente la velocidad del fluido y su caudal circulante, tal y como se demostró en el Capítulo 2 epígrafe 2.11.

$$
\begin{array}{cc}
t_{1}=\frac{L}{c+V \cdot \cos \alpha} \quad t_{2}=\frac{L}{c-V \cdot \cos \alpha} \\
t_{2}-t_{1}=\Delta t=\frac{2 \cdot L \cdot V \cdot \cos \alpha}{c^{2}-V^{2} \cdot \cos ^{2} \alpha}
\end{array}
$$

siendo c la velocidad de propagación del sonido que en el agua a una temperatura de $20^{\circ} \mathrm{C}$ es de $1482 \mathrm{~m} / \mathrm{s}$, y V la velocidad media del fluido en la conducción.

Teniendo en cuenta que la velocidad del sonido es elevada se puede despreciar el término $\mathrm{V}^{2} \cdot \cos ^{2} \alpha$ frente a c, con lo que despejando se obtiene la velocidad del fluido y posteriormente el caudal circulante.

$$
\begin{gathered}
V=\frac{\Delta t \cdot c^{2}}{2 \cdot L \cdot \cos \alpha} \\
Q=A \cdot V=\frac{\pi \cdot D^{2}}{4} \cdot \frac{\Delta t \cdot c^{2}}{2 \cdot L \cdot \cos \alpha}
\end{gathered}
$$


El funcionamiento del instrumento es adecuado cuando las propiedades físicas del fluido, como su temperatura, presión, composición, etcétera, se mantienen constantes, y el perfil de velocidades dentro de la conducción es estable. En estos casos es posible obtener de forma fiable la velocidad media de circulación del agua a partir de la diferencia en tiempo de tránsito.

Hay que tener presente que la velocidad media obtenida en el trayecto de la onda sonora no es exactamente la velocidad media del fluido en el conjunto de la sección, sino que, para perfiles desarrollados en conducciones circulares, ambas velocidades están relacionadas mediante un factor de proporcionalidad $k$ propuesto por Nikuradse (Ecuación 18). Esta diferencia entre la velocidad media en la sección y la velocidad media en la cuerda diametral, cuando el instrumento no se calibra, puede llegar a dar errores de medición del caudal, incluso sin distorsión alguna en el flujo, de hasta el 3\%, como apunta Baker ( 2000).

$$
\bar{V}=k \cdot V \quad \text { donde } \quad K=\frac{1}{1,125-0,011 \cdot \log R e}
$$

Una mejora, como proponen otros autores, es la medición en varios planos y/o en múltiples trayectorias (multiple-path) con el fin de disminuir la dependencia de la medida respecto al perfil de velocidades. Baker y Thompsom (1975) mostraron el efecto sobre la medición de planos a diferentes distancias del eje central de la conducción. Así, demostraron que las trayectorias a 0,52R del eje de la conducción, con un flujo turbulento, mejoraban las mediciones de caudal para un amplio rango de números de Reynolds.

Sin embargo, cuando el flujo de agua se distorsiona al pasar a través de elementos hidráulicos dispuestos en la red, la velocidad media del fluido en la cuerda no mantiene una relación constante y conocida con la velocidad media real del flujo en la conducción. La medida de caudal, en estas situaciones, puede verse significativamente afectada.

Haciendo uso del principio de funcionamiento de estos aparatos de medida, la presente Tesis doctoral como en el caso de los anteriores instrumentos, estima el error que puede provocar la instalación cercana de elementos hidráulicos, como válvulas y codos, mediante el análisis numérico que modela el comportamiento del fluido tras su paso por elementos a diferentes distancias del instrumento.

\subsubsection{Procedimiento de cálculo del error de medida}

Los supuestos estudiados en la presente Tesis son dos. El primero aborda la influencia en la medición de un caudalímetro con una sola cuerda, situada en el plano diametral. El segundo supuesto plantea la medición en dos planos a una distancia $0,52 R$ del plano anterior (Figura 14).
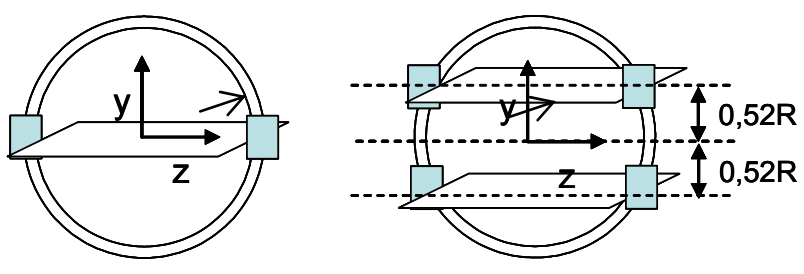

FIGURA 14. CUERDAS DE MEDICIÓN DEL CAUDALÍMETRO DE ULTRASONIDOS POR TIEMPO DE TRÁNSITO.

UNO Y DOS PLANOS DE MEDICIÓN.

De esta forma, la descomposición de velocidades obtenidas mediante el programa Fluent 6.1 en la línea que une ambos transductores se proyecta sobre la cuerda diametral de medición (Figura 15). Así, con estas velocidades discretizadas en 
aproximadamente 100 puntos a lo largo de la cuerda de medición, es posible calcular la variación producida en la velocidad media del fluido y en el tiempo de tránsito entre transductores con un perfil alterado.

Luego, mediante un sencillo cambio de sistema de coordenadas, los vectores de velocidad conseguidos durante las simulaciones numéricas con diferentes tipologías de la instalación servirán para calcular, mediante las ecuaciones descritas anteriormente, el caudal estimado por este aparato de medida, y el error de medición que provocan dichas alteraciones del flujo de agua.

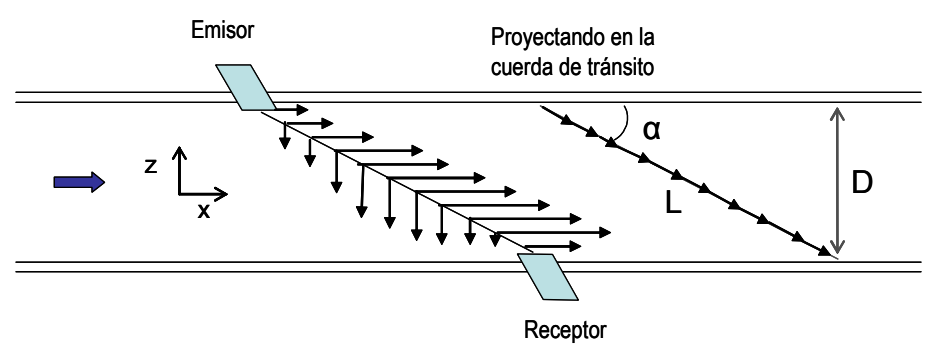

FIGURA 15. PROYECCIÓN DEL PERFIL DE VELOCIDADES SOBRE LA CUERDA DIAMETRAL.

\subsection{ANÁLISIS NUMÉRICO DEL COMPORTAMIENTO DEL FLUJO}

El creciente interés por el estudio en profundidad de los flujos de agua y fenómenos de transferencia de calor junto con la revolución de las calculadoras y ordenadores personales favoreció la aparición de las técnicas de Computacional Fluid Dynamics (CFD). Desde los años 60 la industria aeroespacial ha integrado estas técnicas en el diseño y producción de aviones y turbinas.

Recientemente, el uso de CFD como herramienta para el diseño de elementos hidráulicos y para el análisis del comportamiento del flujo dentro de una tubería se está haciendo cada vez más frecuente. Conjuntamente, la posibilidad de combinar el trabajo experimental con la modelización numérica del fluido en movimiento enriquece su estudio y mejora la fiabilidad de los resultados.

Vaughan, Johnston y Edge (1992) y, Lee y Wellford (1997) combinaron el estudio experimental y el teórico para la modelización de diversos tipos de válvulas ensayadas previamente en laboratorio obteniendo predicciones concordes con los ensayos en todo su rango de funcionamiento. Igualmente, Huang y Kim (1996), modelizaron numéricamente el flujo a través de una válvula de mariposa contrastando sus resultados empíricamente. Trabajos recientes de Davis y Stewart (2002) predicen el comportamiento de una válvula de globo analizando el coeficiente hidráulico de la válvula $C_{v}$, parámetro fundamental para su diseño, tanto de forma experimental como numérica.

Este conjunto de técnicas, también llamadas en castellano técnicas computacionales para la resolución de problemas de dinámica de fluidos, están definidas según Versteeg y Malalasekera (1995) como, el análisis de problemas de dinámica de fluidos y de transferencia de calor, o incluso, de fenómenos asociados con reacciones químicas por medio de simulaciones por ordenador.

La presente Tesis doctoral, utiliza esta técnica simplemente como herramienta para obtener perfiles de velocidad en diferentes puntos de la sección con el fin de conocer de qué forma se altera el flujo dentro de una tubería cuando se instalan accesorios hidráulicos. Las simulaciones se han realizado con la ayuda del programa de modelación de fluidos Fluent 6.1. Esta herramienta de trabajo, como se ha comentado, permite de forma bastante precisa y considerando las características del flujo que discurre por la tubería, modelizar su comportamiento. Para ello, inicialmente se deben integrar en cada fase del procedimiento los parámetros propios que describen cada situación. 
La primera fase será de preprocesado. En ella principalmente se define en detalle la geometría en 3D que se desea modelar y se realiza el mallado del dominio computacional. A su vez, se establecen las propiedades del fluido y las condiciones de contorno adoptadas para cada uno de los casos. En este trabajo se utiliza el interfaz gráfico GAMBIT para caracterizar geométricamente los ejemplos analizados.

La precisión en los resultados del análisis CFD dependerá del número de celdas de la malla creada. En general, con un mallado más fino se obtienen resultados más próximos a los ensayos experimentales. El mallado óptimo, como se cita en Versteeg y Malalasekera (1995), es generalmente no uniforme, lo que significa que será más fino en las zonas donde existen grandes variaciones de velocidad o presión, cuidando siempre en el gasto de memoria computacional y en el tiempo requerido para el cálculo.

En este trabajo se ha considerado en todos los casos una tubería con las características similares a las dispuestas en el laboratorio, y los elementos hidráulicos utilizados durante los ensayos descritos en el capítulo anterior. Estos elementos hidráulicos, empleados como ejemplo en la modelización numérica, son una válvula de compuerta y una de mariposa con diferentes aperturas y distancias al instrumento de medida, de DN 80 , igual que la conducción.

Los casos estudiados son fundamentalmente tres, un primer caso que se definirá como de referencia en el que, únicamente, se supondrá el instrumento de medición con suficientes tramos rectos aguas arriba y abajo del mismo. Abordar cada una de las tecnologías presentadas requiere tratamientos diferentes. En la modelización de un contador Woltman, el caso de referencia se simplifica suponiendo la existencia de un pivote central, semejante al que presenta el modelo comercial ensayado, que ocupa gran parte de la sección, y los estabilizadores de flujo adheridos a él, tal y como se muestra en la Figura 16. Acometer el análisis de elementos móviles requeriría un modelo matemático complejo que podría abarcar una tesis completa y una capacidad computacional muy superior por lo que no se ha incluido su modelización.

De este modo, durante el análisis numérico no ha incorporado la hélice del contador en movimiento, si no que simplemente se ha simulado el flujo de agua con los elementos de la fotografía.

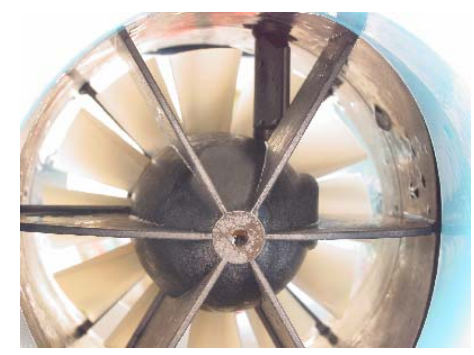

FigURA 16. DETALLE DE LA PARTE INTERNA DEL CONTADOR WOLTMAN.

Cuando la tecnología de medición estudiada es un caudalímetro electromagnético o uno de ultrasonidos el modelo de referencia considerado será una tubería sin ningún tipo de elemento hidráulico que provoque alteración del flujo de agua, ya que ambos instrumentos tienen un interior hueco que no interfiere en el flujo de agua dentro del dominio. Estos casos de referencia servirán para contrastar los perfiles obtenidos con un flujo plenamente desarrollado con los casos en los que el flujo se distorsiona por una válvula en diferentes condiciones de apertura.

El segundo caso comprendería la modelización de una válvula de compuerta junto a cada una de las tecnologías de medición. Para el contador Woltman, el modelo se ajusta con ambos elementos hidráulicos, es decir la válvula y el pivote citado, a diferentes distancias entre ellos y grados de apertura. La influencia de los elementos hidráulicos sobre el caudalímetro electromagnético y el de ultrasonidos se evaluará extrayendo perfiles de velocidad alterados a diferentes distancias del elemento perturbador.

Por último, se plantea el flujo distorsionado por una válvula de mariposa junto al medidor en diferentes condiciones de funcionamiento. 
Una vez dibujada cada configuración, se continua con el mallado donde se discretizan los dominios descritos en volúmenes de control o celdas asimétricas de $1 \mathrm{~mm}$. Posteriormente, en todos los casos se llevan a cabo refinamientos de la malla con el fin de optimizar los cálculos. Este refinado se realiza por la técnica Hanging Node, que añade un nuevo nudo a la arista formada por dos vértices, de forma que las celdas marcadas se subdividen aproximadamente en el doble del número de aristas de la celda. En la Figura 17 puede apreciarse el mallado no uniforme y el doble refinado en las zonas críticas con mayor variación de velocidad de la válvula de compuerta junto al pivote central del contador Woltman de eje horizontal.

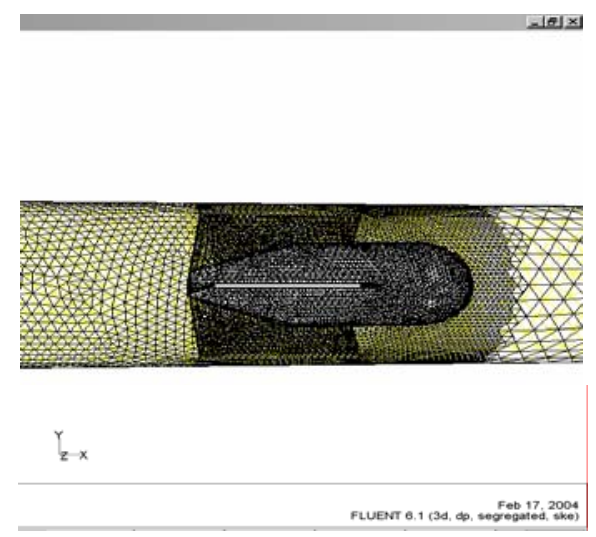

FIGURA 17. MALLADO NO UNIFORME Y DOBLE REFINADO EN LAS ZONAS CRITICAS.

Una vez mallado y refinado el dominio deben establecerse las condiciones de contorno adecuadas para el cálculo numérico. En general, en los ejemplos con los que se ha trabajado, interesa conocer el comportamiento del fluido en todo el rango de caudales del contador. Consecuentemente se ha fijado una condición de contorno variable que corresponde a la velocidad de entrada a la tubería, asignando velocidades de $1,2,3,4,6 \mathrm{~m} / \mathrm{s}$, a cada una de las tipologías simuladas. $Y$ otras condiciones de contorno fijas como la presión a la salida ( 3 bar), la pared de simetría y la condición pared, que corresponde a todas las caras internas y externas de la conducción sin considerar la entrada, la salida del flujo y la cara de simetría (Tabla 2).

En las simulaciones donde la instalación es simétrica, como en el caso del supuesto de referencia o en el de la válvula de compuerta, se agiliza el cálculo efectuando un corte en el plano de simetría, quedando solo la mitad de la tubería y considerándolo como condición de contorno de simetría.

TABLA 2. RESUMEN DE LAS SIMULACIONES Y CONDICIONES DE CONTORNO ESTABLECIDAS EN CADA UNA.

\begin{tabular}{|c|c|c|c|c|c|c|}
\hline & & CASOS & & & & \\
\hline & Referencia & \multicolumn{3}{|c|}{ Válvula de compuerta } & \multicolumn{2}{|c|}{ Válvula de mariposa } \\
\hline Grado de apertura & - & $75 \%$ cerrada & $50 \%$ cerrada & $25 \%$ cerrada & Abierta & $30^{\circ}$ cerrada \\
\hline \multirow{2}{*}{ Distancia } & - & OD & OD & OD & - & - \\
\hline & & $3 \mathrm{D}$ & $3 \mathrm{D}$ & $3 \mathrm{D}$ & $3 \mathrm{D}$ & $3 \mathrm{D}$ \\
\hline \multicolumn{7}{|c|}{ CONDICIONES DE CONTORNO } \\
\hline Velocidad a la entrada $(\mathrm{m} / \mathrm{s})$ & $1,2,3,4,6$ & $1,2,3,4,6$ & $1,2,3,4,6$ & $1,2,3,4,6$ & $1,2,3,4,6$ & $1,2,3,4,6$ \\
\hline Presión a la salida (bar) & 3 & 3 & 3 & 3 & 3 & 3 \\
\hline Pared $\mathrm{k}(\mathrm{mm})$ & 0,1 & 0,1 & 0,1 & 0,1 & 0,1 & 0,1 \\
\hline Pared simetría & si & si & si & si & no & no \\
\hline
\end{tabular}

La segunda fase es la de ejecución del solver o de la simulación numérica. Para ello, es importante seleccionar el método de cálculo adecuado a las características hidrodinámicas de los ejemplos planteados. Teniendo en cuenta que se trata de 
un estudio en 3D, se elige el método de los volúmenes finitos basado en diferencias finitas. Éste es un método numérico para la resolución de ecuaciones diferenciales que consiste en dividir el dominio en volúmenes de control o celdas. Estas ecuaciones diferenciales se aproximan utilizando la técnica de diferencias finitas, y posteriormente, mediante algoritmos matemáticos de cálculo iterativo tipo SIMPLE (Semi-Implicit Method for Pressure-Linked Equations) se establece una unión coherente entre presiones y velocidades del fluido.

Además, este procedimiento de cálculo aporta ciertas ventajas, como la discretización por volúmenes que resuelve mejor problemas de mecánica de fluidos que otras técnicas como la de elementos finitos (Streeter, 1998). Otra ventaja es que las principales ecuaciones que describen el comportamiento de los fluidos, como la ecuación de continuidad, la del momento y la ecuación de la energía, quedan correctamente aproximadas mediante esta técnica matemática. Por último, este método de resolución numérica es el que utilizan la mayoría de los programas comerciales, como es el caso de Fluent 6.1, para la simulación de flujos en 3D.

A su vez, este programa de cálculo, ofrece la posibilidad de estudiar diferentes regímenes de flujo, tanto laminar como turbulento. En el caso particular de los ejemplos simulados en la Tesis, el rango de velocidades y caudales de funcionamiento del contador y el calibre simulado aseguran un flujo turbulento $(R e>2000)$. Consecuentemente se elige uno de los modelos para análisis de flujo turbulento.

Los modelos de flujo turbulento más comunes son los denominados clásicos o RANS (Reynolds Average Navier-Stokes) que desarrollan las fórmulas de Navier-Stokes, básicas en la mecánica de fluidos. Entre los más importantes se encuentra el Standard k- $\varepsilon$ Turbulent Model elegido para este estudio. Este modelo, desarrollado por Launder et al. (1974), plantea modelar la viscosidad turbulenta $\left(\mu_{t}\right)$ en dos ecuaciones. Sus principales ventajas son su robustez, las adecuadas aproximaciones numéricas que hace de los flujos turbulentos y el ahorro de tiempo de cálculo. Existen otros dos modelos más depurados que el citado, $R N G$ k- $\varepsilon$ model y Realizable $k-\varepsilon$ model, pero en estos casos no se ha encontrado diferencias significativas en sus predicciones frente al código utilizado. Asimismo, requieren mayor capacidad de memoria computacional.

Como modo de verificación de los cálculos realizados se contrastan los resultados numéricos obtenidos durante el análisis CFD con resultados experimentales. Las variables hidráulicas obtenidas en los ensayos fueron la pérdida de carga sufrida a través de los accesorios descritos, la variable caudal obtenida y el propio error de medición. Tras comprobar la coherencia de estos resultados numéricos puede darse por válido el modelo turbulento calculado.

Una vez conseguidos los resultados, el programa Fluent 6.1 es muy versátil y ofrece la posibilidad de visualizar los mismos en diferentes planos y líneas de corte, representar la variable velocidad, o la presión utilizando vectores, superficies de isovariable, líneas de corte, etcétera.

Generalmente, para apreciar cómo llega el flujo de agua al contador la forma sistemática utilizada en la presente Tesis doctoral, ha sido extraer planos y líneas con las velocidades axiales en las zonas de interés. Así pues, en el caso del contador Woltman se realizan cortes en la zona de entrada del flujo de agua a los álabes. El perfil de velocidades interesante en un caudalímetro electromagnético es la sección entre electrodos, paralela a la intensidad del flujo magnético. Por otra parte, el caudalímetro de ultrasonidos basa su medición en la relación tiempo-velocidad obtenida en la cuerda ficticia que une ambos transductores. De esta forma, dependiendo de la tecnología de medición estudiada convendrá extraer los perfiles de velocidad axial en planos o líneas de corte diferentes.

A continuación, se muestran algunos de los resultados más interesantes obtenidos de las simulaciones que ayudan a entender el comportamiento del flujo y a apreciar la influencia de los accesorios instalados en el flujo de agua.

En las Figura 18 y Figura 19 se muestra el flujo distorsionado por una válvula de compuerta prácticamente cerrada (75\%) dispuesta a OD aguas a arriba del contador Woltman justo en la sección de entrada a los álabes del contador.

Las condiciones de contorno establecidas son diferentes en cada una de las figuras, por lo que se observan mayores velocidades en la Figura 18 donde se simula un caudal aproximado de $100 \mathrm{~m} 3 / \mathrm{h}$, que en el corte longitudinal mostrado en la figura posterior. En la primera, se aprecia cómo en la sección de entrada a la hélice del contador el flujo se encuentra muy 
distorsionado, teniendo velocidades muy elevadas en su parte inferior y más moderadas en la superior. Esto es debido a que la distancia entre el elemento hidráulico y el instrumento de medida es demasiado corta para que se logre regularizar el perfil, y se homogenicen las fuerzas incidentes que impactan sobre la hélice.

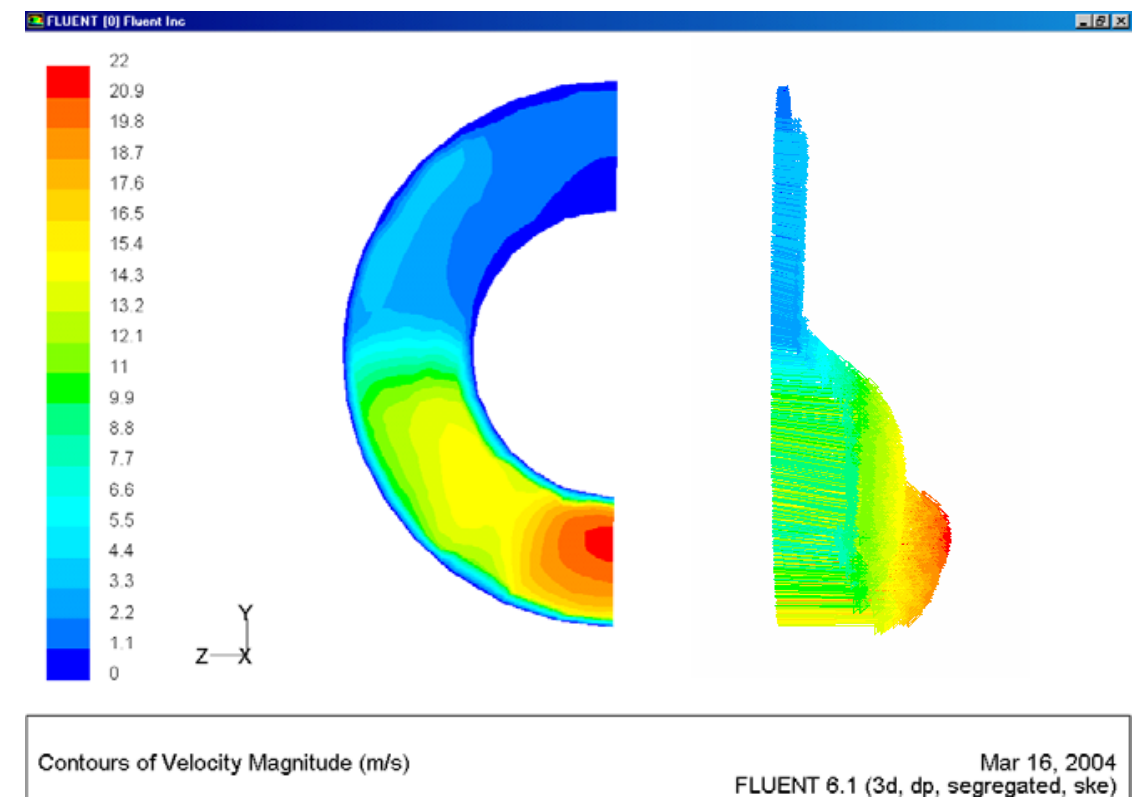

FIGURA 18. CORTE TRANSVERSAL DE LA TUBERÍA MODELIZADA EN EL CASO DE UNA DISTORSIÓN CAUSADA POR UNA VÁLVULA DE COMPUERTA 75\% CERRADA (OD ENTRE ELEMENTOS).

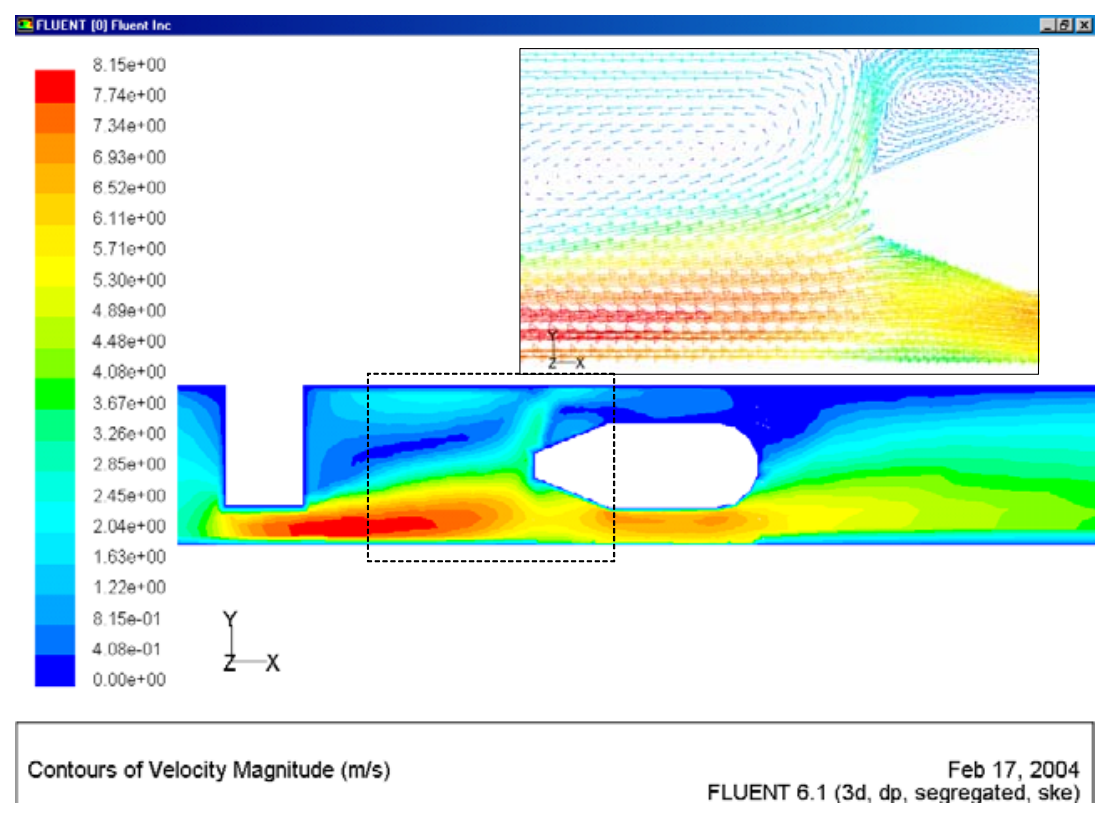

FIGURA 19. CORTE LONGITUDINAL DE LA TUBERÍA EN EL CASO DE UNA DISTORSIÓN CAUSADA POR UNA VÁLVULA DE COMPUERTA 75\% CERRADA (OD ENTRE ELEMENTOS). 
Las distorsiones en el flujo de agua se originan en la zona de la válvula de compuerta, como se aprecia en el corte longitudinal de la Figura 19, donde en esos puntos para un caudal estabilizado de aproximadamente de $34 \mathrm{~m}^{3} / \mathrm{h}$ y una velocidad promedio en toda la sección de $2 \mathrm{~m} / \mathrm{s}$, se llegan a alcanzar velocidades del fluido de $8,15 \mathrm{~m} / \mathrm{s}$. Asimismo, en esta misma figura, es posible observar flujos inversos y torbellinos de agua (ver detalle) e incluso estancamientos del flujo en la zona superior del pivote.

Cuando se comparan los resultados en simulaciones efectuadas con diferentes grados de apertura y distancias entre el elemento perturbador y el instrumento de medida, se extraen resultados interesantes. La Figura 20 muestra diversos cortes transversales de la tubería realizados todos en el punto de entrada del flujo a los álabes, estableciendo como hipótesis, diversas distancias en tramos rectos y condiciones de apertura de la válvula.

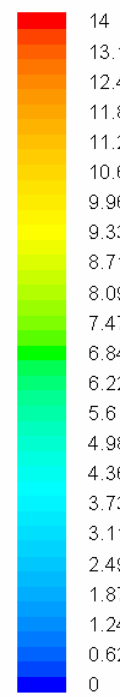

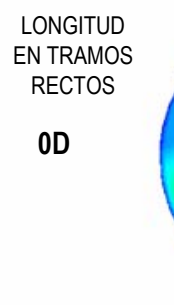

GRADO DE APERTURA

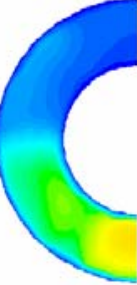

$75 \%$ cerrada

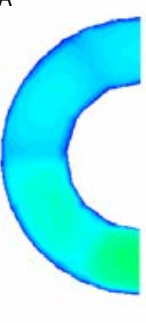

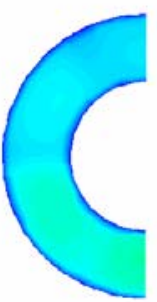

$50 \%$ cerrada

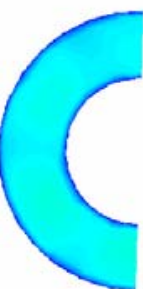

$25 \%$ cerrada

FIgURA 20. CORTES TRANSVERSALES DE LA TUBERÍA EN EL PUNTO DE ENTRADA A LOS ÁLABES DEL WOLTMAN INSTALANDO UNA VÁLVULA DE COMPUERTA A DIFERENTES DISTANCIAS Y CON GRADOS DE APERTURA. Q SIMULADO $=50 \mathrm{M}^{3} / \mathrm{H}$

Se advierte, como es lógico pensar, que a medida que la distancia entre elementos es mayor el flujo de agua llega al contador más uniforme. Sin embargo, esta estabilización del flujo está condicionada por el grado de distorsión ocasionado. Por ejemplo, cuando el grado de apertura de la válvula de compuerta es del $50 \%$ y la distancia entre elementos es nula, se observan velocidades altas en la zona inferior del pivote del orden de 5 a $5,5 \mathrm{~m} / \mathrm{s}$ para un caudal aproximadamente de 50 $\mathrm{m}^{3} / \mathrm{h}$ (velocidad media de $3,7 \mathrm{~m} / \mathrm{s}$ ), pero se comprueba que aún son mayores (de 6 a $7 \mathrm{~m} / \mathrm{s}$ ) cuando se encuentra prácticamente cerrada ( $75 \%$ cerrada) aún manteniendo una distancia recta de 3D entre elementos.

La Figura 21 visualiza en conjunto las distorsiones del flujo originadas por una válvula de compuerta con grados de apertura diferentes, simuladas para el caso de un contador Woltman de eje horizontal, comparándolas con el caso de referencia para un mismo caudal (de aproximadamente $68 \mathrm{~m}^{3} / \mathrm{h}$ ). Naturalmente, a medida que el grado de interferencia es menor el flujo es más estable y el perfil de velocidades del agua llega al contador más equilibrado.

Esto significa que ambos parámetros deben tenerse en cuenta, evaluar la distorsión del flujo que origina cada posible elemento perturbador y estudiar la distancia requerida hasta que éste vuelve a estabilizarse de tal modo que no se vea afectada la medición del instrumento. 


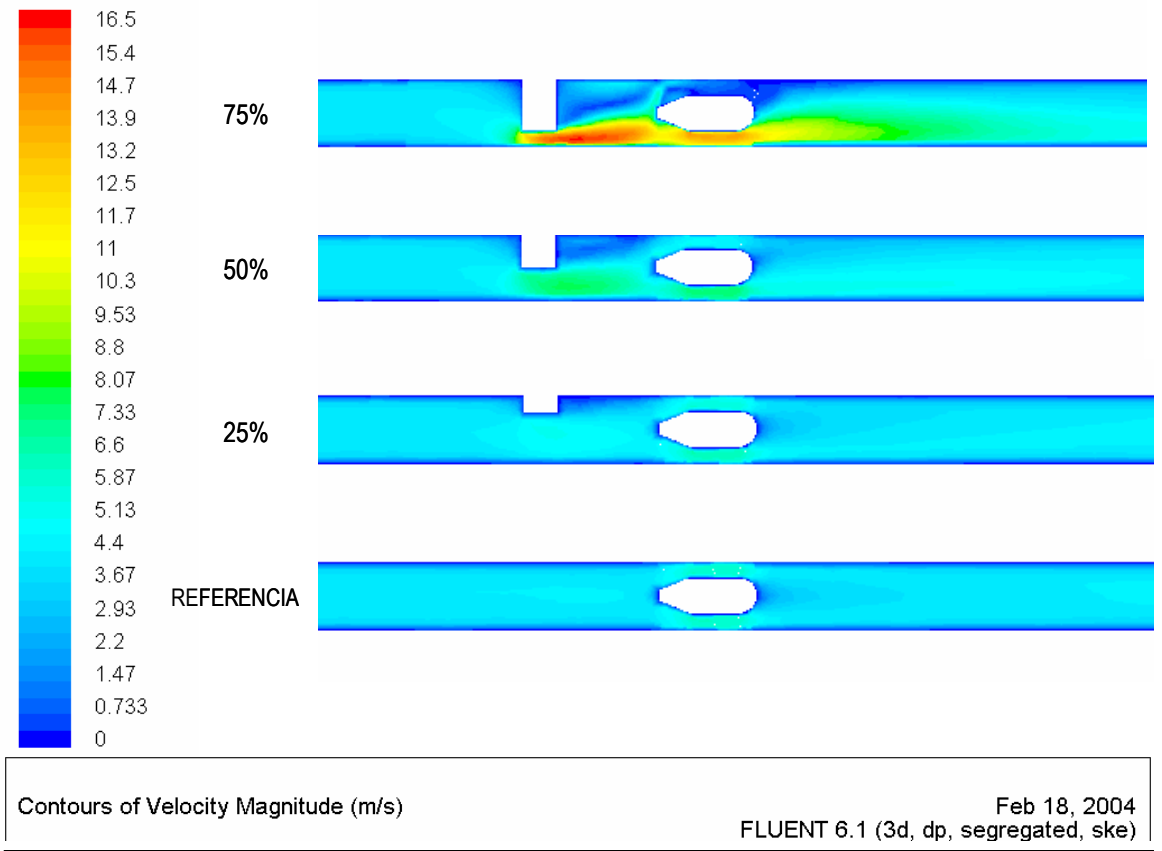

FIGURA 21. CORTES LONGITUDINALES DE LA TUBERÍA INSTALANDO UN CONTADOR WOLTMAN Y UNA VÁLVULA DE COMPUERTA CON GRADOS DE APERTURA.

Los resultados de las simulaciones efectuadas con una válvula de mariposa abierta y $30^{\circ}$ cerrada reflejan una distorsión del fluido diferente a la provocada por la válvula de compuerta. Normalamente, las válvulas de mariposa constan de una lenteja de sección igual a la de la tubería con la que cortan el flujo. Esta lenteja tiene un eje de giro vertical, con lo que el cierre de la válvula produce un cambio de dirección de las partículas del fluido desviándolas hacia trayectorias perpendiculares a este eje de giro. Cuando la válvula se encuentra completamente abierta, básicamente, reduce la sección de paso del agua, incrementando su velocidad. La Figura 22 ilustra este último caso, mostrando cortes longitudinales en dos planos.

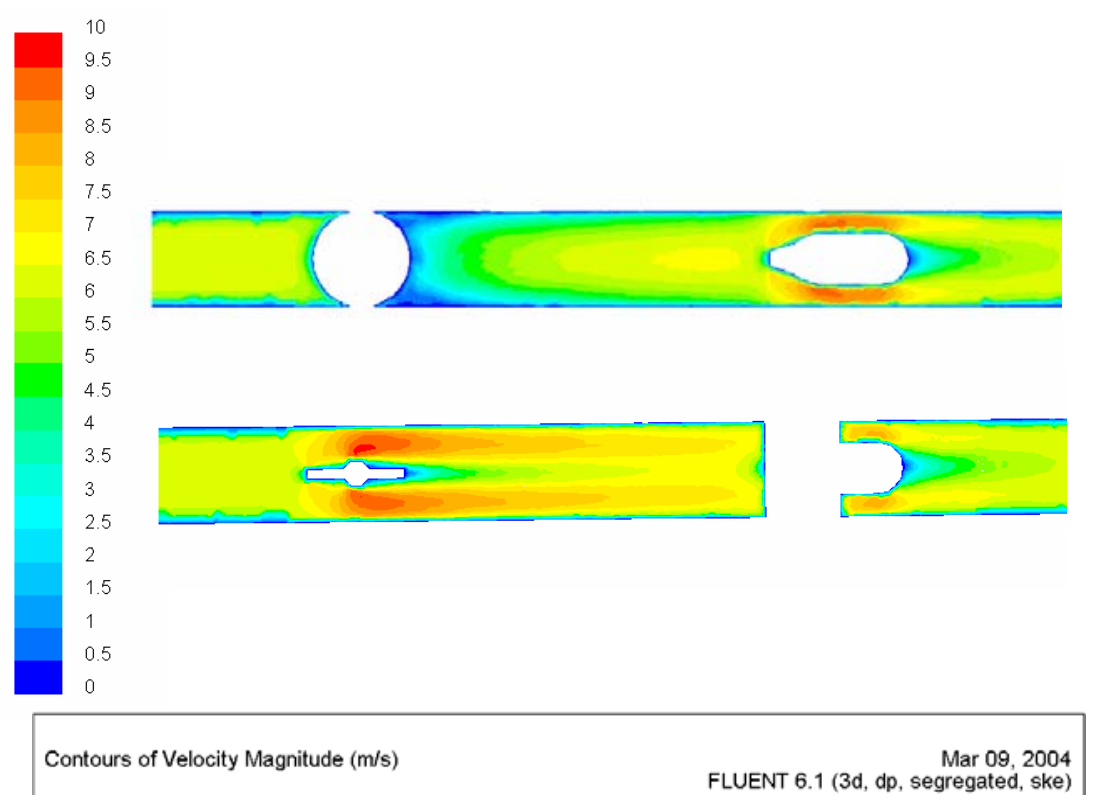

FIGURA 22. CORTE LONGITUDINAL DE LA TUBERÍA INSTALANDO UN CONTADOR WOLTMAN Y UNA VÁLVULA DE MARIPOSA ABIERTA. 


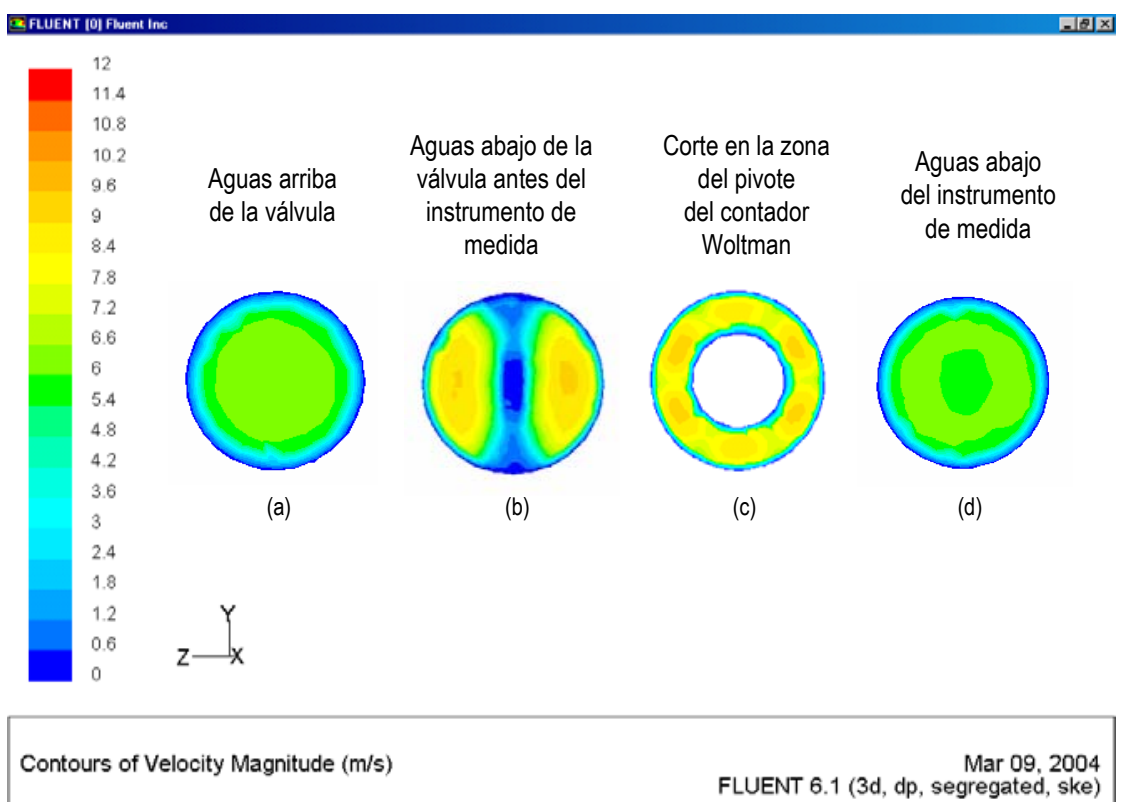

FIGURA 23. CORTES TRANSVERSALES A VARIAS DISTANCIAS CON UN FLUJO DISTORSIONADO POR UNA VÁLVULA DE MARIPOSA ABIERTA SITUADA A 3D.

En la Figura 23 se presentan cortes transversales de la tubería a varias distancias, donde se aprecia de qué forma varía la velocidad del agua cuando el flujo pasa a través de este elemento perturbador estando completamente abierto. La variación de velocidades, bastante homogénea a uno y otro lado de la conducción, produce un flujo incidente equilibrado a la entrada del contador (caso c).

Cuando la válvula cierra $30^{\circ}$, no aparece una distribución simétrica de las velocidades respecto a un plano vertical. Como se comprueba, la perturbación en este caso es muy diferente a la que ocasiona una válvula de compuerta. En el detalle mostrado en la Figura 24 se aprecia la lenteja de la válvula de mariposa ligeramente cerrada, con perturbaciones del flujo asimétricas a uno y otro lado de la conducción.

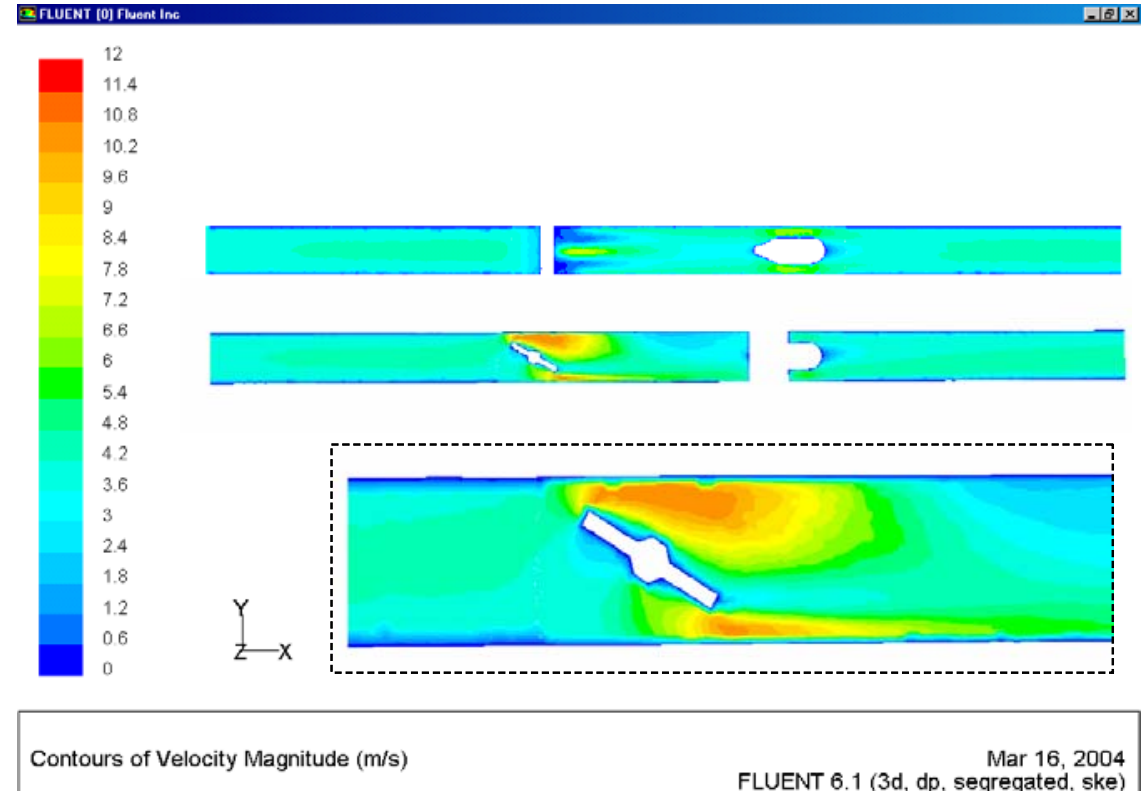

FIGURA 24. CORTES LONGITUDINALES DE LA CONDUCCIÓN CON UNA VÁLVULA DE MARIPOSA $30^{\circ}$ CERRADA. 
La Figura 25 ilustra cortes transversales de la tubería cuando el flujo está distorsionado por una válvula de mariposa $30^{\circ}$ cerrada. Se aprecia la evolución sufrida en el perfil de velocidades desde antes de la válvula hasta el punto de medición, donde la magnitud de las velocidades es bastante homogénea en toda la sección.

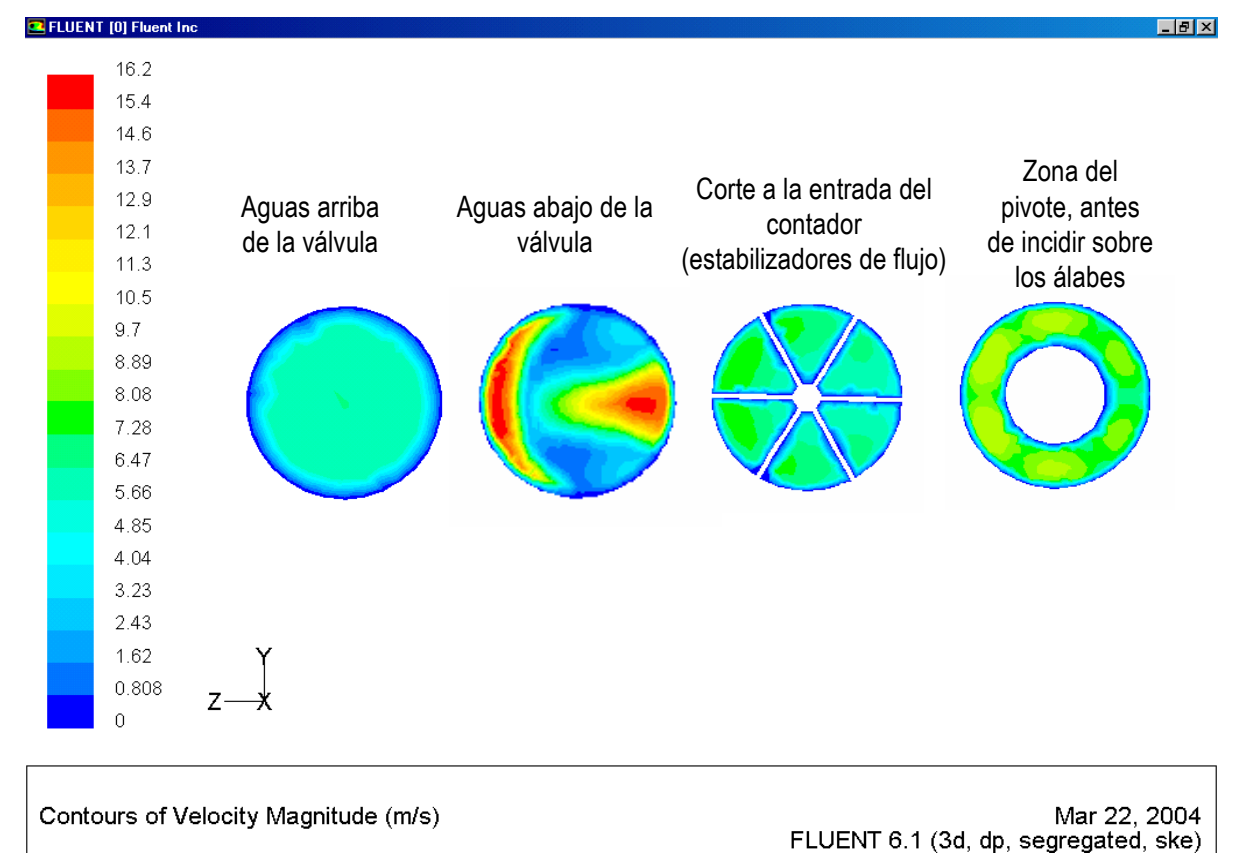

FIGURA 25. CORTES TRANSVERSALES A VARIAS DISTANCIAS CON UN FLUJO ALTERADO POR UNA VÁLVULA DE MARIPOSA 30 ABIERTA SITUADA A 3D.

De la misma forma es posible analizar el perfil de velocidades en la sección entre los electrodos de un caudalímetro electromagnético $o$ en la cuerda que une los transductores de un caudalímetro de ultrasonidos de tiempo de tránsito. En estos instrumentos de medición, como se ha comentado, no existe ningún elemento interno que interfiera en el flujo, por lo que sólo éste se perturba por aquellos elementos instalados aguas arriba del punto de medición.

Cuando se analiza la propia sección de medición del instrumento es posible visualizar de qué forma se distribuyen las velocidades en ese plano. La Figura 26 y Figura 27, muestra una comparativa del comportamiento del flujo en secciones transversales a diferentes distancias, aguas arriba de la válvula, con la válvula instalada junto al instrumento a $0 \mathrm{D}$, con $3 \mathrm{D}$ en tramos rectos entre elementos y con 6D. La distorsión provocada por válvula de compuerta, en el caso de la Figura 26, se simuló para un caudal aproximado de $70 \mathrm{~m}^{3} / \mathrm{h}$, mientras que la Figura 27 ilustra el caso de una válvula de mariposa a $100 \mathrm{~m}^{3 / \mathrm{h}}$. 

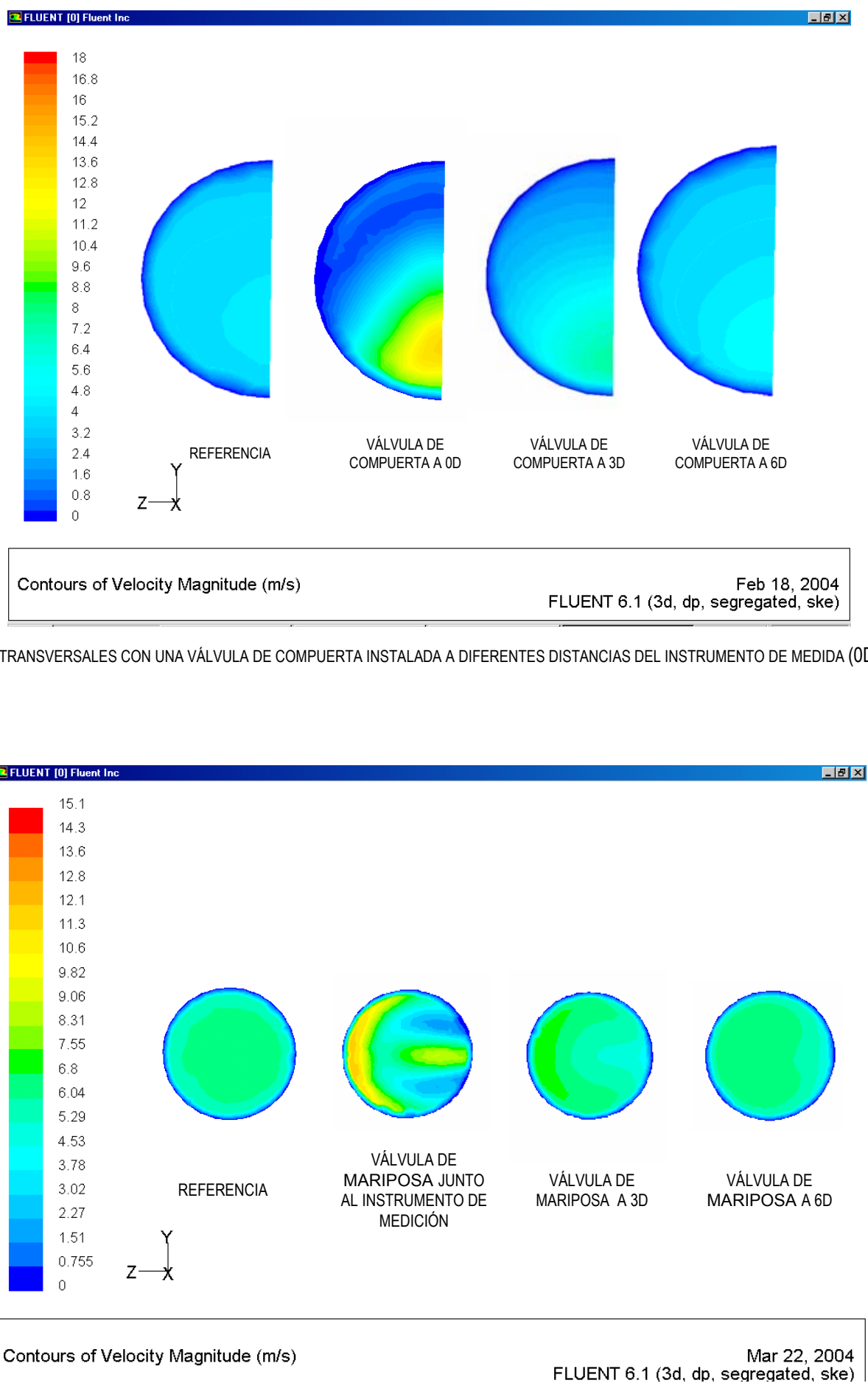

FIGURA 27. CORTES TRANSVERSALES DE LA CONDUCCIÓN CON UNA VÁLVULA DE MARIPOSA $30^{\circ}$ ABIERTA.

También es posible apreciar en estos casos la evolución sufrida por el flujo de agua tras su paso por estas válvulas (Figura 28). En ella se refleja visualmente, el desequilibrio provocado por cada accesorio y la distancia que necesita hasta lograr regularizarse nuevamente. 


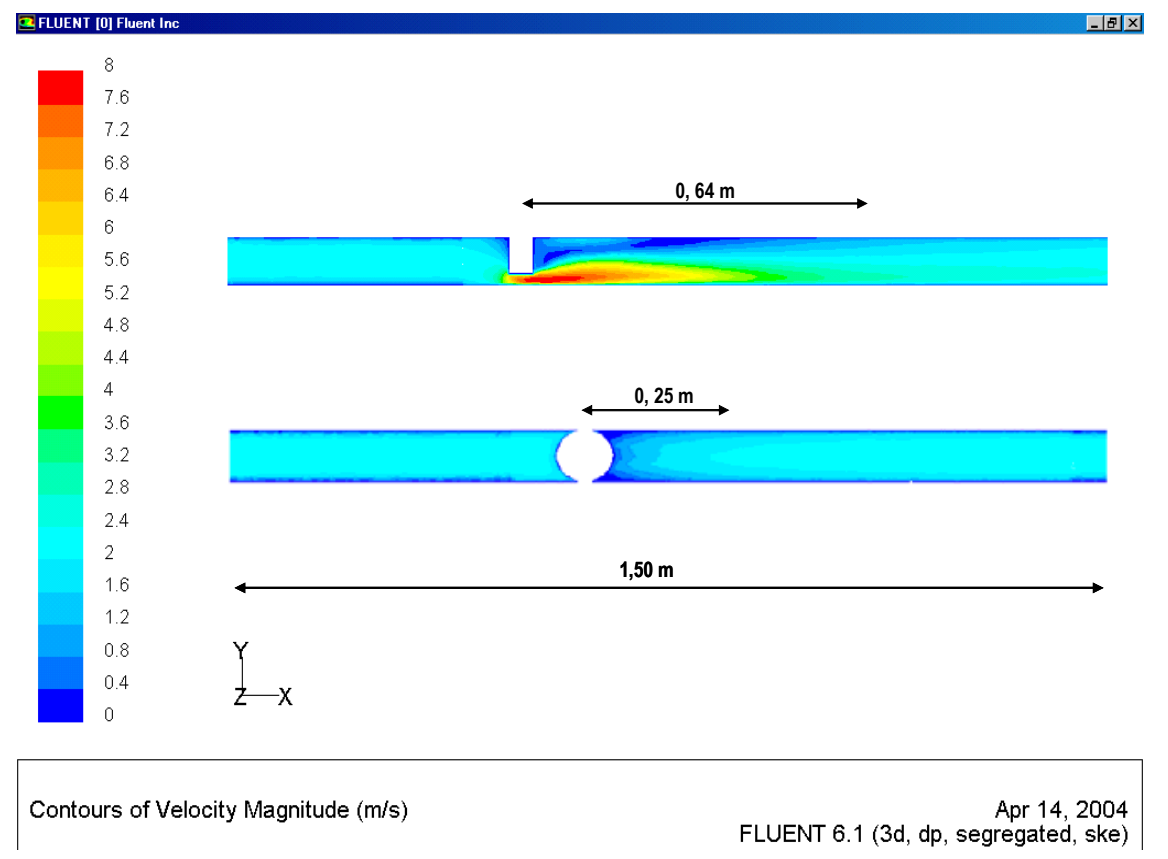

FIGURA 28. CORTES LONGITUDINALES CON UNA VÁLVULA DE COMPUERTA 75\% CERRADA Y OTRA DE MARIPOSA ABIERTA.

Finalmente comentar que para abordar el siguiente epígrafe es necesario extraer los perfiles de velocidad en puntos estratégicos según el principio de medición de cada instrumento. Se ha optado por obtener líneas de corte en lugar de planos para simplificar cálculos posteriores, y a su vez ajustar más fielmente mediante interpolaciones las velocidades en todas las direcciones dentro de ese plano de corte.

Estos perfiles de velocidad serán tratados conforme al principio de medición de cada tecnología. Así pues, los vectores de velocidad extraídos para evaluar el comportamiento de un contador Woltman o de un caudalímetro electromagnético equivaldrán a la velocidad promedio de una sección diferencial que viene condicionada por el número de puntos extraídos de cada simulación. En cambio, el caso del caudalímetro de ultrasonidos es más sencillo, ya que simplemente requiere conocer la magnitud de los vectores de velocidad en la cuerda entre el emisor y el receptor para comprobar cómo se acelera o decelera el tren de ondas sonoras, y con ello el caudal medido.

\subsection{ESTUDIO DE LA INFLUENCIA DE LAS DISTORSIONES EN EL PERFIL DE VELOCIDADES SOBRE CADA TECNOLOGÍA DE MEDICIÓN}

\subsubsection{CONTADOR WOLTMAN}

Para explicar de forma clara la influencia que ejerce un perfil distorsionado en la medición del agua, y comprobarlo posteriormente mediante ensayos en laboratorio, se ha desarrollado un ejemplo con un instrumento real, un contador Woltman de eje horizontal de DN $80 \mathrm{~mm}$, de características metrológicas y geométricas conocidas.

Como paso inicial es fundamental caracterizar geométricamente la turbina del contador conociendo el número de álabes, dimensiones de los mismos, ángulo que forma la cuerda con la vertical, longitud de la cuerda, etcétera. Particularizando, los perfiles hidrodinámicos del Woltman estudiado se observan en la Figura 29 y los parámetros que describen su geometría se resumen en la Tabla 3. 


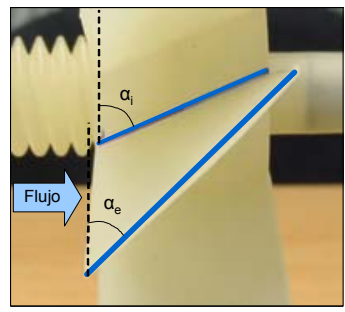

(a)

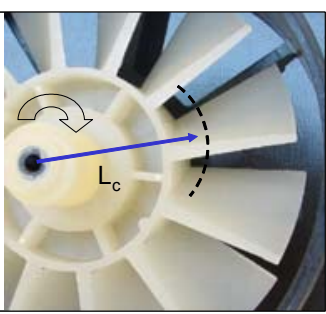

(b)

FIGURA 29. TURBINA DEL CONTADOR WOLTMAN DE EJE HORIZONTAL. VISTA LATERAL (B) VISTA FRONTAL

TABLA 3. CARACTERÍSTICAS GeOMÉtRICAS DE LA TURBINA WOLTMAN DE 80MM

\begin{tabular}{|c|c|c|c|c|c|c|c|}
\hline $\begin{array}{l}\text { Número de } \\
\text { álabes }\end{array}$ & $\begin{array}{l}\text { Número de } \\
\text { paletas } \\
\text { estabilizadoras }\end{array}$ & $\begin{array}{l}r_{\text {pivote }} \\
(\mathrm{m})\end{array}$ & $\begin{array}{l}\text { rálabe } \\
\text { (m) }\end{array}$ & $\begin{array}{l}\alpha_{i} \\
\text { (grados) }\end{array}$ & $\begin{array}{l}a_{e} \\
\text { (grados) }\end{array}$ & $\begin{array}{l}\text { Longitud de la cuerda } L_{c} \\
\text { (m) }\end{array}$ & Relación volumen-giro \\
\hline 12 & 6 & 0,02 & 0,038 & 67 & 47 & $\begin{array}{l}\text { Función lineal del corte } \\
\text { diferencial } \\
L_{c}=0,12 r+0,022 \\
L_{\text {exterior }}=0,025 \mathrm{~m} \\
\text { Linterior }^{2} 0,022 \mathrm{~m}\end{array}$ & 1rev:1,24732 litros \\
\hline
\end{tabular}

La geometría de los álabes viene descrita por sus ángulos de torsión a, variables a lo largo de la longitud del álabe (Figura 29a). La cuerda hace referencia a la longitud del álabe cuando se realiza un corte transversal de la turbina, es decir caracteriza la profundidad de la hélice. A partir de los perfiles de velocidad obtenidos en el análisis numérico del apartado anterior es posible iniciar los cálculos estimativos del error de medición en cada uno de los casos propuestos en la presente Tesis doctoral.

Durante el estudio diferencial de fuerzas se asignan las velocidades medias de las celdas a cada sección de corte. En este estudio es fundamental discernir las velocidades que se producen en cada punto de la sección. Por ello, se opta por extraer líneas de corte independientes, en direcciones distanciadas entre sí $15^{\circ}$, que se ajustan convenientemente a los resultados obtenidos en el modelo para toda la sección (Figura 30).

Además, es importante incidir en el hecho de que no se modelizan los álabes de la hélice en movimiento por su complejidad en el cálculo pero sí se consideran las posibles turbulencias que puede generar el pivote de entrada y la influencia sobre la medición de los estabilizadores de flujo. En cualquier caso, teniendo en cuenta la velocidad de rotación de la hélice, y observando que el ángulo de incidencia del agua sobre los álabes es pequeño, la desviación en la dirección del flujo de agua que provocan estos movimientos puede despreciarse. Por tanto, el error que se comente por no incluirlo está relativamente acotado.

Cada línea de corte (color naranja), contiene 19 vectores de velocidad, y parte del centro de la conducción con una dirección diferente abarcando toda la sección de la tubería, tal y como se muestra en la Figura 30, donde también se dibuja el pivote central del contador Woltman y los estabilizadores de flujo de color negro.
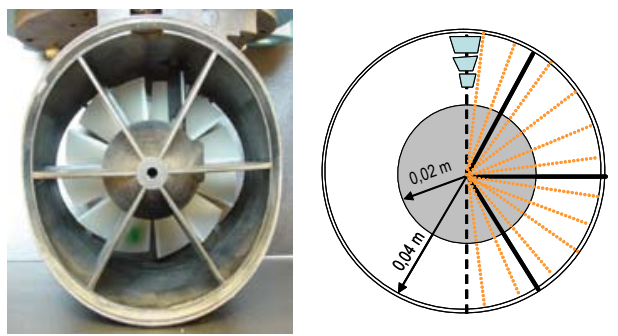

FIGURA 30. LÍNEAS DE CORTE EXTRAIIDAS DE LA SECCIÓN DE ENTRADA A LOS ÁLABES. 
Cuando el dominio computacional es simétrico, el análisis numérico se simplifica modelizando solo la mitad de la tubería, como en el caso de la simulación de la válvula de compuerta o del caso de referencia. Con lo que en estos supuestos se extraerán 12 líneas de corte, mientras que para evaluar la influencia de una válvula de mariposa con diferentes grados de apertura se tomarán 24 líneas de corte. Estas líneas de corte con sus correspondientes vectores de velocidad abarcan toda la sección de la tubería, dividiéndola en secciones diferenciales cuyas velocidades medias corresponden a dicho vectores extraídos del modelo.

Con todo lo expuesto, este apartado presenta los resultados del procedimiento de análisis iterativo descrito en el apartado 4.3.1, en el que se comienza estimando el momento resistente del contador Woltman, es decir la oposición que ofrece la turbina al movimiento rotacional en función de su velocidad de giro. Estas fuerzas resistentes se deben hallar en la hipótesis óptima, cuando el flujo de agua se encuentra estabilizado y el perfil de velocidades plenamente desarrollado, en cuyo caso el error es constante y próximo a cero. Bajo estas condiciones, es decir, cuando el flujo de agua no sufre ningún tipo de obstrucción, el momento resistente del contador se iguala con el momento motriz del flujo de agua, tal y como se vio en la Ecuación 1, el sistema se encuentra en equilibrio y es posible conocer las fuerzas resistentes en todo el rango de medida del instrumento a partir de las del fluido en movimiento.

Por ello, partiendo de los datos obtenidos de Fluent 6.1, se estudia el comportamiento del contador de agua en una tubería con una longitud de tramos rectos suficiente que permita extraer la relación existente entre el momento resistente y la velocidad de rotación de la turbina, proporcional al caudal circulante por la conducción (Figura 31). Esta relación permitirá conocer, a posteriori, la variación en la velocidad de rotación de la turbina cuando un perfil de velocidades alterado impacte sobre la hélice del contador de agua.
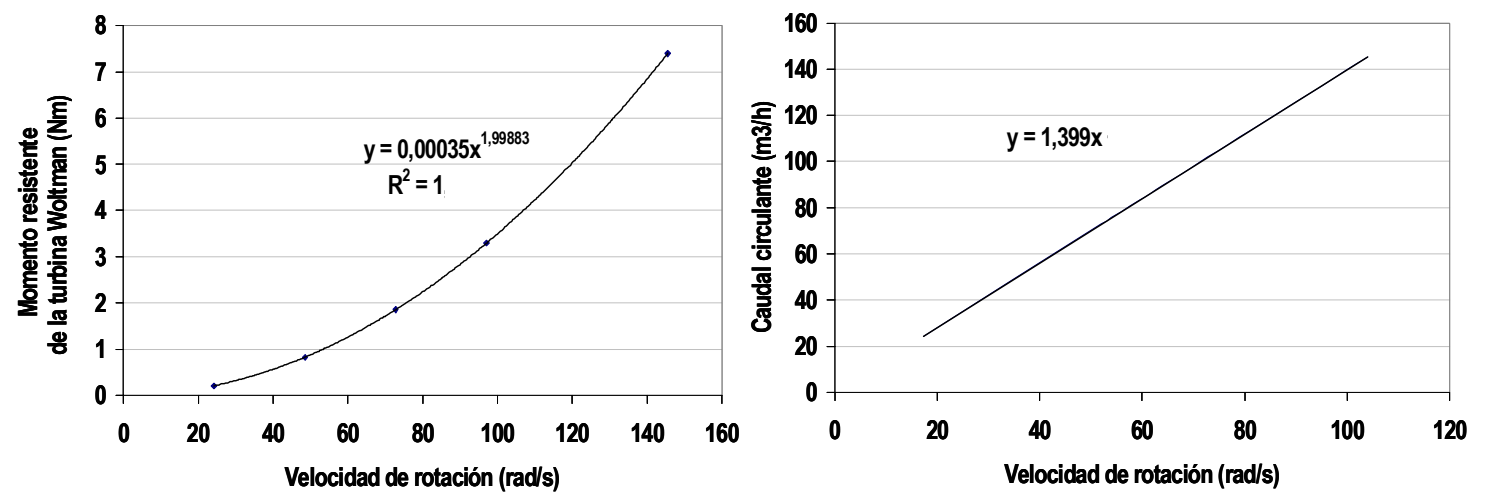

FIGURA 31.RELACIÓN ENTRE EL MOMENTO RESISTENTE DE LA TURBINA, SU VELOCIDAD DE ROTACIÓN Y EL CAUDAL CIRCULANTE.

El comportamiento del flujo en este caso revela, como se muestra en la Figura 32, un perfil de velocidades plenamente desarrollado, donde el frente de agua incide sobre todos los álabes de la hélice de manera equilibrada.
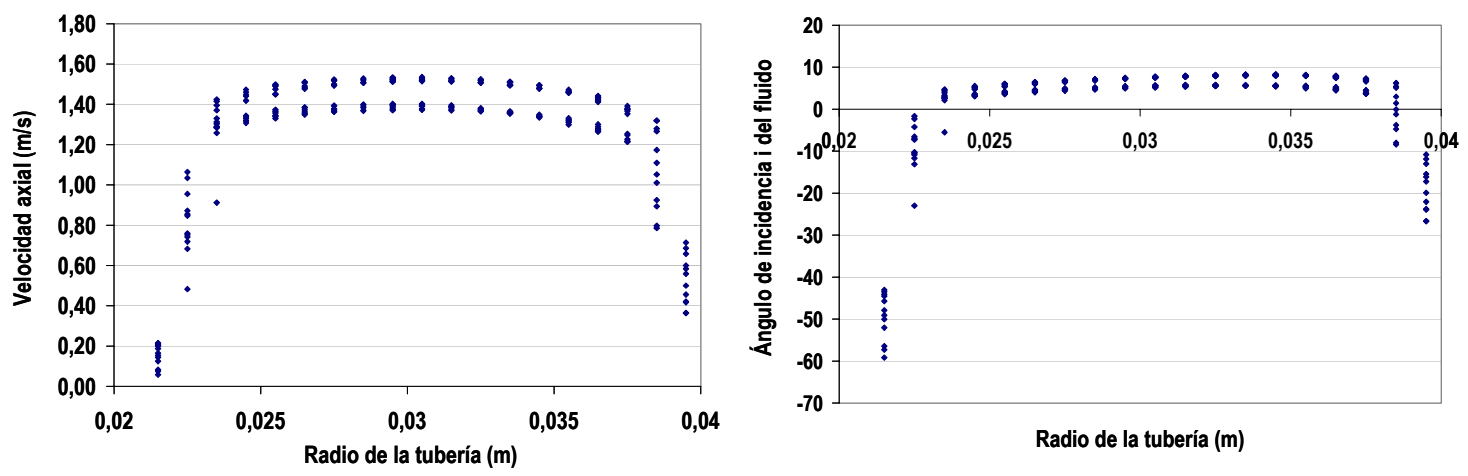

FIGURA 32. VELOCIDAD AXIAL DEL FLUJO Y ÁNGULO DE INCIDENCIA I DEL FLUJO CON LOS ÁLABES CON UN FLUJO SIN DISTORSIONES. 
Además, en este caso, el ángulo de incidencia del flujo con la cuerda de los álabes es aproximadamente de $10^{\circ}$ en la zona central entre el pivote y la pared, y negativo a medida que el flujo se acerca a los extremos. Esto es debido a que la velocidad axial en estas zonas es más pequeña lo que hace variar el ángulo de incidencia i provocando una ligera resistencia al giro de la turbina en los extremos del álabe (Figura 33 y Figura 34).

Como se expuso en el apartado 4.3.1.2, para estimar la velocidad de rotación de la turbina con un flujo de agua alterado, primero se recalculan las fuerzas del agua para diversos caudales, y de una manera iterativa, se comparan con las fuerzas resistentes obtenidas de la relación anterior (Figura 31), hasta encontrar una velocidad de rotación que iguale el par resistente con el par motriz producido por un flujo distorsionado.

Una vez hallada la velocidad de rotación para cada uno de los perfiles de velocidad alterados se compara con la obtenida en el caso de la hipótesis de referencia, es decir, cuando el contador se instala sin ningún tipo de obstáculo aguas arriba y abajo, según la Ecuación 10.

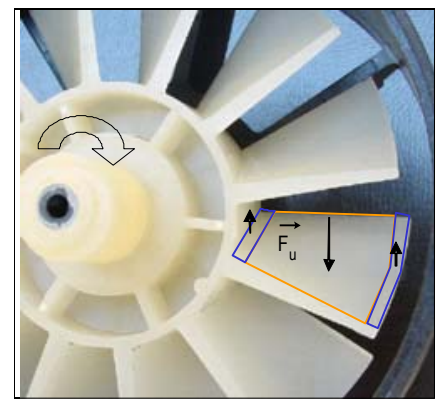

FIGURA 33. SIGNO DE LAS FUERZAS INCIDENTES SOBRE EL ÁLABE WOLTMAN.
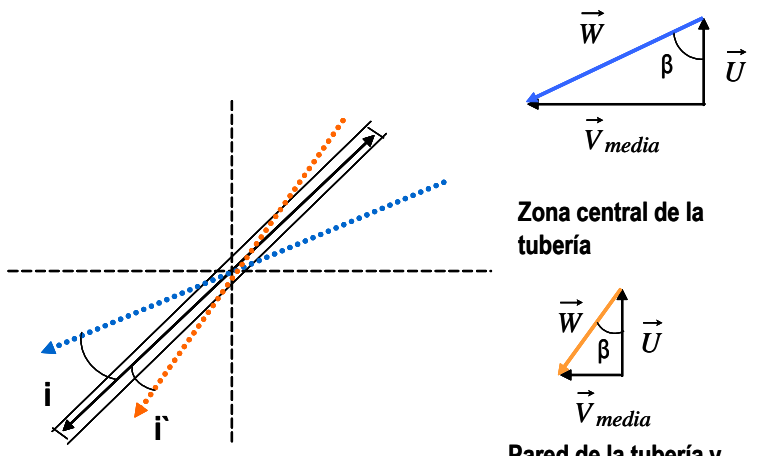

Zona central de la tubería

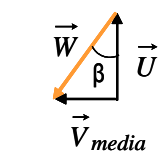

Pared de la tubería y

zona del pivote

central Woltman

FIGURA 34. VARIACIÓN DEL ÁNGULO DE INCIDENCIA I CON LA VELOCIDAD DEL FLUIDO.

Los resultados obtenidos en cada uno de los casos se muestran en las tablas siguientes.

TABLA 4. ERRORES PRODUCIDOS POR LA DISTORSIÓN GENERADA POR UNA VÁLVULA DE COMPUERTA A OD DEL WOLTMAN.

\begin{tabular}{ccccc}
\hline CIERRE & $75 \%$ & $\begin{array}{c}\text { Perfil plenamente } \\
\text { desarrollado }\end{array}$ & $\begin{array}{c}\text { Perfil distorsionado por } \\
\text { val. compuerta }\end{array}$ \\
\hline CAUDAL(m3/h) & $\omega(\mathrm{rad} / \mathbf{s})$ & $\omega(\mathrm{rad} / \mathbf{s})$ & $\begin{array}{c}\text { ERROR DE } \\
\text { MEDIClÓN \% }\end{array}$ \\
17,35 & 24,27 & 34,55 & $\mathbf{4 2 , 3 6}$ \\
34,7 & 48,57 & 69,86 & $\mathbf{4 3 , 8 3}$ \\
52,1 & 72,85 & 105,45 & $\mathbf{4 4 , 7 5}$ \\
69,4 & 97,13 & 141,01 & $\mathbf{4 5 , 1 8}$ \\
104,1 & 145,69 & 212,2 & $\mathbf{4 5 , 6 5}$ \\
\hline
\end{tabular}




\begin{tabular}{|c|c|c|c|c|}
\hline CIERRE & $50 \%$ & $\begin{array}{l}\text { Perfil plenamente } \\
\text { desarrollado }\end{array}$ & $\begin{array}{l}\text { Perfil distorsionado por } \\
\text { val. compuerta }\end{array}$ & \\
\hline \multirow{13}{*}{ CIERRE } & CAUDAL(m3/h) & $\omega(\mathrm{rad} / \mathrm{s})$ & $\omega(\mathrm{rad} / \mathrm{s})$ & $\begin{array}{l}\text { ERROR DE } \\
\text { MEDICIÓN \% }\end{array}$ \\
\hline & 17,27 & 24,17 & 24,56 & 1,63 \\
\hline & 34,55 & 48,34 & 49,26 & 1,90 \\
\hline & 51,83 & 72,52 & 73,88 & 1,87 \\
\hline & 69,11 & 96,69 & 98,54 & 1,91 \\
\hline & 103,66 & 145,04 & 147,83 & 1,92 \\
\hline & $25 \%$ & $\begin{array}{l}\text { Perfil plenamente } \\
\text { desarrollado }\end{array}$ & $\begin{array}{l}\text { Perfil distorsionado por } \\
\text { val. compuerta }\end{array}$ & \\
\hline & CAUDAL(m3/h) & $\omega(\mathrm{rad} / \mathrm{s})$ & $\omega(\mathrm{rad} / \mathrm{s})$ & $\begin{array}{l}\text { ERROR DE } \\
\text { MEDICIÓN \% }\end{array}$ \\
\hline & 17,33 & 24,25 & 24,05 & $-0,82$ \\
\hline & 34,68 & 48,53 & 48,15 & $-0,78$ \\
\hline & 52,02 & 72,79 & 72,21 & $-0,80$ \\
\hline & 69,36 & 97,05 & 96,25 & $-0,83$ \\
\hline & 104,04 & 145,58 & 144,40 & $-0,81$ \\
\hline
\end{tabular}

Si se profundiza en el comportamiento del flujo alterado por la válvula de compuerta con diferentes grados de apertura se distingue claramente que a medida que la distorsión provocada es menor el error de medición del contador Woltman se aproxima más al que tiene en condiciones ideales del flujo. Por ejemplo, el caso extremo, con una válvula de compuerta prácticamente cerrada instalada aguas arriba del contador, sin mantener tramos rectos entre ellos, puede producir errores de sobrecontaje de cerca del $+45 \%$ (Tabla 4).

No obstante, se aprecia una mejora importante en el error simplemente abriendo la válvula y causando menor distorsión. Así pues, cuando el cierre de la válvula es del $25 \%$ a una distancia de OD, los errores de medición obtenidos son menores, aproximadamente de $-0,8 \%$, para todo el rango de caudales de funcionamiento del contador.

En el supuesto más desfavorable, la mejora producida cuando se instala entre la válvula de compuerta ( $75 \%$ cerrada) y el contador una distancia de 3D de tubería recta se refleja en la medición disminuyendo los errores de aproximadamente $+40 \%$ a $+2 \%$ (Tabla 5 ).

TABLA 5. ERRORES DE MEDICIÓN GENERADOS POR UNA VÁLVULA DE COMPUERTA A 3D.

\begin{tabular}{ccccc}
\hline CIERRE & $75 \%$ & $\begin{array}{c}\text { Perfil plenamente } \\
\text { desarrollado }\end{array}$ & $\begin{array}{c}\text { Perfil distorsionado } \\
\text { por val. compuerta }\end{array}$ & \\
\hline CAUDAL(m3/h) & $\omega$ (rad/s) & $\omega$ (rad/s) & $\begin{array}{c}\text { ERROR DE } \\
\text { MEDICIÓN\% }\end{array}$ \\
\hline 17,52 & 24,64 & 25,05 & 1,66 \\
35,12 & 49,14 & 50,4 & $\mathbf{2 , 5 6}$ \\
52,665 & 73,69 & 75,03 & 1,82 \\
70,21 & 98,24 & 100,6 & $\mathbf{2 , 4 0}$ \\
105,33 & 147,38 & 149,91 & 1,72 \\
\hline
\end{tabular}



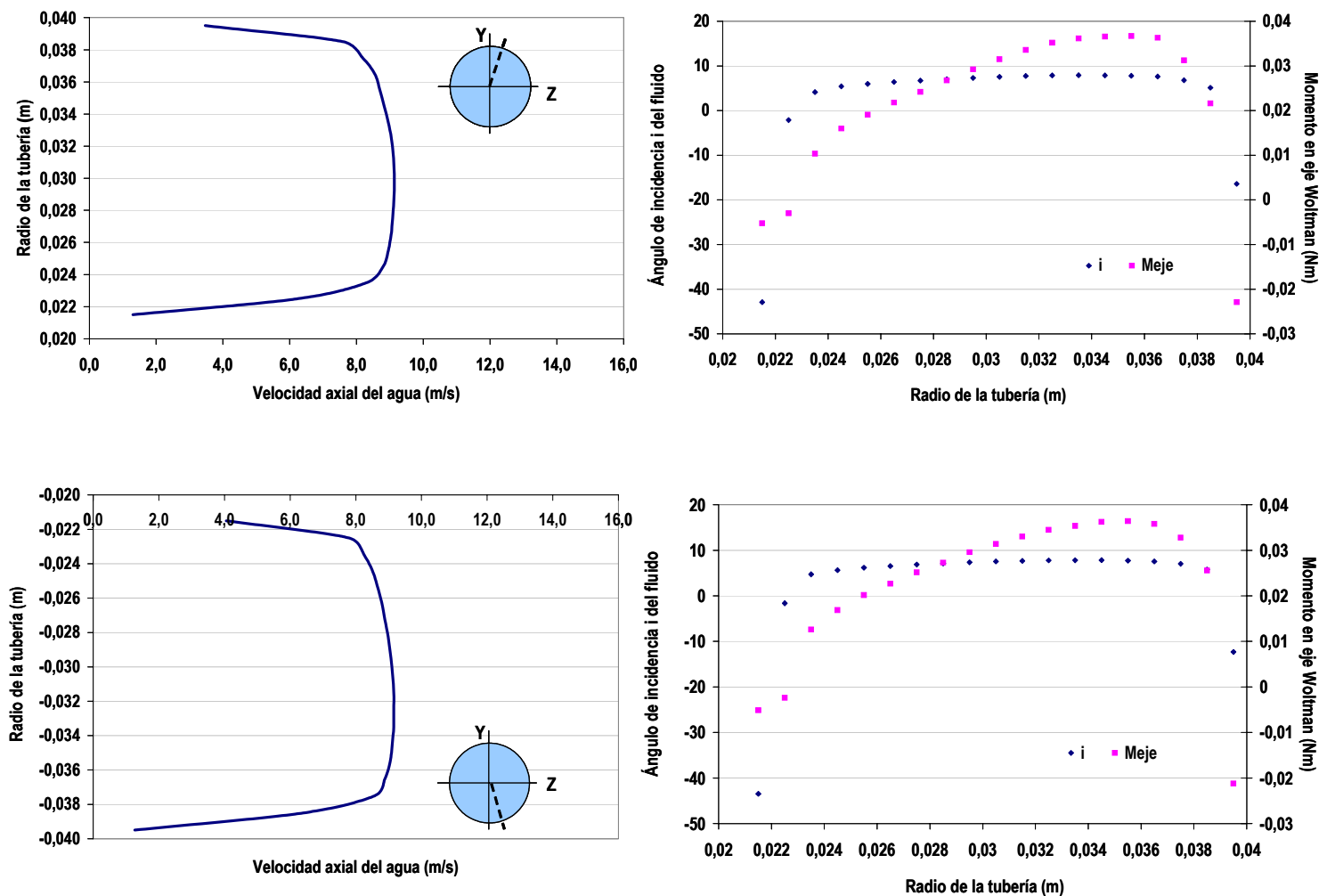

FIGURA 35. RESULTADOS OBTENIDOS CON UN FLUJO PLENAMENTE DESARROLLADO A Q=100 M³/H.

Mediante un análisis de las fuerzas motrices, afectadas tanto por la velocidad como por el ángulo de incidencia del agua sobre la turbina, se puede justificar los errores de medición obtenidos.

De esta manera, observando en detalle el comportamiento del flujo de agua en el supuesto de una válvula de compuerta $75 \%$ cerrada frente a un flujo no distorsionado se llega a una serie de conclusiones importantes. Primero, claramente se aprecia que el perfil de velocidades a la entrada del instrumento (álabes del Woltman) es muy diferente en cada caso.

La Figura 36a muestra que las velocidades en la zona superior de la conducción no alcanzan los $2 \mathrm{~m} / \mathrm{s}$, mientras que en la zona inferior llegan a valores de $14 \mathrm{~m} / \mathrm{s}$ (Figura 36c) para un caudal en régimen permanente de $100 \mathrm{~m} 3 / \mathrm{h}$ y una velocidad media aproximada de $8 \mathrm{~m} / \mathrm{s}$. Consecuentemente, esta circunstancia provoca un ángulo de incidencia negativo en la zona superior de la conducción, donde se dan velocidades bajas, que genera una contribución negativa al momento en el eje lo que frena el giro de la turbina (Figura 36b).

En la zona inferior de la tubería se produce el efecto contrario. Las velocidades elevadas aumentan el ángulo de incidencia hasta valores cercanos a $14^{\circ}$, lográndose una fuerza impulsora muy superior a la obtenida con un perfil plenamente desarrollado (con $i$ aproximadamente de $8^{\circ}$ ). Los valores del par motriz en esta zona inferior, cercanos a 0,15 Nm muy superiores a los $0,035 \mathrm{Nm}$ obtenidos con un perfil no distorsionado (Figura 35), aceleran la turbina Woltman justificando el sobrecontaje deducido de los cálculos. Aunque el par motriz en la zona superior adopta valores incluso negativos no consigue compensar el incremento del par producido en la zona inferior.

Cabe recordar que los perfiles mostrados están extraídos en una sección del contador justamente aguas arriba de los álabes, por lo que se ha tenido en cuenta la influencia ejercida por los estabilizadores de flujo y por el propio pivote central del instrumento. De hecho, los perfiles muestran cierto achatamiento del perfil debido a la fricción del flujo con las paredes del pivote (diámetro de $0,04 \mathrm{~m}$ ). 

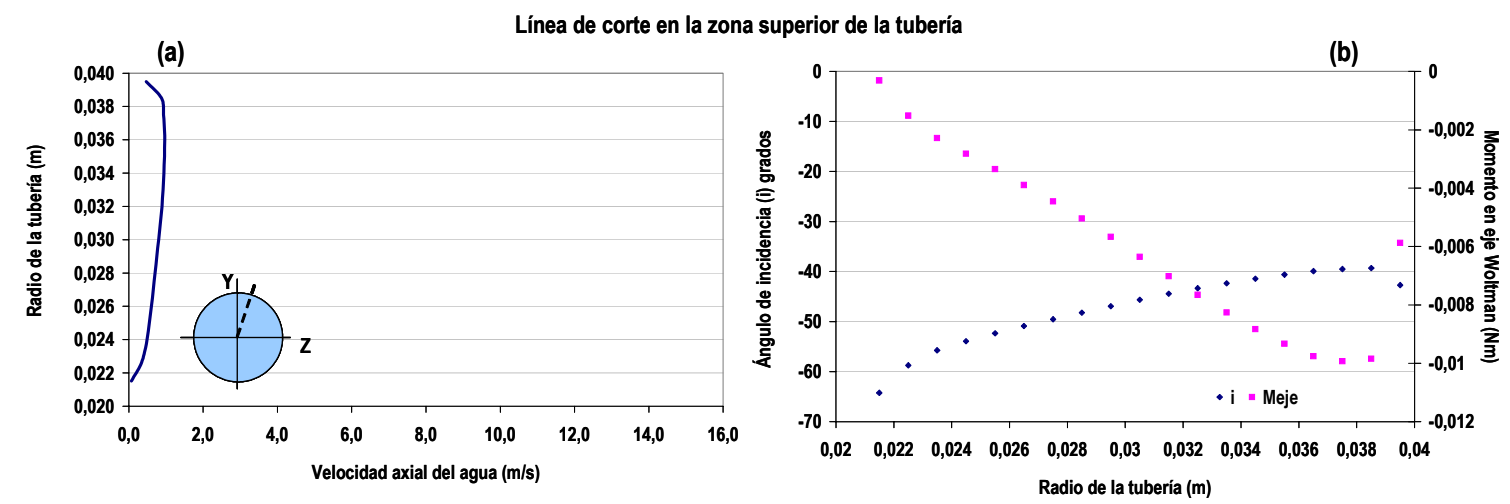

(c)

Línea de corte en la zona inferior de la tubería

(d)
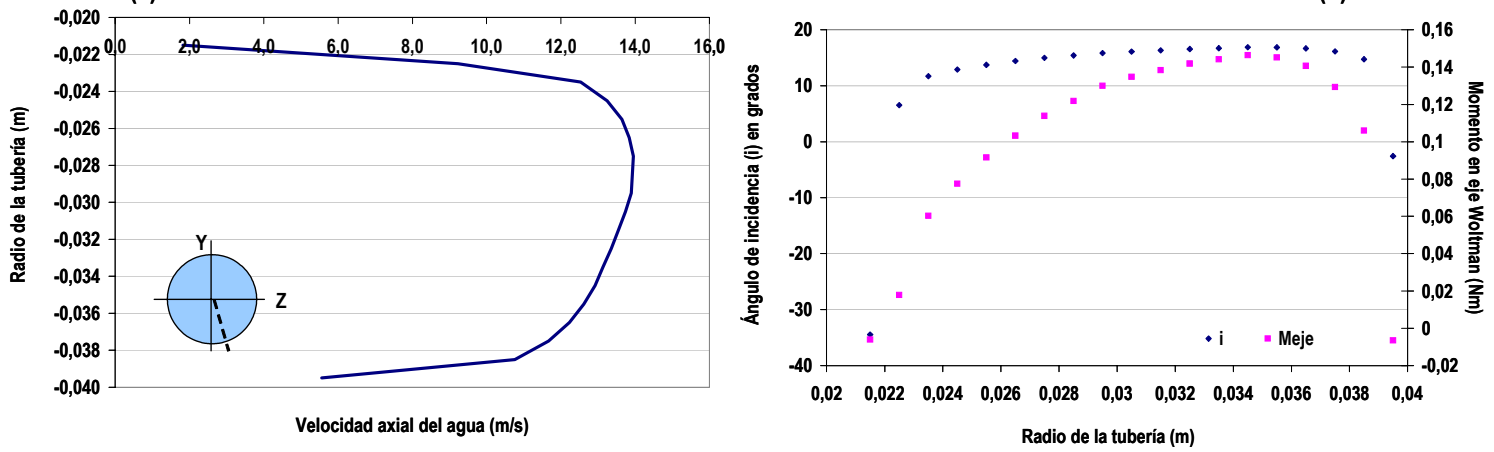

FIGURA 36. FLUJO INCIDENTE DESPUÉS DE UNA DISTORSIÓN DEBIDA A UNA VÁLVULA DE COMPUERTA ,75\% CERRADA A Q=100 M³/H YA OD.

En el caso de la válvula de mariposa, los errores obtenidos tanto abierta como parcialmente cerrada son similares y prácticamente nulos, ya que el flujo logra estabilizarse tras 3D rectos de conducción como se explicó en el apartado 3.

TABLA 6. ERRORES DE MEDICIÓN DE UN WOLTMAN PRODUCIDOS POR UNA VÁLVULA DE MARIPOSA A 3D.

\begin{tabular}{|c|c|c|c|c|}
\hline & ABIERTA & $\begin{array}{l}\text { Perfil plenamente } \\
\text { desarrollado }\end{array}$ & $\begin{array}{l}\text { Perfil distorsionado por } \\
\text { val.mariposa }\end{array}$ & \\
\hline & CAUDAL(m3/h) & $\omega(\mathrm{rad} / \mathrm{s})$ & $\omega(\mathrm{rad} / \mathrm{s})$ & $\begin{array}{l}\text { ERROR DE } \\
\text { MEDICIÓN\% }\end{array}$ \\
\hline & 17,51 & 24,6 & 24,4 & $-0,81$ \\
\hline & 35,3 & 49,08 & 48,9 & $-0,37$ \\
\hline & 52,7 & 73,5 & 73,05 & $-0,61$ \\
\hline & 70,45 & 98,1 & 97,7 & $-0,41$ \\
\hline & 105,33 & 147,38 & 146,85 & $-0,36$ \\
\hline \multirow[t]{7}{*}{ CIERRE } & $30^{\circ}$ & $\begin{array}{l}\text { Perfil plenamente } \\
\text { desarrollado }\end{array}$ & $\begin{array}{l}\text { Perfil distorsionado por } \\
\text { val. mariposa }\end{array}$ & \\
\hline & CAUDAL(m3/h) & $\omega(\mathrm{rad} / \mathrm{s})$ & $\omega(\mathrm{rad} / \mathrm{s})$ & $\begin{array}{l}\text { ERROR DE } \\
\text { MEDICIÓN\% }\end{array}$ \\
\hline & 17,5 & 24,55 & 24,3 & $-1,02$ \\
\hline & 35,15 & 49,3 & 49,1 & $-0,41$ \\
\hline & 52 & 73,8 & 73,5 & $-0,41$ \\
\hline & 70,32 & 98,45 & 98,2 & $-0,25$ \\
\hline & 104,85 & 147,8 & 147,15 & $-0,44$ \\
\hline
\end{tabular}




\subsubsection{CAUDALÍMETRO ELECTROMAGNÉTICO}

Al igual que en el apartado anterior, en esta parte se presentan los resultados obtenidos de la combinación del análisis numérico que modela el comportamiento del fluido ante diversas perturbaciones con la teoría sobre la variación en la señal de salida de un caudalímetro electromagnético.

Como se vio en el apartado 4.3.2., la diferencia de voltaje entre los electrodos de este instrumento depende de la velocidad en cada punto de la sección de medida, ponderada con un coeficiente, obtenido mediante la función de pesos, que indica la importancia que tiene dicho valor de velocidad local sobre el cálculo de la velocidad media y, en consecuencia del caudal.

Aprovechando los cálculos numéricos realizados para diferentes configuraciones se evalúa cómo varía la medida del caudal ante diversas perturbaciones (Ecuación 10). Los resultados obtenidos en cada uno de los casos propuestos se presentan en las siguientes tablas.

TABLA 7. ERRORES DE MEDICIÓN DE UN CAUDALIMMETRO ELECTROMAGNÉTICO PROVOCADOS POR UNA VÁLVULA DE COMPUERTA.

\begin{tabular}{|c|c|c|c|c|c|c|}
\hline CIERRE & $75 \%$ & & & & & \\
\hline & $Q\left(m^{3} / h\right)$ & ERROR (\%) & $Q\left(m^{3} / h\right)$ & ERROR (\%) & $Q\left(m^{3} / h\right)$ & ERROR (\%) \\
\hline Referencia & 33,25 & & 66,88 & & 100,34 & \\
\hline a OD & 31,59 & $-4,99$ & 62,91 & $-5,93$ & 94,24 & $-6,08$ \\
\hline a 3D & 33,13 & $-0,36$ & 66,16 & $-1,08$ & 99,26 & $-1,08$ \\
\hline a 6D & 33,26 & 0,03 & 66,26 & $-0,92$ & 99,48 & $-0,86$ \\
\hline \multirow[t]{2}{*}{ CIERRE } & $50 \%$ & & & & & \\
\hline & $Q\left(m^{3} / h\right)$ & ERROR (\%) & $Q\left(m^{3} / h\right)$ & ERROR (\%) & $Q\left(m^{3} / h\right)$ & ERROR (\%) \\
\hline Referencia & 33,25 & & 66,50 & & 99,78 & \\
\hline a OD & 33,26 & 0,02 & 66,54 & 0,06 & 99,85 & 0,08 \\
\hline a 3D & 32,95 & $-0,90$ & 66,14 & $-0,54$ & 99,31 & $-0,46$ \\
\hline a 6D & 32,74 & $-1,53$ & 65,43 & $-1,61$ & 98,20 & $-1,58$ \\
\hline \multirow[t]{2}{*}{ CIERRE } & $25 \%$ & & & & & \\
\hline & $Q\left(m^{3} / h\right)$ & ERROR (\%) & $Q\left(m^{3} / h\right)$ & ERROR (\%) & $Q\left(m^{3} / h\right)$ & ERROR (\%) \\
\hline Referencia & 33,69 & & 67,47 & & 101,28 & \\
\hline a OD & 35,21 & 4,51 & 70,48 & 4,46 & 105,70 & 4,36 \\
\hline a 3D & 34,40 & 3,43 & 68,80 & 3,53 & 103,30 & 3,60 \\
\hline a 6D & 34,50 & 3,73 & 69,00 & 3,83 & 103,50 & 3,80 \\
\hline
\end{tabular}

Claramente, se aprecia cómo el grado de distorsión en el flujo provocado por la válvula de compuerta, cuando su grado de cierre es de 75\%, disminuye con la distancia entre elementos. En este caso en particular, la estabilización del perfil de velocidades se logra cuando se mantiene una distancia entre elementos de aproximadamente 3D a 6D. Como se ha visto de los gráficos extraídos de Fluent, cuando esta válvula se encuentra casi cerrada se llegan a distinguir en la zona superior de la tubería flujos de agua negativos justificando un mayor error de subcontaje.

El análisis de las simulaciones efectuadas muestra que un mayor grado de apertura de la válvula de compuerta genera velocidades más elevadas en la zona inferior de la tubería (Figura 37) que al ponderarse con la función propuesta por Shercliff disminuyen su magnitud (ver Figura 12), provocando consecuentemente estos errores de medición negativos (Tabla 7). 


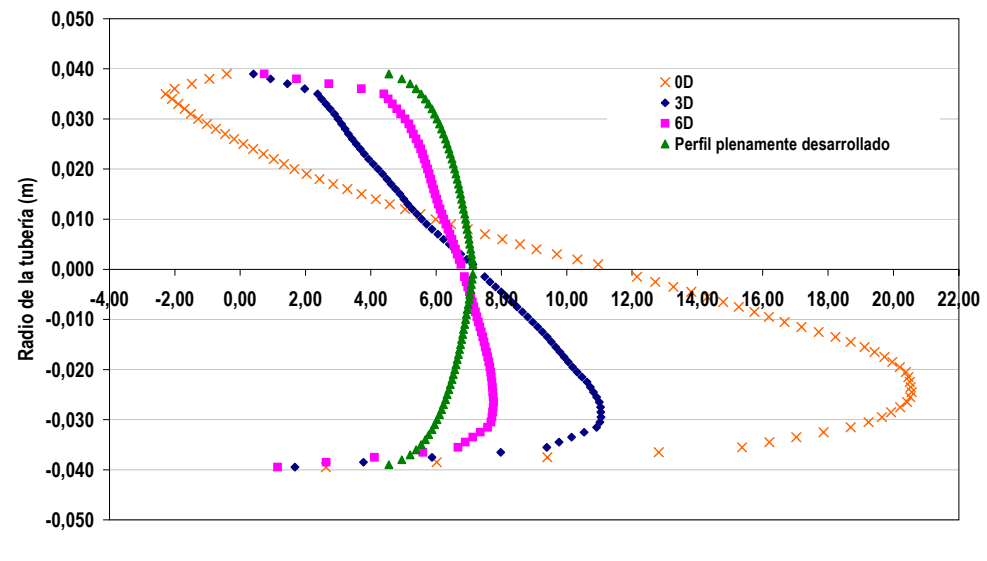

Velocidad axial $(\mathrm{m} / \mathrm{s})$

FIGURA 37. PERFIL DE VELOCIDADES PERPENDICULAR A LA SECCIÓN DE MEDICIÓN ENTRE ELECTRODOS PARA DIFERENTES DISTANCIAS ENTRE LA VÁLVULA 75\% CERRADA Y EL INSTRUMENTO DE MEDICIÓN.

Examinando este mismo parámetro, cuando se varía el grado de apertura de la válvula se aprecia que el desequilibrio del flujo disminuye a medida que se abre la válvula (Figura 38). Sin embargo, este hecho no mejora la medición del caudal en este instrumento como en el caso del contador Woltman. Cuando la válvula se encuentra $25 \%$ cerrada con OD entre elementos, se observa que el perfil de velocidades alcanza valores elevados en la zona central de la sección de medición donde los coeficientes propuestos por Shercliff son mayores. Este fenómeno provoca que se sobreestime la velocidad ponderada y con ello, el caudal circulante.

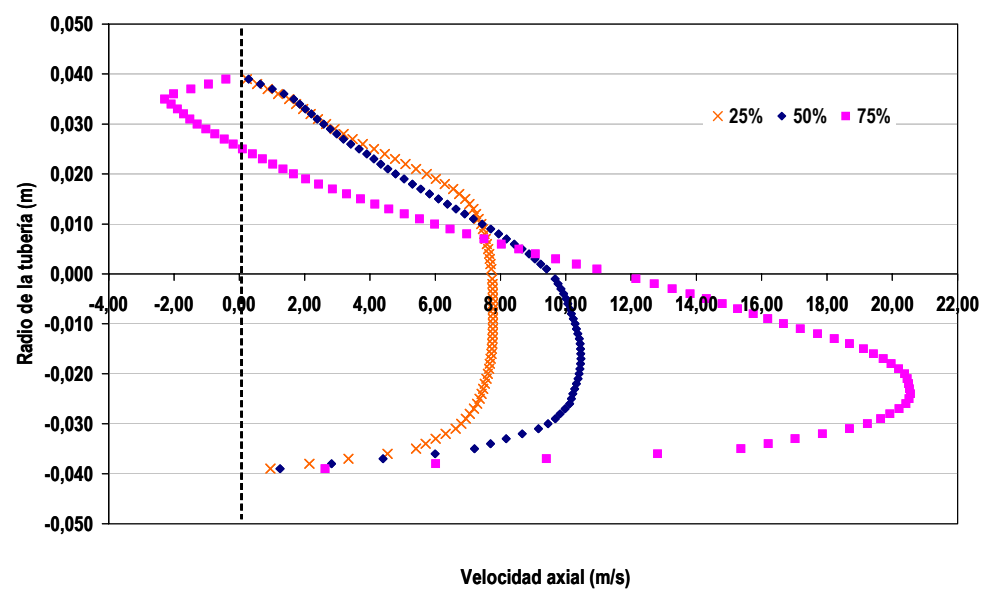

FIGURA 38. PERFIL DE VELOCIDADES PERPENDICULAR A LA SECCIÓN ENTRE ELECTRODOS CON DIFERENTES GRADOS DE CIERRE DE UNA VÁLVULA DE COMPUERTA A OD

TABLA 8. ERRORES DE MEDICIÓN EN UN CAUDALIMMETRO ELECTROMAGNÉTICO CON UN FLUJO DISTORSIONADO POR UNA VÁLVULA DE MARIPOSA

\begin{tabular}{lcccccc}
\hline CIERRE & ABIERTA & & & & \\
\hline & $\mathbf{Q}\left(\mathbf{m}^{3} / \mathbf{h}\right)$ & ERROR $(\%)$ & $\mathbf{Q}\left(\mathbf{m}^{3} / \mathbf{h}\right)$ & ERROR $(\%)$ & $\mathbf{Q}\left(\mathbf{m}^{3} / \mathbf{h}\right)$ & ERROR $(\%)$ \\
\cline { 2 - 7 } Referencia & 34,25 & & 67,7 & & 102,82 & \\
a OD & 34,37 & $\mathbf{0 , 3 5}$ & 68,10 & $\mathbf{0 , 5 9}$ & 103,22 & $\mathbf{0 , 3 9}$ \\
a 3D & 34,22 & $-\mathbf{0 , 0 9}$ & 68,46 & $\mathbf{1 , 1 2}$ & 102,68 & $-\mathbf{0 , 1 4}$ \\
a 6D & 34,14 & $-\mathbf{0 , 3 2}$ & 68,11 & $\mathbf{0 , 6 1}$ & 102,25 & $-\mathbf{0 , 5 5}$ \\
\hline
\end{tabular}




\begin{tabular}{lcccccc}
\hline \multicolumn{1}{c}{ CIERRE } & $30^{\circ}$ cerrada & \multicolumn{7}{c}{} \\
\hline & $\mathbf{Q}\left(\mathbf{m}^{3} / \mathbf{h}\right)$ & ERROR $(\%)$ & $\mathbf{Q}\left(\mathbf{m}^{3} / \mathbf{h}\right)$ & ERROR $(\%)$ & $\mathbf{Q}\left(\mathbf{m}^{3} / \mathbf{h}\right)$ & ERROR $(\%)$ \\
Referencia & 34,24 & & 67,79 & & 102,76 & \\
a 0D & 35,45 & 3,53 & 69,48 & 2,49 & 106,36 & 3,50 \\
a 3D & 33,64 & $-1,75$ & 67,00 & $-1,17$ & 100,87 & $-1,84$ \\
a 6D & 34,20 & $-\mathbf{0 , 1 2}$ & 67,6 & $\mathbf{- 0 , 2 8}$ & 102,65 & $\mathbf{- 0 , 1 1}$ \\
\hline
\end{tabular}

El grado de distorsión producido por la válvula de mariposa, en general, es menor que el de la válvula de compuerta con lo que la medición se ve menos afectada. A su vez, el propio diseño de esta válvula impide la instalación de un instrumento de medida a una distancia menor de tres diámetros lo que ayuda en la estabilización del flujo de agua.

En la Tabla 8 se muestran los resultados obtenidos para este tipo de válvula en diferentes posiciones y aperturas. En este caso, el error producido a OD de distancia ya que numéricamente es posible su cálculo.

También, se observa que cuando la válvula de mariposa se encuentra abierta la influencia sobre el caudalímetro electromagnético es nula. En cambio, se aprecia cierto error de sobrecontaje cuando la válvula se encuentra $30^{\circ}$ cerrada que disminuye, de nuevo, cuando se mantienen tramos rectos entre elementos.

Luego para asegurar una correcta medición de este instrumento, para cualquier configuración de la válvula, sería recomendable mantener al menos $6 \mathrm{D}$ de tramos rectos de tubería. Esta conclusión coincide con las recomendaciones dadas habitualmente por los fabricantes.

\subsubsection{CAUDALIMETRO DE ULTRASONIDOS DE TIEMPO DE TRÁNSITO}

De la teoría expuesta en el apartado 4.3.3 sobre el principio de funcionamiento de los caudalímetros de ultrasonidos de tiempo de tránsito, este punto desarrolla un análisis de sensibilidad del principio de funcionamiento a las distorsiones en el flujo de agua.

En condiciones óptimas de medición, la velocidad del fluido en la cuerda diametral guarda una relación conocida con la velocidad media en toda la sección, obteniendo resultados fiables dentro de los márgenes de precisión del aparato de medida. El problema radica cuando cambia la relación entre la velocidad medida y la velocidad media en la conducción respecto a las condiciones de un flujo plenamente desarrollado. Esto provoca una variación desconocida de la velocidad de las ondas sonoras que se aceleran o deceleran en función del comportamiento irregular del flujo de agua, afectando consecuentemente a la medición del caudal por el instrumento.

Como con los otros instrumentos de medida, en este apartado se combinarán los resultados numéricos de las simulaciones realizadas mediante CFD de las perturbaciones del flujo provocadas por varias válvulas con las ecuaciones teóricas que describen el funcionamiento del caudalímetro.

El procedimiento que aquí se utiliza sido validado anteriormente en otros estudios. De hecho, el informe Auditing water flowmetering systems (2002) describe los experimentos llevados a cabo por el National Engineering Laboratory de Glasgow, donde se evalúa el efecto de un codo sobre la medición de un caudalímetro de ultrasonidos de tiempo de tránsito colocado en dos planos de medida. El estudio revela errores negativos de hasta $-8 \%$ que van disminuyendo a medida que el instrumento se aleja de codo. La medición se realiza en dos planos diferentes con doble trayectoria. Cuando se instala el caudalímetro de ultrasonidos en un solo plano y con una única trayectoria los resultados obtenidos son aproximadamente de $+40 \%$ a 1 diámetro de distancia entre elementos. Como se demuestra en el citado informe, la distancia requerida para que la influencia de la perturbación provocada por un codo sea prácticamente inexistente es de cerca de 18D de tramos rectos aguas arriba del instrumento.

En la presente Tesis se considera el efecto sobre el error de medición de una válvula de compuerta y otra de mariposa con diversos grados de apertura y distancia entre elementos. Para ello, inicialmente suponiendo un caudalímetro de ultrasonidos 
de calibre $80 \mathrm{~mm}$ con transductores integrados, se calculan los parámetros necesarios para la estimación del caudal circulante en el caso de un flujo distorsionado y otro con un perfil de velocidades plenamente desarrollado (Tabla 9).

TABLA 9. PARÁmEtros REQUERIDOS PARA EL CÁlCULO del CAUDAL MEDIANTE UN CAUDALÍMETRO DEL ULTRASONIDOS.

\begin{tabular}{rrrrr}
\hline & $\mathbf{D}_{\text {cálculo }}(\mathrm{mm})$ & $\mathrm{L}(\mathrm{mm})$ & $\boldsymbol{\alpha}^{0}$ & Distancia al plano central \\
\hline 1 PLANO DE MEDICIÓN & 80 & 160 & 30 & 0 \\
1 TRAYECTORIA & 68,33 & 136,66 & 30 & $0,52 \cdot \mathrm{R}$ \\
\hline $\begin{array}{r}\text { 2 PLANO DE MEDICIÓN } \\
\text { 2 TRAYECTORIAS (Figura 14) }\end{array}$ & & & & \\
\hline
\end{tabular}

Los datos extraídos de las simulaciones numéricas corresponden a las velocidades en tres dimensiones dispuestas en la cuerda que une ambos transductores. Así, en este estudio se realiza un cambio de coordenadas de estos vectores de velocidad en la dirección de las ondas sonoras para conocer la velocidad resultante, suma de la velocidad del sonido en el agua y la componente de la velocidad del fluido en cada punto de la cuerda.

Una vez obtenida la velocidad del tren de ondas, y a partir de un cálculo sencillo de la longitud de la cuerda en las dos hipótesis planteadas, es posible conocer el tiempo de tránsito, tanto de ida como de vuelta, de cada trayectoria, y relacionarlo con la velocidad del fluido y el caudal circulante.

El número de puntos extraídos en esta ocasión a lo largo de esta línea es de 98, en el caso de que la medición se realice en el plano horizontal que contiene el eje de la conducción y de 84 cuando se evalúa la medición en dos planos situados a $0,52 \mathrm{R}$ del anterior.

Los resultados obtenidos en este estudio donde se evalúa el error de medición que genera una válvula de compuerta y una de mariposa con diferentes grados de apertura se resumen en las siguientes tablas.

TABLA 10. ERRORES PROVOCADOS EN UN CAUDALIMMETRO DE ULTRASONIDOS DE UNA TRAYECTORIA POR LA INSTALACIÓN DE UNA VÁLVULA DE COMPUERTA.

\begin{tabular}{|c|c|c|c|c|c|c|}
\hline CIERRE & $75 \%$ & & & & & \\
\hline & $Q\left(m^{3} / h\right)$ & ERROR (\%) & $Q\left(m^{3} / h\right)$ & ERROR (\%) & $Q\left(m^{3} / h\right)$ & ERROR (\%) \\
\hline Referencia & 30,85 & & 61,02 & & 92,33 & \\
\hline a OD & 36,92 & 19,68 & 74,35 & 21,85 & 111,95 & 21,25 \\
\hline a 3D & 36,15 & 17,18 & 72,51 & 18,83 & 109,14 & 18,21 \\
\hline a 6D & 35,96 & 16,56 & 71,94 & 17,90 & 108,40 & 17,40 \\
\hline \multirow[t]{2}{*}{ CIERRE } & $50 \%$ & & & & & \\
\hline & $Q\left(m^{3} / h\right)$ & ERROR (\%) & $Q\left(m^{3} / h\right)$ & ERROR (\%) & $Q\left(m^{3} / h\right)$ & ERROR (\%) \\
\hline Referencia & 30,64 & & 61,43 & & 92,30 & \\
\hline a OD & 33,11 & 8,06 & 67,09 & 9,21 & 101,08 & 9,51 \\
\hline a 3D & 32,21 & 5,12 & 64,53 & 5,05 & 97,05 & 5,14 \\
\hline a $6 \mathrm{D}$ & 32,10 & 4,77 & 64,10 & 4,35 & 96,14 & 4,16 \\
\hline \multirow[t]{2}{*}{ CIERRE } & $25 \%$ & & & & & \\
\hline & $Q\left(m^{3} / h\right)$ & ERROR (\%) & $Q\left(m^{3} / h\right)$ & ERROR (\%) & $Q\left(m^{3} / h\right)$ & ERROR (\%) \\
\hline Referencia & 30,65 & & 61,50 & & 92,45 & \\
\hline a OD & 31,54 & 2,89 & 62,85 & 2,20 & 94,30 & 2,00 \\
\hline a 3D & 30,86 & 0,69 & 61,80 & 0,49 & 92,81 & 0,39 \\
\hline a 6D & 30,76 & 0,35 & 61,33 & $-0,28$ & 92,80 & 0,38 \\
\hline
\end{tabular}


La Tabla 10 muestra los errores provocados por una válvula de compuerta instalada a diferentes distancias de un caudalímetro de ultrasonidos y en varios grados de apertura.

En el caso extremo, es decir, cuando la válvula está 75\% cerrada y a OD del instrumento, el perfil de velocidades se encuentra muy distorsionado (Figura 39a). Comparando este perfil con uno en condiciones óptimas de funcionamiento, plenamente desarrollado, se aprecia que las velocidades al proyectarse sobre la cuerda de medición son elevadas en la zona central de la conducción justificando los errores de sobrecontaje encontrados, del orden de $+20 \%$. Cuando se instala entre elementos cierta longitud de tramos rectos de tubería los resultados obtenidos mejoraron sensiblemente, pero sin llegar a considerarlos como válidos ya que la distorsión producida todavía produce errores elevados.

Además, se comprobó que a medida que el cierre de la válvula es menor, estas diferencias de velocidad entre el centro de la tubería y los extremos son muy pequeñas, aproximándose a la forma del perfil plenamente desarrollado y disminuyendo los errores hasta $+8 \%$ para un cierre de $50 \%$ y de $+3 \%$ con una válvula $25 \%$ cerrada a una distancia entre elementos de $0 \mathrm{D}$. En este último ejemplo (Figura 39c), el perfil de velocidades se asemeja al teórico en forma, pero se aprecia que en media las velocidades en toda la cuerda son ligeramente superiores en la zona central, lo que justifica los errores positivos obtenidos cuando la distancia entre elementos es de $0 \mathrm{D}$.
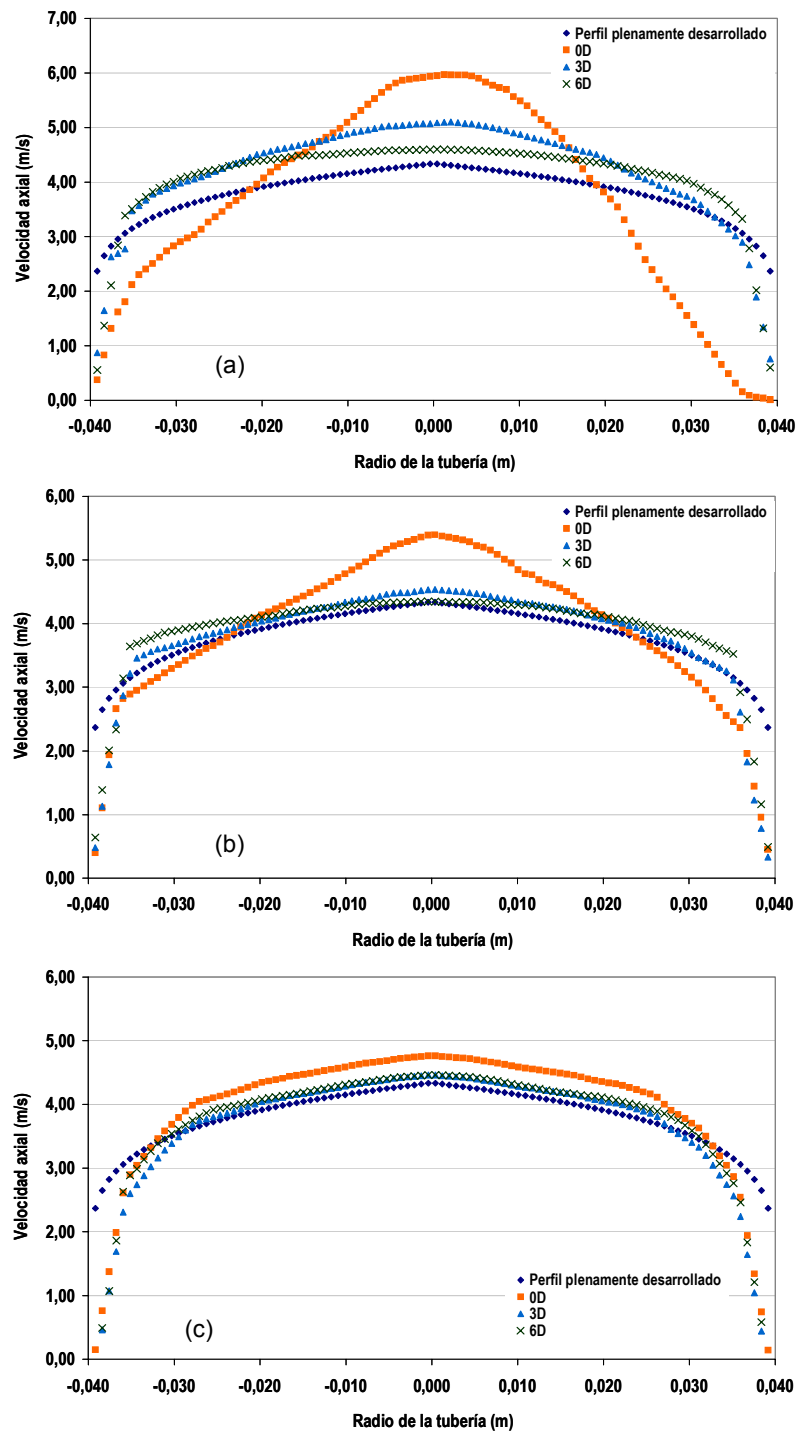

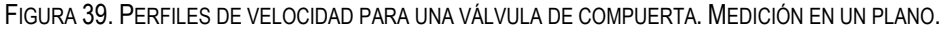

(A) $75 \%$ CERRADA (B) $50 \%$ CERRADA (C) 25\% CERRADA PARA UN CAUDAL APROXIMADO DE 70 M³/H. 
Como se advierte de los resultados, este instrumento es muy sensible a las distorsiones provocadas en el flujo de agua indicando valores muy superiores al caudal realmente circulado, incluso en las simulaciones donde se establece entre el elemento perturbador y el medidor tramos rectos de tubería. Resumiendo, este tipo de accesorio hidráulico debe instalarse a una distancia muy superior a 6D aguas arriba del caudalímetro ya que cualquier distorsión en el flujo de agua sobreestima la medición del caudal.

Asimismo, los resultados del análisis van en consonancia con ensayos realizados por la empresa Danfoss Flow Division, donde se probó el comportamiento del instrumento con múltiples accesorios instalados aguas arriba. En los resultados presentados por dicha empresa se ratifica la influencia de estas válvulas sobre el error de medición produciéndose sobrecontajes similares a los obtenidos durante el análisis numérico desarrollado en este capítulo.

TABLA 11. PRUEBAS REALIZADAS POR DANFOSS FLOW DIVISION.

\begin{tabular}{cccc}
\hline \multicolumn{4}{c}{ CAUDALímETRO DE ULTRASONIDOS } \\
en 1 plano de medición (Danfoss Flow Division) \\
\hline \multirow{4}{*}{ \% Error a } & $\%$ Error a \\
Válvula de compuerta & $2,1 \mathrm{D}$ & $6,2 \mathrm{D}$ \\
& Abierta & 4,1 & 1,9 \\
& $2 / 3$ & 12,3 & 5,9 \\
& $1 / 3$ & 16,7 & 7,6 \\
Válvula de mariposa & Abierta & 11,7 & 8,5 \\
& $2 / 3$ & 21,8 & 9,6 \\
& $1 / 3$ & 26,9 & 6,1 \\
\hline
\end{tabular}

Si se aumentan los planos de medición del caudalímetro de ultrasonidos hasta dos, colocándose los transductores a 0,52R del plano horizontal que contiene el eje de la conducción (ver Figura 14), los errores de medición disminuyen sensiblemente.

En el estudio se ha evaluado la mejora que supone en los casos más desfavorables, es decir, cuando la válvula de compuerta se encuentra cerrada al $75 \%$. Los errores de medición en este supuesto se muestran en la Tabla 12, donde la mejora producida en todo el rango de caudales de funcionamiento cuando la distancia entre elementos es de OD es evidente. El error pasa de $+20 \%$ a $+11 \%$ aproximadamente, considerándose en cualquier caso inaceptable este resultado. Manteniendo mayor distancia entre elementos, 6D, puede llegar a conseguirse con esta disposición de los transductores errores menores de $+3 \%$ cuando en el caso de un plano de medición era de $+17 \%$.

De todos modos, continua siendo esencial en este tipo de instrumento mantener una distancia mínima entre elementos superior a $6 \mathrm{D}$ aún midiendo en dos planos.

TABLA 12. ERRORES PROVOCADOS POR UNA VÁLVULA DE COMPUERTA CON LA MEDICIÓN EN DOS PLANOS A 0,52R.

\begin{tabular}{lcccccc}
\hline \multicolumn{1}{c}{ CIERRE } & $75 \%$ & 2-path & & & \\
\hline & $\mathbf{Q}\left(\mathbf{m}^{3} / \mathbf{h}\right)$ & ERROR $(\%)$ & $\mathbf{Q}\left(\mathbf{m}^{3} / \mathbf{h}\right)$ & ERROR $(\%)$ & $\mathbf{Q}\left(\mathbf{m}^{3} / \mathbf{h}\right)$ & ERROR (\%) \\
Referencia & 30,61 & & 61,30 & & 92,50 & \\
a 0D & 34,16 & $\mathbf{1 1 , 6 0}$ & 68,48 & 11,71 & 102,85 & $\mathbf{1 1 , 1 9}$ \\
a 3D & 33,36 & $\mathbf{8 , 9 8}$ & 67,13 & $\mathbf{9 , 5 1}$ & 101,75 & $\mathbf{1 0 , 0 0}$ \\
a 6D & 31,44 & $\mathbf{2 , 7 1}$ & 61,50 & $\mathbf{0 , 3 3}$ & 93,66 & $\mathbf{1 , 2 5}$ \\
\hline
\end{tabular}


La Figura 40, muestra los perfiles obtenidos en cada uno de los planos de medición, uno de la parte superior de la tubería y otro de la inferior. Además, se comparan con el perfil promedio que computaría el caudal medido por el instrumento y el perfil teórico para un caudal aproximadamente de $70 \mathrm{~m} 3 / \mathrm{h}$. Se observa que el plano inferior de medición adquiere velocidades muy elevadas, del orden de $11 \mathrm{~m} / \mathrm{s}$, debido al cierre de la compuerta, y en cambio, el superior tiene velocidades que no superan los $2 \mathrm{~m} / \mathrm{s}$. El perfil promedio continúa siendo bastante irregular, con velocidades máximas similares al supuesto de un solo plano de medición, aunque con una distorsión menos acusada.

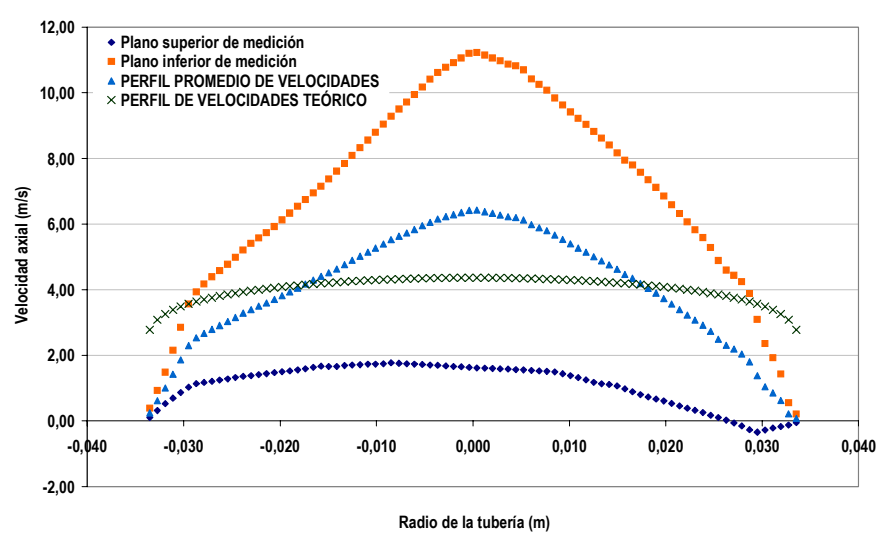

FIGURA 40. PERFILES EN DIFERENTES PLANOS DE MEDICIÓN CAUSADOS POR UNA VÁLVULA DE COMPUERTA 75\% CERRADA A OD DEL INSTRUMENTO DE MEDIDA.

Cuando se analizan los resultados del efecto que causa sobre un caudalímetro de ultrasonidos la instalación de una válvula de mariposa cercana a él se advierte, lógicamente, que el error se incrementa si ésta se encuentra parcialmente cerrada.

TABLA 13. ERRORES PROVOCADOS POR UNA VÁLVULA DE MARIPOSA MIDIENDO EN LA CUERDA DIAMETRAL.

\begin{tabular}{|c|c|c|c|c|c|c|}
\hline CIERRE & ABIERTA & & & & & \\
\hline & $Q\left(m^{3} / h\right)$ & ERROR (\%) & $Q\left(m^{3} / h\right)$ & ERROR (\%) & $Q\left(m^{3} / h\right)$ & ERROR (\%) \\
\hline Referencia & 30,5 & & 61,62 & & 92,4 & \\
\hline a OD & 33,59 & 10,13 & 67,79 & 10,01 & 101,06 & 9,37 \\
\hline a 3D & 32,05 & 5,08 & 64,80 & 5,16 & 95,90 & 3,79 \\
\hline a $6 D$ & 31,59 & 3,57 & 63,73 & 3,42 & 95,20 & 3,03 \\
\hline \multirow[t]{2}{*}{ CIERRE } & $30^{\circ}$ CERRADA & & & & & \\
\hline & $Q\left(m^{3} / h\right)$ & ERROR (\%) & $Q\left(m^{3} / h\right)$ & ERROR (\%) & $Q\left(m^{3} / h\right)$ & ERROR (\%) \\
\hline Referencia & 30,68 & & 61,80 & & 92,62 & \\
\hline a OD & 36,72 & 19,69 & 73,77 & 19,37 & 112,12 & 21,05 \\
\hline a 3D & 36,14 & 17,80 & 71,13 & 15,09 & 108,10 & 16,71 \\
\hline a 6D & 35,39 & 15,35 & 69,82 & 12,98 & 101,62 & 9,72 \\
\hline
\end{tabular}

La instalación de una válvula de mariposa aguas arriba del instrumento de medida desequilibra el flujo de agua fundamentalmente en la zona central de la cuerda, como se observa en la Figura 41, en la que se presentan los perfiles de velocidad en esta cuerda de medición del caudalímetro a varias distancias de la válvula en posición abierta. Cuando ésta se halla a OD del instrumento la forma del perfil es más irregular y el error estimado se encuentra en torno al $+10 \%$. En cambio, cuando la distancia entre elementos es mayor, la forma del perfil se ve prácticamente restablecida aunque sin llegar a la distribución de velocidades de un perfil plenamente desarrollado, obteniéndose errores ligeramente positivos. 


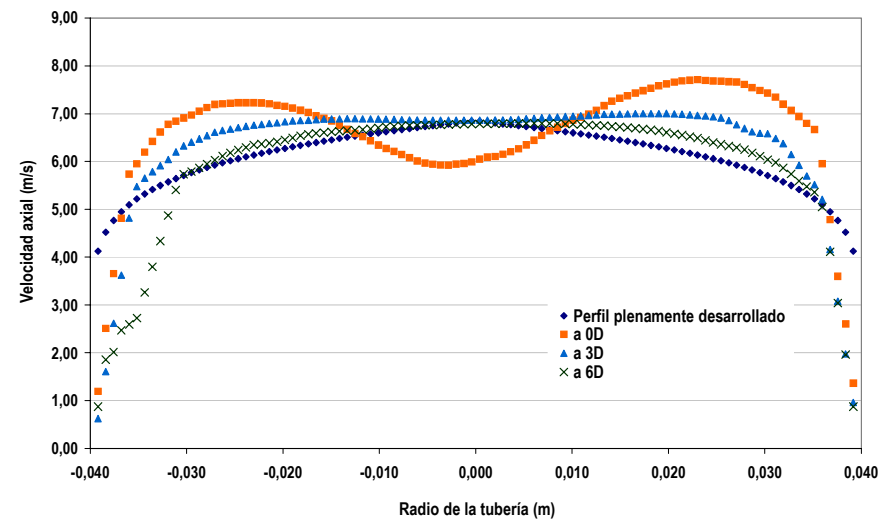

FIGURA 41. PERFIL DE VelocidadeS tRAS UNA VÁlVULA de MARIPOSA ABIERTA. QAprox $=70$ M³/H.

Si la válvula se cierra $30^{\circ}$ la deformación sufrida en los perfiles se evidencia en todas las distancias simuladas (Figura 42). Los errores de medición en este caso son del orden de $+20 \%$ para $0 \mathrm{D}$ y aproximadamente $+15 \%$ a $6 \mathrm{D}$.
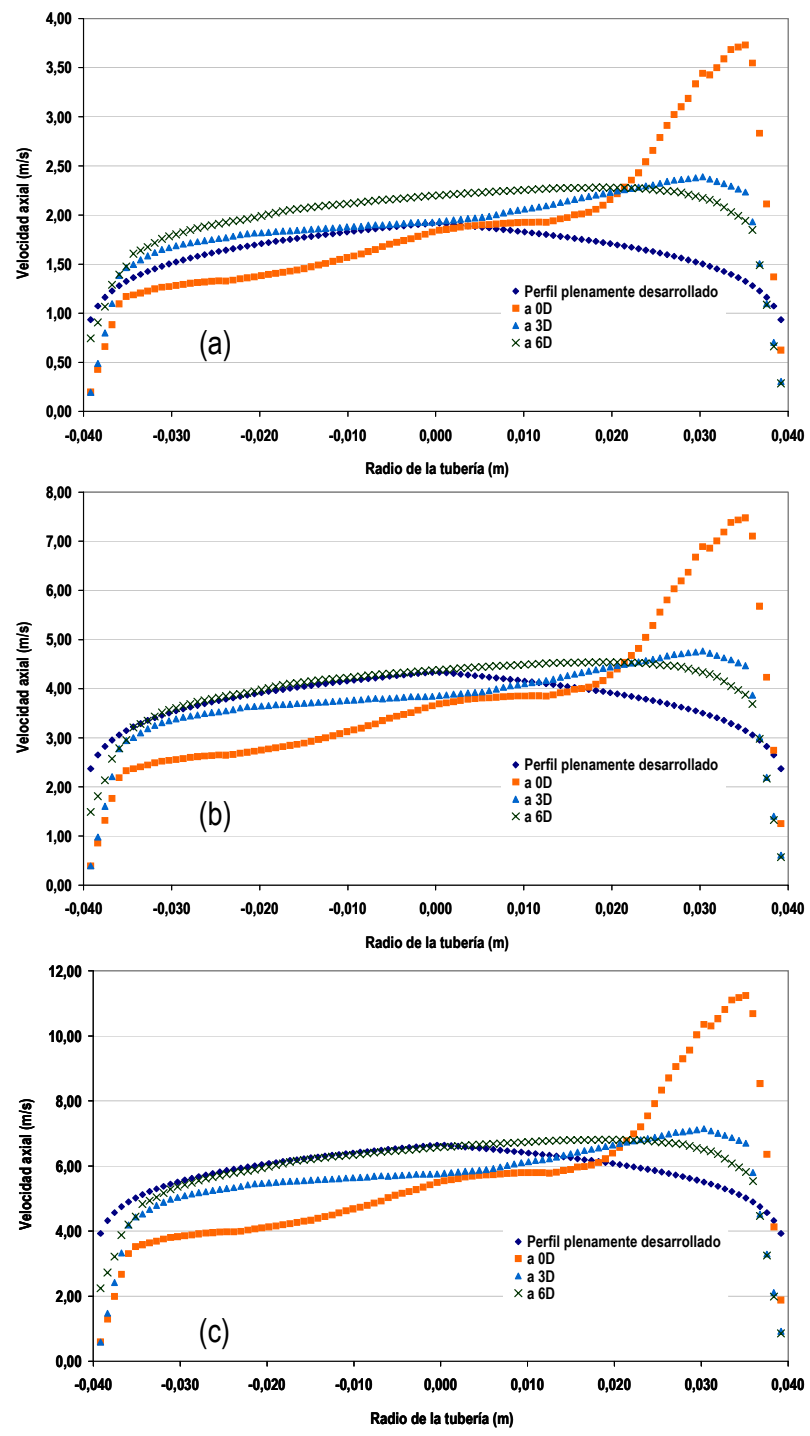

FIGURA 42. PERFILES DE VELOCIDAD DE UNA VÁLVULA DE MARIPOSA $30^{\circ}$ CERRADA SIMULADA A DIVERSOS CAUDALES. 
Si la medición se realiza en dos planos, la mejora obtenida se presenta en la Tabla 14.

TABLA 14. ERRORES PROVOCADOS POR UNA VÁLVULA DE MARIPOSA CON LA MEDICIÓN EN DOS PLANOS A 0,52R.

\begin{tabular}{lcccccc}
\hline CIERRE & $30^{\circ}$ & 2-path & & & & \\
\hline & $\mathbf{Q}$ & ERROR & $\mathbf{Q}$ & ERROR & $\mathbf{Q}$ & ERROR \\
\cline { 2 - 7 } Referencia & 30,68 & & 61,50 & & 92,50 & \\
a 0D & 32,21 & $\mathbf{4 , 9 9}$ & 63,80 & $\mathbf{3 , 7 4}$ & 95,94 & $\mathbf{3 , 7 2}$ \\
a 3D & 31,46 & $\mathbf{2 , 5 4}$ & 62,70 & $\mathbf{1 , 9 5}$ & 94,38 & $\mathbf{2 , 0 3}$ \\
a 6D & 30,65 & $\mathbf{- 0 , 1 0}$ & 61,49 & $\mathbf{- 0 , 0 2}$ & 92,94 & $\mathbf{0 , 4 8}$ \\
\hline
\end{tabular}

\subsection{CONCLUSIONES}

A menudo, la medición en redes de agua no se lleva a cabo correctamente por la inapropiada instalación y utilización de los instrumentos de medida. Por un lado existe un marcado desconocimiento de muchos técnicos del modus operandi de los aparatos. Por otro lado no se siguen las recomendaciones que realizan los fabricantes sobre su manejo e instalación.

Precisamente uno de los objetivos de este capítulo consiste en contrastar estas recomendaciones. Se ha propuesto un procedimiento que mediante simulaciones numéricas realizadas mediante técnicas CFD combinadas con diferentes tecnologías de medición, en condiciones de funcionamiento e instalación diversas, permite cuantificar los errores de medición que se pueden producir como consecuencia de distorsiones en los perfiles de velocidad. Los resultados obtenidos mediante esta técnica coinciden cualitativamente con las pruebas realizadas en laboratorio en el capítulo anterior, y los ensayos de otros laboratorios.

Por un lado, se ha comprobado que las alteraciones en el flujo de agua afectan de forma diferente a cada uno de los instrumentos de medida, por lo que resulta crucial conocer perfectamente el principio de funcionamiento de cada aparato para poder predecir su respuesta en condiciones de trabajo no ideales. En este sentido durante el desarrollo de la Tesis se ha abordado el estudio de los instrumentos más comunes en una red de abastecimiento. Por otro lado, es importante tener en cuenta el tipo de distorsión que genera cada elemento hidráulico con el fin de estimar cómo afecta a la medición en cada uno de los casos estudiados. Es evidente que la distorsión causada por una válvula de mariposa no tiene porque generar errores del mismo orden de magnitud que la distorsión provocada por un codo.

En el caso concreto de un contador Woltman de eje horizontal cuando el flujo de agua llega distorsionado se comprueba que el ángulo de aproximación del fluido con los álabes varía incidiendo en ocasiones, localmente, con ángulos negativos que frenan la hélice del contador. La magnitud de los vectores de velocidad difiere de un perfil plenamente desarrollado, y como se vio en los casos abordados, la incidencia desequilibrada del flujo sobre los álabes del Woltman generaba un error de medición positivo, debido al aumento en la velocidad de rotación consecuencia de un mayor par motriz. Estos errores calculados mediante análisis numérico son marcadamente más altos que los experimentales del Capítulo 3 en el caso de una válvula de compuerta $75 \%$ cerrada donde se llegan a obtener valores de $+40 \%$.

Es importante tener en cuenta que el método de análisis numérico presentado debe considerarse cualitativo, ya que en el caso del contador Woltman no se han considerado detalladamente factores como el diseño de los álabes y tampoco se ha simulado la hélice en movimiento. El objetivo ha sido construir un modelo simplificado con el único fin de cuantificar a grosso modo la magnitud de los errores que se pueden producir.

Con el método propuesto es posible apreciar que cuando una válvula de compuerta se encuentra instalada junto al contador en posición completamente abierta la distorsión del flujo de agua es mínima y, consecuentemente, la medición no se ve afectada de forma significativa. En este caso, la colocación de tres diámetros de tubería recta aguas arriba del contador Woltman es suficiente para paliar los posibles errores de medición en caso de un cierre parcial de la válvula. 
En el caso de la simulación de una válvula de mariposa instaladas tres diámetros aguas arriba del contador Woltman los errores, tanto abierta como parcialmente cerrada, son similares y aproximadamente del $-0,5 \%$. Aunque, el flujo de agua sufre cierta alteración cuando la válvula se cierra, parece que logra estabilizarse antes de llegar a la turbina del contador Woltman instalado a tres diámetros de tubo recto de ella, midiéndose finalmente el caudal con un error reducido.

Por otro lado, las principales conclusiones del estudio del comportamiento sobre un caudalímetro electromagnético ficticio muestran que cuando el flujo se encuentra distorsionado, con velocidades altas en zonas lejanas de los electrodos de medida, el instrumento tiende a subcontar. Al contrario, cuando el flujo está desequilibrado, pero las velocidades más altas se localizan en la zona central o cercana a los electrodos, se sobreestima el caudal circulante por la conducción. Mantener seis diámetros de tramos rectos de conducción entre el instrumento y la perturbación mejorará significativamente el error en todos los casos.

Por último, el caudalímetro de ultrasonidos se ha mostrado muy sensible a las distorsiones en el flujo de agua. Cierres en la válvula de compuerta del $75 \%$ y el $50 \%$ generan alteraciones importantes difíciles de compensar por este instrumento. Sólo cuando la distorsión es prácticamente inapreciable, como en el caso de las válvulas casi o totalmente abiertas, se puede afirmar que la instalación de un elemento perturbador aguas arriba no afecta a la medición de forma significativa. La mejora introducida cuando la medición se realiza mediante un caudalímetro con sondas en dos planos es evidente, reduciéndose el error en todos los ejemplos supuestos.

Como conclusión, estos instrumentos requieren un mínimo de seis diámetros de tubería recta aguas arriba del caudalímetro para conseguir una medición aceptable del caudal circulante, siempre y cuando la perturbación no sea importante. En cambio, la respuesta de aparato de medida exige unas longitudes en tramos rectos mucho mayores ante distorsiones más acentuadas, como la provocada por una válvula de regulación o la combinación de dos codos en diferentes planos.

\subsection{BIBLIOGRAFÍA CONSULTADA}

Al-Rabeh R.H., Baker R.C. (1979). Optimisation of convencional electromagnetic flowmeters. Fluid Mechanics Silver Jubilee Conference. Nacional Engineering Laboratory. Glasgow. Paper 6.1.

Arregui F.J. Instituto Tecnológico del Agua. (2001). Medición en sistemas de distribución de agua. Curso postgrado en la Universidad Politécnica de Valencia.

Arregui F.J., Palau C.V., Garcia-Serra J., Herrero M. (2004). Contadores de agua para riego. Medición y recomendaciones prácticas. Riegos y drenajes XXI. Vol.134. pp. 36-42.

Baker R.C. Flow measurement handbook. (2000). Ed. Cambridge University Press.

Baker R.C. (1993) Turbine Flowmeter II. Theoretical and experimental published information.. Flow measurement and instrumentation. Vol. 4. no 3. pp.123-144.

Baker R.C and Thompson E.J. (1975). A two beam ultrasonic phase-shift flowmeter. Conference on Fluid Flow Measurement in the Mid 1970's.Glasgow. Escocia.

Bates C.J. (2000). Performance of two electromagnetic flowmeters mounted downstream of a $90^{\circ}$ mitre bend/reducer combination. Measurement. Vol. 27. pp.197-206.

Danfoss Flow División. Documentación interna.

Davis J.A., Stewart M. (2002). Predicting globe control valve performance- Part I: Experimental verification. ASME Journal of Fluids Engineering. Vol. 124. pp.772-777.

Davis J.A., Stewart M. (2002). Predicting globe control valve performance- Part II: Experimental verification. ASME Journal of Fluids Engineering. Vol. 124. pp.778-783. 
Espert V. (2003). Apuntes sobre energía eólica. Universidad Politécnica de Valencia.

FLUENT, (2000). User`s Manual. Version 6.1. Ed. Fluent Inc.

Halttunen J. (1990). Installation effects on ultrasonic and electromagnetic flowmeters: a model-based approach. Flow measurement and Instrumentation. Vol.1. pp.287-292.

Hanson B.R., Schwankl, L.J. (1998). Error analysis of flowmeter measurements. Journal of Irrigation and Drainage Engineering. Vol.124. № 5. pp. 248-256.

Huang Ch., Rhyn H.K. (1996). Three-dimensional analysis of partially open butterfly valve flows. ASME Journal of Fluids Engineering. Vol. 118. pp.562-568.

Islam M., Seshadrl V., Singh S.N., Hasan M.M. (2003). Skewed velocity profile effect on turbine flowmeter performance. Proceeding of the Institution of Mechanical Engineers. Vol. 217. Part E. J. Process Mechanical Engineering. pp.25.

Lee J.J, Wellford L.C. (1997). Transient Fluid-Structure interaction in a control valve. ASME J. Fluids Eng, Vol.119. pp. 354359 .

Lim K,W., Myung K.Ch. (1998). Relative errors in evaluating the electromagnetic flowmeter signal using the weight function method and the finite volume method. Flow measurement and Instrumentation. Vol.9. pp. 229-235.

Lim K,W., Myung K.Ch. (1999). Numerical investigation on the installation effects of electromagnetic flowmeter downstream of a $90^{\circ}$ elbow-laminar flow case. Flow measurement and Instrumentation. Vol.10. pp. 167-174.

National Engineering Laboratory (2002). Auditing water flow metering systems. Flow Centre. Glasgow. United Kingdom.

Sánchez G., Rivas A. (2003). Computational fluid dynamic approach to the design of a single-jet water meter. Proceedings Pumps, Electromechanical devices and systems applied to urban water management. Vol.I. pp. 405-413.

Streeter V.L., Wilie E.B., Bedford K.W. (2000). Mecánica de fluidos. Ed. McGrawhill.

Vaughan N.D.,Johnston D.N., Edge K.A. (1992). Numerical simulation of fluid flow in poppet valves. 1992. Proc. Inst. Mech. Eng., Vol. 206. pp119-127.

Versteeg H.K, Malalasekera W. (1995). An Introduction to Computational Fluid Dynamics. The finite volume method. Ed. Longman.

Yoder J. (2002). Despite market declines, turbine flowmeters remain major segment. Flow control. pp. 52-55.

Wadlow D. (1998). Turbine flowmeters. The measurement, Instrumentation and Sensors Handbook.

Wallis R.A (1961).Axial flow fans design and practice, London: George Newnes.

\section{Catálogos / Especificaciones técnicas}

Actaris (Contador tipo Woltman).

Controlotron (Ultrasonidos).

Elster (Electromagnético, Woltman).

Flow Research (Inserción tipo molinete).

Foxboro (Vórtex, electromagnéticos).

Krohne (Vórtex, electromagnéticos, ultrasonidos, área variable).

Panametrics (Ultrasonidos). 
CAPÍTULO 5

CÁLCULO DEL ERROR GLOBAL DE UN CONTADOR DE AGUA 


\section{CÁLCULO DEL ERROR GLOBAL DE UN CONTADOR DE AGUA}

\subsection{INTRODUCCIÓN}

El sistema de micromedición de un abastecimiento urbano es una de las partes fundamentales en la instrumentación de una empresa de agua, pues a partir de los micromedidores o contadores de agua domésticos la empresa factura el agua usada por las familias que puede llegar a representar el $70 \%$ del agua facturada. Es por ello que optimizar la gestión de estos instrumentos debe considerarse un objetivo primordial.

La presente Tesis aborda este tema, continuando el trabajo presentado por Arregui en 1999, con el propósito de plantear ciertas propuestas que mejoren la gestión del parque, compendiando todo el trabajo de campo y laboratorio desarrollado en los últimos años.

Optimizar la gestión de estos instrumentos de medida significa, desde el punto de vista del consumidor contabilizar correctamente el agua que consume, y desde el de la empresa maximizar los ingresos obtenidos de los usuarios y reducir los costes que supone mantener el sistema de medición funcionando.

Para ello, el parque de contadores debe mantenerse en las mejores condiciones posibles, conociendo la vida útil de los diferentes modelos, supervisando la calidad de los contadores nuevos adquiridos a proveedores dentro de un plan de calidad total, controlando mediante el sistema de información comercial (SIC) o mediante GIS la evolución de las facturaciones, reconociendo paradas de contador, consumos anormalmente altos, decrecimiento gradual no justificado de la facturación, etcétera. Todos estos puntos ayudan en la gestión y optimización de los instrumentos de medida de la red urbana, y algunos de ellos, se irán desarrollando en capítulos posteriores.

En el presente capítulo, trata de forma más compleja, que llegaría en ocasiones a pecar de excesivamente afinada, la metodología para la evaluación del error global de medición de un parque de micromedidores. Conocer este error, como se comenta en Cabrera et al. (1999), contribuirá a discriminar los términos del balance de agua de una red y permitirá establecer frentes de ataque en la gestión, identificando los puntos más débiles de cada abastecimiento.

Hasta la fecha se han desarrollado metodologías más o menos simplificadas para obtener el volumen de agua no registrado (VNR) por el sistema de micromedidores, y con ello, la vida útil de los mismos. Este es un objetivo que persigue cualquier técnico encargado de la gestión del parque de contadores. La frecuencia de renovación de los instrumentos de medida depende del tipo de política que practique la empresa. Ésta puede estar basada en criterios de optimización económica de 
costes, como se detalla en la Tesis de Arregui (1999), donde se busca el mínimo de la curva de costes medios anuales considerando como costes fijos los costes de compra e instalación de contadores y, como costes variables, el agua no facturada debido a subcontaje de la población de medidores. Durante el Capítulo 6 (epígrafe 3), se describe de forma práctica el método para el cálculo del periodo óptimo de renovación de micromedidores teniendo en cuenta criterios económicos.

Otro tipo de política de renovación de contadores puede satisfacer criterios legales impuestos por el gobierno autonómico o municipal competente. También existen políticas cuyos criterios se basan en la propia calidad metrológica del instrumento. Generalmente este tipo de gestión es común en empresas de agua donde el precio del metro cúbico es bajo, y aplicar criterios de optimización de costes conduciría a un periodo óptimo de sustitución de contadores muy elevado que no sería "estéticamente correcto".

Luego, conocer el volumen no registrado por un contador, lo que se denomina error global de medición o por algunas empresas del sector, error medio ponderado, permite realizar un analisis económico de la rentabilidad del sistema de medición y considerar la proporción de agua inyectada a un sector que deja de registrarse por subcontaje de medidores.

Como se puede observar en la curva de error de cualquier catálogo de contadores de agua (Figura 1), el error de medición de un contador depende del caudal que circule por el mismo. De esta forma, el error global de medición se calcula a partir de la ponderación de dos parámetros, la curva de error característica de cada instrumento y el patrón de consumo, es decir, los caudales de consumo típicos de los usuarios de dicha localidad.

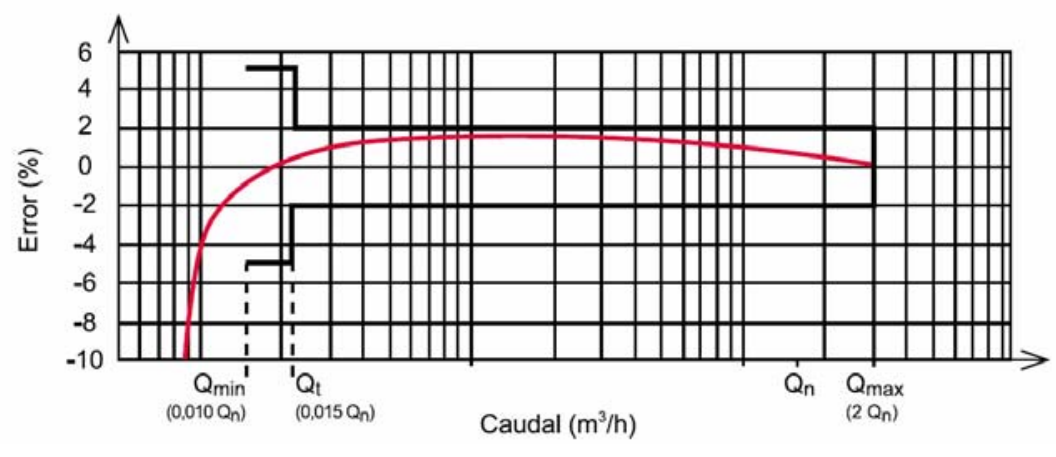

FIGURA 1. CURVA DE ERROR DE UN CONTADOR DE AGUA.

Este fenómeno de dependencia del error respecto la variable física caudal, conlleva el desarrollo de dos líneas de estudio diferentes para el cálculo del error global de un contador. Por una parte, indagar sobre los caudales circulantes por el instrumento de medida estableciendo patrones de consumo de los usuarios del agua. El patrón de consumo o curva de consumos clasificados, como cita Arregui (1999) en su Tesis doctoral, es el volumen de agua que se consume en cada rango de caudales, es decir, similar a un histograma de frecuencias que detalla el porcentaje de volumen consumido en cada intervalo de caudal. Por otra parte, debe profundizarse en el estudio de la evolución del propio error de medición con diferentes tecnologías, marcas, edades, etcétera, tal y como se hizo en el Capítulo 3 con ensayos en laboratorio.

La correcta combinación de estos parámetros proporciona el error global de medición, weighted accuracy en terminología anglosajona, que viene expresado en tanto por ciento de la lectura efectuada. Así, un error negativo del $-10 \%$ vendrá de la ponderación del volumen de agua consumido en cada rango de caudales establecido con el error de medición en esos puntos de la curva. En conjunto, el error global de medición de una subpoblación se estimará mediante muestreos en viviendas sobre la forma de consumo habitual de sus abonados y de la evaluación del estado de su sistema de 
micromedición. Una vez hallada la media muestral de ambos parámetros y sus incertidumbres se pondera para estimar el volumen no registrado de la subpoblación.

Las propuestas para la mejora del cálculo del error global deben ir encaminadas a optimizar aquellos parámetros que afectan a este error global, es decir, la curva de error de un contador y el patrón de consumo del usuario, obtenidos de los resultados de laboratorio y de las mediciones en campo.

Otro de los propósitos de este capítulo es repasar las metodologías de ponderación propuestas por diferentes autores, comparándolas con los resultados de los ensayos en laboratorio y reparando en algunos aspectos críticos en el cálculo del error global de medición del sistema.

El capítulo está estructurado de la siguiente manera. Inicialmente se explica de forma resumida el proceso que se debe seguir para obtener el error global de un parque de contadores de agua, y posteriormente se exponen las propuestas realizadas sobre este tema con el fin de discernir en qué puntos se debe mejorar o variar la ponderación.

\subsection{CURVA DE ERROR}

\subsubsection{ELECCIÓN DE LOS CAUDALES DE ENSAYO}

Uno de los puntos clave en el cálculo del error global es el procedimiento escogido para describir la curva de error de los contadores ensayados en el laboratorio. Conocer de forma precisa el error asociado a cada caudal, detallando la curva de error de todos los contadores, supone un gasto inabordable por cualquier empresa de agua. Es por ello que se recomienda el ensayo de los caudales más significativos que puedan representar de forma más o menos aproximada esta curva.

La elección correcta de estos caudales para simplificar la reconstrucción de la curva de error puede ser importante a la hora de ponderarla con el patrón de consumo.

Los caudales de ensayo encontrados en la bibliografía son diversos, por ejemplo, los estándares de la AWWA (1986) recomiendan el ensayo de tres caudales (bajo, medio y alto) para cubrir todo el rango de medida del contador, 56.78, 454.2 y $3406.8 \mathrm{l} / \mathrm{h}$. Planells et al. 1987, ajusta estos caudales de ensayo a un contador clase metrológica B de $13 \mathrm{~mm}$, proponiendo nuevos ensayos a $39 \mathrm{l} / \mathrm{h}, 300 \mathrm{l} / \mathrm{h}$ y $2.280 \mathrm{l} / \mathrm{h}$, siendo el caudal máximo inferior al propuesto por la AWWA. Arregui, en diversos estudios plantea reducir los caudales altos de ensayo e incrementar el número de ensayos a caudales más bajos, ya que la variabilidad del error a estos caudales es menor que en rangos inferiores de caudal. Durante un tiempo los caudales de ensayo en clase B propuestos por Arregui (1999) fueron 30,60, 120, 500, $1500 \mathrm{l} / \mathrm{h}$, más tarde, en 2001 suprime el caudal de $60 \mathrm{l} / \mathrm{h}$, y el de 500 se sustituye por $750 \mathrm{l} / \mathrm{h}$ al considerarse más representativo que este último. El hecho de suprimir el caudal de $60 \mathrm{l} / \mathrm{h}$ es cuanto menos cuestionable, ya que en los tramos inferiores de caudal los contadores son más imprecisos, a parte de tener mayor variabilidad que a caudales superiores.

La mayoría de los ensayos llevados a cabo en la presente Tesis a contadores de calibre $13 \mathrm{~mm}$ adoptaron esta última propuesta con caudales de ensayo para clase B a 30, 120, 750 y $1500 \mathrm{l} / \mathrm{h}$, además del ensayo al caudal de arranque, como se comentó en el Capítulo 3. A partir de estos resultados y mediante ensayos en detalle realizados para obtener la curva de error de varios modelos y clases metrológicas es posible evaluar los caudales característicos que describirían mejor la curva y con ellos comparar los diversos métodos de ponderación.

\subsubsection{CLASIFICACIÓN DEL RITMO DE DETERIORO DE LA CURVA DE ERROR}

Tras el estudio en profundidad, visto en capítulos anteriores, sobre cómo evoluciona la precisión de los contadores con el tiempo y de los factores que afectan en mayor o menor medida a su curva de error, en este epígrafe se plasman sólo los 
principales resultados obtenidos y se establecen tres categorías que son capaces de describir, de forma generalizada, el ritmo de deterioro de la curva de error de un contador.

Factores como, la posición de instalación que provoca un deterioro prematuro del instrumento, o el grado de dureza del agua que incrementa las deposiciones calcáreas provocando un mayor rozamiento de la turbina del contador y modificando su curva de error, permiten estimar a priori y de forma aproximada el posible ritmo de deterioro de la curva de error de un contador.

Todos estos aspectos deben ser tenidos en cuenta a la hora de categorizar el posible deterioro de un determinado modelo con el objetivo de facilitar la labor del técnico a la hora de calcular el volumen de agua no contabilizado. No obstante, esta clasificación no deja de ser estimativa ya que cada tecnología e instrumento que sale de fábrica puede tener una evolución diferente. Por ello, siempre es recomendable muestrear las diferentes subpoblaciones para hallar el error promedio a cada caudal de ensayo.

Las categorías establecidas van desde aquellos contadores con un ritmo de deterioro alto con el paso tiempo hasta aquellos que mantienen prácticamente constante su precisión inicial. A partir de las experiencias adquiridas durante el desarrollo de la presente Tesis se ha realizado una clasificación de lo que podría considerarse un ritmo de deterioro lento, medio y rápido a cada caudal. Dicha clasificación de los ritmos de deterioro propuestos en la presente Tesis doctoral a partir de los ensayos de contadores en en laboratorio a diferentes caudales de ensayo, se presenta en la Tabla 1.

TABLA 1. CLASIFICACIÓN DEL RITMO DE DETERIORO

\begin{tabular}{cccc}
\hline Error & RÁPIDO (\%) & MEDIO (\%) & LENTO (\%) \\
\hline a $30 \mathrm{l} / \mathrm{h}$ & $-4,3$ & $-1,1$ & $-0,4$ \\
a $120 \mathrm{l} / \mathrm{h}$ & $-0,7$ & $-0,4$ & $-0,0$ \\
a $750 \mathrm{l} / \mathrm{h}$ & $-0,2$ & $-0,2$ & 0,1 \\
a $1500 \mathrm{l} / \mathrm{h}$ & $-0,2$ & $-0,1$ & 0,1 \\
\hline
\end{tabular}

Se observa, que independientemente del ritmo de deterioro del error a los caudales de 750 y $1500 \mathrm{l} / \mathrm{h}$, están muy próximos a cero. Por el contrario, es a caudales bajos donde se aprecian diferencias significativas.

\subsection{PATRÓN DE CONSUMO DE LA POBLACIÓN}

\subsubsection{ESTUDIOS PREVIOS}

Como se justificó en capítulos anteriores, el patrón de consumo de una población es una inquietud que desde siempre han tenido las compañías de agua, no solo para realizar un correcto dimensionado de las tuberías calculando las demandas producidas en los nudos, sino para dimensionar correctamente todos los accesorios de la red y con ello garantizar una buena gestión del sistema.

El patrón de consumo o curva de consumos clasificados es el volumen de agua que se consume en cada rango de caudales. Establecer los rangos de caudal para agrupar los consumos de agua en volúmenes independientes a los cuales se le aplicará una determinada precisión del instrumento es crucial para calcular el volumen de agua no registrado.

El estudio de la AWWARF 1993 (Bowen et al. 1993), es probablemente el más completo y más fiable de los mostrados en la Tabla 2. En él se empezaron a utilizar equipos de adquisición de datos electrónicos. En concreto, se emplearon 
registradores electrónicos que eran capaces de recoger los impulsos eléctricos provenientes de los contadores, calcular el caudal al que se había consumido dicho volumen y almacenarlo dentro de uno de los 17 rangos de caudales que se consideraron. De esta forma se pudo procesar, con una baja probabilidad de error por fallo humano, un volumen de datos considerable.

TABLA 2. PATRÓN DE CONSUMO ESTABLECIDOS POR DIVERSOS AUTORES.

\begin{tabular}{cccccccccc}
\hline & \multicolumn{7}{c}{ Caudal en litros por hora (I/h) } \\
\hline & & $0-57$ & $57-114$ & $114-228$ & $228-456$ & $456-906$ & $906-1362$ & $1362-2268$ & $>2268$ \\
\hline & AÑO & $0-0,25$ & $0,25-0,50$ & $0,50-1$ & $1-2$ & $2-4$ & $4-6$ & $6-10$ & $>10,00$ \\
\hline Kuranz & 1942 & 13,6 & 1,8 & 5 & 11,8 & 52,4 & 14,7 & 0,7 & 0 \\
Graeser & 1958 & 5 & 6 & 8 & 31 & 40 & 10 & 0 & 0 \\
Hudson & 1964 & 13 & 3,4 & 6,8 & 13,3 & 43 & 20,5 & 20,5 & 0 \\
AWWA & 1966 & 4,6 & 5,9 & 13,7 & 59 & 16,8 & 0 & 0 & 0 \\
Sisco & 1969 & 1 & 4 & 81 & 4 & 10 & 0 & 0 & 0 \\
Nielsen & 1969 & 8 & 11 & 18 & 39 & 20 & 4 & 0 & 0 \\
Brittain & 1974 & 2,6 & 1,6 & 10 & 21,9 & 33,5 & 19,7 & 10,5 & 0,2 \\
Yanov & 1987 & 2,6 & 2,3 & 1,2 & 8 & 28,7 & 20,5 & 18,9 & 17,8 \\
Bowen AWWA & 1993 & 8,8 & 1,2 & 3,1 & 27,6 & 14,8 & 28,0 & 13,1 & 3,4 \\
\hline
\end{tabular}

A la baja fiabilidad, asociada a la gran discrepancia de resultados sobre patrones mostrada en la Tabla 2, hay que añadir que éstos corresponden a ciudades americanas en las que claramente las variables que influyen en los mismos, como la tipología de las instalaciones interiores, el tamaño de la vivienda, las características de los aparatos de consumo, la climatología, etcétera, adoptan valores distintos a los que se pueden encontrar hoy en día en España.

Allender (1996) y Yee (1999) en diversos estudios más actualizados clasifican los consumos en tres amplios rangos de caudal, bajo, medio y alto, correspondientes a consumos con caudales menores de 0.25 , de 0.25 a 2 y mayores que 2 gpm. En la Tabla 4 pueden verse estos patrones de consumo. Arregui (2001) propone rangos de caudal diferentes debido, en parte, a la buena resolución del equipo de adquisición de datos utilizado (emisor de pulsos 0,1 l/pulso)

TABla 3. PAtrones de Consumo de Allender (1996) Y YEE (1999).

\begin{tabular}{cccc}
\hline PROPUESTA & RANGOS & $\begin{array}{c}\text { Rangos del } \\
\text { patrón (l/h) }\end{array}$ & \% consumo \\
\hline \multirow{3}{*}{ Allender (1996) } & BAJO & $0-56.78$ & 12 \\
& MEDIO & $56.78-454.25$ & 86 \\
& ALTO & $>454.25$ & 2 \\
\hline \multirow{3}{*}{ Yee (1999) } & BAJO & $0-56.78$ & 5 \\
& MEDIO & $56.78-454.25$ & 15 \\
& ALTO & $>454.25$ & 80 \\
\hline
\end{tabular}

TABLA 4. RANGOS DE CAUDAL EN EL PATRÓN DE ARREGUI (2001).

\begin{tabular}{cc}
\hline PROPUESTA & $\begin{array}{c}\text { Rango del patrón } \\
(\mathrm{I/h})\end{array}$ \\
\hline Arregui (2001) & $0-12$ \\
& $12-24$ \\
& $24-36$ \\
& $36-72$ \\
& $72-180$ \\
& $180-1500$ \\
& $1500-3000$ \\
& $>3000$ \\
\hline
\end{tabular}


Durante las mediciones llevadas a cabo en los últimos años se ha logrado medir en diferentes poblaciones donde se han obtenido patrones de consumo bastante dispares dependientes de las variables que determinan el consumo de sus habitantes. A continuación se describen los resultados obtenidos.

\subsubsection{MEDICIONES EN CAMPO}

La medición de los caudales que se trasiegan, tanto por las tuberías principales como por las instalaciones interiores, es fundamental en todo abastecimiento urbano. En el presente epígrafe, se describen las mediciones realizadas en distintas localidades del la Comunidad Valenciana por Arregui (1999) y la continuación de su labor mostrada en la presente Tesis.

De cara a calcular el volumen no registrado por un contador interesa especialmente el porcentaje de agua usada a caudales bajos, donde la curva de error se deteriora con mayor facilidad. A caudales medios y altos, la curva de error de los contadores es muy plana, por lo que las posibles variaciones del porcentaje usado a dichos caudales tendrían un efecto mínimo sobre el error global de medición.

Un error en el que se incurre fácilmente es atribuir a una población un solo patrón de consumo. Existen numerosos factores que influyen en la forma de consumir de una población. Cuando se habla de la forma de consumir se piensa en los hábitos de las personas, que fundamentalmente dependen de su forma de vida y del clima de la zona. Estos factores influyen de forma similar en el patrón de consumo de la población, y en media suelen ser comunes para toda la subpoblación 0 población.

Existen factores que afectan al patrón de consumo y que son ocasionados por estado de las instalaciones de agua. De esta forma, el consumo a caudales bajos tienen orígenes perfectamente conocidos y se puede considerar no intencionado, es decir, son consumos "involuntarios". Las fugas en las instalaciones de los abonados, normalmente con caudales asociados cercanos a $10 \mathrm{l} / \mathrm{h}$, que se agravan a medida que la instalación interior es más antigua y la calidad de los materiales, tuberias y aparatos de consumo es peor. También como se comentó en el Capítulo 3, la ultima fase de llenado de las cisternas de los inodoros condiciona el volumen de agua no registrado. Admitiendo 0.6 litros de volumen no registrado por cisterna y con 20 usos diarios, se obtiene un total de 12 litros/día que para una vivienda con un consumo de $500 \mathrm{l} /$ día representa un $2.4 \%$ del volumen diario consumido.

Por otra parte, otros factores que influyen sobre los consumos propiamente intencionados son los factores climáticos, la tipología de vivienda, la presencia de un jardín, etcétera. Evidentemente, el usuario en estos casos variará su forma de consumo y deberá tenerse en cuenta a la hora de establecer subpoblaciones.

Por último, hay factores que son inherentes al equipo de adquisición de datos utilizado. Arregui (1999) realizó un minucioso análisis de las distorsiones que introducen los equipos de medida empleados en campo sobre el patrón. Teniendo en cuenta sus apreciaciones durante la fase de medición en campo se utilizaron los siguientes equipos para establecer los patrones de consumo de cada subpoblación muestreada:

- Contadores volumétricos de precisión, clase metrológica $C$, con un caudal de arranque de $1 \mathrm{l} / \mathrm{h}$ que logran detectar practicamente cualquier tipo de consumo.

- Emisores de impulsos inductivos acoplados al contador que envian una señal cada 0,1 litros. La distorsión en el patrón está directamente relacionada con el volumen asociado, un volumen alto (p.e $1 \mathrm{l} /$ pulso) lamina los caudales punta detectados y aumenta artificialmente el volumen asignado a caudales más bajos. 
- $\quad$ Equipos registradores (dataloggers) programables con 4 entradas digitales, lo que posibilita la medición de 4 viviendas al mismo tiempo, con una memoria de $256 \mathrm{~Kb}$. Intervalo de muestreo cada 10 segundos.

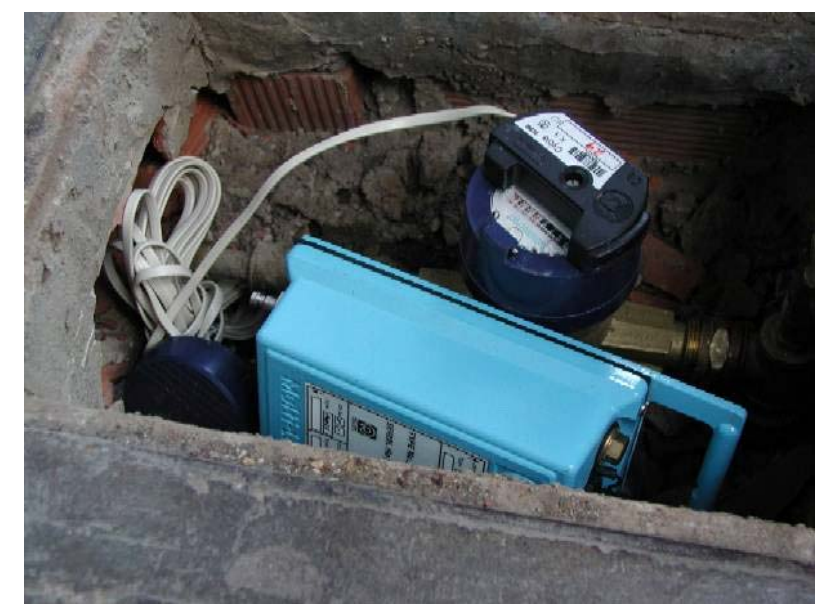

FIGURA 2. EQUIPO DE ADQUISICIÓN DE DATOS PARA LA ESTIMACIÓN DEL PATRÓN DE CONSUMO.

De esta forma se establecen subpoblaciones de viviendas con características similares y se mide su consumo en cada franja de caudal. Por ejemplo, si se registran 2000 pulsos/hora durante las 15 a 16 horas significa que se han consumido 200 litros de agua en ese tiempo sin saber a qué caudales. Clasificar este consumo por franjas de caudal es posible agrupando los pulsos en intervalos de tiempo pequeños de $10 \circ 30$ segundos. Luego, cuando se recibe un pulso en un intervalo de 10 segundos, significa que se consume a un caudal de 0,1 litros en 10 segundos o lo que es lo mismo $36 \mathrm{l} / \mathrm{h}$. Cuando se agrupan los pulsos recibidos en 30 segundos se puede llegar a una resolución de $12 \mathrm{l} / \mathrm{h}$, es decir 1 pulso $(0,1$ litros) en 30 segundos. Así pues, la resolución de caudal mínima en los rangos del patrón de consumo que se podrá apreciar con cierta fiabilidad es de $12 \mathrm{l} / \mathrm{h}$ (agrupando los pulsos recibidos cada 30 segundos).

Además, el número de días durante los cuales se registra en continuo el consumo de una vivienda es importante debido a que el peso que se asigna a una fuga es función del volumen total de agua utilizado. Si el consumo durante dichos días es menor que el consumo promedio real de la vivienda, el porcentaje de volumen asignado a caudales bajos para la misma será mayor que el que debiera. Por ello, en algún caso, puede ser conveniente corregir el patrón de consumo y volver a calcular el peso de la fuga en función de los datos históricos de consumo disponibles.

Las mediciones realizadas durante estos años junto con las iniciadas por Arregui (1999) se resumen en la Tabla 5. Además, han permitido conocer qué factores condicionan al patrón de consumo y en qué medida, con el fin de realizar un clasificación coherente en subpoblaciones dentro de cada abastecimiento de agua.

Las mediciones de las cuatro últimas columnas corresponden a las realizadas por Arregui (1999 y 2000), donde la tipología de vivienda fue bastante uniforme, es decir, se midió en fincas con viviendas de tamaño medio, aproximadamente $100 \mathrm{~m}^{2}$ de superficie, alimentadas en directo 0 con la ayuda de un grupo de bombeo. La edad de las instalaciones interiores estaba entre 25 y 30 años. La única discrepancia entre las diferentes localidades medidas por Arregui (1999) fue la época del año. El consumo de las viviendas de la localidad 7 se midió durante el periodo vacacional estival, mientras que en las localidades 4 y 8 fue durante los meses de septiembre y mayo, respectivamente. 
TABLA 5. PATRONES DE CONSUMO DE DIFERENTES POBLACIONES.

\begin{tabular}{|c|c|c|c|c|c|c|c|c|}
\hline \multicolumn{5}{|c|}{ Etapa doctoral } & \multicolumn{3}{|c|}{ Arregui (1999) } & \multirow[t]{2}{*}{ Arregui (2000) } \\
\hline \multicolumn{8}{|c|}{$\%$ CONSUMO } & \\
\hline $\begin{array}{c}\text { RANGO DE } \\
\text { CAUDALES } \\
(\mathrm{l} / \mathrm{h})\end{array}$ & $\begin{array}{c}\text { Población } \\
1 \\
\text { (34 viv) }\end{array}$ & $\begin{array}{c}\text { Población } 2 \\
\text { (16 viv) }\end{array}$ & $\begin{array}{c}\text { Población } 4 \\
\text { (30 viv) }\end{array}$ & $\begin{array}{c}\text { Poblacion } 6 \\
\text { (58 viv) }\end{array}$ & $\begin{array}{c}\text { Población } 4 \\
\text { (16 viv) }\end{array}$ & $\begin{array}{c}\text { Población } 7 \\
\text { (18 viv) }\end{array}$ & $\begin{array}{c}\text { Población } 8 \\
\text { (11 viv) }\end{array}$ & $\begin{array}{c}\text { Población } 9 \\
\text { (305 viv) }\end{array}$ \\
\hline $0-12$ & 3 & 7 & 6 & 10 & 4 & 4 & 2 & 3 \\
\hline $12-24$ & 2 & 4 & 2 & 3 & 2 & 6 & 1 & 3 \\
\hline $24-36$ & 1 & 3 & 2 & 2 & 2 & 3 & 1 & 2 \\
\hline $36-72$ & 4 & 11 & 5 & 4 & 3 & 1 & 1 & 5 \\
\hline $72-180$ & 6 & 10 & 15 & 12 & 5 & 4 & 4 & 11 \\
\hline $180-1500$ & 64 & 65 & 69 & 69 & 81 & 81 & 90 & 70 \\
\hline $1500-3000$ & 17 & 0 & 0 & 0 & 3 & 1 & 1 & 5 \\
\hline$>3000$ & 3 & 0 & 0 & 0 & 0 & 0 & 0 & 1 \\
\hline
\end{tabular}

Aun así, los resultados obtenidos por Arregui en 1999 fueron un poco contradictorios respecto a lo que en primera instancia cabría esperar. El patrón de consumo de la localidad 7 no presentaba un alto porcentaje de consumo a caudales altos. Durante la época estival, el número de habitantes en esta localidad, y consecuentemente la proporción de consumo de agua a caudales altos (p.e. duchas) no aumentaba de forma significativa. Los resultados, como se aprecia en la Tabla 5, señalan un $18 \%$ del consumo por debajo de $180 \mathrm{l} / \mathrm{h}$. Este dato es bastante indicativo del deterioro de las instalaciones interiores con una elevada presencia de fugas. Por lo tanto, no se puede caracterizar el patrón de consumo teniendo en cuenta solo la tipología de vivienda, ya que como se ha comentado, dentro de una misma tipología existen otras variables como el estado de las instalaciones o la época del año que afectan también a su modo de consumo.

Cuando se observan las mediciones en otras viviendas con tipologías diferentes, residencias con jardín o con un depósito intermedio entre la red y la propia instalación interior, se advierte que el hecho de tener esta característica sí puede ser determinante, a la hora de definir su patrón de consumo.

En las localidades 2 y 6 de la Tabla 5, donde se instalaron en décadas anteriores aljibes regulados con válvulas de boya para garantizar el servicio durante todo el año, se confirma que los consumos en los rangos inferiores de caudal son superiores. Además, esta situación se agrava con el natural deterioro de las instalaciones interiores de dichas viviendas. En estos casos, el porcentaje de consumo medio por debajo de $180 \mathrm{l} / \mathrm{h}$ puede llegar hasta el 31\% (población 6).

Por último comentar que actualmente se comienzan a realizar pruebas con contadores domésticos electrónicos. Estos instrumentos son capaces de almacenar un elevado volumen de datos para luego procesarlos. Como se muestra en la Figura 3, es posible configurar la electrónica del aparato para que acumule el volumen por franjas de caudal, exactamente como un datalogger. Esta innovación en los contadores domésticos puede ser de gran ayuda en la gestión del parque ya que permite, entre otras cosas, la estimación del patrón de consumo sin necesidad de instalar equipos adicionales. También, puede discriminar del volumen de agua que se consume durante las horas nocturnas, o ayudar en el dimensionado de medidores en ciertas viviendas que se consideren potenciales grandes consumidores.

La utilidad de este tipo de contador es indudable, aunque presenta dos inconvenientes que en ocasiones hace inviable su instalación generalizada, por un lado su coste y, por otro, el escaso provecho que extraen, todavía, las empresas suministradoras de los datos. Esto provoca que se acumule un volumen muy importante de datos, lo que lleva asociado un coste, que nunca son convertidos en información útil para la empresa. 


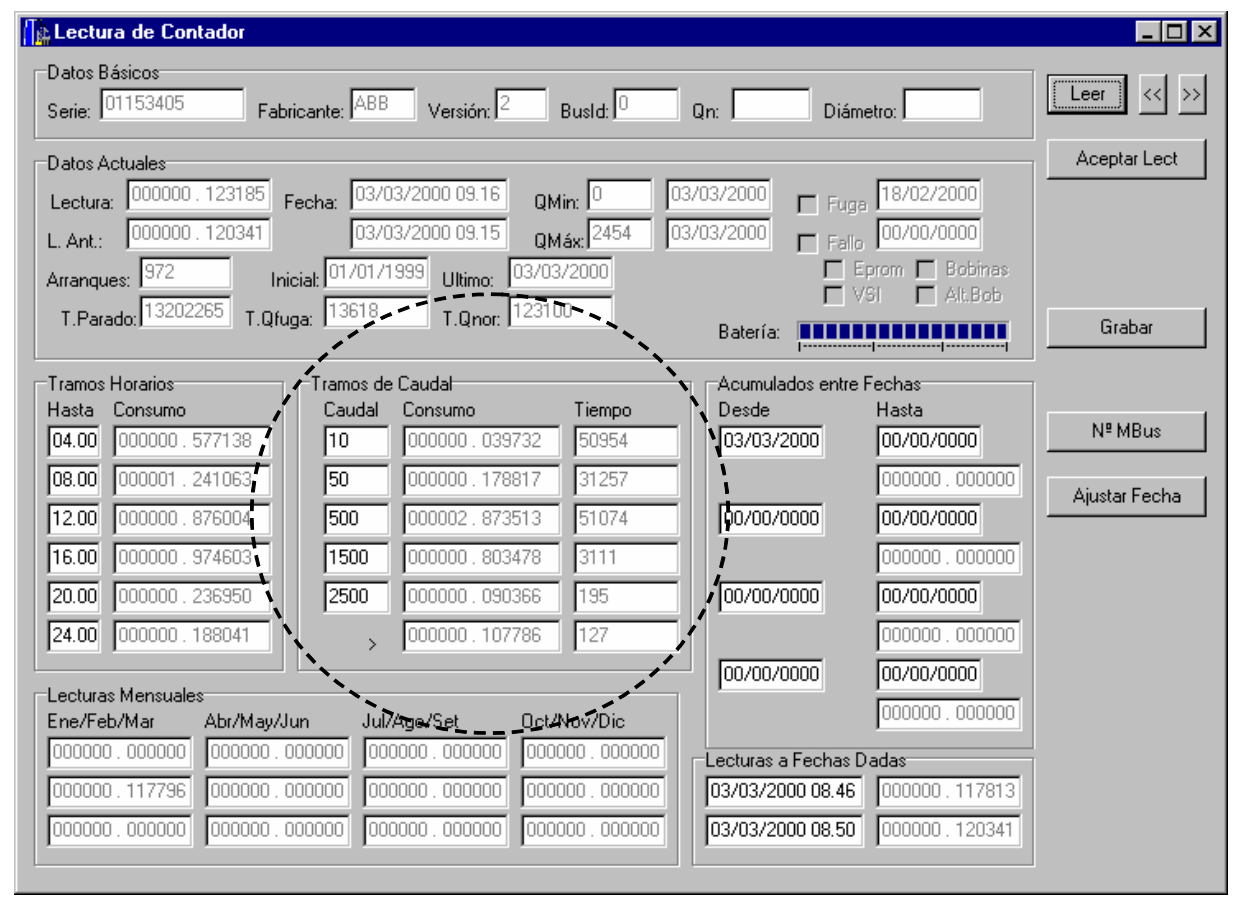

FIGURA 3. DATOS RECOGIDOS POR UN CONTADOR DOMÉSTICO ELECTRÓNICO.

\subsubsection{CLASIFICACIÓN DEL PATRÓN DE CONSUMO DE LOS ABONADOS}

Considerando la notable amplitud de patrones de consumo medidos en distintas poblaciones con características de viviendas variadas, se han propuesto 5 categorías generales, que podrían ser utilizadas por los técnicos de la empresa (Tabla 6).

El tipo de patrón de consumo debería seleccionarse en función de las características de consumo de los usuarios. Teniendo en cuenta los factores que se comentan, la categorización se presenta a continuación.

TABLA 6. CATEGORIZACIÓN DEL PATRÓN DE CONSUMO

\begin{tabular}{cccccc}
\hline $\begin{array}{c}\text { RANGO DE } \\
\text { CAUDALES }\end{array}$ & $\begin{array}{c}\text { Muy desfavorable } \\
\text { (MD) } \\
\text { \%consumo }\end{array}$ & $\begin{array}{c}\text { Desfavorable (D) } \\
\text { \%consumo }\end{array}$ & $\begin{array}{c}\text { Medio (MED) } \\
\text { \%consumo }\end{array}$ & $\begin{array}{c}\text { Favorable (F) } \\
\text { \%consumo }\end{array}$ & $\begin{array}{c}\text { Muy favorable } \\
\text { (MF) } \\
\text { \%consumo }\end{array}$ \\
\hline $0-12 / \mathrm{h}$ & 10 & 4 & 4 & 1 & 1 \\
$12-24 / \mathrm{h}$ & 3 & 6 & 3 & 2 & 1 \\
$24-36 \mathrm{l} / \mathrm{h}$ & 2 & 3 & 2 & 1 & 1 \\
$36-72 \mathrm{l} / \mathrm{h}$ & 4 & 2 & 3 & 3 & 1 \\
$72-180 \mathrm{l} / \mathrm{h}$ & 12 & 4 & 5 & 6 & 4 \\
$180-1500 \mathrm{l} / \mathrm{h}$ & 69 & 80 & 81 & 79 & 91 \\
$1500-3000 \mathrm{l} / \mathrm{h}$ & 0 & 1 & 2 & 5 & 1 \\
$>3000$ & 0 & 0 & 0 & 3 & 0 \\
\hline
\end{tabular}




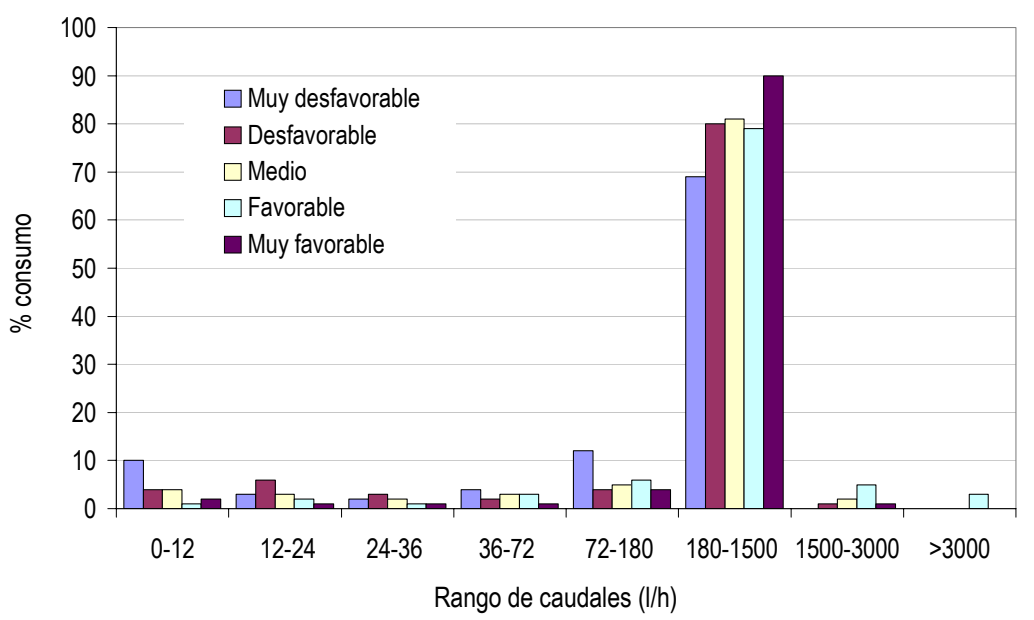

FIGURA 4. CLASIFICACIÓN GRÁFICA DE PATRONES DE CONSUMOS TíPICOS.

Un patrón de consumo desfavorable implica que un gran porcentaje del consumo se produce a caudales bajos, es decir, típico de una subpoblación con viviendas antiguas donde las instalaciones y los aparatos de consumo de agua se encuentran en malas condiciones de mantenimiento. O también, de viviendas que disponen de aljibes entre la red y el medidor. Por ejemplo, una población que reside en viviendas del centro histórico de una ciudad donde un elevado porcentaje de las instalaciones interiores se encuentra en muy mal estado, no solo por la cantidad de fugas sino también por los consumos a bajos caudales debidos a las elevadas pérdidas de carga que se producen en las mismas, se evaluaría como viviendas con un patrón desfavorable o muy desfavorable.

Cuando el patrón de consumo se clasifica como medio, los consumos de agua entre los caudales altos y los bajos no destacan significativamente hacia un lado u otro. Es decir, la subpoblación estudiada no se considera con características particulares que afecten a su forma de consumo, por ejemplo, cualquier zona urbana con viviendas relativamente nuevas.

El estudio realizado por Gascón (2003), donde se desarrollaba una metodología para el análisis de los usos residenciales del agua, muestra los caudales de consumo reales de los aparatos disponibles en una vivienda típica y el porcentaje de consumo de los mismos en esa franja de caudales.

TABLA 7. CAUDALES DE CONSUMO MEDIDOS EN UNA VIVIENDA TíPICA GASCÓN (2003).

\begin{tabular}{ccc}
\hline Aparato de consumo & $\begin{array}{c}\text { Caudal de } \\
\text { consumo }(\mathbf{l} / \mathrm{h})\end{array}$ & $\begin{array}{c}\text { \% consumo en esa } \\
\text { franja }\end{array}$ \\
\hline Grifos & $240-600$ & 75 \\
Duchas & $360-840$ & 77 \\
WC & & 100 \\
(Q de llenado válvula & $300-800$ & 100 \\
abierta) & & 100 \\
Lavadora & $400-450$ & \\
Lavavajillas & $200-250$ & \\
Riego & Variable & \\
Fugas & Variable & \\
\hline
\end{tabular}

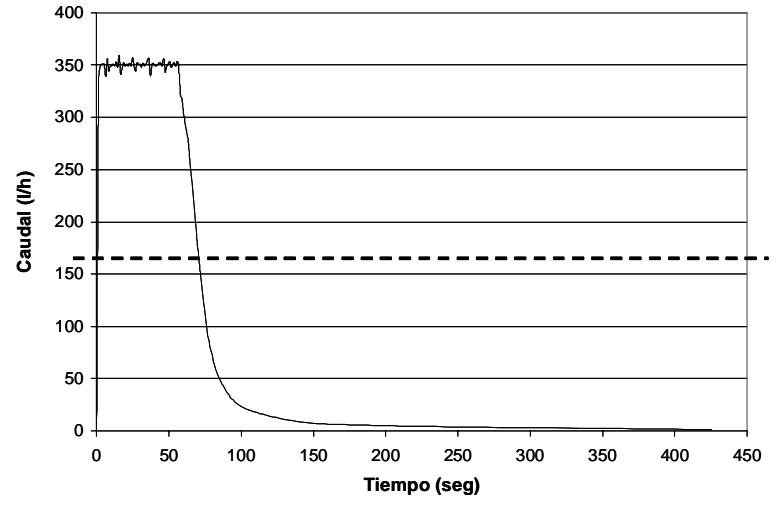

FIGURA 5. CAUDALES DE LLENADO DE UNA CISTERNA TÍPICA CON VÁLVULA DE BOYA. 
En la Figura 7 se aprecia que la gran mayoria de dispositivos de consumo usan el agua a caudales superiores a $200 \mathrm{l} / \mathrm{h}$. Luego, en un patrón medio el porcentaje de volumen consumido a caudales altos (superior a $200 \mathrm{l} / \mathrm{h}$ ) se encuentra en torno al $80-85 \%$, y la proporción que corresponde al rango inferior es debida generalmente al consumo inevitable producido por las cisternas de los inodoros en la fase final de su llenado (Figura 5) y algunas fugas.

Cuando el patrón de consumo es muy favorable, los consumos de agua se dan principalmente a caudales altos donde los errores del medidor son pequeños. Estos casos son habituales en viviendas con jardin con usos para riego o en el llenado de piscinas donde los porcentajes de consumo se desplazan hacia caudales altos sin sobrepasar el máximo, categorizándo el patrón como muy favorable, ya que la mayor parte del consumo se realiza en la zona óptima de medición para un instrumento con un caudal nominal de $1,5 \mathrm{~m}^{3} / \mathrm{h}$.

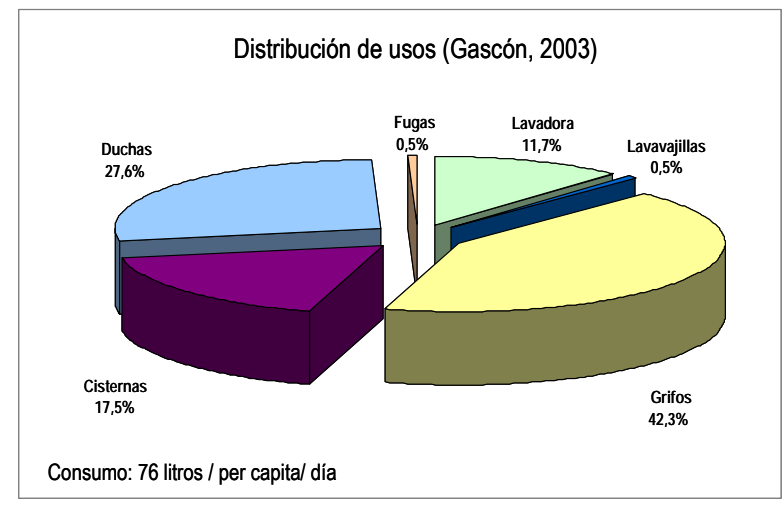

FIGURA 6. DISTRIBUCIÓN DE USOS CON UN PATRÓN MUY FAVORABLE.

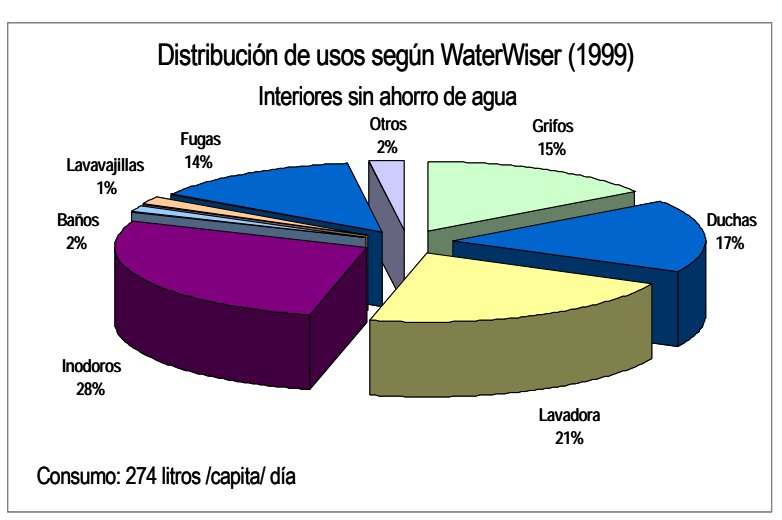

FIGURA 7. DISTRIBUCIÓN DE USOS EN UNA VIVIENDA AMERICANA.

En Figura 6 y Figura 7 se ilustra la distribución de usos en subpoblaciones con características bien diferentes. La primera corresponde a un edificio relativamente joven (10-15 años), con 3 o 4 habitaciones y sin un elevado porcentaje de fugas. En conjunto, el uso del agua por factores críticos como cisternas o fugas en este caso se reduce a un $18 \%$ del total lo que podría clasificar a esta vivienda con un patron muy favorable. La segunda figura representa los usos de una vivienda americana con mayor porcentaje de fugas y menor uso de lavadoras y grifos lo que desplazaría el patrón hacia caudales más bajos y desfavorables de medir.

Además, cada día es más común el uso de válvulas para cisternas con un sistema todo-nada, es decir, cuando ésta acaba de llenarse cierra instantáneamente la válvula, lo que puede reducir considerablemente el porcentaje de consumo a caudales bajos y consecuentemente mejorar la medición.

Los patrones favorable y desfavorable se consideran casos intermedios de los extremos descritos.

La ventaja de establecer este tipo de clasificaciones es que ayuda al técnico a tener una estimación del volumen no registrado mediante la definición de características de la población de estudio y de la edad de los instrumentos del parque. Además, ahorra el intenso trabajo de campo necesario para establecer los valores de estos parámetros.

No obstante, debe tenerse siempre presente que la utilización de estos valores de referencia puede conducir a errores importantes en las estimaciones. Por ello, la única alternativa realmente fiable consiste en obtener el valor real del patrón de consumo. 


\subsection{CÁLCULO DEL ERROR GLOBAL}

\subsubsection{ANTECEDENTES}

Aunque a primera vista la ponderación de la información disponible sobre la curva de error de los contadores y el patrón de consumo de los usuarios pudiera parecer sencilla, en la práctica esta operación resulta complicada, y fácilmente se encuentran en la bibliografía simplificaciones que conducen a resultados que no se ajustan del todo a la realidad, como en AWWA (1993), Allender (1996) y Yee (1999).

El problema estriba, por una parte, como se explicó de forma minuciosa en la Tesis de Arregui (1999), en que algunos autores durante la fase de ponderación del error global no tienen en cuenta los consumos por debajo del caudal de arranque de los contadores instalados en campo. En Arregui (2001), se realiza una interesante comparativa entre diversos métodos de ponderación del error global. En ella se observa una clara diferencia cuando se considera el caudal de arranque del contador. El término correspondiente al volumen no registrado por el instrumento aumenta con el deterioro del mismo, es decir, a medida que pasa el tiempo el caudal de arranque se hace mayor y con él el agua no controlada. Si este parámetro no se considera, el ritmo de deterioro calculado será menor, falseando cualquier resultado. Otros autores como Male et al. (1985), deciden subsanar este problema minorando el volumen registrado a caudales bajos, es decir, disminuyendo su coeficiente de ponderación dándole así mayor valor al error asociado a caudales inferiores.

Además, otro de los inconvenientes encontrados en los citados trabajos, es que el error de un determinado caudal de ensayo se asigna a un intervalo de caudales del patrón de consumo excesivamente amplio donde los errores no se mantienen estables. De esta manera, la ponderación no se ajusta de forma correcta a la realidad, ya que el error en el rango de caudales inferior, de 0-68.19 I/h como en Allender (1996), es muy variable para asignarle una sola precisión a todo el intervalo.

Por otra parte, Gómez Sánchez y De Almeida (1999) describen una metodología similar a la presentada por Arregui et al. (2004), donde mediante mediciones en viviendas de diferentes tipologías y ensayos de error de diversos contadores construyen el patrón de consumo y el ritmo de deterioro de los instrumentos, respectivamente. A partir de estos datos y considerando también, gracias al tipo de instrumentación utilizada, los consumos a caudales inferiores al caudal de arranque de un contador habitual de $13 \mathrm{~mm}$, clase metrológica $B$, estiman el porcentaje de agua no medida de esa subpoblación.

Todos estos factores dejan entrever una disparidad de criterios en cuanto al cálculo del error de medición, es por ello que en el presente capítulo se proponen mejoras en las técnicas de ponderación del error global aprovechando la gran cantidad de medidas y ensayos realizados, expuestos en capítulos anteriores.

\subsubsection{CÁLCULO DEL ERROR GLOBAL}

Como se mostró en la Figura 1, el agua que deja de registrarse de un contador depende del caudal al que trabaja el instrumento. Por ello, el cálculo del error global de medición se obtiene de la ponderación entre el error promedio de cada intervalo de caudal y el peso del consumo de dicho rango.

Los métodos de ponderación de Allender (1996) y Yee (1999) podría decirse que son equivalentes. Ambas técnicas combinan el error al caudal de ensayo con el porcentaje de consumo del intervalo correspondiente. Además, éstas utilizan el término real meter accuracy o precisión global del contador de forma incorrecta. Las dos estiman el volumen registrado en lugar del no registrado por el instrumento de medida. Como se comentó en párrafos anteriores, y viene definido en 
numerosos libros ${ }^{1}$, la precisión de un contador de agua alude a la máxima discrepancia entre el volumen consumido por el usuario y el medido por el contador.

Luego por estos métodos, el cálculo del error global de medición corregido sería sencillamente, el producto de ambos parámetros menos cien para conocer la precisión global expresada en porcentaje sobre la lectura (Ecuación 1).

$$
\text { ERROR GLOBAL }=\left[\% T C_{Q_{B}} \cdot\left(100+\varepsilon_{Q_{B}}\right)+\% T C_{Q_{M}} \cdot\left(100+\varepsilon_{Q_{M}}\right)+\% T C_{Q A} \cdot\left(100+\varepsilon_{Q_{A}}\right)\right]-100
$$

siendo $T C$ el porcentaje total de agua consumido a caudales bajos $\left(Q_{B}\right)$, medios $\left(Q_{M}\right)$ y altos $\left(Q_{A}\right)$ y $\varepsilon$ el error de medición a los mismos caudales.

La ponderación propuesta por Arregui et al. (2004), más compleja, está basada en una linealización de la curva de error (Figura 8) y un reparto uniforme del volumen consumido en cada rango de caudales. Este autor propone para el cálculo del error global una interpolación lineal entre pares de puntos de ensayo obteniéndose rectas que reproducen de forma aproximada la curva de error. En la siguiente figura se ilustra la aproximación a la curva de error. Se aprecia también, que el error asignado al caudal de arranque se supone de $-70 \%$.

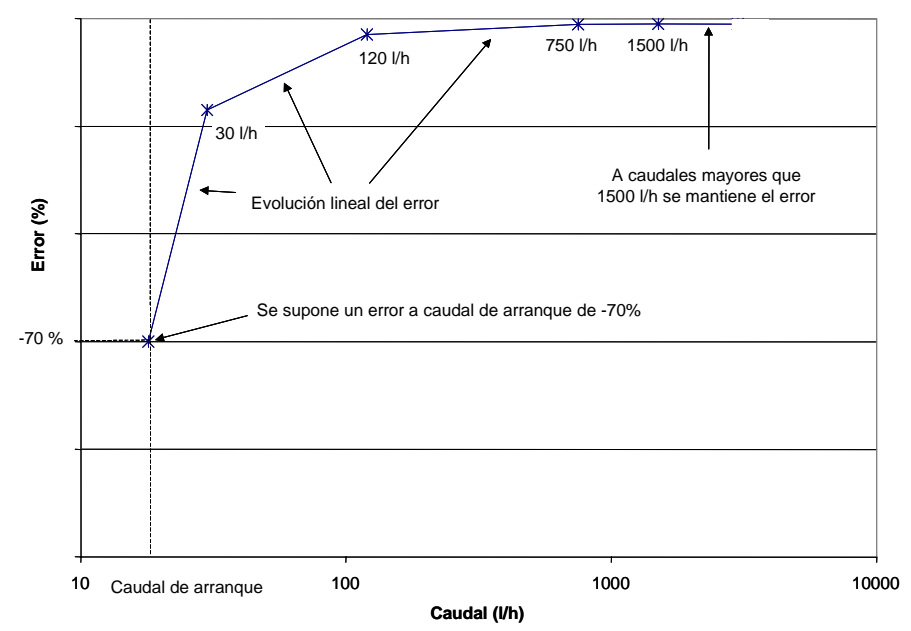

FIGURA 8. SUPOSICIÓN DE UNA EVOLUCIÓN LINEAL DE LOS ERRORES DE MEDICIÓN (ARREGUI, 2004).

En la Figura 9, se expone en forma de esquema la metodología seguida. Como se observa al punto intermedio de cada rango de caudales del patrón de consumo se le asigna el error a dicho caudal, calculado a partir de la linealización previa entre errores a los caudales ensayados, y se pondera con el peso del consumo en ese intervalo.

\footnotetext{
1 Creus (1989), en su libro "Instrumentación industrial" define la precisión de un instrumento de medida como la tolerancia de dicho instrumento que determina los límites de error cuando este trabaja en condiciones normales de funcionamiento. En el caso de contadores de agua, la precisión del instrumento se expresa en tanto por ciento de la lectura efectuada.
} 


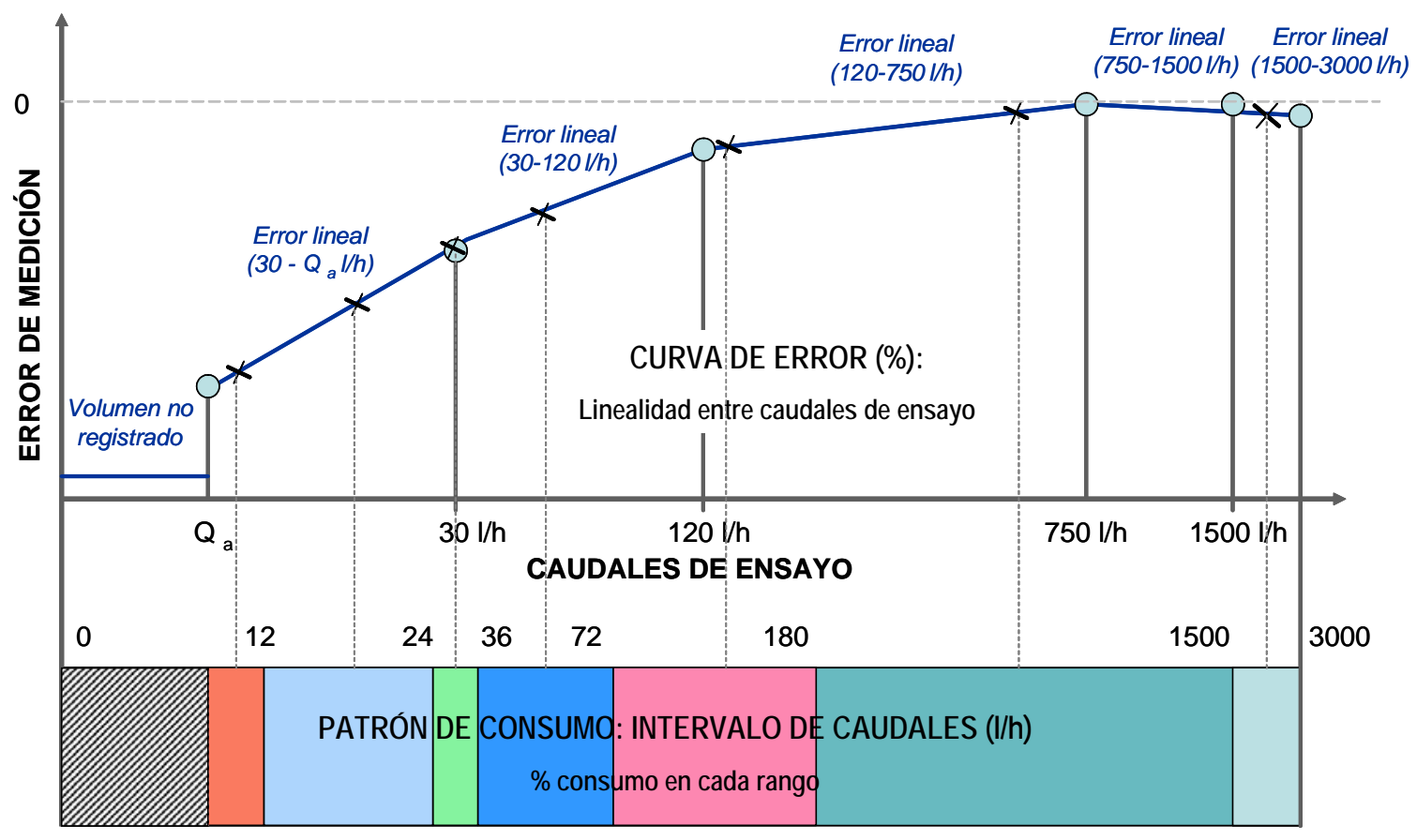

FIGURA 9. ESQUEMA DE PONDERACIÓN DEL PATRÓN DE CONSUMO CON LA CURVA DE ERROR DE UN CONTADOR.

Por ejemplo, para el rango de caudales entre 72 y $180 \mathrm{l} / \mathrm{h}$, el volumen de agua consumido por una vivienda es del $11.6 \%$. El punto medio de este intervalo se encuentra en $126 \mathrm{l} / \mathrm{h}$ y el error obtenido de la linealización entre los caudales de ensayo conocidos (120-750 l/h), y es de $-0.85 \%$. Por ello, la parte del error global correspondiente a este tramo vendría del producto de ambos porcentajes, $-0.85 \%$ por $11,6 \%$.

De esta forma, una vez obtenidos los errores en el punto medio de cada uno de los intervalos del patrón de consumo, el error global de contador se calcula mediante el sumatorio de este error por el peso correspondiente a dicho tramo, tal y como se indica en la Ecuación 2.

$$
\begin{aligned}
& \text { ERROR GLOBAL }=\left[\sum_{i=1}^{i=n} C_{i} \cdot\left[100+\varepsilon_{Q_{i}}(\%)\right]\right]-100 \\
& \text { Ei: ERROR ASIGNADO A CADA TRAMO DEL PATRÓN DE CONSUMO. } \\
& \text { Ci: PESO DEL CONSUMO DE AGUA EN CADA INTERVALO DE CAUDALES. }
\end{aligned}
$$

\subsubsection{VOLUMEN NO REGISTRADO DE UNA SUBPOBLACIÓN}

La metodología propuesta para la obtención del error global de un sistema de micromedición se basa en la obtención del error global de cada subpoblación mediante técnicas de inferencia estadística. Para ello resulta necesario realizar un muestreo del estado de los parques de contadores de las subpoblaciones a analizar y de la forma de consumir de sus abonados. El esquema que aparece en la figura siguiente resume la metodología a seguir. 


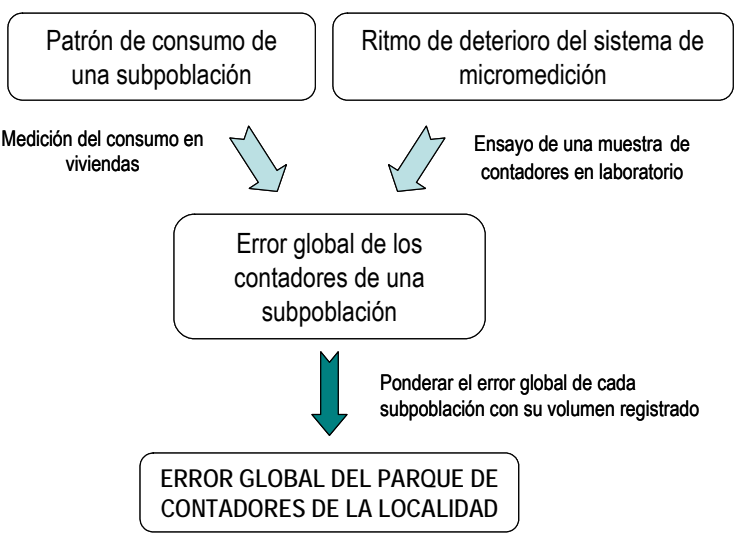

FIGURA 10. ESQUEMA DE LA METODOLOGÍA SEGUIDA EN EL CÁLCULO DEL ERROR GLOBAL DE UN PARQUE DE CONTADORES.

Siguiendo esta metodología, si se asocia un deterioro promedio de una determinada subpoblación de contadores con la forma de consumir media de los usuarios de dicha subpoblación, será posible obtener el error global de la misma, así como el volumen realmente consumido y el no registrado.

La estratificación del parque en diferentes subpoblaciones de contadores debe realizarse atendiendo a las características de los medidores existentes. También los abonados pueden clasificarse por subpoblaciones, dando como resultado la posibilidad de combinar diferentes subpoblaciones de abonados con diferentes subpoblaciones de contadores. Finalmente, y ponderando adecuadamente el peso de cada subpoblación en el total del parque, será posible obtener el error global del mismo.

De cara a analizar los resultados, se debe tener en cuenta que tanto el patrón de consumo promedio como los errores medios obtenidos a cada caudal son una estimación extraída de una muestra de la población (o subgrupo) considerado. Por tanto, el valor encontrado no tiene porqué coincidir exactamente con el verdadero valor y estará sujeto a cierta incertidumbre (Ecuación 3 y 4).

La incertidumbre se asocia a las propias características del muestreo estadístico y puede calcularse mediante técnicas de inferencia estadística. Para ello, cabe recordar el Teorema Central del Límite que garantiza, cuando el tamaño de muestra es suficientemente grande $(n>30)$, una distribución normal de la media muestral. Los intervalos de confianza de ambas muestras, tanto de los contadores ensayados en laboratorio como de los consumos medidos en viviendas, podrán estimarse mediante las ecuaciones siguientes para un grado de fiabilidad del muestreo fijado por el técnico. La amplitud de estos intervalos dará un orden de magnitud de la calidad del estudio muestral.

$$
\begin{aligned}
\text { Estimación Consumo }_{\left(Q_{i}-Q_{j}\right)} & =\text { Consumo Promedio }_{\left(Q_{i}-Q_{j}\right)} \pm z_{1-\frac{\alpha}{2}} \frac{s}{\sqrt{n}} \\
\text { Estimación Error }_{Q_{e}} & =\text { Error Promedio }_{Q_{e}} \pm z_{1-\frac{\alpha}{2}} \frac{s}{\sqrt{n}}
\end{aligned}
$$

donde $Z_{1-\frac{\alpha}{2}}$ es el factor de fiabilidad , $1-\alpha$ es la fiabilidad, s es la desviación típica muestral de las observaciones, $Q_{\mathrm{e}}$ el caudal de ensayo y $z_{1-\frac{\alpha}{2}} s / \sqrt{n}$ incertidumbre sobre el valor estimado asociado a dicha muestra. 
La estimación del consumo y del error de medición de una subpobalción con su correspondientes intervalos de confianza, permite analizar los casos extremos, más favorable y desfavorable, que con cierta probabilidad pueden acontecer. De esta forma, se evalúa el volúmen no registrado que será utilizado en futuros estudios de gestión del abastecimiento de agua.

\subsubsection{EVOLUCIÓN DEL ERROR GLOBAL CON EL TIEMPO. CASO DE ESTUDIO}

En este epígrafe se pretende conocer las posibles combinaciones de estos dos parámetros para poder realizar una categorización aproximada del estado de cada sector de medida, y justificar de forma sencilla, el volumen de agua que se dejaría de registrar a medida que pasa el tiempo.

Como se ha comentado, uno de los intereses del técnico de un abastecimiento, a la hora de gestionar el parque de contadores es conocer el periodo óptimo en el que conviene renovar los medidores, tanto aquellos que se encuentran instalados como los que se instalarán en un futuro. De esta forma, amortizar los costes fijos invertidos en dicho instrumento y justificar la compra de un contador de mayor o menor precisión en función del rendimiento económico que se le puede extraer. En Arregui et al. (2004) se realiza un analisis económico de los costes inherentes a la instalación y funcionamiento de una subpoblación de contadores domésticos.

Por tanto, este apartado propone una evaluación simplificada y aproximada de lo que sería supuestamente el error global en función del patrón de consumo de una población y del estado de sus instrumentos de medición.

Los casos estudiados combinan las diferentes clasificaciones detalladas anteriormente, y en ellos se estima cómo afectaría a la gestión del parque de contadores cada uno de los criterios de decisión adoptados. Por ejemplo, se combina, tal y como se ha explicado en el punto 5.4.2, el patrón de consumo establecido como muy desfavorable (ver Tabla 6) con un ritmo de deterioro alto (ver Tabla 1) calculándose la evolución del error global de medición en el tiempo para ese caso.

Así pues, los supuestos establecidos se presentan en la siguiente tabla:

TABLA 8. CASOS DE ESTUDIO SUPUESTOS.

\begin{tabular}{cccc}
\hline SUPUESTOS & PATRÓN DE CONSUMO & $\begin{array}{c}\text { RITMO DE } \\
\text { DETERIORO }\end{array}$ & ERROR GLOBAL DE MEDICIÓN \\
\hline Caso 1 & MD & Alto & Error $=-0,45 \cdot$ edad $-12,0$ \\
Caso 2 & MD & Medio & Error $=-0,34 \cdot$ edad $-11,7$ \\
Caso 3 & MD & Bajo & Error $=-11,7$ \\
Caso 4 & D & Alto & Error $=-0,53 \cdot$ edad $-8,0$ \\
Caso 5 & D & Medio & Error $=-0,36 \cdot$ edad $-7,4$ \\
Caso 6 & D & Bajo & Error $=-0,01 \cdot$ edad $-7,3$ \\
Caso 7 & MED & Bajo & Error $=0,01 \cdot$ edad $-5,7$ \\
Caso 8 & MED & Medio & Error $=-0,32 \cdot$ edad $-5,7$ \\
Caso 9 & MED & Alto & Error $=-0,42 \cdot$ edad $-5,9$ \\
Caso 10 & F & Bajo & Error $=0,02 \cdot$ edad $-4,2$ \\
Caso 11 & F & Medio & Error $=-0,31 \cdot$ edad $-4,2$ \\
Caso 12 & F & Alto & Error $=-0,36 \cdot$ edad $-4,3$ \\
Caso 13 & MF & Bajo & Error $=0,04 \cdot$ edad $-2,6$ \\
Caso 14 & MF & Medio & Error $=-0,27 \cdot$ edad $-2,6$ \\
Caso 15 & MF & Alto & Error $=-0,27 \cdot$ edad $-2,6$ \\
\hline
\end{tabular}


A continuación, se ilustran las curvas de evolución con el tiempo del error global de medición para cada uno de los diferentes casos supuestos.

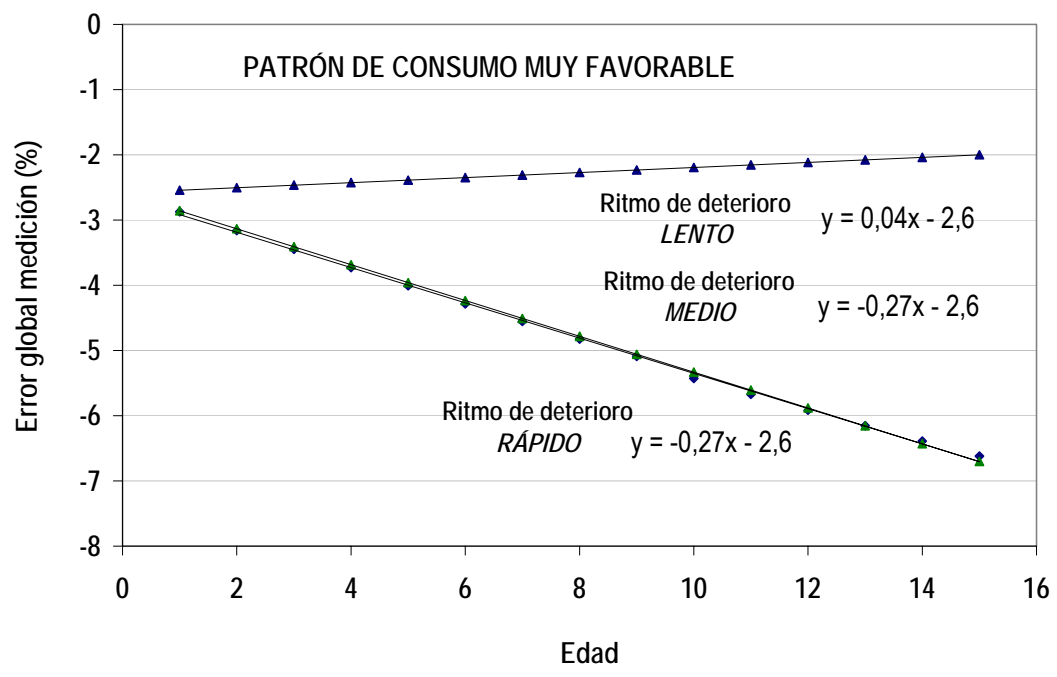

FIGURA 11. RITMO DE DETERIORO DE UN PATRÓN MUY FAVORABLE.

Cuando el patrón de consumo considerado es muy favorable, que el error inicial adopta un valor de aproximadamente el 2,5\% (caso más favorable), y a medida que empeora el patrón de consumo este punto se inicia con mayor error negativo. Este error global inicial correspondería a un contador típico de chorro único Clase B ponderado con un patrón de consumo muy favorable.

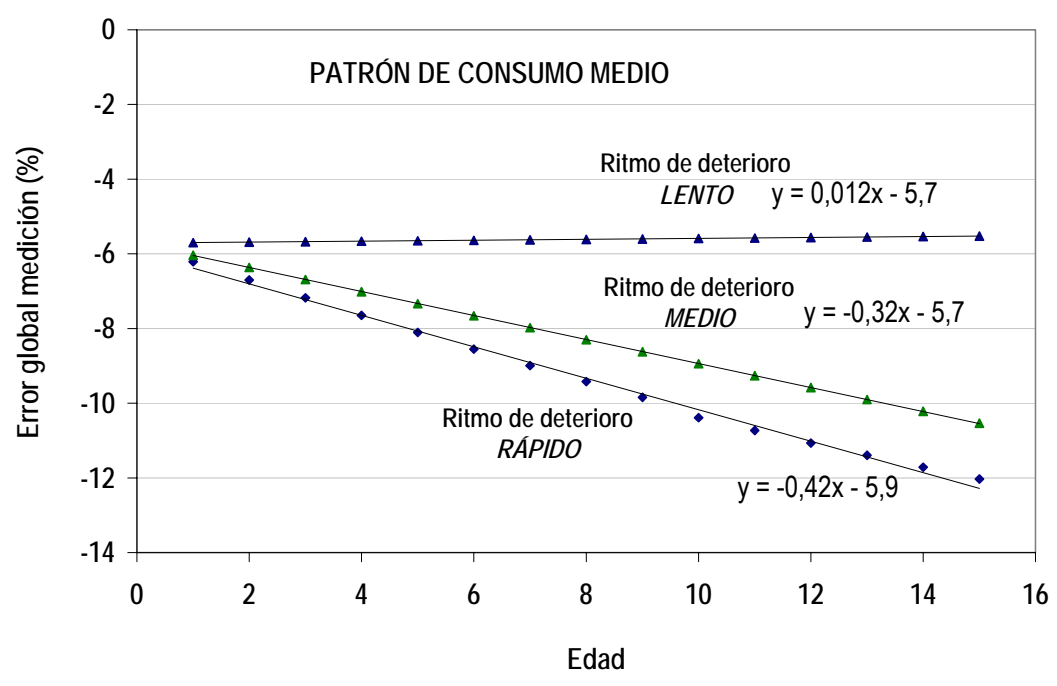

FIGURA 12. RITMO DE DETERIORO DE UN PATRÓN MEDIO. 


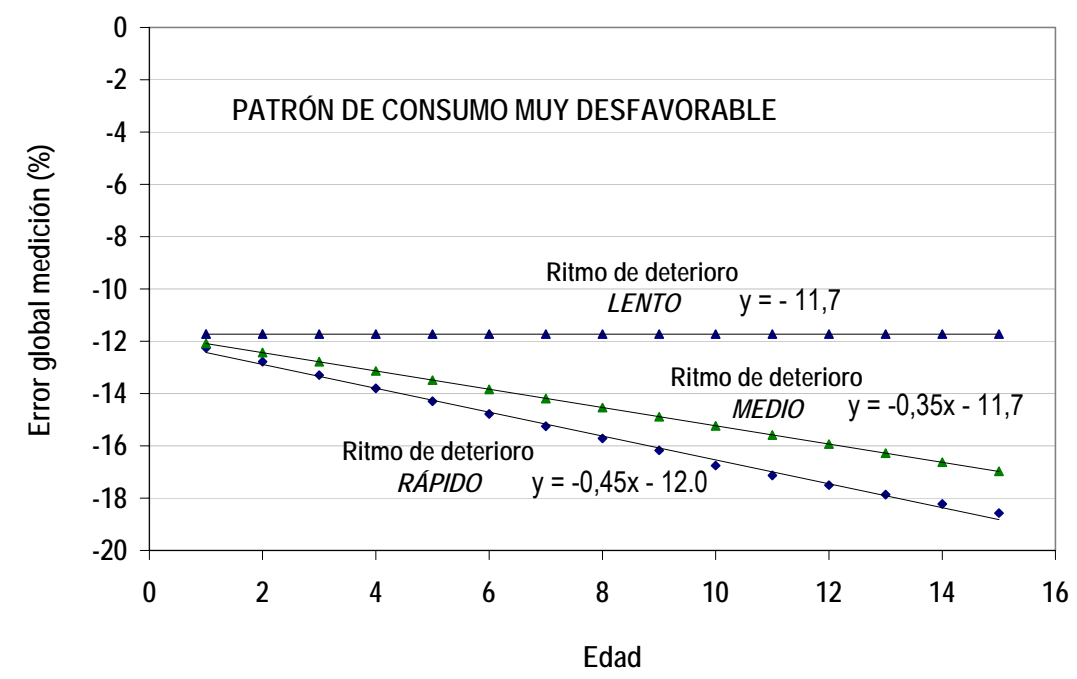

FIGURA 13. RITMO DE DETERIORO DE UN PATRÓN MUY DESFAVORABLE.

Evidentemente, los errores iniciales considerados dependerán únicamente del patrón de consumo supuesto ya que la curva de error utilizada para simular un instrumento nuevo cumplirá las especificaciones metrológicas de la Norma ISO 4064 satisfaciendo los requerimientos de la Clase B. En estos supuestos se ha considerado un error inicial para contadores nuevos ajustados en fábrica al $-3 \%$ a un caudal de $30 \mathrm{l} / \mathrm{h}$ y a $0 \%$ para caudales superiores. Consecuentemente, al ponderar este error inicial (año cero) con los diversos patrones de consumo se obtienen errores globales iniciales de $-2,6 \%$ para el caso más favorable y de $-12 \%$ para el patrón más desfavorable.

Además, en las figuras anteriores se puede observar claramente que ritmos de deterioro de la curva de error altos provocan que la evolución de la calidad metrológica de los contadores decrezca significativamente, lo que implica, obviamente, una pendiente de la curva mayor y errores de subregistro de los contadores más elevados. Así, el error global decrece con

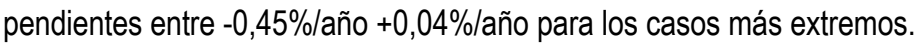

De esta forma, las pendientes del error global de medición a lo largo del tiempo pueden agruparse por ritmos de deterioro obteniéndose los siguientes resultados para cualquier patrón de consumo supuesto:

TABLA 9.RITMOS DE DETERIORO.

\begin{tabular}{|c|c|}
\hline RITMO DE DETERIORO DE LA SUBPOBLACIÓN & PENDIENTE DEL ERROR GLOBAL \\
\hline Alto & $-0,27 \% /$ año a $-0,53 \% /$ año \\
\hline Medio & $-0,3 \% / a n ̃ o$ \\
\hline Bajo & 0\%/año \\
\hline
\end{tabular}

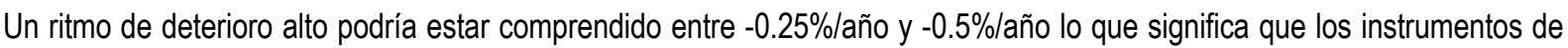
medida se encuentran, en general en muy mal estado, que las condiciones de calidad e instalación no son las óptimas. Además, la calidad inicial del instrumento y sus características constructivas no son del todo robustas. Estos hechos hacen pensar que estos aparatos han sufrido un gran deterioro. En cambio, un ritmo medio atiende a instrumentos que a primera vista no tienen variables que influyan sobre ellos. Por último, un ritmo de deterioro bajo se atribuye a instrumentos que, en 
general, tienen unas características constructivas robustas con resultados históricos buenos, e instalados en condiciones propicias para su funcionamiento.

\subsubsection{COMPARATIVA ENTRE MÉTODOS}

La comparación de estas metodologías de ponderación con un mismo patrón de consumo y con curvas de ensayo detalladas de contadores de diversas marcas comerciales permite conocer de qué forma se evalúa el volumen no registrado por un contador de agua, y proponer mejoras y criterios claros que determinen el subcontaje o sobrecontaje producido.

Para ello, en este apartado se pretende comparar, con las mismas condiciones iniciales de error y consumo de agua, tres casos concretos en los que la ponderación del error global de medición se ha realizado de forma diferente.

\subsubsection{Curva de error}

La curva de error en cada una de las metodologías mencionadas ha sido simplificada de forma diversa, lo que en algunos casos, sobre o infravalora el error global. El primer caso, comentado ya en apartados anteriores, se basa en la metodología explicada por Allender (1996). Ésta fundamentalmente se basa en la combinación de tres caudales de ensayo (alto, medio y bajo) con tres rangos de caudal de trabajo. El segundo caso representaría el método desarrollado por Yee en 1999, muy similar al propuesto por Allender, cuya única diferencia es que el error en el rango alto se ensaya a un caudal mayor. Los valores de caudal de ensayo utilizados en estos métodos se muestran en la Tabla 10. En la propuesta presentada por Arregui el al. en 2004 se realizan algunos cambios sustanciales, se ensaya el error a 30, 120, 750 y 1500 l/h, además de considerar el caudal de arranque (Tabla 11).

TABLA 10. CAUDALES DE ENSAYO UTILIZADOS POR ALLENDER Y YEE.

\begin{tabular}{ccc}
\hline PROPUESTA & \multicolumn{2}{c}{ Qensayo $_{\text {(l/h) }}$} \\
\hline \multirow{3}{*}{ Allender (1996) } & BAJO & 56.78 \\
& MEDIO & 454.25 \\
& ALTO & 2271.25 \\
Yee (1999) & BAJO & 56.78 \\
& MEDIO & 454.25 \\
& ALTO & 3406,87 \\
\hline
\end{tabular}

TABLA 11.CAUDALES DE ENSAYO PROPUESTOS POR ARREGUI ET AL. (2004).

\begin{tabular}{c}
\hline Q ensayo $(\mathrm{l} / \mathrm{h})$ \\
\hline$Q_{\mathrm{a}}$ \\
30 \\
120 \\
750 \\
1500 \\
\hline
\end{tabular}

Con el fin de clarificar estas técnicas se describe un ejemplo en el que se compara, por un lado, la reconstrucción de las curvas de error que proponen las diferentes técnicas mencionadas y, por otro, se perfila la curva de ensayo detallada de diferentes marcas de contadores, nuevos y usados con clases metrológicas $B$ y $C$. En ellos se realiza un análisis donde se valora en qué casos se infra o sobreestima la curva de error de un contador. 


\section{CONTADORES CLASE METROLÓGICA B}

Los modelos de contador doméstico utilizados en el ejemplo, clase metrológica $B$, de caudal nominal $1,5 \mathrm{~m} 3 / \mathrm{h}$ son de chorro único y corresponden a diferentes casas comerciales. Este tipo de contadores son los más comunes en los sistemas de micromedición de una red urbana. Los contadores usados objeto de estudio, son de clase metrológica B y han acumulado un volumen de aproximadamente $600 \mathrm{~m}^{3}$ para el modelo 1 y $1.360 \mathrm{~m}^{3}$ para el modelo 2. En la Tabla 12 se presentan los resultados obtenidos de los ensayos en detalle de la curva de error para ambos modelos, tanto nuevos como usados.

TABLA 12. RESULTADOS DE LOS ENSAYOS A DIFERENTES MODELOS Y EDADES DE CONTADOR CLASE B.

\begin{tabular}{|c|c|c|c|c|c|c|c|}
\hline \multicolumn{2}{|c|}{$\begin{array}{l}\text { MODELO } 1 \\
\text { (en servicio) }\end{array}$} & \multicolumn{2}{|c|}{$\begin{array}{l}\text { MODELO } 2 \\
\text { (en servicio) }\end{array}$} & \multicolumn{2}{|c|}{$\begin{array}{c}\text { MODELO } 1 \\
\text { (nuevo) }\end{array}$} & \multicolumn{2}{|c|}{$\begin{array}{c}\text { MODELO } 2 \\
\text { (nuevo) }\end{array}$} \\
\hline Qensayado $(1 / h)$ & $\begin{array}{l}\text { Error contador } \\
(\%)\end{array}$ & Qensayado $(/ / h)$ & $\begin{array}{c}\text { Error contador } \\
(\%)\end{array}$ & $Q_{\text {ensayado }}(/ / h)$ & $\begin{array}{c}\text { Error contador } \\
(\%)\end{array}$ & $\begin{array}{c}\text { Qensayado } \\
(I / / h)\end{array}$ & Error contador (\%) \\
\hline 18 & $-99,5$ & 18 & $-100,0$ & 6 & $-99,3$ & 13 & $-78,0$ \\
\hline 22 & $-100,0$ & 22 & $-98,5$ & 8,5 & $-91,5$ & 14 & $-52,0$ \\
\hline 24 & $-99,5$ & 24 & $-95,5$ & 10 & $-53,0$ & 16 & $-34,2$ \\
\hline 26 & $-98,5$ & 26 & $-100,0$ & 12 & $-36,3$ & 18 & $-21,2$ \\
\hline 28 & $-47,7$ & 28 & $-87,1$ & 14 & $-23,7$ & 20 & $-17,1$ \\
\hline 30 & $-34,8$ & 30 & $-42,1$ & 16 & $-16,9$ & 22 & $-13,2$ \\
\hline 32 & $-28,0$ & 32 & $-36,2$ & 18 & $-12,5$ & 24 & $-9,2$ \\
\hline 34 & $-23,3$ & 34 & $-31,2$ & 20 & $-8,1$ & 26 & $-5,3$ \\
\hline 36 & $-20,6$ & 36 & $-29,3$ & 22 & $-5,8$ & 28 & $-5,2$ \\
\hline 38 & $-15,4$ & 38 & $-26,4$ & 24 & $-4,5$ & 30 & $-3,2$ \\
\hline 40 & $-10,3$ & 40 & $-24,3$ & 26 & $-2,5$ & 32 & $-3,2$ \\
\hline 42 & $-9,8$ & 42 & $-24,3$ & 28 & $-3,1$ & 34 & $-2,4$ \\
\hline 50 & $-4,7$ & 50 & $-20,2$ & 30 & $-2,7$ & 36 & $-1,3$ \\
\hline 60 & $-3,7$ & 60 & $-18,4$ & 60 & 0,5 & 38 & $-1,5$ \\
\hline 120 & 1,5 & 120 & $-9,1$ & 120 & $-0,8$ & 40,0 & 0,5 \\
\hline 450 & 1,0 & 450 & $-4,8$ & & & 42,0 & $-0,5$ \\
\hline 750 & 0,8 & 750 & $-4,6$ & & & 44 & 0,6 \\
\hline 1500 & 0,7 & 1500 & $-2,9$ & & & 50 & 1,4 \\
\hline 3000 & 0,6 & 3000 & $-2,8$ & & & 80 & 2,2 \\
\hline & & & & & & 120 & 1,0 \\
\hline
\end{tabular}

A continuación, a partir de los datos de error presentados, se realiza una comparativa entre las diferentes curvas presentadas en cada uno de los métodos. Así pues, en la Tabla 13 y Tabla 14, se exponen los datos utilizados cuando se simplifica la curva de error mediante el método de Allender, Yee y Arregui aplicados a los resultados anteriores.

TABLA 13. ESTIMACIÓN DE LA CURVA DE ERROR UTILIZANDO LA PROPUESTA DE YEE Y ALLENDER.

\begin{tabular}{cccc}
\hline YEE & ALLENDER & MODELO 1 (en servicio) & MODELO 2 (en servicio) \\
\hline \multirow{2}{*}{ Q ensayo } & \multirow{2}{*}{ Q ensayo } & Error contador (\%) & Error contador (\%) \\
\hline 56,8 & 56,8 & $-3,7$ & $-18,4$ \\
454,2 & 454,2 & 1,0 & $-4,6$ \\
3406,87 & 2271,25 & 0,6 & $-2,8$ \\
\hline
\end{tabular}




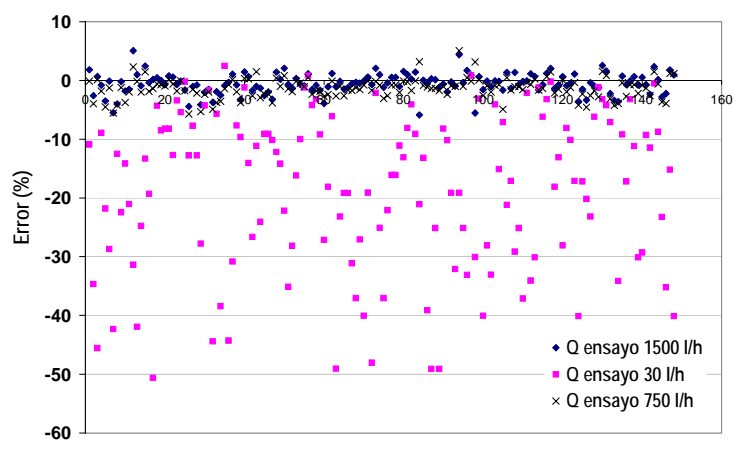

TABLA 14. DATOS UTILIZADOS EN LA LINEALIZACIÓN DE LA CURVA DE ERROR POR ARREGUI.

\begin{tabular}{cccc}
\hline \multicolumn{2}{c}{ MODELO 1 (en servicio) } & \multicolumn{2}{c}{ MODELO 2 (en servicio) } \\
\hline Q ensayo & $\begin{array}{c}\text { Error } \\
\text { contador (\%) }\end{array}$ & Q ensayo & $\begin{array}{c}\text { Error } \\
\text { contador (\%) }\end{array}$ \\
\hline 26 & $-70,0$ & 27 & $-70,0$ \\
30 & $-34,8$ & 30 & $-42,1$ \\
120 & 1,5 & 120 & $-9,1$ \\
750 & 0,8 & 750 & $-4,6$ \\
1500 & 0,7 & 1500 & $-2,9$ \\
\hline
\end{tabular}

FIGURA 14. DISPERSIÓN PRESENTADA EN EL ERROR DE MEDICIÓN ENTRE CAUDALES ALTOS Y BAJOS.

La mejora en la ponderación del error global parte de un buen ajuste de la curva de error. Las propuestas presentadas no poseen un ajuste adecuado de la curva de error especialmente a caudales bajos. Cuando se compara con la curva de error detallada, se observan las inexactitudes que conlleva realizar las simplificaciones de estos autores.

Las propuestas de Allender (1996) y Yee (1999) asignan un error de medición inferior y muy diferente al real (más cercano a cero) a caudales bajos. En cambio, en los rangos superiores de caudal, a partir de $180 \mathrm{l} / \mathrm{h}$, la discrepancia en los errores es mucho menor, como se aprecia en la Figura 14, donde el promedio de los errores a caudales superiores se encuentran cercano a cero.

Como consecuencia, las mejoras en la ponderación intentarán ajustar la curva a caudales bajos, ya que estas técnicas tienen un grado de ajuste suficientemente bueno a caudales altos (Figura 15 y Figura 16).

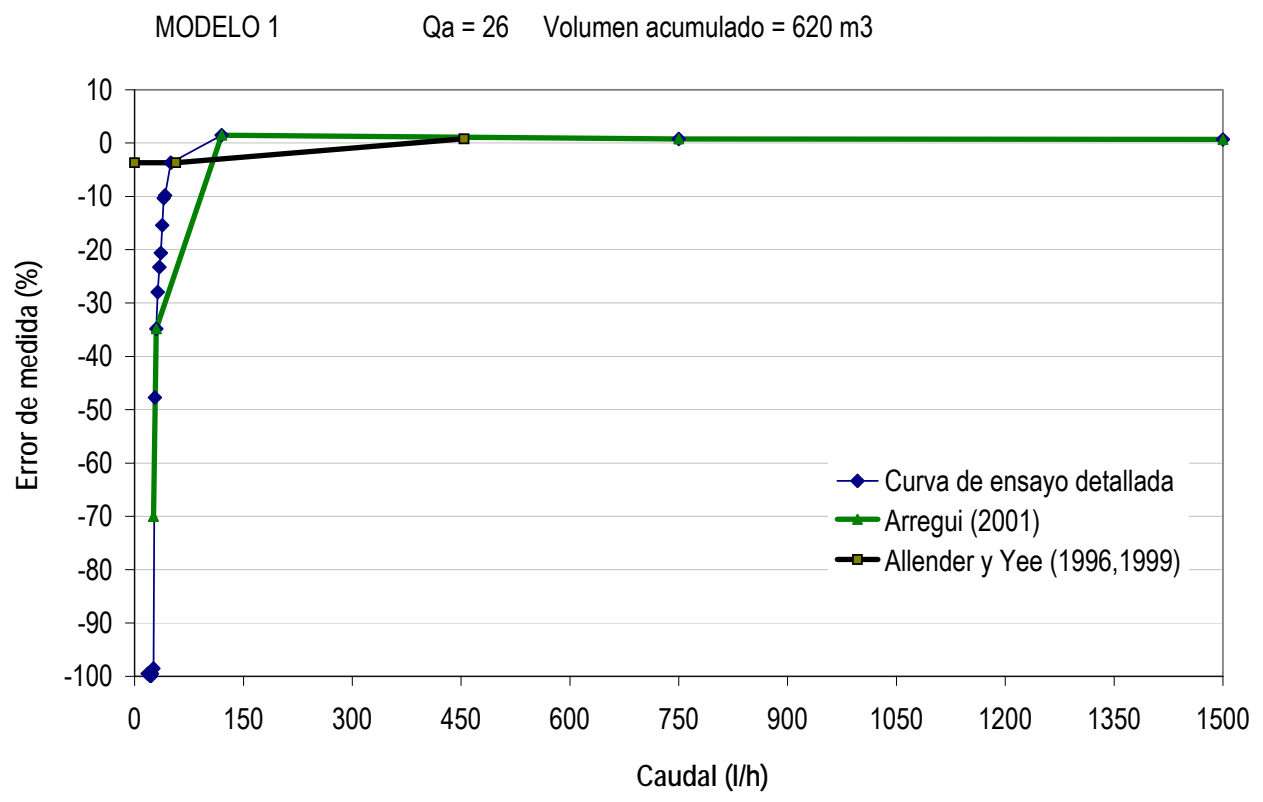

FIGURA 15. MODELO 1. CURVAS DE ERROR ESTIMADAS PARA TODO EL RANGO DE CAUDALES POR LAS DIFERENTES PROPUESTAS Y CURVA DETALLADA. 
De estas figuras se aprecia, en primer lugar, que el ajuste propuesto por Arregui reproduce mejor la curva de error real que las propuestas presentadas por Allender (1996) y Yee (1999).

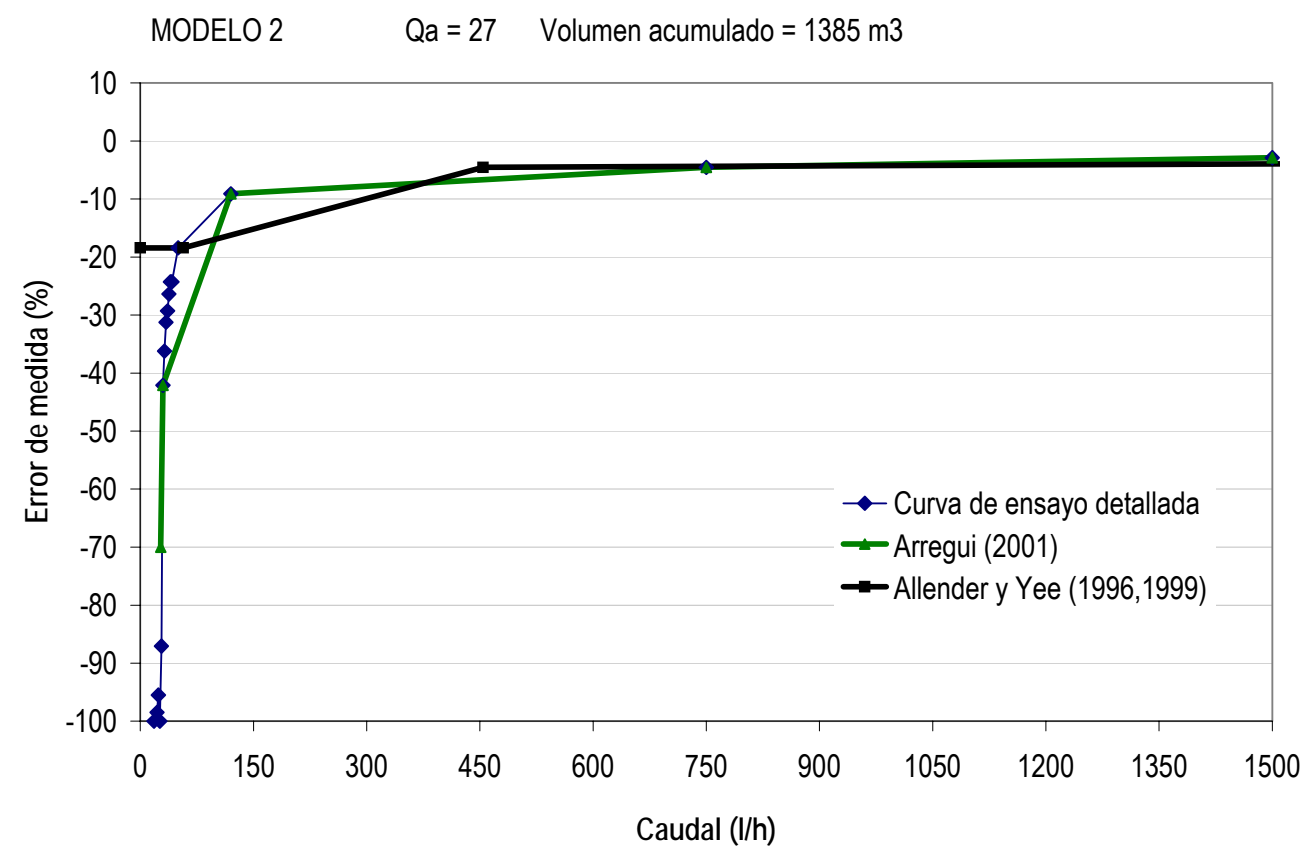

FIGURA 16. MODELO 2. CURVAS DE ERROR ESTIMADAS PARA TODO EL RANGO DE CAUDALES POR LAS DIFERENTES PROPUESTAS Y CURVA DETALLADA.

Esto es debido a que en la propuesta de Allender y Yee se asigna un único error a todo el rango inferior de caudales. Particularmente, el tramo comprendido entre un caudal nulo y el siguiente caudal de ensayo $(56.8 \mathrm{l} / \mathrm{h})$ se considera con un error de $-3.7 \%$, siendo que en realidad el contador no arranca hasta $26 \mathrm{l} / \mathrm{h}$ por lo que a caudales inferiores le corresponde un error de $-100 \%$ (Figura 17).

Este supuesto conduce a un fallo de cálculo del volumen no medido al considerar este agua consumida antes del caudal de arranque como registrada con un error que no se corresponde con el comportamiento real del contador. Cuando se pondera con la técnica de Arregui se considera el caudal de arranque reproduciéndose mejor la realidad. Además, al introducir mayor número de caudales de ensayo la curva de error queda más definida. Aún así, la propuesta realizada por Arregui no representa correctamente el comportamiento del contador a caudales bajos.

Cuando se observa la curva de error de los modelos ensayados, se aprecia un ascenso rápido de la precisión una vez el contador de agua ha arrancado. Por ejemplo, en la curva detallada de la Figura 17, se comprueba que el modelo 1 arranca a un caudal de 25-26 I/h, y bruscamente pasa a un error dentro de los límites establecidos en la ISO 4064 con un caudal de $50 \mathrm{l} / \mathrm{h}$. 


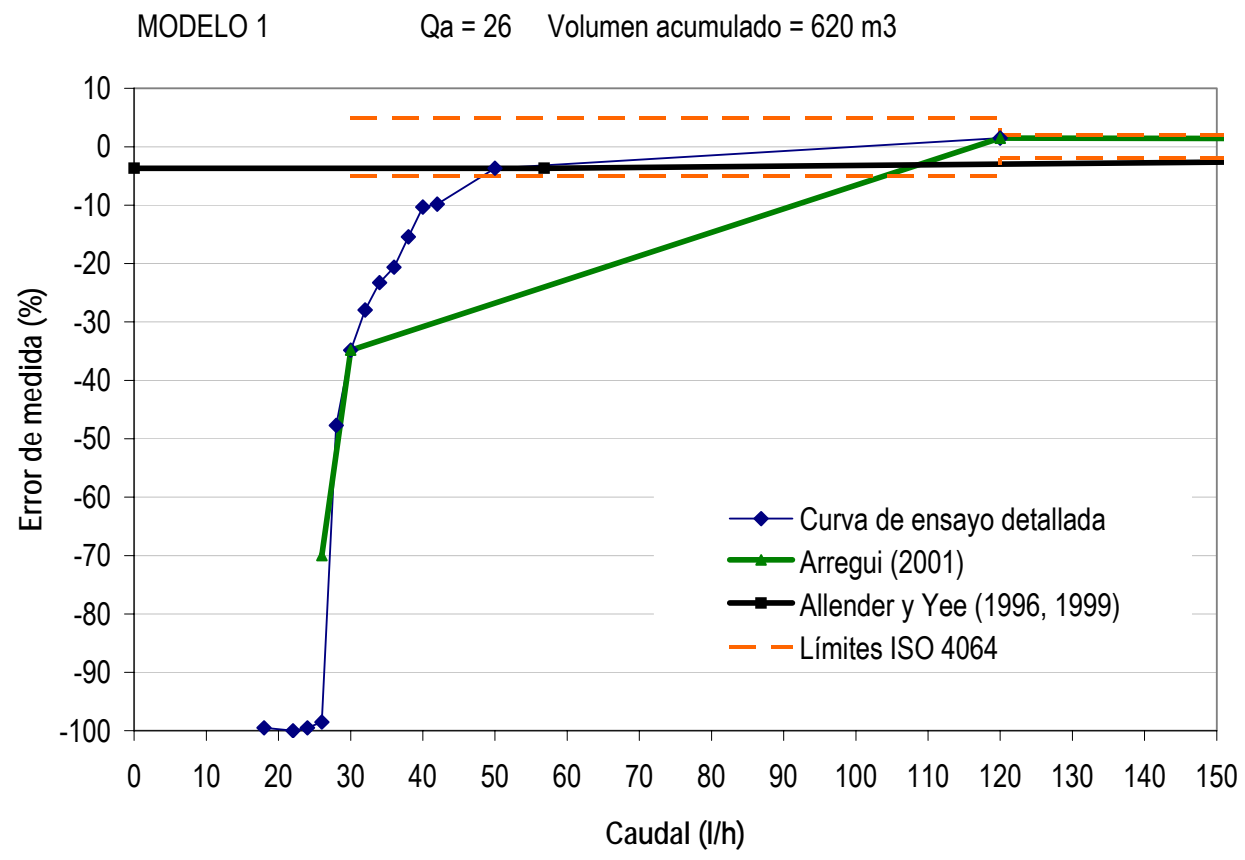

FIGURA 17. MODELO 1. COMPARATIVA ENTRE CURVA DE ERROR ENSAYADA Y LA PONDERACIÓN ESTIMADA A CAUDALES BAJOS.

Este hecho se agudiza cuando el contador ensayado es nuevo, como es el caso de la Figura 18, donde desde el momento en que arranca el contador hasta que éste entra dentro de los límites de error del $\pm 5 \%$ apenas se incrementa el caudal en aproximadamente $15 \mathrm{l} / \mathrm{h}$.

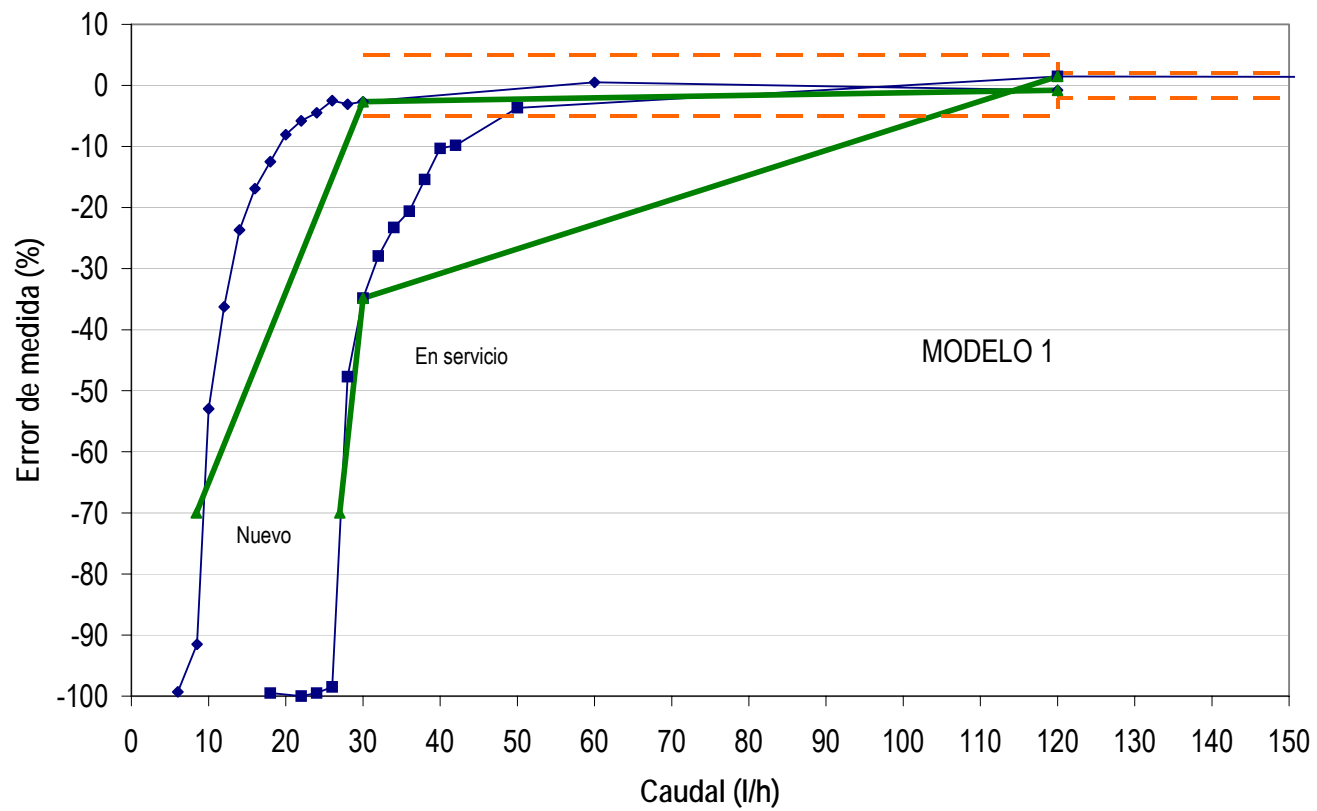

FIGURA 18. CURVAS DE ERROR DETALLADAS DE UN CONTADOR NUEVO Y USADO DEL MODELO 1. 
Asimismo, en esta figura es posible apreciar que la interpolación lineal entre el caudal de arranque $\left(Q_{a}\right)$ y el siguiente caudal de ensayo, de $30 \mathrm{l} / \mathrm{h}$, en los contadores más deteriorados se ajusta mejor a la realidad que en los contadores nuevos. Evidentemente, a medida que el caudal de arranque sea más cercano a caudal de ensayo de $30 \mathrm{l} / \mathrm{h}$ la aproximación será más fiel, y este fenómeno ocurre a medida que envejece el contador.

Al contrario sucede cuando se interpola el error obtenido a $30 \mathrm{l} / \mathrm{h}$ y a $120 \mathrm{l} / \mathrm{h}$ donde la interpolación es más ajustada para instrumentos que han sufrido un menor deterioro. Los aparatos nuevos deben cumplir los requisitos de la norma entrando dentro de los límites de error antes del caudal mínimo, a partir de éste, los errores tienen escasa variabilidad. A caudales superiores a $30 \mathrm{l} / \mathrm{h}$, donde en los modelos usados (Figura 17 y Figura 19), la curva de ponderación se encuentra por debajo de la curva de error real.

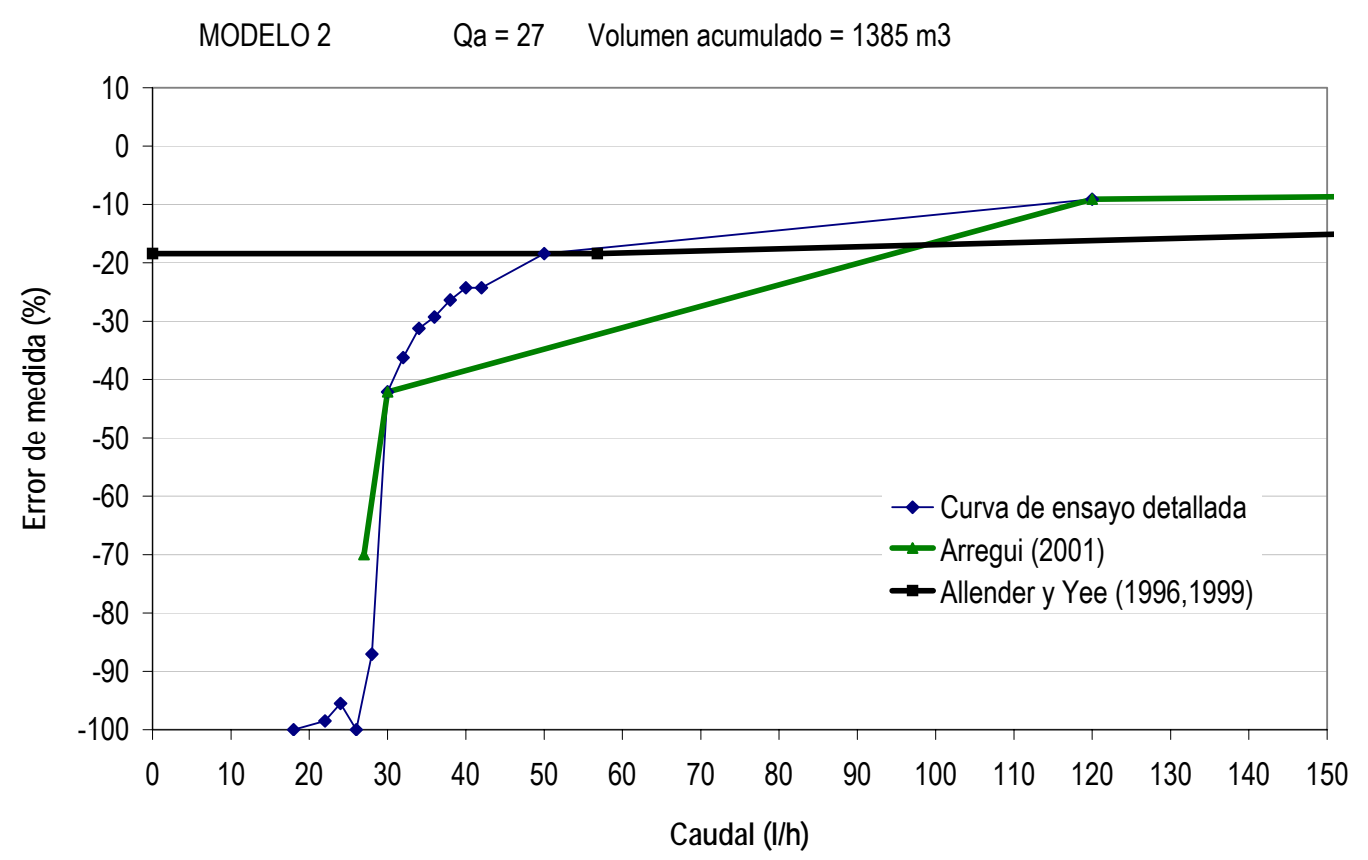

FIGURA 19. MODELO 2. COMPARATIVA ENTRE CURVA DE ERROR ENSAYADA Y LA PONDERACIÓN ESTIMADA.

En general, la propuesta de Arregui comete una sobrevaloración del volumen no registrado, estimando mayor cantidad de agua no registrada. Como ejemplo, en la Figura 19, se comprueba que para un caudal de $50 \mathrm{l} / \mathrm{h}$, el error según la linealización es de -35\%, mientras que en el laboratorio el resultado obtenido es de aproximadamente -18\%.

En los contadores nuevos esta diferencia a caudales bajos no es tan acusada, lo que significa menor discrepancia entre los errores a un mismo caudal, y consecuentemente, mejor estimación del volumen no registrado que en los contadores usados. 


\section{CONTADORES CLASE METROLÓGICA C}

Los contadores de clase metrológica superior tienen exigencias metrológicas diferentes que los de clase B. Este hecho repercute en la forma de la curva de error y consecuentemente en el modo en que debe llevarse a cabo su reconstrucción.

Los contadores de clase C, según la Norma ISO 4064 y la Orden Ministerial del 28 de Diciembre de 1988 donde se establecen las clases metrológicas, deben entrar dentro de los límites establecidos por dicha norma al caudal mínimo. Es decir, para un contador doméstico de caudal nominal de $1,5 \mathrm{~m} 3 / \mathrm{h}$ a $15 \mathrm{l} / \mathrm{h}$ el error no debe superar el $\pm 5 \%$.

Conjuntamente, los contadores con esta clase metrológica suelen ser interesantes para abastecimientos con un precio del agua elevado donde contabilizar un metro cúbico adicional puede rentabilizar rápidamente el mayor coste del contador.

Por estas razones conviene analizar de qué forma se pondera en estos casos la curva de error con el patrón de consumo medido. La bibliografía encontrada no hace mención especial a esta clase metrológica, siendo los criterios para simplificar la curva de error iguales a los presentados por los diferentes autores del apartado anterior para clase B. Las particularidades que aparecen, hacen recomendable que durante el proceso de reconstrucción se traten de forma diferente.

En la presente Tesis se han ensayado en detalle contadores de Clase $C$ nuevos, de igual forma que se hizo para los de clase $B$, con los resultados mostrados en la Tabla 15.

TABLA 15. RESULTADOS DE LOS ENSAYOS A DIFERENTES MODELOS DE CONTADOR CLASE C.

\begin{tabular}{cccc}
\hline \multicolumn{2}{c}{ MODELO 3 (nuevo) } & \multicolumn{2}{c}{ MODELO 4 (nuevo) } \\
\hline Qensayado $(l / h)^{2}$ & Error contador & Qensayado $(\mathrm{l} / \mathrm{h})$ & Error contador \\
8 & $-28,0$ & 4 & $-94,1$ \\
10 & $-11,1$ & 7 & $-79,2$ \\
12 & $-6,2$ & 10 & $-18,6$ \\
14 & $-3,4$ & 12 & $-6,1$ \\
16 & $-2,1$ & 14 & $-2,9$ \\
18 & $-0,9$ & 16 & 0,2 \\
20 & $-1,1$ & 18 & 4,0 \\
24 & $-0,7$ & 20 & 2,7 \\
26 & $-0,5$ & 22 & 3,9 \\
28 & $-1,4$ & 24 & 4,1 \\
30 & 0,9 & 26 & 4,5 \\
32 & 0,3 & 28 & 4,9 \\
& & & \\
\hline
\end{tabular}

\begin{tabular}{cccc}
\hline Qensayado $(\mathrm{l} / \mathrm{h})$ & Error contador & Qensayado $(\mathrm{l} / \mathrm{h})$ & Error contador \\
\hline 34 & 0,0 & 30 & 4,6 \\
36 & 0,1 & 32 & 4,2 \\
38 & 0,1 & 34 & 4,5 \\
40 & 0,3 & 36 & 4,0 \\
42 & 0,1 & 38 & 3,7 \\
44 & 0,7 & 40 & 2,9 \\
46 & 0,8 & 42 & 3,8 \\
48 & 0,8 & 44 & 3,9 \\
50 & 1,2 & 46 & 3,3 \\
60 & 0,8 & 48 & 3,0 \\
120 & 1,9 & 50 & 2,6 \\
750 & $-0,2$ & 60 & 2,5 \\
1500 & $-0,3$ & 120 & 2,0 \\
& & 750 & $-0,1$ \\
& & 1500 & 0,4 \\
\hline
\end{tabular}

Instalar una clase metrológica $\mathrm{C}$ presupone contabilizar mejor el agua consumida pero además es importante ponderar los resultados obtenidos de forma correcta para tener una estimación fiable del volumen no registrado (VNR) en estos casos.

Como en el caso anterior las ponderaciones propuestas por Allender y Yee, al no considerar el caudal de arranque del contador falsean los resultados atribuyendo al contador menor error de medición que el realmente conseguido. La ponderación propuesta por Arregui que linealiza los errores entre el caudal de arranque y el error a $30 \mathrm{l} / \mathrm{h}$ simplifica la curva peor que para clase B. Aproximadamente, a $14 \mathrm{l} / \mathrm{h}$ tanto el modelo 3 como el 4 , tienen un error dentro del $\pm 5 \%$ mientras que la linealización del error estima $-45 \%$. La simplificación de la curva propuesta por Arregui infravalora el error sobre todo a caudales bajos. En clase $\mathrm{C}$ a partir de $30 \mathrm{l} / \mathrm{h}$ la linealización entre puntos perfila correctamente la curva real de un contador nuevo puesto que el error de amntiene estable. Consecuentemente, en esta clase metrológica, más precisa, conviene hacer 
hincapié en la zona de caudales inferiores a $30 \mathrm{l} / \mathrm{h}$, proponiendo otro caudal de ensayo que capte mejor la curva (Figura 20 y Figura 21).

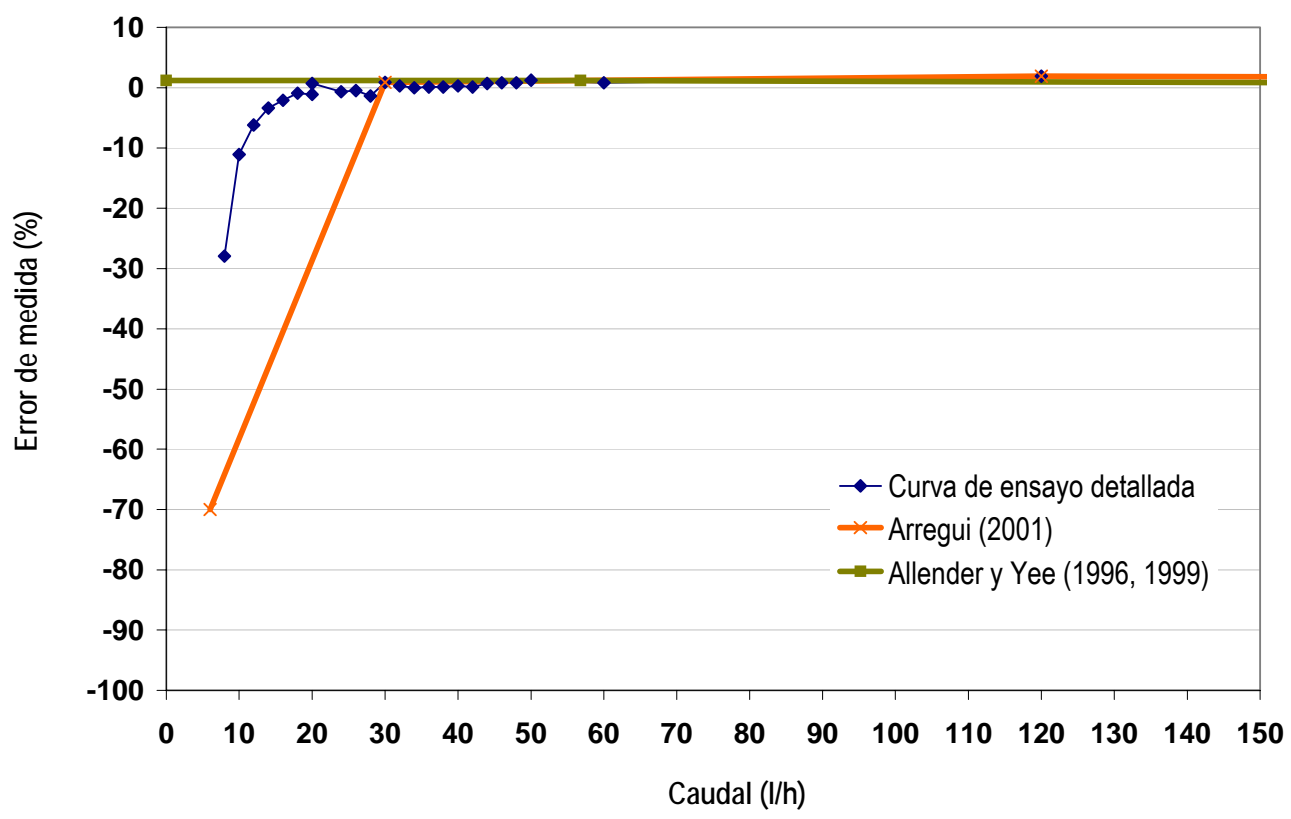

FIGURA 20. MODELO 3. COMPARATIVA ENTRE LA CURVA DE ERROR ENSAYADA Y LA PONDERACIÓN ESTIMADA.

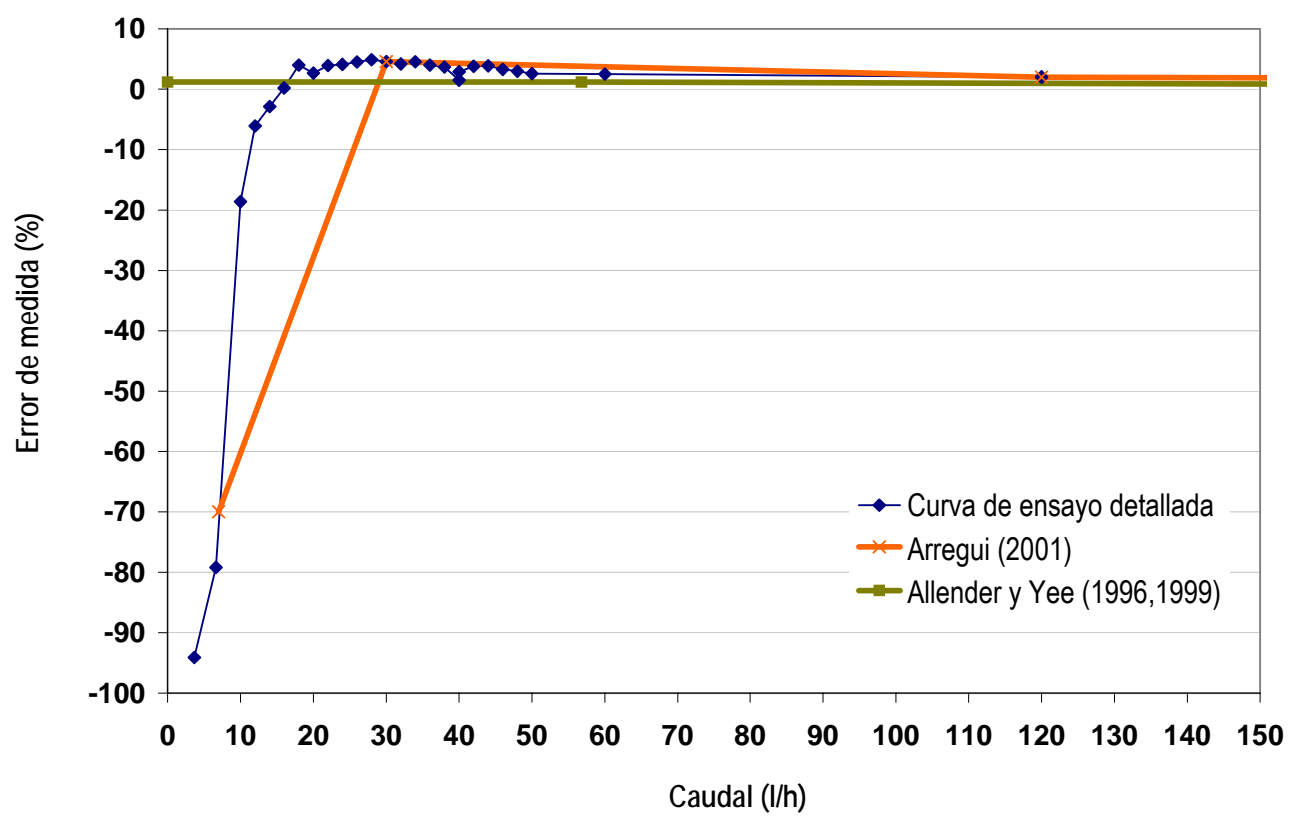

FIGURA 21. MODELO 4. COMPARATIVA ENTRE LA CURVA DE ERROR ENSAYADA Y LA PONDERACIÓN ESTIMADA. 


\subsubsection{Resultados de la comparativa entre métodos de ponderación}

Continuando el ejemplo propuesto se combinan las curvas de error simplificadas mediante las diferentes técnicas descritas con un patrón de consumo muy desfavorable y otro medio. Los patrones de consumo propuestos que consideran los diversos rangos de caudal se presentan en la Tabla 16 y Tabla 17.

TABLA 16. ADAPTACIÓN DE LOS PATRONES DE CONSUMO PROPUESTOS A LA METODOLOGÍA DE YEE Y ALLENDER.

\begin{tabular}{ccccc}
\hline & \multicolumn{2}{c}{ PATRÓN MUY DESFAVORABLE } & \multicolumn{2}{c}{ PATRÓN MEDIO } \\
\hline Rango & YEE & ALLENDER & YEE & ALLENDER \\
& (\% de consumo) & (\% de consumo) & (\% de consumo) & (\% de consumo) \\
BAJOS & 17,33 & 17,33 & 10,75 & 10,75 \\
MEDIOS & 27,77 & 27,77 & 22,82 & 22,82 \\
ALTOS & 54,90 & 54,90 & 66,43 & 66,43 \\
\hline
\end{tabular}

TABLA 17.AdAPTACIÓN DEL PATRÓN DE CONSUMO EJeMPLO (ARREGUI, 2003).

\begin{tabular}{ccc}
\hline Rango & $\begin{array}{c}\text { PATRÓN MUY DESFAVORABLE } \\
\text { (\% de consumo) }\end{array}$ & $\begin{array}{r}\text { PATRÓN MEDIO } \\
\text { (\% de consumo) }\end{array}$ \\
\hline $0-12 \mathrm{l} / \mathrm{h}$ & 10,00 & 4 \\
$12-24 \mathrm{l} / \mathrm{h}$ & 3,10 & 3 \\
$24-36 \mathrm{l} / \mathrm{h}$ & 1,80 & 2 \\
$36-72 \mathrm{l} / \mathrm{h}$ & 4,20 & 3 \\
$72-180 \mathrm{l} / \mathrm{h}$ & 11,60 & 5 \\
$180-1500 \mathrm{l} / \mathrm{h}$ & 69,30 & 81 \\
$1500-3000 \mathrm{l} / \mathrm{h}$ & 0,00 & 2 \\
$>3000 \mathrm{l} / \mathrm{h}$ & 0,00 & 0 \\
\hline
\end{tabular}

Cuando se calcula con los datos del ejemplo expuesto el volumen no registrado por los contadores de clase B en servicio (Modelos 1 y 2) y de clase $C$ nuevos con cada método se advierten claras diferencias, entre el método utilizado por Arregui y los de Allender y Yee (Tabla 18 y Tabla 19). Efectivamente, los resultados muestran para ambos patrones que la estimación del volumen atribuido a errores de subcontaje realizada por el primero se ajusta más al volumen no registrado real que las propuestas de Allender (1996) y Yee (1999).

Estos últimos métodos incurren en graves errores al considerar como registrado el volumen consumido por debajo del caudal de arranque, es decir, cuando el contador se encuentra parado. Como consecuencia la diferencia en las estimaciones está en torno al $15 \%$ en modelos viejos de clase metrológica B y cerca del $6 \%$ en contadores nuevos de clase $\mathrm{C}$ con la curva de error más desplazada hacia caudales bajos con un patrón de consumo muy desfavorable. Evidentemente, a medida que el porcentaje de volumen consumido a caudales bajos sea mayor (patrón más desfavorable) estas diferencias se acentuan ya que la zona crítica donde se deja de registrar más volumen de agua se localiza en estos rangos (Tabla 19).

Los resultados demuestran claramente que la metodología propuesta por Yee y Allender no debe utilizarse nunca y que las simplificaciones realizadas reproducen incorrectamente el comportamiente real de los medidores. 
TABLA 18. VOLUMEN NO REGISTRADO ESTIMADO POR LOS DIFERENTES MÉTODOS. PATRÓN MUY DESFAVORABLE.

\begin{tabular}{ccccc}
\hline & \multicolumn{2}{c}{ Clase B } & \multicolumn{2}{c}{ Clase C } \\
\hline & $\begin{array}{c}\text { MODELO 1 } \\
\text { (en servicio) }\end{array}$ & $\begin{array}{c}\text { MODEL0 2 } \\
\text { (en servicio) }\end{array}$ & $\begin{array}{c}\text { MODELO 3 } \\
\text { (nuevo) }\end{array}$ & $\begin{array}{c}\text { MODELO 4 } \\
\text { (nuevo) }\end{array}$ \\
\hline Allender (1996) Yee (1999) & $-0,03$ & $-6,1$ & 0 & $+0,9$ \\
Arregui (2001) & $-14,5$ & $-20,4$ & $-9,2$ & $-8,8$ \\
\hline CURVA DE ENSAYO DE ERROR EN DETALLE & $-13,5$ & $-18,6$ & $-5,6$ & $-5,8$ \\
\hline
\end{tabular}

TABLA 19. Volumen NO REgISTRAdo ESTIMADO POR LOS DIFERENTES MÉTODOS. PATRÓN MEDIO.

\begin{tabular}{|c|c|c|c|c|}
\hline & \multicolumn{2}{|c|}{ Clase B } & \multicolumn{2}{|c|}{ Clase C } \\
\hline & $\begin{array}{c}\text { MODELO } 1 \\
\text { (en servicio) }\end{array}$ & $\begin{array}{c}\text { MODELO } 2 \\
\text { (en servicio) }\end{array}$ & $\begin{array}{c}\text { MODELO } 3 \\
\text { (nuevo) }\end{array}$ & $\begin{array}{c}\text { MODELO } 4 \\
\text { (nuevo) }\end{array}$ \\
\hline Allender (1996), Yee (1999) & $+0,3$ & $-5,0$ & $-0,1$ & $+0,7$ \\
\hline Arregui (2001) & $-8,2$ & $-14,1$ & $-4,3$ & $-3,9$ \\
\hline CURVA DE ENSAYO DE ERROR EN DETALLE & $-7,4$ & $-12,1$ & $-1,8$ & $-2,1$ \\
\hline
\end{tabular}

\subsection{CONCLUSIONES}

Tras el estudio en profundidad de los parámetros que afectan al cálculo del error global y sus métodos de ponderación, en este apartado se resumen las principales conclusiones y aportaciones en este ámbito de la presente Tesis doctoral.

La propuesta de mejora se realiza en base a la metodología de ponderación propuesta por Arregui en 2004. Esta técnica es más precisa para las condiciones en las que se encuentran los abastecimientos urbanos peninsulares donde existe gran cantidad de aljibes, frecuentes fugas en las instalaciones interiores y además, la demanda de agua no se produce a caudales excesivamente altos, normalmente por debajo de $1500 \mathrm{l} / \mathrm{h}$.

Este método propuesto por Arregui en 2004 se realizó bajo las ciertas suposiciones que se comentan y contrastan en el capítulo. La primera de ellas, es que el error de medición al caudal de arranque ( $\left.Q_{a}\right)$ se supone de - 70\%. El caudal de arranque de un contador es un parámetro difícil de determinar, ya que en primer lugar, no en todos los contadores es posible precisar cuando la turbina cesa o comienza a girar y, además, muy a menudo esta turbina se encuentra desequilibrada y puede ocurrir que al cabo de cierto tiempo pare provocando incertidumbres importantes en su determinación. No obstante, como se demuestra en el apartado 3.2.3 del Capítulo 3, una aproximación del error a -70\% es bastante correcta, considerando la baja velocidad y estabilidad de la turbina a esos caudales.

Otra de las suposiciones realizadas por este autor es considerar una evolución lineal de la curva de error entre caudales de ensayo. Por una parte, este supuesto está justificado, pero por otra puede conducir a graves errores si no se eligen los caudales de ensayo adecuados.

Como se recomienda en Bowen en la AWWARF (1993), el número de ensayos para determinar la curva de error de un contador es de tres, a caudales altos, medios y bajos. Arregui aumenta esta cifra a cuatro más el caudal de arranque, siendo los caudales propuestos, como se comentó en el apartado 5.2.1 de este capítulo, son el $Q_{a}$, error a $30 \mathrm{l} / \mathrm{h}$, a $120 \mathrm{l} / \mathrm{h}$, a $750 \mathrm{l} / \mathrm{h}$ y a $1500 \mathrm{l} / \mathrm{h}$. 
Un número escaso de caudales de ensayo presenta inconvenientes ya que provoca una ponderación del patrón de consumo con la curva de error incorrecta falseando el volumen que deja de registrar el contador de agua. Al contrario, un número elevado de caudales de ensayo es inviable y poco práctico para las empresas de agua que necesitan controlar la metrología de gran cantidad de instrumentos.

De esta forma, determinar qué número de caudales de ensayo y a qué valores son los apropiados para ponderar correctamente ambos parámetros es otro de los objetivos de este capítulo.

La metodología de ponderación presentada por Arregui, generalmente sobrevalora el volumen no registrado debido a que no se ajusta adecuadamente a la curva de error real del instrumento ensayado en algunos puntos. Fundamentalmente, el problema aparece por el desconocimiento del funcionamiento del contador en la zona crítica de la curva al no realizarse ningún ensayo a dichos caudales, sobre todo el desajuste que se produce en el tramo de 30 a $120 \mathrm{l} / \mathrm{h}$ para contadores de clase metrológica B.

Esto no ocurre de forma tan acusada en contadores con un caudal de arranque bajo o contadores nuevos, que como se vió durante los ensayos de laboratorio del Capítulo 3, desde que arrancan hasta que entran dentro de los límites de error establecidos en la norma europea se incrementa poco el caudal, con lo que la linealización del error, en clase $B$, entre $Q_{a}-30$ I/h y $30-120 \mathrm{l} / \mathrm{h}$ es más ajustada que en contadores en peor estado.

Por ello, una de las propuestas que se plantea en la presente Tesis es un ensayo de error adicional a un caudal aproximadamente de $50 \mathrm{l} / \mathrm{h}$. De esta forma, el problema se soluciona en gran medida para contadores usados aportando un punto de ensayo más en la linealización de la curva de error en la zona de caudales bajos donde el ajuste es más problemático (Figura 22).

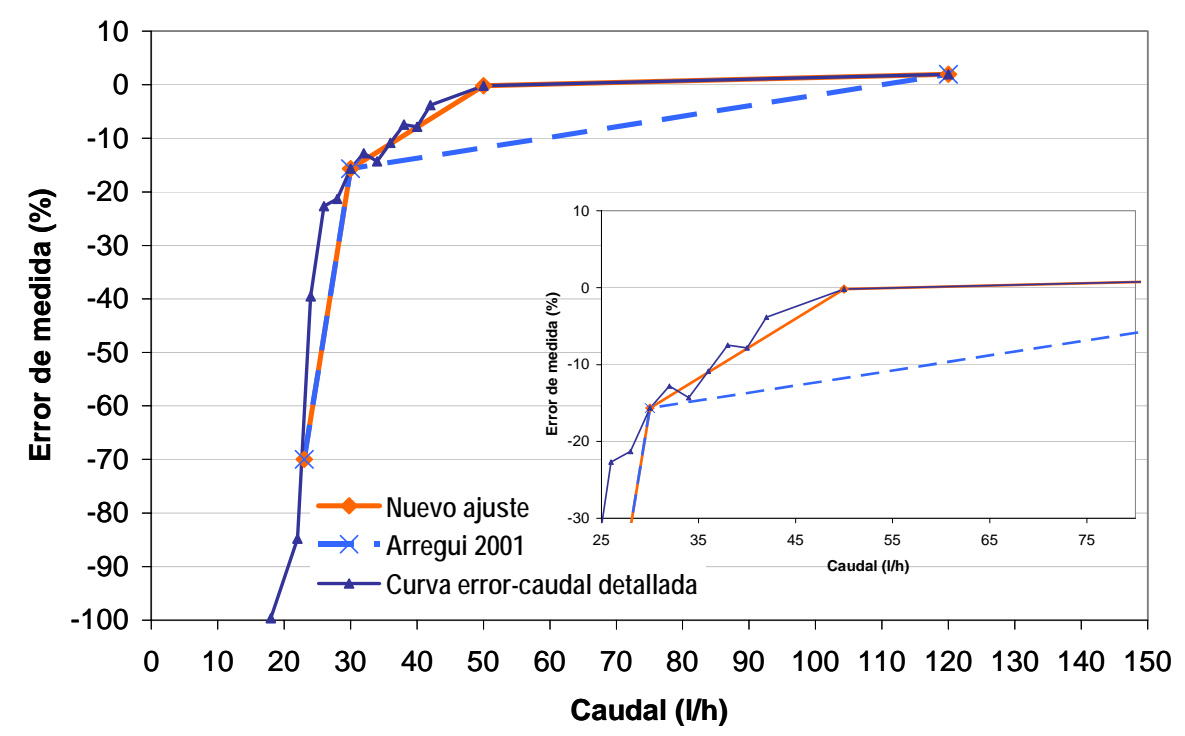

FIGURA 22. COMPARACIÓN DE LAS DIFERENTES PROPUESTAS DE PONDERACIÓN EN CONTADORES DE CLASE B.

Por otro lado, los contadores nuevos de clase metrológica $\mathbf{C}$ no se ajustan en el primer tramo de la curva, es decir, la linealización entre el caudal de arranque y el error a $30 \mathrm{l} / \mathrm{h}$ resulta con mayor error que la curva real del contador. A medida que este contador se deteriora su precisión se aproxima más a la de un clase $B$, con lo que la estimación del error global es más aproximada. No obstante, se recomienda trasladar el ensayo a otro caudal entre el de arranque y el caudal a $30 \mathrm{I} / \mathrm{h}$, por 
ejemplo al caudal mínimo, que en el caso de un calibre de $13 \mathrm{~mm}$ corresponde a $15 \mathrm{l} / \mathrm{h}$ (Figura 23). De este modo, los caudales de ensayo de un contador de 13/15 mm Clase C quedarían a 15, 30, 120, 750 y $1500 \mathrm{l} / \mathrm{h}$.

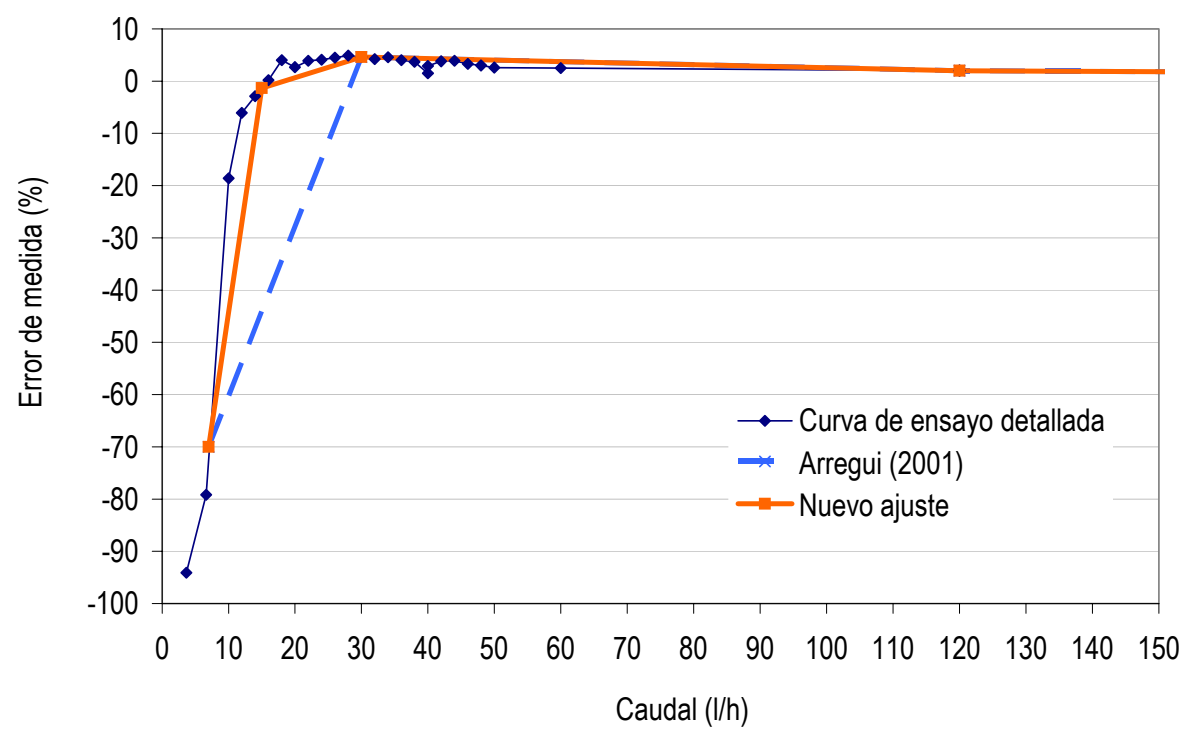

FIGURA 23. COMPARACIÓN DE LAS DIFERENTES PROPUESTAS DE PONDERACIÓN EN CONTADORES DE CLASE C.

Otra aportación que reduce el tiempo de ensayo, son las relaciones existentes entre caudales de ensayo mostradas en el apartado 2.3 del Capítulo 3. El uso de la correlación existente entre el caudal de arranque y el error a $30 \mathrm{l} / \mathrm{h}$ puede ser de gran utilidad durante la ponderación del patrón de consumo con el error de medición ya que agiliza y simplifica las anteriores metodologías propuestas.

Finalmente, comentar que de los trabajos realizados se ha podido comprobar que el error a 750 y $1500 \mathrm{l} / \mathrm{h}$ es prácticamente idénticos por lo que podría descartarse el ensayo de uno de estos caudales.

\subsection{BIBLIOGRAFÍA CONSULTADA}

Allender H D. (1996). Determinig the economical optimum life of residencial water meters. Water Engineering and management.

Arregui F.J. (1999). Propuesta de una metodología para el análisis y gestión del parque de contadores de agua. Tesis doctoral. Universidad Politécnica de Valencia.

Arregui F.J. (2000). Informe Cálculo del patrón de consumo y la vida útil de los contadores de Santa Fé de Bogotá. Documento interno. Instituto Tecnológico del Agua. Universidad Politécnica de Valencia.

Arregui F.J. (2000). Evaluación de la precisión de diversos contadores durante el llenado de cisternas. Documento interno. Instituto Tecnológico del Agua. Universidad Politécnica de Valencia.

Arregui F.J. (2001). Algunas consideraciones sobre la elección del tipo de contador doméstico y el cálculo de su vida útil. Jornadas técnicas Baleares 2015: La Gestión del Agua. 
Arregui F.J., Garcia-Serra J, Palau C.V, Gascón L. (2004). Metodología para la evaluación del error de un parque de contadores. Evaluación y control de pérdidas en redes urbanas. Ed. Cabrera E.

AWWA Manual M6 (1986). Water meter- Selection, installation, testing and maintenance. Denver CO.

AWWA (1999). Residential water use- Potencial saving by end use.

Bowen P. T Harp J.F. Baxter J.W. Shull R.D. (1993).Residential water use patterns. Ed. American Water Works Association Research Foundation. Denver Co.

Brittain R.L. (1974). Small meter periodic test limit extension study. Unpublished Report, Philadelphia Suburban Water Company.

Cabrera E., Almandoz J. Arregui F, García-Serra J. (1999). Auditoría de redes de distribución de agua. Ingeniería del Agua. Vol.6 No 4. pp. 387-399.

Creus A. (1989). Instrumentación industrial. Marcombo

Gascón L. (2003). Metodología para el análisis de los usos residenciales del agua. Estudio de la demanda de agua residencial. Trabajo de insvestigación programa de doctorado en Hidráulica y Medioambiente. Universidad Politécnia de Valencia.

Gomes Sanchez y De Almeida (1999). Estimation of not measured water volume supplied to residential consumers. 10 th FLOMEKO Conference. Salvado. Brasil.

Graeser H.J (1958). Detecting lost water at Dallas. Journal of AWWA.Jul. pp. 925-932.

Hudson W.D. (1964). Reduction of Unaccounted-for Water. Journal of AWWA. Feb. pp. 143-148.

Instituto Tecnológico del Agua (2001). La medición en sistemas de distribución de agua. Primera parte. Documento interno. Curso de la Universidad Politécnica de Valencia.

ISO 4064-1:1993. Medición del caudal de agua en conductos cerrados. Parte 1. Especificaciones.

ISO 4064-2:1978. Medición del caudal de agua en conductos cerrados. Parte 2. Con diciones de instalación..

ISO 4064-3:1983. Medición del caudal de agua en conductos cerrados. Parte 3. Métodos y materiales de ensayo.

Male J.W. Noss R. R Moore I.C (1985). Identifying and Reducing losses in Water Distribution Systems. Noyes Publications.

Nielsen N. (1969). Determination of proper age for $5 / 8$ inch meters in the Hackensack and Spring Valley Systems. Report of Hackensack Water Company, Harrington Park, NJ.

Planells F, Antolí A, López V, Sanz F, García-Serra J (1987). Diagnóstico de la gestoón óptima de contadores en un sistema de distribución de agua. Tecnología del agua. Vol. 38. pp. 42-55.

Sisco R.J. (1967). The case of meter replacement programs. Journal of AWWA. Nov. pp. 1149-1455.

Terriel, J.C.; Daniel, W.W.(1994). Business statistics for management and economics. Ed. Houghton Mifflin Company. Boston.

Yanov D.A. Koch R.N (1987). A modern residential flow demand study. Session 27 of AWWA Annual conference, Kansas city, KS.

Yee M D. (1999). Economic analysis for replacing residential meters. Journal AWWA. Vol. 91. Num.7. pp. 72-77 


\section{CAPÍTULO 6}

GESTIÓN DE LOS SISTEMAS DE MEDICIÓN EN REDES HIDRÁULICAS A PRESIÓN 


\section{GESTIÓN DE LOS SISTEMAS DE MEDICIÓN EN REDES HIDRÁULICAS A PRESIÓN}

\subsection{INTRODUCCIÓN}

Los recursos disponibles y la presión social y de la administración están forzando a las empresas de suministro de agua a establecer mayores controles y mejorar el rendimiento hidráulico de sus redes de distribución. Para ello, se perfilan diferentes estrategias que les permitan mejorar la gestión del abastecimiento con el objetivo de reducir el volumen de agua incontrolada, tanto el que se pierde por fugas en la red como el agua no contabilizada debido a ausencia de contador y a errores de medición de instrumentos de medida de caudal instalados.

Este capítulo centra su atención, fundamentalmente, en este último punto, proponiendo una guía práctica de las principales estrategias que pueden aplicarse para gestionar correctamente el sistema de medición de caudal de una red hidráulica y aumentar tanto su eficacia como su eficiencia.

El contenido de este tema estará dividido en dos partes diferenciadas. Una primera parte que abordará las prácticas más convenientes para el control y gestión del sistema de micromedidores y una segunda parte concerniente a la eficacia de la instrumentación de gran calibre, particularmente, en lo referente a contadores de velocidad (Tabla 1). La descripción de dichas actuaciones y sus beneficios se irán desarrollando en profundidad durante el presente capítulo con el fin de compendiar, en una guía práctica, las estrategias más adecuadas para gestionar estos sistemas. 
TABLA 1. GeStIÓN DE LOS SISTEMAS DE MEDICIÓN.

\begin{tabular}{|c|c|c|}
\hline Sistema & MICROMEDICIÓN & MACROMEDICIÓN \\
\hline ACCIONES & $\begin{array}{l}\text { - Control estadístico de calidad a la } \\
\text { recepción de los contadores nuevos. } \\
\text { - Periodo óptimo de renovación desde un } \\
\text { punto de vista económico. } \\
\text { - Análisis de las facturaciones como } \\
\text { herramienta de apoyo en la gestión de } \\
\text { contadores. }\end{array}$ & $\begin{array}{l}\text { - Elección de la tecnología más apropiada. } \\
\text { - Dimensionado adecuado de instrumentos de } \\
\text { medida. } \\
\text { - Verificación in-situ de los instrumentos de } \\
\text { medida de caudal. } \\
\text { - Análisis estadístico de los caudales } \\
\text { inyectados para la detección de fallos o } \\
\text { anomalías en la red. }\end{array}$ \\
\hline BENEFICIOS & $\begin{array}{l}\text { - Reducción del volumen de agua } \\
\text { incontrolado. } \\
\text { - Reducción de costes asociados a la } \\
\text { utilización de contadores. } \\
\text { - Mayor capacidad de predicción de la } \\
\text { demanda de agua. } \\
\text { - Discriminación de porcentaje de agua } \\
\text { incontrolada perdida por fugas en la red. } \\
\text { - Mayor eficacia de toma de decisiones. }\end{array}$ & $\begin{array}{l}\text { - Dimensionado de accesorios y tuberías de la } \\
\text { red de distribución. } \\
\text { - Mejora en el rendimiento por control de } \\
\text { fugas. } \\
\text { - Mayor rapidez en la detección de fallos en la } \\
\text { red. } \\
\text { - Mejoras en la modelización de la red de } \\
\text { distribución. }\end{array}$ \\
\hline
\end{tabular}

El primer objetivo que debe plantearse un técnico para mejorar la gestión del sistema de medición es la elección de la instrumentación más adecuada. Para ello, a la hora de seleccionar un instrumento de medida de caudal se deben considerar ciertos aspectos que justifiquen su adquisición tanto en lo referente a su calidad metrológica como a criterios de minimización de costes garantizando una calidad de medición mínima.

La precisión es un parámetro ampliamente abordado durante toda la tesis. Es importante conocer qué factores pueden afectar y en qué grado a los distintos instrumentos de medida. La elección de un medidor más o menos preciso estará condicionada, primero, por unos requerimientos mínimos de calidad metrológica y, posteriormente, por criterios de optimización económica de la inversión realizada. Por ello, el continuo debate sobre la conveniencia de instalar un instrumento más preciso atenderá a criterios de rentabilidad que están directamente asociados a la fiabilidad del aparato en el tiempo. El epígrafe 6.3 del presente capítulo plantea un análisis económico donde se estudia la rentabilidad que se obtiene de un contador de agua durante el periodo de tiempo que se encuentra instalado, en función de diversos parámetros, unos característicos del abastecimiento y sus usuarios y otros del propio instrumento de medida.

Otro parámetro a tener en cuenta en la elección del instrumento es el rango de medida definido como el conjunto de valores de la variable observada para los cuales el aparato funciona con la precisión establecida. El conocimiento de este parámetro es imprescindible para el dimensionado del mismo. Específicamente cuando el instrumento es un caudalímetro o contador, conviene realizar estimaciones de los caudales máximos y mínimos de la instalación o mediciones de los caudales circulantes por la misma, siendo éste modo el más eficaz para escoger correctamente la capacidad.

Otro concepto importante que indica la probabilidad de que un instrumento mantenga su calidad metrológica a lo largo del tiempo es la fiabilidad (Creus, 1989). Repetidamente, durante toda la tesis doctoral se ha comprobado que la fiabilidad de los instrumentos depende de sus condiciones de funcionamiento, tanto internas por los caudales circulantes, la calidad del agua, la presión, etcétera, como externas por su instalación. Esto justifica estudios individualizados de cada parque de micromedidores o de cada aplicación concreta evaluando las condiciones particulares de cada instrumento. El Capítulo 3 
mostró la evolución de la curva de error en el tiempo de diferentes modelos instalados en varios abastecimientos. La fiabilidad de instrumentos de mayor calibre se encuentra menos investigada posibilitando la continuidad de esta línea de investigación en un futuro.

Respecto a la fiabilidad exigible a un instrumento de medida se evidencia una carencia en cuanto a normativa metrológica en cuanto al deterioro que pueden sufrir los instrumentos que se comercializan. En Johnson (2004) se cita una normativa sur-africana que amplia los límites de error respecto a los originales especificados en la ISO 4064 para instrumentos en servicio hasta $\pm 8 \%$ entre $Q_{\min }$ y $Q_{t} y \pm 3,5 \%$ después $Q_{t}$.

El conocimiento por parte del técnico del rango de aplicación de cada tecnología de medición de caudal y de los factores que se deben tener en cuenta puede optimizar al máximo su vida útil. Por ello, se considera fundamental este aspecto a la hora de elegir el instrumento.

También se aconseja estar al día en las innovaciones tecnológicas disponibles en el mercado y de las nuevas prestaciones de los instrumentos de medida. Por ejemplo, la comercialización de contadores electrónicos o el conocimiento de las fuentes de incertidumbre que pueden aparecer durante la medición ayuda en la gestión del abastecimiento en múltiples campos.

Evidentemente, el coste inicial del instrumento es un criterio primordial a considerar. Cuando el presupuesto para instrumentación es limitado debe optimizarse al máximo su inversión. No obstante, el conocimiento de las diferentes alternativas posibles permitirá decidir mejor cual es la más adecuada en cada circunstancia. No se trata de escoger la opción más económica de entre las disponibles, sino la más económica de las que permiten resolver el problema.

Otros factores como el mantenimiento, la facilidad de reparación o la necesidad de calibración son atributos a tener presente a la hora de elegir un modelo u otro. Existen tecnologías donde el conjunto de medición puede renovarse sin necesidad de desinstalar el cuerpo del instrumento. Estos casos pueden ser interesantes en lugares de difícil maniobra reduciendo el tiempo y los costes de instalación o sustitución.

Otros términos como el alcance, la repetibilidad del instrumento o la resolución de la señal de salida pueden tenerse en cuenta para casos donde se requiera un estudio en detalle de los datos de caudal aportados por el aparato.

El presente capítulo se expone en dos partes. Una primera que propone estrategias para los sistemas de micromedición de agua urbana fundamentalmente, donde los costes que intervienen en la medición están condicionados por el propio precio del agua. Temas como el control estadístico de calidad a la recepción o un análisis de los costes de medición aportan una visión nueva en la gestión del sistema.

La segunda parte, más práctica, plantea tácticas para mejorar el funcionamiento de los sistemas de mayor calibre 0 macromedidores, incluyendo temas como el dimensionado de instrumentos o su verificación in situ. 


\section{PARTE I. SISTEMA DE MICROMEDICIÓN}

\subsection{CONTROL DE CALIDAD DE CONTADORES DOMÉSTICOS}

\subsubsection{VISIÓN GENERAL Y PROBLEMÁTICA}

En el presente apartado se aborda la gestión de micromedidores desde el punto de vista del control de la calidad de lotes de contadores nuevos recién suministrados por el proveedor. Por un lado, como se ha visto los contadores nuevos deben cumplir con la normativa establecida en la ISO-4064 para cada clase metrológica. En esta norma se establecen unos límites de error, en función de los caudales de ensayo entre los cuáles debe oscilar la curva de error del contador.

A su vez, los contadores de agua fría, como se describe en la Orden ministerial del 28 de diciembre de 1988, son objeto de aprobación del modelo y de verificación primitiva. La aprobación del modelo es el procedimiento mediante el cual se somete dicho instrumento a diferentes pruebas, definidas en la Directiva europea 74/33/CEE, a una muestra del modelo de contador a aprobar por una entidad habilitada por el Centro Nacional de Metrología. Tras la aprobación del modelo, la Directiva europea exige que éste se fabrique con las mismas características constructivas que el contador que superó las pruebas de aprobación.

Para ello, se impone al fabricante que cada contador que sale de fábrica pase unos ensayos de comprobación de su curva de error a caudales de ensayo entre $0,9 \cdot Q_{\max }$ y $Q_{\max }$, entre $Q_{t}$ y $1,1 \cdot Q_{t}$ y por último, entre $Q_{\min }$ y $1,1 \cdot Q_{t}$, lo que se denomina verificación primitiva.

Tras pasar estas pruebas de calidad el contador puede ser comercializado a cualquier abastecimiento de agua. En este momento es cuando el instrumento de medida llega a las manos del técnico encargado de llevar a cabo la gestión del parque de contadores. No obstante, en ocasiones, estos lotes verificados en fábrica pueden verse afectados durante las posteriores manipulaciones o en el transporte y no llegar a su destino en las condiciones metrológicas adecuadas.

La instalación en domicilios de contadores de agua en mal estado puede provocar inconvenientes importantes a la empresa de suministro de agua. Estos inconvenientes son tanto de índole económico debido a la pérdida de facturación del agua por subcontaje, como técnico, ya que dificulta el control de los caudales circulantes por la red, disminuyendo el rendimiento hídrico del sistema.

Además, no todos los fabricantes de contadores suministran la misma calidad para unas mismas características metrológicas. Como se aprecia en los ensayos en detalle mostrados en el Capítulo 3, las curvas de error en modelos de contador nuevos de la misma clase metrológica no tienen las mismas características. Esto es debido a que cada modelo se monta con procesos de fabricación en los que los controles de calidad y las exigencias productivas son muy diferentes al resto. Por ello, antes de proceder a la instalación es recomendable realizar una serie de comprobaciones que garanticen la calidad de la partida de contadores adquiridos, especialmente si no se cuenta con una amplia experiencia en la utilización de dicho modelo. 
En este apartado se proponen planes de muestreo que permiten asegurar la calidad de los contadores nuevos recibidos por la empresa de servicio de agua, verificando que cumplen todos los requisitos y especificaciones técnicas aplicables, y que se ajustan perfectamente a las características exigidas por la red de suministro.

\subsubsection{CONSIDERACIONES SOBRE LA CALIDAD DE LOS INSTRUMENTOS}

Al conjunto de técnicas planificadas por la empresa de suministro de agua necesarias para proporcionar confianza sobre el producto o materia prima comprada se engloban dentro de lo que se viene a denominar aseguramiento de la calidad.

Cuando una empresa de abastecimiento de agua solicita cierto número de contadores, es recomendable revisar la calidad de ese lote para comprobar que, efectivamente, el proveedor está proporcionando el nivel de calidad comprometido.

A este punto debe llegarse mediante acuerdos de calidad concertada. Es decir, es importante fijar relaciones sobre la calidad del producto suministrado establecidas por mutuo acuerdo entre el proveedor y el cliente, en este caso, entre la empresa de fabricación de contadores y la empresa de servicios. En estos acuerdos de calidad, deben quedar claramente reflejados puntos como los niveles de calidad a suministrar, informes detallados sobre los controles realizados en fábrica, especificaciones de su calidad y fiabilidad y, por último, las decisiones que se deben tomar en caso de que un contador 0 una muestra de contadores no cumpla las especificaciones del acuerdo.

La filosofía de calidad concertada (Deming, 1986) o de la gestión total de la calidad (TQM) plantea establecer lazos de confianza con el proveedor como una organización integrante del propio sistema, mejorando el rendimiento de las redes hacia la sostenibilidad e incluyéndose en la preocupación actual sobre la correcta gestión del recurso.

Este tipo de relación formalizada, donde el proveedor se compromete a garantizar el cumplimiento de los acuerdos establecidos, tiene ciertas ventajas para ambas partes:

- Prestigio de suministrar el producto bajo un acuerdo de calidad concertada, ya que para ganar este status es necesario ganarse la confianza del cliente, superando auditorias de calidad, evaluaciones de históricos instalados, e incluso, inspecciones de calidad de los contadores.

- Evitar criterios subjetivos de aceptación o rechazo de ciertas marcas de contadores. La calidad concertada exige una clara y perfectamente definida documentación técnica lo que permite equiparar inicialmente a las diferentes marcas existentes en el mercado.

- Agilización de los trámites, al ser evitable, una vez conseguida la calidad concertada los niveles de inspección inicialmente establecidos y los costes atribuidos a ésta.

- La empresa de suministro de agua también consigue ventajas como asegurar con el cliente, de forma sistemática, la calidad de los contadores de agua recibidos en cada partida comprada reduciendo los costes de comprobación. Esta calidad obtenida proporciona cierta tranquilidad sobre la calidad metrológica de los contadores instalados, desviando la atención hacia la mejora de otros puntos más críticos de la gestión del abastecimiento.

Generalmente, el acuerdo parte por establecer un nivel de calidad aceptable del lote suministrado por el proveedor. De esta manera, cuando se sobrepasa este nivel, es decir, el número de unidades defectuosas acordado, ambas partes deben estar de acuerdo en rechazar dicho lote. Para ello, asimismo, deben estar conformes con el plan de muestreo y método de aceptación de lotes adoptado. 
Como se describe en abundante bibliografía, existen diferentes enfoques para juzgar la calidad de un lote de productos:

- Aceptar sin inspección, es una alternativa adecuada cuando el proceso de fabricación es tan exacto que casi nunca se generan elementos defectuosos, o cuando el coste de la inspección es más elevado que el propio elemento en cuestión, lo que no resulta rentable económicamente.

- Efectuar una inspección al 100\%, supone un coste elevado y sólo es viable cuando el elemento a inspeccionar es un elemento crítico de un sistema, y no detectarlo supondría un coste adicional, no solo económico, a la empresa compradora.

- Inspeccionarlo mediante muestreo, es decir, tomando una muestra y decidiendo con base a la información aportada por ella. Este procedimiento es el más asequible. El muestreo es interesante cuando el coste de la inspección al $100 \%$ y el tiempo invertido en realizar la prueba es muy elevado, cuando el ensayo del producto es destructivo, 0 incluso, cuando el proveedor tiene un excelente historial de calidad y no se hace necesario evaluar todos los productos sino sólo una muestra de ellos.

Es obvio que esta última forma de inspección es la que más se ajusta al caso concreto del control metrológico por parte de la empresa de abastecimiento de contadores de agua domésticos. La justificación se encuentra en que si se decide llevar un control sobre los contadores, tanto nuevos como instalados un corto periodo de tiempo, no es rentable para las empresas de suministro de agua comprobar la metrología de todos los instrumentos.

Aceptar el lote sin tomar ningún tipo de medida es lo que se viene haciendo hasta ahora en la mayoría de las empresas. Esto puede suponer un problema grave para la empresa. No es la primera vez que se detecta un determinado lote con características homogéneas, es decir, misma marca, mismo año de fabricación e incluso con números de registro seguidos, con un claro defecto de fabricación que provoca errores de medición considerables y salen a la luz, más tarde, en las facturaciones de la empresa.

Se considera que conocer la calidad metrológica inicial de los contadores inspeccionados para un cierto criterio de aceptabilidad, es decir, una estimación del número de unidades defectuosas admitidas con un nivel de confianza dado, supone un avance importante en la gestión del parque. Este epígrafe hace hincapié en el control a la recepción de contadores de agua domésticos mediante muestreo y, en general, de todos los instrumentos y elementos cuyo control de calidad sea importante para la empresa.

\subsubsection{MÉTODOS DE MUESTREO}

En la actualidad, el control estadístico de calidad se encuentra en auge debido a la alta competitividad entre las empresas. El muestreo por aceptación (acceptance sampling) es una herramienta que facilita la toma de decisiones sobre la calidad de un lote de productos mediante la inspección de una muestra. En este procedimiento se mide una característica específica, cuantitativa o cualitativa, para establecer estadísticamente la aceptabilidad de dicha partida, a partir de los resultados obtenidos de los elementos de una muestra.

Como se ha dicho, esta característica especificada de calidad puede ser cuantitativa o cualitativa, lo que diferencia el muestreo de aceptación por atributos -variable cualitativa- o por variables -cuantitativa.

La elección de un tipo u otro de muestreo depende de diferentes factores. En el caso particular de control metrológico de micromedidores el muestreo por variables puede resultar más beneficioso. Esta afirmación tiene diversas justificaciones. La primera sería que el coste económico de la inspección resulta el mismo, tanto para muestreo por atributos como por 
variables, ya que para ambos tipos es necesario el ensayo de error de medición a varios caudales de la muestra, con el fin de determinar si se rechaza o acepta el lote. La segunda ventaja es que aporta información adicional y más precisa que puede combinarse con la utilización de gráficos de control, sobre el nivel de calidad de la partida de contadores comprados por la empresa de aguas.

Además, el error de medición es una variable continua, por lo que será recomendable realizar un Muestreo de aceptación por variables, definido en la norma internacional ISO-3951 o su equivalente española UNE 66-030/84.

En cualquier caso, ambas técnicas de aceptación tienen en común constituir, en definitiva, una prueba de hipótesis (Tryfos, 2001). Como consecuencia de ello, el planteamiento del problema se convierte en realizar un contraste de hipótesis. Es decir, definir una hipótesis nula $\left(\mathrm{H}_{0}\right)$ y una alternativa $\left(\mathrm{H}_{1}\right)$ mutuamente excluyentes que ayuden a tomar una decisión final sobre la calidad del lote. El contraste de hipótesis puede generar dos tipos de errores. El primero aparece cuando se rechaza un lote bueno y el segundo cuando se acepta un lote defectuoso. El primer caso es lo que se designaría como error Tipo I o a, y el segundo como error Tipo II o $\beta$. Ambos tipos de errores suponen un riesgo conocido, tanto por parte del comprador del lote de contadores de agua como por parte de la empresa suministradora de contadores.

El riesgo del vendedor es, evidentemente, la probabilidad que tiene éste de que se rechace un lote que sea bueno, es decir, la probabilidad de que el error a suceda. El riesgo del comprador o error $\beta$, por el contrario, es la probabilidad de aceptar un lote defectuoso. Ambos riesgos no son deseables para ninguna de las partes, el vendedor por los gastos que le supondría a su empresa -costes de personal, de material, de tiempo- y el comprador por recibir instrumentos de medida en malas condiciones lo que provocaría gastos de instalación y personal, y pérdidas debido al agua no contabilizada por dichas unidades defectuosas.

Ambos errores son complementarios, si se reduce mucho el riesgo del vendedor aumenta el del comprador, y viceversa, con lo que se debe llegar a un compromiso de aceptación entre ambas partes que no perjudicar a una más que a la otra.

\subsubsection{MUESTREO DE ACEPTACIÓN POR VARIABLES}

El muestreo de aceptación por variables es una técnica difundida dentro del sector industrial tanto para controlar un proceso en continuo como un producto ya acabado. Para explicar el procedimiento a seguir, previamente se definirán una serie de conceptos que se utilizan en la elección de un plan de muestreo.

\subsubsection{Conceptos previos}

Uno de los conceptos más importantes que maneja esta técnica de muestreo estadístico, es como ya se ha comentado, establecer un umbral a partir del cual sea posible tomar una decisión sobre el lote de contadores inspeccionado. A este término se le denomina estadísticamente nivel de calidad aceptable (NCA) o en inglés aceptable quality level (AQL) y, viene definido en la norma ISO-3951 como, el porcentaje máximo de unidades defectuosas que, desde el punto de vista de la inspección por muestreo, puede considerarse satisfactorio como calidad media de fabricación.

Otro término necesario es el límite de especificación que es el valor especificado como aceptable de la característica de estudio. Este límite es inferior $\left(\mathrm{L}_{\mathrm{i}}\right)$ cuando se trata del mínimo valor, o superior $\left(\mathrm{L}_{\mathrm{s}}\right)$ cuando se atribuye al valor máximo aceptable. En el caso de los contadores el límite superior sería del $+5 \%$ entre $Q_{\min }$ y $Q_{t}$, y de $+2 \%$ entre $Q_{t}$ y $Q_{\max }$ y de forma equivalente, el inferior será de $-5 \%$ y de $-2 \%$ para cada tramo citado.

Estos límites de especificación son muy variados dependiendo, claro está, de la variable cuantitativa en juego. Existen límites simples cuando exclusivamente hay un valor de frontera, o por el contrario, límites dobles cuando hay dos, uno superior y otro inferior. 
- el límite de especificación doble combinado existe cuando se definen a la vez el límite superior e inferior aplicándose un NCA dado al porcentaje total de unidades defectuosas correspondiente al conjunto de los dos límites.

- por el contrario, límite de especificación doble separado, se aplica cuando el NCA es distinto para cada uno de los límites por separado.

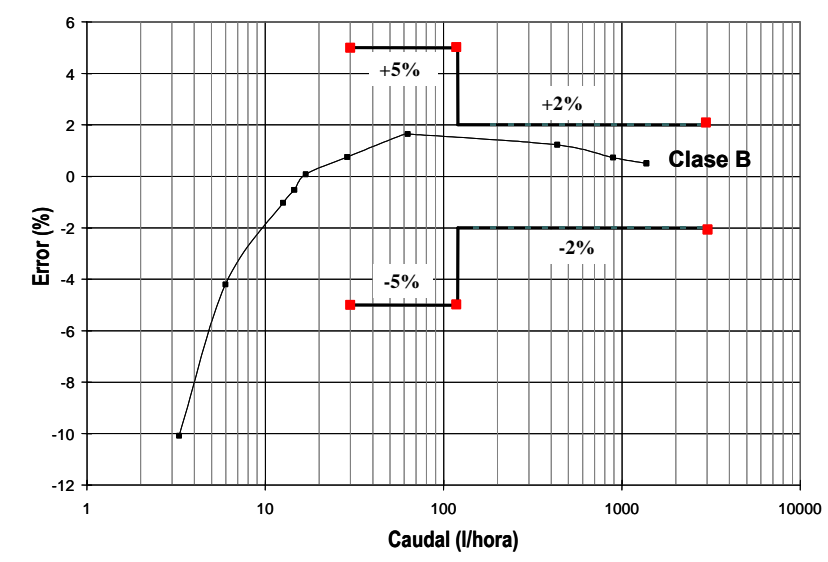

FIGURA 1. LÍMITES DE ESPECIFICACIÓN PARA CONTADORES DE AGUA DOMÉSTICOS.

La constante de aceptabilidad (k) queda definida en función de un valor especificado sobre el nivel de calidad aceptable y el tamaño de muestra, que depende del plan de muestreo elegido.

Por último, el estadístico de calidad $(Q)$ estará definido por el límite de especificación, por la media de la muestra $(\bar{x})$ y por la estimación de la desviación típica del lote (s).

$$
\begin{aligned}
& \text { Estadístico de calidad superior } Q_{s}=\frac{L_{s}-\bar{x}}{s} \\
& \text { Estadístico de calidad inferior } Q_{i}=\frac{\bar{x}-L_{i}}{s}
\end{aligned}
$$

siendo la media muestral y su desviación típica calculadas mediante la expresión 3.

$$
\bar{x}=\frac{\sum x}{n} s=\sqrt{\frac{\sum(x-\bar{x})^{2}}{(n-1)}}
$$

Los estadísticos de calidad del lote son comparados con la constante de aceptabilidad k establecida por el plan de muestreo elegido y sirven como criterio de aceptabilidad o rechazo del lote examinado. Por tanto, las condiciones de aceptación del lote serán:

$$
Q_{s}=\frac{L_{s}-\bar{x}}{s} \geq k \quad Q_{i}=\frac{\bar{x}-L_{i}}{s} \geq k
$$




\subsubsection{Descripción y características del plan de muestreo.}

El muestreo de aceptación por variables, como ya se ha comentado, es el que presenta más ventajas en el caso del control de calidad de contadores de agua domésticos, ya que a igual coste de inspección, permite obtener mayor cantidad de información sobre el estado metrológico inicial de la partida de instrumentos que se renueva.

Dentro de esta técnica, dependiendo del nivel de calidad exigido y el presupuesto, existen diferentes tipos de inspección, la normal, la rigurosa y la reducida. La inspección normal es la que se aplica, generalmente, cuando no existe ningún motivo de inquietud hacia el lote que se revisa. Usualmente, se emplea al comienzo del muestreo y continua hasta que se permite una inspección reducida, donde el tamaño de muestra es menor disminuyendo así los costes, o en detrimento, se requiere una inspección rigurosa con un tamaño de muestra mayor.

El cambio de un tipo de inspección normal a otra rigurosa, como se detalla en la norma internacional, se precisa "con el fin de evitar que el porcentaje medio de unidades defectuosas exceda del NCA". Cuando los resultados de la inspección indican que la calidad media de la muestra excede, o por el contrario, es de manera estable menor que el NCA estipulado, entonces se justifica un cambio de normal a rigurosa, en el primer caso, o a inspección reducida, en el segundo.

Habitualmente, las empresas de agua llevan a cabo cada cierto tiempo planes de renovación de contadores donde se sustituyen aquellos contadores parados o en mal estado por contadores nuevos. Un ejemplo de estos planes de renovación se puede leer en Tzamtzis (2003), donde pone como ejemplo el caso de la ciudad de Atenas donde 150.000 contadores de agua se renuevan todos los años.

Como se ha explicado, los instrumentos de medida que llegan a la empresa de aguas salen de fábrica después de pasar una verificación primitiva, es por ello que no se hace necesaria una inspección rigurosa. Normalmente, es recomendable comenzar con una inspección normal.

Otro de los parámetros que se deben elegir es el método de muestreo que se emplea. Existen tres métodos diferentes, el método $s$ que permite decidir la aceptabilidad de un lote utilizando la estimación de la desviación típica de ese lote, el método $\sigma$ que no se utiliza en este caso ya que decide la aceptabilidad del lote a partir de su desviación típica conocida previamente, y el método $R$ que utiliza la estimación de la desviación típica de este lote, obtenida a partir del recorrido medio de las medidas efectuadas sobre los elementos de los subgrupos de una muestra.

Una vez tomada una decisión sobre el tipo y método de muestreo más adecuado a las condiciones de la variable cuantitativa que determina la calidad de los contadores de agua, se pasa a definir los criterios de aceptabilidad y el plan de muestreo adoptado.

\subsubsection{Elección del plan de muestreo}

La elección de un plan de muestreo requiere conocer el producto a inspeccionar, es decir la metrología del instrumento de medida, su precisión y características técnicas, el modo de fabricación, etcétera. A su vez, para establecer los criterios y elegir un plan de muestreo adecuado es necesario tener conocimientos de estadística general.

Otra cuestión importante es definir el nivel de calidad aceptable (NCA) mediante mutuo acuerdo entre el proveedor y el comprador. Este parámetro, como se ha definido, es el porcentaje máximo de unidades defectuosas en cada lote examinado. Aunque puede elegirse cualquier valor, es recomendable ajustarse a los valores establecidos en la norma ISO-3951. El método aplicado será en este caso el $s$ ya que la desviación típica de la muestra no es conocida previamente. A su vez, el tipo de inspección inicialmente será normal (Nivel II).

Tras fijar estos parámetros es posible comenzar el procedimiento de muestreo. Para ello, la norma ISO-3951, en una de sus tablas presentadas en el Anexo I del presente capítulo, establece una letra código que referencia cada plan de muestreo en 
función del nivel de inspección y del tamaño del lote (Tabla I-A). Esta letra código, para el método s, tiene asignada un tamaño de muestra independiente del NCA (Tabla I-B). Una vez conocidas la letra código, el nivel de inspección k, el método de muestreo y el tamaño de muestra, la Tabla II-A del Anexo I define la constante de aceptabilidad para diferentes niveles de calidad aceptables. Esta constante servirá como estadístico de control para contrastar los resultados obtenidos de la muestra.

De esta manera, comparando los estadísticos superior e inferior con la constante de aceptabilidad es posible tomar una decisión sobre la calidad del lote examinado.

\subsubsection{Ejemplo de plan de muestreo y resultados}

Como aplicación a lo explicado hasta el momento se supone un caso real de una partida de contadores de agua domésticos de $Q_{n}=1.5 \mathrm{~m}^{3} / \mathrm{h}$. Las hipótesis consideradas en el ejemplo son las siguientes:

- $\quad$ Nivel de inspección II

- Métodos

- Tamaño del lote: 1000 contadores de agua.

- Limites especificados por la norma internacional ISO 4064.

- Se llega a un acuerdo con el proveedor en el que a partir de un $1 \%$ de unidades defectuosas, el lote de contadores comprados será rechazado ( $N C A=1$ ).

- Para un nivel de inspección normal, es decir, nivel II, se establecen tamaños de muestra $\mathbf{n}$ y constantes de aceptabilidad $\mathbf{k}$ resumidos en la siguiente tabla:

TABLA 2. RESUMEN DE LAS TABLAS I-A, I-B Y II-A DE LA NORMA ISO 3951.

\begin{tabular}{|c|c|c|c|c|c|c|c|c|}
\hline Tamaño lote & $\begin{array}{l}\text { Letra } \\
\text { código }\end{array}$ & $\begin{array}{l}\text { Tamaño de } \\
\text { muestra (n) }\end{array}$ & $N C A=0,65$ & $N C A=1$ & $\mathrm{NCA}=2,5$ & $\mathrm{NCA}=4$ & $\mathrm{NCA}=6,5$ & $\mathrm{NCA}=10$ \\
\hline & & & k & k & k & $\mathrm{k}$ & $\mathrm{k}$ & $\mathrm{k}$ \\
\hline $9-15$ & $B$ & 3 & - & - & 1,12 & 0,958 & 0,765 & 0,566 \\
\hline $16-25$ & C & 4 & - & 1,45 & 1,17 & 1,01 & 0,814 & 0,617 \\
\hline $26-50$ & $D$ & 5 & 1,65 & 1,53 & 1,24 & 1,07 & 0,874 & 0,675 \\
\hline $151-280$ & G & 15 & 1,91 & 1,79 & 1,47 & 1,3 & 1,09 & 0,886 \\
\hline $281-401$ & $\mathrm{H}$ & 20 & 1,96 & 1,82 & 1,51 & 1,33 & 1,12 & 0,917 \\
\hline $401-500$ & I & 25 & 1,98 & 1,85 & 1,53 & 1,35 & 1,14 & 0,936 \\
\hline $501-1200$ & J & 35 & 2,03 & 1,89 & 1,57 & 1,39 & 1,18 & 0,969 \\
\hline
\end{tabular}

La elección del plan de muestreo comienza determinando la letra código de la Tabla I-A a partir del tamaño del lote y del nivel de inspección normal, en este ejemplo, la letra código será la J. Consultando la Tabla II-A de dicha norma se requiere un tamaño de muestra para ensayar de 35 contadores y una constante de aceptabilidad k de 1,89 (Anejo I). Un resumen de las tablas requeridas en estas condiciones se presenta en la Tabla 2. 
En este punto, el laboratorio autorizado deberá seleccionar una muestra al azar de 35 contadores del lote. Estos contadores serán ensayados en laboratorio a los caudales indicados por el comprador de donde se extraerá una media de error a cada caudal y una desviación típica muestral (Ecuación 3). Los resultados estadísticos del plan de muestreo elegido se presentan el la Tabla 3 y Tabla 4.

TABLA 3. RESULTADOS DE ENSAYO DE ERROR DEL EJEMPLO.

\begin{tabular}{|c|c|c|c|}
\hline Tamaño de muestra & & 35 & \\
\hline Caudales de ensayo & $30 \mathrm{l} / \mathrm{h}$ & $120 \mathrm{I} / \mathrm{h}$ & $3000 \mathrm{l} / \mathrm{h}$ \\
\hline Error (\%) Media muestral & $-3,1$ & 1,0 & 0,4 \\
\hline Desviación típica muestral $(\sigma)$ & 1,5 & 0,6 & 0,3 \\
\hline \multicolumn{4}{|c|}{ TABLA 4. RESULTADOS ESTADÍSTICOS. } \\
\hline k & & 1,89 & \\
\hline Caudales de ensayo & $30 \mathrm{l} / \mathrm{h}$ & $120 \mathrm{l} / \mathrm{h}$ & $3000 \mathrm{I} / \mathrm{h}$ \\
\hline$Q_{s}$ & 6,06 & 1,66 & 5,33 \\
\hline$Q_{i}$ & 1,26 & 6,66 & 8,00 \\
\hline
\end{tabular}

Los errores sistemáticos, es decir aquellos constantes en el tiempo como un mal ajuste de la curva de error, tendrían efecto sobre el valor de la media muestral, mientras que los aleatorios afectarían a su desviación típica.

Observando los resultados de la Tabla 4, se aprecia que el lote se acepta en todas las pruebas a excepción del ensayo a $30 \mathrm{l} / \mathrm{h}$ y a $120 \mathrm{l} / \mathrm{h}$ donde los resultados muestran que el estadístico de calidad es inferior al estadístico de control 1,89, para un nivel de calidad aceptable del 1\%. En este caso, se debería rechazar el lote adquirido, o bien, a criterio del técnico, aumentar el nivel de calidad aceptable para los instrumentos en la zona baja de caudal con menor precisión y mayor variabilidad.

En cualquier caso, los procedimientos de ensayo de contadores nuevos deben ser muy estrictos ya que un banco de calibración inadecuado puede conducir a errores sistemáticos desechando partidas que podrian ser provechosas. Por ello, es conveniente definir el procedimiento operativo que consiga una alta repetibilidad y realizar comparativas periódicas con otros laboratorios que certifiquen nuevas partidas.

Como conclusión, esta propuesta pretende mostrar un procedimiento de control de los contadores recién salidos de fábrica. Las pruebas como se ha explicado se realizarán a tres caudales de ensayo que pueden ser diferentes en función del presupuesto disponible y del nivel de confianza adquirido con la empresa fabricante.

Otra aplicación de estos planes de muestreo por variables será el control lotes de contadores en servicio. Para ello, se agruparán los instrumentos del parque en lotes homogéneos del mismo calibre, edad, clase metrológica y tipología de vivienda, y se realizarán las mismas pruebas explicadas con anterioridad. De esta forma, se llevará una verificación exhaustiva tanto de contadores nuevos como de contadores en servicio. En la legislación no han sido definidos todavía los límites de error admisibles para contadores en servicio que deberían ser más amplios. Además, el nivel de calidad aceptable de la muestra no será tan severo como en el caso de aparatos verificados en fábrica. 


\subsection{ANÁLISIS DE COSTES EN EL USO DE MICROMEDIDORES}

El periodo óptimo de renovación de un instrumento de medida, utilizado como elemento de facturación, hace referencia al tiempo que debe permanecer instalado para obtener el máximo beneficio del mismo desde un punto de vista económico. Se hace necesario evaluar en este punto todos los costes asociados con la actividad y sustraerlo de los ingresos que la utilización del instrumento puede reportar.

En cambio, la renovación de los macromedidores utilizados para el control de caudales en la propia red de distribución estará, principalmente, condicionada por la calidad metrológica de los aparatos, ya que su máximo provecho irá ligado a una buena medición de los caudales circulantes. En estos casos el periodo óptimo de renovación del instrumento está condicionado por la precisión que se le exija. El gestor del sistema o la propia legislación fijará unos márgenes de error máximo admisible y un periodo de tiempo, pasado el cual el instrumento deberá someterse a una verificación metrológica y a una calibración, en los casos requeridos.

Volviendo a la gestión de los contadores de pequeño calibre, el plan de renovación de los micromedidores se puede trazar desde diferentes ópticas. Un primer criterio puede tener carácter legal siendo impuesto por las autoridades estatales 0 municipales que exigen a partir de cierta edad o volumen acumulado que los instrumentos sean renovados. Por ejemplo, en el Pliego de Condiciones Técnicas para la nueva gestión del servicio de abastecimiento de Aguas del Ayuntamiento de Valencia, en su artículo 10.9 cita, "el gestor asegurará, en un plazo fijado por el Ayuntamiento de Valencia desde el inicio de la gestión, que el tiempo medio en servicio de los contadores de agua del abastecimiento no sobrepase los 15 años".

En otras ocasiones, cuando no existen restricciones legales se recomienda adoptar criterios económicos de minimización de costes. Teniendo en cuenta que los contadores domésticos, industriales o agrícolas son utilizados, comúnmente, para la facturación del consumo de agua, los posibles costes de operación del contador vendrían asociados al volumen de agua consumida y no registrada y a las posibles actuaciones de mantenimiento y lectura a realizar sobre el instrumento. Consecuentemente, realizando un estudio económico de los costes y beneficios es posible estimar un periodo óptimo de renovación.

\subsubsection{FORMULACIÓN MATEMÁTICA DEL PROBLEMA}

El análisis económico requiere que se acumulen los costes a lo largo de la vida útil del contador. Dichos costes se podrían dividir en dos partidas. Una compuesta por los costes fijos, en los que se incurre una sola vez al comienzo del periodo considerado, que corresponden al precio de adquisición de los instrumentos y su instalación. Y otra partida que engloba los denominados costes variables distribuidos a lo largo de la vida útil del medidor. Estos últimos costes están compuestos por la pérdida económica que representa el volumen de agua que deja de registrarse por el gradual deterioro del contador.

Para evaluar el montante de los costes variables es necesario estimar el volumen no registrado anualmente (VNRi) por los contadores. Este volumen no registrado, tal y como se ha mencionado en diversos capítulos a lo largo de la tesis, depende tanto del estado de la curva de error como del patrón de consumo de los usuarios. Se puede calcular mediante la Ecuación 6 , en la que se corrige el volumen registrado asociado a cada instrumento o modelo con su error global de medición $\left(\varepsilon_{i}\right)$, que será variable en función de su edad (Capítulo 5). En términos globales los costes variables provocado por el volumen de agua consumida y no registrada serán función de tres parámetros: la evolución del error global de medición del instrumento con el tiempo, el volumen consumido y el precio de venta del agua cada año. 


$$
\begin{aligned}
& \text { Volumen consumido promedio }=\frac{\text { Volumen registrado promedio }}{1-\varepsilon_{\text {parque o modelo }}(\%)} \\
& \qquad \sum_{i=0}^{i=n} \mathrm{VNR}_{\mathrm{i}}=\text { Volumen consumido promedio } \cdot \varepsilon_{l}(\%)
\end{aligned}
$$

Las empresas de agua pueden tener una sola tarifa por metro cúbico o tarifas escalonadas dependiendo del consumo del abonado atribuyéndose un precio a cada bloque de consumo. En estos casos, las pérdidas económicas causadas por el agua no registrada se calcularán con la tarifa asociada al último bloque.

Tal y como se verá la repercusión del precio del agua es evidente, precios elevados aumentan el valor añadido de cada metro cúbico consumido siendo necesarias frecuencias de renovación más altas. Claro está, las pérdidas económicas causadas por el volumen no registrado serán mucho mayores. Por el contrario, cuando el precio del agua es bajo estas pérdidas no tienen tanto efecto sobre los costes totales, prolongándose los periodos de renovación de contadores.

La metodología de acumulación de costes ha sido presentada en numerosos trabajos (Male et al (1985), Planells et al (1987), Yee (1999), Arregui (1999)). La propuesta general de dichos autores es la que se muestra en la expresión 7. En estos trabajos la elección del instrumento de menor coste se realiza mediante el cálculo de costes medios durante el periodo considerado (Ecuación 8), y la búsqueda del mínimo de la función.

$$
\begin{aligned}
& \text { COSTE TOTAL (VAN) }=C_{\text {INST }}+C_{\text {CONTADOR }}+C_{\text {OTROS }}+\sum_{i=0}^{n} \forall_{\text {consumido }} \cdot \varepsilon_{1} \cdot C_{H_{2} \mathrm{O}} \frac{1}{(1+r)^{i}} \\
& \text { COSTE MEDIO ANUAL }=\frac{C_{\text {INST }}+C_{\text {CONTADOR }}+C_{\text {OTROS }}+\sum_{i=0}^{n} \forall_{\text {consumido }} \cdot \varepsilon_{1} \cdot C_{\mathrm{H}_{2} \mathrm{O}} \frac{1}{(1+r)^{i}}}{n}
\end{aligned}
$$

Coste total: Valor actual neto de los costes acumulados durante $n$ años

Coste medio anual: Valor actual neto medio de los costes acumulados durante $n$ años

Cinstalación: Coste atribuido a la instalación del instrumento.

$\mathrm{C}_{\text {contador: }}$ Coste atribuido a la compra del instrumento.

Cotros: Costes administrativos, de calibración, de reparación, etc.

$\forall$ consumido: Volumen de agua real consumido.

$\varepsilon_{i}$ : Error global de medición del instrumento cada año.

$\mathrm{C}_{\mathrm{H} 2 \mathrm{O}}$ : Precio del agua.

$r^{\prime}:$ Tasa de actualización deflactada, parámetro que actualiza al valor monetario actual considerando el efecto de la propia inflación la inversión o las pérdidas económicas por subcontaje de cada año.

No obstante, como apunta Arregui et al. (2004), este procedimiento de cálculo no es válido cuando se comparan instrumentos con diversas vidas útiles. La Ecuación 7 estima el valor actual neto (VAN) de los costes producidos cuando la frecuencia de renovación de contadores es fija y dura $n$ años. Por ejemplo, cuando una localidad tiene en su normativa municipal una frecuencia de renovación estipulada en 10 años. En ese caso no se busca el tiempo óptimo de renovación 
que se encuentra fijado legalmente, sino que utiliza el análisis económico para comparar los modelos instalados identificando aquellos con un comportamiento metrológico eficiente que son más rentables para la empresa de agua.

Por otro lado, cuando no existen restricciones en la frecuencia de renovación y se busca el periodo óptimo de sustitución de diversos modelos conviene utilizar la aproximación del VAN de la Cadena de Renovaciones (VANC) que se presenta en la Ecuación 9. En estos casos el técnico se enfrenta a modelos con vidas útiles y beneficios diferentes que deben ser actualizados al momento presente (Figura 2).

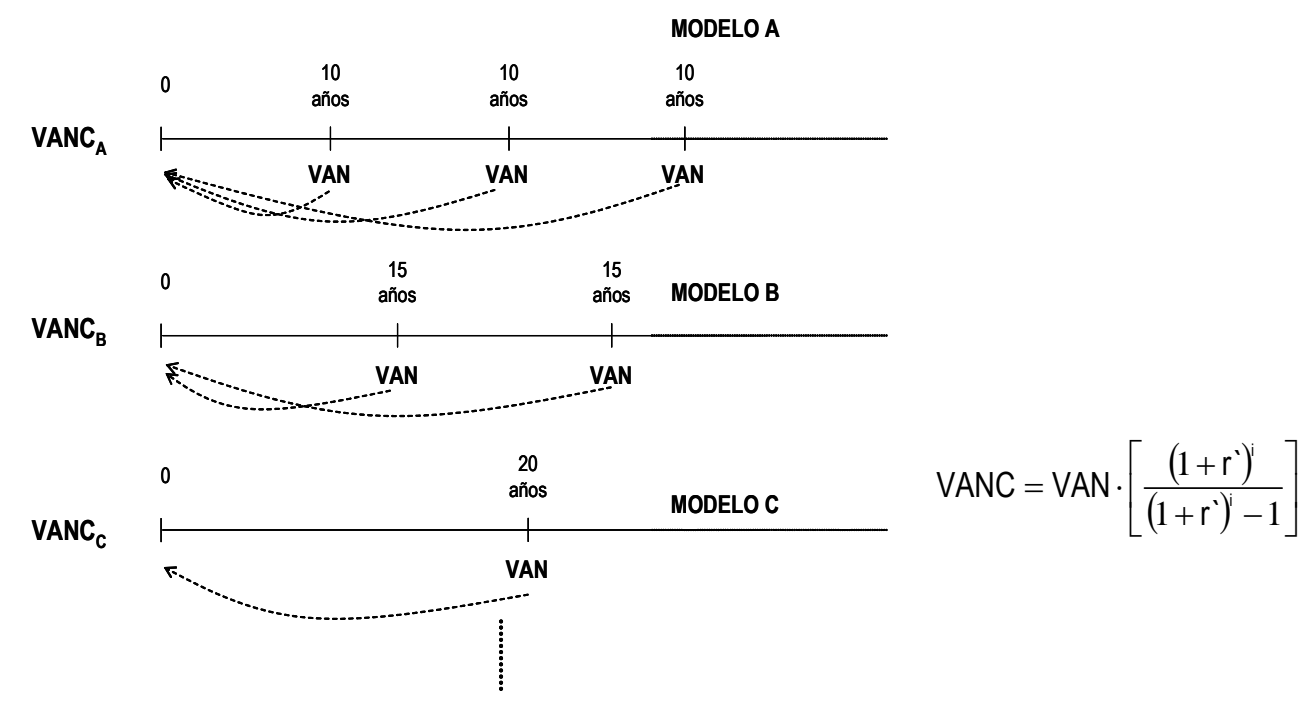

FIGURA 2. ACTUALIZACIÓN DE LOS COSTES TOTALES QUE SUPONE LA MEDICIÓN DE AGUA.

Una vez actualizados todos los instrumentos al momento presente mediante la Ecuación 9 que calcula el valor actual neto de la cadena de renovaciones (VANC). Aquellos contadores que minimicen éste parámetro determinarán la frecuencia de renovación óptima del conjunto de micromedidores.

$$
\operatorname{COSTE} \text { TOTAL }(\text { VANC })_{i}=\left[C_{\text {INST }}+C_{\text {CONTADOR }}+C_{\text {OTROS }}+\sum_{i=0}^{n} \forall_{\text {consumido }} \cdot \varepsilon_{1} \cdot C_{H_{2} O} \frac{1}{\left(1+r^{\prime}\right)^{i}}\right] \cdot \frac{\left(1+r^{\prime}\right)^{i}}{\left(1+r^{\prime}\right)^{i}-1}
$$

\subsubsection{CASOS PRÁCTICOS}

En este sentido la presente tesis doctoral evalúa los casos presentados con anterioridad calculando sus frecuencias de renovación óptimas. En el apartado 5.4.4 del Capítulo 5 se presenta la Tabla 8 con algunos de los supuestos de estudio realizados. Esta tabla definía ritmos de evolución del error global que han sido ponderados con diversos patrones de consumo y ritmos de deterioro en el tiempo. En particular, se analiza el patrón más desfavorable, el más favorable y el medio.

De esta forma es posible estimar el volumen de agua no registrado anualmente desde que se instala el contador hasta que se retira del servicio, y consecuentemente el coste económico que representa.

La Figura 3 muestra una hoja de cálculo donde se estiman anualmente los costes totales que supone el uso de un determinado aparato. En este caso se ha supuesto una situación muy favorable, donde la mayor parte del consumo se 
produce a caudales altos, y además, el ritmo de deterioro del instrumento no es elevado (pendiente no muy acusadas). El precio de venta del agua es elevado lo que incrementa las pérdidas económicas debidas al agua no registrada por error de medición resultando un período de renovación corto de 11 años, a pesar del favorable comportamiento metrológico del contador.

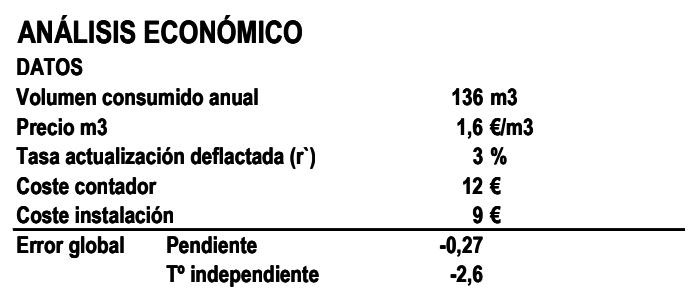

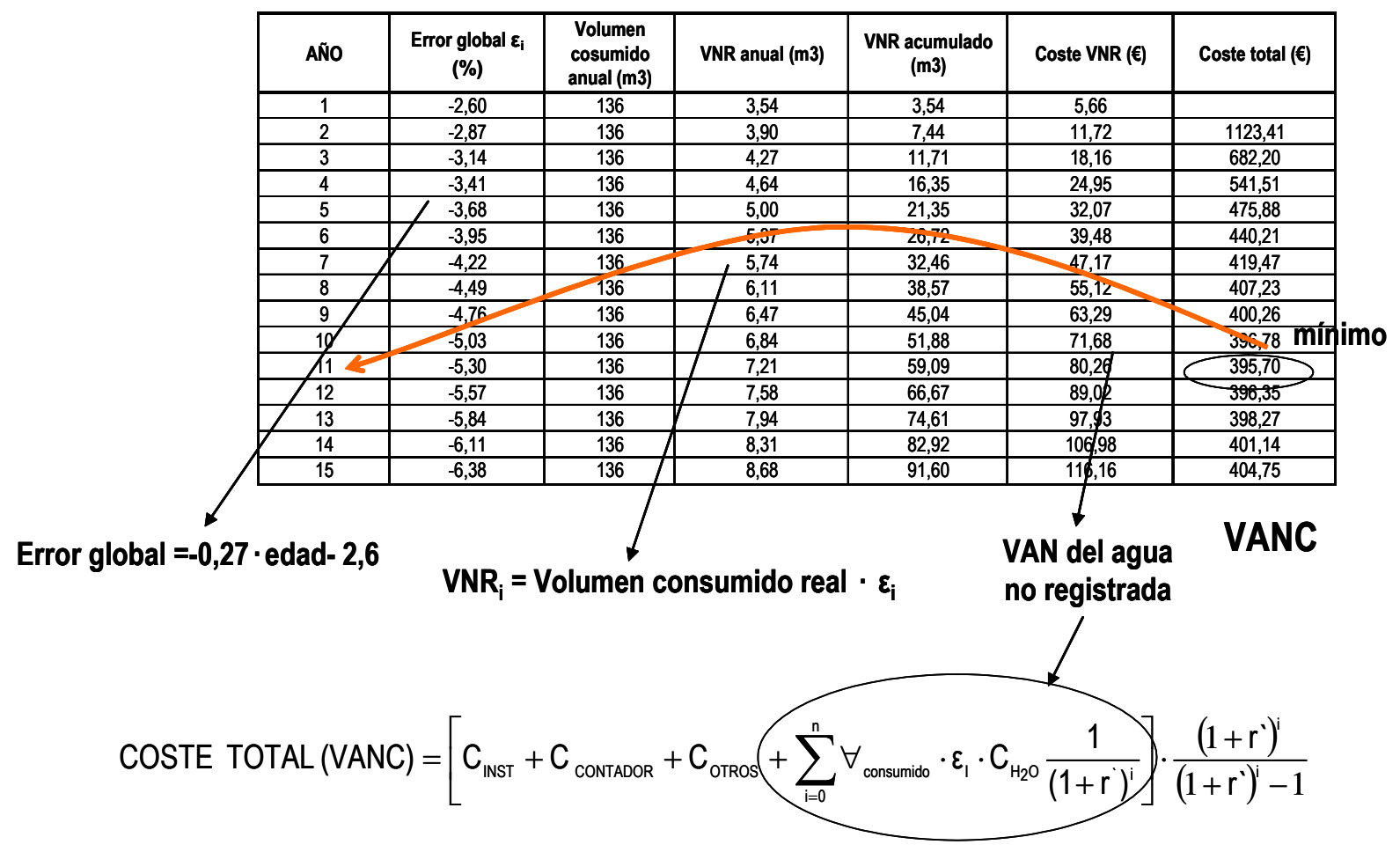

FIGURA 3. EJEMPLO DE CÁLCULO DEL PERIODO ÓPTIMO DE SUSTITUCIÓN.

Además, los cálculos se llevan a cabo para varias tasas de actualización deflactadas (de 1,2,3\%) fijando los costes fijos y el precio del agua. Posteriormente se analiza la sensibilidad de la frecuencia de renovación al precio de venta del agua y al coste a adquisición del instrumento.

La sensibilidad del periodo óptimo de renovación al precio del contador no es muy elevada. En general, precios mayores de los instrumentos, por ejemplo de clases metrológicas más precisas, requieren periodos para recuperar la inversión realizada más altos. A su vez, a medida que la tasa de actualización deflactada es mayor se valorarán menos las pérdidas económicas futuras y se alargará su vida útil (frecuencia de renovación menor).

Las siguientes tablas muestran los resultados obtenidos para los supuestos citados. Por ejemplo, en el caso de un patrón de consumo muy desfavorable frente al más favorable con un ritmo de deterioro de la curva de error elevado, un precio de contador de $18 €$ y una tasa de actualización del 2\%, la vida útil estimada es de 16 frente a 18 años (Tabla 6 y Tabla 7). 
También se aprecia que un ritmo de deterioro bajo del instrumento de medida, para la misma clase metrológica en estudio (clase B), siempre deriva en una vida útil elevada. Es decir, el periodo de recuperación de la inversión en estos casos se alarga a valores superiores a 20 años para cualquier patrón de consumo. Por el contrario, se comprueba que cuando el ritmo de deterioro del error global es mayor, es decir su pendiente es alta, el volumen no registrado a medida que pasa el tiempo será mayor y el periodo necesario para recuperar estas pérdidas será menor

TABLA 5. SENSiBILIDAD AL PRECIO DE COMPRA DEL INSTRUMENTO. PRECIO DEL AGUA 0,6€.

\begin{tabular}{|c|c|c|c|c|c|c|c|c|c|c|c|c|}
\hline & & & Precio contador & $24 €$ & & & $18 €$ & & & $12 €$ & & \\
\hline $\begin{array}{l}\text { PATRÓN } \\
\text { CONSUMO }\end{array}$ & $\mathrm{DE}$ & $\begin{array}{l}\text { RITMO DE } \\
\text { DETERIORO }\end{array}$ & ERROR GLOBAL DE MEDICIÓN & $r^{\prime}=1 \%$ & $r^{\prime}=2 \%$ & $r^{\prime}=3 \%$ & $r^{\prime}=1 \%$ & $r^{\prime}=2 \%$ & $r^{\prime}=3 \%$ & $r^{\prime}=1 \%$ & $r^{\prime}=2 \%$ & $r^{\prime}=3 \%$ \\
\hline MED & & Alto & Error $=-0,42 \cdot$ edad $-5,9$ & 16 & 17 & 17 & 15 & 15 & 16 & 14 & 14 & 14 \\
\hline MED & & Medio & Error $=-0,32 \cdot$ edad $-5,7$ & 19 & 19 & 20 & 17 & 18 & 18 & 15 & 16 & 16 \\
\hline MED & & Bajo & Error $=0,01 \cdot$ edad $-5,7$ & $>20$ & $>20$ & $>20$ & $>20$ & $>20$ & $>20$ & $>20$ & $>20$ & $>20$ \\
\hline
\end{tabular}

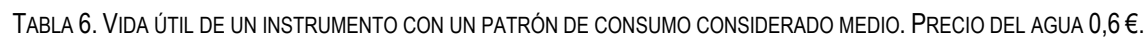

\begin{tabular}{|c|c|c|c|c|c|c|c|c|c|c|c|}
\hline \multicolumn{3}{|r|}{ Precio contador } & \multicolumn{3}{|c|}{$24 €$} & \multicolumn{3}{|c|}{$18 €$} & \multicolumn{3}{|c|}{$12 €$} \\
\hline $\begin{array}{l}\text { PATRÓN DE } \\
\text { CONSUMO }\end{array}$ & $\begin{array}{l}\text { RITMO DE } \\
\text { DETERIORO }\end{array}$ & ERROR GLOBAL DE MEDICIÓN & $r=1 \%$ & $r^{\prime}=2 \%$ & $r^{\prime}=3 \%$ & $r^{r}=1 \%$ & $r^{\prime}=2 \%$ & $r^{\prime}=3 \%$ & $r=1 \%$ & $r^{\prime}=2 \%$ & $r^{\prime}=3 \%$ \\
\hline MD & Alto & Error $=-0,45 \cdot$ edad $-12,0$ & 17 & 17 & 18 & 16 & 16 & 16 & 14 & 15 & 15 \\
\hline MD & Medio & Error $=-0,34 \cdot$ edad $-11,7$ & 19 & 20 & 20 & 18 & 18 & 19 & 16 & 17 & 17 \\
\hline MD & Bajo & Error $=-11,7$ & $>20$ & $>20$ & $>20$ & $>20$ & $>20$ & $>20$ & $>20$ & $>20$ & $>20$ \\
\hline
\end{tabular}

TABLA 7.VIDA ÚTIL DE UN INSTRUMENTO CON UN PATRÓN DE CONSUMO CONSIDERADO MUY FAVORABLE. PRECIO DEL AGUA 0,6€.

\begin{tabular}{|c|c|c|c|c|c|c|c|c|c|c|c|}
\hline \multicolumn{3}{|r|}{ Precio contador } & \multicolumn{3}{|c|}{$24 €$} & \multicolumn{3}{|c|}{$18 €$} & \multicolumn{3}{|c|}{$12 €$} \\
\hline $\begin{array}{l}\text { PATRÓN DE } \\
\text { CONSUMO }\end{array}$ & $\begin{array}{l}\text { RITMO DE } \\
\text { DETERIORO }\end{array}$ & ERROR GLOBAL DE MEDICIÓN & $r^{\prime}=1 \%$ & $r^{\prime}=2 \%$ & $r^{\prime}=3 \%$ & $r^{r}=1 \%$ & $r^{\prime}=2 \%$ & $r^{\prime}=3 \%$ & $r^{\prime}=1 \%$ & $r^{\prime}=2 \%$ & $r^{\prime}=3 \%$ \\
\hline MF & Alto & Error $=-0,27 \cdot$ edad $-2,6$ & 19 & 20 & 21 & 18 & 18 & 19 & 16 & 16 & 17 \\
\hline MF & Medio & Error $=-0,27 \cdot$ edad $-2,6$ & 19 & 20 & 21 & 18 & 18 & 19 & 16 & 16 & 17 \\
\hline MF & Bajo & Error $=0,04 \cdot$ edad $-2,6$ & $>20$ & $>20$ & $>20$ & $>20$ & $>20$ & $>20$ & $>20$ & $>20$ & $>20$ \\
\hline
\end{tabular}




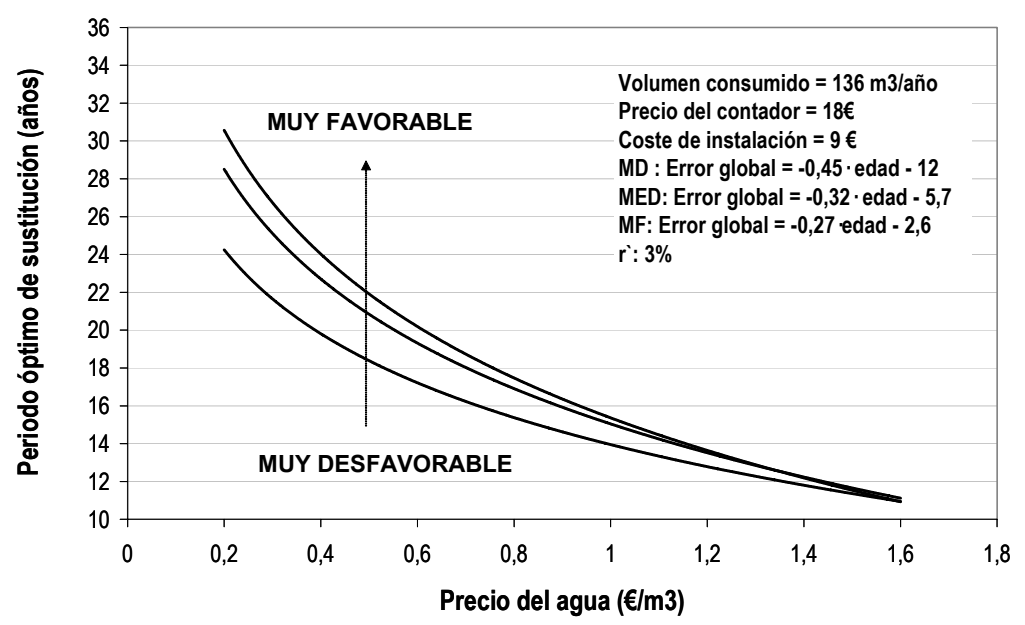

FIGURA 4. SENSIBILIDAD DEL PERIODO DE RENOVACIÓN ÓPTIMO AL PRECIO DE VENTA DEL AGUA.

La Figura 4 muestra la sensibilidad del periodo óptimo de sustitución frente al precio del agua. En ella, se ha supuesto tres condiciones, una muy desfavorable donde el patrón de consumo tiene un elevado porcentaje de volumen asignado en la zona de menor precisión del contador y la curva de error sufre un ritmo de deterioro alto (corresponde al caso 1 de la Tabla 10, Capítulo 5). Un segundo supuesto considerado con condiciones medias donde la pendiente del error global es

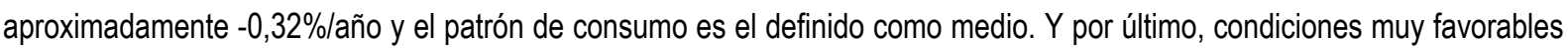
con ritmos de deterioro lentos y patrones de consumo desplazados hacia caudales altos. En todos los casos se ha supuesto una tasa de actualización deflactada de $3 \%$ y unos costes fijos de $27 €$.

En Arregui et al. (2003) se realiza un interesante análisis de sensibilidad al precio del agua y del instrumento de dos modelos de contador instalados en una localidad española. Cada uno de los modelos tiene un comportamiento a lo largo de su vida diferente con lo que se muestra claramente que dependiendo de su evolución metrológica y su modo de consumo la frecuencia de renovación óptima varía.

En resumen, de los resultados pueden extraerse las siguientes conclusiones:

- Ritmos de evolución del error global de medición elevados producen volúmenes no registrados considerables y consecuentemente pérdidas económicas sustanciales que se compensa introduciendo periodos de renovación cortos.

- Ritmos de deterioro más lentos dan periodos de renovación superiores a 25 años. En estos casos se recomienda establecer un periodo de renovación que garantice que el error máximo del parque no supere un determinado valor, en lugar de buscar la minimización de costes.

- Precios de venta del agua elevados aumentan los ingresos producidos por el agua facturada, pero también aumentan las pérdidas económicas del agua no registrada disminuyendo el periodo óptimo de sustitución de los instrumentos.

- Tasas de actualización deflactadas mayores valorarán menos las pérdidas futuras de agua no registrada por los instrumentos alargando su vida útil económica.

- Aumentar los costes fijos, tanto el precio de compra del contador como los costes de mantenimiento, reparaciones, calibraciones, etcétera, suponen alargar el periodo de recuperación de la inversión realizada. 


\section{PARTE 2. SISTEMA DE MACROMEDICIÓN}

\subsection{DIMENSIONADO ÓPTIMO DE MEDIDORES}

\subsubsection{PROBLEMÁTICA DEL DIMENSIONADO}

El dimensionado de instrumentos de medida de caudal, especialmente contadores de agua, se efectúa teniendo en cuenta su caudal nominal. Este caudal, como se ha comentado en repetidas ocasiones, es aquel para el cual el contador puede funcionar de manera continua sin deterioro alguno en su funcionamiento.

Cada fabricante tiene su propio diseño de contador que, aun siendo del mismo calibre, puede tener capacidades de caudal diferentes. Por ejemplo, dentro de una misma tecnología de medición se comprueba que se comercializan instrumentos del mismo calibre con rangos de caudal y características metrológicas desiguales, como se aprecia del estudio presentado en la Tabla 8.

TABLA 8. TABLA RESUMEN CON LAS PRINCIPALES MARCAS COMERCIALES. RECOMENDACIONES DE DIMENSIONADO PARA CONTADOR TIPO WOLTMAN DE EJE HORIZONTAL CALIBRE $100 \mathrm{~mm}$.

\begin{tabular}{lllll}
\hline & Marca A & Marca B & Marca C & Marca D \\
\hline$Q_{\max }\left(m^{3} / \mathrm{h}\right)$ & 200 & 250 & 120 & 120 \\
$Q_{n}\left(m^{3} / \mathrm{h}\right)$ & 100 & 180 & 60 & 60 \\
Capacidad volumen máximo mensual $\left(\mathrm{m}^{3}\right)$ & 72.000 & 129.600 & 43.200 & 43.200 \\
$Q_{\max }$ durante 10 horas/día $\left(\mathrm{m}^{3} / \mathrm{h}\right)$ & 150 & - & $100^{*}$ & - \\
$Q_{\max }$ pocos minutos $\left(\mathrm{m}^{3} / \mathrm{h}\right)$ & 300 & 250 & 200 & 120 \\
\hline
\end{tabular}

\section{${ }^{*} Q_{\max }$ en continuo}

Además, como se ha visto, el error de estos instrumentos de medición es dependiente del caudal demandado por el consumidor. Por tanto, una adecuada elección de la capacidad de caudal del instrumento, revisando que las especificaciones técnicas aportadas por cada fabricante se ajusten al máximo a sus condiciones de funcionamiento. Esta práctica resulta fundamental en la selección de cualquier aparato de medida ya que aumenta su vida útil y garantiza una correcta medición del consumo de agua.

En el caso de los contadores de agua, un infradimensionado implica que por el instrumento circulan caudales excesivamente altos para su capacidad máxima de funcionamiento, lo que puede dañar en un periodo corto de tiempo sus elementos internos, deteriorando su curva de error. Por el contrario, un contador está sobredimensionado cuando su rango de funcionamiento habitual se encuentra en la zona inferior del rango de medida donde los errores de medición son más elevados (Figura 5), y consecuentemente los volúmenes de agua que quedan sin registrar son significativos. 


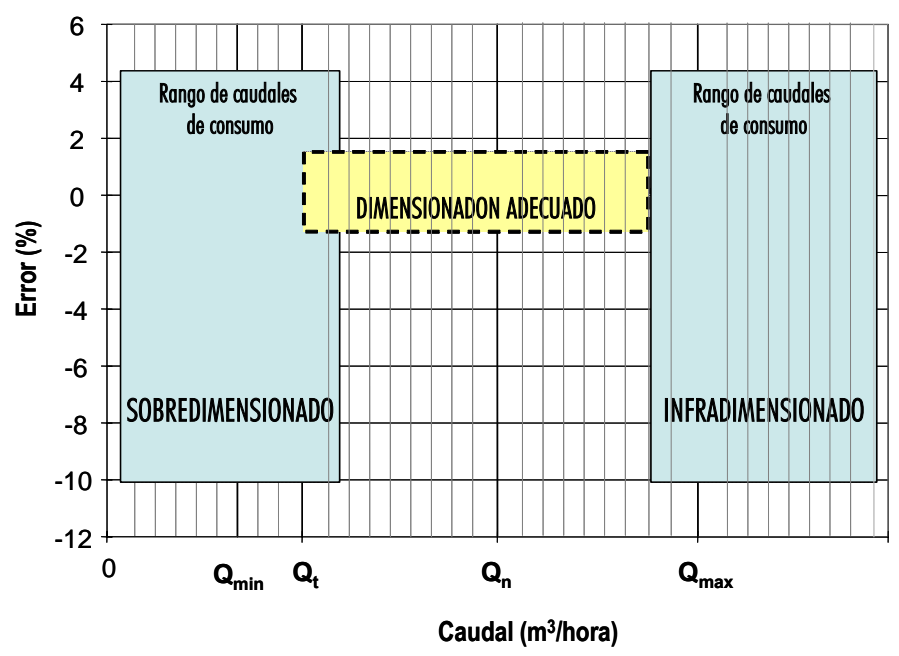

FIGURA 5. CRITERIO DE DIMENSIONADO DE CONTADORES DE AGUA

Por tanto un incorrecto dimensionado puede ocasionar graves inconvenientes en los instrumentos de medición:

- Errores en la medición del consumo, provocando un incremento del agua incontrolada.

- En caso de infradimensionado del aparato se produce una disminución de la capacidad de suministro a una acometida.

- En caso de sobredimensionado, pérdidas económicas por el mayor coste del instrumento.

- Los caudales excesivamente altos para la capacidad del instrumento provocan un deterioro acelerado del aparato con el consecuente aumento en el coste de mantenimiento.

- Escasa fiabilidad de las medidas.

De este modo, para dimensionar correctamente un contador se deben conocer primero la magnitud de los caudales de agua que circularán por él y, segundo, el tiempo durante el cual circularán estos caudales. Un tiempo de uso prolongado a caudales altos hace recomendable elegir un contador cuyo caudal nominal esté cercano a los caudales circulantes. En cambio, si el periodo donde el consumo a caudales elevados es más corto y disperso en el tiempo, es admisible el uso de contadores de calibres más pequeños, siempre y cuando los caudales circulantes no superen el $Q_{\max }$ del mismo y las pérdidas de carga que originen estén dentro de los valores admisibles en el sistema.

En un estudio llevado a cabo durante el 2002 en un importante abastecimiento sobre los volúmenes registrados diarios de una muestra de medidores se advierte que un alto porcentaje de instrumentos se encuentran sobredimensionados al comparar las facturaciones reales con las expectativas de consumo que corresponderían a un contador de dicho caudal nominal (Tabla 9).

TABLA 9. ESTUDIO DE UNA MUESTRA DE MACROMEDIDORES DE UNA POBLACIÓN (2002).

\begin{tabular}{cc}
\hline Calibre $(\mathrm{mm})$ & Posibles sobredimensionados \\
\hline 50 & $80 \%$ \\
$60 / 65$ & $70 \%$ \\
80 & $76 \%$ \\
100 & $74 \%$ \\
150 & $67 \%$ \\
200 & $100 \%$ \\
\hline
\end{tabular}


Generalmente, los instrumentos sobredimensionados registran menor volumen de agua diario ya que el usuario consume unos caudales reducidos para ese calibre de contador, es decir, consume en rangos de caudal donde los errores de registro son mayores. No obstante, hay que ser consciente que cuando el volumen diario registrado es anormalmente bajo puede ser debido a otros factores, como por ejemplo un instrumento con una curva de error deteriorada, un medidor parado 0 manipulado, un consumo realmente bajo, etcétera.

Otro estudio realizado por la ingeniería brasileña BBL que presta servicios principalmente de saneamiento y racionalización del uso del agua, muestra de nuevo, el inadecuado dimensionado de un alto porcentaje de tecnologías y calibres analizados. Dicho programa que revisó un total de 446 contadores de grandes consumidores generó una facturación adicional de $281.776 \mathrm{~m}^{3}$ de agua en un año al redimensionar un total de 315 aparatos, de los cuales 7 se encontraban infradimensionados y 308 sobredimensionados.

El siguiente apartado revisa los métodos existentes y las consideraciones que se deben tener en cuenta para dimensionar correctamente estos sistemas y evitar que una elección incorrecta del aparato afecte a su medición y a su vida útil.

\subsubsection{MÉTODOS Y CONSIDERACIONES SOBRE EL DIMENSIONADO DE MEDIDORES}

Estrictamente, la elección de un medidor debe estar basada únicamente en los caudales que circulan por él, es decir, en la demanda de agua del usuario. Criterios de dimensionado basados en la pérdida de carga 0 aquellos que adoptan directamente el mismo diámetro o uno inferior que la conducción pueden ocasionar errores de medición que afecten significativamente a la facturación y al control de los caudales en las líneas de distribución. Durante el dimensionado de un instrumento de medición se deben tener en cuenta los siguientes aspectos:

- Ajustar, siempre que sea posible, los caudales de consumo del usuario al rango de funcionamiento del instrumento, abarcando entre el caudal de transición y el máximo tanto los caudales más bajos como los más altos de consumo.

- Los caudales máximos admisibles del aparato no se deben sobrepasar.

- No provocar una pérdida de carga excesivamente alta y siempre tener presente la disponibilidad de presión en cada instalación.

Luego, a la hora de elegir el medidor es importante examinar las especificaciones técnicas de cada aparato. Fundamentalmente, su rango de medición, su caudal nominal y la pérdida de carga que produce. En este apartado se exponen técnicas, algunas de ellas desarrolladas en la bibliografía, que ayudan a dimensionar un instrumento y se realizan ciertas puntualizaciones que es conveniente considerar.

\subsubsection{Dimensionado mediante la estimación del caudal punta}

Esta técnica consiste, básicamente, en el dimensionado del contador a partir de una estimación del caudal punta que se puede producir en la instalación.

Para ello, se utilizan métodos estadísticos para el cálculo del caudal punta de una instalación interior a partir de los caudales instalados. De esta manera, el caudal máximo del instrumento debe adecuarse al caudal punta estimado en cada instalación.

La Norma básica para Instalaciones interiores de suministro de Agua (NIA, 1975) recomienda unos caudales mínimos para el funcionamiento adecuado de cada uno de los aparatos domésticos de una casa o local. Además, según la cuantía del caudal instalado ésta clasifica las viviendas en cinco tipos (A, B, C, D y E), de menor a mayor caudal instalado. A partir de la 
estimación de estos caudales de consumo y del número de aparatos por recinto es posible calcular estadísticamente la simultaneidad en el uso de los mismos y su caudal punta (Ecuación 11).

$$
Q_{\text {puntavivienda }}=k \cdot Q_{\text {instalado }}=\frac{Q_{\text {instalado }}}{(j-1)^{1 / 2}}
$$

siendo k el coeficiente de simultaneidad y j el número de aparatos domésticos instalados en la red interior.

Generalmente, los calibres de contador en viviendas individuales van desde 10 a $20 \mathrm{~mm}$ dependiendo del caudal instalado, es decir, del tipo de vivienda y de la altura a la calzada. La Tabla 10 resume estas indicaciones. En la práctica, los contadores de $10 \mathrm{~mm}$ han caído en desuso y solamente se emplean en condiciones excepcionales.

TABLA 10. INDICACIONES PARA EL DIMENSIONADO DE CONTADORES EN VIVIENDAS (NIA, 1975).

\begin{tabular}{|c|c|c|c|}
\hline Tipo de suministro & $\mathrm{Q}$ instalado (I/s) & Altura & Diámetro contador $(\mathrm{mm})$ \\
\hline \multirow{2}{*}{ A } & \multirow{2}{*}{$Q_{i}<0,6$} & Menos de $15 \mathrm{~m}$ & 10 \\
\hline & & De 15 a 25 m & 10 \\
\hline \multirow{2}{*}{ B } & \multirow{2}{*}{$0,6 \leq Q_{\mathrm{i}}<1$} & Menos de $15 \mathrm{~m}$ & 10 \\
\hline & & De 15 a 25 m & 13 \\
\hline \multirow{2}{*}{ C } & \multirow{2}{*}{$1 \leq Q_{i}<1,5$} & Menos de $15 \mathrm{~m}$ & 13 \\
\hline & & De 15 a 25 m & 15 \\
\hline \multirow{2}{*}{ D } & \multirow{2}{*}{$1,5 \leq Q_{i}<2$} & Menos de $15 \mathrm{~m}$ & 15 \\
\hline & & De 15 a 25 m & 20 \\
\hline \multirow{2}{*}{$E$} & \multirow{2}{*}{$2 \leq Q_{i}<3$} & Menos de $15 \mathrm{~m}$ & 15 \\
\hline & & De 15 a $25 \mathrm{~m}$ & 20 \\
\hline
\end{tabular}

El criterio predominante que utiliza es el de asegurar la presión de alimentación en las viviendas garantizando una baja pérdida de carga. Sin embargo, sobredimensionar un medidor para reducir las pérdidas de carga puede ocasionar subregistros importantes cuando el consumo de agua es bajo. Además, dicha norma considera de forma diferente los contadores de 13 y $15 \mathrm{~mm}$ siendo sus características metrológicas y constructivas exactamente iguales, provocando la misma pérdida de carga. Su única diferencia son las roscas de entrada y salida.

Existen otros métodos que permiten dimensionar un instrumento que controla un conjunto de $\mathrm{N}$ viviendas, estimando también el caudal punta mediante la fórmula propuesta por Arizmendi en 1991:

$$
Q_{N \text { (viv) }}=\frac{19+N}{10(\mathrm{~N}+1)} \cdot N \cdot Q_{\text {puntavivienda }}
$$

siendo $\mathrm{N}$ el número de viviendas y Qpunta vivienda el de la vivienda tipo en función de los aparatos que tenga instalados.

No obstante, en ocasiones estos métodos contemplados en la Norma Básica (NIA) no predicen adecuadamente los caudales punta reales que circulan por las instalaciones de los usuarios. Por ejemplo, dicha norma:

- No contempla la simultaneidad de viviendas de diferentes tipos, con lo que el dimensionado de sectores de medición con locales de diferentes características no ajusta las características metrológicas del instrumento tendiendo a mayorar el posible caudal circulante, y consecuentemente a sobredimensionar los instrumentos. 
- No se tienen en cuenta posibles variaciones en la probabilidad de consumo del tipo de vivienda, es decir se considera la misma probabilidad de consumo a caudales altos en una vivienda Tipo $\mathrm{A}$ que en una Tipo $\mathrm{E}$, es decir en un apartamento 0 en un chalet con riego.

- En general, como apunta Gascón (2003), los caudales efectivos de funcionamiento de los aparatos domésticos de consumo de agua son ligeramente inferiores a los propuestos en la NIA (Título 1, apartado 1.2), consecuentemente los contadores tienden a sobredimensionarse ya que los cálculos utilizan mayores caudales punta de los que realmente circulan.

- Asimismo, se ha comprobado durante las mediciones realizadas en campo que la tipología de la instalación interior debe tenerse en cuenta durante el dimensionado de los instrumentos. Considérese el caso de una vivienda alimentada a través de un tanque de almacenamiento.

Profundizando en este último punto hay que tener en cuenta que las tipologías de las instalaciones interiores de suministro de agua pueden ser muy variadas. Algunos edificios están alimentados en directo desde la red. Otros, disponen de un depósito intermedio que actúa como reserva de agua en caso de cortes de suministro o laminando las puntas de consumo algo esencial en redes infradimensionadas. También son frecuentes, instalaciones alimentadas a través de un grupo de sobreelevación que aspira directamente de las tuberías de distribución. En la Normas Tecnológicas (NTE-IFF) aparecen los esquemas previstos y sus posibles combinaciones de alimentación.

La influencia que la tipología de la vivienda puede ejercer sobre un correcto dimensionado del contador, y consecuentemente sobre su metrología, se explica en la siguiente experiencia. Durante el 2001, se realizaron mediciones de consumo a un edificio de viviendas con alimentación en directo y en derivación con un grupo de sobreelevación cuya aspiración está conectada a un depósito intermedio. El nivel del depósito se controla con una válvula de flotador, tal y como se muestra en la Figura 6, cuya apertura es función del nivel de agua en el mismo.

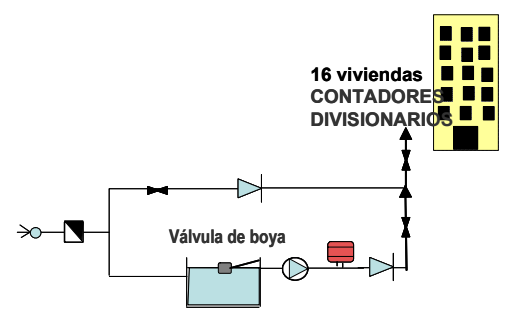

FIGURA 6. TIPOLOGÍA DE LA INSTALACIÓN GENERAL DEL EDIFICIO MEDIDO.

La finca se encuentra en una zona de cotas altas. Habitualmente, la instalación funcionará en directo excepto cuando la demanda de agua sea elevada y se reduzca excesivamente la presión de entrada en la acometida. En ese momento, la demanda de caudal de los usuarios se suple desde el depósito intermedio. El grupo de bombeo estará ajustado para arrancar cuando la presión baje hasta la de tarado, presión mínima para que el suministro a los usuarios se realice sin problemas, aportando el caudal requerido en la finca. En principio, durante un número considerable de horas al día la presión de tarado es inferior a la presión de la red, manteniéndose en este periodo la bomba parada.

La monitorización de la finca se llevó a cabo mediante dataloggers, tal y como se explicó en el Capítulo 5 para el cálculo del patrón de consumo. Se instaló un registrador de pulsos con su correspondiente emisor en el contador general, dispuesto antes de la instalación interior general de la finca, y en cada uno de los contadores divisionarios a la entrada de cada instalación particular. 
En el análisis de las mediciones se observó claramente cuándo la alimentación de las viviendas era en directo y cuándo se alimentaba a través del depósito intermedio. El agua demandada a la red en conexión directa genera caudales punta muy superiores a los detectados cuando trabaja el grupo de bombeo y la red solamente rellena el depósito de aspiración de al bomba. Este fenómeno se aprecia claramente en la Figura 7, donde se efectúa una comparación entre los caudales demandados por el contador general y la suma de todos los caudales demandados en las instalaciones interiores. En ella se distingue un punto a partir del cual los caudales circulantes por el contador general son mucho menores que la suma de los contadores individuales, laminándose la demanda de agua a causa de la existencia del depósito intermedio que se llena mediante una válvula de boya. La instalación de estas válvulas, con un $\mathrm{K}_{\mathrm{v}}$ pequeño a causa de la reducida apertura con que trabajan habitualmente, lamina los caudales punta encubriendo los caudales de la instalación que se utilizarían para dimensionar el instrumento. Por ello, cuando la vivienda se alimenta con un depósito intermedio se tiende a sobredimensionar el mismo.

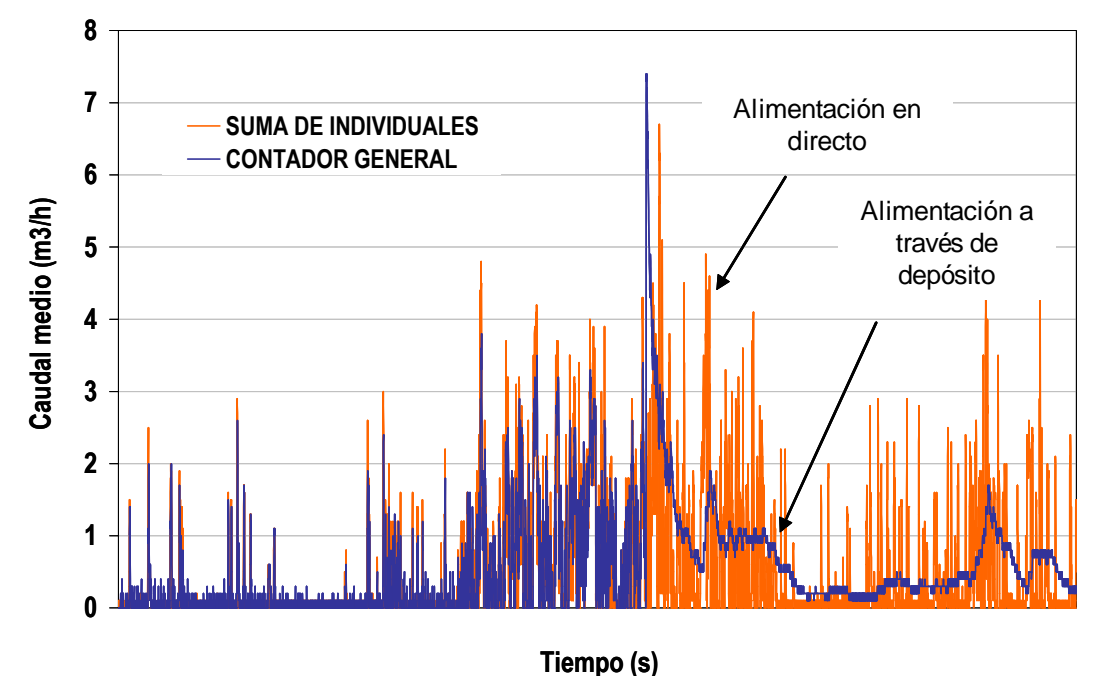

FIGURA 7. DEMANDAS DE CAUDAL EN DIFERENTES TIPOLOGIAS DE INSTALACIÓN DE SUMINISTRO.

En estos casos, si existe depósito intermedio, se recomiendan dos opciones. Primero, usar válvulas de llenado del depósito todo-nada que dejan circular un caudal suficientemente alto que pueda ser registrado por cualquier contador en buenas condiciones, o segundo, instalar contadores generales de caudal nominal reducido, $1,5 \circ 2,5 \mathrm{~m}^{3} / \mathrm{h}$ a lo sumo, si el número de viviendas supera 15 para posteriormente cuadrar los volúmenes medidos.

\subsubsection{Dimensionado por volumen mensual registrado}

Otro método al que se recurre frecuentemente para dimensionar caudalímetros y contadores utiliza los datos de sus lecturas periódicas como el volumen mensual o el volumen diario registrado. A partir de esta información, accesible en cualquier abastecimiento con un nivel de gestión medio, se puede seleccionar el caudal nominal o máximo del medidor relacionando los volúmenes de agua consumidos en un periodo de tiempo con los caudales punta que se pueden producir (Tabla 11 y Tabla 12). De esta forma, analizando, por ejemplo, el consumo mensual de una instalación se estima el caudal punta que puede alcanzarse y, consecuentemente, se recomienda el caudal máximo que debería ser capaz de soportar un medidor que se montase en dicha instalación. 
TABLA 11.RECOMENDACIONES DE DIMENSIONADO EN FUNCIÓN DEL VOLUMEN REGISTRADO. SABESP (SAO PAULO, 1979)

\begin{tabular}{ccc}
\hline \multicolumn{2}{c}{ Consumo estimado } & \multicolumn{2}{c}{ Medidor adecuado $(\mathrm{mm})$} \\
\hline $\mathrm{m}^{3} / \mathrm{mes}$ & $\mathrm{m}^{3} / \mathrm{dia}$ & $\mathrm{Q}_{\max }\left(\mathrm{m}^{3} / \mathrm{h}\right)$ \\
\hline $0-180$ & $0-6$ & 3 \\
$120-250$ & $4-8$ & 5 \\
$210-350$ & $6-12$ & 7 \\
$300-540$ & $8-18$ & 10 \\
$430-900$ & $14-30$ & 20 \\
$750-1500$ & $25-50$ & 30 \\
$1200-4500$ & $40-120$ & 50 \\
$1800-7500$ & $90-250$ & 80 \\
$4500-13000$ & $180-500$ & 120 \\
\hline
\end{tabular}

TABLA 12.RECOMENDACIONES DE DIMENSIONADO EN FUNCIÓN DEL VOLUMEN REGISTRADO. COMPESA (1989)

\begin{tabular}{cccc}
\hline $\begin{array}{c}\text { Capacidad medidor }\left(\mathbf{Q}_{\max }\right) \\
\text { en } \mathbf{~ m}^{3 / \mathrm{h}}\end{array}$ & $\begin{array}{c}\text { Rango recomendado } \\
\left(\mathbf{m}^{3} / \mathrm{mes}\right)\end{array}$ & $\begin{array}{c}\text { Lectura máxima (antes de } \\
\text { la sustitución) }\end{array}$ & $\begin{array}{c}\text { Número de } \\
\text { viviendas }\end{array}$ \\
\hline 3 & $0-150$ & 3000 & hasta 5 \\
3 & $151-210$ & 4200 & 6 a 7 \\
7 & $211-420$ & 8400 & 8 a 14 \\
10 & $421-600$ & 12000 & 15 a 20 \\
20 & $601-1.200$ & 24000 & 21 a 40 \\
30 & $1.201-1.800$ & 36000 & 41 a 60 \\
300 & $1.801-9.000$ & 180000 & 61 a 600 \\
1.100 & $9.001-33.000$ & 600000 & industrial \\
1.800 & $33.001-54.000$ & 1.000 .000 & industrial \\
4.000 & $54.001-120.000$ & 1.000 .000 & industrial
\end{tabular}

*lectura máxima antes del cambio o sustitución.

\subsubsection{Dimensionado mediante levantamiento del perfil de caudales}

Por último, el método más adecuado para dimensionar correctamente un contador consiste en realizar un levantamiento del perfil de caudales. Esta técnica, como se explicó en el Capítulo 5 durante el cálculo del patrón de consumo, consiste en instalar dataloggers que registren el consumo en continuo de aquellos abonados a los cuales se les quiere dimensionar el contador. De esta manera, es posible analizar los caudales instantáneos circulantes por la instalación evaluando si el calibre del instrumento es el adecuado.

No obstante, se debe tener en cuenta que las mediciones reflejan el consumo de agua durante un periodo en el que duren las mediciones y que la extrapolación temporal conlleva cierto grado de incertidumbre. Así pues, cuando el consumo es estacional conviene medir durante la temporada de máximo consumo donde se producirán los caudales punta más altos.

Existen usos cuyo consumo es bastante constante en el tiempo, mientras que otros varían dependiendo de la época del año. Por ejemplo, el volumen mensual registrado por una industria cerámica será aproximadamente el mismo durante todo el año, mientras que un parador de turismo en la zona de costa tendrá un consumo mucho más irregular.

Precisamente, y como ejemplo, la Figura 8 muestra las mediciones realizadas durante distintos meses del año en el parador de una localidad costera. Se aprecia claramente que el consumo medio diario durante el verano es muy superior que en invierno. 


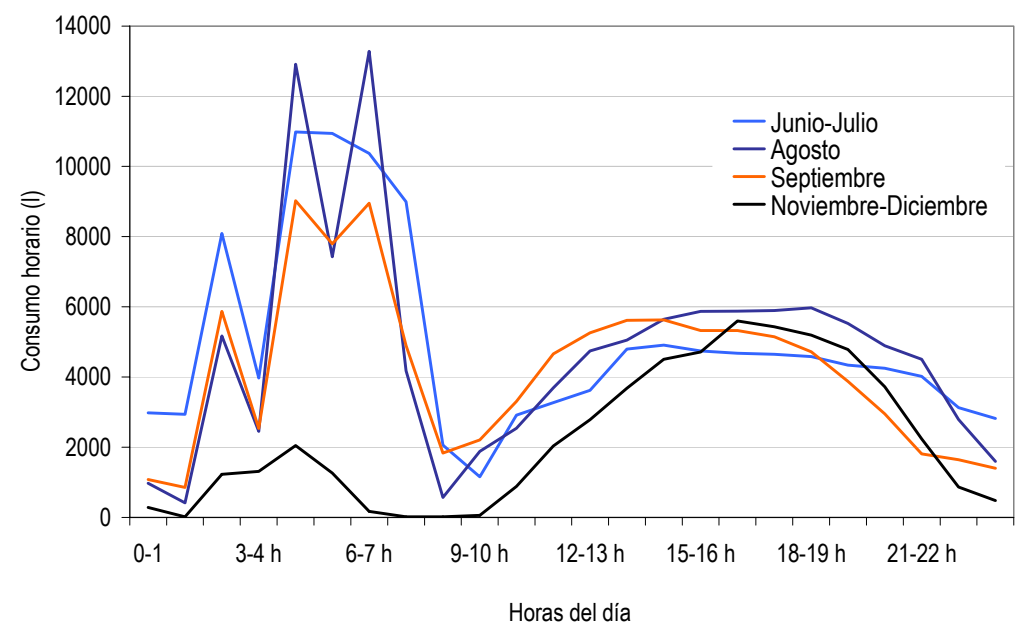

FIGURA 8. CAUDALES DIARIOS DEMANDADOS POR UN PARADOR DE TURISMO.

Sin embargo, en este caso, los caudales demandados durante las horas diurnas en los diferentes periodos son muy similares ya que se produce una laminación de la demanda de agua al existir un depósito de agua intermedio entre los puntos de consumo y el contador. De esta manera, durante los meses de verano este depósito se llena cada noche a caudales muy elevados que son almacenados y luego distribuidos durante el día. En noviembre-diciembre este caudal de llenado es mucho menor ya que la demanda de agua durante el día disminuye.

En cualquier caso, las instalaciones de agua de los grandes consumidores son muy heterogéneas y los hábitos de consumo no siguen un patrón que pueda predecirse fácilmente. Un alto porcentaje de este tipo de usuarios tendrá patrones de usos que podrían calificarse de extraños por lo que se hace completamente necesario medir los consumos en continuo para poder predecir los caudales punta que se pueden producir.

Por ello, es recomendable llevar un seguimiento de las facturaciones y volúmenes registrados. Dos viviendas aparentemente similares pueden requerir instrumentos de diferente calibre dependiendo de los usos particulares de cada una. Por ejemplo, se midió durante aproximadamente 60 días en dos viviendas controladas mediante contadores de chorro único de $13 \mathrm{~mm}\left(Q_{n} 1,5 \mathrm{~m}^{3} / \mathrm{h}\right)$, de tipología y características aparentemente similares, es decir con aljibe y jardín, observándose demandas totalmente desiguales. Una de ellas, la de mayor consumo mensual, poseía una instalación de riego programada durante las horas nocturnas. Los consumos medidos en cada una de ellas y su correspondiente patrón de consumo durante el periodo de medición se detallan en las siguientes tablas.

TABLA 13. CONSUMOS Y CAUDALES MEDIDOS.

\begin{tabular}{c|cc} 
DATOS & Viv 1 & Viv 2 \\
\hline Consumo total en 57 días $\left(\mathrm{m}^{3}\right)$ & 67,8 & 220,7 \\
Q máx (I/h 10seg) & 1932,0 & 2220,0 \\
Tiempo a Q>1500 I/h (promedio/día) & $3 \mathrm{~min}$ & $1 \mathrm{~h} 25 \mathrm{~min}$ \\
Consumo promedio diario (I) & 1210,8 & 3749,1
\end{tabular}

TABLA 14. PATRÓN DE CONSUMO.

\begin{tabular}{c|cc} 
Rango de caudales & Viv 1 & Viv 2 \\
\hline $0-12 \mathrm{l} / \mathrm{h}$ & 6,01 & 1,56 \\
$12-24 \mathrm{l} / \mathrm{h}$ & 3,71 & 0,75 \\
$24-36 \mathrm{l} / \mathrm{h}$ & 2,75 & 0,60 \\
$36-72 \mathrm{l} / \mathrm{h}$ & 6,03 & 1,48 \\
$72-180 \mathrm{l} / \mathrm{h}$ & 11,34 & 3,84 \\
$180-1500 \mathrm{l} / \mathrm{h}$ & 66,16 & 30,45 \\
$>1500$ & 4,00 & 61,33
\end{tabular}

Tras el análisis de los datos aportados por los equipos de adquisición se extrae información muy relevante sobre la demanda de agua de ambos usuarios. En primera instancia, se observa de forma evidente en los patrones de consumo, que la vivienda 1 consume principalmente a caudales comprendidos entre 180-1500 l/h (Tabla 14), mientras que la vivienda 2 
consume principalmente por encima de $1500 \mathrm{l} / \mathrm{h}$ durante periodos de tiempo relativamente altos $(1 \mathrm{~h} 25$ min a caudales superiores a $1500 \mathrm{l} / \mathrm{h}$ ). También en la Tabla 13, se puede ver que la diferencia en la facturación es de aproximadamente 2500 litros de agua diarios.

A partir de estos resultados es posible determinar la conveniencia de un calibre u otro. En este caso, el contador de la vivienda 2 estaría infradimensionado ya que los caudales de consumo se dan principalmente en la zona alta del rango por encima del caudal nominal, que en este caso es de $1,5 \mathrm{~m}^{3} / \mathrm{h}$, con lo que sería más adecuado la instalación de un medidor de calibre superior es decir de $20 \mathrm{~mm}$ y $Q_{n}=2,5 \mathrm{~m}^{3} / \mathrm{h}$.

En la vivienda 2 el consumo horario promedio es muy elevado durante las horas nocturnas de 19 a $24 \mathrm{~h}$, observándose un pico de consumo de 21 a 23 horas, probablemente originado por el riego por aspersión (caudales muy elevados durante más de una hora diaria). En la vivienda 1, los consumos son también elevados comparados con una vivienda típica sin jardín. En ella la demanda alta se produce durante las horas centrales del día de 13 a 18 horas pero sin comparación con los caudales demandados en la otra vivienda (Figura 9).

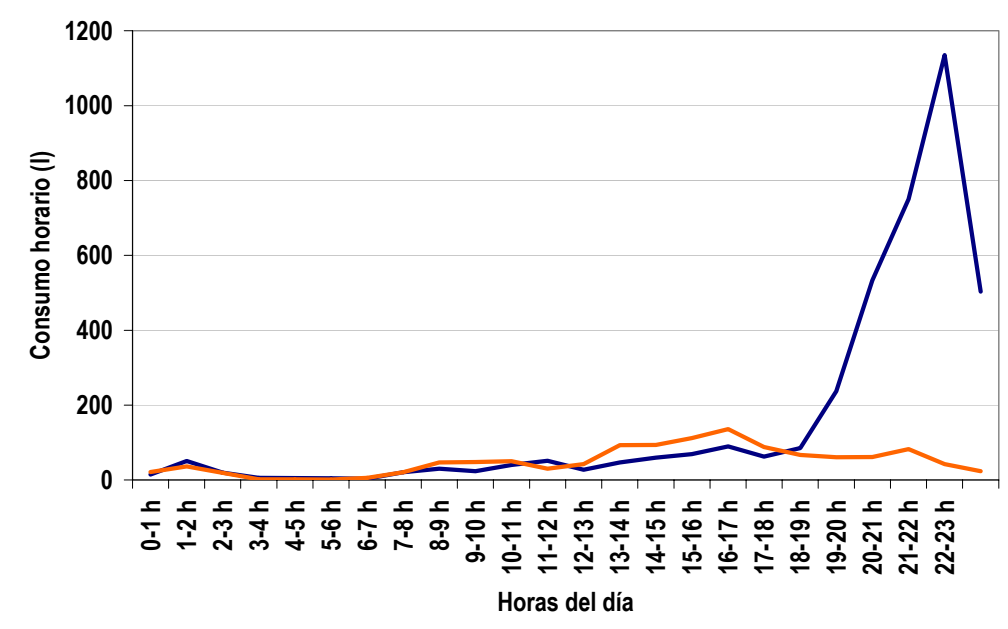

FIGURA 9. COMPARATIVA ENTRE LOS CONSUMOS HORARIOS PROMEDIO DE CADA VIVIENDA.

De esta forma, el levantamiento de un perfil de caudales es el método que mejor determina el dimensionado de un contador. Este método es costoso y laborioso, por lo que en general, se recomienda realizar mediciones sólo en aquellos usuarios críticos con gran consumo de agua, y utilizar otras técnicas propuestas, para los usuarios más estándar.

Desarrollos futuros en este sentido van encaminados a establecer reglas de dimensionado en función de las características de los abonados y de las mediciones de los consumos reales de cada tipo de uso. De esta manera, a partir de muestreos estadísticos de los caudales de consumo de diversos consumidores se podrá relacionar el consumo registrado y su uso, con el calibre de instrumento apropiado.

En la actualidad, la aparición de contadores electrónicos aporta ciertas ventajas en este sentido, ya que esta tecnología permite obtener los perfiles de consumo de un elevado número de usuarios. Además, en grandes consumidores, estos instrumentos son muy útiles establecer los caudales de consumo, mucho más difíciles de estimar que en el caso de consumidores domésticos. 
No obstante, se debe tener en cuenta que estos instrumentos tiene un alto coste en comparación con un contador normal, aunque menor que el sistema propuesto para realizar el levantamiento del perfil, es decir, un contador de precisión (generalmente un volumétrico con emisor de impulsos) junto con un datalogger.

Asimismo, el levantamiento del perfil de caudales puede estar distorsionado en función del comportamiento del propio instrumento. Por ejemplo, un contador electrónico deteriorado marcará un perfil de caudales falso sobre todo a caudales bajos donde el instrumento se deteriora con mayor facilidad. Luego, conviene llevar un seguimiento de su estado metrológico con el fin de obtener mayor fiabilidad en su información.

\subsection{AUDITORIAS DEL ESTADO METROLÓGICO DE LOS SISTEMAS DE MACROMEDICIÓN}

\subsubsection{INTRODUCCIÓN}

La importancia del control metrológico de los instrumentos de medida de caudal, y en general de cualquier instrumento, tanto los utilizados para la facturación de grandes consumidores como aquellos dedicados al control de la red, dentro de un plan de aseguramiento de la calidad queda perfectamente justificada hacia el camino de una adecuada gestión del agua.

Para ello, la presente tesis doctoral plantea una serie de estrategias y técnicas, similares a las desarrolladas ya en Inglaterra dentro de un plan denominado Auditing water flowmetering systems (2002), para examinar los diferentes instrumentos dispuestos en la red. Inicialmente, estas auditorias de macromedidores requieren establecer unos niveles de confianza para las medidas. Cuando el nivel requerido es más alto, las actuaciones que se deben realizar son más rigurosas y frecuentes. Al contrario, cuando no se tiene interés alguno en los datos aportados por los caudalímetros y contadores, las auditorias son muy precarias o inexistentes. Es por ello, que cada empresa de suministro dependiendo de sus necesidades debe concretar la fiabilidad que desea obtener en sus datos de caudal.

Indudablemente, conocer la precisión de estos instrumentos con cierto grado de confianza ayuda en múltiples aspectos de la gestión de la red de distribución. Como se comenta en el Capítulo 8, los datos de caudal tanto de los puntos de inyección a la red como los aportados a sectores hidrométricos son de gran utilidad. Estos caudales analizados debidamente posibilitan un control activo de fugas, prelocalizando aquellas zonas en peores condiciones, permiten conocer el rendimiento hidráulico de la red (Cabrera et al, 1999), ayudan al dimensionado de nuevos tramos y durante el manejo operacional de la red.

Los instrumentos de medida de caudal dispuestos en las redes urbanas son fundamentalmente contadores de velocidad tipo Woltman, caudalímetros de ultrasonidos y electromagnéticos. En numerosas ocasiones, estos instrumentos son de gran calibre y se encuentran instalados en lugares de difícil accesibilidad. Esto dificulta cualquier labor encaminada a mejorar la calidad de sus medidas ya que los costes de renovación o calibración pueden llegar a ser muy elevados.

Consecuentemente, es importante encontrar métodos alternativos que permitan verificar su estado metrológico, y las condiciones de funcionamiento de los medidores, sin necesidad de desinstalarlos ni de interrumpir el suministro de agua durante largos periodos de tiempo. Evidentemente, este chequeo o verificación in situ, no es comparable con una calibración en laboratorio pero permite determinar con cierto grado de confianza el estado metrológico del instrumento.

Este apartado plantea el seguimiento de los sistemas de macromedición evaluando la instalación, el tipo de medidor y considerando los factores que pueden afectar a su correcto funcionamiento para establecer un criterio sobre las condiciones en las que puede estar trabajando el medidor. Tras este estudio previo se proponen prácticas para verificar su estado metrológico con un grado de confianza establecido por la empresa y se exponen los inconvenientes que pueden surgir durante cada procedimiento. Finalmente, mediante un cruce adecuado de la información se podría conocer qué variables han podido influir en mayor grado en el desgaste de los aparatos. 


\subsubsection{UNA PRIMERA INSPECCIÓN DEL SISTEMA DE MEDICIÓN}

Durante una auditoria previa conviene elaborar un informe que detalle todas las características tanto del instrumento de medida como del entorno en el que se encuentra instalado. Este subapartado describe aquellos puntos interesantes que pueden ser útiles para conocer el sistema y los factores que pueden afectar a la medición del agua.

TABLA 15. INPECIÓN BÁSICA DE UN SISTEMA DE MEDICIÓN

Descripción del aparato de medida (características intrínsecas a cada instrumento)

- Tipo de contador: Se clasificará el contador según su principio de funcionamiento o tecnología de medición, ya sea de velocidad (Woltman, chorro único, chorro múltiple, etc.), volumétrico (pistón rotativo o disco nutante), electromagnético o de ultrasonidos.

- Datos del fabricante, modelo, marca, año de fabricación, número de serie del contador, etcétera.

- Características técnicas: Se especificarán las características técnicas más importantes de cada uno de los contadores, como son la Clase metrológica del mismo, indicativa de la precisión de fabricación y por tanto de su calidad de medición (Clase $A, B, C$ ). A su vez, se especificará tanto el calibre como el caudal nominal del aparato de medida.

- Verificación de la homologación del dispositivo de medida según la Directiva 75/33/CEE

- Integridad del contador, confirmando que el estado del mismo es el adecuado y no ha sufrido ningún tipo de manipulación.

- Posibilidad de conexión de emisores de impulsos y su tipo, para un posible levantamiento del perfil de consumo de cara a comprobar el correcto dimensionado del contador.

\section{Características de la instalación}

- Diámetro, espesor y material de la tubería entrada/salida

- Existencia, tipo y diámetro de válvulas de aislamiento.

- Cumplimiento de tramos rectos aguas arriba (longitud de tubería recomendada por los fabricantes para una correcta medición).

- Condiciones ambientales que pudieran deteriorar el contador o dificultar su lectura (ambientes con excesiva humedad, polvo...).

- $\quad$ Accesibilidad de lectura y posición de instalación del contador (vertical/horizontal/inclinado).

- Presencia de filtros, enderezadores de flujo y existencia de tomas en carga para una posible verificación in-situ.

\section{Caudales circulantes}

- $\quad$ Levantamiento de caudales circulantes mediante registradores locales.

- Monitorización mediante un sistema de telemedida o SCADA permite analizar los datos históricos del medidor durante su primer año de funcionamiento, comprobando el caudal máximo, mínimo y nominal, y su presión asociada. 


\subsubsection{VERIFICACIÓN IN SITU DE LOS INSTRUMENTOS DE MEDICIÓN DE CAUDAL}

Cuando se detecta algún tipo de anomalía, o simplemente como una práctica rutinaria, en un caudalímetro o contador de agua es recomendable verificar su estado metrológico. La calibración en un laboratorio certificado supone retirar el instrumento, cortar el suministro mientras se realiza la operación y sustituirlo por otro mientras se llevan a cabo los ensayos de calibración. Estas operaciones suponen un coste económico importante.

Incluso, cuando se instala un nuevo instrumento de medida de caudal en la red con una precisión garantizada por el fabricante, pueden surgir numerosos factores que afecten a su comportamiento. Casos como daños efectuados a algún dispositivo interno durante la instalación o condiciones inapropiadas del flujo pueden afectar negativamente a su medición.

Esta tesis plantea la necesidad de realizar un seguimiento de los instrumentos de mayor calibre (superiores a $20 \mathrm{~mm}$ ) instalados en grandes consumidores de agua, en puntos de inyección a la red o en sectores de medición. Para ello, se exponen distintas técnicas que no garantizan una precisión comparable a la de un laboratorio metrológico certificado pero que permiten evaluar con cierto grado de confianza el sistema de macromedidores. Evidentemente, cualquier instrumento utilizado como patrón en estos casos debe tener su certificado de calibración emitido por un laboratorio homologado.

Durante la verificación in situ se deben ensayar varios caudales de funcionamiento, los más representativos, como el nominal y el de transición o el mínimo que indican el estado del instrumento en su rango bajo de funcionamiento, zona más critica de medición.

Asimismo, es importante que el personal encargado de esta labor esté cualificado para ello. Es aconsejable que conozca qué variables pueden afectar durante los ensayos de medición, los tramos rectos que se deben mantener, la configuración de la instalación, el tipo de tecnología de medición que se comprueba y que tenga una profunda formación en calibración de instrumentos de medida. A continuación se presentan diferentes prácticas que pueden emplearse para verificar in-situ el estado de un instrumento de medida de caudal.

\subsubsection{Medidor patrón en serie}

La verificación in situ mediante la instalación en serie de un caudalímetro de referencia permite comprobar instrumentos hasta calibres aproximados de 40-50 mm. Instrumentos de referencia de mayor calibre son más costosos de transportar e instalar siendo otras técnicas más manejables para estos casos.

La instalación de una toma en derivación aguas abajo del instrumento a comprobar es imprescindible. A ella se acopla el módulo de verificación que consta de una válvula de regulación que permite ajustar el caudal de ensayo, una válvula de corte y el instrumento de referencia. Este equipo debe poderse transportar y conectar fácilmente mediante los acoples adecuados (Figura 11 y Figura 10).

El medidor de referencia conviene que totalice el volumen trasegado e indique el caudal de circulación en cada caso. Existen contadores electrónicos de clase metrológica $\mathrm{C}$ y caudalímetros electromagnéticos de $0,5 \%$ de precisión sobre la lectura que poseen estas características de funcionamiento y que podrían utilizarse para esta función. 


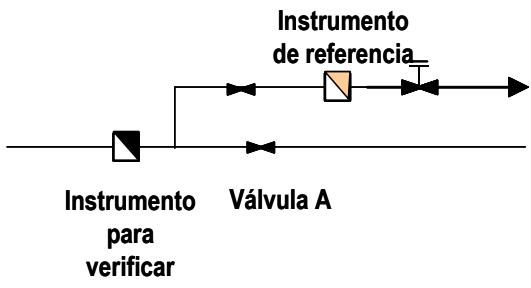

FIGURA 10. VERIFICACIÓN MEDIANTE COMPARACIÓN CON MEDIDOR DE REFERENCIA.

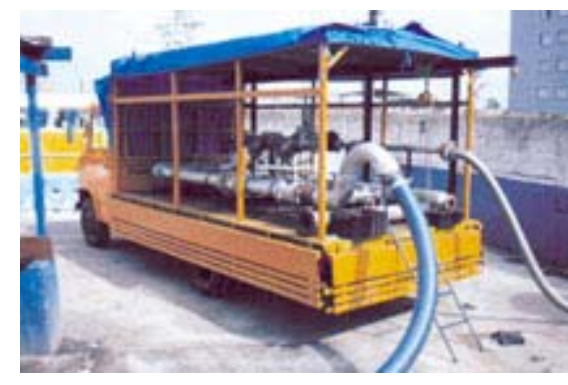

FIGURA 11. CAUDALÍMETRO DE REFERENCIA PORTÁTIL.

De esta forma, mediante comparativa entre lecturas de volumen en un instrumento y otro a diferentes caudales es posible estimar el error de medición con un grado de confianza aceptable. No obstante, es importante que el instrumento de referencia cumpla los requisitos de instalación para que su medida sea lo más fiable posible. Es decir, por ejemplo en un caudalímetro electromagnético conviene respetar un mínimo de 5D de tramos rectos para asegurar un perfil de velocidades plenamente desarrollado.

\subsubsection{Aforo a un depósito calibrado}

Otra posibilidad para verificar instrumentos de menor calibre es mediante el aforo de agua a un depósito calibrado portátil. Este método plantea más inconvenientes a la hora del manejo de los elementos necesarios. Además solo permite calibrar hasta calibres de $30 \mathrm{~mm}$ con un caudal nominal de $5 \mathrm{~m} 3 / \mathrm{h}$ lo que supone, para un depósito de 50 litros, un tiempo de llenado de 36 segundos. Calibres superiores requerirían tiempos inferiores para un mismo volumen obteniéndose, además de unos esfuerzos físicos por parte de los operarios considerables, imprecisiones importantes.

Así pues, instrumentos con caudales nominales de hasta $5 \mathrm{~m}^{3} / \mathrm{h}$ es posible verificarlos con cierta precisión. Para caudales superiores no se garantiza una verificación adecuada para este volumen de aforo. Además, es aconsejable instalar en el sistema propuesto un caudalímetro en derivación para ajustar los caudales de ensayo durante la prueba.

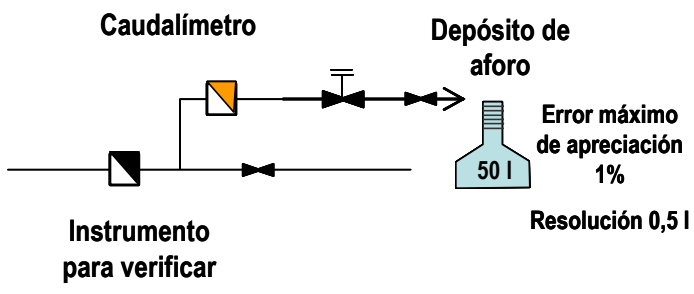

FIGURA 12. VERIFICACIÓN MEDIANTE AFORO A UN DEPÓSITO CALIBRADO.

\subsubsection{Verificación con sonda de inserción}

La verificación mediante sondas de inserción es otra alternativa. En general estos instrumentos se insertan dentro de la tubería midiendo la velocidad del fluido en diferentes puntos con algún tipo de sensor e integrándola hasta obtener la velocidad media en toda la sección, y finalmente, el caudal circulante. 
Por ello, como se estudió en el Capítulo 4, su inconveniente principal es la influencia que ejerce el perfil de velocidades sobre los instrumentos de medida se incrementa cuanto menor es el número de puntos de medida. La localización de los puntos de medida cobra especial importancia ya que la relación entre la velocidad medida y la velocidad media en la sección difiere dependiendo de la situación del sensor.

Básicamente las técnicas para la obtención del caudal mediante sondas de inserción podrían agruparse en tres modalidades (Figura 13), como se describe en el Capítulo 2.

- Medición de la velocidad en la línea central de la conducción.

- Medición de la velocidad axial media (profundidad de inserción de aproximadamente 1/8D o 7/8D).

- Medición de la velocidad en dos o varias cuerdas diametrales o medición del perfil de velocidad completo.
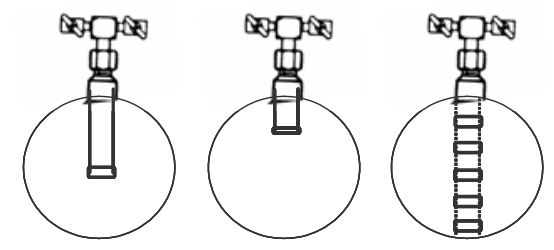

FIGURA 13. MÉTODOS DE MEDIDA DE CAUDAL CON SONDA DE INSERCIÓN.

Este tipo de sondas se puede utilizar en un amplio rango de diámetros comenzando, usualmente, en 100mm hasta tuberías de más de $4000 \mathrm{~mm}$. No obstante, y debido a restricciones estructurales del caudalímetro, el rango de diámetros y caudales admisibles depende tanto del grado de inserción del mismo como de su frecuencia natural. Por un lado, se genera un momento máximo en el punto de contacto entre el caudalímetro y la tubería, siendo este el punto crítico, y por otro la formación de vórtices aguas abajo de la sonda genera esfuerzos periódicos, que si son de una frecuencia similar a la frecuencia natural del vástago pueden vencerlo rápidamente.

Si se opta por insertar la sonda 1/8D, la longitud insertada es mínima y, el diámetro máximo de la conducción en la que se puede utilizar el instrumento puede alcanzar los valores comentados, de más de $4000 \mathrm{~mm}$. No obstante, cuando el método de medida empleado es el del eje central, la capacidad de medición en grandes tuberías se reduce, tal y como se muestra en la Figura 14. En esta opción, la resistencia de la sonda adquiere relevancia y limita tanto el diámetro de la conducción como las velocidades de circulación del agua.

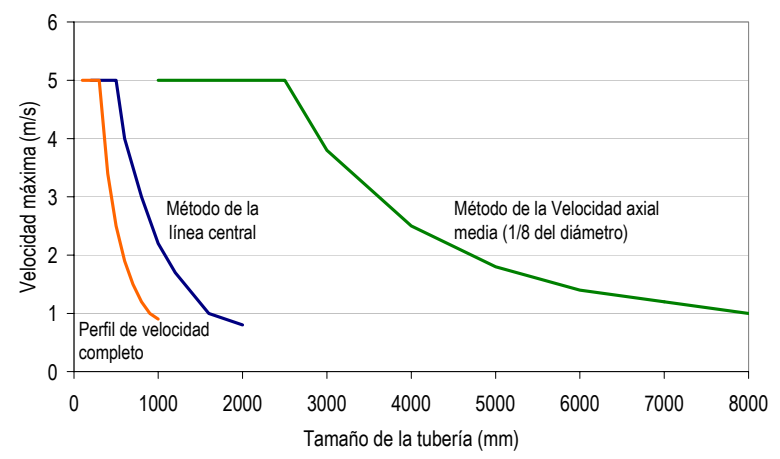

FIGURA 14. VELOCIDAD MÁXIMA ADMISIBLE PARA DIFERENTES LONGITUDES DE INMERSIÓN (ABB-KENTTAYLOR 1993) 
Actualmente, estos instrumentos han evolucionado tecnológicamente mejorando su precisión, su recogida y almacenamiento de datos, e incluso, su software de análisis. No obstante, incluso con todas las herramientas de ayuda que incorporan, estos instrumentos requieren personal cualificado ya que están expuestos a gran cantidad de fuentes de error que pueden surgir y conviene reconocer.

Como se describe en el Capítulo 2, existen varios principios de funcionamiento dentro de este tipo de aparatos. Los más comunes son las sondas electromagnéticas o las de tipo turbina. Las primeras, emplean para la medición de la velocidad un campo electromagnético generado por unas bobinas que incorpora el cabezal. La fuerza electromotriz captada por unos electrodos también situados en el cabezal, resulta proporcional a la velocidad del fluido en dicha zona. La segunda tecnología, tipo turbina, relaciona la velocidad de rotación de este elemento con la velocidad local del fluido (Figura 15).

En general, la precisión en campo de las sondas de inserción no es demasiado elevada, aunque frecuentemente en las especificaciones de los fabricantes pueden encontrarse precisiones teóricas excelentes. La precisión teórica facilitada por los fabricantes oscila entre el $5 \%$ y el $1 \%$ de la velocidad medida. Sin embargo, los valores de repetibilidad son mucho más bajos, del orden del $0.2 \%$ de la medida.

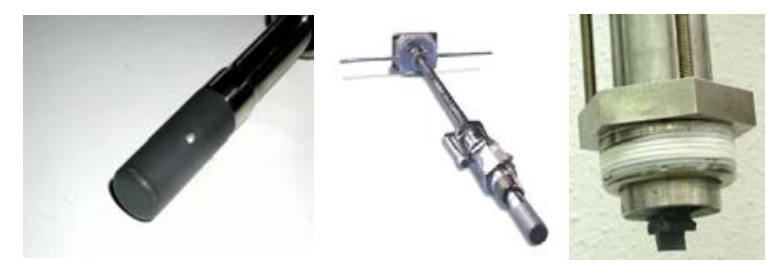

FIGURA 15. SONDAS DE INSERCIÓN ELECTROMAGNÉTICAS Y DE TURBINA.

De esta manera es importante conocer los posibles fallos que pueden surgir durante la verificación que atienden tanto a las inexactitudes del propio aparato de medida como al procedimiento de ensayo. A continuación se describen las fuentes de error más comunes cuando se usa este método de verificación descritas por el citado informe del National Engineering Laboratory (NEL), 2002.

En primer lugar, el efecto sobre la medición de la instalación de sondas de inserción cuando el flujo de agua no se encuentra plenamente desarrollado. Las medidas obtenidas con la sonda de inserción a D/8 no corresponden a la velocidad media de circulación del fluido sino que pueden cometerse errores importantes de $-88 \%$ cuando se introduce $7 / 8 \mathrm{D}$ o de $+118 \%$ cuando se mide a $1 / 8 \mathrm{D}$.

Otra fuente de incertidumbre es la que existe sobre el área interior de la sección. La posible acumulación de sedimentos o deformación de la tubería puede reducir el área efectiva de paso. Además, las variaciones en la rugosidad de la pared interna de la tubería afectan al perfil de velocidades, por lo que puede cambiar la relación entre la velocidad medida y la velocidad media en la sección.

En estos aparatos la colocación de las sondas de inserción con respecto al flujo de agua es fundamental. Como se observó durante el Capítulo 4, el par neto producido por el impacto del agua en un caudalímetro de turbina depende de la alineación entre los vectores de velocidad y el eje de giro de la turbina. Es decir, la velocidad de rotación de la turbina, es función tanto de la velocidad local como de su ángulo de incidencia sobre los álabes. Lo mismo sucede con los caudalímetros electromagnéticos, donde la tensión inducida en los electrodos, depende del ángulo que forme los vectores de velocidad y el campo electromagnético. Por tanto, en este caso, los electrodos de la sonda deben colocarse en la cuerda diametral perfectamente perpendicular al flujo (Figura 16). 
Por otro lado las sondas de inserción requieren que la toma en carga se realice totalmente perpendicular al eje de la conducción (Figura 17). Cierto ángulo de inserción con respecto a la vertical en cualquier sentido puede provocar errores en la medida del caudal. En estos casos, cuando se inserta la sonda electromagnética con cierto ángulo pueden cometerse errores de medida del orden de -0.16 a 2,38\%, en función del ángulo.

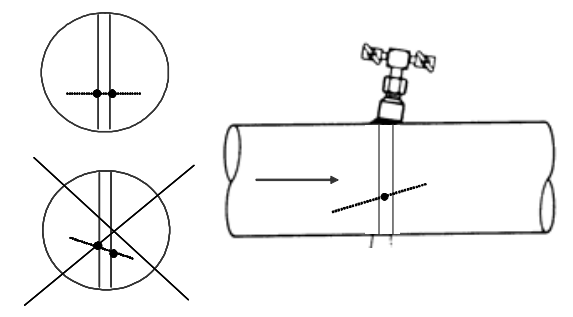

FIGURA 16. COLOCACIÓN DE LA SONDA RESPECTO DEL FLUJO DE AGUA.

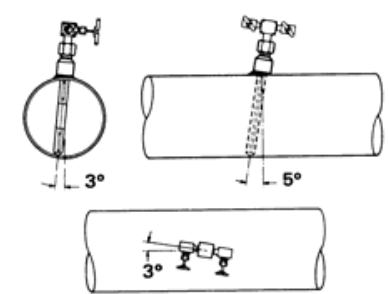

FIGURA 17. ÁNGULO DE INSERCIÓN DEL CAUDALIMETRO DE INSERCIÓN.

Por otro lado, cuando el cálculo del caudal se realiza en un único punto, la profundidad de inserción es un aspecto crítico en la obtención de una medida fiable. Tal y como han demostrado diversos trabajos (Cascetta et al., 2001) los caudales obtenidos mediante el método de la medición de la velocidad máxima en el eje, son menos sensibles a la correcta inserción del caudalímetro. Por el contrario, cuando se obtiene la velocidad en la corona crítica, de radio $3 / 4 R$, los errores provocados por este factor pueden llegar a ser significativos.

Estos instrumentos, como cualquier otro, tienen una vida útil que depende del desgaste de sus elementos. Este deterioro hace variar el factor de calibración lo que provoca cierto error sobre la medida de la velocidad media. En general, la tecnología electromagnética, sin ningún elemento móvil, tiene un factor de calibración más estable.

\subsubsection{Verificación con caudalímetro de ultrasonidos portátil}

Este tipo de tecnología de medición se utiliza en las redes urbanas para conocer el caudal circulante en zonas donde no existe otro tipo de medidor instalado. A su vez, en otros casos estos equipos de ultrasonidos portátiles permiten verificar otros instrumentos con cierto grado de confianza (Figura 18). Aproximadamente, con una configuración correcta de todos los parámetros requeridos y unas condiciones adecuadas de instalación, su precisión oscila entre 2 y $5 \%$ sobre la medida. En general, como en el caso de los caudalímetros electromagnéticos, velocidades del fluido inferiores a $0,5 \mathrm{~m} / \mathrm{s}$ empeoran su medición aumentando la incertidumbre.

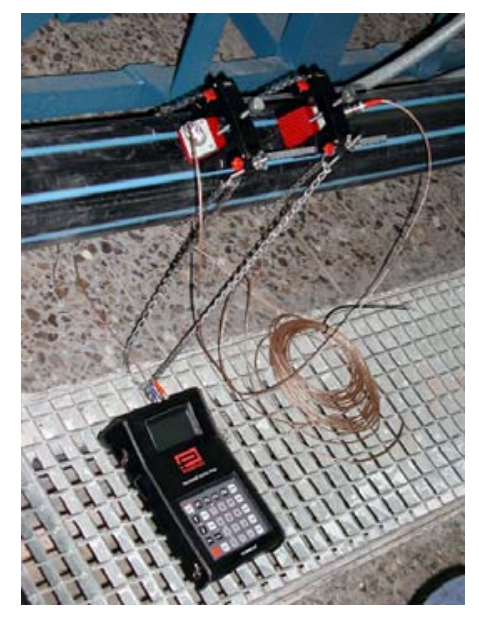

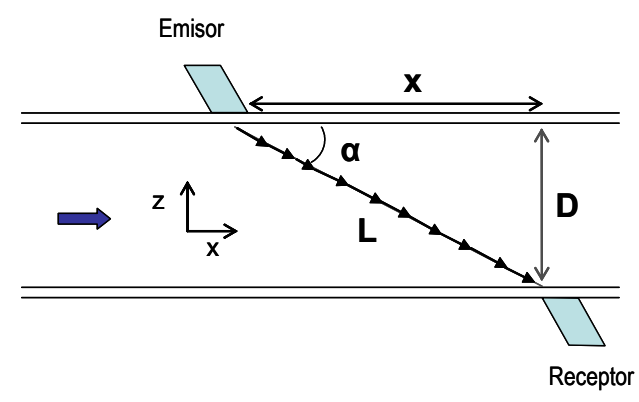

FIGURA 19. CONFIGURACIÓN GEOMÉTRICA DEL CAUDALÍMETRO DE ULTRASONIDOS.

FigURA 18. CAUDALIMMETRO DE ULTRASONIDOS DE TIEMPO DE TRÁNSITO PORTÁTLL. 
El principio de medición de este tipo de instrumentos se explicó durante el Capítulo 4 (apartado 2.3), donde se estudiaba la influencia que ejercía un flujo distorsionado sobre la medida de caudal. Estos instrumentos basan su medición de caudal en el tiempo de tránsito de las ondas sonoras emitidas por los transductores que circulan a través del fluido en movimiento. El resto de variables requeridas para la estimación del caudal se determinan mediante tablas experimentales y la información aportada por el técnico sobre la propia instalación.

Por tanto, el buen uso de este tipo de instrumentos para verificar in situ el caudal circulante comienza por el conocimiento del material de la tubería y de sus características dimensionales. La integración de la velocidad circulante en la cuerda de medición permite calcular el caudal. Para ello, es imprescindible saber el espesor y el diámetro exterior de la conducción. Imprecisiones en este sentido suelen ser fuentes de incertidumbre críticas en la medida de este instrumento.

Un análisis de las incertidumbres que pueden aparecer durante la medida de caudal con este tipo de instrumento proporciona información sobre cómo afectan las diferentes variables que entran en juego durante la verificación. Como se explicó en el Capítulo 4 apartado 4.3.3.1, el caudal medido (ecuación 17) es función del diámetro interior de la conducción, la velocidad del sonido en el agua, la longitud de la cuerda entre transductores, el ángulo que forma la cuerda con el eje de la conducción (Figura 19) y la diferencia en tiempo de tránsito.

$$
\begin{gathered}
\mathrm{Q}=\mathrm{A} \cdot \mathrm{V}=\frac{\pi \cdot \mathrm{D}^{2}}{4} \cdot \frac{\Delta \mathrm{t} \cdot \mathrm{C}^{2}}{2 \cdot \mathrm{L} \cdot \cos \alpha} \\
\text { como } \mathrm{L}=\frac{\mathrm{D}}{\operatorname{sen} \alpha} \text { y } \operatorname{tg} \alpha=\frac{\mathrm{D}}{\mathrm{x}} \text { (ver Figura 19) }
\end{gathered}
$$

El caudal circulante vendrá determinado por dicha expresión 13 , cuyas variables son medidas y por tanto pueden ser fuente de incertidumbre. La influencia que ejerce cada uno de estos parámetros sobre el caudal se estimará calculando las derivadas parciales de dicha expresión respecto de cada variable. La relación entre el caudal y los parámetros implicados precisará su sensibilidad.

$$
\mathrm{Q}=\frac{\pi \cdot \mathrm{D}^{2} \cdot \Delta \mathrm{t} \cdot \mathrm{c}^{2}}{8 \cdot \mathrm{x}}
$$

TABLA 16. COEFICIENTES DE SENSIBILIDAD EN LA MEDIDA DE CAUDAL POR TIEMPO DE TRÁNSITO.

\begin{tabular}{cccc}
\hline$\frac{\partial \mathrm{Q}}{\partial \mathrm{D}} \frac{\mathrm{Q}}{\mathrm{Q}}$ & $\frac{\partial \mathrm{Q}}{\partial \mathrm{c}} \frac{\mathrm{c}}{\mathrm{Q}}$ & $\frac{\partial \mathrm{Q}}{\partial \Delta \mathrm{t}} \frac{\Delta \mathrm{t}}{\mathrm{Q}}$ & $\frac{\partial \mathrm{Q}}{\partial \mathrm{x}} \mathrm{Q}$ \\
\hline 2 & 2 & 1 & -1 \\
\hline
\end{tabular}

De esta forma, teniendo en cuenta estas consideraciones un $1 \%$ del error en la medida del diámetro interior 0 en la estimación de la velocidad del sonido en el agua resulta un $2 \%$ en la medida de caudal. En cambio, errores en la diferencia de tiempo de tránsito entre transductores son directamente proporcionales a variaciones en el caudal, e inversamente proporcionales a imprecisiones en la longitud establecida entre transductores. 
Por otro lado, la incertidumbre asociada a la velocidad del sonido en el agua depende, a su vez, de la temperatura del fluido, estando la relación entre estas variables representada en la Figura 20. Por tanto, variaciones en la estimación de la temperatura influirán indirectamente en la determinación del caudal.

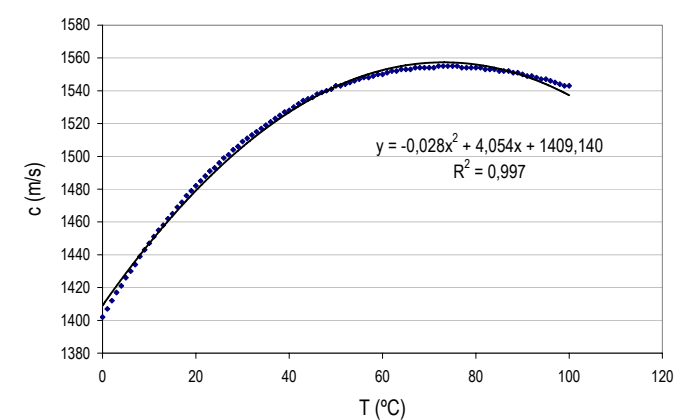

FIGURA 20. RELACIÓN ENTRE LA VELOCIDAD DEL SONIDO EN EL AGUA Y SU TEMPERATURA.

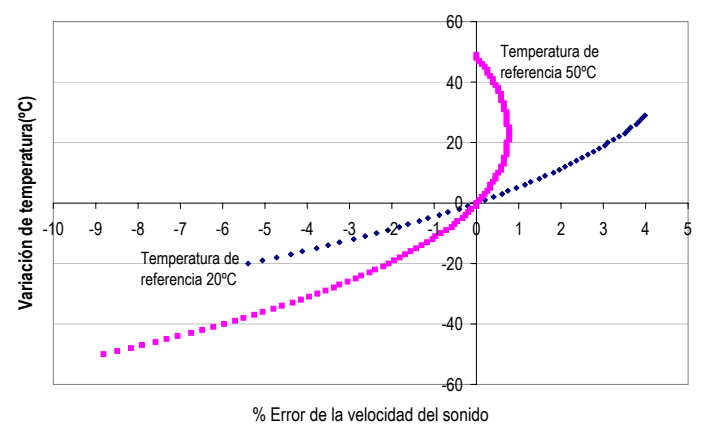

FIGURA 21. ERROR EN LA ESTIMACIÓN DE LA VELOCIDAD DEL SONIDO EN EL AGUA.

Los caudalímetros de ultrasonidos portátiles, generalmente, tiene la opción de introducir la velocidad del sonido, o por defecto, la estiman a partir de la distancia entre transductores y el tiempo de tránsito de las ondas sonoras. Ambos procedimientos implican cierto error.

Por ejemplo, cuando se fija la velocidad del sonido a la temperatura de $20^{\circ} \mathrm{C}$ siendo realmente la temperatura del fluido de $25^{\circ} \mathrm{C}$, se produce una variación de $5^{\circ} \mathrm{C}$ lo que supone un error en la velocidad del sonido en el agua de cerca del $1 \%$. A medida que ésta variación sea mayor el error será más acusado. Otra opción posible es no introducir ningún dato de temperatura y seleccionar ésta por intervalos de 0 a $100^{\circ} \mathrm{C}$, de esta forma, la temperatura por defecto establecida por el aparato es de $50^{\circ} \mathrm{C}$. Con este supuesto, los errores que se pueden producir en la velocidad del sonido oscilan entre $0 \mathrm{y}$ $3,5 \%$ para variaciones de la velocidad con respecto a $50^{\circ} \mathrm{C}$ (Figura 21).

Por lo tanto, el caudalímetro no es capaz de medir la velocidad del sonido conviene reducir al máximo las incertidumbres sobre las variables físicas que intervienen en la estimación de esta velocidad del sonido.

De igual manera, a la hora de medir se pueden introducir parámetros en el caudalímetro con cierta desviación de la realidad. Frecuentemente, se desconoce el espesor de la tubería o el diámetro exterior no se ha medido correctamente. Esto origina fallos en la estimación del diámetro interior, y consecuentemente se duplica el error relativo de caudal. La Figura 22 muestra la relación entre el diámetro exterior de la tubería y el error de medida de caudal cuando se produce una desviación de 1, 2 y $5 \mathrm{~mm}$ en el diámetro interior. Por ejemplo, una tubería envejecida por la acumulación de sólidos puede llegar a aumentar su espesor en 2,5 mm lo que supone una disminución de su diámetro interior en $5 \mathrm{~mm}$ del inicialmente supuesto. Esta incertidumbre provoca, en una tubería de $1000 \mathrm{~mm}$, un error de $-1 \%$ en la medida de caudal. 


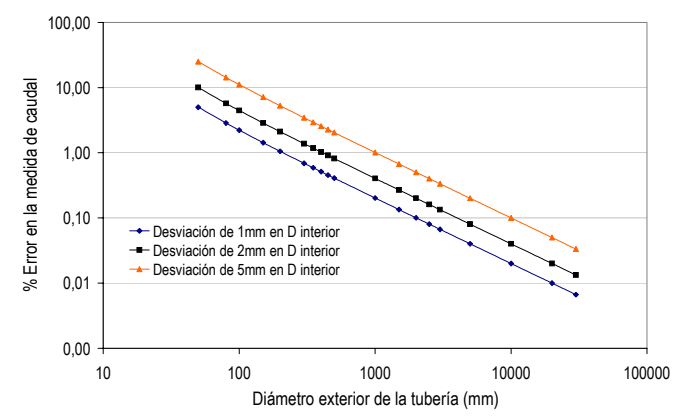

FIGURA 22. ERROR EN LA MEDIDA DE CAUDAL OCASIONADA POR INCERTIDUMBRES DEL DIÁMETRO INTERIOR.

Otro factor que ha evolucionado en los últimos años es la resolución de tiempo de la electrónica que contabiliza la diferencia en tiempo de tránsito de las ondas sonoras. Este parámetro llega a ser de nanosegundos, por lo que el equipo debe tener esta característica constructiva para que la incertidumbre en la medida sea menor.

El material de la tubería también puede influir en la transmisión de la señal. Así pues, materiales porosos atenúan la señal impidiendo, en ocasiones, que atraviese la pared de la tubería. También, aguas turbias o con un alto grado de impurezas impiden que la señal sonora llegue al receptor originando problemas y proporcionando resultados no fiables.

Los caudalímetros de ultrasonidos de tiempo de tránsito, como se comentó durante el Capítulo 4, son muy sensibles al perfil de velocidades aguas arriba de la conducción. Consecuentemente, durante la verificación in situ con estos equipos se requiere un flujo plenamente desarrollado para reducir al máximo las incertidumbres originadas por este parámetro.

Durante el citado capítulo se estudió la influencia de las perturbaciones del flujo sobre la medición el caudal. En él se constató la necesidad de una longitud recta de más de $6 \mathrm{D}$ aguas arriba del equipo para evitar la distorsión generada por una válvula de compuerta prácticamente cerrada. Igualmente, en el estudio llevado a cabo por el National Engineering Laboratory (2002), se simula con técnicas de Computacional Fluid Dynamics (CFD) el flujo de agua a través de un codo concluyéndose que después de aproximadamente $20 \mathrm{D}$ los vórtices generados prácticamente desaparecen.

Evidentemente, mantener esta distancia de tubería recta, en ocasiones, puede resultar imposible ya que los instrumentos que se desea verificar se encuentran en arquetas donde la conducción aguas arriba y abajo se encuentra enterrada y es inaccesible para el técnico encargado.

La medición con este tipo de tecnología en dos cuerdas reduce la incertidumbre producida por un flujo distorsionado, ya que mayor número de cuerdas de medición definen mejor el perfil de velocidades real del flujo de agua. En el estudio inglés citado anteriormente se demuestra una alta sensibilidad al perfil de velocidades en el caso de una cuerda de medición, reduciéndose a más de la mitad cuando el equipo mide en otra posición. La medición en tres cuerdas, simplemente, mejora ligeramente los resultados no siendo realmente justificada.

\subsection{CONCLUSIONES}

Este capítulo propone una guía práctica de diferentes estrategias que pueden aplicarse para gestionar correctamente el sistema de medición de caudal de una red de distribución y aumentar tanto su eficacia como su eficiencia.

En primer lugar, con respecto a la gestión de micromedidores se propone un método de control estadístico de calidad a la recepción que analiza los lotes de contadores nuevos y ayuda en la toma de decisiones en cuanto a la aceptabilidad de 
dicha partida. Mediante el ensayo de una muestra de instrumentos a caudales característicos como el mínimo, transición y máximo, y fijando un nivel de aceptación acordado entre comprador y vendedor, se establece si la partida es aceptada o rechazada, y cual es su estado metrológico inicial.

Un segundo epígrafe analiza los costes que supone el uso de medidores de agua, y calcula el periodo óptimo de renovación del mismo para obtener el máximo beneficio desde un punto de vista económico. Para ello, es necesario evaluar todos los costes asociados con la actividad y sustraerlo de los ingresos que la utilización del instrumento puede reportar.

Con respecto a los macromedidores, el dimensionado de instrumentos de medida de caudal, especialmente contadores de agua es uno de los puntos clave para una buena gestión de los instrumentos. Para ello, una adecuada elección de la capacidad de caudal del instrumento parte por ajustar al máximo su caudal nominal a las condiciones de funcionamiento de la instalación. Este apartado expone técnicas, algunas de ellas desarrolladas en la bibliografía, que ayudan a dimensionar un instrumento y se realizan ciertas puntualizaciones que es conveniente considerar.

El último apartado plantea el seguimiento de los sistemas de macromedición evaluando la instalación, el tipo de medidor y considerando los factores que pueden afectar a su correcto funcionamiento para establecer un criterio sobre las condiciones en las que puede estar trabajando el medidor. Tras este estudio previo se proponen prácticas para verificar su estado metrológico con un grado de confianza establecido por la empresa y se exponen los inconvenientes que pueden surgir durante cada procedimiento. Finalmente, mediante un cruce adecuado de la información se podría conocer qué variables han podido influir en mayor grado en el desgaste de los aparatos.

\subsection{BIBLIOGRAFÍA CONSULTADA}

Arizmendi, L.J. (1991). Instalaciones Urbanas. Infraestructura y Planeamiento. Ed. Bellisco, Madrid.

Arregui F.J. (1999). Propuesta de una metodología para el análisis y gestión del parque de contadores de agua. Tesis doctoral. Universidad Politécnica de Valencia.

Arregui F.J. (2001). Algunas consideraciones sobre la elección del tipo de contador doméstico y el cálculo de su vida útil. Jornadas técnicas Baleares 2015: La Gestión del Agua.

Arregui F.J, García-Serra J, Palau C.V., Gascón L. (2004). Evaluación y control de pérdidas en redes urbanas. Metodología para la evaluación de un parque de contadores. Curso de Formación. Instituto Tecnológico del Agua.

ABB Kent-Taylor, (1993). Manual de instalación. Medidor electromagnético de caudal. Tipo inserción.

AWWA (1975). M22 Sizing water service lines and meters. Manual of Water supply practices. ED. American Water Works Association.

Cabrera E., Almandoz J. Arregui F, García-Serra J. (1999). Auditoría de redes de distribución de agua. Ingeniería del Agua. Vol.6 № 4. pp. 387-399.

Cascetta R, Palombo A, Scalabrini G . (2001). Water flow measurement in large bore pipes: An experimental comparison between two different types of insertion flowmeters .Inst. Systems and Automation Society, ISA Transactions.

Creus A. (1989). Instrumentación industrial. Marcombo

Deming W.E. 1986. Out of the crisis. MIT/CAES.

Flow programme (2002). Best practices guide calibration of flowmeters. Nacional Engineering Laboratiry. United Kingdom. 
Johnson E.H. (2004). Estimating uncertainty of flow measurement of the in situ calibration of large water meter. The Institution of Engineers, Australia. 8th National Conference on Hydraulics in Water Engineering.

ISO 4064-1:1993. Medición del caudal de agua en conductos cerrados. Parte 1. Especificaciones.

ISO 4064-2:1978. Medición del caudal de agua en conductos cerrados. Parte 2. Condiciones de instalación.

ISO 4064-3:1983. Medición del caudal de agua en conductos cerrados. Parte 3. Métodos y materiales de ensayo.

ISO-3951-1981 o UNE 66-030-84. Reglas y tablas de muestreo para inspección por variables de los porcentajes de unidades defectuosas.

Male J.W., Noss R.R., Moore I.C. 1985. Identifying and Reducing Losses in Water Distribution Systems. Noyes Publications.

National Engineering Laboratory (2002). Auditing water flowmetering systems. Flow center. Nacional Engineering Laboratory. United Kingdom.

NIA. (1975). Norma Básica de Instalaciones Interiores.

Orden ministerial 28 de diciembre de 1988 por la que se regulan los contadores de agua fria (BOE num.5, de 6 de marzo de 1989).

Planells F., Antolí A., López V., Sanz F., García-Serra J. 1987. Diagnóstico de la gestión óptima de contadores en un sistema de distribución de agua. Tecnología del agua. №38 1987.

Tryfos P. (2001). Acceptance sampling. York University.

Tzamtzis A.D., Paralika M. (2003). A decision support system for the control and replacement of water meters in the city of Athens. Proceedings Pumps, Electromechanical devices and systems applied to urban water management. Vol.I. pp.289296.

Yee M.D. 1999. Economic analysis for replacing residential meters. Journal of American Water Works Association. Vol. 91, Issue 7. pp 72-77. 


\section{ANEXO 1. CONTROL DE CALIDAD A LA RECEPCIÓN}

PLAN DE MUESTREO. MÉTOdO S CON UN NIVEL DE INSPECCIÓN NORMAL

\begin{tabular}{|c|c|c|c|c|c|}
\hline \multirow{2}{*}{ Tamaño del lote } & \multicolumn{2}{|c|}{ Niveles de inspección especiales } & \multicolumn{3}{|c|}{ Niveles de inspección generales } \\
\hline & S-3 & $\$-4$ & 1 & ॥ & ill \\
\hline $2 a \quad 8$ & & & - & & $\mathrm{c}$ \\
\hline$\Xi a \quad 15$ & & & & B & D \\
\hline $16 a$ & & & $\mathrm{~B}$ & c & E \\
\hline $26 a 50$ & & & c & $\mathrm{D}$ & $\mathrm{F}$ \\
\hline 51 a 90 & & B & $\mathrm{D}$ & E & G \\
\hline$\$ 1$ a $\quad 150$ & & c & $\varepsilon$ & $\mathrm{F}$ & H \\
\hline 151 a 280 & B & $\mathrm{D}$ & $\mathrm{F}$ & $G$ & 1 \\
\hline $281 \& \quad 500$ & c & E & G & $H / /^{*}$ & $\mathrm{~J}$ \\
\hline 501 a 1200 & D & $\mathrm{F}$ & H & J & k \\
\hline 1201 a 3200 & E & G & 1 & k & L \\
\hline 3201 a 10000 & $\mathrm{~F}$ & H & J & L & $m$ \\
\hline $10001 \approx 35000$ & $G$ & 1 & K & m & N \\
\hline 35001 a 150000 & H & 3 & L & $N$ & $\mathrm{P}$ \\
\hline 150001 a 500000 & 1 & K & M & $P$ & \\
\hline 500001 en adelante & 小 & L & $\mathrm{N}$ & 1 & \\
\hline
\end{tabular}

. " smese $\mathrm{H}$ para un tamako de lote de 281 a $400 \mathrm{e} 1$ para un tameño de lote de 401 a 500. 
Tabla I-B

Letras código y tamaños de las muestras en una inspección normal

\begin{tabular}{|c|c|c|c|c|c|c|c|c|c|c|c|c|c|}
\hline \multirow{2}{*}{\multicolumn{2}{|c|}{$\begin{array}{c}\text { Método } \\
\begin{array}{c}\text { Nivel de calidad } \\
\text { aceptable }\end{array}\end{array}$}} & \multirow{2}{*}{$\begin{array}{c}\text { Ros: } \\
\begin{array}{c}\text { Todos } \\
\text { los } \\
\text { NCA }\end{array}\end{array}$} & \multicolumn{11}{|c|}{$\alpha \sigma 0$} \\
\hline & & & 0.10 & 0,15 & 0,25 & 0,40 & 0,65 & 1,0 & 1,5 & 2,5 & 4.0 & 6,5 & \multirow[t]{2}{*}{10,0} \\
\hline \multirow{14}{*}{$\begin{array}{l}\text { 茴 } \\
\text { 总 } \\
\text { 密 } \\
\text { 总 }\end{array}$} & B & 3 & & & a & & 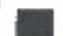 & 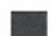 & 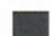 & & & & \\
\hline & $c$ & 4 & & & & & & 2 & 2 & 2 & 2 & 3 & 3 \\
\hline & 0 & 5 & & & & & 2 & 2 & 2 & 3 & 3 & 3 & 4 \\
\hline & $E$ & 7 & & & 2 & & & 3 & 3 & 4 & 4 & 5 & 5 \\
\hline & $\mathrm{F}$ & 10 & 1 & 3 & 3 & 3 & 4 & 4 & 4 & 5 & 5 & 6 & 7 \\
\hline & G & 15 & 4 & 4 & 4 & 5 & 5 & 6 & 6 & 7 & \& & 9 & 11 \\
\hline & $\mathrm{H}$ & 20 & 5 & 5 & 6 & 6 & 7 & 7 & 8 & 9 & 10 & 12 & 14 \\
\hline & 1 & 25 & 6 & 6 & 7 & 8 & 8 & 9 & 10 & 11 & 13 & 15 & 17 \\
\hline & $J$ & 35 & 8 & 9 & 9 & 10 & 11 & 12 & 14 & 15 & 18 & 20 & 24 \\
\hline & K & 50 & 11 & 12 & 13 & 14 & 16 & 17 & 19 & 22 & 25 & .29 & 33 \\
\hline & L & 75 & 16 & 17 & 19 & 21 & 23 & 25 & 28 & 32 & 36 & 42 & 49 \\
\hline & $\mathrm{M}$ & 100 & 22 & 23 & 25 & 27 & 30 & 33 & 36 & 42 & 48 & 55 & 64 \\
\hline & $\mathrm{N}$ & 150 & 31 & 34 & 37 & 40 & 44 & 49 & 54 & 61 & 70 & 82 & 95 \\
\hline & $\mathrm{P}$ & 200 & 42 & 45 & 49 & 54 & 59 & 65 & 71 & 81 & 93 & 109 & 127 \\
\hline
\end{tabular}

\begin{tabular}{|c|c|}
\hline \multicolumn{2}{|c|}{$\begin{array}{c}\text { Muestra equivalente } \\
\text { para una inspección } \\
\text { por atributos }\end{array}$} \\
\hline $\begin{array}{c}\text { Letra } \\
\text { código }\end{array}$ & $\begin{array}{c}\text { Tamaño } \\
\text { de la } \\
\text { muestra }\end{array}$ \\
\hline B & 3 \\
\hline C & 5 \\
\hline D & 8 \\
\hline E & 13 \\
\hline F & 20 \\
\hline H & 52 \\
\hline J & 50 \\
\hline F & 500 \\
\hline
\end{tabular}

NOTAS

1 Todos los valores de los NCA se expresan en porcentaje de unidaces defectuosas,

2 Las letros código utilizadas en esta norma istarnacional, correspanden a las que figuran en la norma ISO 2859 (=UNE $66-020$ ): no son idénticas a las Ltilizadas en el documento MIL STD 414 .

3 Símbolos

No existe un plan de muestreo comeniente en esta zona; utilipase al primer plan de muestréo que se encuentre siguiendo la direc ción de la flecha, Se aplica tanto al tamaño de la muestra como a la constan ze de jcestabilidad $k$. 


\section{Método " $s "$}

Tabla II-A

Planes de muestreo simples para la inspección normal (Tabla general): método " $s$ "

\begin{tabular}{|c|c|c|c|c|c|c|c|c|c|c|c|c|}
\hline \multirow{3}{*}{$\begin{array}{l}\text { Letra } \\
\text { código }\end{array}$} & \multirow{3}{*}{$\begin{array}{l}\text { Tamafio } \\
\text { de la } \\
\text { muestra }\end{array}$} & \multicolumn{11}{|c|}{ Nivel de calidad aceptable (inspección normal) } \\
\hline & & 0,10 & 0,15 & 0,25 & 0,40 & 0,65 & 1,00 & 1,50 & 2,50 & 4,00 & 6,50 & 10,00 \\
\hline & & $k$ & $k$ & $k$ & $k$ & k & * & $k$ & k & * & * & $k$ \\
\hline B & 3 & & & & 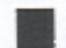 & 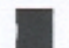 & 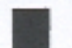 & 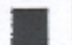 & 1,12 & 0,958 & 0,765 & 0.566 \\
\hline $\mathrm{c}$ & 4 & & & & & & 1.45 & 1,34 & 1,17 & 1,01 & 0,814 & 0,617 \\
\hline D & 5 & & & & & 1,65 & 1,53 & 1,40 & 1,24 & 1,07 & 0,874 & 0,675 \\
\hline$\varepsilon$ & 7 & & & 2,00 & 1,88 & 1,75 & 1,62 & 1,50 & 1,33 & 1,15 & 0,955 & 0,755 \\
\hline$F$ & 10 & 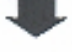 & 2.24 & 2,11 & 1,98 & 1,84 & 1,72 & 1,58 & 1,41 & 1,23 & 1,03 & 0.828 \\
\hline G & 15 & 2.42 & 2,32 & 2,20 & 2,06 & $1,91$. & 1,79 & 1,65 & 1,47 & 1,30 & 1,09 & 0,886 \\
\hline H & 20 & 2,47 & 2,36 & 2,24 & 2,11 & 1,96 & 1,82 & 1,69 & 1,51 & 3,33 & 1,12 & 0,917 \\
\hline t & 25 & 2,50 & 2,40 & 2,26 & 2,14 & 1,98 & 1,85 & 1,72 & 1,53 & 1,35 & 1,14 & 0,936 \\
\hline J & 35 & 2,54 & 2,45 & 2,31 & 2,18 & 2,03 & 1.89 & 1,76 & 1,57 & 1,39 & 1,18 & 0,969 \\
\hline K & 50 & 2,60 & 2,50 & 2,35 & 2,22 & 2,08 & 1,93 & 1,80 & 1,61 & 1,42 & 1,21 & 1,00 \\
\hline L & 75 & 2,66 & 2,55 & 2,41 & 2,27 & 2,12 & 1,98 & 1,34 & 1,65 & 1,46 & 1,24 & 1,03 \\
\hline M & 100 & 2,69 & 2,58 & 2.43 & 2.29 & 2.14 & 2,00 & 1,86 & 1.67 & 1,48 & $-1,26$ & 1,05 \\
\hline$N$ & 150 & 2,73 & 2,61 & 2,47 & 2.33 & 2,18 & 2.03 & 1.89 & 1.70 & 1,51 & 1,29 & 1,07 \\
\hline$P$ & 200 & 2,73 & 2,62 & 2,47 & 2,33 & 2,18 & 2,04 & 1,89 & 1,70 & 1,51 & 1,29 & 1,07 \\
\hline
\end{tabular}

NOTAS

1 Tados los valores de los NCA se expresan en porcentaje de unidades defectuosas.

2 Las letras código utilizadas en esta norma internacional, corresponden a las que figuran en la norma ISO 2859 f=UNE 66-020 no son idénticas a las utillizadas en el documento MIL STO 414.

3 Símbolos

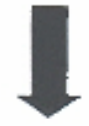

No existe un plan de muestreo comeniente en esta zona; utilicese el primer plan de muestreo que se encuentres guiendo la dirección de la flecha. Se aplica tanto al tamaño de la muestra como a la constante de aceptabil dad $k$.

El pian que figura en esta zona ofrece un alto grado de seguridad, aunque requiere un gran tamaño de muestrí A discreción de la au toridad competente, puede utilizarse el plun que señala la flecha situado más arriba. 


\section{CONTROL ESTADÍSTICO DE LOS CAUDALES MEDIDOS}

\subsection{INTRODUCCIÓN}

En la actualidad, la medición de los caudales inyectados en sectores hidrométricos es aprovechada por numerosas técnicas de gestión y control de redes de distribución de agua. Para ello, es fundamental introducir gradualmente instrumentos de medida de caudal. Estos aparatos se disponen en puntos estratégicos de la red conectados a una estación de control central desde donde se monitorizan sus mediciones de caudal inyectado $\left(Q_{i}\right)$ mediante un sistema de telemedida.

La sectorización de redes posibilita una gestión más eficiente encaminada a mejorar su rendimiento hidráulico. Por una parte, permite llevar a cabo un balance de caudales más fiable que en el caso de una red no sectorizada al tener controlados los flujos de agua, y por otra, limita las presiones evitando que superen ciertos valores en horas de bajo consumo de agua, reduciendo el volumen de agua fugada.

Una vez controladas las direcciones del flujo de agua y las entradas y salidas de caudal es posible gestionar el balance hídrico neto que se produce en ese sector de medición. En terminología anglosajona, estos sectores bien caracterizados hidráulica y geográficamente, se denominan district metering areas (DMA). Su particularidad estriba en que posibilitan un mejor control del caudal fugado en esa zona de la red de distribución de agua.

En consecuencia, la sectorización ayuda mediante el análisis de los caudales circulantes al control activo de fugas. Técnicas de gestión de fugas como el control de los caudales mínimos nocturnos o la monitorización de los caudales inyectados en intervalos cortos de tiempo permiten conocer el estado de la red y priorizar las estrategias de actuación.

Para ello, es fundamental que los instrumentos de medida de estos sectores estén adecuadamente elegidos para la labor que se les encomienda. En particular, como se comenta durante el Capítulo 6, el dimensionado debe ajustarse al rango de caudales que circularán por el aparato, sin sobrepasar el caudal máximo que lo deteriore ni impedir que capte los caudales más bajos que circulan durante la noche. También es importante tener en cuenta los parámetros que influyen sobre su medición cuantificando su error y el sentido de circulación del agua en cada caso. En estos casos, siempre es recomendable instrumentos de medición de doble sentido como los caudalímetros de ultrasonidos o los electromagnéticos, o incluso ciertos contadores Woltman con totalizador electrónico. 
En este capítulo se presenta una técnica estadística nueva en la gestión de redes hidráulicas, el análisis por componentes principales, con el mismo objetivo, controlar de forma activa el nivel de fugas. De forma resumida, este método investiga los caudales inyectados estableciendo márgenes de tolerancia que permitan reducir el tiempo de detección de cualquier tipo de anomalía que se produzca en el sector.

\subsection{ANÁLISIS POR COMPONENTES PRINCIPALES}

Este epígrafe presenta la base teórica de esta técnica estadística, describiendo sus objetivos y la metodología previa que debe seguirse para obtener modelos capaces de predecir situaciones de alarma en la red de distribución. Posteriormente, se comprueba su eficacia aplicando este método a los datos reales aportados de un sector hidrométrico.

\subsubsection{BJETIVOS DEL ANÁLISIS DE COMPONENTES PRINCIPALES (ACP)}

Dada una muestra de observaciones, descritas con un número elevado de variables, el ACP es una técnica para representar dichas observaciones en un espacio de pequeñas dimensiones que facilita la interpretación de las relaciones existentes entre las variables. Comúnmente, los datos de partida se organizan según una matriz constituida por i filas correspondientes a las observaciones, y $k$ columnas correspondientes a las variables, $y$ donde el elemento $Z_{i, k}$ es el valor del parámetro o dato medido de la variable k-ésima en la observación i-ésima.

Debido a que los vínculos entre las variables estudiadas son muy variados, a veces, puede ocurrir que el comportamiento de ciertas variables esté muy relacionado con el de otras, y por tanto se pueda prescindir de algunas de ellas reduciéndose el espacio original de las variables, k-dimensional, a un espacio de menores proporciones donde se encuentre comprendida la información principal de la matriz de datos original.

En concreto, para condensar la información existente en la nube de datos original se hallan A nuevas variables 0 componentes, incorrelacionadas entre sí, definidas como combinación lineal de las variables primitivas. Puesto que la reducción de dimensionalidad implica una pérdida de información, se debe buscar un nuevo espacio A-dimensional que explique con la mayor fidelidad posible la nube de datos original. Precisamente el ACP permite esta reducción de dimensionalidad con la mínima pérdida de información (Figura 1).

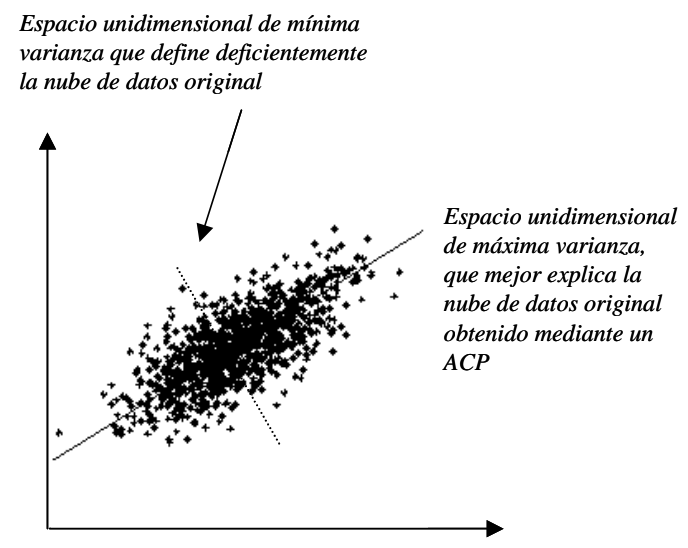

FIGURA 1.ANÁLISIS POR COMPONENTES PRINCIPALES DE UNA NUBE DE DATOS BIDIMENSIONAL. 
Como ejemplo obsérvese la Figura 1, donde se representa una nube de datos en un espacio bidimensional. Realizando un ACP se obtiene un espacio unidimensional donde está contenida, como se aprecia en la figura, la mayor parte de la información relativa a la nube de datos original. Esto es debido a que dicho espacio unidimensional (recta) tiene como dirección la de máxima dispersión de la nube de datos, y por ello, la pérdida de información es mínima. Por el contrario, si la transformación de los datos se produjese a un espacio unidimensional de dirección la de mínima dispersión de los datos, la pérdida de información sería máxima.

En consecuencia, el objetivo principal de este método de análisis multivariante consiste en hallar un subespacio de variables, de dimensiones reducidas, que conserve el máximo de información de la nube de datos de partida. Este espacio debe ser capaz de dejar entrever aquellos datos que tengan una pauta de comportamiento diferente al resto de observaciones.

Al mismo tiempo, el ACP modeliza el comportamiento de dichas variables observadas, indicando aquellos parámetros de especial interés debido a su notoria influencia en el proceso y aquellas observaciones cuyo comportamiento es diferente al previsto. Además, aprovechando el modelo generado se evalúan los resultados de futuras mediciones y se investiga si estas se comportan de acuerdo a las pautas propuestas 0 , por el contrario, constituyen lo que se denominan casos anómalos 0 en terminología sajona outliers.

Las anomalías detectadas por el modelo pueden aportar información suficiente como para determinar qué variables 0 parámetros son los causantes de dichas desviaciones, lo que es de inestimable ayuda a la hora de corregir fallos en el proceso.

\subsubsection{GENERALIDADES SOBRE LA METODOLOGÍA DEL ANÁLISIS}

Los métodos multivariantes surgen como una alternativa para resolver los problemas que presentan los métodos estadísticos clásicos. Estas técnicas solucionan dificultades como la alta dimensionalidad de la matriz de datos, la colinealidad entre variables 0 incluso son útiles en casos donde se manejan datos faltantes. Además, las técnicas estadísticas clásicas asumen frecuentemente normalidad en los datos de partida, hecho que limita las posibilidades de análisis. En cambio, las técnicas de proyección explotan datos que no necesariamente siguen distribuciones normales.

La metodología que se debe seguir en el ACP tiene diferentes fases. En primer lugar y antes de iniciar el estudio, es importante elegir una matriz de datos apropiada para ser analizada. Estas matrices generalmente son del tipo individuosvariables, y en ellas las variables y los individuos constituyen grupos homogéneos.

La primera fase comprende el pretratamiento de los datos donde se transforma la matriz de datos original $\overline{\bar{Z}}$ mediante técnicas de escalado y estandarizado de variables, en una nueva matriz $\overline{\bar{X}}$ donde las variables tienen media nula y varianza la unidad. La justificación a este pretratamiento se encuentra en que los métodos de proyección o multivariantes, son muy sensibles a las unidades de medida y a los rangos con los que se trabaja. Una correcta realización de esta fase puede marcar la diferencia entre un buen análisis donde se extraigan conclusiones fiables y un análisis incorrecto que conduzca a resultados erróneos.

Tras la fase de pretratamiento comienza el propio análisis donde se condensa la información contenida en las k-variables primitivas a un número reducido de $\mathrm{A}$ nuevas variables o componentes principales, no observables e incorrelacionadas entre sí, consideradas como las más relevantes del proceso.

Las nuevas variables o componentes principales son combinaciones lineales de las primitivas, y se calculan como el producto de unos coeficientes (pesos) por las variables primitivas combinadas de forma aditiva para formar lo que se han 
denominado como componentes principales. Estas combinaciones lineales constituyen un modelo que integra la información esencial extraída de los datos originales separándola del resto, que podría considerarse como ruido.

Por tanto, el ACP descompone la matriz de datos original pretratada $\overline{\bar{x}}$ en un producto de dos matrices de menores dimensiones, una formada por los "scores" $\overline{\bar{T}}$ o proyecciones de cada observación sobre el espacio de las nuevas componentes principales, y otra por los "loadings" $\overline{\bar{P}}$ que corresponde a la matriz de pesos o direcciones principales del nuevo espacio (Figura 2). La pérdida de información que supone dicha transformación se refleja en la matriz de residuos $\overline{\bar{E}}$.

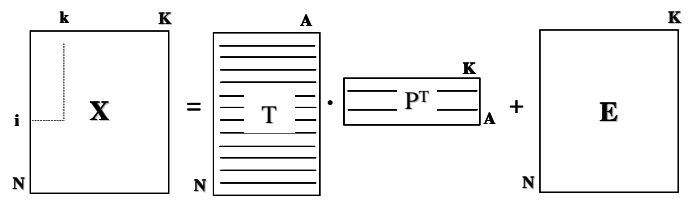

FIGURA 2.MATRIZ DE DATOS ORIGINAL DESCOMPUESTA.

En el ejemplo de la Figura 3, se resume la metodología a seguir en un ACP. Como se ha explicado en párrafos anteriores, la nube de puntos del espacio original se centra y escala para poder ser analizada correctamente. Después del pretratamiento de los datos, comienza el estudio propiamente dicho, con la búsqueda de aquellas direcciones que maximizan la inercia del conjunto de puntos.

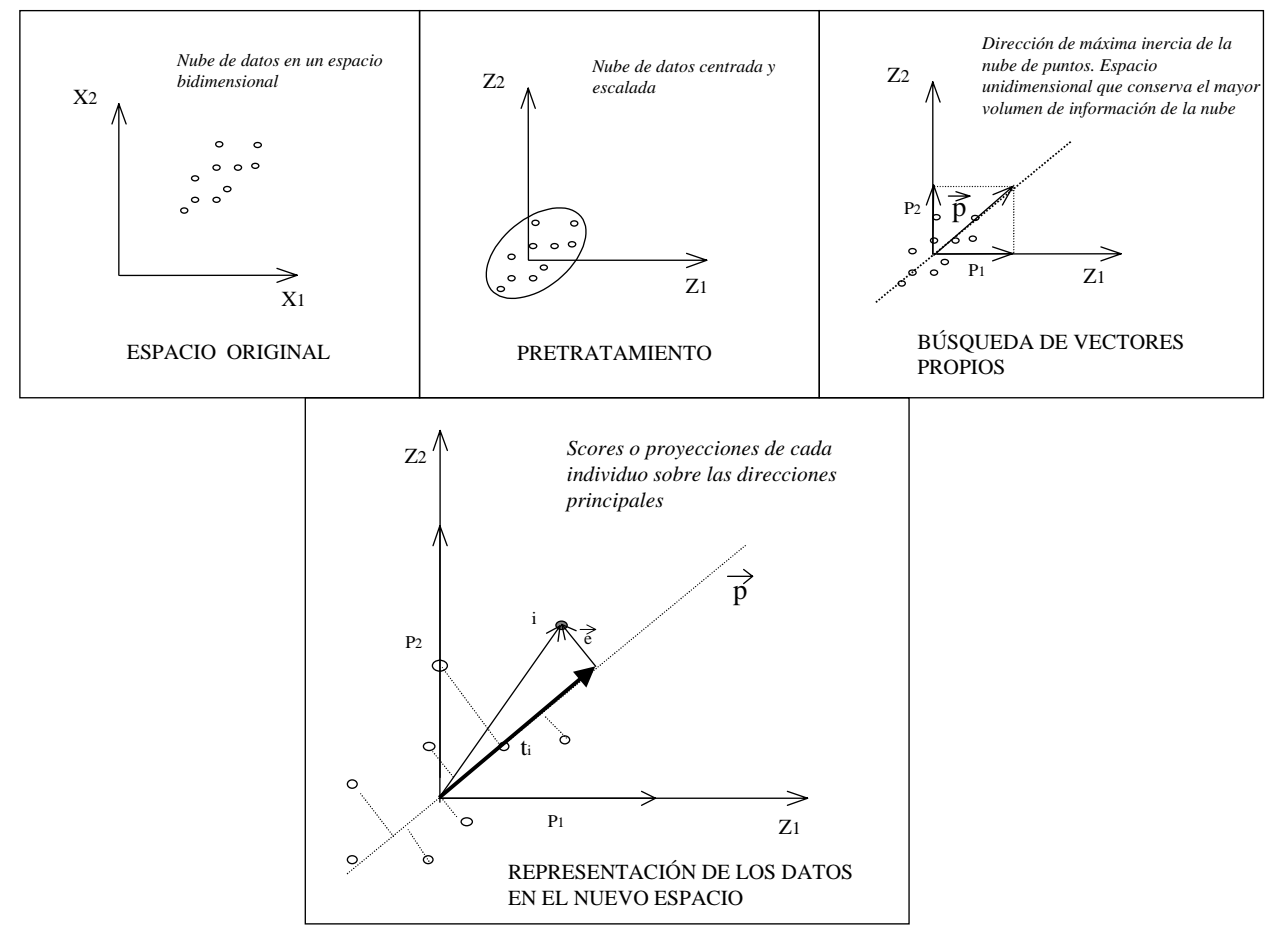

FIGURA 3.RESUMEN DE LA METODOLOGIA DEL ANÁLISIS DE COMPONENTES PRINCIPALES.

La primera dirección principal, es aquella de mayor inercia o varianza de la nube de puntos de datos originales y, en consecuencia, la que explica en mayor grado la variabilidad de las observaciones. La segunda dirección principal $p_{2}$, será ortogonal a la primera $p_{1}$, haciéndose de esta forma independiente de ella. Esta componente, a su vez es la que maximiza la variabilidad residual de la nube de puntos una vez extraída la parte de variabilidad explicada por la primera componente. 
Una vez halladas estas direcciones, se proyectan sobre ellas las observaciones. De esta forma se descompone cada individuo en la suma de dos vectores, uno correspondiente a la proyección sobre cada dirección principal y otro al vector residuo (Figura 4). Esta aproximación es característica para cada observación, y la diferencia formada por la observación real en el espacio original y la estimada en el nuevo espacio, es lo que se denomina residuo $\vec{e}$ que muestra el grado de aproximación al modelo obtenido.

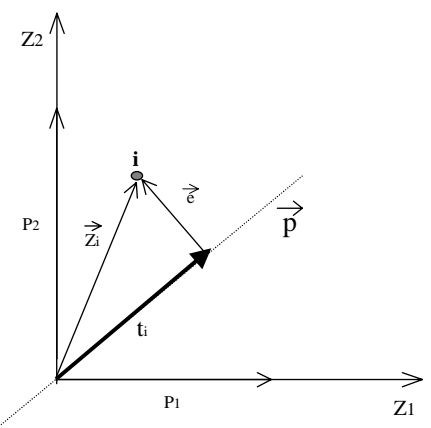

FIGURA 4.DESCOMPOSICIÓN VECTORIAL DE UNA OBSERVACIÓN EN EL NUEVO ESPACIO DE LAS COMPONENTES PRINCIPALES.

Un problema habitual que se presenta en este análisis es la selección del número de componentes principales a retener. La excesiva reducción del espacio de variables puede ocasionar una importante pérdida de información.

Es importante lograr un alto grado de ajuste sin perder fiabilidad, es decir el número de componentes principales extraídas de la nube de puntos debe ser el adecuado para definir oportunamente el comportamiento de las variables, pero a su vez, debe alcanzar el fundamento del análisis que es la reducción del espacio original para facilitar la interpretación de los datos.

\subsubsection{DEFINICIÓN MATEMÁTICA DE ACP}

\subsubsection{Definición de la matriz de datos}

El punto de partida del análisis de componentes principales es la matriz de datos compuesta, como ya se ha comentado, por $\mathrm{N}$ observaciones 0 individuos y $\mathrm{K}$ variables, que generalmente corresponden a los diferentes parámetros medidos a dichas observaciones.

Existen múltiples ejemplos de matrices de datos individuos - variables, como los resultados de diversos análisis clínicos en individuos sanos o que padezcan cierta enfermedad, variables físicas medidas a lo largo de un día en una cadena de producción, respuestas de i individuos a las j cuestiones de una encuesta, los caudales inyectados en diferentes puntos de la red de distribución de agua a lo largo del tiempo, etc.

Las variables que pueden ser utilizadas en este tipo de análisis son de diversa naturaleza. En función de los valores que pueden adoptar, las variables se clasifican en los siguientes tipos (Terriel y Daniel, 1994): 
- Variable continua. Es una variable cuantitativa que por su naturaleza puede adoptar cualquier valor numérico. Todo par de valores tiene uno intermedio que está solo limitado por la precisión del aparato de medida.

- Variable discreta. Es una variable cuantitativa o cualitativa que solo adopta un número finito de valores distintos. En este tipo de variables, entre dos valores distintos consecutivos no existen valores intermedios.

- Variable dicotómica o binaria. Es aquella que solamente toma dos valores. Cuando estos se etiquetan como 0 y 1 se le denomina binaria.

- Variables ficticias (dummy), son variables cualitativas categóricas que convierten sus diferentes niveles en números, para facilitar el análisis estadístico. Para convertir una variable cualitativa en dummy se necesitan tantas variables como niveles de la variable categórica menos 1.

Como ya se ha comentado, el ACP es una herramienta sensible a las escalas de medida de cada una de las variables, por ello se debe comenzar con un pretratamiento de la matriz de datos original.

\subsubsection{Pretratamiento de datos}

Cuando se realizan operaciones con números, ya sea el análisis estadístico uni, bi o multivariante, el resultado del mismo está directamente ligado a las unidades de medida con las que se trabaja. Este hecho condiciona cualquier técnica estadística que se aplique.

Frecuentemente el principio de los problemas en este tipo de análisis reside en que los parámetros de la matriz de datos original provienen de variables muy heterogéneas con rangos de medida extremadamente diferentes. Por ejemplo, cuando se trabaja con presiones y caudales en una red de agua los rangos numéricos de estas variables son totalmente diferentes. A la hora de calcular las componentes principales surgen problemas, ya que un rango numérico más elevado automáticamente tendrá mayor dispersión de datos $\mathrm{y}$, como se ha comentado, la dirección de la componente principal depende precisamente de esta dispersión.

Para solucionar este inconveniente, se debe transformar la matriz de datos previamente al análisis. Las transformaciones más usuales son, el centrado de datos, donde se sustrae a las observaciones la media de cada variable, y el estandarizado, donde se multiplica por el inverso de la desviación típica. La realización de ambas transformaciones simultáneamente se denomina tipificación (Figura 5). La tipificación de las variables originales $X_{1}, X_{2}, \ldots X_{k}$ es casi obligatoria si se quiere trabajar simultáneamente con muchas variables medidas en distintas unidades y con rangos desiguales. Dicha transformación proporciona un conjunto de observaciones, compuestas cada una por k-variables, en el que la media de las mismas es cero y la varianza 1.

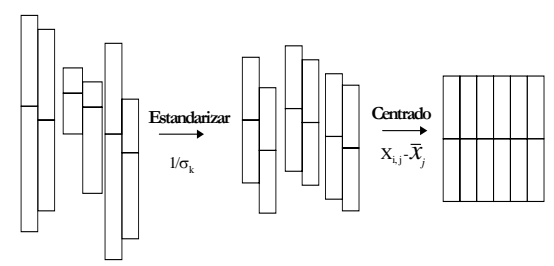

FIGURA 5.PRETRATAMIENTO DE LOS DATOS DE LA MATRIZ ORIGINAL (TIPIFICADO).LOS DATOS ORIGINALES TIPIFICADOS CON MEDIA O Y VARIANZA 1. 


\subsubsection{Cálculo de las componentes principales}

El empleo de componentes principales no presupone ningún modelo matemático subyacente. Es sólo una técnica fundamentalmente descriptiva, que obtiene una representación de menor dimensionalidad en un conjunto de puntos 0 datos.

El método selecciona un subespacio $R^{A}$, cuyos ejes vienen dados por las direcciones principales $\vec{p}_{1}, \vec{p}_{2} \ldots \vec{p}_{A}$. Estos ejes son ortogonales entre sí e indican las direcciones de mayor dispersión de datos medidos. Las componentes principales se obtienen calculando los vectores propios de la matriz de varianzas/covarianzas de $\overline{\bar{Z}}$ (matriz de datos transformada).

Para ello, suele ser necesario utilizar un procedimiento de maximización matemática, que suele requerir el uso de algún algoritmo específico de ordenador como el algoritmo NIPALS (Wold, 1966) o la Descomposición en valores singulares (SVD) (ver Anexo I).

La matriz de varianzas/covarianzas $\overline{\bar{V}}$ tiene como elementos en la diagonal principal las varianzas de cada una de las variables y como elementos externos a ella, las covarianzas entre las variables. Recordando la estadística básica, las varianzas son las sumas de cuadrados promediadas para todos los sujetos mientras que las covarianzas son las sumas de productos cruzados también promediadas.

Así, estos estadísticos se calculan mediante las siguientes expresiones:

$$
\begin{aligned}
& \sigma_{X}^{2}=\frac{1}{n-1} \sum_{i=1}^{n}\left(X_{i j}-\overline{X_{j}}\right)^{2} \\
& \sigma_{j k}^{2}=\operatorname{cov}\left(X_{j}, X_{k}\right)=\frac{1}{n-1} \sum_{i=1}^{n}\left(X_{i j}-\overline{X_{j}}\right)\left(X_{i k}-\overline{X_{k}}\right)
\end{aligned}
$$

siendo i los individuos y, j y $\mathrm{k}$ las variables de la matriz de datos original

Por lo tanto, la estructura de esta matriz $\overline{\bar{V}}$, de naturaleza simétrica y cuadrada será la siguiente:

$$
\overline{\bar{V}}=\left[\begin{array}{cccc}
\sigma_{11}^{2} & \sigma^{2}{ }_{21} & \cdot & \sigma^{2}{ }_{n 1} \\
\cdot & \sigma^{2}{ }_{22} & \cdot & \cdot \\
\cdot & \cdot & \sigma^{2}{ }_{33} & \cdot \\
\sigma_{1 n}^{2} & \sigma^{2}{ }_{2 n} & \cdot & \sigma^{2}{ }_{n n}
\end{array}\right]
$$

Esta matriz de varianzas/covarianzas $\overline{\bar{V}}$ mide la relación entre las variables, y sus vectores propios son los pesos o loadings $\vec{p}_{1}, \vec{p}_{2} \ldots \vec{p}_{A}$, que señalan las direcciones del nuevo espacio. 
Por tanto, y reincidiendo en el fundamento de esta técnica, el modelo de ACP viene definido analíticamente por los siguientes términos (Wold, 1987):

$$
\overline{\overline{\mathbf{X}}}_{(\mathrm{N}, \mathrm{K})}=\overline{\overline{\mathbf{X}}}_{(\mathrm{N}, \mathrm{K})}-\overline{\overline{\mathrm{E}}}_{(\mathrm{N}, \mathrm{K})}=\overline{\overline{\mathbf{T}}}_{(\mathrm{N}, \mathrm{A})} \cdot \overline{\overline{\mathrm{P}}}_{(\mathrm{A}, \mathrm{K})}^{T}+\overline{\overline{\mathrm{E}}}_{(\mathrm{N}, \mathrm{K})}
$$

$\overline{\overline{x^{\prime}}}$ :matriz de datos estimada

$\overline{\bar{E}}$ : matriz de residuos

$\overline{\bar{P}}$ : matriz de pesos

$\overline{\bar{T}}$ :matriz de proyecciones sobre cada dirección principal.

Así pues, para el cálculo del nuevo espacio de componentes principales se obtienen los vectores propios de la matriz $\overline{\bar{V}}$ y sus valores propios $\lambda_{1}, \lambda_{2}, \ldots, \lambda_{\mathrm{A}}$. mediante el algoritmo NIPALS (Wold ,1966).

El número de valores propios distintos de cero es igual al rango de la matriz de datos. Los valores propios obtenidos verifican $\lambda_{1}>\lambda_{2}>\ldots>\lambda_{A}$, el primer valor propio corresponde al vector propio que explica la máxima varianza. El segundo valor propio corresponde a la segunda dirección principal que es ortogonal a la primera, y a su vez, maximiza la varianza de los datos en el hiperplano perpendicular a la dirección del primer vector propio (Figura 6).

$$
\operatorname{var}\left(t_{A}\right)=\lambda_{A}
$$

Los valores propios correspondientes a dichos vectores propios indican la variabilidad extraída de dicha dirección:

$$
\begin{aligned}
& \overline{\bar{V}} \cdot \overrightarrow{p_{1}}=\lambda_{1} \cdot \overrightarrow{p_{1}} \\
& \overline{\bar{V}} \cdot \overrightarrow{p_{2}}=\lambda_{2} \cdot \overrightarrow{p_{2}}
\end{aligned}
$$

Los pesos correspondientes a los menores valores propios están compuestos únicamente por errores, por ello conviene simplificar la matriz de datos en otra de variables latentes que sinteticen la información esencial, eliminando el ruido aleatorio que dificulta el análisis.
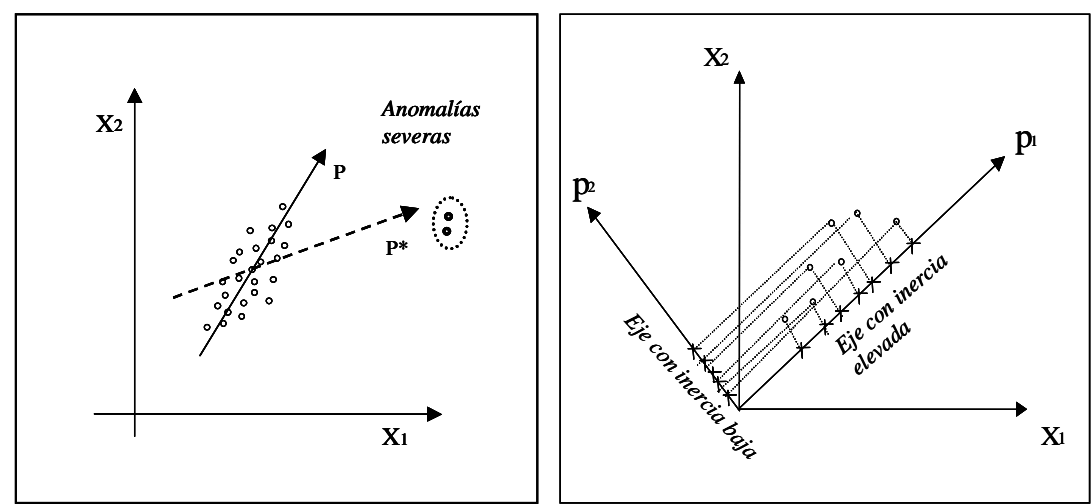

$\lambda_{1}>\lambda_{2}$ PARA DOS COMPONENTES PRINCIPALES P $=2$

FIGURA 6.COMPONENTES PRINCIPALES EN EL ESPACIO ORIGINAL, ELIPSE CENTRADA EN DATOS ORIGINALES. LAS COMPONENTES SIGUEN LAS DIRECCIONES DE MÁXIMA VARIANZA O INERCIA DE LOS DATOS. 
Mediante los algoritmos de cálculo descritos en el Anexo I se extraen de forma sencilla A componentes principales hasta que la aproximación a los datos originales se considere suficiente, reduciéndose el hiperplano K-dimensional, formado por todas las variables consideradas en el caso estudiado, a un espacio de A-dimensional definido por las correspondientes direcciones principales.

Para reconstruir perfectamente la matriz inicial se debe realizar el producto escalar con $\mathrm{K}$ variables, mientras si solo se calcula para A componentes principales se tiene una reconstrucción parcial próxima a la matriz original, una matriz estimada $Z^{\prime}$.

$$
\overline{\bar{Z}}=\overrightarrow{t_{1}} \cdot \overrightarrow{p_{1}}+\overrightarrow{t_{2}} \cdot \overrightarrow{p_{2}}+\ldots+\overrightarrow{t_{A}} \cdot \vec{p}_{A}+\overrightarrow{t_{A+1}} \cdot \vec{p}_{A+1}+\ldots+\overrightarrow{t_{k}} \cdot \overrightarrow{p_{k}}
$$

La diferencia entre la matriz de datos original y la estimada constituye una matriz de residuos $\mathrm{E}$, que representa la parte de variabilidad no explicada por el modelo de ACP.

Esta matriz de residuos es importante a la hora de evaluar el comportamiento de cada uno de los individuos, ya que cuando el residuo es pequeño, el individuo se ajusta bien a la nube de puntos proyectados en el subespacio, es decir, su distancia euclídea al modelo es pequeña.

De esta forma evaluando el módulo $\overrightarrow{e_{i}}$ (Figura 7), conocemos la distancia entre cada individuo i y su proyección en el espacio de las componentes.

$$
\left\|\overrightarrow{e_{i}}\right\|={\overrightarrow{e_{i 1}}}^{2}+{\overrightarrow{e_{i 2}}}^{2}+{\overrightarrow{e_{i 3}}}^{2}
$$

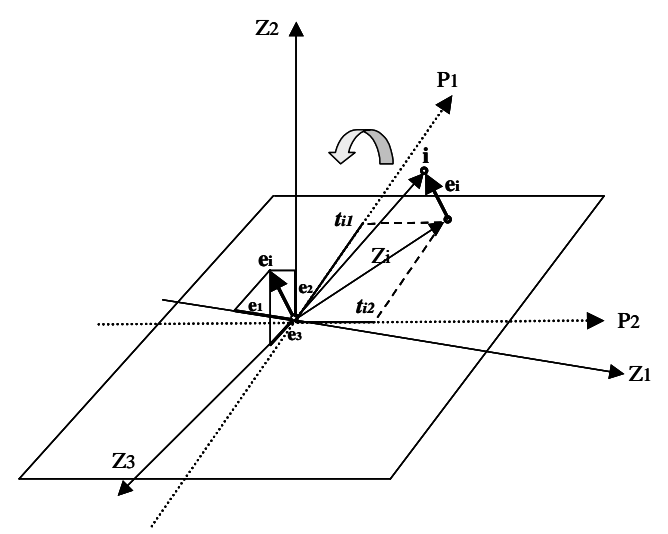

FIGURA 7.DISTANCIA AL MODELO CONSIDERANDO LA MATRIZ DE DATOS CENTRADA Y ESCALADA

De forma inversa, se puede construir la matriz de proyecciones ${ }^{\overline{\bar{T}}_{N, A}}$, cuyas A columnas corresponden a las componentes principales o nuevas variables (Ecuación 10). En cada dirección $\overrightarrow{p_{A}}$ las proyecciones $t$ de las $n$ observaciones, al ser combinaciones lineales del las $\mathrm{k}$-variables originales, puede asumirse que siguen una distribución normal de media cero y varianza $\lambda_{\mathrm{A}}$. 


$$
\begin{gathered}
\overline{\bar{T}}_{N, A}=\overline{\bar{X}}_{N, K} \cdot \overline{\bar{P}}_{K, A} \\
\overline{\bar{X}}_{N, K}=\overline{\bar{T}}_{N, A} \cdot \overline{\bar{P}}_{A, K}^{T}+\overline{\bar{E}}_{N, K}
\end{gathered}
$$

Estas nuevas variables son combinaciones lineales de las primitivas:

$$
t_{i, a}=\sum_{k=1}^{k} x_{i, k} \cdot p_{k, a}
$$

$1^{\text {a Componente principal }} t_{i, 1}=X_{i, 1} \cdot p_{1,1}+X_{i, 2} \cdot p_{2,1}+X_{i, 3} \cdot p_{3,1}+\ldots+X_{i, K} \cdot p_{K, 1}$

$2^{\text {a Componente principal }} t_{i, 2}=X_{i, 1} \cdot p_{1,2}+X_{i, 2} \cdot p_{2,2}+X_{i, 3} \cdot p_{3,2}+\ldots+X_{i, K} \cdot p_{K, 2}$

i: Individuo número i

A: Número de componentes principales

K: Número de variables originales

$\mathrm{N}$ : Número de observaciones

Tras el cálculo de las proyecciones de las observaciones en el espacio de las componentes principales, se debe tener en cuenta que estas satisfacen una serie de propiedades que corrigen las restricciones de los métodos tradicionales, mejorando la interpretación de semejante cantidad de datos.

Las propiedades más importantes son:

- La media de cada componente $t_{a}$ es nula, ya que la matriz de datos originales está centrada.

- Las componentes principales $t_{a}$ están incorrelacionadas, es decir corr $\left(t_{a}, t^{\cdot}\right)=0$ con $a \neq a^{\prime}$.

Las componentes principales están ordenadas en orden decreciente de importancia, con respecto a la varianza. Además se cumple que:

$$
\begin{gathered}
\operatorname{var}\left(t_{A}\right)=\lambda_{A} \\
\text { varianza total (tk) }=\sum_{k=1}^{k} \operatorname{var}\left(t_{k}\right)=\sum_{l=1}^{k} \lambda_{l}
\end{gathered}
$$

y por tanto el porcentaje de la varianza explicada por cada componente tA se calcula mediante la expresión15:

$$
\frac{\lambda_{A}}{\sum_{l=1}^{k} \lambda_{l}} \cdot 100 \%
$$

\subsubsection{Diagnóstico del modelo}

El propósito del análisis es hallar un modelo que explique correctamente el comportamiento de los datos medidos, para ello, es esencial encontrar un número apropiado de A componentes principales. 
Existen diferentes técnicas como apunta Malinowski (1987) para determinar el número de componentes principales y diagnosticar la calidad del modelo obtenido. Una de ellas es la validación cruzada o cross- validation en terminología sajona, desarrollada por el sueco Wold. en 1978, que evalúa la calidad de predicción del modelo de ACP.

Este método consiste en eliminar cierto grupo de observaciones de la matriz de datos $\overline{\bar{Z}}$, reajustar el modelo con las observaciones restantes y predecir el comportamiento de las primeras comparándolas con las observaciones originales separadas. Este procedimiento se repite varias veces, separando en cada ocasión diferentes grupos de observaciones hasta que cada una haya sido aislada una vez.

La evaluación de estas observaciones se realiza con diferentes estimadores del error de predicción, como el PRESS o suma de cuadrados de los errores de predicción, que mide la capacidad de predicción del modelo y se calcula mediante la fórmula siguiente:

$$
\text { PRESS }=\sum_{i} \sum_{k}\left(X_{i k}-\hat{X}_{i k}\right)^{2}
$$

$\hat{X}_{i k}$ : valor predicho de la variable k para la observación i con el modelo ajustado sin dicha observación

$X_{i k}$ : valor original de la variable k en la observación i..

En el ACP la técnica de validación cruzada se realiza comenzando con un número de componentes nulo $(A=0)$. Cada vez, se añade una nueva componente al modelo, es decir, se aumenta la dimensionalidad de su espacio y se obtiene un nuevo valor de PRESS.

Este valor es comparado con la suma de cuadrados residual (SCR) en una dimensión menor, es decir, el sumatorio de los residuos que se mantiene tras la construcción del modelo con A-1 componentes.

$$
S C R=\sum_{k=1}^{k} S C R_{k}
$$

*de la matriz residual E con un modelo de ACP con A-1 componentes.

Cuando el parámetro PRESS es significativamente mayor que dicha SCR, la última componente añadida es despreciable y se considera que el modelo generado explica ampliamente el comportamiento de los datos.

Esta técnica se simplifica en la tabla que a continuación se presenta:

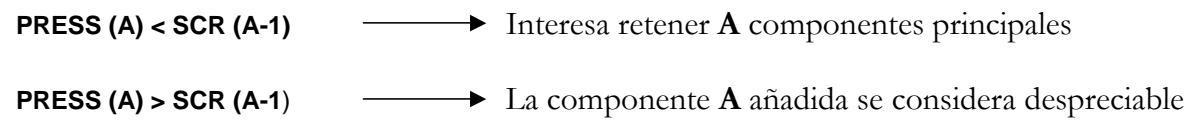


Otro parámetro intrínsecamente vinculado con los anteriores es Q2 o bondad de predicción, que mide el poder de predicción del modelo ACP con $\mathrm{A}$ componentes principales, es decir la fracción del total de variación de $\mathrm{X}$ que puede ser predicha con A componentes. Ambos estimadores están relacionados entre sí mediante la Ecuación 18.

Bondad de predicción de la componente a-ésima:

$$
Q^{2}(a)=1-\operatorname{PRESS}(a) / \operatorname{SCR}(a-1)
$$

La bondad de predicción acumulada para todo el modelo con A componentes, considera la suma de cuadrados de los errores de predicción en la validación cruzada.

Bondad de predicción del modelo acumulada:

$$
Q^{2}(\text { cum })=1-P R E S S ~ / S C T
$$

Otra medida cuantitativa es el parámetro $\mathrm{R}^{2} \mathrm{o}$ bondad del ajuste del modelo de ACP con A componentes principales. Éste es indicativo de la variabilidad que explica cada una de las componentes individualmente y de forma acumulada $R^{2}(\mathrm{cum})$. La variación de $\mathrm{X}$ explicada por la componente A se obtiene con la siguiente expresión.

Bondad de ajuste de la componente a-ésima:

$$
R^{2}(a)=1-\operatorname{SCR}(a) / \operatorname{SCR}(a-1)
$$

Bondad de ajuste del modelo acumulada:

$$
R^{2}(\text { cum })=1-S C R / S C T
$$

De esta manera, cuando el grado de ajuste es suficientemente bueno y, además, agregar una componente nueva al modelo no supone un incremento cuantioso en la resolución del mismo, puede significar que se ha llegado a un número de componentes suficiente que explican convenientemente el comportamiento de los datos.

En la Figura 8 se puede observar que el parámetro $R^{2}$ muestra una curva creciente, es decir, a medida que aumenta el número de componentes el modelo se ajusta más a los datos originales. Esto es lógico, ya que el fundamento de este tipo de análisis es la reducción de la dimensionalidad, y cuando el número de componentes se aproxima al número de variables del espacio original el acercamiento al hiperplano original va siendo cada vez mejor. Por el contrario, el parámetro Q2 presenta un máximo a partir del cual, la bondad de predicción comienza a decrecer a medida que aumenta el número de componentes, indicando problemas de sobreajuste del modelo.

La combinación de ambos parámetros sirve para conocer el momento, en el cual, extraer otra componente no aportará información adicional y, por el contrario, la predicción de nuevas observaciones empeorará. 


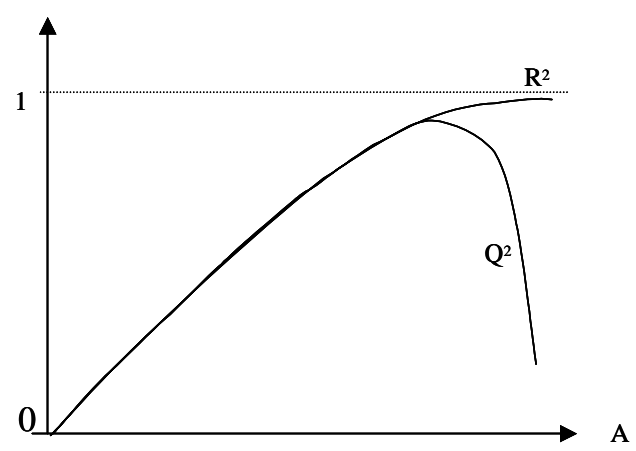

FIGURA 8.CURVAS R2 Y Q2.ESTAS MARCAN LA COMBINACIÓN ÓPTIMA ENTRE LA BONDAD DE LA PREDICCIÓN Y LA DE AJUSTE A MEDIDA QUE SE AUMENTA EL NÚMERO DE COMPONENTES PRINCIPALES.

\subsubsection{Validación del modelo}

Uno de los objetivos más importantes de los modelos ACP es detectar nuevos individuos u observaciones que tengan características similares a las del modelo, o por el contrario, individuos anómalos que tengan un comportamiento diferente. También, es fundamental establecer las condiciones ideales de un determinado proceso con el objetivo de modelizarlo correctamente.

La validación del modelo forma parte de las etapas del análisis de componentes principales. En ella, se deben buscar aquellos individuos que puedan perturbar de alguna forma las direcciones principales que definen el modelo.

Es interesante realizar una clasificación entre los tipos de anomalías o outliers que se pueden encontrar cuando se trabaja con esta técnica de análisis de componentes principales. Estos tipos se agrupan, en el presente trabajo, en función de la influencia que ejercen estas observaciones sobre el modelo, en moderadas y severas y moderadas.

Anomalías moderadas son aquellas observaciones cuya distancia euclidea al modelo (DMOD) es elevada, es decir, evaluando el módulo de los residuos se observa que la separación entre dichos individuos i y el espacio de las componentes es notable (Figura 9).

$$
\mathrm{DMOD}=\left\|\overrightarrow{e_{i}}\right\|=e_{i, 1}{ }^{2}+e_{i, 2}{ }^{2}+\ldots+e_{i, k}{ }^{2}=\sum_{k} e_{i k}{ }^{2} / g . l
$$

\section{g. I : Grados de libertad K-A}

Esta expresión es equivalente a SCR i o suma cuadrados residual de i.

La distancia al modelo absoluta de una observación viene definida por la siguiente expresión:

$$
S_{i}=\sqrt{\frac{\sum_{K=1}^{K} e_{i k}^{2}}{(K-A)}}
$$


$v$ : Factor de corrección cercano a 1 , que es función de las observaciones y del número de componentes.

$\mathrm{K}$ : Número de variables

A: Número de componentes

eik: Residuos del individuo i sobre la variable $k$.

El factor de corrección ajusta la distancia al modelo, que se ve de alguna forma reducida, debido a la influencia que ejerce dicha observación sobre el modelo.

Cuando el residuo es pequeño, el individuo se ajusta bien a la nube de datos proyectada sobre el subespacio de las componentes y su distancia al modelo es menor.

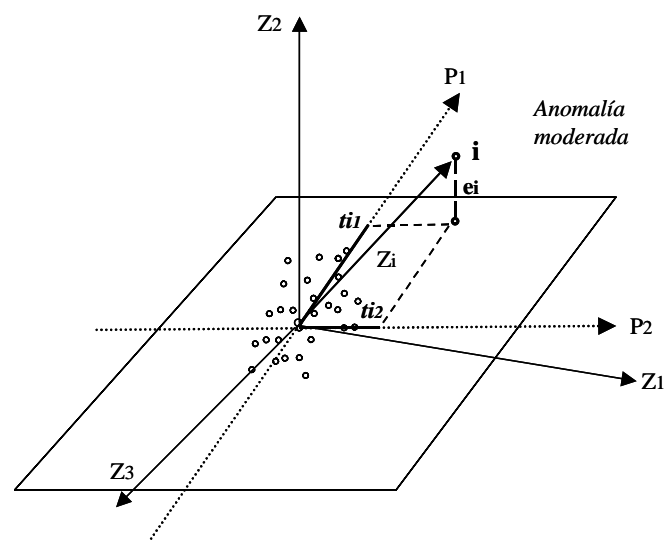

FIgURA 9. ANOMALÍA MODERADA. DISTANCIA AL MODELO FORMADO POR DOS COMPONENTES PRINCIPALES ELEVADA

La distancia normalizada del modelo de una observación es la siguiente:

$$
S_{o}=\sqrt{\frac{\sum_{i=1}^{n} \sum_{K=1}^{K} e_{i K}{ }^{2}}{\left(N-A-A_{0}\right) \cdot(K-A)}}
$$

$A_{0}: 1$ si el modelo esta centrado, 0 si no lo está.

El cociente al cuadrado entre la distancia absoluta y la normalizada $\left(\mathrm{Si} / \mathrm{S}_{0}\right)^{2}$, se aproxima a una distribución $\mathrm{F}$ de Snedecor con K-A, N-A grados de libertad (Figura 10). Por ello, la probabilidad de pertenencia al modelo de una observación se puede evaluar considerando esta función de distribución. 


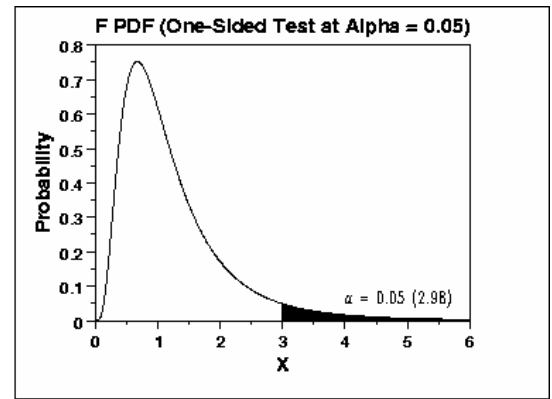

FIGURA 10. DISTANCIA AL MODELO (SI/SO)2 F(A, N-A)(A)

Anomalías severas son aquellos individuos que pueden generar una nueva dirección ficticia en el modelo. Al proyectarlos, la distancia al mismo puede llegar a ser muy pequeña, pero su distancia al centro de gravedad de la nube es elevada. Además, estas anomalías generan que la varianza sea máxima al estar emplazadas dentro de esa dirección lo que origina dicha falsa dirección.

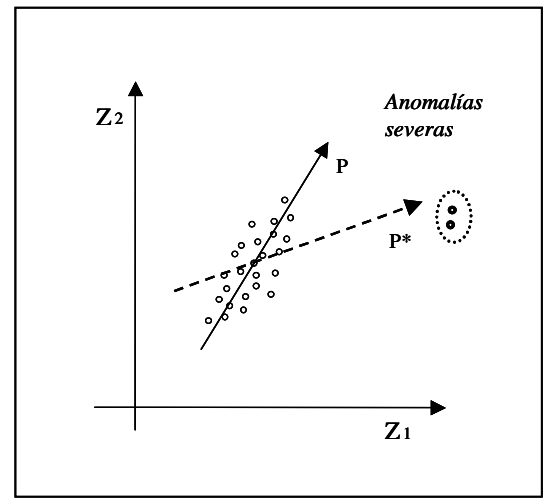

FIGURA 11.ANOMALÍA SEVERA.

Sirva como ejemplo el caso de la Figura 11, donde las observaciones señaladas fuerzan a la dirección principal a pasar por ellas, ya que la variación en esta dirección es máxima. Esto falsea el modelo, debido a la gran influencia que estos individuos ejercen sobre las direcciones principales. La información en dicha dirección, considerada como válida, será escasa e incluso errónea.

Este tipo de anomalías se pueden detectar mediante lo que se denomina distancia de Mahalanobis, definida como la distancia entre un punto y el centro de gravedad de una nube de datos medida en desviaciones típicas. De esta forma se tiene en cuenta la forma de la nube, determinada por las varianzas y covarianzas entre las variables, y por ello, aquellos individuos cuya distancia al centro de gravedad, expresada en términos de desviaciones típicas, sea excesiva serán considerados como anomalías severas.

$$
D^{2} \text { Mahalanobis }=\left(\vec{X}_{i}-\vec{m}\right)^{T} \cdot\left[\begin{array}{cc}
\sigma_{1}^{2} & \sigma_{12}{ }^{2} \\
\sigma_{12}{ }^{2} & \sigma_{2}^{2}
\end{array}\right]^{-1} \cdot\left(\vec{X}_{i}-\vec{m}\right)=\left(\vec{X}_{i}-\vec{m}\right)^{T} \cdot \bar{V}^{-1} \cdot\left(\vec{X}_{i}-\vec{m}\right)
$$




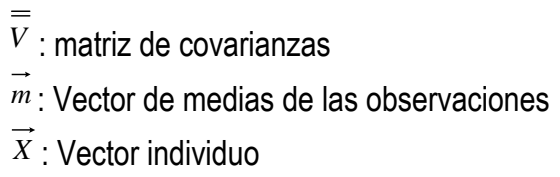

Un ejemplo característico de este tipo de observaciones se contempla en la Figura 12, donde la distancia euclidea de los puntos $\mathrm{A}$ y $\mathrm{B}$ es la misma. En cambio, debido a la mayor dispersión en la dirección A, la distancia de Mahalanobis indica que dicho punto $A$ se encuentra más cercano a la nube que el $B$, y por tanto, se asemeja más al resto de observaciones.

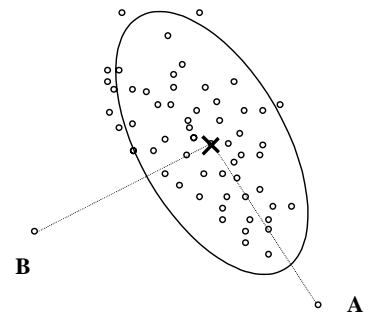

FIGURA 12.DISTANCIA DE MAHALANOBIS MEDIDA DESDE LOS PUNTOS A Y B AL CENTRO DE GRAVEDAD DE LA NUBE.

Otra forma de evaluar los individuos que salen fuera de la región de confianza del modelo es mediante la $\mathrm{T}^{2}$ de Hotelling (Jackson, 1991). La $\mathrm{T}^{2}$ de Hotelling es una medida similar a la distancia de Mahalanobis donde los individuos examinados han sido proyectados sobre las direcciones principales del modelo. Es decir, en lugar de evaluar los datos originales se examinan los "scores t" de la nube proyectada.

$$
\begin{aligned}
& T^{2}{ }_{i}=\sum_{a=1}^{A} \frac{t_{i A}{ }^{2}}{S_{t A}{ }^{2}}=\left[\begin{array}{c}
t_{i, 1} \\
t_{i, 2} \\
\vdots \\
t_{i, A}
\end{array}\right] \cdot\left[\begin{array}{ccc}
\frac{1}{s_{t 1}{ }^{2}} & 0 & 0 \\
0 & \frac{1}{s_{t 2}{ }^{2}} & 0 \\
& & \ddots \\
0 & 0 & \frac{1}{s_{\mathrm{tA}}{ }^{2}}
\end{array}\right] \cdot\left[t_{i, 1,} t_{i, 2, \ldots} t_{i, A}\right]=\vec{t}_{i}{ }^{T} \cdot\left[\begin{array}{ccc}
\frac{1}{s_{t 1}{ }^{2}} & 0 & 0 \\
0 & \frac{1}{s_{t 2}{ }^{2}} & 0 \\
& & \ddots \\
0 & 0 & \frac{1}{s_{\mathrm{tA}}{ }^{2}}
\end{array}\right] \cdot \vec{t}_{i}=\vec{t}_{i}^{T} \cdot \overline{\bar{S}}_{t}{ }^{-1} \cdot \vec{t}_{i} \\
& \vec{t}_{i} \text { : "scores" o proyecciones sobre las direcciones principales de la observación i } \\
& \overline{\overline{S_{t}}} \text { : matriz de varianzas de } t
\end{aligned}
$$

La T2 de Hotelling se distribuye con una $\mathrm{F}$ de Snedecor de A, N-A grados de libertad, lo que permite evaluar si un individuo se encuentra dentro de los límites de confianza fijados. Por ello, cuando Ti2 > A (N2-1)/ N (N-A) · Fcrítica $(p=0,05)$, siendo A el número de componentes y $\mathrm{N}$ el número de observaciones, la observación i se encuentra fuera de los límites de confianza del modelo al $95 \%$ y se sospecha que es anómala. Modificar el límite de confianza del análisis únicamente exige recalcular el valor de F crítica (Figura 13). 


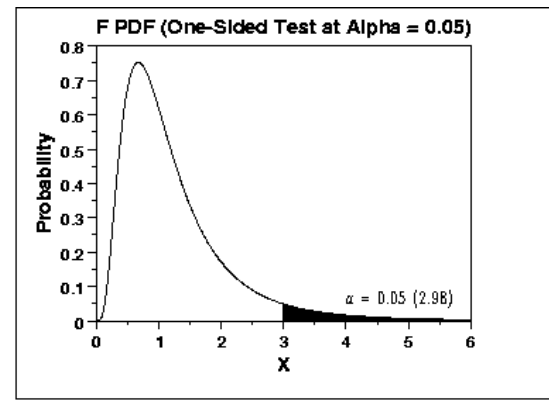

Figura 13.Distribución F( A, N-A)(A)DE LA T2 de HOtelling PARA Un NIVEL DE CONFIANZA DEL 95\%.

Los límites calculados a partir de la $\mathrm{T}^{2}$ de Hotelling se representan, generalmente, en forma de elipse en un plano bidimensional como se verá posteriormente, donde se observa gráficamente de forma clara, qué puntos se desvían del comportamiento habitual del proceso.

Una vez detectados ambos tipos de anomalías, el modelo se reajusta determinando las nuevas direcciones principales y observando aquellos puntos críticos que puedan considerarse como nuevas anomalías.

\subsection{ANÁLISIS ESTADÍSTICO POR COMPONENTES PRINCIPALES DE LOS CAUDALES INYECTADOS A UNA RED}

En ocasiones, el volumen de datos que llega los sistemas de medida y control (SCADA) desde los macromedidores puede ser inabordable para el ser humano, ya que éste adquiere miles de valores de diferentes variables en poco tiempo. Precisamente, para ayudar a analizar dichos datos y convertirlos en información útil surgen las técnicas de análisis multivariante, cuyos fundamentos teóricos se conocen desde hace tiempo y se han desarrollado en multitud de áreas como la sociología, la medicina, la biología o incluso la hidráulica, como es el caso.

Desde el punto de vista puramente estadístico y de forma restrictiva puede definirse el análisis multivariante como "un conjunto de técnicas cuyo objetivo es el análisis descriptivo y/o la realización de inferencias a partir de datos de naturaleza multivariante, es decir, en los que cada observación está constituida por los valores de varias variables interrelacionadas"(Romero.R ,1997).

Entre estas técnicas destaca el análisis de componentes principales (ACP), cuya teoría se explica en el epígrafe anterior. Como se ha comentado, este método condensa la información de un grupo homogéneo de variables en un número reducido de nuevas variables, las más explicativas, construidas como combinación lineal de las variables originales. A estas nuevas variables son las componentes principales (Jackson, 1991).

Los vínculos existentes entre las variables originales es un aspecto esencial de este análisis, que explota estas relaciones para lograr un estudio más completo, sencillo y profundo de los datos observados. Si las variables estudiadas fueran independientes sería posible estudiarlas por separado mediante técnicas univariantes clásicas. No obstante, las dependencias existentes entre ellas hace que su estudio como variables univariantes pase por alto las influencias de unas sobre otras. 
Este capítulo, en su aplicación práctica, aprovecha el análisis de componentes principales para determinar las diferentes estructuras de correlación presentes en los caudales inyectados a una red de distribución, con el fin de obtener modelos que condensen la información más importante almacenada por los equipos de adquisición de datos de cualquier puesto de medida de un abastecimiento de agua.

Como ya se ha comentado, el seguimiento diario de estos sistemas de macromedición desde la unidad central o telemando es un procedimiento habitual que, hoy en día, utilizan los abastecimientos urbanos. De este modo, el operario supervisa los caudales instantáneos que llegan diariamente al telemando, particularmente los caudales nocturnos inyectados en red con el objetivo de identificar incidencias, y evaluar si éstos entran dentro de los límites idóneos del abastecimiento, o por el contrario, sufren incrementos o disminuciones no justificados.

Por consiguiente, el desarrollo de estudios sobre el control de los caudales inyectados en una red de distribución de agua mediante técnicas estadísticas de análisis multivariante puede ser ventajoso para la detección de caudales de fuga.

El problema radica en que en la actualidad estos sistemas de macromedición adquieren niveles de complejidad notables, es decir, captan señales de múltiples instrumentos en continuo, de ahí la trascendencia de estas nuevas técnicas de análisis multivariante que condensan la información recibida y facilitan la posterior interpretación de los datos.

Además, con tal número de variables y valores de referencia, los técnicos, a veces son incapaces de apreciar posibles tendencias que se producen en los caudales inyectados a lo largo del tiempo, y valorar correctamente el funcionamiento de la red.

Esto es un hecho habitual, ya que los caudales introducidos en una red no son constantes en el tiempo, y dependen de la demanda de los consumidores a lo largo del día y del estado de la misma. Además, hay que tener en cuenta que los consumos de los habitantes varían dependiendo de la época del año (verano-invierno) o del día de la semana (festivolaboral), al igual que el propio estado de la red que está sujeto a la política de mantenimiento y rehabilitación del abastecimiento. Por ello, los límites racionales establecidos por el técnico generalmente no tienen en consideración estas tendencias, y no advierten las desviaciones graduales que pueden sufrir los caudales inyectados a la red. Al mismo tiempo, este sistema tradicional exige al operario estar continuamente alerta, ya que sólo existen sistemas de alarma básicos que detectan alteraciones en los caudales inyectados, nocturnos o diurnos, importantes.

El análisis de componentes principales es una técnica, como se ha visto en apartados anteriores, que permite manejar gran cantidad de información con el objetivo de discriminar diferentes tendencias de consumo de los habitantes de una población, además de ser capaz de detectar irregularidades producidas en la red. La principal aportación de esta técnica reside en que permite condensar la información recibida en el telemando, visualizando de forma rápida, sin necesidad de leer todos los datos, las perturbaciones producidas en una red de distribución y la evolución de los caudales inyectados a la red durante los meses de estudio.

Por ello, el seguimiento diario de los caudales inyectados en un sector mediante ACP permite detectar de manera más sencilla, en un tiempo relativamente corto, las anomalías de cierta entidad que vayan apareciendo en el sector controlado. Además, proporciona a medio-largo plazo un indicador de la evolución del índice de fugas en la misma.

\subsubsection{BJETIVOS DEL ESTUDIO}

Estas técnicas parten de un elemento básico que es una matriz de datos, constituida por $\mathrm{i}$ filas correspondientes a las observaciones, y $\mathrm{k}$ columnas correspondientes a las variables, y donde el elemento $\mathrm{X}_{\mathrm{i}, \mathrm{k}}$ es el valor del parámetro $\mathrm{o}$ dato medido de la variable k-ésima en la observación i-ésima. 


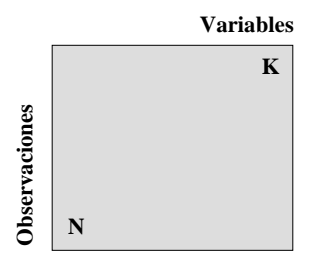

FIGURA 14.MATRIZ DE DATOS.

Para ello, en este estudio se investiga sobre una matriz de datos donde las variables consideradas corresponden a las 24 horas del día, es decir, los datos aportados por el telemando son organizados en caudales inyectados por hora. Por otra parte, las filas de dicha matriz corresponden a los días debidamente analizados, procedentes de un periodo con condiciones homogéneas.

EI ACP busca relaciones entre las variables, concentrando la información aportada por el telemando en un número reducido de variables capaces de describir las condiciones de funcionamiento de la red. Para facilitar la condensación de los datos obtenidos y reducir a su vez la heterogeneidad existente en los consumos a las diferentes horas del día se crean grupos de variables homogéneos. En este sentido, está claro que el consumo nocturno se diferencia claramente del de mañana y del de tarde con patrones muy diferentes. Lo mismo ocurre con el tipo de día laboral-no laboral.

En este punto, se debe tener en cuenta que los días festivos o de fin de semana, tienen tendencias de consumo diferentes al resto de días laborables (Figura 15). Este hecho, bastante obvio, es fácil de observar tanto gráficamente mediante las curvas de modulación horarias promedio (130 días), como en gráficos característicos del análisis de componentes principales (Figura 16).

Como consecuencia y con el fin de optimizar esta técnica de detección de anomalías conviene, en un primer lugar, obtener a partir de los datos de los caudales inyectados a un sector que se presentan en el Anexo II a este capítulo, un modelo en el que se identifiquen las diferentes tendencias de consumo de los abonados y en el que se establezcan las relaciones existentes entre las variables (caudales medios horarios). 


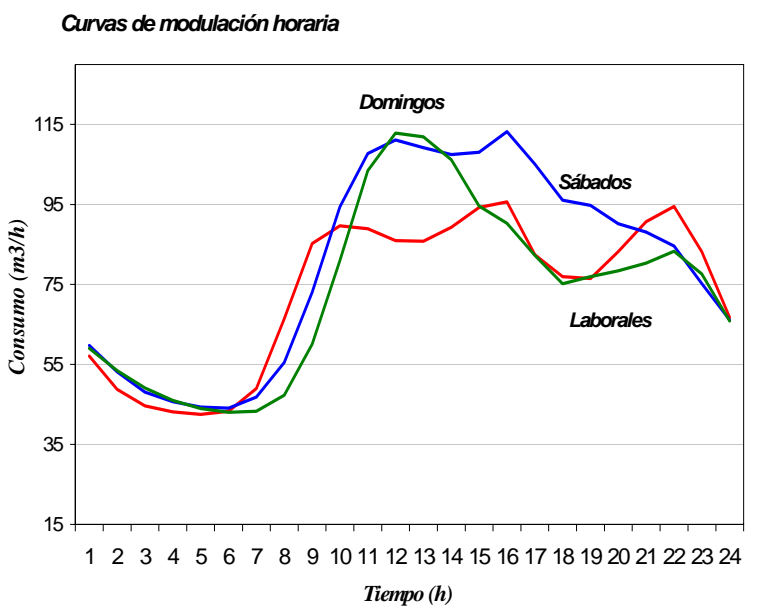

FIGURA 15.CURVAS DE MODULACIÓN HORARIA PROMEDIO.

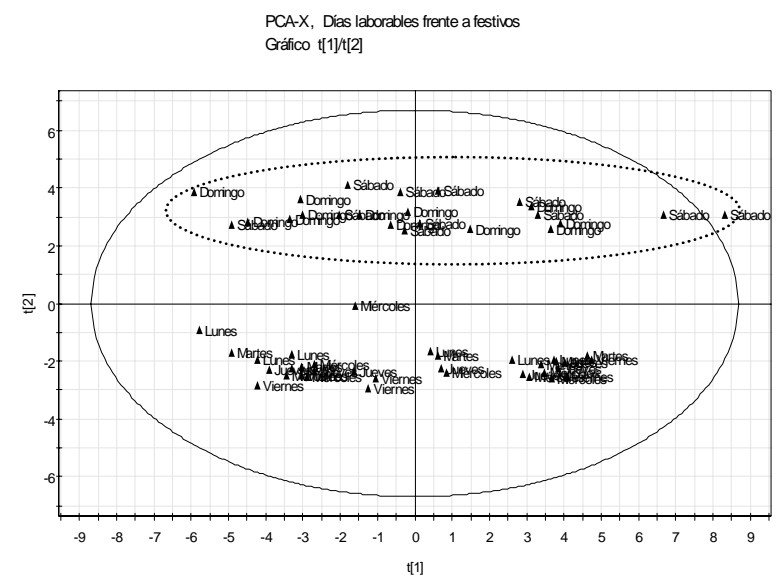

FIGURA 16.GRÁFICO DE LAS PROYECCIONES SOBRE DOS DIRECCIONES PRINCIPALES

Con esta información se obtienen modelos diferentes para mejorar la eficacia de esta técnica de análisis, y de esta forma, optimizar la sensibilidad del modelo ACP que se encuentra condicionada por la homogeneidad de los datos de partida.

En este estudio se generan varios modelos, centrados particularmente en los días laborables, uno nocturno de 0-7 horas, otro durante las horas diurnas, es decir 7-16 horas, y por último, otro durante la tarde de 16-24 horas. La separación en tres modelos tiene el objetivo de disminuir el rango de variabilidad de dichos caudales inyectados, y ajustar convenientemente el modelo a las direcciones principales de dichas horas del día o variables.

Los modelos ACP de mañana y de tarde poseen mayor aleatoriedad debido a que incluyen la mayor parte de los caudales consumidos durante el día. Por tanto, las relaciones entre variables no están tan bien definidas como en los nocturnos.

Así mismo, la creación de tres modelos diferentes mejora el tiempo de reacción ante una posible incidencia que acontezca en la red, sin tener que esperar al día siguiente para reconocer la señal de alarma.

Estos modelos se aprovechan, principalmente, para distinguir aquellos consumos que se encuentran fuera de los límites de control del modelo, como por ejemplo una rotura en una tubería donde la pérdida de agua es importante, un llenado de un 
depósito, un corte en el suministro de agua, o incluso fallos en las comunicaciones entre el instrumento de medida y la estación de control central. A su vez, permiten tener un conocimiento sobre la evolución de la propia red, pudiendo analizar tendencias y/o posibles desviaciones del estado habitual de funcionamiento.

\subsubsection{ELABORACIÓN DE LOS MODELOS DE REFERENCIA}

La monitorización en continuo de procesos industriales adquiere una gran importancia en los tiempos actuales, en los que existe una gran competencia entre los mercados con exigencias de niveles de calidad cada vez más altas.

La metodología consiste en la detección en tiempo real de eventos o incidencias que no respondan a las condiciones operativas normales de funcionamiento provocando que salgan fuera de los límites de control del proceso, lo que en la actualidad viene a denominarse control estadístico de procesos (Kourti y MacGregor, 1996).

El sistema de monitorización en continuo debe ser configurado mediante criterios que permitan el control de los parámetros que mejor describan el funcionamiento del sistema, y que alerten de cualquier suceso en el menor tiempo posible. De esta forma, el análisis de la red de distribución mediante gráficos de control avisa de la existencia de anomalías y de las variables que influyen sobre ellas. Esto permite tener una visión a corto plazo (de 1 a 6 horas) de una posible rotura que produzca pérdidas de agua considerables, mejorando así el servicio y la buena gestión de la red.

Para ello, como paso previo a la definición de los modelos definitivos que se apliquen a la monitorización en continuo, los modelos iniciales deben ser depurados para obtener lo que se llama pauta normal del proceso, es decir, los consumos horarios que "típicamente" se demandan en la localidad, eliminando aquellos días con sucesos irregulares. De este modo, se hallan diferentes modelos de ACP hasta llegar a uno óptimo, que sintetice al máximo la información y que, a su vez, no se vea afectado por las anomalías o perturbaciones de los datos de partida.

Para que el método de detección de anomalías tenga cierta fiabilidad, estos modelos óptimos o de referencia deberán ser actualizados con cierta frecuencia dependiendo de las características de la red y del tipo de consumo de la población. Una red con un plan activo de búsqueda de fugas tendrá modelos más estables y que habrá que actualizar con menos frecuencia que en caso contrario. A su vez, en los abastecimientos donde el tipo de consumo difiera según la época del año (estival o invernal) se deberán generar diferentes modelos según el caso.

\subsubsection{CONSIDERACIONES SOBRE EL NIVEL DE SIGNIFICACIÓN DEL MODELO}

El propósito principal de esta técnica es discriminar los caudales inyectados a la red que sean de alguna forma irregulares, tanto por ser excesivamente altos como excesivamente bajos. No obstante, la técnica de análisis propuesta, esencialmente visual, puede conducir a errores en la toma de decisiones, como por ejemplo el no detectar un día en el que se ha producido una fuga o generar una falsa alarma, es decir, considerar como anomalía en la red una observación que tiene un comportamiento normal.

Por ello, es conveniente someter los resultados obtenidos a un contraste de hipótesis que sirva para diferenciar con cierto criterio, aquellas observaciones o días que con un nivel de confianza (1-a) pueden ser consideradas como anomalías 0 outliers.

Como siempre, a la hora de realizar un test de hipótesis se debe seguir una serie de pasos (Terriel y Daniel, 1994). Lógicamente el primero de ellos consiste en formular las hipótesis, definiendo claramente lo que se desea probar. 
Se establecen dos hipótesis mutuamente excluyentes y complementarias, la hipótesis nula ( $\mathrm{H} 0$ ) y la alternativa (H1). En la presente Tesis, se establece $\mathrm{H} 0$ como aquellas observaciones dentro de la matriz que presentan un comportamiento normal en el sistema. Por otro lado, se define la hipótesis alternativa $\mathrm{H} 1$ como los caudales inyectados con ciertas irregularidades sobre las tendencias habituales.

Para contrastar una hipótesis nula formulada se debe elaborar un modelo probabilístico que permita tomar una decisión final razonable. Por tanto, como paso segundo en este tipo de contraste se define un estadístico de contraste que marca la región de aceptación y de rechazo. La región de aceptación la conforman el conjunto de valores del estadístico que permiten aceptar $\mathrm{H} 0$, mientras que la región crítica o de rechazo está constituida por los valores del estadístico que permiten rechazar $\mathrm{H} 0$, y por tanto aceptar $\mathrm{H} 1$.

Los parámetros utilizados para rechazar caudales anormales inyectados al sector son, como se comenta en el epígrafe 7.2.3.5, la $\mathrm{T}^{2}$ Hotelling y la distancia al modelo (DMOD).

Ambos parámetros siguen una distribución $\mathrm{F}$ de Snedecor con un nivel de significación a seleccionado por el técnico. Este estadístico $\mathrm{F}$ establece la zona crítica, la cual constituye el conjunto de valores de $\mathrm{F}$ que permiten considerar estos días como anomalías. Lógicamente, la decisión de aceptar o rechazar la hipótesis puede originar errores de diferente tipo (error a o $\beta$, Tabla 1).

TABLA 1. TIPOS DE ERROR GENERADOS EN LA DETECCIÓN DE FUGAS.

\begin{tabular}{l|lll}
\hline \multirow{2}{*}{$\begin{array}{l}\text { Hipótesis Ho: } \\
\text { Día CONSIDERADO } \\
\text { NORMAL }\end{array}$} & \multicolumn{2}{|c}{ SITUACIÓN REAL } \\
\cline { 2 - 4 } & ACEPTAR & Correcta & Falsa (DíA ANÓMALO) \\
\hline & RECHAZAR & Incorrecta (Error Tipo l o a $)$ & Correcta (Error Tipo II o $\beta$ ) \\
\hline
\end{tabular}

Los errores tipo a son los que se cometen cuando se indica que un día es anómalo y no existe anomalía alguna, es decir, se rechaza la hipótesis nula siendo ésta verdadera. Esto provoca una falsa alarma que deberá ser supervisada por el técnico con la consiguiente perdida de tiempo. Por el contrario, se incurre en un error tipo $\beta$, cuando una observación es aceptada por el modelo como normal siendo ésta realmente una fuga, un fallo en la red, etc. Las implicaciones en este caso son claras, el coste económico del agua perdida en la rotura o incluso el de los daños materiales que pueda generar.

En la definición del contraste de hipótesis, el tercer paso, consistiría en definir un nivel de significación a, que representa la probabilidad de que un valor concreto del estadístico de contraste $\mathrm{F}$ caiga en la región crítica, o lo que es lo mismo sea considerado como fuga. El nivel de confianza representa el complemento de esta probabilidad y $\beta$ indica la probabilidad de que el error tipo $\beta$ suceda, es decir que el modelo de ACP no detecte anomalias en aquellas observaciones con incidencias.

- Nivel de significación $(a)=P($ Error $a)=P($ Rechazar Ho/ Ho es verdadera $)$

- Nivel de confianza $(1-\alpha)=1-P($ Error $\alpha)=P($ Aceptar Ho/ Ho es verdadera $)$

- $\beta=P($ Error $\beta)=P($ Aceptar Ho/ Ho es falsa $)$

Lógicamente, al construir el modelo los niveles de significación de los parámetros de rechazo deben ser ajustados, de tal forma que se llegue a un compromiso que minimice estos errores a o $\beta$. Claro está, que ninguno de los dos tipos de errores 
es deseable, por ello dependiendo de las condiciones del abastecimiento y su política de detección de fugas los niveles de confianza adoptados serán más o menos restrictivos.

Para la depuración de la matriz de datos original se establecen unas condiciones de ajuste rígidas con el objetivo de conseguir un grado de aproximación a las curvas de modulación horaria originales elevado.

Los parámetros elegidos en el programa informático SIMCA-P 9.0. para depurar los modelos son:

TABLA 2. RESTRICCIONES DEL ANÁLISIS DE COMPONENTES PRINCIPALES

\begin{tabular}{ll}
\hline RESTRICCIONES DEL MODELO & GRADO DE AJUSTE \\
\hline \%Datos faltantes admitidos & $30 \%$ \\
Nivel de confianza T2 de Hotelling & $95 \%$ \\
Nivel de confianza DMOD & $95 \%$ \\
\hline
\end{tabular}

\subsection{METODOLOGÍA SEGUIDA EN LA CONSTRUCCIÓN DE LOS MODELOS ACP}

La metodología seguida en la construcción de los modelos de ACP es siempre la misma, por ello, durante los epígrafes siguientes de este capítulo se presentará de forma abreviada los resultados más importantes obtenidos durante el análisis realizado con la ayuda del programa informático SIMCA-P 9.0.

El procedimiento para construir los modelos de referencia ACP es iterativo, es decir, se repite hasta encontrar un óptimo que se ajuste satisfactoriamente al comportamiento "normal" de la red de distribución. Por ello, en este punto se presentará de forma resumida la sistemática utilizada en la construcción de un modelo de referencia. La teoría que explica este análisis estadístico se detalla en el Anexo I (Figura 17)

Conjuntamente, durante la elaboración de los modelos óptimos o de referencia, se tiene en cuenta la propia variabilidad entre los consumos de un día y otro. Es por ello que surgen las bandas de confianza que asumen cierta aleatoriedad en los datos, pero son capaces de detectar aquellos días que de alguna forma perturban la caracterización del modelo de ACP.

Como se comentó en el punto 7.2.3.2, el punto de partida es el pretratamiento de la matriz de datos (Eriksson et al., 1999), mediante la tipificación de los caudales inyectados cada hora. Seguidamente al pretratamiento de la matriz de datos original, la siguiente fase aborda el cálculo de las componentes principales del modelo inicial de ACP que más tarde se aprueba mediante validación cruzada.

Las componentes principales se obtienen calculando los vectores propios de la matriz de varianzas/covarianzas de la matriz pretratada, y sus valores propios $\lambda_{1}, \lambda_{2}, \ldots, \lambda_{2}$ verifican $\lambda_{1}>\lambda_{2}>\ldots>\lambda_{A}$, que indican la varianza explicada por cada componente extraída. Mediante el algoritmo de cálculo NIPALS (Anexo I de este capítulo), se obtienen secuencialmente de forma sencilla A componentes principales hasta que la aproximación a los datos originales se considere suficiente, reduciéndose el hiperplano K-dimensional, formado por todas las variables consideradas en el caso estudiado, a un espacio de A-dimensional definido por las correspondientes direcciones principales.

Una vez finalizada esta fase se vuelve a iterar tantas veces como sea necesario hasta llegar a un modelo propicio definitivo el cual viene definido por: 


$$
\overline{\overline{\mathbf{X}}}_{(\mathrm{N}, \mathrm{K})}=\overline{\overline{\mathbf{T}}}_{(\mathrm{N}, \mathrm{A})} \overline{\overline{\mathrm{P}}}^{T}(\mathrm{~A}, \mathrm{~K})+\overline{\overline{\mathrm{E}}}_{(\mathrm{N}, \mathrm{K})}
$$

$\overline{\bar{T}}$ : Matriz de proyecciones sobre cada dirección principal.

$\overline{\bar{P}}$ : Matriz de vectores propios o direcciones principales.

$\overline{\bar{E}}$ : Matriz de residuos.

De esta manera, se calculan componentes hasta llegar a un grado de ajuste suficientemente bueno, o lo que es lo mismo, agregar una componente nueva al modelo puede suponer un sobreajuste del mismo, lo que empeora la capacidad predictiva del modelo. Conocer este punto es difícil sin técnicas especiales, por ello se ha desarrollado métodos de ayuda en la fase de diagnóstico de variables del modelo que determinan qué número de componentes principales es suficiente para explicar convenientemente el comportamiento de los datos.

Uno de estos métodos es la validación cruzada que consiste en eliminar cierto grupo de observaciones de la matriz de datos $\overline{\bar{X}}$, reajustar el modelo con las observaciones restantes y predecir el comportamiento de las primeras comparándolas con las observaciones originales separadas. Este procedimiento se repite varias veces, separando en cada ocasión diferentes grupos de observaciones hasta que cada una haya sido aislada una vez. La evaluación de estas variables se realiza con diferentes estimadores del error de predicción, como el PRESS o suma de cuadrados de los errores de predicción, y la suma de cuadrados residual (SCR). La comparativa de estos parámetros permite decidir el número de componentes que conviene retener (Wold, 1978).

En estudios realizados la reducción de dimensionalidad ha sido satisfactoria, disminuyendo el número de direcciones, generalmente, a dos o tres. Esta reducida dimensionalidad del espacio favorece el estudio del comportamiento operativo de la red, ya que el uso de pocas variables facilita la representación gráfica de los datos y posibilita la detección de tendencias o incidencias en los caudales inyectados con mayor sencillez.

Una vez construido el primer modelo con A componentes se procede a la fase de validación (Figura 17), fundamental en la construcción de los modelos de ACP, y que se caracteriza por ser básicamente gráfica. En ella se identifican aquellas observaciones que por algún motivo sobrepasan los límites establecidos por el propio modelo calculando su distancia al modelo (DMOD) y su $T^{2}$ de Hotelling y visualizándolos en gráficos de control. Se interroga al modelo para tratar de identificar las variables causantes de las anomalias, y se reestima de nuevo el modelo, eliminando dichas observaciones anómalas hasta obtener un modelo de referencia del comportamiento de los consumos diarios.

Este modelo depurado sintetiza la información de la matriz de datos, prescindiendo de aquellos días en que se produce algún tipo de incidencia. En él, las bandas de tolerancia definen los márgenes entre los cuales oscilan los valores considerados válidos para un determinado parámetro. Por ello, abastecimientos con más incidencias de fugas, en general más "inestables", tendrán bandas de tolerancia en condiciones normales de funcionamiento más amplias, lo que influirá negativamente en la capacidad de detección de fugas de menor calibre.

En este capítulo se desarrolla esta técnica aplicándola a los caudales inyectados durante cada hora para los días laborables, discriminando los días en fin de semana. 


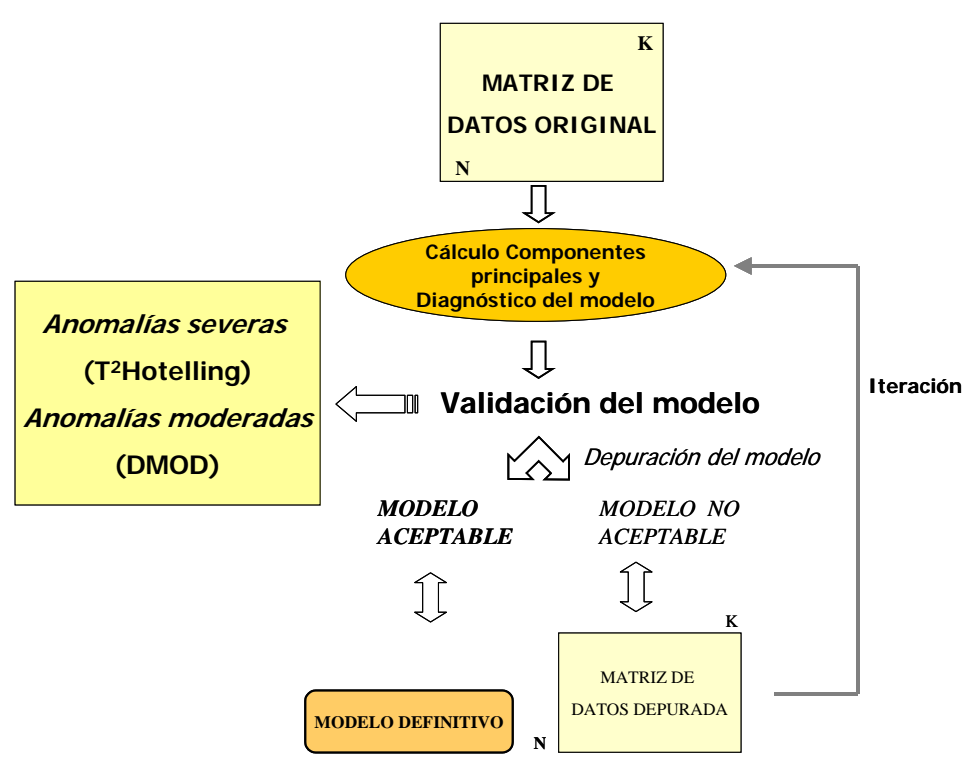

FIGURA 17.METODOLOGÍA SEGUIDA EN LA CONSTRUCCIÓN DE LOS MODELOS DE ACP.

\subsubsection{VALIDACIÓN DEL MODELO: DETECCIÓN DE ANOMALÍAS EN LA RED.}

Como se ha comentado, el análisis estadístico mediante la técnica de componentes principales puede ser una herramienta interesante para la detección de situaciones anormales que puedan producirse en el sistema. Particularmente, en este caso, se utiliza esta metodología en la detección de fugas en la red de distribución, tanto durante las horas nocturnas como las diurnas. Para ello, a continuación, se evalúan dos métodos aplicados a la detección de anomalías en la red de distribución de agua.

\subsubsection{Método T2 Hotelling}

Esta técnica, utilizada también durante la construcción del modelo, identifica individuos futuros que salen fuera de los límites del modelo al proyectarlos sobre cada una de las direcciones principales del mismo.

En los fundamentos matemáticos de este análisis se demuestra que los scores o proyecciones sobre cada dirección principal son combinaciones lineales de las variables y los pesos en dicha dirección (ver Ecuación 1) extraídas mediante alguno de los algoritmos matemáticos descritos en el Anexo I.

$$
t_{i, A}=\sum_{k=1}^{K} x_{i, k} \cdot p_{k, a}
$$

$$
\text { 1a dirección principal } \quad t_{i, 1}=X_{i, 1} \cdot p_{1,1}+X_{i, 2} \cdot p_{2,1}+X_{i, 3} \cdot p_{3,1}+\ldots+X_{i, 24} \cdot p_{24,1}
$$

$$
2^{\mathrm{a}} \text { dirección principal } \quad t_{i, 2}=X_{i, 1} \cdot p_{1,2}+X_{i, 2} \cdot p_{2,2}+X_{i, 3} \cdot p_{3,2}+\ldots+X_{i, 24} \cdot p_{24,2}
$$


Los individuos del modelo han sido centrados y escalados durante el pretratamiento de los datos. Por ello, sus proyecciones en el espacio de las componentes cumplen que para cada dirección principal $\sum_{i=1}^{N} t_{i, a} \approx 0$, indicando en el segundo subíndice la dirección principal estudiada. Esto significa que la nube de puntos que representan los scores o proyecciones del modelo de referencia, tras ser depurados, se encuentran centrados como se muestra en la Figura 18.

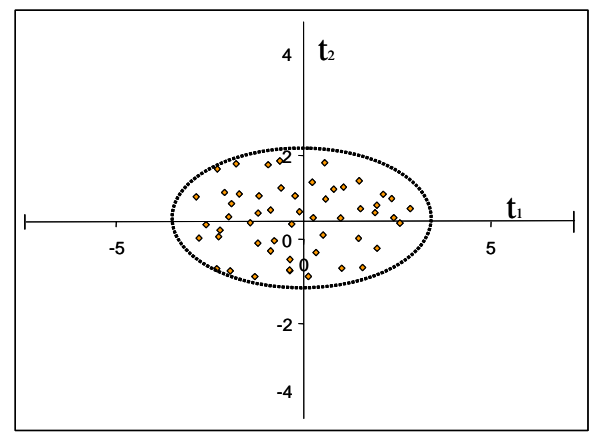

FIGURA 18. NUBE DE PUNTOS PROYECTADOS Y CENTRADO EN EL ESPACIO DE LAS COMPONENTES.

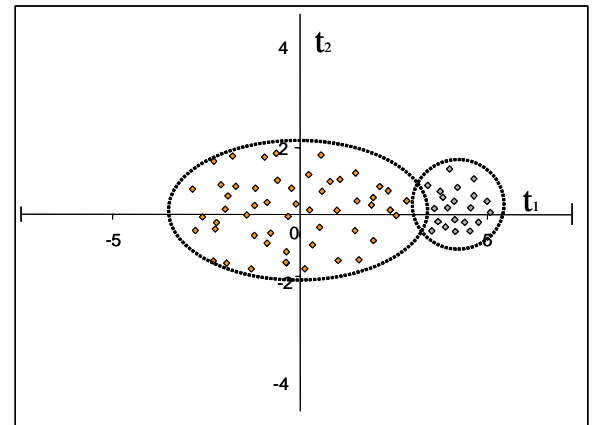

FIGURA 19.NUBE DE PUNTOS PROYECTADOS DESPLAZADOS DEBIDO A LA DETECCIÓN DE OBSERVACIONES CON FUGAS.

Cuando se produce una fuga, los datos llegados al telemando cada hora varían, ya que la demanda en la red es mayor, lo que hace que ese día tenga un comportamiento inusual que se refleja en el gráfico de las proyecciones o scores con desplazamientos de la nube de puntos sobre las diferentes direcciones (Figura 19). Estos desplazamientos serán diferentes en cada dirección en función de los valores que adopten los pesos.

De esta forma, los caudales inyectados pueden ser discriminados en dos términos, un caudal normal y un caudal de fuga. Cuando esta variable, caudal inyectado, se tipifica la expresión queda del siguiente modo:

$$
Q_{i}=\frac{\left(Q_{\text {normal }}+Q_{f}-\bar{Q}\right)}{\sigma}=\frac{Q_{\text {normal }}-\bar{Q}}{\sigma}+\frac{Q_{f}}{\sigma}
$$

$\sigma:$ Desviación típica para cada variable.

Q: Caudal inyectado tipificado.

Qf: Caudal de fuga constante.

Qnormal: Caudal inyectado a la red en condiciones normales de funcionamiento. 
Para medir dicho desplazamiento provocado por los caudales de fuga, éstos se consideran constantes en el tiempo y, por lo tanto, pueden ser fácilmente discriminados como se muestra en la siguiente Ecuación 6.

$$
\underset{q_{\text {fuga }}^{\text {Dia }}}{i, K}=\sum_{K=1}^{\text {24horas }}\left(q_{i, k}+q_{i, k}^{\text {fuga }}\right)
$$

\footnotetext{
$\underset{q_{\text {fuga }}^{\text {Dia }}}{i, K}$ :Caudal total tipificado inyectado a la red de distribución correspondiente a un día con fuga

$q_{i, k}:$ Caudales tipificados inyectados a la red en condiciones normales de funcionamiento.

$q_{i, k}{ }^{\text {fuga }}:$ Caudal tipificado inyectado correspondiente a fugas.
}

No obstante, la metodología es perfectamente aplicable con caudales de fuga no constantes. Para ello, bastaría con sustituir en el sumatorio el valor de qi, fuga asignado a cada hora.

Matemáticamente, el desplazamiento de las proyecciones producido en cada una de las direcciones cuando se produce una fuga se podría calcular:

$$
\begin{aligned}
& \text { ffuga }_{i, a}=\left(q_{i, 1}+q_{i, 2}^{\text {figa }}\right) \cdot p_{1, a}+\left(q_{i, 2}+q_{i, 2}^{\text {ffuga }}\right) \cdot p_{2, a}+\left(q_{i, 3}+q_{i, 3}^{\text {ffiga }}\right) \cdot p_{3, a}+\ldots+\left(q_{i, 24}+q_{i, 24}^{\text {fuga }}\right) \cdot p_{24, a}
\end{aligned}
$$

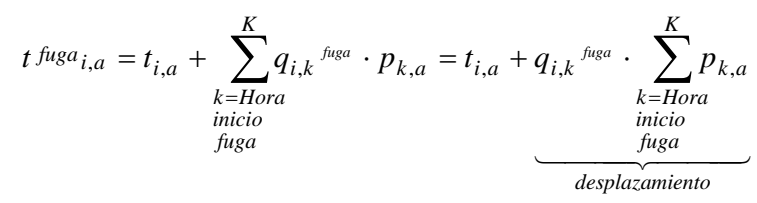

Evidentemente, el valor de la traslación de las proyecciones en cada dirección será directamente proporcional a la suma de los pesos en dicha dirección e inversamente proporcional a $\sigma_{\kappa}$, desviaciones típicas del modelo utilizadas en la tipificación (Figura 19). Luego las direcciones que centrarán el análisis serán aquellas en las que $\sum_{K=1}^{K} p_{K, A}$ adquiera un mayor valor. Por el contrario, las proyecciones sobre las componentes principales en las que el sumatorio de los pesos está próximo a cero no se verán prácticamente afectadas por un incremento del caudal inyectado.

Con el cálculo del parámetro $\mathrm{T}^{2}$ de Hotelling, que se distribuye con una $\mathrm{F}$ de Snedecor de A, N-A grados de libertad, se evalúa si un individuo se encuentra desplazado debido a algún tipo de incidencia. Es decir, cuando $T_{i}^{2}>A \cdot\left(N^{2}-1\right) / N \cdot(N-A)$. Foritica $(p=0,05)$, se puede afirmar que la observación i se encuentra con un $95 \%$ de probabilidad fuera de los límites de confianza del modelo.

\subsubsection{Método DMOD}

Esta nueva técnica de detección, complementaria a la anterior, utiliza en el análisis de los residuos generados entre los datos originales y los datos estimados por el modelo. Es complementaria, ya que como se verá más adelante, detecta las fugas de diferente manera. La T2 Hotelling revela aquellas observaciones donde la curva de modulación horaria conserva su forma a lo largo del periodo de monitorización, es decir, mantiene la relación entre variables durante todas las horas del 
modelo. La técnica DMOD, en cambio, tiene la ventaja de detectar cambios en la forma de dicha curva con mucha mayor eficacia, o lo que es lo mismo, indica observaciones donde la relación entre variables ha cambiado (Figura 20).

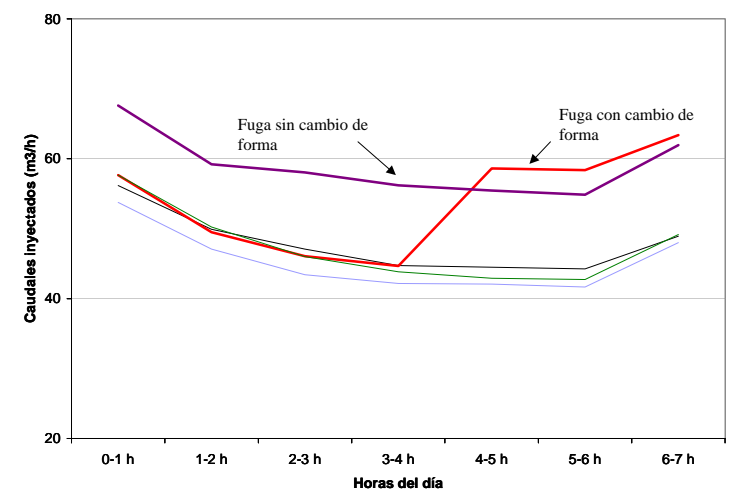

FIGURA 20.ANOMALÍAS CON DIFERENTE FORMA EN LA CURVA DE MODULACIÓN HORARIA.

De este modo, la matriz de residuos, diferencia entre los datos originales y los del modelo (Figura 21), sirve para evaluar la distancia al modelo de cada individuo, tal y como se explica durante la fase de validación del modelo (epígrafe 7.2.3.5), mediante el cálculo de la distancia al modelo normalizada $\left(\mathrm{S}_{0}\right)$, dato que aporta el propio modelo de referencia, y la distancia al modelo de cada individuo $\left(\mathrm{S}_{\mathrm{i}}\right)$.

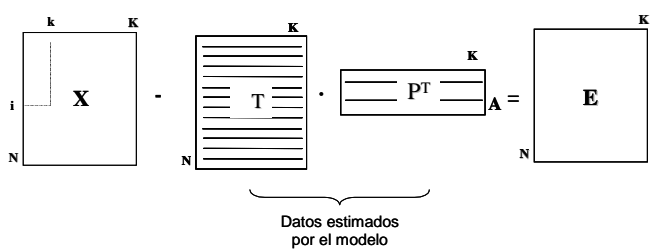

FIGURA 21. MATRIZ DE RESIDUOS DEL MODELO.

Cuando se produce una rotura se provoca un comportamiento irregular que viene reflejado inmediatamente en los residuos de dicha observación. Por una parte, este individuo contendrá los residuos propios del ajuste al modelo de ACP, e eil,k, sujetos a la bondad de ajuste. Por otra parte, los residuos debidos al incremento de caudal demandado por la fuga e fuga ${ }_{i, k}$. La suma de ambos residuos deberá ser determinada para hallar los parámetros que permiten revelar el defecto en la red de distribución. Analíticamente se expresaría de la siguiente forma:

$$
\begin{aligned}
& e^{2}{ }_{i 2, K}=\left(e_{i 1, K}+e^{f u g a}{ }_{i, K}\right)^{2}=e^{2}{ }_{i 1, K}+e^{f u g a}{ }_{i, K}{ }^{2}+2 \cdot e_{i 1, K} \cdot e^{f u g a}{ }_{i, K} \\
& e_{i 1, k:} \text { Residuos causados por } Q_{i} \text { del modelo de referencia. } \\
& e^{\text {fuga }}{ }_{i, k}: \text { Residuos causados por Qfuga }
\end{aligned}
$$

A modo de ejemplo y con el fin de facilitar la comprensión del análisis se estudiará una caso sencillo en donde el espacio de las variables inicial sea bidimensional $\left(\mathrm{Z}_{1}, \mathrm{Z}_{2}\right)$ y el final unidimensional $\mathrm{p}$ (Figura 22). 


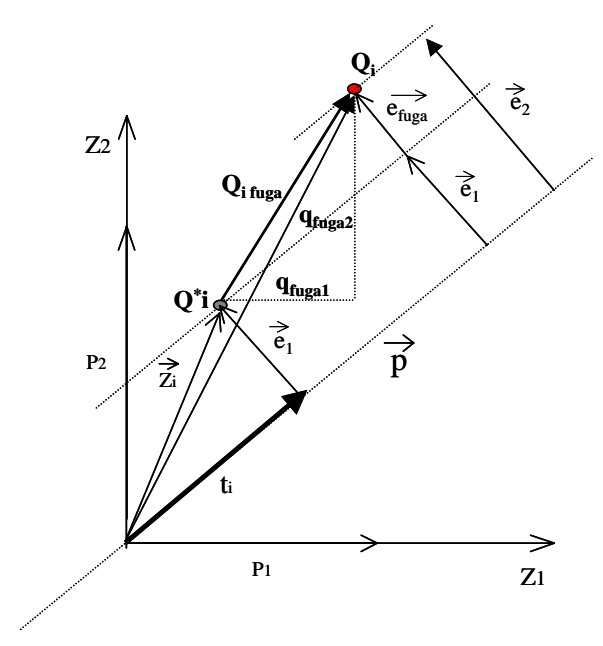

FIGURA 22.DESPLAZAMIENTO PROVOCADO POR QFUGA. $Q^{*}$ I: CAUDAL INYECTADO EN CONDICIONES NORMALES DE FUNCIONAMIENTO.

Es importante tener en cuenta que se ha considerado un Qfugado constante a lo largo del día, es decir, en el espacio original los datos sufren un incremento similar en todas las variables o lo que es lo mismo durante todas las horas. En cambio, cuando se reduce la dimensionalidad en el modelo de referencia, el Qúgado varia en función del peso que tiene cada variable del modelo, es por ello que sus longitudes serán diferentes (Figura 22).Como se observa en esta figura, cuando se añade una fuga $\overrightarrow{e_{1}}$ el residuo se transforma en $\overrightarrow{e_{2}}$, debido al desplazamiento causado por el caudal de fuga.

A diferencia del otro método de detección, $\mathrm{T}^{2}$ de Hotelling, la variación en el residuo depende tanto de la magnitud de la fuga como de los propios residuos de la observación a través del término $2 \cdot e_{i 1, K} \cdot e$ fuga ${ }_{i, K}$.

Por tanto, simulando días con fuga será posible determinar el porcentaje de simulaciones rechazadas para cada nivel de confianza estudiado mediante los límites de control fijados por la distancia al modelo, ya que ((Si/So)2) que sigue una distribución $\mathrm{F}$ de Snedecor con (K-A), (N-A-1)(K-A) grados de libertad.

\subsection{MODELOS DE REFERENCIA}

En el caso concreto del presente estudio, el proceso a controlar es la inyección de agua a una red de distribución. Para el ejemplo de aplicación se dispone de los caudales inyectados a un sector de una red de distribución de una localidad de Castellón, con aproximadamente 30.000 habitantes (Anexo II). Los caudales vienen expresados en $\mathrm{m}^{3} /$ hora durante un periodo de 6 meses (desde 1 enero de 2001 al 30 de junio de 2001).

\subsubsection{MODELO NOCTURNO DE REFERENCIA}

Este modelo consta en principio de 130 observaciones, es decir 6 meses de mediciones continuas, y de 7 variables, que como se ha comentado corresponden a los caudales inyectados al sector entre las 0 y las 7 de la mañana (Anexo II. Tabla A). 
La red de agua se encuentra en mal estado y durante las horas nocturnas el consumo intencionado por parte de los abonados es muy bajo con respecto al consumo total , lo que origina unos caudales inyectados relativamente constantes en todo el rango considerado (Figura 23). Esta situación influye positivamente en la determinación del modelo ya que al tener menor dispersión, comparado con los otros modelos, tendrá mayor capacidad de detección de futuras fugas de menor caudal.

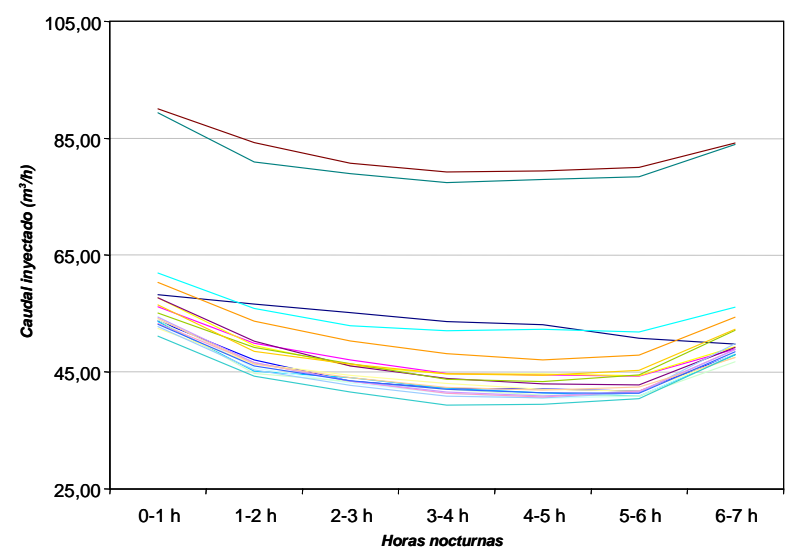

FIGURA 23.CURVAS DE MODULACIÓN HORARIA DURANTE LAS HORAS NOCTURNAS DE VARIOS DÍAS.

\subsubsection{Cálculo de las componentes principales y diagnóstico del modelo}

Una vez definida la matriz de datos original, comienza el análisis con un pretratamiento (centrado y escalado) de los caudales inyectados. En este caso en particular, todas las variables medidas son las mismas, es decir, caudales inyectados cada hora, y tienen el mismo orden de magnitud. Sin embargo, se ha optado por el pretratamiento de los datos para optimizar el análisis comparativo entre las tendencias de los diferentes sectores de la red de agua.

Tras uniformar la matriz de datos, mediante el algoritmo de cálculo NIPALS para el cálculo de las componentes principales se extraen las direcciones más significativas de este primer modelo, bien utilizando el propio SIMCA-P 9.0 que lo tiene implementado y las extrae de forma automática, o bien resolviendo el algoritmo en el programa de análisis matemático Matlab. Con las primeras componentes se recompone la mayor parte de la información sobre los caudales inyectados (Tabla 3), pero para determinar el número de direcciones principales que se deben retener se recurre a la técnica de validación cruzada (Tabla 4). Los parámetros logrados por el primer modelo nocturno son bastante satisfactorios.

TABLA 3. PRIMER MODELO NOCTURNO .COMPONENTES PRINCIPALES.

\begin{tabular}{lll}
\hline Componentes principales & Valor propio $\Lambda$ & $\begin{array}{l}\text { Número de iteraciones } \\
\text { (Algoritmo NIPALS) }\end{array}$ \\
\hline 1 & 5,9 & 7 \\
2 & 0,736 & 10 \\
\hline
\end{tabular}

TABLA 4. PRIMER MOdELO NOCTURNO. PARÁMETROS dE AJUSTE Y PREDICCIÓN.

\begin{tabular}{llllll}
\hline Componente principal & R2 (\%) & R2(\%cum) & Q2 & Q2(cum) & Grado de significación \\
\hline 1 & 84,3 & 84,3 & 76,8 & 76,8 & R1 \\
2 & 10,5 & 94,8 & 28,1 & 83,3 & R1 \\
\hline
\end{tabular}

R1: Componente significativa mediante la técnica de validación cruzada. 


\subsubsection{Validación del modelo}

Durante la fase de validación del modelo se deben buscar aquellos individuos que pueden perturbar de alguna forma las direcciones principales que lo definen.

Ya se ha remarcado en epígrafes anteriores, las técnicas de análisis de componentes principales son fundamentalmente gráficas. Por ello, las representaciones tanto de la distancia al modelo como del parámetro $\mathrm{T}^{2}$ Hotelling son los procedimientos que se utilizan para depurar días anormales. La $T^{2}$ Hotelling es una medida similar a la distancia de Mahalanobis donde los individuos examinados son las proyecciones t sobre cada dirección principal, en lugar de los datos originales. En este caso, puesto que han sido necesarias únicamente dos componentes principales, un gráfico bidimensional donde se representan las proyecciones sobre $\overrightarrow{p_{1}}$ y $\overrightarrow{p_{2}}$ es suficiente para detectar las anomalías severas (Figura 24). Hay que tener en cuenta que la detección de anomalías severas es muy importante ya que estas pueden perturbar considerablemente el modelo.

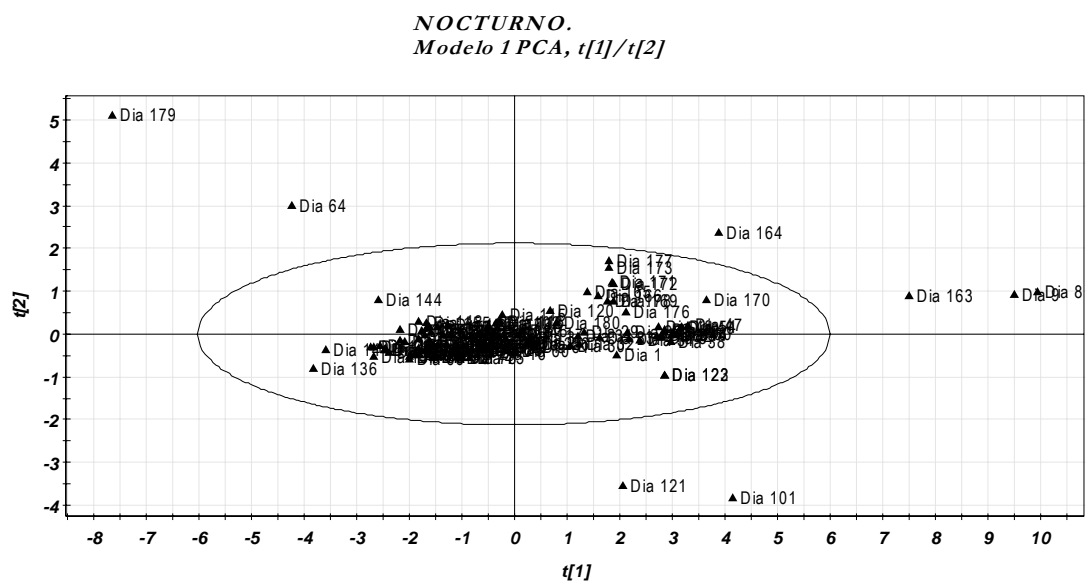

FIGURA 24.GRÁFICO DE LAS PROYECCIONES PRIMER MODELO.

Las anomalías moderadas, aquellas que poseen una distancia euclidea al modelo considerable, se evalúan calculando dicha distancia o módulo de los residuos (DMOD). En otras palabras, este parámetro mide la separación real entre dicho individuo i y el espacio de las componentes. Gráficamente estas incidencias son detectadas mediante gráficos de control de dicho parámetro (DMOD, Figura 25). 


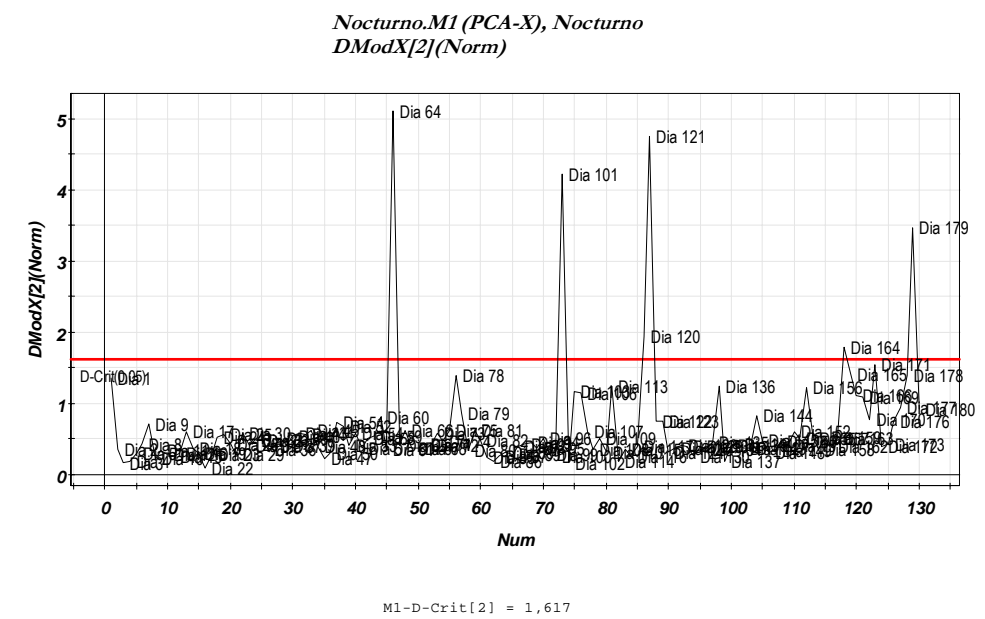

FIGURA 25. GRÁFICO DE CONTROL DMOD PARA DETECTAR ANOMALIAS MODERADAS.

Como se observa en el gráfico de las proyecciones, los datos anómalos generan "falsa aleatoriedad" lo que provoca que los límites del elipsoide $T^{2}$ Hotelling sean mayores de lo que debiera (Figura 24). A medida que se depura el modelo, la nube de puntos se ajustará más y de forma más homogénea a los límites del elipsoide.

Por otro lado, hay que tener en cuenta que estas técnicas de detección de anomalías son complementarias entre sí. El gráfico de las proyecciones permite identificar aquellos individuos que tienen un comportamiento irregular pero mantienen la relación entre variables. En cambio, la distancia al modelo, indica observaciones donde la relación entre variables ha cambiado. En el caso abordado este hecho quedaría reflejado en una variación en la forma de la curva de modulación horaria en la que los caudales inyectados no guardan la relación esperada entre ellos.

El día 9 es un claro ejemplo de lo comentado, al detectar unos caudales inyectados a la red anormalmente altos. Gráficamente (Figura 24), este día se identifica como anómalo ya que sale fuera de los límites de la $\mathrm{T}^{2}$ Hotelling $(\alpha=5 \%)$. Por el contrario, cuando se representa su distancia al modelo este no se manifiesta como anómalo (Figura 25). La justificación se encuentra rápidamente en la Figura 26 donde se puede ver que el día 9 posee una curva de modulación no alterada en forma, pero sí supera en gran medida los caudales inyectados cada hora respecto a los promedio.

Tras generar el primer modelo nocturno mediante el programa informático de análisis multivariante SIMCA P-9, se depura el modelo siguiendo la metodología descrita. Las anomalías halladas se detallan en la Tabla 5.

TABLA 5. MOdelo NOCTURNo 1. ANOMALías deteCtAdAS.

\begin{tabular}{ll}
\hline ANOMALÍA & INDIVIDUOS (días) \\
\hline Severa (T2Hotelling) & $8,9,64,101,163,164,121,179$ \\
Moderada (DMOD) & $64,101,121,179$ \\
\hline
\end{tabular}

Las curvas de modulación horaria nocturna de algunos de los días anómalos se representan en los Figura 26 y Figura 27. 


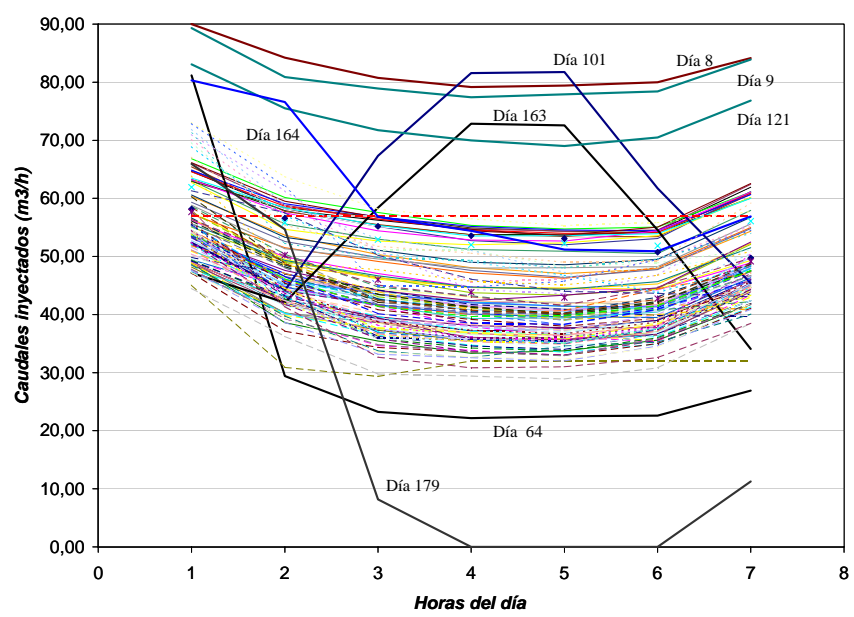

FIGURA 26. DÍAS CON CURVAS CON CAUDALES INYECTADOS A RED ANÓMALOS.

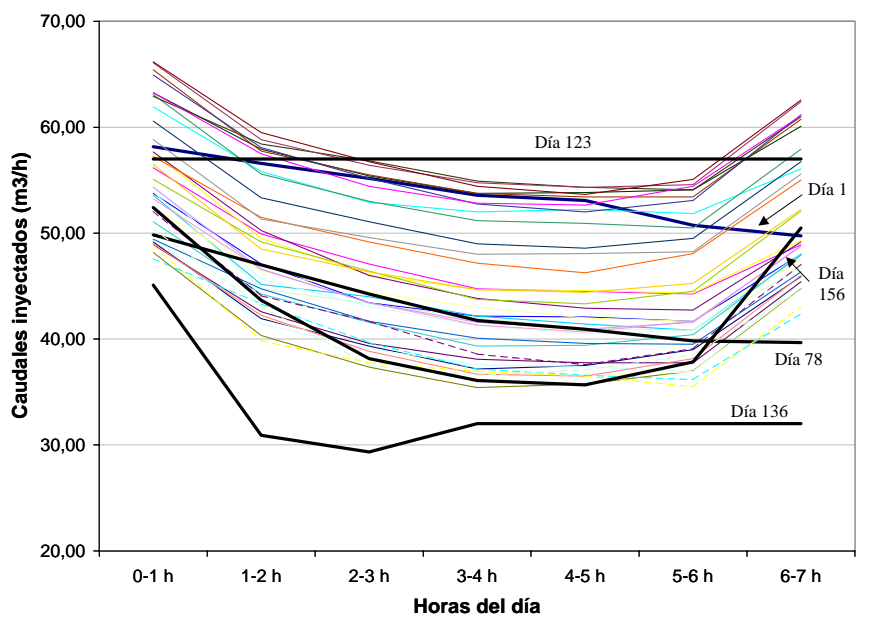

FIGURA 27. DÍAS QUE PRESENTAN ANOMALÍAS EN SUS CAUDALES INYECTADOS MODERADAS.

\subsubsection{Resultados del modelo nocturno de referencia}

Tras sucesivas repeticiones del proceso de validación se obtiene un modelo que se ajusta satisfactoriamente a las condiciones de consumo demandado por el sector, y en el cual se han eliminado los consumos ocasionados por roturas, días festivos entre semana en los cuales los hábitos de los abonados se asemejan a días de fin de semana o incluso días en los que se ha producido cortes en el suministro o fallos en las comunicaciones. De esta forma, se obtiene el modelo nocturno patrón con 75 días ( $58 \%$ de los datos originales), modelo que servirá en un futuro para evaluar los datos llegados al telemando y tener una referencia objetiva sobre los consumos demandados en la red de distribución analizada.

Los resultados obtenidos que describen el modelo nocturno obtenido mediante análisis por componentes principales son los mostrados en la Tabla 6 y Tabla 7 donde se indican los días excluidos durante la depuración del modelo. 
TABLA 6. RESULTADOS DEL MODELO NOCTURNO PATRÓN

\begin{tabular}{lllllllll}
\hline $\begin{array}{l}\text { Componentes } \\
\text { principales }\end{array}$ & $\begin{array}{l}\text { Valor } \\
\text { propio } \boldsymbol{\Lambda}\end{array}$ & $\begin{array}{l}\mathbf{R}^{2} \\
(\%)\end{array}$ & $\mathbf{R}^{2}(\%$ cum) & $\mathbf{Q}^{2}$ & $\mathbf{Q}^{2}$ (cum) & $\begin{array}{l}\text { Grado } \\
\text { significación }\end{array}$ & $\begin{array}{l}\text { Número de iteraciones } \\
\text { (Algoritmo NIPALS) }\end{array}$ \\
\hline 1 & 6,14 & 87,7 & 87,7 & 83,4 & 83,4 & $\mathrm{R} 1$ & 6 \\
2 & 0,52 & 7,43 & 95,2 & 36,5 & 89,5 & $\mathrm{R} 1$ & 9 \\
\hline
\end{tabular}

TABLA 7. ANOMALÍAS ELIMINADAS DURANTE LA DEPURACIÓN DEL MODELO.

\begin{tabular}{ll}
\hline ANOMALÍA & INDIVIDUOS (días) \\
\hline & $1,4,8,9,29,30,31,32,33,34,35,36,37,38,39,40,41,42,43,44,45$, \\
Severa (T2Hotelling) & $46,47,48,49,50,51,52,53,54,55,56,57,61,78,100,103,106,113$, \\
Moderada (DMOD) & $117,120,122,141,144,156,163,164,165,166,169,170,172,176$ \\
& $64,79,101,107,121,136,171,173,177,178,179,180$, \\
\hline
\end{tabular}

Las proyecciones sobre el plano formado por las dos direcciones principales del modelo definitivo se encuentran dentro de los límites fijados por la $\mathrm{T}^{2}$ de Hotelling (Figura 28), aunque sí es cierto que se pueden observar algunos días cuya distancia al modelo es elevada (Figura 29). Y es que llegar a un grado de depuración elevado conlleva reducir la muestra en exceso. Por ello es conveniente llegar a un compromiso entre el número de observaciones que se mantienen y el número de anomalías extraídas del modelo. En el caso concreto del abastecimiento estudiado el número de observaciones descartadas es relativamente alto debido a la alta frecuencia de incidencias en la red de distribución.

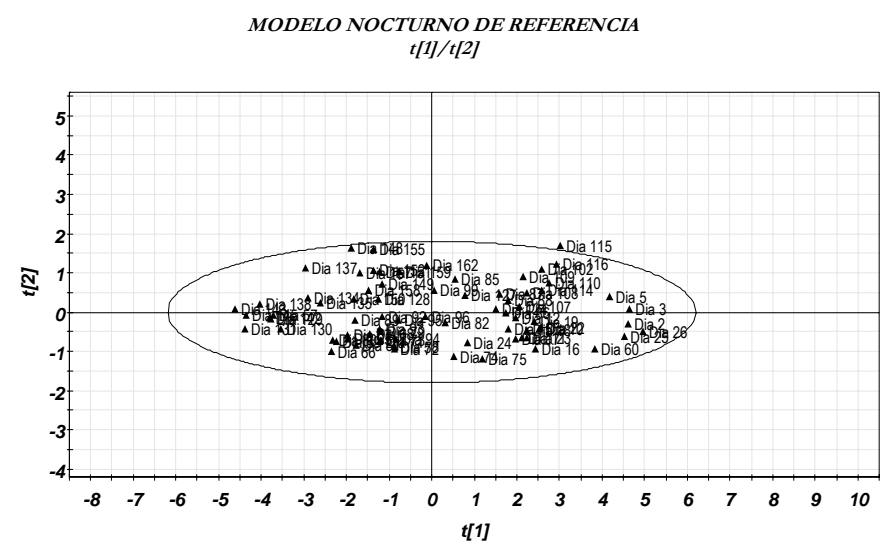

FIGURA 28.GRÁFICO DE LAS PROYECCIONES SOBRE LAS DIRECCIONES PRINCIPALES DEL MODELO NOCTURNO DE REFERENCIA. 


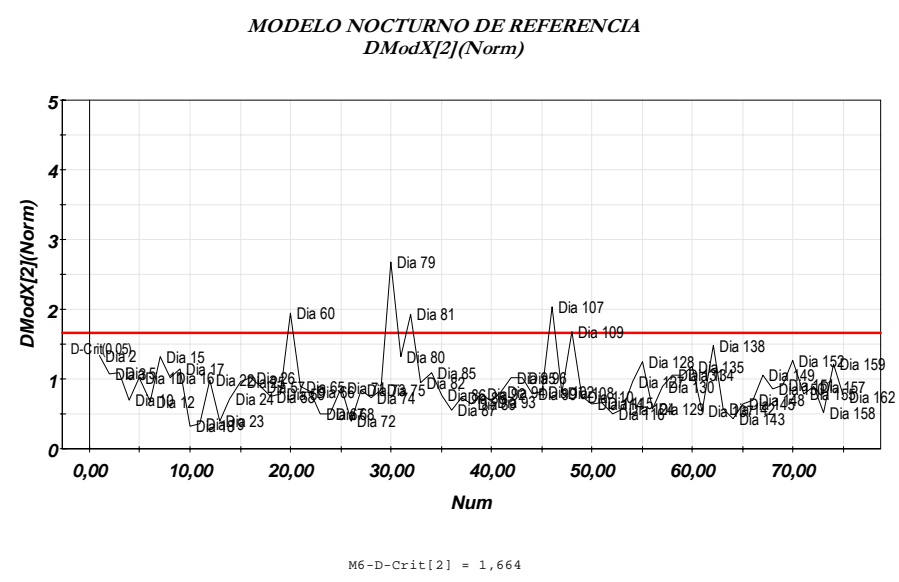

FIGURA 29.DISTANCIA AL MODELO PATRÓN DE LAS OBSERVACIONES.

Las variables más influyentes de este modelo se pueden apreciar en la Tabla 8 de los pesos, donde se indican las direcciones que mayor dominio ejercen sobre el modelo nocturno. El modelo está explicado fundamentalmente por la primera componente principal, como se puede apreciar en la tabla, y cada una de las variables hora nocturna tienen un peso similar sobre esta componente. En cambio, la segunda componente marca diferencias en el consumo a partir de las 2 de la mañana, con pesos muy bajos, al contrario que de 0 a 2 de la madrugada, horas en la cuales los pesos de la segunda componente difieren considerablemente del resto de horas, adoptando valores positivos.

TABLA 8. PESOS DE LAS VARIABLES SOBRE CADA DIRECCIÓN PRINCIPAL.

\begin{tabular}{lll}
\hline Variables & $\mathrm{p}[1]$ & $\mathrm{p}[2]$ \\
\hline $0-1 \mathrm{~h}$ & 0,32 & 0,82 \\
$1-2 \mathrm{~h}$ & 0,38 & 0,30 \\
$2-3 \mathrm{~h}$ & 0,39 & $-0,28$ \\
$3-4 \mathrm{~h}$ & 0,39 & $-0,22$ \\
$4-5 \mathrm{~h}$ & 0,39 & $-0,28$ \\
$5-6 \mathrm{~h}$ & 0,39 & $-0,01$ \\
$6-7 \mathrm{~h}$ & 0,38 & $-0,18$ \\
Total & 2,64 & 0,15 \\
\hline
\end{tabular}

TABLA 9. BONDAD DEL AJUSTE (POR COMPONENTES Y ACUMULADA).

\begin{tabular}{llll}
\hline Variable & $\mathbf{R}^{2}$ [1] & $\mathbf{R}^{2}$ [2] & $\mathbf{R}^{2}$ (acum) \\
\hline 0-1 h & 0,63 & 0,35 & 0,98 \\
1-2 h & 0,88 & 0,05 & 0,93 \\
2-3 h & 0,92 & 0,04 & 0,96 \\
$3-4 \mathrm{~h}$ & 0,95 & 0,03 & 0,97 \\
$4-5 \mathrm{~h}$ & 0,94 & 0,04 & 0,98 \\
$5-6 \mathrm{~h}$ & 0,94 & 0,00 & 0,94 \\
$6-7 \mathrm{~h}$ & 0,88 & 0,02 & 0,90 \\
\hline
\end{tabular}


No obstante, el porcentaje de variabilidad total del modelo explicado por esta segunda componente, como se aprecia en la Figura 30, es muy pequeño comparado con el de la primera.

En consecuencia, un aumento del consumo debido, por ejemplo, a fugas se reflejaría principalmente en la primera dirección, mientras que la segunda dirección no se vería prácticamente afectada. Esto implica que la componente más significativa a la hora de detectar si existe fuga en la red o si ha habido un aumento significativo del consumo será la primera, como se confirma en la Tabla 8, donde el peso total de la primera componente es muy superior al de la segunda. El grado de ajuste total del modelo es elevado debiéndose en gran parte de nuevo a la primera componente principal.

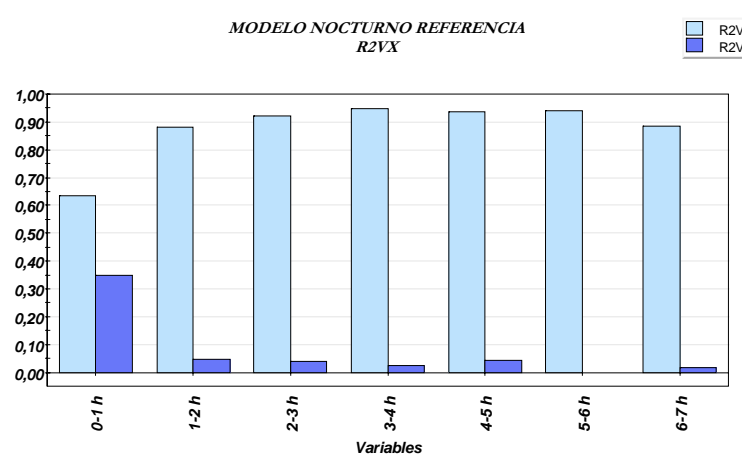

FIGURA 30.BONDAD DE AJUSTE DE CADA COMPONENTE..

\subsubsection{MODELO DE REFERENCIA DE MAÑANA (7-16 HORAS)}

Este modelo consta en principio de 130 observaciones, es decir 6 meses de mediciones continuas, y de 9 variables, que corresponden a los caudales inyectados entre las 7 de la mañana y las 16 horas (Anexo II. Tabla B).

Al contrario que el anterior, está sujeto a mayor aleatoriedad debido a que durante estas horas del día los consumos de los abonados, aleatorios, adquieren mayor peso con respecto a los consumos constantes, fugas, que en las horas nocturnas.

\subsubsection{Componentes principales y diagnóstico del modelo}

Al igual que en el caso anterior, el procedimiento seguido es el mismo que se detalla en la Figura 17, es decir, primero se genera un modelo de ACP mediante el cálculo de la componentes principales con el algoritmo NIPALS, se diagnostica con la técnica de validación cruzada y por último se valida el modelo eliminando aquellas observaciones que no entren dentro de los límites establecidos por él.

Tras sucesivas iteraciones de esta metodología, los resultados que se obtienen del modelo depurado de mañana son los siguientes.

TABLA 10. Modelo de MAÑANA DEFINITIVO

\begin{tabular}{ccc}
\hline $\begin{array}{c}\text { Componentes } \\
\text { principales }\end{array}$ & $\begin{array}{c}\text { Valor propio } \\
\Lambda\end{array}$ & $\begin{array}{c}\text { Número de iteraciones } \\
\text { (Algoritmo NIPALS) }\end{array}$ \\
\hline 1 & 4,31 & 24 \\
2 & 2,15 & 17 \\
3 & 1,12 & 14 \\
\hline
\end{tabular}


El modelo de nuevo está explicado fundamentalmente por la primera componente principal, con una varianza de las proyecciones sobre esta dirección de 4,31. Por lo tanto, como en el modelo anterior, la presencia de fugas o consumos anómalos se manifestaría principalmente en esta dirección a partir de las 10 de la mañana.

TABLA 11. PESOS DE LAS VARIABLES SOBRE CADA DIRECCIÓN PRINCIPAL.

\begin{tabular}{llll}
\hline Variables & $\mathrm{p}[1]$ & $\mathrm{p}[2]$ & $\mathrm{p}[3]$ \\
\hline $7-8 \mathrm{~h}$ & 0,004 & 0,521 & 0,316 \\
$8-9 \mathrm{~h}$ & $-0,010$ & 0,643 & $-0,097$ \\
$9-10 \mathrm{~h}$ & 0,223 & 0,534 & $-0,201$ \\
$10-11 \mathrm{~h}$ & 0,432 & 0,020 & $-0,274$ \\
$11-12 \mathrm{~h}$ & 0,419 & $-0,132$ & $-0,278$ \\
$12-13 \mathrm{~h}$ & 0,427 & $-0,077$ & $-0,163$ \\
$13-14 \mathrm{~h}$ & 0,431 & $-0,054$ & 0,007 \\
$14-15 \mathrm{~h}$ & 0,391 & 0,008 & 0,409 \\
$15-16 \mathrm{~h}$ & 0,259 & $-0,058$ & 0,710 \\
Total & 2,575 & 1,405 & 0,429 \\
\hline
\end{tabular}

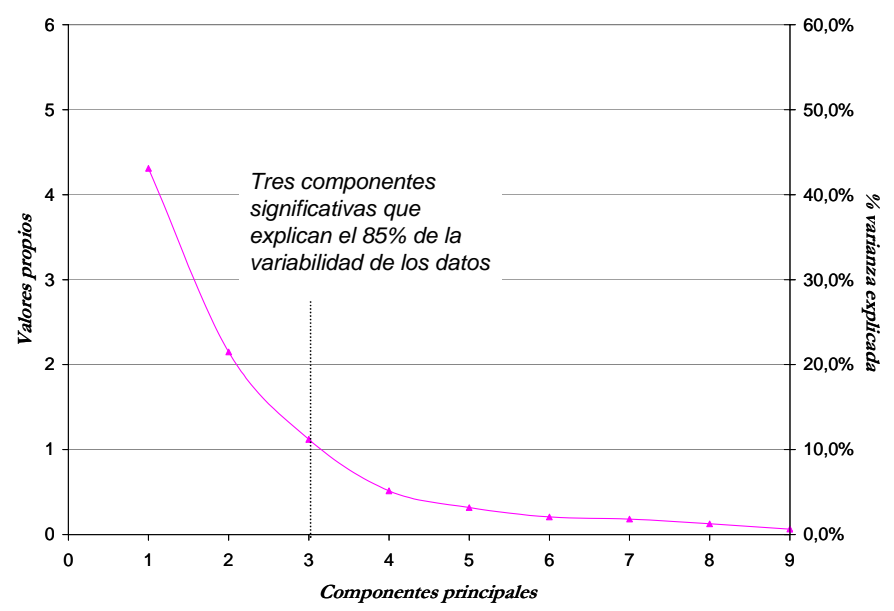

FIGURA 31. VALORES PROPIOS DE LAS COMPONENTES PRINCIPALES DEL MODELO DE MAÑANA.

En el Figura 31 se puede comprobar que la extracción de mayor número de componentes principales no aporta mayor información, mostrándose que las tres primeras componentes contienen casi el $85 \%$ de la variabilidad de los datos, como se obtuvo con la técnica de validación cruzada.

\subsubsection{Validación del modelo}

Durante la fase de validación se han eliminado aquellos individuos que de alguna forma son capaces de perturbar el modelo de análisis de componentes principales, quedando un total de 68 observaciones modelo ( $52 \%$ del total de datos originales). Las anomalías detectadas en este caso son las siguientes: 
TABLA 12. ANOMALÍAS ELIMINADAS DURANTE LA DEPURACIÓN DEL MODELO.

\begin{tabular}{ll}
\hline ANOMALÍA & INDIVIDUOS (días) \\
\hline \multirow{2}{*}{ Severa (T2Hotelling) } & $1,2,3,4,5,8,9,23,30,31,32,33,36,37,38,39,40,43,44,45,46,47,50,51$, \\
& $52,53,54,58,59,61,64,65,75,78,94,95,103,106,107,113,114,120,121$, \\
Moderada (DMOD) & $122,123,135,136,162,163,164,165,166,169,170171,172,173,176,177$, \\
& $178,179,180$ \\
\hline
\end{tabular}

Los días con caudales inyectados irregulares son detectados por estas técnicas como se advierte en la Figura 32, donde se representa el promedio de los días que se admiten en el modelo de mañana con los días anómalos hallados por el modelo. En la figura se percibe la diferencia significativa entre la curva de modulación promedio durante las 7 a 16 horas y el resto de días en los que se produce algún tipo de incidencia.

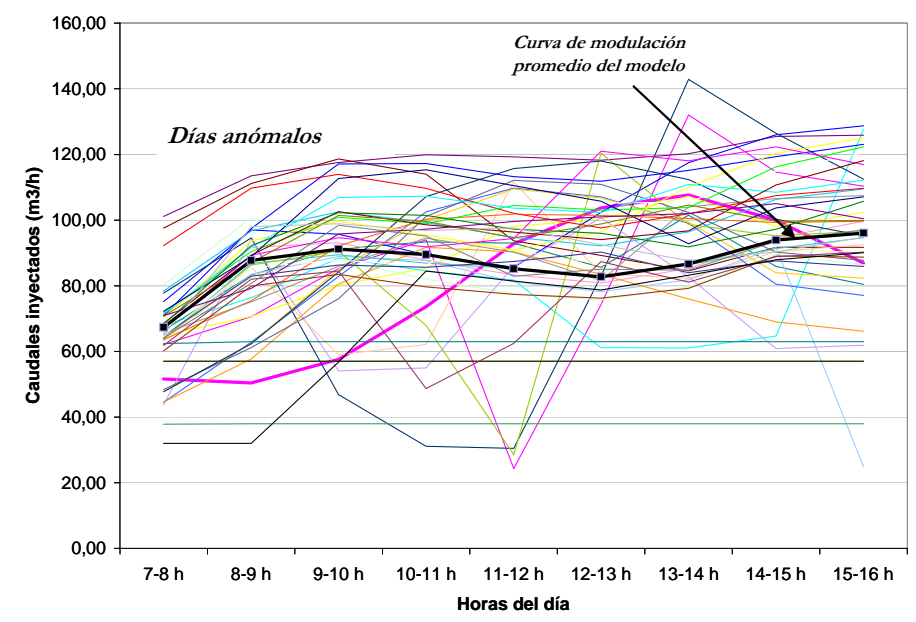

FIGURA 32. DÍAS CON CURVAS CON CAUDALES INYECTADOS A RED ANÓMALOS.

TABLA 13. Modelo de MAÑana definitivo. PARÁmetros de AJUSTE Y PREdicCión.

\begin{tabular}{llllll}
\hline Componente principal & $\mathrm{R}^{2}(\%)$ & $\mathrm{R}^{2}(\%$ cum $)$ & $\mathrm{Q}^{2}$ & $\mathrm{Q}^{2}(\mathrm{cum})$ & Grado de significación \\
\hline 1 & 47,9 & 47,9 & 36,4 & 36,4 & $\mathrm{R} 1$ \\
2 & 23,9 & 71,8 & 23,7 & 51,4 & $\mathrm{R} 1$ \\
3 & 12,5 & 84,3 & 14,5 & 58,5 & $\mathrm{R} 1$ \\
\hline
\end{tabular}

R1: Componente significativa

\subsubsection{MODELO DE REFERENCIA DE TARDE (16 - 24 HORAS)}

En principio el modelo está compuesto, como el modelo de mañana y el nocturno, por 130 observaciones, es decir 6 meses de mediciones continuas, y 8 variables u horas de 16 a 24 (Anexo II. Tabla C). 


\subsubsection{Componentes principales y diagnóstico del modelo}

Como en los otros casos, el procedimiento seguido es el mismo que se detalla en la Figura 17. Finalmente, tras sucesivas iteraciones de esta metodología quedan 89 días modelo, un $68 \%$ sobre el total, con los que se obtienen los siguientes resultados.

TABLA 14. MODELO TARDE PATRÓN

\begin{tabular}{lll}
\hline Componentes principales & Valor propio $\Lambda$ & $\begin{array}{l}\text { Número de iteraciones } \\
\text { (Algoritmo NIPALS) }\end{array}$ \\
\hline 1 & 6,22 & 8 \\
2 & 1,09 & 7 \\
\hline
\end{tabular}

\subsubsection{Validación del modelo}

Durante la fase de validación, las anomalías detectadas (41 días) son las siguientes:

TABLA 15. ANOMALÍAS ELIMINADAS DURANTE LA DEPURACIÓN DEL MODELO.

\begin{tabular}{ll}
\hline ANOMALI'A & INDIVIDUOS (días) \\
\hline Severa (T2Hotelling) & $1,4,5,8,23,33,58,59,61,64,75,78,102,103,106,113,115,120,121,122,123,134$, \\
Moderada (DMOD) & $143,156,157,158,162,163,164,165,166,169,170,171,172,173,176,177,178,179,180$ \\
\hline
\end{tabular}

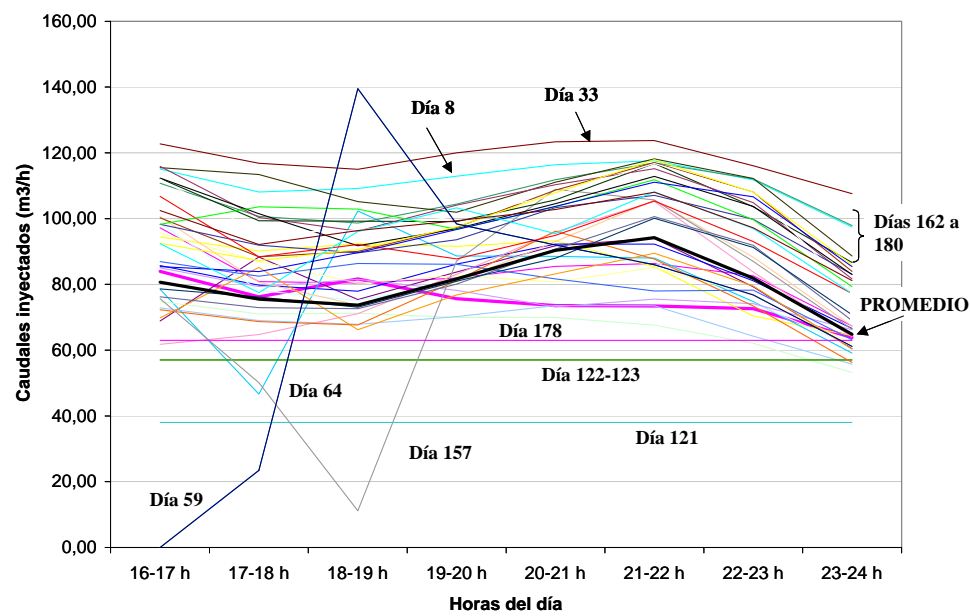

FIGURA 33.DÍAS CON CURVAS CON CAUDALES INYECTADOS DURANTE LA TARDE ANÓMALOS

Después de excluir aquellos días en los que ocurren incidencias de diferente índole (Figura 33), el modelo final obtenido muestra una distribución de scores o proyecciones convenientemente uniforme (Figura 34), y un gráfico de control de la distancia al modelo (Figura 35). 


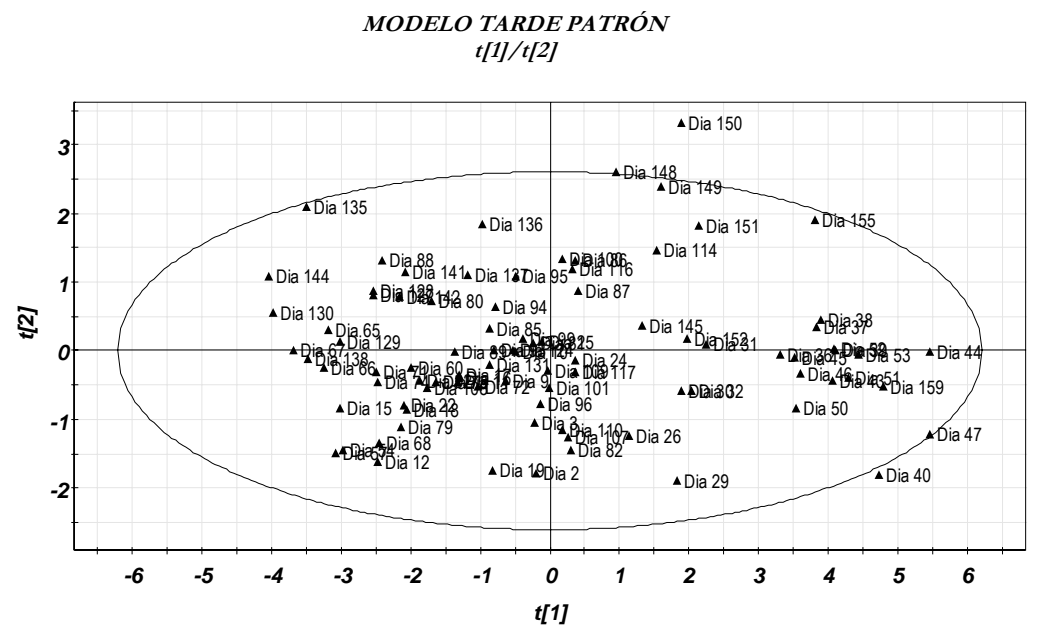

FIGURA 34. GRÁFICO DE LAS PROYECCIONES DEL MODELO DE REFERENCIA DE LA TARDE.

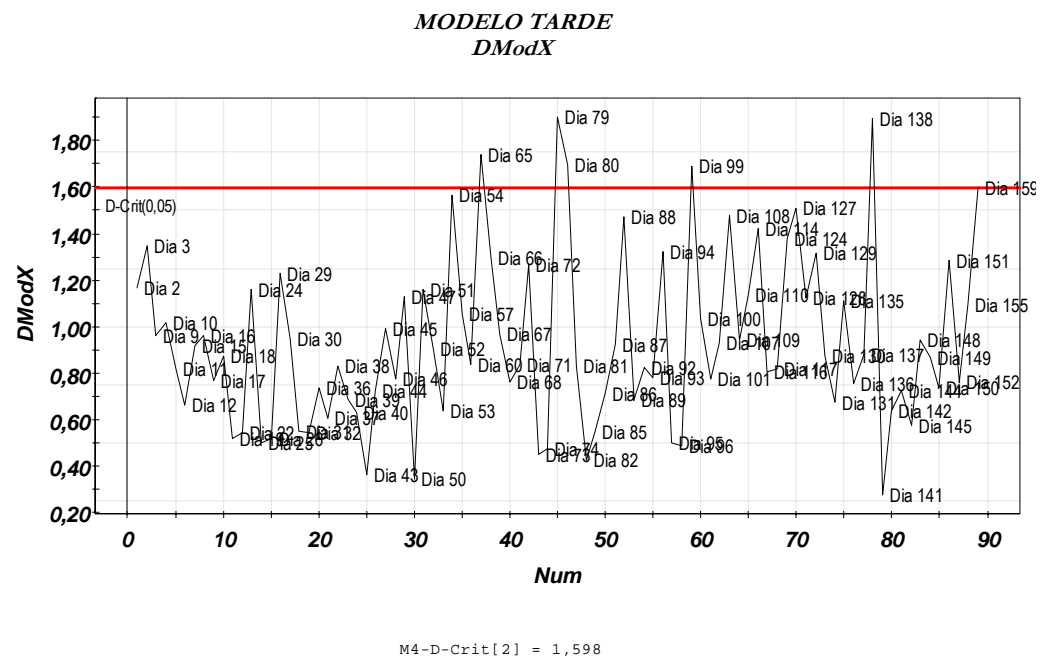

FIGURA 35.GRÁFICO DE CONTROL DMOD PARA DETECTAR ANOMALIAS MODERADAS.

En la Tabla 16 se detalla el peso de cada variable sobre las direcciones principales. Se observa que durante las horas de mayor consumo el peso en la segunda componente es positivo y más elevado que en la primera, lo que difiere del resto de horas se caracterizan por tener pesos menores en esa dirección. A pesar de ello, en este caso, el modelo de la tarde está explicado fundamentalmente por la primera componente.

TABLA 16. PESOS DE LAS VARIABLES SOBRE CADA DIRECCIÓN PRINCIPAL.

\begin{tabular}{ccc}
\hline Variables & $\mathrm{p}[1]$ & $\mathrm{p}[2]$ \\
\hline $16-17 \mathrm{~h}$ & 0,353 & $-0,345$ \\
$17-18 \mathrm{~h}$ & 0,366 & $-0,272$ \\
\hline
\end{tabular}




\begin{tabular}{ccc}
\hline $18-19 \mathrm{~h}$ & 0,364 & $-0,336$ \\
$19-20 \mathrm{~h}$ & 0,377 & $-0,192$ \\
$20-21 \mathrm{~h}$ & 0,355 & 0,180 \\
$21-22 \mathrm{~h}$ & 0,287 & 0,638 \\
$22-23 \mathrm{~h}$ & 0,337 & 0,466 \\
$23-24 \mathrm{~h}$ & 0,380 & 0,033 \\
Total & 2,819 & 0,172 \\
\hline
\end{tabular}

TABLA 17. BONDAD DEL AJUSTE (POR COMPONENTES Y ACUMULADA).

\begin{tabular}{cccc}
\hline Variable & $\mathbf{R}^{\mathbf{2}}$ [1] & $\mathbf{R}^{\mathbf{2}}$ [2] & $\mathbf{R}^{\mathbf{2}}$ (acum.) \\
\hline $16-17 \mathrm{~h}$ & 0,776 & 0,130 & 0,91 \\
$17-18 \mathrm{~h}$ & 0,834 & 0,081 & 0,92 \\
$18-19 \mathrm{~h}$ & 0,826 & 0,123 & 0,95 \\
$19-20 \mathrm{~h}$ & 0,882 & 0,041 & 0,925 \\
$20-21 \mathrm{~h}$ & 0,784 & 0,035 & 0,82 \\
$21-22 \mathrm{~h}$ & 0,511 & 0,445 & 0,95 \\
$22-23 \mathrm{~h}$ & 0,706 & 0,237 & 0,94 \\
$23-24 \mathrm{~h}$ & 0,897 & 0,001 & 0,90 \\
\hline
\end{tabular}

MODELO TARDE

$R 2 V X$

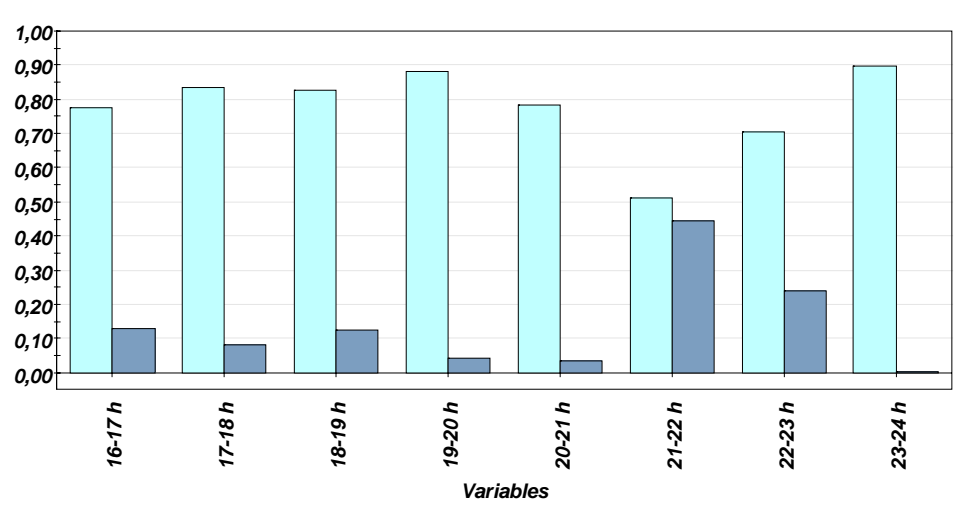

FIGURA 36. HISTOGRAMA DE LA BONDAD DEL AJUSTE AL MODELO.

TABLA 18. MOdELO DE MAÑANA DEFINITIVO. PARÁMETROS DE AJUSTE Y PREDICCIÓN.

\begin{tabular}{llllll}
\hline Componente principal & $\mathbf{R}^{\mathbf{2}}(\%)$ & $\mathbf{R}^{\mathbf{2}}$ (\%cum) & $\mathbf{Q}^{2}$ & $\mathbf{Q}^{2}$ (cum) & Grado de significación \\
\hline 1 & 77,7 & 77,7 & 70,2 & 70,2 & $\mathrm{R} 1$ \\
2 & 13,7 & 91,4 & 48,5 & 84,7 & $\mathrm{R} 1$ \\
\hline
\end{tabular}

R1: Componente significativa. 


\subsection{ANÁLISIS DE SENSIBILIDAD DE LOS MÉTODOS DE DETECCIÓN}

Uno de los principales objetivos de este tipo de análisis reside en mejorar la efectividad de los métodos de detección de anomalías, en el sentido de aumentar la capacidad de detección de incidencias de menor magnitud. La duda que surge en estos casos es si el método detecta, por ejemplo, fugas o roturas de menor caudal que lo que sería capaz de identificar con una determinada probabilidad un método de análisis estadístico multivariante.

\subsubsection{SIMULACIÓN DE CAUDALES INYECTADOS EN UN SECTOR CON FUGAS}

\subsubsection{Caso: T2 Hotelling}

Con el fin de analizar la sensibilidad de este método de detección, conviene generar consumos que pertenezcan al modelo a los cuales se les añadirá un caudal de fuga. De esta manera se observará el potencial identificador del mismo.

Para generar consumos que pertenezcan al modelo, es decir, que se encuentren definidos en el espacio de las componentes se asume que las proyecciones sobre cada dirección principal, combinaciones lineales de los caudales inyectados, siguen una distribución normal de media cero (datos de partida centrados) y desviación típica $\sqrt{\lambda_{A}}$.

$$
\begin{gathered}
t_{A} \sim N\left(0, \sqrt{\lambda_{A}}\right) \text { cuando la matriz } \overline{\bar{Z}} \text { está centrada } \\
t_{A} \sim N\left(m_{0}, \sqrt{\lambda_{A}}\right) \text { cuando la matriz } \overline{\bar{Z}} \text { no está centrada }
\end{gathered}
$$

La anterior suposición sirve, en el presente trabajo, para simular caudales inyectados que serán considerados como pertenecientes al modelo, a la red de distribución estudiada con el objetivo de determinar la sensibilidad del método en la detección anomalías o defectos en el sistema.

Para ello, se elabora un procedimiento en el que se generan 30.000 números aleatorios que siguen una distribución normal $\mathrm{N}\left(0, \sqrt{\lambda_{A}}\right)$, con el programa informático Statgraphics 4.0 para cada una de las direcciones de los modelos de ACP. Estos números aleatorios, simulan días de consumo estable, ya que han sido creados a partir de los modelos de referencia depurados. Los datos de partida para cada simulación son:

\begin{tabular}{|c|c|c|c|c|c|c|c|}
\hline MODELO & $\begin{array}{l}\text { NaCOMPONENTES } \\
\text { PRINCIPALES }\end{array}$ & $\begin{array}{l}\text { MEDIA } \\
\mathrm{t}\end{array}$ & $\begin{array}{l}\text { DESVIACIÓN } \\
\text { TÍPICA DE t }\end{array}$ & $\begin{array}{l}\text { No DIAS } \\
\text { MODELO }\end{array}$ & $\mathrm{N}^{0}$ VARIABLES & $\begin{array}{l}\text { CAUDAL } \\
\text { INYECTADO } \\
\text { ( } \mathrm{m}^{3} / \mathrm{hora} \text { ) }\end{array}$ & MEDIO \\
\hline Nocturno & 1 & $0^{*}$ & $\begin{array}{l}2,48 \\
0,72\end{array}$ & 75 & 7 & 42,6 & \\
\hline & 1 & & 2,08 & & & 84,6 & \\
\hline De mañana & $\begin{array}{l}2 \\
3\end{array}$ & $0^{*}$ & $\begin{array}{l}1,46 \\
1,06\end{array}$ & 68 & 9 & & \\
\hline Tarde & $\begin{array}{l}1 \\
2\end{array}$ & $0^{*}$ & $\begin{array}{l}2,49 \\
1,04\end{array}$ & 89 & 8 & 80,3 & \\
\hline
\end{tabular}

TABLA 19. CARActerísticas deL MODELO de REFERENCIA.

*Los datos originales se encuentran escalados y centrados. 
Tras simular 30.000 días con curvas de modulación horaria dentro de los límites establecidos por los diferentes modelos de ACP con un nivel de confianza del $95 \%$, se adiciona a estas proyecciones un término constante que representa un caudal de fuga. Este término de pérdidas de agua en la red se agrega obedeciendo al peso que posee cada una de las variables del modelo.

$$
t \text { fuga }_{i, a}=t_{i, a}+\sum_{\substack{k=\text { Hora } \\
\text { inicio } \\
\text { fuga }}}^{K} p_{k, a} \cdot \frac{Q_{i \text { fuga }}}{\sigma_{K}}=t_{i, a}+\underbrace{Q_{\text {fuga }} \cdot \sum_{\text {desplazamiento }}^{K} \frac{p_{k, a}}{\sigma_{K}}}_{\begin{array}{c}
\text { inicio } \\
\text { fuga }
\end{array}}
$$

Esta forma de proceder posibilita estudiar la capacidad de detección de fallos del método estadístico propuesto sin necesidad de poseer datos reales. Además, permite analizar su sensibilidad con diferentes caudales de fuga, duraciones del consumo debido a la fuga, y distintos niveles de confianza. Lo que a su vez, ayudará a una adecuada selección de estos niveles (valores de a y $\beta$ ), en función de la situación específica de cada abastecimiento de agua.

\subsubsection{Caso: DMOD}

De igual forma, para conocer la sensibilidad y eficacia de este método de detección (DMOD), asimismo interesante, se propone una sistemática para simular de nuevo días con fuga con la mayor similitud posible. Para ello, conviene evaluar por separado cada uno de los residuos. En caso de un individuo, los residuos se descompondrían en:

$$
\overrightarrow{e_{i 2, K}}=\overrightarrow{e_{i 1, K}}+\overrightarrow{e^{f u g a} a_{i, K}}
$$

$$
\begin{aligned}
& \overrightarrow{e_{i 1, k}}: \text { Residuos propios del modelo de referencia. } \\
& \overrightarrow{e \text { fuga } i 2, k}: \text { Residuos generados al proyectar sobre el modelo caudales de fuga simulados. }
\end{aligned}
$$

Donde los residuos propios del modelo(e1), son la diferencia entre los datos de la matriz original y los datos estimados a partir de las variables latentes de cada modelo de referencia, es decir:

$$
\overrightarrow{e_{i 1, K}}=\overrightarrow{q_{i, K}}-\overrightarrow{\hat{q}_{i, K}}=\overrightarrow{q_{i, K}}-\overrightarrow{t_{i, A}} \cdot{ }^{p}{ }^{T} k, A
$$

$$
\begin{aligned}
& \overrightarrow{\hat{q}_{i, K}}: \text { Caudal inyectado cada hora tipificado. } \\
& \overrightarrow{q_{i, K}} \text { : Caudal estimado por el modelo ACP. }
\end{aligned}
$$

Estos residuos, aleatorios, se considera que siguen una distribución normal, a partir de la cual se pueden generar $\mathrm{N}$ simulaciones: 


$$
e_{N, K} \sim N\left(0, \sigma_{e_{K}}\right)
$$

Por otra parte, el residuo formado por la adición del caudal de fuga se estima simultáneamente, calculando la diferencia entre la matriz de datos originales donde se han introducido las fugas reales a diferentes caudales y la matriz estimada deducida a partir de las direcciones principales del nuevo espacio, tal y como se expone analíticamente, generándose 30.000 simulaciones que serán evaluadas en apartados posteriores.

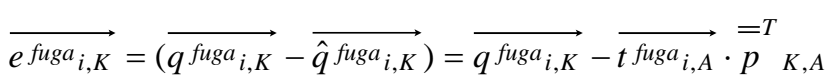

siendo * Gruga : Caudales de inyectados de fuga tipificados.

\subsubsection{ANÁLISIS DE SENSIBILIDAD T² HOTELLING}

La eficacia de la técnica estadística propuesta para detectar anomalías en la red de distribución depende de varios factores, entre ellos la magnitud del caudal fugado, la hora en que se inicia la fuga y el nivel de confianza que se desea tener en la detección del mismo.

Por ello, siempre es conveniente realizar un análisis de sensibilidad, en el cual se examina para diferentes ordenes de magnitud del defecto (Qfugado), considerando éstos como porcentaje sobre el caudal promedio inyectado en cada modelo (0 a $20 \mathrm{~m}^{3}$ ), y para diferentes niveles de significación ( $a=5,10,15,20,25 \%$ ), el porcentaje de días rechazados. Otra de las variables tratadas en este análisis es la sensibilidad que posee cada uno de los modelos para detectar anomalías cuando ésta se inicia a diferentes horas del día.

Actuando sobre estas variables se podrá estimar la validez del método y, a su vez, se aportará conocimiento suficiente al técnico para que pueda tomar decisiones en función de las condiciones de su sistema de abastecimiento de agua.

Una primera conclusión indiscutible es que a mayor caudal supuesto de fuga, mayor es el porcentaje de observaciones rechazadas por el modelo, como se aprecia en cualquier curva de las presentadas a continuación.

Cuando se analiza la sensibilidad de cada uno de los modelos de ACP a diferentes horas de inicio de la fuga, se advierte que durante las primeras horas de cada modelo su eficacia es más alta. Esto quiere decir que para un caudal de fuga añadido, por ejemplo del $15 \%$, equivalente en el modelo nocturno a $6 \mathrm{~m}^{3} / \mathrm{h}$ perdidos, el defecto será detectado con mayor probabilidad si se produce durante las primeras horas de la madrugada (Figura 37).

La explicación a este hecho se encuentra en que este método $\mathrm{T}^{2}$ de Hotelling detecta cambios en el consumo total. Por tanto, cuanto antes se produce la fuga mayor será el caudal medio y mayor será la probabilidad de encontrarla. 


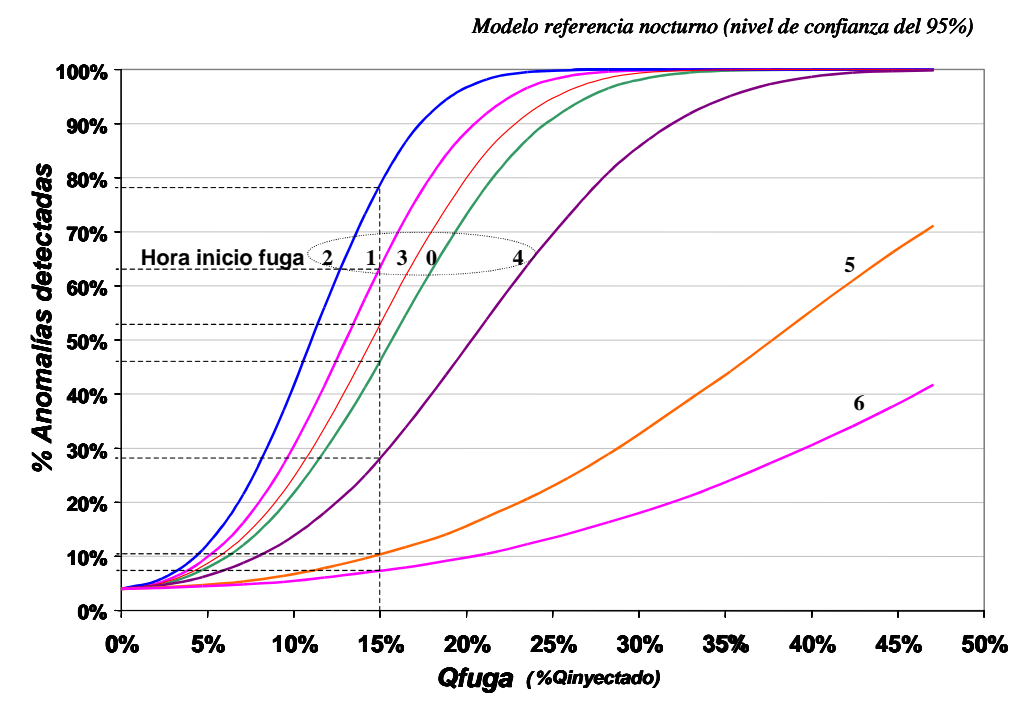

FIGURA 37.ANÁLISIS DE SENSIBILIDAD POR HORAS DEL MODELO NOCTURNO.

Cuando se analiza la situación desde otra óptica, quizá más habitual ya que el técnico no puede actuar sobre la eficacia del modelo en sí mismo, sino sobre variables que optimicen esta técnica de detección de fallos a las condiciones del abastecimiento, una de las variables, posiblemente la más importante, es el nivel de fiabilidad en la detección adecuado para cada situación.

Como se ha comentado en el epígrafe 2.3, el nivel de significación a que se puede adoptar es variable, y debe ser elegido dependiendo de las condiciones del sistema. Hay que tener en cuenta que este parámetro tiene una influencia significativa en la detección de fallos, ya que varía los límites de control del estadístico $F$, siendo más restrictivo respecto a las observaciones que deben ser rechazadas con un nivel de confianza alto (1-a) y menos restrictivo, en caso contrario. No obstante, ambas situaciones pueden conducir a error en la detección de fallos del sistema. Por una parte, un nivel de confianza bajo puede provocar errores tipo falsa alarma, observaciones con comportamiento normal que salen fuera de los límites de confianza del modelo de referencia, al contrario que un nivel de confianza alto, cuyos límites podrían envolver una observación siendo esta anómala. Estas afirmaciones se aclaran gráficamente en la Figura 38.

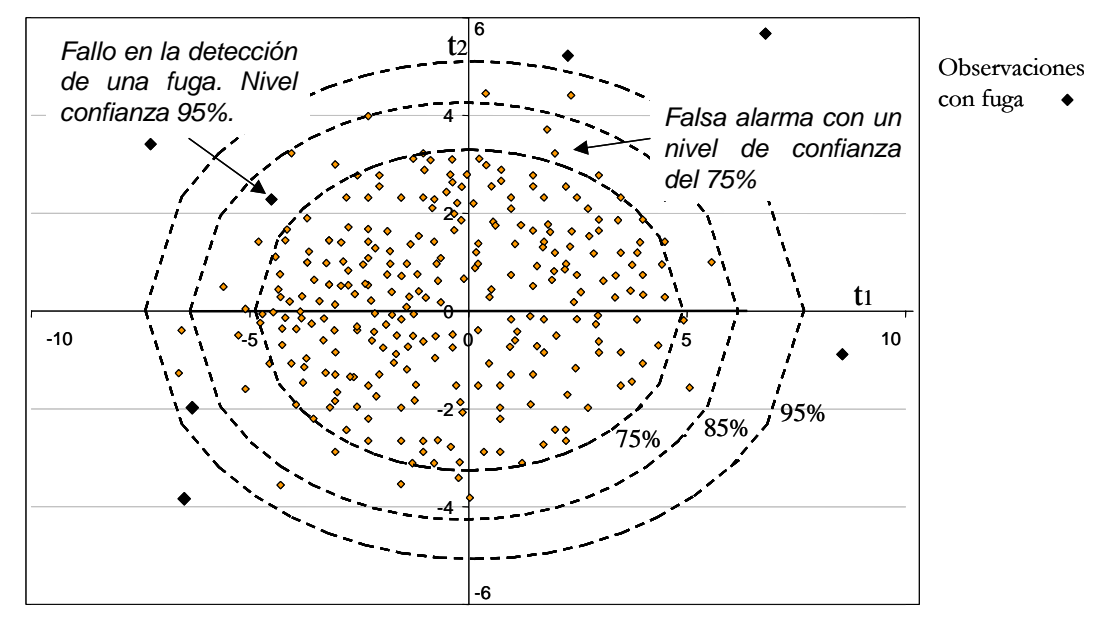

FIGURA 38.VARIACIÓN EN LOS LIMITES DE CONTROL DEL MODELO DEPENDIENDO DEL NIVEL DE CONFIANZA. 
Para evaluar la eficacia de esta técnica en función de los caudales de fuga y de los diferentes niveles de significación se realiza un análisis de sensibilidad para cada uno de los modelos estudiados (Figura 39). Los resultados obtenidos son muy desiguales dependiendo del grado de fiabilidad tomado.

El caso estudiado en particular posee una tasa de aparición de fugas bastante elevada, debido al estado de la propia red, a las irregularidades del terreno, a los cortes de suministro producidos en el pasado que agravaron la situación, etcétera. En este contexto, la política de gestión del abastecimiento está conduciendo a una fuerte campaña de detección y localización de fugas en el sistema. Debido a ello, la introducción adecuada de estas técnicas de detección siempre es importante para mejorar las condiciones de distribución de agua. No obstante, estas deben ser incluidas de manera sensata, ya que de otro modo, pueden causar un excesivo número de desaciertos en la detección de caudales perdidos por fugas de gran tamaño.

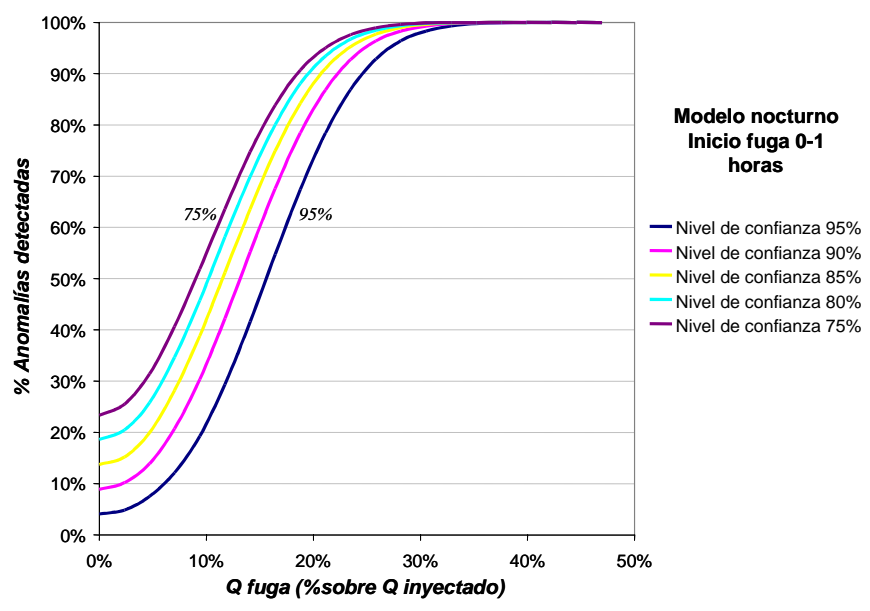

FIGURA 39. ANÁLISIS DE SENSIBILIDAD DEL MODELO NOCTURNO PARA DIFERENTES NIVELES DE CONFIANZA CON UNA FUGA INICIADA A LAS 0 HORAS.

Como ejemplo que ayuda a aclarar ideas, se muestra las diferencias que ocasionaría la elección de diversos grados de fiabilidad en la detección de días con fugas. Para ello se ha elegido primero un nivel de confianza del $95 \%$, es decir adoptando una gestión conservadora, en la cual se debe conocer con certeza la existencia de una supuesta fuga y no malgastar tiempo en falsas alarmas. Evidentemente, esta elección puede provocar por una parte, que fugas de menor caudal no sean detectadas (Figura 40), y por otra, admitir como normal un día con una fuga considerable con la consiguiente pérdida de agua, deterioro de imagen de la empresa de aguas, etcétera.

Las figuras muestran las diferencias entre los dos niveles de confianza extremos del $75 \%$ y del $95 \%$. Ambos casos mantienen las primeras horas del cada modelo determinantes para detectar fallos por medio de la $\mathrm{T}^{2}$ de Hotelling, pero se advierte que para un mismo nivel de anomalías detectadas $(60 \%)$, los caudales de fuga son más elevados con un nivel de confianza más alto. Lógicamente esta afirmación concuerda, ya que una fiabilidad alta solicita reducir el número de falsas alarmas, y esto ocurre cuando los caudales de fuga son más elevados. 


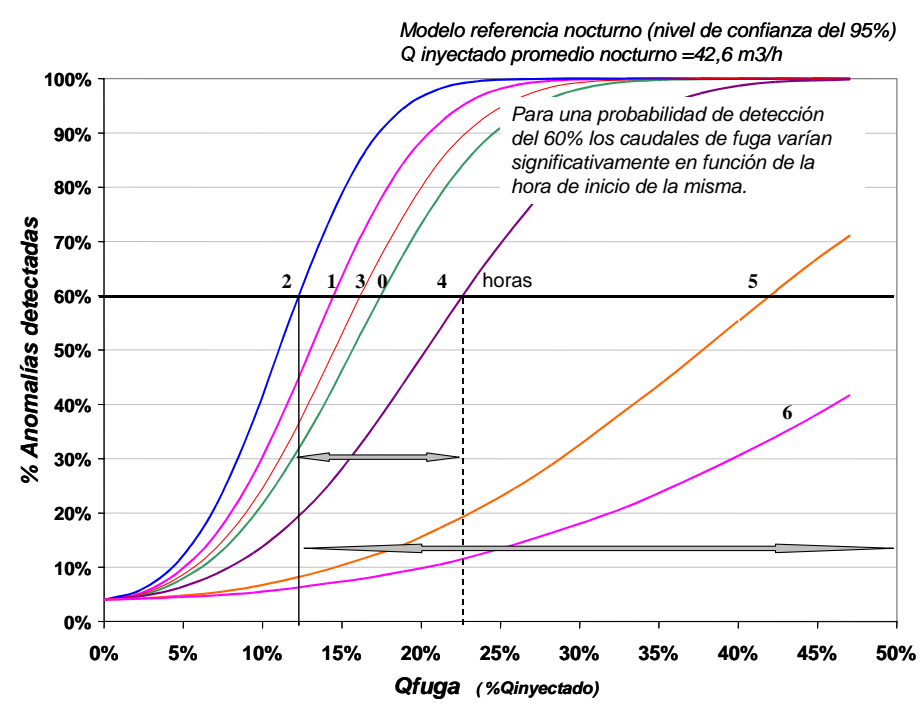

FigurA 40. MOdELO NOCTURNO PARA DIFERENTES NIVELES DE CONFIANZA. NIVEL DE CONFIANZA 95\%.

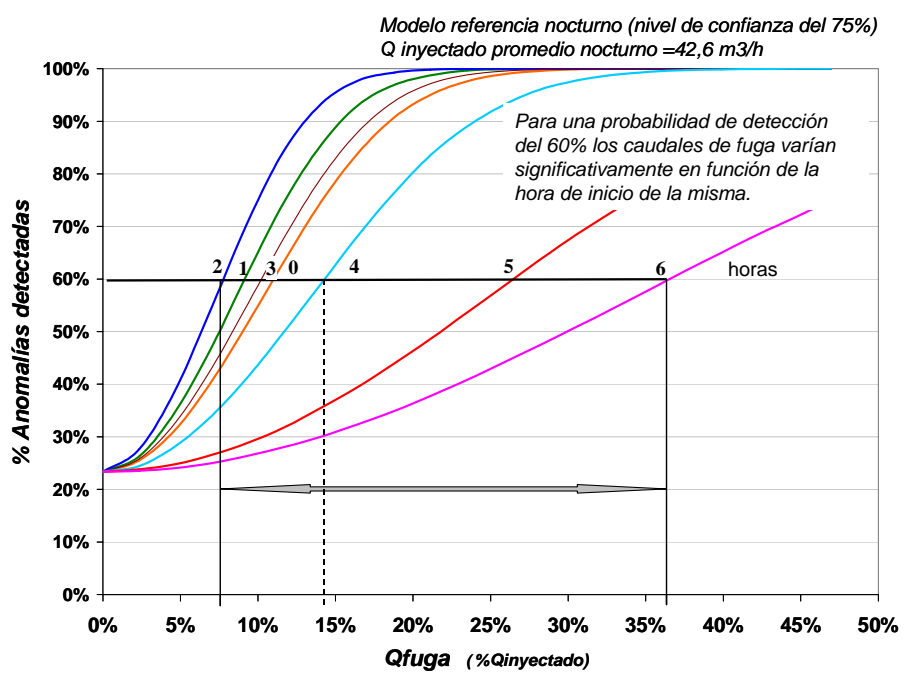

FigURA 41. MOdELO NOCTURNO PARA DIFERENTES NIVELES DE CONFIANZA. NIVEL DE CONFIANZA 75\%.

Para un nivel de confianza del $75 \%$ (Figura 41), un caudal de fuga aproximadamente del $10 \%$ del caudal medio inyectado se detectaría con una probabilidad del $60 \%$, si la fuga se produjese entre las 0 y las 3 horas de la madrugada. Sin embargo, para conseguir una probabilidad de acierto equivalente en una fuga iniciada a las 4 horas el caudal de la misma debería aumentar hasta el $14 \%$ Qmedio inyectado. Si el nivel de confianza fuera del $95 \%$ el caudal de fuga que se produciría entre las 0 y las 3 horas, necesario para que sea detectado con un $60 \%$ de probabilidad, subiría hasta casi el $15 \%$.

A continuación se analiza, como ejemplo, un día en el que se produce una rotura durante las últimas horas de la mañana (13 horas), que fuga un caudal del $8 \%$ del caudal promedio inyectado, es decir, cerca de $6,77 \mathrm{~m}^{3} / \mathrm{h}$. 
TABLA 20. CASO PRÁCTICO. MÉTOdO DE DETECCIÓN T2HOTELLING. APARICIÓN DE UNA FUGA EQUIVALENTE AL 8\% DEL CAUDAL INYECTADO DURANTE LA MAÑANA.

\begin{tabular}{lllll}
\hline MODELO & Qiny & Fuga & $\begin{array}{l}\mathbf{Q}_{\text {fuga }} \\
(\% \text { sobre }\end{array}$ & Qiny $)$ \\
\hline Día & 84,6 & 6,77 & 8,0 & 55 \\
Tarde & 80,3 & 6,77 & 8,4 & 58 \\
Noche & 42,6 & 6,77 & 15,9 & 82 \\
\hline
\end{tabular}

Se comprueba que para un nivel de confianza, por ejemplo del $75 \%$, la probabilidad de que dicha fuga sea detectada durante el día es del $55 \%$. Es decir, la probabilidad de que se produzca alguna alarma durante la mañana es muy reducida.

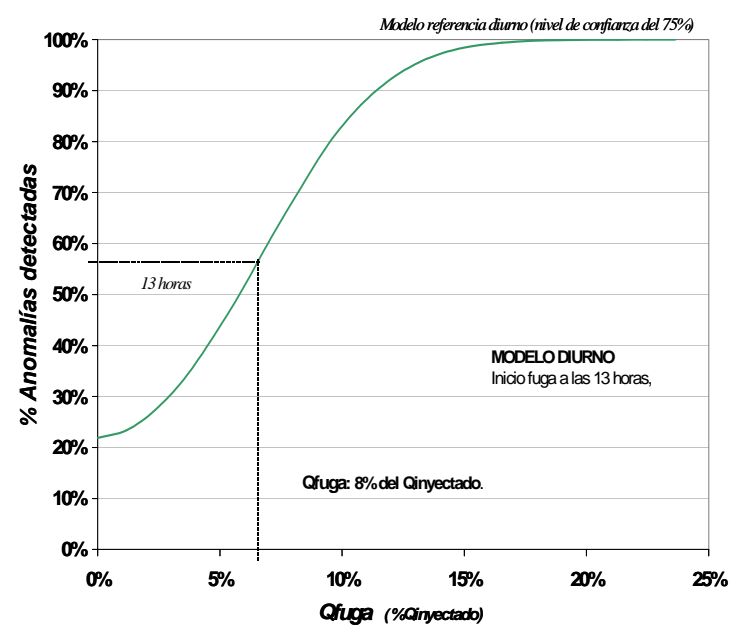

FIGURA 42. EJEMPLO DE DETECCIÓN DE UNA FUGA DE 8\% DEL CAUDAL INYECTADO PRODUCIDA A LAS $13 \mathrm{H}$.

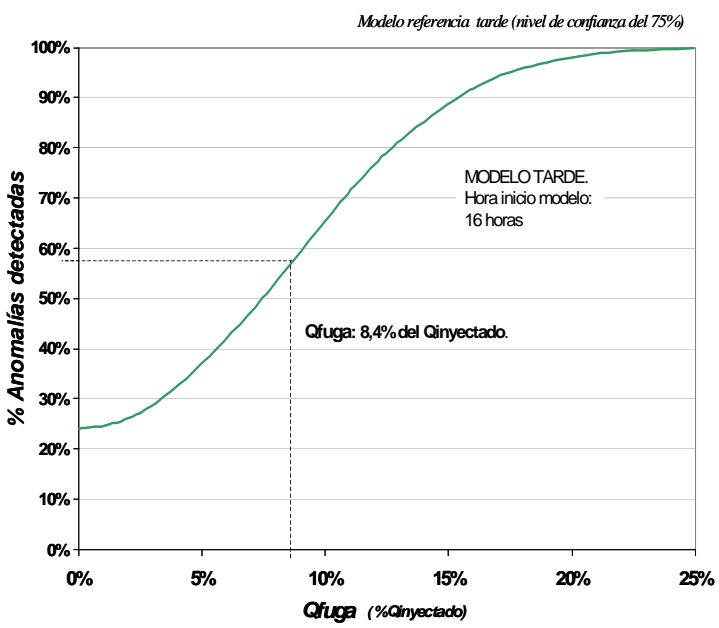

FIGURA 43.EJEMPLO DE DETECCIÓN DE UNA FUGA CUANDO ALCANZA EL MODELO DE LA TARDE. 
Esta baja probabilidad aumenta cuando se llega al modelo de tarde hasta un $58 \%$ (Figura 43), donde la fuga equivale entonces a un $8,4 \%$ del caudal inyectado y se considera iniciada, evidentemente, en la primera hora del modelo. Este porcentaje de acierto, todavía bajo, hace que esta fuga de escaso caudal continúe, un alto porcentaje de veces, sin ser hallada. Cuando la fuga, todavía sin reparar, alcanza el modelo nocturno este caudal de fuga representa casi el $16 \%$ del caudal inyectado, lo que significa un porcentaje de acierto de 82\% (Figura 44), bastante más elevado (Tabla 20).

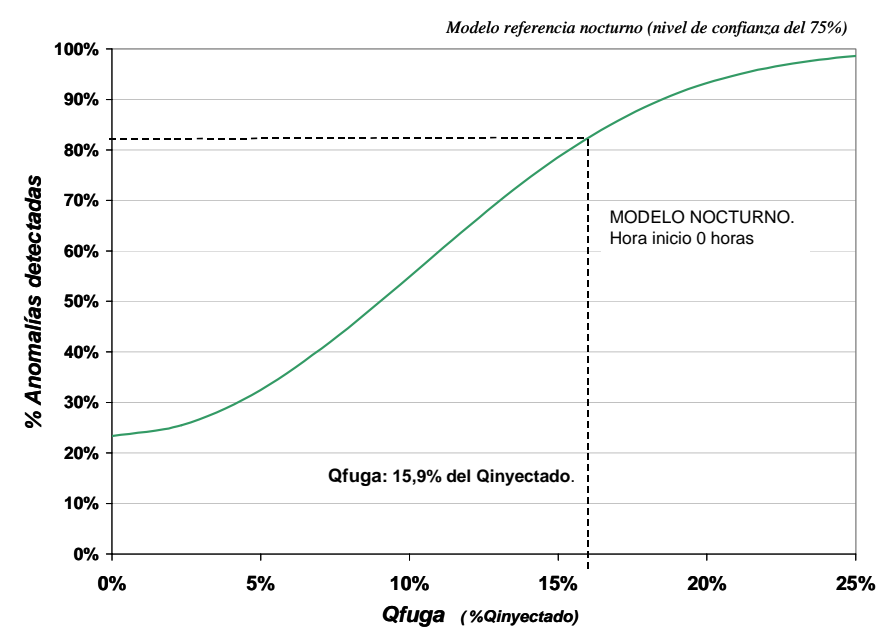

FIGURA 44.EJEMPLO DE DETECCIÓN DE UNA FUGA CUANDO ALCANZA EL MODELO DE NOCTURNO.

Este resultado es importante, ya que la probabilidad de encontrar una fuga provocada el mismo día en que se produjo es elevada, lo que supone un gran avance para los técnicos de los abastecimientos de agua, cuando esta técnica de análisis estadística sea implementada en el SCADA como sistema de alerta.

\subsubsection{ANÁLISIS DE SENSIBILIDAD MEDIANTE LA DMOD}

Al igual que el método anterior, la eficacia de esta técnica de detección depende de la magnitud del caudal fugado, la hora en que se inicia la fuga y el nivel de confianza que se desea tener en la detección del mismo, con lo que el análisis de sensibilidad será muy similar al anterior.

En este caso se reducen los niveles de significación a dos extremos, $a=10 \%$ y $a=25 \%$ con el fin de reducir los cálculos. El resto de variables es similar, es decir, inicio de la fuga a diferentes horas del día y Qúgado de diferente magnitud en función del caudal medio inyectado a la red del modelo de ACP monitorizado (nocturno, de mañana, tarde).

Como es obvio, de nuevo a mayor caudal de fuga supuesto mayor es el porcentaje de observaciones rechazadas por el modelo con esta técnica.

En cambio, cuando se analiza la sensibilidad del modelo de ACP a diferentes horas de inicio de la fuga, inicialmente se advierte que durante las últimas horas, al contrario que en el caso anterior, su eficacia es más alta (Figura 45 y Figura 46). 


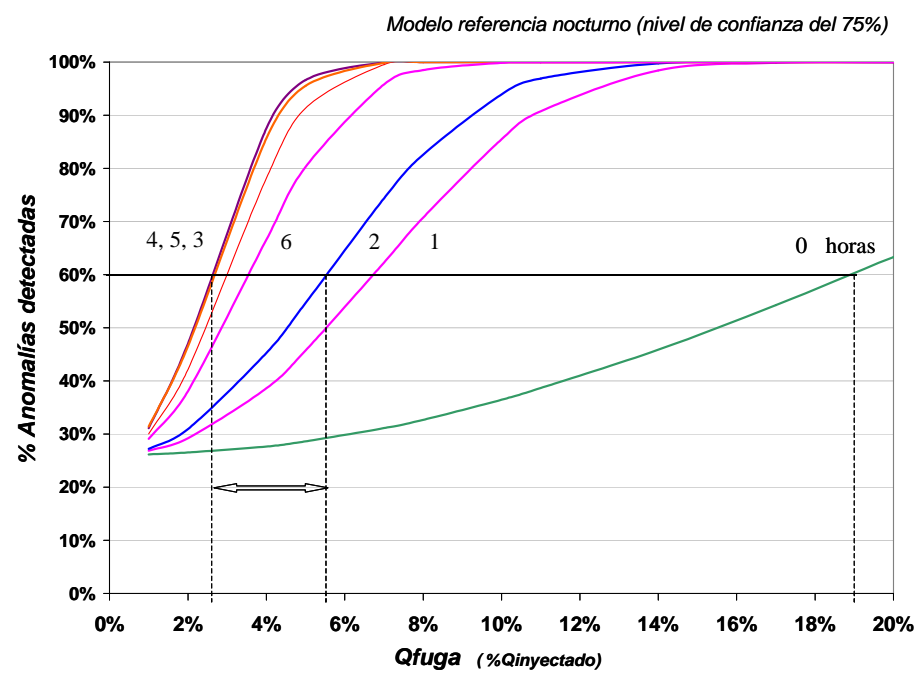

FIGURA 45. ANÁLISIS DE SENSIBILIDAD MODELO NOCTURNO. NIVEL DE CONFIANZA DEL 75\%.

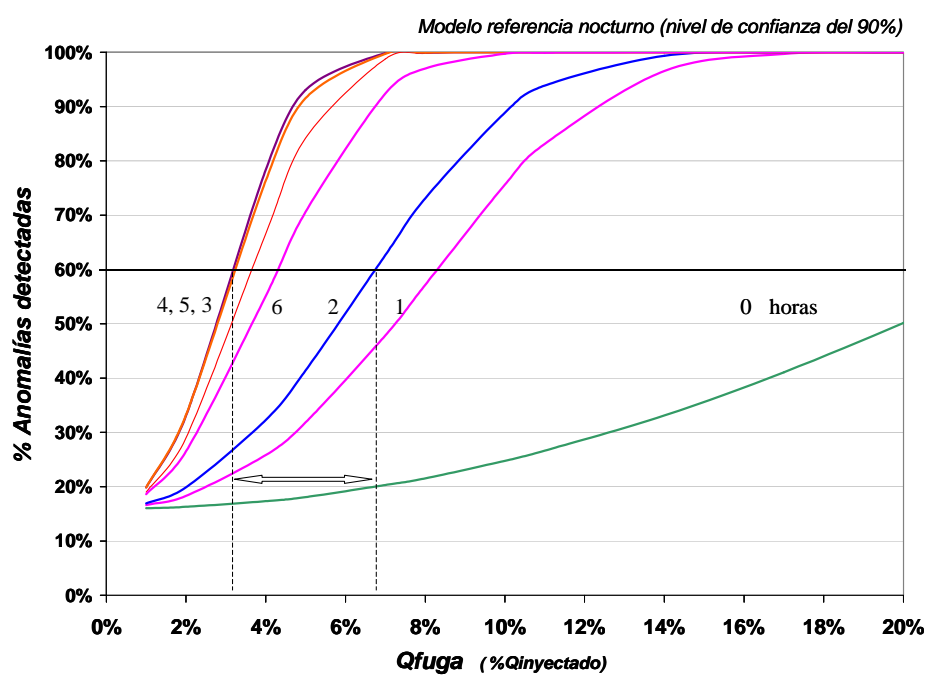

FIGURA 46. ANÁLISIS DE SENSIBILIDAD POR HORAS DEL MODELO NOCTURNO. NIVEL DE CONFIANZA 90\%.

Asimismo, la Figura 45 y Figura 46 muestra las diferencias entre los dos niveles de confianza estudiados, advirtiéndose que con este método de detección se obtienen mejores resultados que con el anterior.

Esto se comprueba observando que para caudales de fuga menores los porcentajes de detección de anomalías son mayores durante las últimas horas de cada modelo, horas más eficaces. Por ejemplo, como en el apartado anterior, para un nivel de confianza del modelo nocturno del $75 \%$, un caudal de fuga aproximadamente del $3-4 \%$ del caudal medio inyectado (mucho menor que en el caso anterior) se detectaría con la misma probabilidad, es decir del $60 \%$ de días rechazados por algún tipo de incidencia, si ésta se produjese durante las últimas horas del modelo nocturno. 


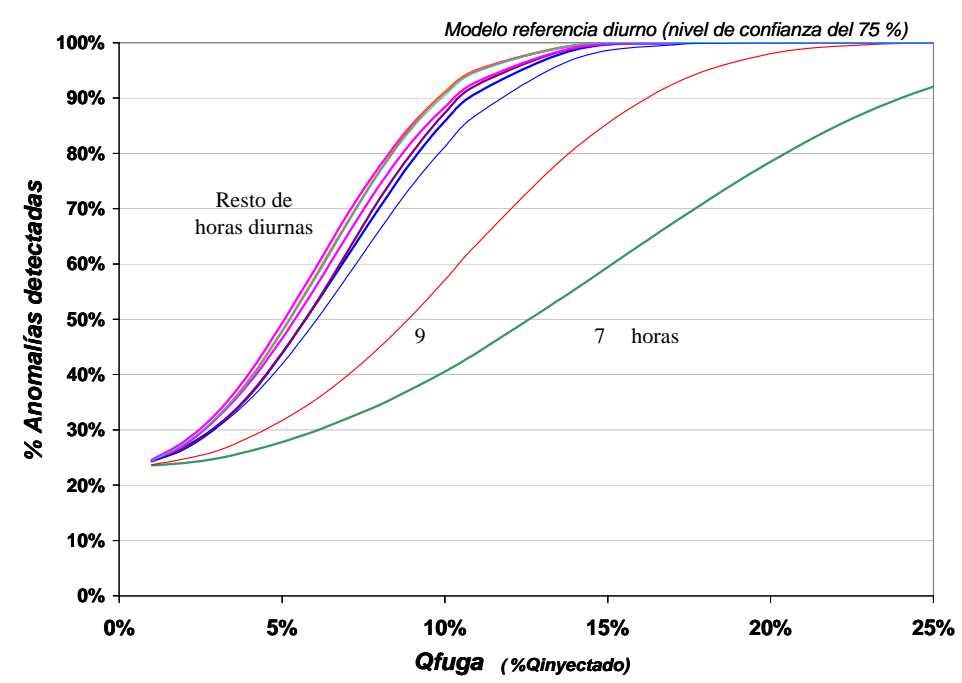

FIGURA 47.ANÁLISIS DE SENSIBILIDAD POR HORAS DEL MODELO DE MAÑANA.

La explicación a este hecho, como se ha comentado, es debida a que esta técnica detecta mejor cambios bruscos en la forma de la curva de modulación horaria, y estos se originan cuando la fuga se inicia en las últimas horas del periodo de monitorización donde el cambio es más acusado que durante las primeras horas.

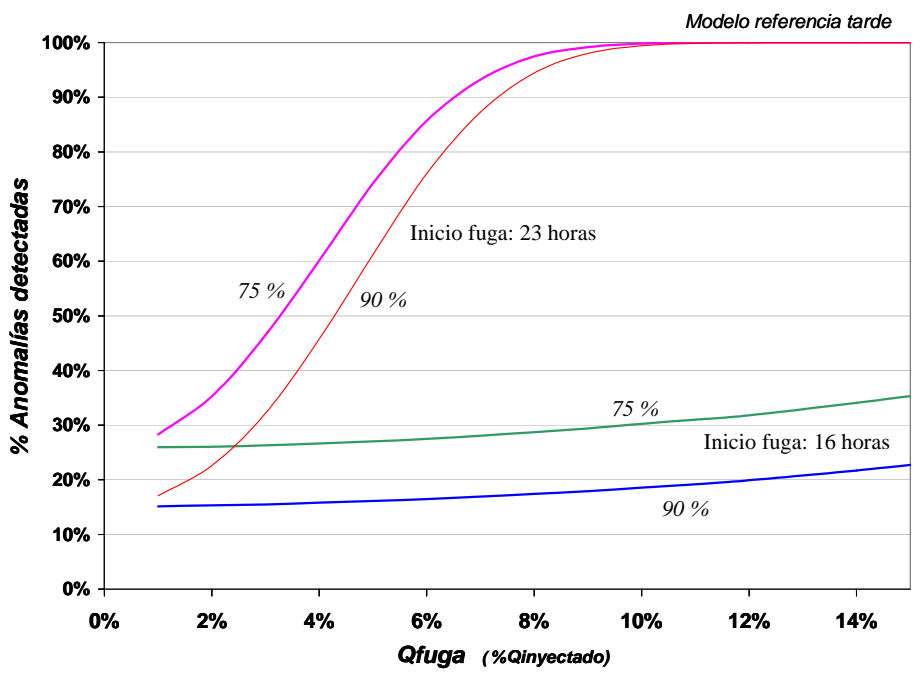

FIGURA 48.ANÁLISIS INDEPENDIENTE DE LA PRIMERA Y ÚLTIMA HORA DEL MODELO TARDE.

En el Figura 48 se confirma que durante las últimas horas del modelo (tarde: 23 horas) el porcentaje de anomalías detectadas continua siendo superior que durante las primeras horas. A su vez, se observa también que para un nivel de confianza menor, es decir del 75\%, el porcentaje de detección es mayor. Esta afirmación es lógica, ya que un nivel de 
confianza menor ocasiona que los márgenes de tolerancia de la DMOD sean más estrechos rechazando mayor número de individuos críticos con un grado de fiabilidad menor.

No obstante, las ventajas que se establecían en el método anterior en la monitorización en continuo, es decir en el tiempo, no se presentan en este método. Esto se comprueba considerando el mismo ejemplo del apartado anterior, donde se suponía una fuga equivalente al $8 \%$ del caudal inyectado, empleando este método los resultados varían. Se advierte claramente en este caso que el método en continuo no es tan efectivo y dependerá, fundamentalmente, de la hora de comienzo de la fuga. Esto quiere decir, que si la fuga comienza a las 13 horas (modelo de mañana) tendrá una probabilidad del $79 \%$ de ser detectada con una fiabilidad del $75 \%$, y si no se detecta esta probabilidad disminuirá en las siguientes horas (Tabla 21).

TABLA 21. CASO PRÁCTICO. MÉTODO DE DETECCIÓN DMOD. APARICIÓN DE UNA FUGA EQUIVALENTE AL 8\% DEL CAUDAL INYECTADO DURANTE LA MAÑANA.

\begin{tabular}{lll}
\hline MODELO & $\begin{array}{l}\mathbf{Q}_{\text {fuga }} \\
(\% \text { sobre }\end{array}$ & $\%$ Acierto \\
\hline Día & $8,0 \%$ & $79 \%$ \\
Tarde & $8,4 \%$ & $30 \%$ \\
Noche & $15,9 \%$ & $38 \%$ \\
\hline
\end{tabular}

Durante los modelos siguientes la probabilidad de detección de incidencias disminuye (Figura 49). La explicación a este hecho se halla en que durante las simulaciones se considera que el inicio de la fuga se produce, en los modelos siguientes al inicial, durante la primera hora. Por ello, la curva de modulación horaria no cambia su forma y el porcentaje de detección es mucho menor. Esto hace que este método no sea tan adecuado para la monitorización en continuo, ya que los modelos siguientes en el tiempo disminuirán su capacidad detección, al contrario que la T2 Hotelling.

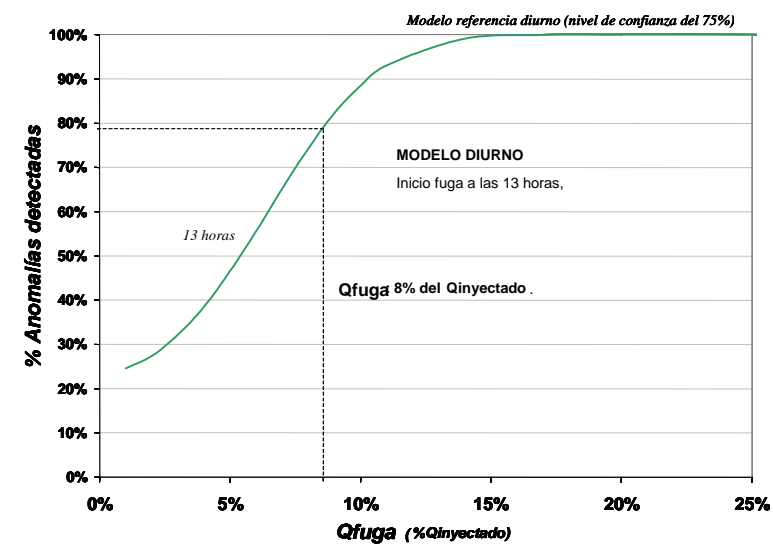

FIgURA 49.CASO PRÁctico. Fuga INICIADA DURANTE LA MAÑANA CON QFUgado DEL 8\% DEL QINY. 

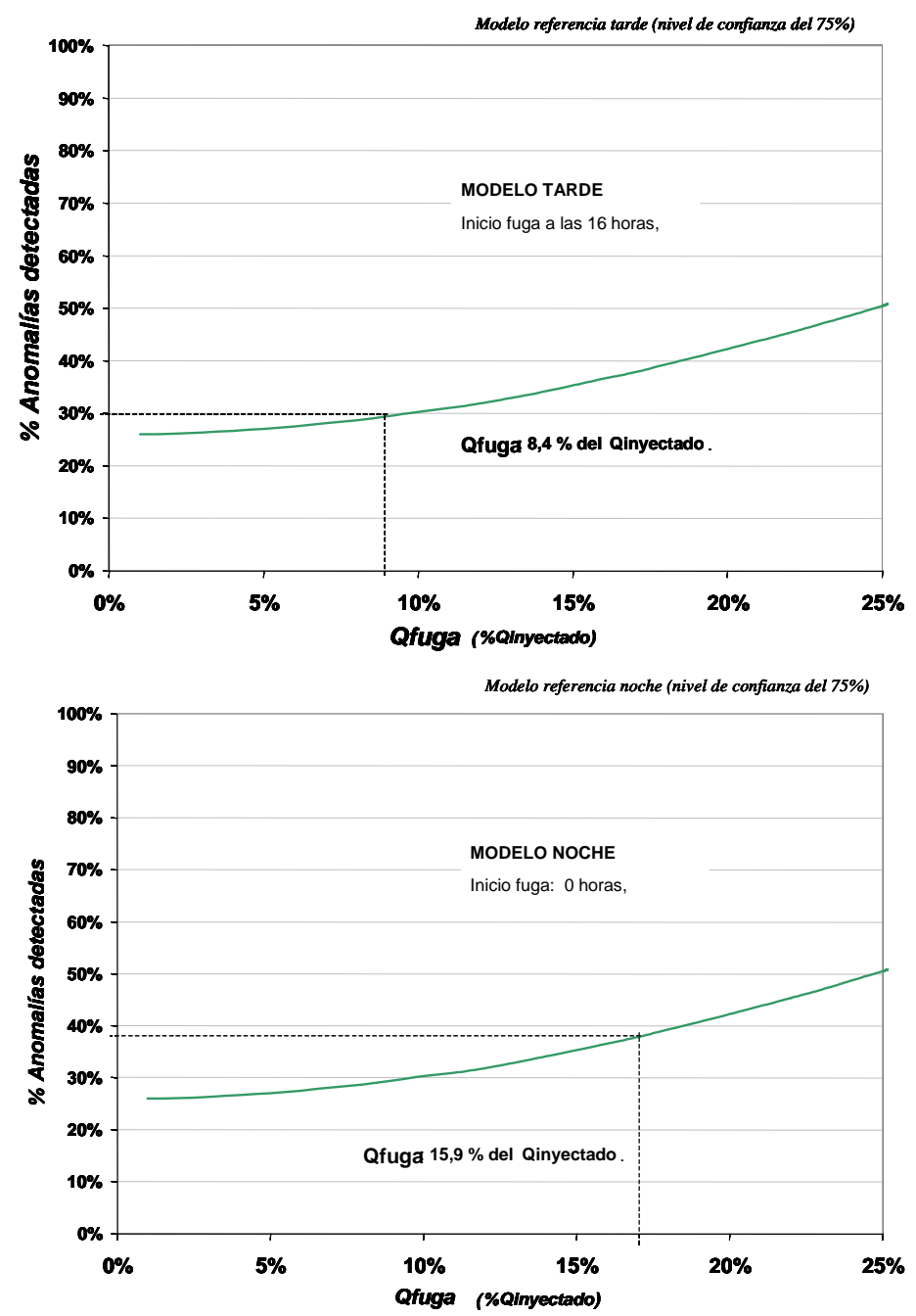

FIGURA 50. INICIO DE LA FUGA DURANTE LA TARDE O LA NOCHE.

\subsection{ANÁLISIS DE TENDENCIAS}

\subsubsection{ESTUDIO DE TENDENCIAS DE CONSUMO}

Como se ha visto durante el presente trabajo, el análisis por componentes principales aporta al técnico una nueva perspectiva en el estudio de pérdidas de agua, tanto a corto plazo con el sistema de alarmas de caudales de fuga puntuales, como en la evolución del sistema en conjunto mediante el estudio de tendencias de consumo.

Por ello, tras hallar los modelos de ACP es importante saber interpretar los resultados obtenidos y visualizar aquellos gráficos que proporcionen también información sobre la evolución de los caudales inyectados a cada sector. 
Los gráficos que visualizan estas tendencias pueden ser de distintos tipos, no obstante, los gráficos de control son los más ventajosos para este tipo de análisis son:

\subsubsection{Aumento natural de los caudales inyectados debido a la aparición de pequeñas fugas.}

Con el gráfico de las proyecciones sobre la primera dirección principal se muestra la tendencia que poseen los caudales nocturnos inyectados a la red, además se manifiestan las condiciones de estabilidad del abastecimiento o el resultado de posibles campañas de detección y localización de fugas que se lleven a cabo.

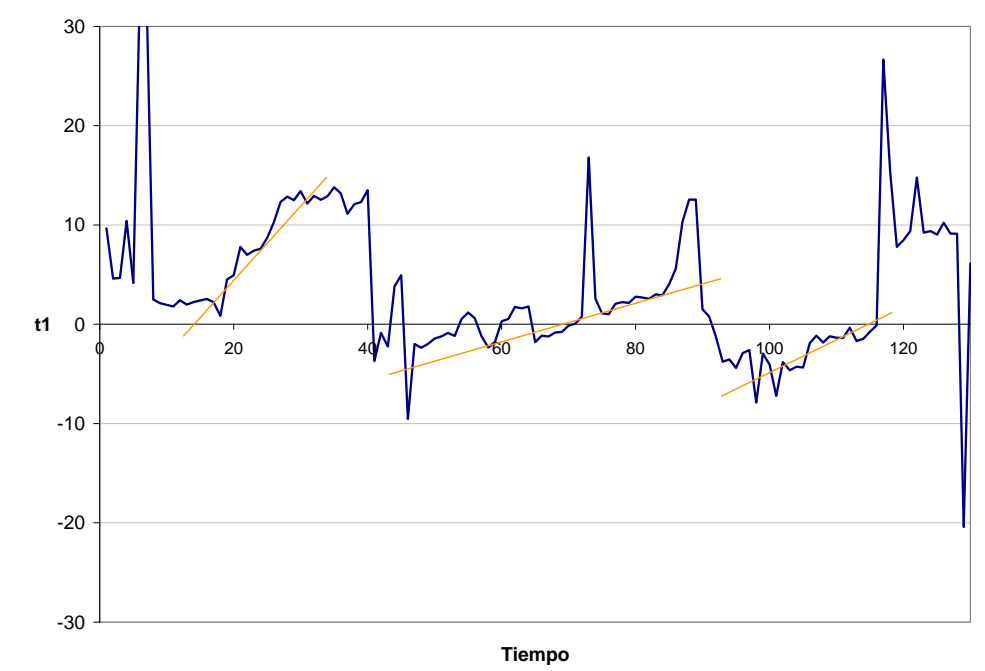

FIGURA 51.TENDENCIA NATURAL DE LOS CAUDALES INYECTADOS DEBIDO A PÉRDIDAS DE AGUA EN LA RED.

Cuando se representa los gráficos de control de las componentes es importante destacar que las tendencias evolutivas de los caudales inyectados se acusan fuertemente con esta técnica de análisis.

Estas tendencias ascendentes, intrínsecamente relacionadas con el rendimiento volumétrico del sector, en gran medida son debidas a la tasa natural de aparición de fugas en la red, es decir, al aumento del porcentaje del término correspondiente a fugas. Cuando se realiza una campaña de detección y localización de fugas donde se reparan fugas de cierta importancia, este rendimiento mejora lo que se refleja en un descenso brusco del valor de t1.

\subsubsection{Roturas en el sistema de distribución o fallo en las comunicaciones estación central- estación remota.}

La información aportada por la primera componente principal $t_{1}$ tiene que ver fundamentalmente con la detección de alteraciones graves en el sistema, objetivo principal de este análisis de los caudales inyectados. La representación gráfica de un fallo en las comunicaciones es similar a la de una rotura pero con proyecciones negativas, ya que los consumos en este caso son menores a la media o nulos y por tanto, los pesos de cada variable hacen que las proyecciones sean negativas. 


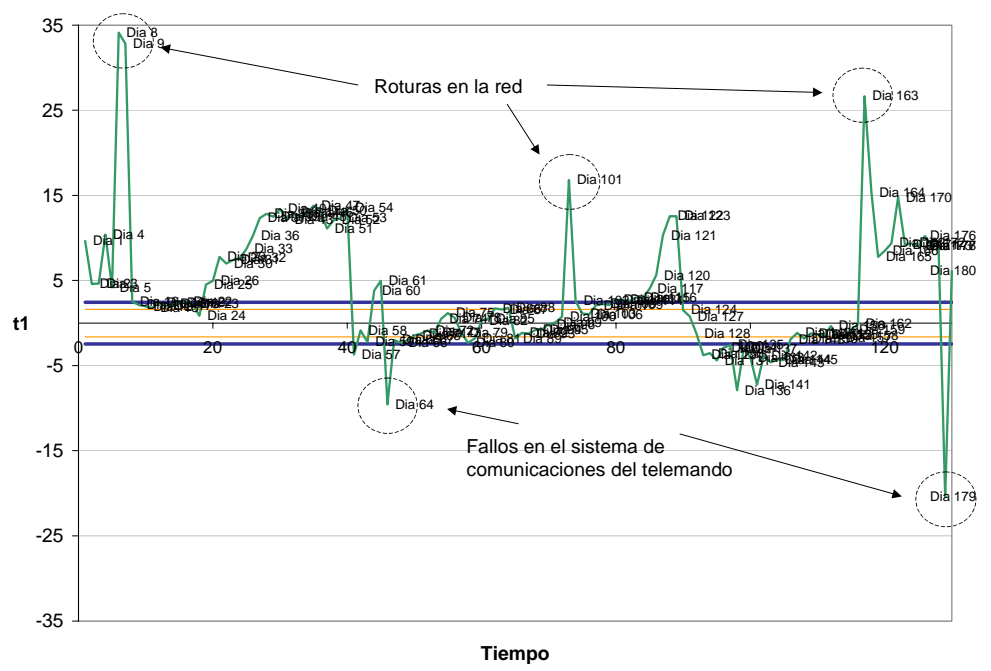

FIGURA 52.ROTURAS PUNTUALES DE CORTA DURACIÓN EN EL SISTEMA O FALLO EN LAS COMUNICACIONES.

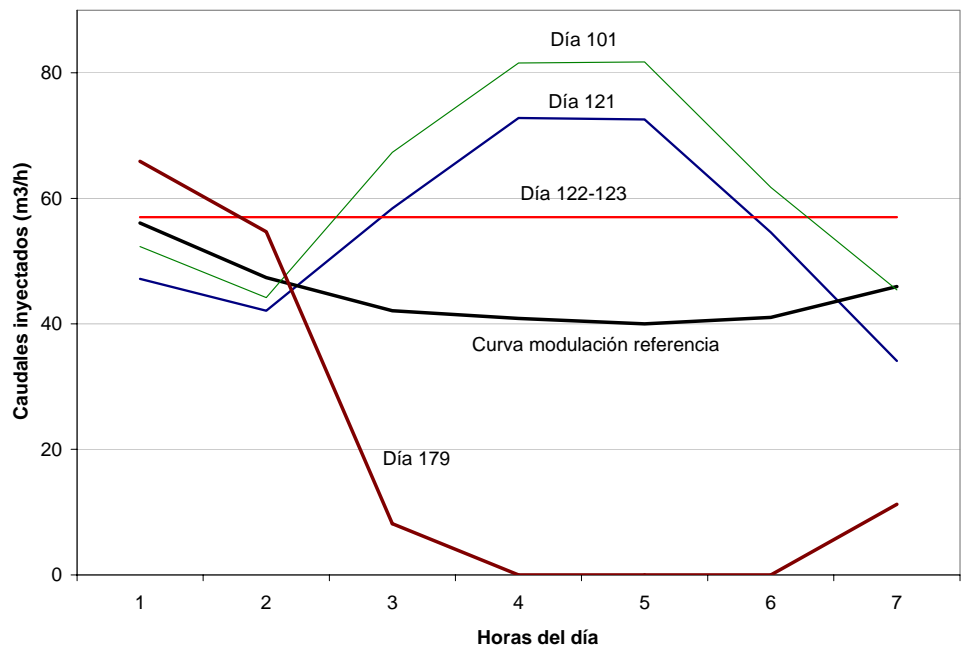

FIGURA 53.CURVAS DE MODULACIÓN HORARIA NOCTURNA. FALLOS EN EL SISTEMA DE COMUNICACIONES O PÉRDIDAS DE AGUA.

\subsubsection{Consumo estacional.}

El estudio de la segunda componente $t_{2}$ puede aportar información adicional sobre el estado de la red estudiando su evolución en el tiempo, las diversas formas de consumo de sus habitantes, etcétera. Cuando se analiza esta componente se observa que los pesos son desiguales para cada variable, al contrario que la primera en la cual los pesos son similares en cada hora. Esta desigualdad marca diferencias entre las relaciones entre variables, y determina posibles evoluciones en los caudales inyectados, tendencias de consumo, etcétera.

Como ejemplo en la Figura 54, se advierte que la curva de modulación durante las horas nocturnas, 0-1 horas, posee un consumo diferente durante el periodo de primavera - verano que durante el periodo invernal, en él, los abonados tienden a aprovechar más las horas de sol. Esto se refleja de forma clara, en el gráfico de las proyecciones sobre las dos direcciones principales (Figura 55). 


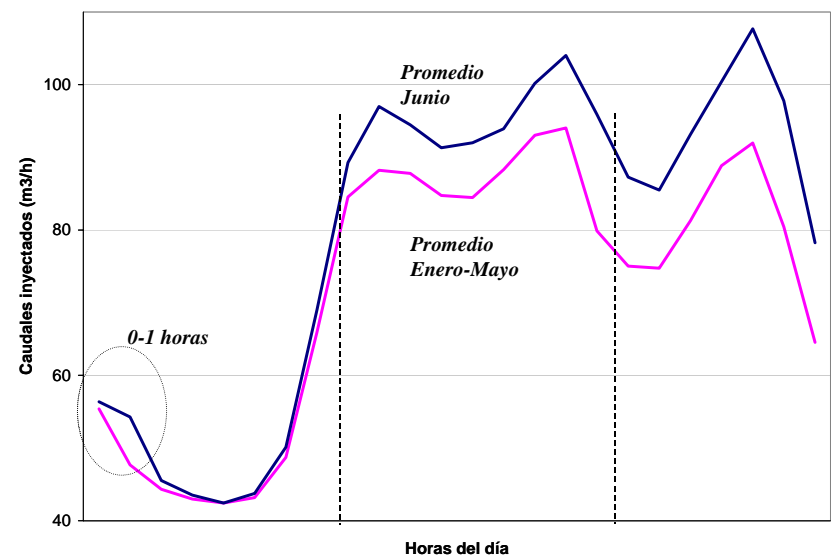

FIGURA 54.COMPARACIÓN DE LAS CURVAS DE MODULACIÓN PROMEDIO JUNIO Y RESTO DE MESES.
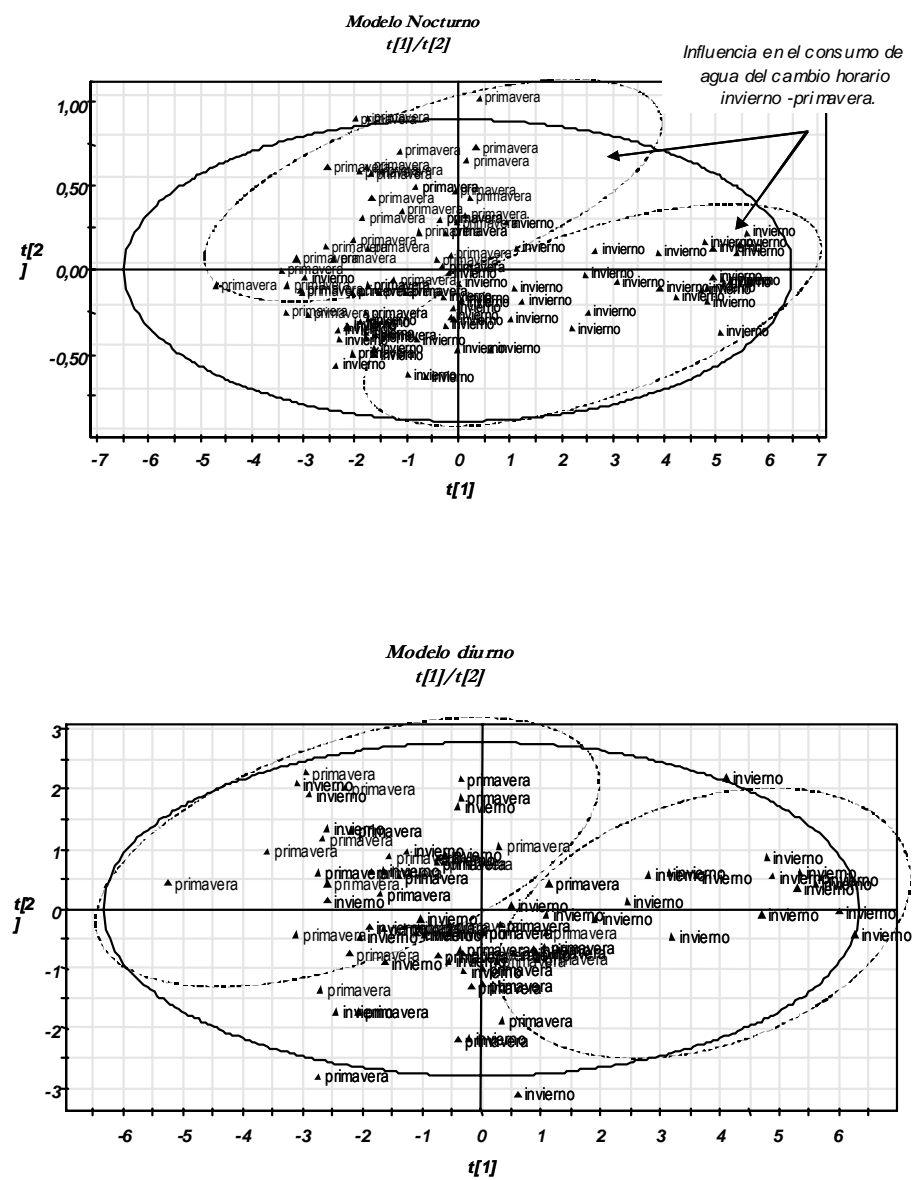

FIGURA 55.GRÁFICO DE LAS PROYECCIONES SOBRE LA PRIMERA Y LA SEGUNDA DIRECCIÓN PRINCIPAL.

Así pues, en el modelo nocturno se observó que el peso de la segunda componente recaía sobre la variable horaria 0-1 horas (Figura 56), es decir por algún motivo esta variable ofrecía un comportamiento diferente del resto. La justificación a este hecho, aunque lógica, es importante tenerla en cuenta ya que de otra forma puede conducir a engaño cuando se 
realiza un análisis simplista de los caudales nocturnos inyectados a red. La influencia del cambio de horario en los consumos inyectados al sector se refleja en el modelo nocturno y en el de mañana (Figura 55).

Asimismo, esta técnica permite discriminar tendencias diferentes de consumo dependiendo del día de la semana (Figura 57 y Figura 58).

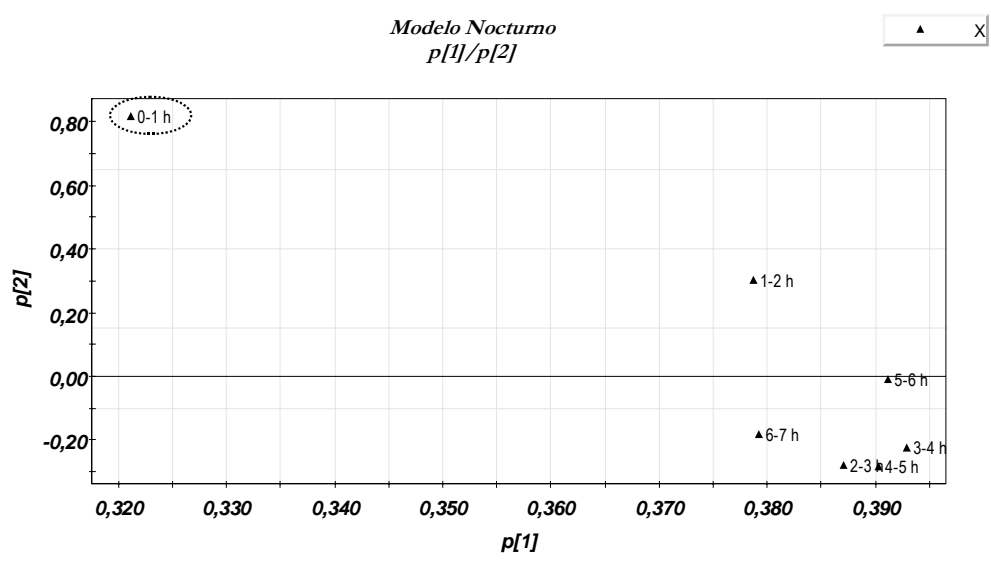

FIGURA 56.GRÁFICO DE LOS PESOS DE CADA VARIABLE DEL MODELO DE REFERENCIA.

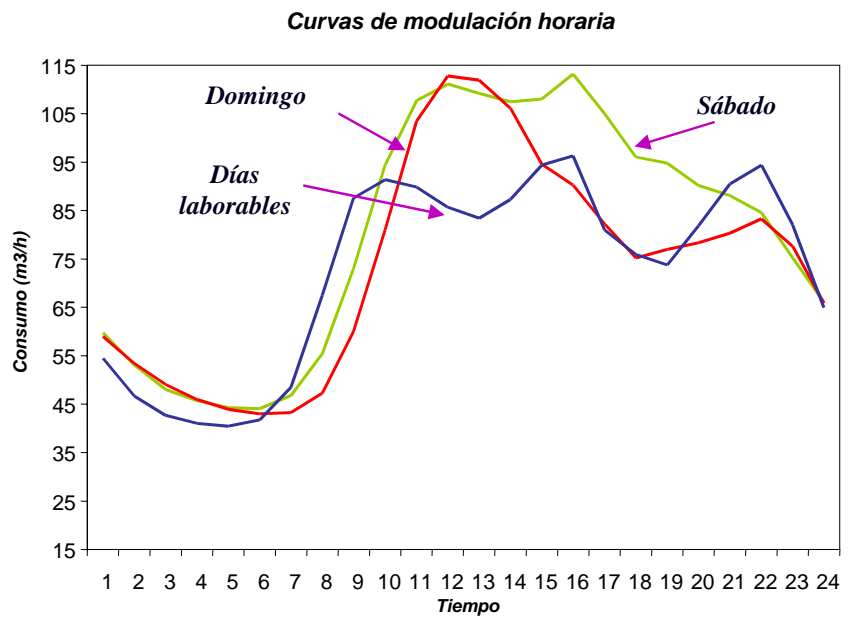

FIGURA 57.CURVAS DE MODULACIÓN HORARIA DÍAS FESTIVOS- DÍAS LABORABLES. 


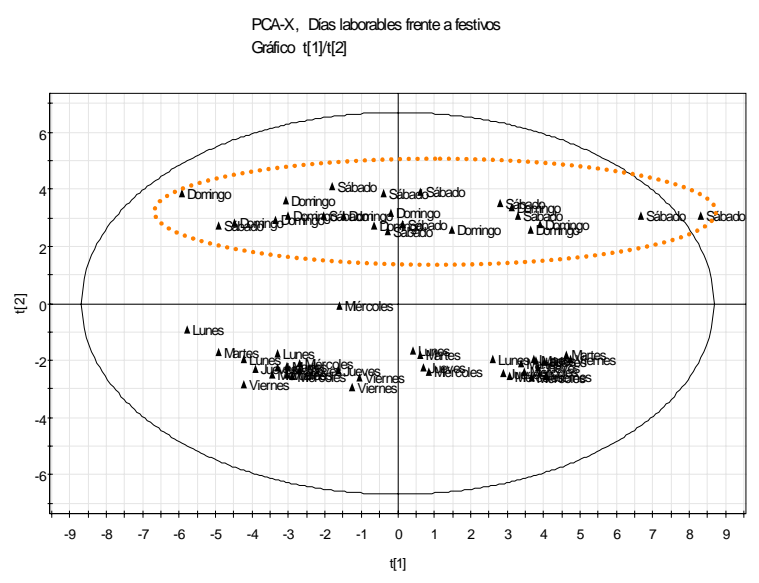

FIGURA 58.PROYECCIONES SOBRE LAS DOS PRIMERAS DIRECCIONES PRINCIPALES DEL MODELO ACP. DÍAS FESTIVOS- DÍAS LABORABLES.

\subsection{CONCLUSIONES}

Este estudio desarrolla una técnica de análisis estadístico, el análisis de componentes principales, no empleada anteriormente en este campo que aporta información para el técnico del abastecimiento urbano, que de alguna forma puede ser de gran ayuda en la gestión y mejora de las condiciones operativas de la red. Esta técnica es una herramienta de diagnóstico, es decir, un indicador de problemas en el proceso normal de demanda de agua, no identifica la fuente del problema ni la acción correctora que debe tomarse pero ayuda al gestor en la toma de decisiones.

En este aspecto, los trabajos desarrollados por Kurokawa et al. (2002) van encaminados a la detección de fugas producidas en la red de distribución mediante control estadístico de procesos (SPC, Statistical Process Control). En ellos se controlan las pérdidas de agua mediante un análisis estadístico de los caudales inyectados a la red, tanto nocturnos como de mañanas, estableciendo unos límites de control que indican posibles comportamientos anormales de los consumos demandados.

En el presente capítulo, de igual manera, se propone una metodología que maneja el SPC multivariante para la detección de pérdidas de agua en redes urbanas a partir de los datos obtenidos del sistema de macromedición. Los métodos de detección de anomalías en la red utilizados están basados en la geometría de la nube de puntos que representan los caudales inyectados cada hora. Estos se analizan desde diferentes ópticas extrayendo parámetros, como $\mathrm{T}^{2} \mathrm{Hotelling}$, la distancia al modelo o las proyecciones sobre cada dirección principal que con funciones de distribución establecidas determinan los límites de control de los caudales inyectados a la red de distribución.

Estos parámetros manifiestan una alta sensibilidad a las incidencias o tendencias de los caudales inyectados debido a que esta técnica no sólo tiene en cuenta la propia variabilidad de los datos si no también las relaciones establecidas entre las variables o caudales inyectados.

En este sentido hay que comentar que generalmente, la variabilidad de los caudales cada hora es más elevada que la dispersión de las relaciones entre variables con lo que el ACP alcanza una ventaja considerable frente a otro tipo de estudios, como los que consideran la evolución del caudal mínimo nocturno en el tiempo (Kurokawa. E, 2002), al tener este 
último método los límites de control significativamente más amplios. En otras palabras, anomalías de pequeña magnitud detectables por medio del ACP no serían consideradas como incidencias en los métodos estadísticos tradicionales.

Además, como se ha visto, esta técnica de análisis estadístico extrae patrones dominantes dentro de los caudales de agua demandados a la red. A partir de estos modelos patrón monitorizados a lo largo del día se establecen unos límites de control que reconocen, como se ha visto a través de los parámetros citados, agrupamientos que indican semejanzas en los caudales inyectados, tendencias estacionales o temporales en los consumos, etcétera, lo que facilita la detección de incidencias en la red.

Se ha realizado, a su vez, un análisis de sensibilidad de esta técnica estadística en la que se abordan dos métodos de detección donde se reflejan unos porcentajes de acierto elevados en el reconocimiento de incidencias, particularmente fugas simuladas. Para ello se generaron simulaciones de consumo sobre las que se añadieron diferentes caudales de fuga con distintas horas de inicio. Ambos métodos se mostraron complementarios en la eficacia de detección de anomalías.

Mientras que el método $\mathrm{T}^{2}$ Hotelling mejora su eficacia cuando la fuga se inicia durante las primeras horas del modelo, el método DMOD se muestra más eficaz si la fuga aparece en las horas finales del mismo. Por otro lado, se demostró que debido a la menor variabilidad de los consumos nocturnos, el método $\mathrm{T}^{2}$ Hotelling revelaba un mayor porcentaje de acierto en dicho modelo, para un caudal de fuga similar, en comparación con el de mañana o de tarde.

Los caudales de fuga detectados con la DMOD fueron mas pequeños, del orden de un $5 \%$ del caudal inyectado promedio de cada modelo, que con la. T2 Hotelling. Esto es debido a que el primer parámetro posee menor dispersión que el segundo, lo que acota más estrechamente sus límites haciéndolo más sensible. Para visualizar con más claridad esta conclusión, se muestra la Figura 59:
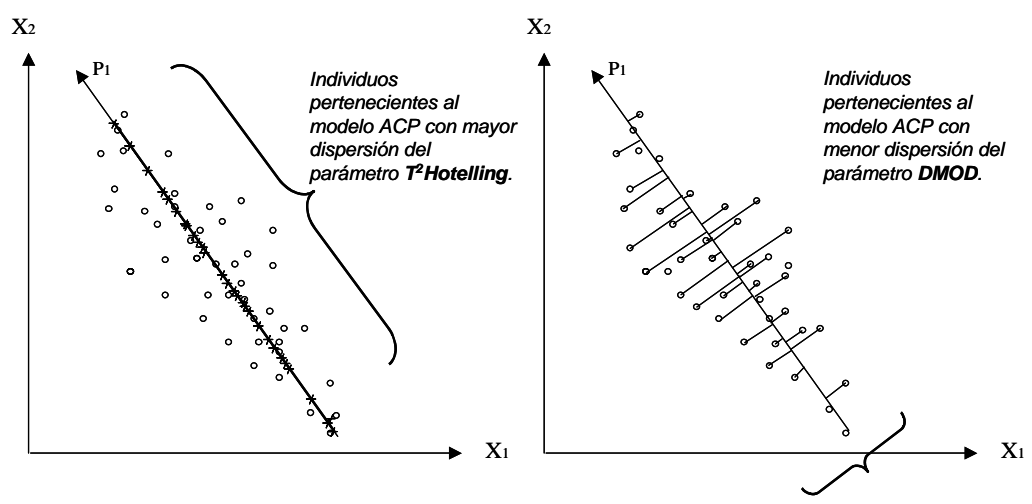

FIGURA 59. COMPARACIÓN ENTRE LA VARIABILIDAD ACEPTADA POR LOS DIFERENTES MÉTODOS DE DETECCIÓN.

Otra ventaja que presenta la técnica propuesta frente a los tradicionales es la posibilidad de monitorizar en continuo las variables estudiadas, lo que disminuye en gran medida el tiempo de reacción y, en consecuencia, los costes económicos originados por las incidencias.

Finalmente, comentar que una de las características más importantes del ACP es la capacidad del método para condensar y sintetizar la información analizada. En muchas ocasiones gran parte de los datos almacenados por el telemando no se convierten en información útil por la falta de tiempo y de herramientas que permitan analizar los mismos convenientemente. La introducción de técnicas como el ACP supone siempre un avance importante en la gestión técnica de las redes de abastecimiento al simplificar el análisis de los datos disponibles. 
Por todo lo anterior esta herramienta puede ser de gran utilidad para estimar el rendimiento de la red en abastecimientos con gran variabilidad en el consumo estacional de agua 0 en aquellos en los que la complejidad del sistema de telemando exija el seguimiento de un número elevado de caudales.

El ejemplo de aplicación desarrollado en el presente trabajo de investigación para un sector real de un abastecimiento urbano reveló una clara inestabilidad de la red estudiada debido en gran parte a la elevada edad y mal estado de conservación de la red urbana provocado por los habituales cortes en el suministro de agua que sufrió en el pasado, a la topología del sistema con importantes cambios de cota en toda el área urbana y los frecuentes cambios en la regulación del sistema de distribución de agua que afectaban al caudal inyectado al sector objeto del estudio.

Evidentemente, dicha inestabilidad del sistema dificultó enormemente la generación de modelos de referencia mediante técnicas ACP, lo que obligó a la eliminación de un número considerable de días durante la depuración de dichos modelos. No obstante, estas dificultades son las mismas a las que se enfrenta el técnico, normalmente sin ningún tipo de apoyo estadístico, en el seguimiento diario de, por ejemplo, los caudales mínimos nocturnos o los volúmenes diarios inyectados. En estas ocasiones es difícil fijar referencias que ayuden a determinar si el comportamiento de la red se sale del patrón habitual.

El mal estado de conservación de la red también se traduce en una alta tasa de aparición de fugas, lo que se refleja en una tendencia ascendente en los caudales inyectados. Estas tendencias se visualizan más acusadamente cuando los datos se proyectan sobre el espacio de las componentes.

Los resultados obtenidos durante la investigación identifican positivamente fugas, cortes en el suministro de agua y fallos en las comunicaciones entre la estación central de telemando y la estación remota.

Para concluir, pese a la dificultad encontrada en el caso objeto de estudio por la inestabilidad del sistema, se puede afirmar que el método propuesto es de gran ayuda en la detección de anomalías o incidencias en la red. No obstante, se reconoce que, los modelos generados deberán ser actualizados periódicamente para preservar la eficacia del método. La frecuencia de actualización de los modelos deberá ser más o menos alta en función de los cambios en la regulación del sistema, la renovación de la tuberías de distribución, las variaciones de consumo ya sean estacionales o por incremento en el número de abonados, etc.

\subsection{BIBLIOGRAFÍA CONSULTADA}

Aluja, T. Morineau, A. (1999) Aprender de los datos: El análisis de componentes principales. Ediciones Universitarias de Barcelona. EUB.

Anónimo (2001). SIMCA-P 9.0. User guide and tutorial. Ed. Umetrics.

Eriksson, L., Johansson, E. Kettaneh-Wold, N; Wold, S. (1999). Introduction to Multi- and Megavariate data analysis using projection methods. Umetrics AB.

Gallagher, N. Wise,M. Watts,S. White, D. Barna,G. Development and benchmarking of multivariate statistical process control tools for a semiconductor etch process: Improving robustness through model updating. 
Harris, Ch.; Ironmonger, R. (1998). Socrates-Improving the accuracy of measured night flows. Driving down water leakage Conference. London.

Jackson, J.E. (1991). A user’s guide to principal components. Wiley. New York.

Kourti, T.; MacGregor, J. (1996). Multivariate SPC methods for process and product monitoring. Journal of Quality Technology. Vol. 28, No. 4. pp.409-428.

Kurokawa, E.; Bornia, A.C. (2002). Utilizando a carta X para avaliaçao de datos diarios da macromediçao de um setor de distribuiçao de agua tratada da cidade de Goiania (Caso Jardim América). Seminario Planejamento, projeto e operação de redes de abastecimento de agua. Joao Pessoa. Brasil.

Kurokawa, E.; Bornia, A.C. (2002).. Uma proposta para a utilizaçao do controle estatístico de processo (CEP) a través da carta $\mathrm{X}$ como uma ferramenta gerencial para a avaliaçao da vazao mínima noturna de um setor. Seminario Planejamento, projeto e operação de redes de abastecimento de agua. Joao Pessoa. Brasil.

Malinowski, E.R. Theory of the distribution of error eigenvalues resulting from PCA with applications to spectroscopic data" J. Chemom. 1 (1987) 33-40.

Terriel, J.C.; Daniel, W.W.(1994). Business statistics for management and economics. Ed. Houghton Mifflin Company. Boston.

Rodriguez,R. ;Tobias, R. (2001). Multivariate methods for process knowledge discovery: The power to know your process. Statistics, data analysis and data mining. SUGI 26 Proceedings Paper 252-26.

Romero, R. (1997).Curso de introducción a los métodos de análisis multivariante. ETSEA. Universidad Politécnica de Valencia.

Water Research Centre WRc. (1994). Managing leakage. Report E. Using night flow data. U.K Water Industry.

Water Research Centre WRc. (1994). Managing leakage. Report F. Using night flow data. U.K Water Industry,

Wold, S.; Esbensen, K.; Geladi, P. (1987). Principal Component Analysis. Chemometrics and Intelligent Laboratory Systems, 2 , pp. 37-52.

Wold, S. (1978). Cross validation estimation of the number of components in factor and principal component models. Technometrics, 20, pp 397-406.

Wold, H. (1966). NIPALS (Nonlinear Iterative Partial Least Squares). Nonlinear estimation by iterative least squares procedures, Research papers in Statistics, Wiley, New York, pp 411-444. 


\section{ANEXO I. ALGORITMOS PARA EL CÁLCULO DE COMPONENTES PRINCIPALES}

\section{ALGORITMO NIPALS (NON-LINEAR ITERATIVE PARTIAL LEAST SQUARES) PARA ACP}

El algoritmo NIPALS para ACP optimiza el cálculo de las componentes principales, sacándolas secuencialmente con la ventaja de detener el proceso cuando convenga.

Además este se fundamenta en determinar la correlación existente entre la variable Xk y los "scores" t.

El procedimiento a seguir es el que sigue:

1. La matriz de datos original debe ser pretratada, es decir centrada y escalada (condición necesaria para poder comparar con los resultados obtenidos en el software SIMCA-P 9.0)

2. Se inicia el algoritmo con $t=X k$, donde $X K$ es la columna de máxima varianza.

$$
X=[\quad] \quad . . \text { i }
$$

$\mathrm{xk}$

Algoritmo NIPALS para ACP (Non-linear iterative partial least squares) $\mathbf{t}=\mathbf{X}_{\mathbf{K}}$

Regresión lineal múltiple (RLM) de las columnas de X sobre t.

$\mathrm{p}=\mathrm{X}^{\mathrm{T}} \cdot \mathrm{t} /\|\mathrm{t}\|^{2}=\mathrm{X}^{\mathrm{T}} \cdot \mathrm{t} /\left(\mathrm{t}^{\mathrm{T}} \cdot \mathrm{t}\right)$

$\mathrm{p}_{\text {est }}=\mathrm{p} /\|\mathrm{p}\|$ se normaliza $\mathrm{p}$.

iteración

RLM de $X$ sobre $\mathrm{p}$.

$\mathrm{t}_{\mathrm{est}}=\mathrm{X} \cdot \mathrm{p} /\left(\mathrm{p}^{\mathrm{T}} \cdot \mathrm{p}\right)$

convergencia $\left\|\mathrm{t}_{\mathrm{est}}-\mathrm{t}\right\| \leq \mathrm{z}$

NO
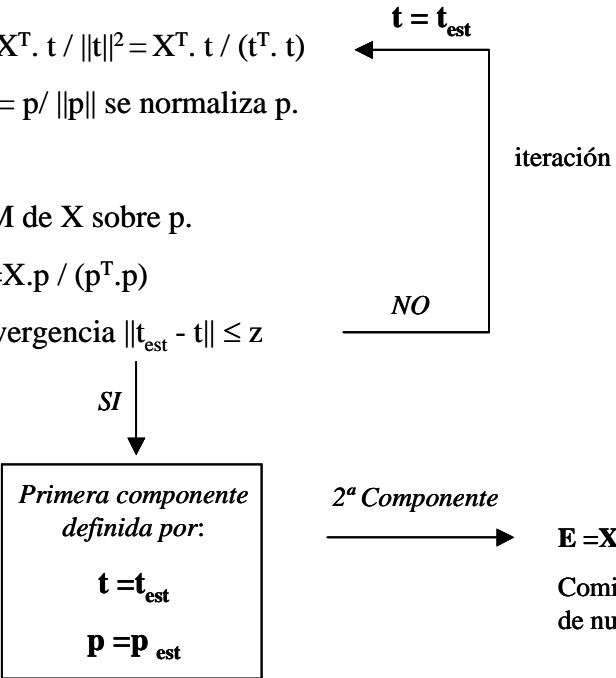

3. Volver a hacer (2), y repetir el procedimiento de cálculo de componentes principales $A=1,2$.. $A$.

$$
X=t 1 \cdot p T 1+t 2 \cdot p T 2+\ldots+t A \cdot p T A+E
$$




\section{DESCOMPOSICIÓN EN VALORES SINGULARES (SVD)}

Otro algoritmo interesante para el cálculo de las componentes principales es la descomposición en valores singulares (SVD, Singular Value Decomposition). Este método descompone la matriz original en tres partes bien diferenciadas; ${ }^{\bar{V}}$ matriz cuadrada que contiene los vectores singulares derechos de $\overline{\bar{X}}, \overline{\bar{U}}$ matriz cuadrada de vectores singulares izquierdos asociados a $\overline{\bar{X}}$ y una matriz diagonal $\overline{\bar{D}}$ que contiene la raíz cuadrada de los valores propios o componentes singulares en orden decreciente.

Esta matriz diagonal denota claramente el fundamento del análisis de componentes principales, es decir, escasos valores propios de peso en la parte superior de dicha matriz caracterizan la máxima información contenida en la matriz de datos original, mientras que los valores cercanos a cero situados en la parte inferior representan el ruido blanco.

$$
\begin{aligned}
& U T \cdot X \cdot V=D \\
& X=U \cdot D \cdot V T
\end{aligned}
$$

sabiendo que U $\cdot U T=U T \cdot U=I$ y $V \cdot V T=V T \cdot V=I$ (matriz identidad)

$$
\mathrm{XTX}=\mathrm{VDTUTUDVT}=\mathrm{VDTDVT}=\mathrm{VD} 2 \mathrm{~V}
$$

Luego, los valores propios de XTX son $\lambda i=d i 2$, $U$ son los vectores propios de XXT y $V$ son los vectores propios de XTX. Se puede concluir pues, que:

$$
\begin{aligned}
& T=U \cdot D \\
& P=V
\end{aligned}
$$

Siendo T la matriz de proyecciones sobre cada dirección principal y $\mathrm{P}$ la matriz de pesos o vectores propios asociados a X. 
Matriz datos originales : Caudales inyectados ( $\left.\mathrm{m}^{3} / \mathrm{hora}\right)$

TABLA A

Modelo nocturno

\begin{tabular}{|c|c|c|c|c|c|c|c|c|}
\hline & DIA & $0-1 \mathrm{~h}$ & $1-2 \mathrm{~h}$ & $2-3 \mathrm{~h}$ & $3-4 \mathrm{~h}$ & $4-5 \mathrm{~h}$ & $5-6 \mathrm{~h}$ & 6-7 h \\
\hline Dia 1 & Lunes & 58,2 & 56,6 & 55,2 & 53,6 & 53,1 & 50,8 & 49,8 \\
\hline Dia 2 & Martes & 56,2 & 49,9 & 47,1 & 44,8 & 44,5 & 44,3 & 48,9 \\
\hline Dia 3 & Miercoles & 57,7 & 49,5 & 46,1 & 44,7 & 44,6 & 44,3 & 49,3 \\
\hline Dia 4 & Jueves & 61,9 & 55,8 & 52,9 & 52,0 & 52,3 & 51,8 & 56,1 \\
\hline Dia 5 & Viernes & 57,7 & 50,3 & 46,0 & 43,8 & 42,9 & 42,8 & 49,2 \\
\hline Dia 8 & Lunes & 90,0 & 84,3 & 80,8 & 79,2 & 79,4 & 80,0 & 84,2 \\
\hline Dia 9 & Martes & 89,3 & 80,9 & 78,9 & 77,4 & 77,9 & 78,4 & 83,9 \\
\hline Dia 10 & Miércoles & 53,8 & 47,1 & 43,4 & 42,2 & 42,1 & 41,7 & 48,0 \\
\hline Dia 11 & Jueves & 53,6 & 45,2 & 44,0 & 42,2 & 41,4 & 40,8 & 47,9 \\
\hline Dia 12 & Viernes & 54,5 & 45,7 & 43,1 & 41,3 & 40,5 & 40,8 & 48,1 \\
\hline Dia 15 & Lunes & 53,9 & 44,8 & 43,3 & 42,0 & 41,0 & 40,8 & 46,8 \\
\hline Dia 16 & Martes & 52,4 & 46,4 & 44,4 & 43,0 & 42,0 & 41,7 & 47,5 \\
\hline Dia 17 & Miércoles & 52,8 & 45,3 & 42,7 & 40,8 & 40,6 & 41,4 & 49,8 \\
\hline Dia 18 & Jueves & 53,3 & 46,6 & 43,4 & 41,3 & 40,7 & 41,7 & 48,8 \\
\hline Dia 19 & Viernes & 54,3 & 46,6 & 43,4 & 41,6 & 40,9 & 41,6 & 48,8 \\
\hline Dia 22 & Lunes & 54,2 & 46,3 & 44,0 & 42,3 & 41,9 & 42,4 & 47,4 \\
\hline Dia 23 & Martes & 53,2 & 46,0 & 43,5 & 42,0 & 41,4 & 41,3 & 48,4 \\
\hline Dia 24 & Miércoles & 51,1 & 44,3 & 41,6 & 39,3 & 39,4 & 40,4 & 48,0 \\
\hline Dia 25 & Jueves & 55,1 & 49,2 & 46,4 & 43,8 & 43,3 & 44,5 & 52,1 \\
\hline Dia 26 & Viernes & 56,5 & 48,5 & 46,3 & 44,7 & 44,4 & 45,3 & 52,3 \\
\hline Dia 29 & Lunes & 60,3 & 53,7 & 50,3 & 48,1 & 47,1 & 47,8 & 54,3 \\
\hline Dia 30 & Martes & 57,3 & 51,5 & 49,2 & 47,2 & 46,3 & 48,1 & 55,0 \\
\hline Dia 31 & Miércoles & 59,3 & 52,6 & 49,8 & 47,6 & 46,4 & 47,8 & 54,8 \\
\hline Dia 32 & Jueves & 58,8 & 51,3 & 49,6 & 48,0 & 48,1 & 48,3 & 55,6 \\
\hline Dia 33 & Viernes & 60,6 & 53,3 & 51,1 & 49,0 & 48,6 & 49,5 & 56,8 \\
\hline Dia 36 & Lunes & 63,1 & 55,6 & 53,0 & 51,2 & 50,9 & 50,5 & 57,9 \\
\hline Dia 37 & Martes & 63,3 & 57,9 & 55,4 & 53,8 & 53,8 & 54,1 & 60,1 \\
\hline Dia 38 & Miércoles & 62,9 & 58,4 & 56,8 & 54,9 & 54,3 & 54,1 & 61,0 \\
\hline Dia 39 & Jueves & 65,4 & 57,8 & 55,5 & 53,8 & 53,4 & 53,4 & 60,8 \\
\hline Dia 40 & Viernes & 66,1 & 58,8 & 56,4 & 54,8 & 54,3 & 54,6 & 62,4 \\
\hline Dia 43 & Lunes & 64,9 & 58,1 & 55,2 & 52,8 & 52,0 & 53,1 & 61,2 \\
\hline Dia 44 & Martes & 64,7 & 58,0 & 56,3 & 54,7 & 53,5 & 54,4 & 61,9 \\
\hline Dia 45 & Miércoles & 64,3 & 58,1 & 55,2 & 53,6 & 53,3 & 54,0 & 61,7 \\
\hline Dia 46 & Jueves & 64,6 & 58,7 & 56,4 & 54,6 & 54,0 & 54,1 & 60,9 \\
\hline Dia 47 & Viernes & 66,8 & 60,2 & 57,6 & 55,3 & 54,8 & 55,1 & 61,1 \\
\hline Dia 50 & Lunes & 64,8 & 59,1 & 56,8 & 55,2 & 54,6 & 54,4 & 60,7 \\
\hline Dia 51 & Martes & 62,8 & 54,7 & 52,7 & 52,0 & 52,3 & 53,6 & 60,2 \\
\hline Dia 52 & Miércoles & 63,3 & 57,5 & 54,4 & 52,8 & 52,7 & 54,4 & 61,1 \\
\hline Dia 53 & Jueves & 63,5 & 58,4 & 55,3 & 53,5 & 53,6 & 53,9 & 60,0 \\
\hline Dia 54 & Viernes & 66,2 & 59,5 & 56,8 & 54,4 & 53,7 & 55,1 & 62,6 \\
\hline Dia 57 & Lunes & 48,8 & 38,6 & 35,4 & 33,3 & 33,8 & 35,6 & 41,8 \\
\hline Dia 58 & Martes & 49,2 & 41,9 & 39,3 & 37,2 & 37,5 & 39,0 & 45,9 \\
\hline Dia 59 & Miércoles & 48,2 & 40,3 & 37,3 & 35,4 & 35,8 & 37,0 & 44,8 \\
\hline Dia 60 & Jueves & 53,5 & 47,6 & 44,2 & 42,4 & 43,3 & 44,6 & 52,5 \\
\hline Dia 61 & Viernes & 55,6 & 49,3 & 46,7 & 44,8 & 44,3 & 45,7 & 51,5 \\
\hline Dia 64 & Lunes & 81,2 & 29,4 & 23,3 & 22,2 & 22,5 & 22,6 & 26,9 \\
\hline Dia 65 & Martes & 49,2 & 40,3 & 38,6 & 36,8 & 35,8 & 36,4 & 44,3 \\
\hline Dia 66 & Miércoles & 47,3 & 40,2 & 37,5 & 35,8 & 35,3 & 36,7 & 45,0 \\
\hline Dia 67 & Jueves & 48,7 & 41,7 & 38,6 & 36,1 & 35,7 & 36,6 & 43,9 \\
\hline Dia 68 & Viernes & 49,4 & 42,1 & 39,0 & 37,0 & 36,5 & 36,9 & 44,7 \\
\hline Dia 71 & Lunes & 49,7 & 41,4 & 39,1 & 37,6 & 37,4 & 36,9 & 45,3 \\
\hline Dia 72 & Martes & 48,9 & 42,6 & 39,6 & 38,1 & 37,8 & 37,8 & 45,4 \\
\hline Dia 73 & Miércoles & 49,0 & 42,3 & 38,8 & 36,7 & 36,5 & 38,2 & 46,0 \\
\hline Dia 74 & Jueves & 49,4 & 44,8 & 41,7 & 40,1 & 39,6 & 39,5 & 46,3 \\
\hline Dia 75 & Viernes & 50,3 & 44,3 & 42,2 & 40,2 & 40,2 & 40,6 & 48,8 \\
\hline Dia 78 & Lunes & 49,8 & 47,0 & 44,3 & 41,8 & 40,9 & 39,8 & 39,7 \\
\hline Dia 79 & Martes & 49,2 & 44,8 & 41,4 & 37,9 & 36,2 & 35,3 & 43,4 \\
\hline Dia 80 & Miércoles & 48,9 & 39,8 & 37,8 & 36,9 & 36,5 & 35,5 & 43,1 \\
\hline Dia 81 & Jueves & 47,6 & 43,3 & 39,7 & 37,2 & 36,6 & 36,2 & 42,4 \\
\hline Dia 82 & Viernes & 52,1 & 44,1 & 41,7 & 38,6 & 37,6 & 39,1 & 47,1 \\
\hline Dia 85 & Lunes & 55,4 & 45,4 & 40,8 & 39,2 & 38,0 & 39,3 & 44,7 \\
\hline Dia 86 & Martes & 53,9 & 46,6 & 42,5 & 41,3 & 39,8 & 41,4 & 46,7 \\
\hline Dia 87 & Miércoles & 55,5 & 45,8 & 41,7 & 40,4 & 39,1 & 41,2 & 47,4 \\
\hline Dia 88 & Jueves & 55,3 & 46,1 & 42,8 & 40,7 & 39,0 & 40,9 & 48,0 \\
\hline Dia 89 & Viernes & 49,8 & 41,8 & 38,1 & 36,6 & 35,2 & 37,8 & 43,5 \\
\hline Dia 92 & Lunes & 50,4 & 43,1 & 37,5 & 36,6 & 37,1 & 38,5 & 44,7 \\
\hline Dia 93 & Martes & 49,4 & 42,8 & 38,5 & 36,8 & 36,2 & 38,7 & 44,8 \\
\hline Dia 94 & Miércoles & 49,3 & 42,8 & 38,8 & 38,0 & 36,8 & 39,3 & 45,3 \\
\hline Dia 95 & Jueves & 50,4 & 44,3 & 39,3 & 38,3 & 36,4 & 38,0 & 44,5 \\
\hline Dia 96 & Viernes & 51,7 & 43,7 & 38,9 & 38,0 & 37,3 & 40,0 & 46,7 \\
\hline Dia 99 & Lunes & 54,4 & 43,8 & 40,2 & 38,4 & 37,3 & 39,3 & 45,2 \\
\hline Dia 100 & Martes & 52,5 & 44,9 & 41,6 & 40,1 & 38,3 & 40,8 & 45,7 \\
\hline Dia 101 & Miércoles & 52,3 & 44,2 & 67,3 & 81,6 & 81,8 & 61,8 & 45,4 \\
\hline Dia 102 & Jueves & 57,7 & 49,1 & 43,1 & 41,2 & 39,5 & 41,5 & 47,5 \\
\hline Dia 103 & Viernes & 53,9 & 48,8 & 43,9 & 40,8 & 39,1 & 40,0 & 41,3 \\
\hline
\end{tabular}


TABLA A

Modelo nocturn

\begin{tabular}{|c|c|c|c|c|c|c|c|c|}
\hline \multicolumn{2}{|c|}{ DIA } & $0-1 \mathrm{~h}$ & $1-2 \mathrm{~h}$ & $2-3 h$ & $3-4 \mathrm{~h}$ & $4-5 \mathrm{~h}$ & $5-6 \mathrm{~h}$ & $6-7 \mathrm{~h}$ \\
\hline Dia 106 & Lunes & 51,8 & 47,1 & 43,5 & 41,2 & 40,2 & 42,0 & 40,8 \\
\hline Dia 107 & Martes & 54,6 & 45,9 & 41,5 & 40,0 & 40,7 & 44,4 & 47,2 \\
\hline Dia 108 & Miércoles & 55,3 & 48,1 & 41,8 & 40,3 & 40,1 & 42,2 & 48,3 \\
\hline Dia 109 & Jueves & 55,7 & 50,0 & 42,7 & 40,1 & 39,1 & 41,4 & 46,8 \\
\hline Dia 110 & Viernes & 56,7 & 48,6 & 42,7 & 40,6 & 40,3 & 43,0 & 48,8 \\
\hline Dia 113 & Lunes & 58,7 & 50,4 & 44,8 & 43,3 & 41,5 & 40,8 & 42,3 \\
\hline Dia 114 & Martes & 56,2 & 48,3 & 43,5 & 41,3 & 40,2 & 42,3 & 47,6 \\
\hline Dia 115 & Miércoles & 60,3 & 48,8 & 42,1 & 41,4 & 39,9 & 42,0 & 48,7 \\
\hline Dia 116 & Jueves & 58,5 & 48,8 & 42,4 & 40,8 & 40,2 & 42,7 & 48,9 \\
\hline Dia 117 & Viernes & 56,4 & 50,1 & 45,1 & 43,1 & 41,6 & 44,7 & 49,8 \\
\hline Dia 120 & Lunes & 61,3 & 57,5 & 50,3 & 46,1 & 44,0 & 43,7 & 43,1 \\
\hline Dia 121 & Martes & 47,2 & 42,1 & 58,4 & 72,8 & 72,6 & 54,6 & 34,1 \\
\hline Dia 122 & Miércoles & 57,0 & 57,0 & 57,0 & 57,0 & 57,0 & 57,0 & 57,0 \\
\hline Dia 123 & Jueves & 57,0 & 57,0 & 57,0 & 57,0 & 57,0 & 57,0 & 57,0 \\
\hline Dia 124 & Viernes & 53,8 & 46,2 & 41,4 & 39,7 & 39,8 & 41,5 & 47,6 \\
\hline Dia 127 & Lunes & 53,5 & 46,6 & 40,2 & 38,5 & 38,3 & 40,9 & 46,0 \\
\hline Dia 128 & Martes & 50,9 & 44,6 & 37,6 & 36,9 & 35,8 & 38,4 & 43,3 \\
\hline Dia 129 & Miércoles & 47,8 & 39,3 & 34,7 & 33,8 & 33,0 & 35,8 & 41,9 \\
\hline Dia 130 & Jueves & 47,3 & 40,3 & 36,4 & 34,8 & 33,5 & 34,9 & 41,3 \\
\hline Dia 131 & Viernes & 47,3 & 37,2 & 34,3 & 33,6 & 33,0 & 35,0 & 41,1 \\
\hline Dia 134 & Lunes & 49,4 & 42,7 & 35,9 & 34,3 & 33,8 & 36,0 & 41,9 \\
\hline Dia 135 & Martes & 49,3 & 43,1 & 36,3 & 34,6 & 34,0 & 36,7 & 42,4 \\
\hline Dia 136 & Miércoles & 45,1 & 30,9 & 29,3 & 32,0 & 32,0 & 32,0 & 32,0 \\
\hline Dia 137 & Jueves & 52,3 & 41,8 & 35,8 & 33,7 & 33,0 & 35,6 & 41,8 \\
\hline Dia 138 & Viernes & 48,6 & 39,8 & 33,8 & 32,6 & 34,6 & 35,3 & 40,1 \\
\hline Dia 141 & Lunes & 44,5 & 36,3 & 29,8 & 29,4 & 28,9 & 30,8 & 38,5 \\
\hline Dia 142 & Martes & 47,8 & 39,3 & 34,8 & 33,6 & 32,9 & 35,8 & 41,8 \\
\hline Dia 143 & Miércoles & 47,7 & 38,7 & 33,2 & 32,6 & 32,0 & 34,6 & 40,9 \\
\hline Dia 144 & Jueves & 57,9 & 41,4 & 32,7 & 30,8 & 31,0 & 32,6 & 38,5 \\
\hline Dia 145 & Viernes & 47,3 & 39,5 & 33,5 & 32,8 & 32,3 & 34,3 & 41,9 \\
\hline Dia 148 & Lunes & 54,7 & 43,8 & 35,8 & 35,5 & 34,3 & 36,5 & 42,4 \\
\hline Dia 149 & Martes & 53,4 & 43,2 & 39,4 & 35,8 & 35,3 & 37,3 & 44,3 \\
\hline Dia 150 & Miércoles & 51,2 & 42,4 & 36,7 & 35,3 & 34,9 & 37,2 & 44,9 \\
\hline Dia 151 & Jueves & 53,6 & 44,1 & 36,9 & 35,7 & 35,0 & 37,5 & 45,3 \\
\hline Dia 152 & Viernes & 54,2 & 42,5 & 36,1 & 35,8 & 35,2 & 37,8 & 45,3 \\
\hline Dia 155 & Lunes & 55,6 & 43,3 & 36,0 & 35,7 & 35,5 & 37,5 & 43,7 \\
\hline Dia 156 & Martes & 52,4 & 43,7 & 38,2 & 36,1 & 35,7 & 37,8 & 50,5 \\
\hline Dia 157 & Miércoles & 53,8 & 41,9 & 36,4 & 35,4 & 35,1 & 37,6 & 44,1 \\
\hline Dia 158 & Jueves & 52,2 & 43,1 & 37,1 & 36,1 & 35,1 & 37,6 & 44,7 \\
\hline Dia 159 & Viernes & 54,5 & 43,8 & 37,3 & 36,0 & 36,1 & 38,0 & 46,2 \\
\hline Dia 162 & Lunes & 55,9 & 44,3 & 38,8 & 37,3 & 36,7 & 38,8 & 45,7 \\
\hline Dia 163 & Martes & 83,1 & 75,5 & 71,8 & 70,0 & 69,0 & 70,5 & 76,8 \\
\hline Dia 164 & Miércoles & 80,3 & 76,6 & 56,8 & 54,4 & 51,2 & 50,9 & 56,9 \\
\hline Dia 165 & Jueves & 68,9 & 57,1 & 50,5 & 49,1 & 46,8 & 43,8 & 48,4 \\
\hline Dia 166 & Viernes & 69,7 & 55,7 & 50,4 & 49,1 & 46,5 & 48,2 & 50,1 \\
\hline Dia 169 & Lunes & 69,6 & 56,5 & 51,2 & 51,1 & 48,3 & 48,9 & 51,2 \\
\hline Dia 170 & Martes & 73,1 & 63,8 & 58,2 & 56,5 & 55,3 & 55,8 & 57,8 \\
\hline Dia 171 & Miércoles & 71,9 & 59,0 & 53,0 & 51,1 & 47,3 & 43,9 & 50,5 \\
\hline Dia 172 & Jueves & 70,2 & 58,8 & 50,9 & 45,7 & 46,1 & 49,5 & 55,3 \\
\hline Dia 173 & Viernes & 71,0 & 61,3 & 51,0 & 44,3 & 43,6 & 46,8 & 55,8 \\
\hline Dia 176 & Lunes & 67,1 & 55,4 & 51,8 & 50,6 & 49,0 & 49,3 & 59,3 \\
\hline Dia 177 & Martes & 72,9 & 62,1 & 45,0 & 44,8 & 45,8 & 49,5 & 54,5 \\
\hline Dia 178 & Miércoles & 71,3 & 52,3 & 49,8 & 49,3 & 48,0 & 49,6 & 54,0 \\
\hline Dia 179 & Jueves & 65,9 & 54,7 & 8,2 & 0,0 & 0,0 & 0,0 & 11,3 \\
\hline Dia 180 & Viernes & 63,9 & 48,8 & 47,8 & 45,8 & 45,1 & 46,8 & 50,9 \\
\hline
\end{tabular}


TABLA B

Modelo diurno

\begin{tabular}{|c|c|c|c|c|c|c|c|c|c|c|}
\hline \multicolumn{2}{|c|}{ DÍA } & $7-8 \mathrm{~h}$ & 8-9 h & $9-10 \mathrm{~h}$ & $10-11 \mathrm{~h}$ & $11-12 \mathrm{~h}$ & $12-13 \mathrm{~h}$ & 13-14 h & $14-15 \mathrm{~h}$ & $15-16 \mathrm{~h}$ \\
\hline$\overline{\text { Dia } 1}$ & Lunes & 51,6 & 50,4 & 57,6 & 73,7 & 92,8 & 103,8 & 107,7 & 100,0 & 86,9 \\
\hline Dia 2 & Martes & 62,1 & 70,6 & 85,3 & 94,0 & 24,3 & 74,3 & 132,0 & 114,7 & 110,3 \\
\hline Dia 3 & Miercoles & 64,8 & 70,7 & 80,3 & 85,4 & 98,1 & 100,4 & 107,3 & 98,1 & 102,3 \\
\hline Dia 4 & Jueves & 67,9 & 76,3 & 88,5 & 84,6 & 81,8 & 61,2 & 61,1 & 64,7 & 127,7 \\
\hline Dia 5 & Viernes & 66,8 & 73,1 & 76,5 & 80,4 & 83,3 & 79,3 & 80,2 & 90,8 & 102,8 \\
\hline Dia 8 & Lunes & 101,2 & 113,5 & 117,6 & 119,9 & 119,3 & 118,3 & 120,3 & 125,5 & 125,9 \\
\hline Dia 9 & Martes & 97,6 & 111,2 & 118,7 & 114,0 & 93,8 & 89,3 & 84,6 & 91,8 & 91,8 \\
\hline Dia 10 & Miércoles & 68,8 & 81,8 & 87,3 & 86,0 & 83,1 & 82,5 & 83,5 & 93,3 & 93,5 \\
\hline Dia 11 & Jueves & 65,5 & 84,8 & 87,4 & 86,8 & 84,3 & 83,3 & 82,9 & 93,2 & 94,7 \\
\hline Dia 12 & Viernes & 70,8 & 86,0 & 88,8 & 82,0 & 76,5 & 74,8 & 77,5 & 86,9 & 88,6 \\
\hline Dia 15 & Lunes & 67,3 & 79,8 & 83,2 & 83,7 & 81,8 & 81,4 & 86,2 & 93,8 & 92,5 \\
\hline Dia 16 & Martes & 66,3 & 82,8 & 92,3 & 91,0 & 85,1 & 80,5 & 83,7 & 94,7 & 92,9 \\
\hline Dia 17 & Miércoles & 69,4 & 84,3 & 86,9 & 87,7 & 84,8 & 82,3 & 83,1 & 91,4 & 92,2 \\
\hline Dia 18 & Jueves & 66,3 & 81,1 & 84,8 & 82,8 & 82,2 & 80,0 & 81,8 & 90,8 & 92,4 \\
\hline Dia 19 & Viernes & 69,3 & 86,5 & 89,4 & 85,5 & 75,8 & 75,4 & 81,1 & 92,8 & 98,8 \\
\hline Dia 22 & Lunes & 65,3 & 84,0 & 88,3 & 91,3 & 91,1 & 85,3 & 84,2 & 93,7 & 93,7 \\
\hline Dia 23 & Martes & 66,4 & 83,3 & 91,3 & 93,4 & 93,0 & 85,7 & 101,5 & 85,9 & 80,4 \\
\hline Dia 24 & Miércoles & 68,0 & 87,5 & 89,8 & 91,7 & 89,3 & 86,9 & 90,5 & 96,2 & 97,6 \\
\hline Dia 25 & Jueves & 71,0 & 88,8 & 92,4 & 91,4 & 89,3 & 88,0 & 88,6 & 95,8 & 96,4 \\
\hline Dia 26 & Viernes & 70,7 & 92,8 & 92,1 & 87,8 & 75,5 & 74,8 & 84,8 & 94,4 & 98,4 \\
\hline Dia 29 & Lunes & 71,5 & 90,7 & 94,1 & 94,3 & 93,2 & 91,7 & 88,3 & 96,3 & 97,6 \\
\hline Dia 30 & Martes & 70,9 & 89,8 & 96,5 & 97,6 & 88,3 & 86,3 & 103,3 & 103,8 & 101,3 \\
\hline Dia 31 & Miércoles & 73,5 & 95,5 & 97,8 & 96,9 & 90,8 & 90,0 & 91,8 & 100,0 & 103,2 \\
\hline Dia 32 & Jueves & 73,4 & 93,9 & 98,3 & 95,9 & 90,9 & 88,3 & 91,8 & 99,0 & 101,4 \\
\hline Dia 33 & Viernes & 75,2 & 97,0 & 95,8 & 89,4 & 85,7 & 102,4 & 117,5 & 126,0 & 128,8 \\
\hline Dia 36 & Lunes & 77,3 & 94,0 & 98,6 & 98,0 & 98,8 & 94,8 & 97,1 & 103,8 & 106,7 \\
\hline Dia 37 & Martes & 77,3 & 95,9 & 105,5 & 108,0 & 103,5 & 96,3 & 98,2 & 103,3 & 105,8 \\
\hline Dia 38 & Miércoles & 78,4 & 98,8 & 100,8 & 99,0 & 96,3 & 92,8 & 95,8 & 104,3 & 104,4 \\
\hline Dia 39 & Jueves & 78,2 & 96,8 & 103,7 & 101,3 & 96,6 & 93,8 & 96,8 & 105,0 & 107,8 \\
\hline Dia 40 & Viernes & 80,7 & 99,8 & 102,3 & 97,0 & 83,3 & 88,5 & 92,7 & 102,5 & 108,1 \\
\hline Dia 43 & Lunes & 78,1 & 99,4 & 102,1 & 101,6 & 98,7 & 96,3 & 98,2 & 106,3 & 106,8 \\
\hline Dia 44 & Martes & 77,6 & 95,3 & 103,5 & 106,4 & 104,9 & 99,4 & 98,8 & 105,4 & 107,3 \\
\hline Dia 45 & Miércoles & 77,2 & 95,1 & 98,3 & 97,7 & 95,3 & 92,2 & 92,6 & 100,2 & 100,4 \\
\hline Dia 46 & Jueves & 74,7 & 92,0 & 93,8 & 94,4 & 91,3 & 91,2 & 92,7 & 98,4 & 98,8 \\
\hline Dia 47 & Viernes & 78,4 & 96,8 & 102,5 & 99,3 & 94,8 & 92,2 & 96,4 & 106,3 & 109,5 \\
\hline Dia 50 & Lunes & 77,8 & 94,6 & 46,8 & 31,2 & 30,5 & 83,0 & 142,9 & 126,4 & 112,5 \\
\hline Dia 51 & Martes & 76,9 & 96,5 & 105,8 & 108,1 & 102,0 & 92,8 & 94,8 & 104,5 & 99,6 \\
\hline Dia 52 & Miércoles & 78,2 & 97,1 & 100,8 & 99,8 & 96,4 & 94,6 & 96,5 & 104,0 & 104,9 \\
\hline Dia 53 & Jueves & 79,3 & 96,9 & 99,3 & 98,3 & 94,4 & 91,7 & 101,9 & 114,2 & 107,3 \\
\hline Dia 54 & Viernes & 80,3 & 100,7 & 87,8 & 82,1 & 77,6 & 75,7 & 79,7 & 89,6 & 86,3 \\
\hline Dia 57 & Lunes & 58,6 & 81,5 & 88,3 & 90,2 & 90,3 & 89,1 & 90,3 & 94,3 & 94,9 \\
\hline Dia 58 & Martes & 63,5 & 82,8 & 91,3 & 94,7 & 90,8 & 86,6 & 86,6 & 90,9 & 90,2 \\
\hline Dia 59 & Miércoles & 64,2 & 83,5 & 88,9 & 87,8 & 81,3 & 78,3 & 81,8 & 91,7 & 24,8 \\
\hline Dia 60 & Jueves & 70,8 & 88,6 & 90,8 & 92,4 & 86,4 & 84,5 & 88,9 & 95,3 & 92,8 \\
\hline Dia 61 & Viernes & 71,0 & 91,7 & 93,2 & 87,8 & 83,3 & 80,9 & 85,3 & 94,5 & 99,7 \\
\hline Dia 64 & Lunes & 43,8 & 94,0 & 54,1 & 55,0 & 86,0 & 100,7 & 82,8 & 60,9 & 61,9 \\
\hline Dia 65 & Martes & 63,3 & 85,6 & 59,0 & 62,2 & 111,6 & 83,8 & 82,3 & 90,4 & 92,6 \\
\hline Dia 66 & Miércoles & 66,3 & 88,4 & 89,1 & 85,3 & 80,7 & 77,1 & 81,9 & 92,8 & 88,8 \\
\hline Dia 67 & Jueves & 63,4 & 84,6 & 86,7 & 82,4 & 77,9 & 77,9 & 80,9 & 89,1 & 89,4 \\
\hline Dia 68 & Viernes & 66,9 & 90,3 & 88,8 & 77,1 & 71,3 & 71,8 & 77,3 & 90,1 & 91,8 \\
\hline Dia 71 & Lunes & 63,4 & 85,5 & 88,2 & 88,5 & 85,7 & 85,7 & 88,1 & 94,8 & 91,3 \\
\hline Dia 72 & Martes & 64,7 & 87,7 & 91,7 & 91,8 & 90,4 & 88,3 & 87,1 & 94,0 & 96,4 \\
\hline Dia 73 & Miércoles & 65,8 & 92,3 & 92,7 & 88,3 & 82,9 & 79,1 & 82,8 & 91,7 & 94,4 \\
\hline Dia 74 & Jueves & 68,1 & 89,2 & 91,5 & 84,4 & 76,0 & 83,8 & 83,9 & 94,8 & 94,0 \\
\hline Dia 75 & Viernes & 68,6 & 93,0 & 91,8 & 82,9 & 76,1 & 80,5 & 75,2 & 76,3 & 82,3 \\
\hline Dia 78 & Lunes & 44,5 & 62,8 & 82,8 & 102,5 & 109,8 & 107,1 & 99,0 & 80,5 & 77,1 \\
\hline Dia 79 & Martes & 56,8 & 77,8 & 91,1 & 98,3 & 95,2 & 91,8 & 89,6 & 94,4 & 97,8 \\
\hline Dia 80 & Miércoles & 62,1 & 84,8 & 86,8 & 86,7 & 80,2 & 78,6 & 82,6 & 91,7 & 91,9 \\
\hline Dia 81 & Jueves & 62,7 & 89,3 & 96,4 & 91,8 & 90,0 & 90,3 & 89,1 & 96,9 & 94,9 \\
\hline Dia 82 & Viernes & 69,1 & 94,7 & 94,3 & 84,9 & 76,1 & 75,9 & 86,1 & 94,5 & 97,1 \\
\hline Dia 85 & Lunes & 62,0 & 81,9 & 89,1 & 91,3 & 90,9 & 88,3 & 89,9 & 96,4 & 97,4 \\
\hline Dia 86 & Martes & 64,3 & 84,4 & 88,5 & 89,8 & 92,0 & 86,5 & 87,4 & 94,1 & 95,5 \\
\hline Dia 87 & Miércoles & 64,7 & 84,3 & 89,9 & 88,6 & 86,3 & 84,1 & 85,1 & 93,8 & 96,9 \\
\hline Dia 88 & Jueves & 65,0 & 84,9 & 89,3 & 87,0 & 77,6 & 75,8 & 84,5 & 90,6 & 92,7 \\
\hline Dia 89 & Viernes & 62,8 & 84,3 & 88,3 & 84,2 & 74,2 & 72,1 & 77,4 & 90,3 & 93,8 \\
\hline Dia 92 & Lunes & 64,6 & 83,9 & 89,9 & 89,3 & 87,8 & 84,9 & 88,7 & 95,3 & 96,5 \\
\hline Dia 93 & Martes & 63,3 & 83,7 & 89,3 & 91,0 & 91,7 & 86,3 & 86,0 & 92,2 & 95,7 \\
\hline Dia 94 & Miércoles & 63,9 & 86,8 & 89,4 & 86,9 & 85,3 & 82,7 & 86,4 & 91,3 & 94,7 \\
\hline Dia 95 & Jueves & 63,8 & 86,3 & 90,6 & 67,9 & 28,6 & 120,3 & 98,8 & 95,3 & 96,6 \\
\hline Dia 96 & Viernes & 66,0 & 89,6 & 87,8 & 80,9 & 84,2 & 74,7 & 86,4 & 92,1 & 93,8 \\
\hline Dia 99 & Lunes & 65,8 & 86,8 & 92,8 & 91,8 & 90,2 & 85,9 & 89,1 & 98,3 & 97,5 \\
\hline Dia 100 & Martes & 64,9 & 85,0 & 94,4 & 89,5 & 87,8 & 78,3 & 90,1 & 93,7 & 96,6 \\
\hline Dia 101 & Miércoles & 63,3 & 91,8 & 93,0 & 88,8 & 96,3 & 83,3 & 86,3 & 92,4 & 94,8 \\
\hline Dia 102 & Jueves & 65,0 & 82,1 & 86,7 & 84,5 & 79,3 & 85,4 & 87,0 & 92,9 & 102,2 \\
\hline Dia 103 & Viernes & 47,7 & 62,3 & 85,1 & 100,1 & 109,5 & 106,8 & 99,4 & 84,0 & 82,3 \\
\hline Dia 106 & Lunes & 44,6 & 57,8 & 80,6 & 91,8 & 90,3 & 83,5 & 76,0 & 69,0 & 66,2 \\
\hline Dia 107 & Martes & 63,7 & 75,5 & 92,2 & 100,3 & 101,8 & 101,4 & 100,5 & 99,3 & 99,7 \\
\hline Dia 108 & Miércoles & 58,6 & 70,5 & 78,0 & 86,2 & 83,2 & 78,3 & 85,3 & 91,3 & 96,1 \\
\hline
\end{tabular}


TABLA B

Modelo diurno

\begin{tabular}{|c|c|c|c|c|c|c|c|c|c|c|}
\hline \multicolumn{2}{|c|}{ DÍA } & $7-8 \mathrm{~h}$ & $8-9 \mathrm{~h}$ & $9-10 \mathrm{~h}$ & $10-11 \mathrm{~h}$ & $11-12 \mathrm{~h}$ & $12-13 \mathrm{~h}$ & $13-14 \mathrm{~h}$ & $14-15 \mathrm{~h}$ & $15-16 \mathrm{~h}$ \\
\hline Dia 109 & Jueves & 63,1 & 75,8 & 85,8 & 92,2 & 85,1 & 81,8 & 92,7 & 95,5 & 99,0 \\
\hline Dia 110 & Viernes & 60,8 & 75,4 & 83,1 & 87,4 & 82,3 & 78,8 & 81,8 & 90,7 & 99,9 \\
\hline Dia 113 & Lunes & 48,4 & 61,3 & 76,1 & 101,2 & 112,1 & 110,9 & 102,3 & 90,3 & 87,8 \\
\hline Dia 114 & Martes & 65,5 & 75,1 & 86,0 & 94,5 & 90,3 & 81,6 & 104,0 & 106,6 & 107,5 \\
\hline Dia 115 & Miércoles & 67,8 & 91,5 & 92,4 & 90,3 & 87,8 & 79,7 & 81,8 & 88,7 & 89,3 \\
\hline Dia 116 & Jueves & 68,1 & 93,8 & 94,5 & 92,9 & 87,8 & 86,3 & 88,9 & 95,3 & 95,5 \\
\hline Dia 117 & Viernes & 70,7 & 95,0 & 95,3 & 84,7 & 75,8 & 75,6 & 85,0 & 92,9 & 97,8 \\
\hline Dia 120 & Lunes & 47,8 & 62,3 & 84,3 & 107,2 & 115,8 & 118,0 & 112,3 & 100,3 & 95,3 \\
\hline Dia 121 & Martes & 37,8 & 38,0 & 38,0 & 38,0 & 38,0 & 38,0 & 38,0 & 38,0 & 38,0 \\
\hline Dia 122 & Miércoles & 57,0 & 57,0 & 57,0 & 57,0 & 57,0 & 57,0 & 57,0 & 57,0 & 57,0 \\
\hline Dia 123 & Jueves & 57,0 & 57,0 & 57,0 & 57,0 & 57,0 & 57,0 & 57,0 & 57,0 & 57,0 \\
\hline Dia 124 & Viernes & 68,5 & 87,6 & 88,0 & 82,4 & 74,9 & 72,5 & 79,3 & 89,7 & 95,3 \\
\hline Dia 127 & Lunes & 67,1 & 88,0 & 85,8 & 87,4 & 86,3 & 80,2 & 89,4 & 92,8 & 94,4 \\
\hline Dia 128 & Martes & 64,6 & 85,7 & 89,4 & 89,4 & 84,3 & 82,3 & 83,7 & 90,8 & 91,6 \\
\hline Dia 129 & Miércoles & 60,2 & 79,9 & 83,5 & 79,7 & 77,4 & 76,3 & 79,3 & 89,1 & 88,8 \\
\hline Dia 130 & Jueves & 61,8 & 82,0 & 84,5 & 48,8 & 62,5 & 87,3 & 81,2 & 88,8 & 90,3 \\
\hline Dia 131 & Viernes & 62,9 & 86,3 & 83,9 & 78,3 & 71,3 & 68,8 & 78,9 & 88,8 & 92,7 \\
\hline Dia 134 & Lunes & 62,5 & 82,8 & 86,8 & 89,5 & 85,8 & 80,9 & 81,8 & 85,3 & 85,8 \\
\hline Dia 135 & Martes & 64,9 & 82,9 & 86,3 & 85,7 & 87,4 & 90,3 & 84,0 & 87,6 & 85,9 \\
\hline Dia 136 & Miércoles & 32,0 & 32,0 & 56,8 & 84,5 & 81,4 & 78,8 & 83,3 & 87,9 & 90,1 \\
\hline Dia 137 & Jueves & 61,0 & 84,3 & 92,4 & 88,0 & 81,2 & 78,8 & 84,9 & 92,0 & 92,6 \\
\hline Dia 138 & Viernes & 60,9 & 80,9 & 80,3 & 74,4 & 70,3 & 69,0 & 74,2 & 84,8 & 86,7 \\
\hline Dia 141 & Lunes & 58,4 & 79,3 & 82,5 & 83,8 & 80,2 & 78,8 & 83,2 & 90,7 & 92,8 \\
\hline Dia 142 & Martes & 64,0 & 85,5 & 90,1 & 90,3 & 84,7 & 82,8 & 93,2 & 90,6 & 94,0 \\
\hline Dia 143 & Miércoles & 61,9 & 86,5 & 87,3 & 85,8 & 77,1 & 74,5 & 78,8 & 88,7 & 91,7 \\
\hline Dia 144 & Jueves & 61,3 & 83,7 & 85,8 & 86,8 & 84,2 & 73,2 & 86,1 & 82,4 & 81,6 \\
\hline Dia 145 & Viernes & 64,8 & 87,3 & 88,6 & 81,3 & 73,3 & 72,0 & 78,3 & 89,2 & 94,7 \\
\hline Dia 148 & Lunes & 63,1 & 86,8 & 90,2 & 91,1 & 85,3 & 86,0 & 91,8 & 94,9 & 96,1 \\
\hline Dia 149 & Martes & 65,3 & 88,1 & 91,3 & 90,4 & 89,8 & 89,3 & 91,2 & 94,1 & 99,8 \\
\hline Dia 150 & Miércoles & 66,6 & 89,3 & 94,6 & 91,2 & 81,8 & 79,0 & 83,0 & 88,8 & 94,3 \\
\hline Dia 151 & Jueves & 65,2 & 89,5 & 94,7 & 93,3 & 89,0 & 84,3 & 92,3 & 96,8 & 96,0 \\
\hline Dia 152 & Viernes & 66,3 & 93,5 & 88,8 & 80,6 & 71,7 & 71,3 & 79,9 & 89,3 & 95,4 \\
\hline Dia 155 & Lunes & 62,5 & 85,2 & 86,9 & 85,8 & 82,8 & 80,8 & 81,0 & 87,8 & 97,6 \\
\hline Dia 156 & Martes & 73,0 & 90,2 & 93,5 & 89,5 & 83,0 & 80,0 & 86,3 & 93,5 & 96,6 \\
\hline Dia 157 & Miércoles & 64,2 & 88,0 & 89,9 & 86,3 & 78,3 & 77,2 & 80,8 & 89,0 & 92,4 \\
\hline Dia 158 & Jueves & 65,2 & 88,5 & 92,6 & 87,2 & 78,8 & 76,6 & 81,2 & 87,6 & 93,7 \\
\hline Dia 159 & Viernes & 66,7 & 93,1 & 89,5 & 80,6 & 71,2 & 72,8 & 74,6 & 84,1 & 93,3 \\
\hline Dia 162 & Lunes & 64,8 & 85,6 & 87,8 & 86,3 & 101,5 & 105,2 & 105,5 & 115,0 & 120,5 \\
\hline Dia 163 & Martes & 92,3 & 109,8 & 113,9 & 109,7 & 102,1 & 97,7 & 101,9 & 107,5 & 109,7 \\
\hline Dia 164 & Miércoles & 71,8 & 90,4 & 100,9 & 98,9 & 104,5 & 103,1 & 103,8 & 116,3 & 122,3 \\
\hline Dia 165 & Jueves & 70,9 & 97,4 & 117,1 & 117,3 & 113,3 & 111,8 & 115,2 & 119,3 & 123,1 \\
\hline Dia 166 & Viernes & 70,4 & 93,8 & 99,8 & 95,5 & 90,9 & 96,4 & 110,2 & 120,3 & 125,1 \\
\hline Dia 169 & Lunes & 66,8 & 89,3 & 94,7 & 91,8 & 94,4 & 121,0 & 118,1 & 122,3 & 116,9 \\
\hline Dia 170 & Martes & 71,4 & 91,8 & 106,9 & 107,3 & 103,7 & 102,3 & 110,9 & 108,5 & 112,2 \\
\hline Dia 171 & Miércoles & 68,6 & 89,3 & 102,6 & 98,6 & 96,3 & 94,1 & 96,8 & 110,8 & 118,2 \\
\hline Dia 172 & Jueves & 68,3 & 92,3 & 102,3 & 101,4 & 97,3 & 96,0 & 91,8 & 97,3 & 105,8 \\
\hline Dia 173 & Viernes & 72,3 & 88,8 & 112,7 & 115,3 & 110,5 & 105,8 & 92,8 & 103,8 & 107,1 \\
\hline Dia 176 & Lunes & 70,8 & 87,1 & 101,4 & 99,7 & 94,6 & 98,8 & 104,6 & 99,7 & 99,9 \\
\hline Dia 177 & Martes & 70,9 & 79,3 & 95,8 & 97,3 & 99,6 & 101,0 & 102,0 & 105,1 & 100,4 \\
\hline Dia 178 & Miércoles & 62,4 & 63,0 & 63,0 & 63,0 & 63,0 & 63,0 & 63,0 & 63,0 & 63,0 \\
\hline Dia 179 & Jueves & 65,2 & 98,0 & 98,9 & 96,8 & 97,7 & 92,5 & 87,7 & 90,3 & 94,8 \\
\hline Dia 180 & Viernes & 64,1 & 80,8 & 98,5 & 95,2 & 82,9 & 85,1 & 84,8 & 93,6 & 97,1 \\
\hline
\end{tabular}


TABLA C

Modelo tarde

\begin{tabular}{|c|c|c|c|c|c|c|c|c|c|}
\hline & DIA & $16-17 \mathrm{~h}$ & $17-18 \mathrm{~h}$ & $18-19 \mathrm{~h}$ & $19-20 \mathrm{~h}$ & $20-21 \mathrm{~h}$ & $21-22 \mathrm{~h}$ & $22-23 \mathrm{~h}$ & $23-24 \mathrm{~h}$ \\
\hline Dia 1 & Lunes & 83,9 & 76,3 & 81,7 & 75,7 & 73,6 & 73,4 & 72,6 & 63,8 \\
\hline Dia 2 & Martes & 85,8 & 79,9 & 76,2 & 81,1 & 85,7 & 88,8 & 78,8 & 64,0 \\
\hline Dia 3 & Miercoles & 82,8 & 76,9 & 77,2 & 80,3 & 85,7 & 89,9 & 82,1 & 64,9 \\
\hline Dia 4 & Jueves & 97,2 & 80,8 & 80,4 & 81,9 & 85,5 & 86,3 & 82,6 & 67,3 \\
\hline Dia 5 & Viernes & 94,4 & 90,2 & 92,3 & 91,5 & 93,3 & 85,4 & 70,4 & 64,4 \\
\hline Dia 8 & Lunes & 115,1 & 108,1 & 109,2 & 112,9 & 116,3 & 117,6 & 111,8 & 97,4 \\
\hline Dia 9 & Martes & 80,4 & 72,6 & 74,3 & 83,1 & 87,0 & 92,3 & 80,5 & 63,3 \\
\hline Dia 10 & Miércoles & 77,8 & 72,7 & 75,0 & 81,8 & 89,3 & 91,8 & 83,1 & 63,8 \\
\hline Dia 11 & Jueves & 80,3 & 71,3 & 71,2 & 80,8 & 86,8 & 90,2 & 79,3 & 63,1 \\
\hline Dia 12 & Viernes & 76,8 & 73,8 & 72,3 & 77,6 & 84,1 & 84,8 & 73,8 & 61,8 \\
\hline Dia 15 & Lunes & 76,8 & 70,4 & 68,3 & 76,5 & 82,3 & 86,1 & 76,3 & 60,8 \\
\hline Dia 16 & Martes & 79,6 & 71,3 & 72,9 & 81,6 & 87,3 & 92,5 & 77,9 & 60,9 \\
\hline Dia 17 & Miércoles & 78,5 & 71,2 & 72,3 & 81,7 & 87,8 & 91,4 & 78,5 & 62,0 \\
\hline Dia 18 & Jueves & 76,5 & 72,7 & 72,7 & 76,3 & 86,0 & 87,6 & 76,4 & 63,2 \\
\hline Dia 19 & Viernes & 81,2 & 76,5 & 75,8 & 82,5 & 88,6 & 87,5 & 75,2 & 62,5 \\
\hline Dia 22 & Lunes & 77,3 & 71,3 & 71,1 & 79,3 & 87,5 & 87,8 & 76,0 & 60,7 \\
\hline Dia 23 & Martes & 68,8 & 88,3 & 75,4 & 83,8 & 91,8 & 94,0 & 79,3 & 60,4 \\
\hline Dia 24 & Miércoles & 79,7 & 75,3 & 73,6 & 86,4 & 92,1 & 94,3 & 80,3 & 65,7 \\
\hline Dia 25 & Jueves & 79,8 & 74,9 & 73,3 & 80,2 & 91,5 & 93,8 & 81,8 & 65,5 \\
\hline Dia 26 & Viernes & 84,5 & 79,1 & 78,7 & 85,7 & 92,4 & 91,7 & 79,8 & 67,2 \\
\hline Dia 29 & Lunes & 85,9 & 86,0 & 82,1 & 86,1 & 91,0 & 91,8 & 80,3 & 66,6 \\
\hline Dia 30 & Martes & 83,8 & 79,8 & 77,4 & 89,2 & 94,1 & 93,9 & 83,9 & 67,8 \\
\hline Dia 31 & Miércoles & 85,4 & 79,4 & 76,7 & 86,8 & 95,4 & 97,5 & 85,3 & 69,2 \\
\hline Dia 32 & Jueves & 87,6 & 80,1 & 77,6 & 85,5 & 93,8 & 94,7 & 84,1 & 69,3 \\
\hline Dia 33 & Viernes & 122,8 & 116,8 & 115,0 & 120,0 & 123,3 & 123,8 & 116,1 & 107,6 \\
\hline Dia 36 & Lunes & 89,7 & 81,2 & 79,2 & 89,0 & 94,2 & 98,9 & 88,3 & 71,9 \\
\hline Dia 37 & Martes & 86,8 & 81,5 & 81,1 & 90,5 & 97,4 & 99,9 & 90,3 & 71,9 \\
\hline Dia 38 & Miércoles & 86,5 & 81,3 & 79,9 & 91,7 & 97,8 & 100,4 & 89,8 & 72,7 \\
\hline Dia 39 & Jueves & 89,3 & 81,7 & 82,5 & 90,3 & 96,5 & 99,6 & 89,7 & 74,0 \\
\hline Dia 40 & Viernes & 95,3 & 87,1 & 87,3 & 93,1 & 96,3 & 97,2 & 84,0 & 72,9 \\
\hline Dia 43 & Lunes & 89,8 & 84,2 & 83,3 & 90,1 & 97,5 & 99,2 & 87,1 & 71,9 \\
\hline Dia 44 & Martes & 90,2 & 86,3 & 85,3 & 92,6 & 100,7 & 101,5 & 90,8 & 75,9 \\
\hline Dia 45 & Miércoles & 84,8 & 82,1 & 82,2 & 89,8 & 96,4 & 97,5 & 88,3 & 72,8 \\
\hline Dia 46 & Jueves & 87,5 & 82,8 & 81,3 & 89,1 & 96,6 & 97,3 & 87,0 & 73,7 \\
\hline Dia 47 & Viernes & 98,7 & 87,6 & 86,7 & 92,1 & 96,1 & 98,4 & 90,4 & 74,6 \\
\hline Dia 50 & Lunes & 90,9 & 83,5 & 82,9 & 88,8 & 94,8 & 97,3 & 86,2 & 71,2 \\
\hline Dia 51 & Martes & 89,3 & 81,7 & 83,5 & 91,9 & 99,1 & 98,3 & 87,0 & 74,7 \\
\hline Dia 52 & Miércoles & 88,1 & 82,8 & 81,8 & 89,9 & 99,8 & 99,1 & 88,3 & 72,8 \\
\hline Dia 53 & Jueves & 90,8 & 82,9 & 82,5 & 90,5 & 99,3 & 99,8 & 89,1 & 73,4 \\
\hline Dia 54 & Viernes & 71,1 & 72,3 & 73,3 & 79,3 & 85,8 & 84,7 & 72,1 & 58,5 \\
\hline Dia 57 & Lunes & 78,9 & 71,3 & 68,8 & 77,6 & 86,6 & 85,2 & 71,5 & 56,8 \\
\hline Dia 58 & Martes & 76,1 & 69,8 & 67,1 & 76,4 & 87,6 & 88,9 & 74,7 & 56,1 \\
\hline Dia 59 & Miércoles & 0,0 & 23,4 & 139,5 & 98,4 & 92,0 & 86,0 & 76,8 & 61,2 \\
\hline Dia 60 & Jueves & 75,9 & 70,0 & 69,7 & 79,6 & 87,3 & 88,8 & 78,3 & 62,7 \\
\hline Dia 61 & Viernes & 85,8 & 79,8 & 77,9 & 86,2 & 92,3 & 92,3 & 81,1 & 66,6 \\
\hline Dia 64 & Lunes & 78,5 & 46,6 & 102,3 & 88,7 & 88,5 & 88,0 & 74,8 & 59,1 \\
\hline Dia 65 & Martes & 72,8 & 67,2 & 65,7 & 74,3 & 91,2 & 89,3 & 74,2 & 59,5 \\
\hline Dia 66 & Miércoles & 74,3 & 67,5 & 67,8 & 76,2 & 88,8 & 87,3 & 75,1 & 57,1 \\
\hline Dia 67 & Jueves & 73,1 & 67,3 & 64,3 & 74,3 & 87,1 & 87,5 & 74,3 & 59,2 \\
\hline Dia 68 & Viernes & 79,8 & 71,4 & 70,5 & 78,4 & 87,1 & 85,8 & 74,0 & 58,9 \\
\hline Dia 71 & Lunes & 78,7 & 69,8 & 69,2 & 75,9 & 87,3 & 89,9 & 76,3 & 58,9 \\
\hline Dia 72 & Martes & 78,5 & 74,7 & 73,8 & 80,3 & 91,3 & 92,0 & 76,8 & 59,9 \\
\hline Dia 73 & Miércoles & 77,6 & 73,3 & 72,3 & 78,6 & 87,6 & 91,1 & 77,2 & 60,9 \\
\hline Dia 74 & Jueves & 77,8 & 71,0 & 69,2 & 76,0 & 86,9 & 88,9 & 76,2 & 60,1 \\
\hline Dia 75 & Viernes & 98,6 & 78,2 & 75,1 & 80,8 & 88,2 & 86,8 & 74,3 & 61,2 \\
\hline Dia 78 & Lunes & 74,8 & 71,0 & 71,3 & 69,9 & 69,9 & 67,6 & 62,1 & 53,3 \\
\hline Dia 79 & Martes & 80,2 & 77,8 & 69,7 & 78,0 & 85,8 & 90,6 & 73,9 & 56,1 \\
\hline Dia 80 & Miércoles & 74,8 & 68,4 & 70,5 & 78,0 & 93,3 & 93,5 & 78,8 & 59,8 \\
\hline Dia 81 & Jueves & 79,9 & 74,3 & 73,7 & 81,2 & 92,2 & 95,0 & 80,0 & 63,0 \\
\hline Dia 82 & Viernes & 83,6 & 79,3 & 77,6 & 83,8 & 89,3 & 90,3 & 79,0 & 64,3 \\
\hline Dia 85 & Lunes & 79,5 & 73,2 & 70,9 & 78,0 & 88,8 & 93,5 & 82,0 & 64,1 \\
\hline Dia 86 & Martes & 80,4 & 74,6 & 70,9 & 79,9 & 91,6 & 100,6 & 84,3 & 66,6 \\
\hline Dia 87 & Miércoles & 81,8 & 74,7 & 72,9 & 81,6 & 92,2 & 99,9 & 83,0 & 63,8 \\
\hline Dia 88 & Jueves & 66,5 & 71,9 & 67,4 & 76,4 & 87,3 & 94,6 & 80,6 & 61,5 \\
\hline Dia 89 & Viernes & 76,1 & 73,8 & 72,6 & 77,9 & 88,2 & 93,3 & 78,2 & 62,5 \\
\hline Dia 92 & Lunes & 78,7 & 73,3 & 71,2 & 78,4 & 85,0 & 91,5 & 78,0 & 59,8 \\
\hline Dia 93 & Martes & 80,5 & 73,0 & 70,1 & 81,1 & 90,6 & 92,4 & 80,4 & 62,7 \\
\hline Dia 94 & Miércoles & 78,1 & 72,8 & 70,6 & 78,8 & 93,2 & 96,5 & 78,5 & 62,6 \\
\hline Dia 95 & Jueves & 76,9 & 73,8 & 70,7 & 80,5 & 89,4 & 97,8 & 83,8 & 63,2 \\
\hline Dia 96 & Viernes & 81,1 & 77,3 & 73,8 & 82,0 & 89,9 & 90,8 & 79,6 & 65,5 \\
\hline Dia 99 & Lunes & 77,9 & 77,4 & 75,2 & 78,3 & 85,4 & 95,0 & 84,1 & 64,3 \\
\hline Dia 100 & Martes & 78,8 & 71,5 & 75,0 & 79,0 & 91,6 & 99,9 & 84,8 & 65,5 \\
\hline Dia 101 & Miércoles & 83,5 & 77,6 & 73,2 & 80,0 & 89,7 & 92,0 & 81,3 & 65,3 \\
\hline Dia 102 & Jueves & 95,7 & 87,0 & 80,4 & 82,7 & 80,8 & 85,2 & 76,8 & 61,9 \\
\hline Dia 103 & Viernes & 72,8 & 69,0 & 67,8 & 70,2 & 73,6 & 73,5 & 64,3 & 55,8 \\
\hline Dia 106 & Lunes & 61,8 & 64,8 & 71,1 & 83,1 & 95,9 & 105,3 & 83,8 & 64,0 \\
\hline Dia 107 & Martes & 85,6 & 80,3 & 74,0 & 83,1 & 88,6 & 90,9 & 79,8 & 64,6 \\
\hline Dia 108 & Miércoles & 79,6 & 74,0 & 70,3 & 74,7 & 85,0 & 88,9 & 78,8 & 65,1 \\
\hline Dia 109 & Jueves & 81,4 & 76,7 & 73,2 & 81,6 & 87,8 & 92,2 & 83,3 & 66,0 \\
\hline
\end{tabular}


TABLA C

Modelo tarde

\begin{tabular}{|c|c|c|c|c|c|c|c|c|c|}
\hline & IA & $16-17 \mathrm{~h}$ & $17-18 \mathrm{~h}$ & $18-19 \mathrm{~h}$ & $19-20 \mathrm{~h}$ & $20-21 \mathrm{~h}$ & $21-22 \mathrm{~h}$ & $22-23 \mathrm{~h}$ & $23-24 \mathrm{~h}$ \\
\hline Dia 110 & Viernes & 87,6 & 78,0 & 74,0 & 82,2 & 88,0 & 90,8 & 80,8 & 64,6 \\
\hline Dia 113 & Lunes & 85,0 & 79,3 & 81,5 & 78,2 & 73,2 & 75,5 & 74,1 & 66,3 \\
\hline Dia 114 & Martes & 85,2 & 78,3 & 72,7 & 79,8 & 92,7 & 103,6 & 87,3 & 67,8 \\
\hline Dia 115 & Miércoles & 100,6 & 80,7 & 73,7 & 80,8 & 93,0 & 105,6 & 88,3 & 67,3 \\
\hline Dia 116 & Jueves & 80,3 & 75,6 & 72,2 & 78,8 & 90,2 & 99,4 & 85,9 & 65,9 \\
\hline Dia 117 & Viernes & 81,8 & 77,8 & 75,4 & 81,8 & 88,3 & 94,1 & 82,7 & 66,7 \\
\hline Dia 120 & Lunes & 86,9 & 82,5 & 86,3 & 86,1 & 81,7 & 78,0 & 78,3 & 63,2 \\
\hline Dia 121 & Martes & 38,0 & 38,0 & 38,0 & 38,0 & 38,0 & 38,0 & 38,0 & 38,0 \\
\hline Dia 122 & Miércoles & 57,0 & 57,0 & 57,0 & 57,0 & 57,0 & 57,0 & 57,0 & 57,0 \\
\hline Dia 123 & Jueves & 57,0 & 57,0 & 57,0 & 57,0 & 57,0 & 57,0 & 57,0 & 57,0 \\
\hline Dia 124 & Viernes & 77,1 & 76,2 & 72,5 & 79,3 & 86,8 & 92,7 & 81,8 & 67,6 \\
\hline Dia 127 & Lunes & 72,8 & 74,1 & 63,9 & 74,0 & 85,3 & 91,8 & 81,6 & 61,3 \\
\hline Dia 128 & Martes & 76,2 & 67,7 & 64,4 & 74,5 & 89,0 & 92,3 & 78,9 & 61,8 \\
\hline Dia 129 & Miércoles & 73,0 & 67,5 & 66,0 & 77,1 & 89,1 & 89,7 & 74,3 & 60,2 \\
\hline Dia 130 & Jueves & 72,0 & 66,5 & 63,8 & 71,9 & 82,6 & 89,4 & 77,4 & 60,0 \\
\hline Dia 131 & Viernes & 77,8 & 75,3 & 72,8 & 81,1 & 87,1 & 92,8 & 80,3 & 62,7 \\
\hline Dia 134 & Lunes & 69,8 & 85,2 & 66,3 & 76,8 & 83,2 & 89,4 & 79,5 & 60,3 \\
\hline Dia 135 & Martes & 69,1 & 64,2 & 63,1 & 75,7 & 84,5 & 97,7 & 80,6 & 57,4 \\
\hline Dia 136 & Miércoles & 74,5 & 69,9 & 68,3 & 77,8 & 92,1 & 97,2 & 85,8 & 62,7 \\
\hline Dia 137 & Jueves & 76,6 & 73,1 & 68,3 & 78,9 & 86,9 & 97,6 & 82,8 & 62,0 \\
\hline Dia 138 & Viernes & 71,7 & 70,1 & 68,6 & 73,3 & 79,1 & 88,5 & 78,2 & 61,7 \\
\hline Dia 141 & Lunes & 74,1 & 69,8 & 67,5 & 75,5 & 87,3 & 95,2 & 81,0 & 61,8 \\
\hline Dia 142 & Martes & 75,2 & 69,6 & 68,4 & 77,0 & 85,8 & 94,1 & 81,2 & 60,3 \\
\hline Dia 143 & Miércoles & 72,3 & 68,7 & 67,7 & 81,2 & 96,2 & 87,7 & 73,4 & 56,3 \\
\hline Dia 144 & Jueves & 69,1 & 65,3 & 63,9 & 72,6 & 82,9 & 92,1 & 77,4 & 59,7 \\
\hline Dia 145 & Viernes & 83,7 & 78,0 & 75,3 & 82,7 & 92,8 & 96,5 & 86,7 & 66,9 \\
\hline Dia 148 & Lunes & 79,5 & 74,3 & 71,6 & 78,8 & 92,3 & 106,2 & 89,9 & 66,3 \\
\hline Dia 149 & Martes & 78,4 & 76,7 & 70,3 & 81,5 & 95,8 & 102,9 & 91,2 & 69,5 \\
\hline Dia 150 & Miércoles & 75,4 & 76,2 & 72,5 & 81,9 & 96,3 & 108,3 & 93,5 & 67,6 \\
\hline Dia 151 & Jueves & 77,8 & 78,5 & 73,3 & 88,2 & 94,9 & 102,7 & 90,8 & 68,3 \\
\hline Dia 152 & Viernes & 85,2 & 80,6 & 75,8 & 86,7 & 92,9 & 99,2 & 84,9 & 67,3 \\
\hline Dia 155 & Lunes & 87,3 & 81,0 & 78,9 & 86,0 & 97,8 & 108,0 & 93,4 & 68,9 \\
\hline Dia 156 & Martes & 76,3 & 72,9 & 72,6 & 80,1 & 90,8 & 100,6 & 91,8 & 69,0 \\
\hline Dia 157 & Miércoles & 75,7 & 50,1 & 11,2 & 87,1 & 108,9 & 105,7 & 87,0 & 66,3 \\
\hline Dia 158 & Jueves & 78,7 & 76,2 & 73,1 & 81,0 & 87,9 & 100,1 & 91,3 & 70,8 \\
\hline Dia 159 & Viernes & 93,2 & 85,3 & 87,0 & 93,4 & 96,9 & 102,6 & 88,8 & 68,4 \\
\hline Dia 162 & Lunes & 110,8 & 100,7 & 98,7 & 104,4 & 111,8 & 116,9 & 112,1 & 97,9 \\
\hline Dia 163 & Martes & 112,2 & 99,3 & 99,2 & 99,1 & 105,7 & 116,8 & 103,6 & 86,7 \\
\hline Dia 164 & Miércoles & 115,5 & 113,4 & 105,2 & 101,9 & 111,1 & 118,2 & 112,2 & 88,7 \\
\hline Dia 165 & Jueves & 100,3 & 88,4 & 90,0 & 97,3 & 108,7 & 117,0 & 108,0 & 83,9 \\
\hline Dia 166 & Viernes & 115,9 & 100,3 & 96,2 & 104,1 & 110,3 & 115,2 & 104,8 & 81,7 \\
\hline Dia 169 & Lunes & 98,3 & 91,9 & 89,6 & 93,6 & 103,3 & 107,1 & 99,8 & 83,1 \\
\hline Dia 170 & Martes & 112,3 & 101,5 & 91,8 & 96,9 & 104,5 & 112,8 & 103,8 & 83,0 \\
\hline Dia 171 & Miércoles & 112,0 & 95,7 & 96,3 & 100,7 & 107,1 & 116,8 & 107,8 & 78,3 \\
\hline Dia 172 & Jueves & 106,8 & 88,4 & 92,1 & 87,8 & 94,9 & 105,3 & 93,0 & 77,3 \\
\hline Dia 173 & Viernes & 98,3 & 103,6 & 102,9 & 96,8 & 103,6 & 111,8 & 99,7 & 79,3 \\
\hline Dia 176 & Lunes & 85,4 & 83,8 & 89,7 & 96,7 & 103,8 & 111,1 & 106,6 & 85,4 \\
\hline Dia 177 & Martes & 92,5 & 87,3 & 90,6 & 97,5 & 107,8 & 117,9 & 108,0 & 86,0 \\
\hline Dia 178 & Miércoles & 63,0 & 63,0 & 63,0 & 63,0 & 63,0 & 63,0 & 63,0 & 63,0 \\
\hline Dia 179 & Jueves & 92,3 & 77,5 & 96,1 & 103,3 & 95,4 & 108,2 & 97,0 & 77,3 \\
\hline Dia 180 & Viernes & 102,4 & 92,1 & 96,3 & 99,3 & 102,8 & 108,0 & 97,2 & 81,2 \\
\hline
\end{tabular}




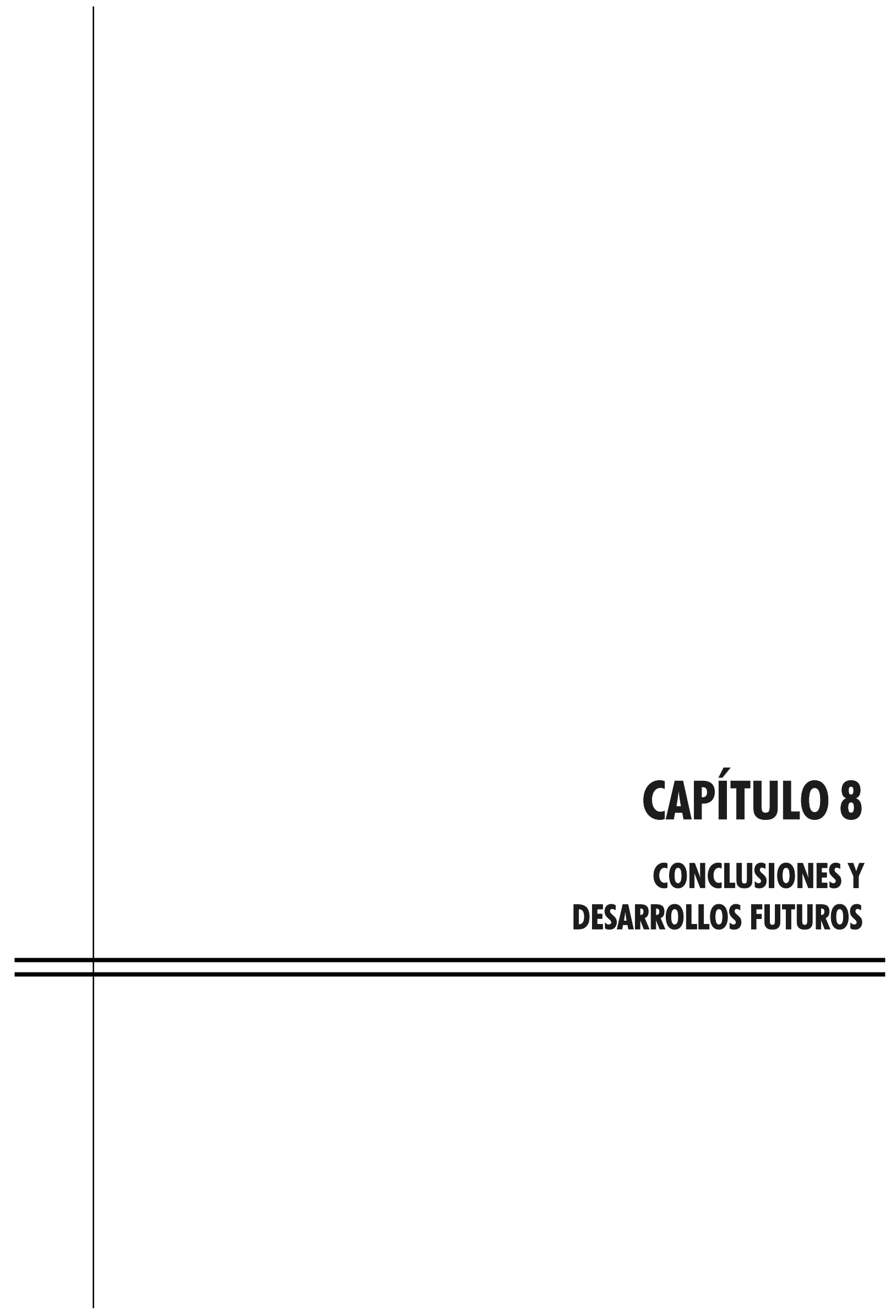




\section{CONCLUSIÓN}

\subsection{INTRODUCCIÓN}

Uno de los puntos esenciales en una adecuada gestión del agua corresponde a la medición de los caudales circulantes por las tuberías y los consumos de los usuarios. Solamente, a partir de estas mediciones es posible evaluar la calidad y cantidad disponible y utilizada de este recurso y trazar diferentes estrategias de mejora en la red de distribución de agua. Pese a que nadie discute la importancia y utilidad de la medición del agua, la realidad muestra una escasa atención por parte de las empresas y autoridades implicadas en esta materia.

Por un lado, las posibles ineficiencias en la medición siempre se pueden achacar a otros factores. Por ejemplo, un descuadre entre los volúmenes inyectados a un sector y los registrados por los contadores de los usuarios se atribuye en numerosas ocasiones a un elevado índice de fugas, sin tener en cuenta que el origen puede estar también en los errores de los equipos de medida, tanto en los caudalímetros de control como en los medidores de los usuarios. Otras veces sí se tiene en cuenta las posibles deficiencias en la medición, pero éstas se estiman sin una metodología apropiada. Precisamente uno de los objetivos de la presente Tesis consiste en aportar mejoras a los procedimientos publicados en este sentido previamente por otros autores.

Por otro lado, al final siempre es el usuario quien paga las ineficiencias en la gestión de las empresas. A la hora de elaborar las tarifas es frecuente dividir los costes entre los volúmenes registrados. Las perdidas económicas provocadas por una deficiente medición quedan camufladas, puesto que se diluyen entre el conjunto de los usuarios. El exceso de costes se reparte proporcionalmente entre los usuarios a través del precio del metro cúbico. Por ello, este modo de confeccionar las tarifas no garantiza la equidad entre los usuarios ya que unos están pagando por los consumos de otros.

En otras ocasiones, los que pagan el medidor son los propios usuarios, por lo que las empresas no tienen necesidad alguna de optimizar su renovación, salvo las derivadas de una buena imagen pública.

La Tesis doctoral presentada pretende ser una aportación de diversas técnicas y experiencias que permitan optimizar y profundizar en el conocimiento que se tiene del funcionamiento de los sistemas de medición utilizados en los abastecimientos de agua, tanto urbana como agrícola. El motivo no es otro que mostrar que una correcta medición del caudal y de los consumos de los usuarios puede mejorar significativamente la gestión técnica de estos sistemas y reducir 
las pérdidas en la red. El control del agua desde los puntos de aducción hasta los puntos finales de consumo, depende de las mediciones que se lleven a cabo en la red.

Durante el trabajo en campo se ha comprobado que uno de los principales problemas en los sistemas de medición es la incorrecta instalación de los aparatos, que afecta muy negativamente a su curva de error. Esto se refleja claramente en las recomendaciones de los fabricantes, a menudo ignoradas por los instaladores y proyectistas, que indican la posición más conveniente del instrumento y los tramos rectos que se deben establecer entre el medidor y cualquier elemento perturbador. La instalación de elementos perturbadores del flujo, cercanos al instrumento, hace que el perfil de velocidades se distorsione. Este fenómeno es otra fuente de error a tener en cuenta ya que los flujos distorsionados influyen en el funcionamiento de los instrumentos de medición generando incertidumbres no cuantificables.

Otra fuente de error es la derivada de una inadecuada selección del instrumento, tanto en cuanto al tipo de tecnología como a su calibre. Generalmente, la elección del tipo de tecnología es uno de los puntos donde existe mayor acierto atribuido a la experiencia de las empresas de agua. Los técnicos tienen en cuenta las condiciones de uso y ubicación del instrumento en cuanto a calidad del agua, existencia de fibras que obturen el movimiento de los elementos móviles o la posibilidad de descargas eléctricas. No obstante, a medida que las tecnologías de medición mejoran conviene reflexionar en qué otros factores son importantes a la hora de elegir el tipo de tecnología.

El dimensionado incorrecto sí es un problema constatado en la presente Tesis doctoral donde se han encontrado gran cantidad de instrumentos de gran calibre, en su mayoría, sobredimensionados. En ocasiones, los procedimientos empleados por las empresas de agua durante el dimensionado de los instrumentos no tienen en cuenta los caudales circulantes por el conducto. Este factor es fundamental, ya que cuando estos caudales no se ajustan al máximo al rango de medición del instrumento se producen importantes errores, tanto de medición como de funcionamiento en el tiempo. En este aspecto, los micromedidores presentan menos inconvenientes. Los contadores de agua para consumo doméstico presentan un rango de caudales más o menos acotado con lo que el dimensionado, generalmente, es apropiado. No obstante, sí se ha constatado para este tipo de tecnología, que la franja inferior de caudales muestra errores importantes que podrían subsanarse, en gran medida, con un calibre de contador inferior.

Por último, en general durante la etapa doctoral se ha advertido una falta de mantenimiento en los sistemas de medición. En general el parque de micromedidores de las ciudades estudiadas tiene una edad promedio elevada. En parte debido a que se ha encontrado un elevado número de instrumentos parados o deteriorados que no pueden ser repuestos con facilidad ya que se encuentran en el interior de viviendas. Además, es ahora cuando se comienza a cuestionar el precio del agua que se advierte cierto interés en establecer planes de renovación de instrumentos.

A veces, se infravaloran las ventajas que supone tener unos datos fiables de caudal. Por ejemplo, cuando se realiza un balance hídrico de caudales de una red de distribución es fundamental conocer de manera más o menos precisa el agua que maneja un sistema de distribución. Para ello, se parte de un caudal inyectado inicial medido en los puntos de entrada a la red o sector que puede subdividirse en diferentes niveles. Un primer nivel corresponde al caudal consumido por los usuarios tanto domésticos como no domésticos. El caudal restante o incontrolado es el que en terminología sajona se denomina unaccounted for water. Evidentemente, a medida que la gestión global de la red es mejor el volumen de agua incontrolada será menor. Un segundo nivel distribuye el caudal incontrolado anterior en dos, un caudal incontrolado fugado y otro caudal incontrolado consumido. Éste último representa el volumen de agua que se consume pero no se mide, ya sea por error de medición, por falta de medidor o por robo del mismo, a volúmenes de agua autorizados (redes de riego en parques públicos, bocas de incendio, limpieza urbana, etcétera), o incluso el volumen gastado en tomas fraudulentas.

Mejorar el control de la red comienza por medir con cierto grado de fiabilidad los caudales inyectados mediante un seguimiento de los instrumentos en los puntos de inyección, y posteriormente, discernir entre caudales consumidos tanto 
registrados como no registrados debido a errores de medición. A su vez, estimar o incluso medir los consumos autorizados permitiría acotar parte de este volumen de agua no controlado.

Por otro lado, el seguimiento en continuo de los caudales inyectados a un sistema ayuda a detectar anomalías que se producen en la red mejorando, por ejemplo, el control de fugas o roturas en tiempo real.

En este contexto, este trabajo aporta diversas experiencias encaminadas a ampliar el conocimiento de las diferentes tecnologías de medición de caudal en conductos cerrados, tanto en abastecimientos urbanos como en redes agrícolas, así como técnicas que permitan mejorar la utilización de estos sistemas, minimizando el efecto de las fuentes de error mencionadas.

\subsection{ESTUDIO DEL COMPORTAMIENTO DE LOS INSTRUMENTOS DE MEDIDA}

Durante los primeros capítulos de la Tesis doctoral, del segundo al cuarto, se lleva a cabo un estudio, bajo distintos enfoques, del comportamiento de caudalímetros y contadores de agua, investigando sobre los cambios que se puedan producir, con diferentes condiciones de funcionamiento, en su curva de error.

A continuación se desarrollan las principales aportaciones y conclusiones de cada capítulo.

\subsubsection{CAPITULO 2}

En el Capítulo 2 se realiza una breve revisión de los principios de funcionamiento de los principales instrumentos de medida de caudal y contadores de agua utilizados en los sistemas de distribución. Estos conocimientos son necesarios para entender aspectos desarrollados posteriormente durante la Tesis.

Los instrumentos de medida pueden clasificarse por tipo de uso, tecnología, calibre, etcétera. En este trabajo se ha optado, además, por agruparlos por tipo de instrumento, contador o caudalímetro, habida cuenta de la confusión constatada entre los técnicos. Por definición, un contador es un instrumento que totaliza el volumen de agua que circula por su interior mediante la integración del caudal en el tiempo. En cambio, un caudalímetro proporciona el caudal instantáneo circulante en el instante de la observación.

En el ámbito de los contadores, una de las innovaciones introducidas durante estos años, interesante de remarcar, han sido los contadores electrónicos frente a los tradicionales. Su principal atractivo es su capacidad de almacenamiento y análisis de las medidas de consumo de agua. Estos datos son información muy valiosa para la empresa de agua. Por ejemplo, permite investigar sobre los hábitos de consumo de los usuarios lo que facilita su posterior dimensionado y selección. También, puede analizar las ventajas del uso de aparatos de bajo consumo sin necesidad de instalar dataloggers. Estos aparatos suponen un avance en la gestión de las facturaciones de un consumidor en los sucesivos periodos de pago.

Los contadores y caudalímetros, como cualquier instrumento de medida, son susceptibles de cometer errores. En este capítulo se describen las diferentes fuentes de error que pueden influir en la medición del caudal, o de los consumos de agua, y que generan errores que se pueden agrupar en dos categorías: errores sistemáticos y errores aleatorios. Uno de los objetivos de cualquier medición consiste en reducir la magnitud de los errores cometidos.

En este sentido, cabe señalar que los errores sistemáticos pueden ser cuantificados y eliminados de forma relativamente sencilla mediante procedimientos de calibración, tanto en laboratorio como in situ, ya que su magnitud es aproximadamente constante para unas condiciones fijas de funcionamiento. La sedimentación de partículas de arena en el cuerpo de un contador o caudalímetro, la distorsión en el perfil de velocidades entrante provocada por una válvula cercana al instrumento 
de medida, la posible deformación de la conducción o, incluso, una posición de montaje incorrecta son ejemplos claros de este tipo de error.

Por el contrario, los errores aleatorios son más difíciles de eliminar ya que ocurren de forma circunstancial sin seguir un patrón fijo. La magnitud y signo de los errores aleatorios cambia constantemente. En este sentido, errores producidos por un ruido eléctrico que interfiere en la señal de un caudalímetro electromagnético, o una mala conexión a tierra, puede ocasionar errores aleatorios. En estos casos, el promediado de varias medidas, suponiendo que la variable observada no ha sufrido cambio, puede ayudar a reducir la magnitud del error. No obstante, otros errores, como los debidos a una turbina temporalmente atascada, no pueden reducirse mediante este procedimiento y deben ser detectados mediante un análisis detallado de los datos.

\subsubsection{CAPITULO 3}

Tras la descripción de cada uno de los aparatos y de los conceptos previos relativos a la medida de caudal, el Capítulo 3 presenta un detallado estudio en laboratorio del comportamiento de diversos tipos de contadores de agua. Este apartado incluye el análisis, tanto de contadores de uso doméstico (micromedidores) como de uso industrial, comercial o de riego (macromedidores), de la estabilidad de la curva de error frente a diversas variables.

En primer lugar se ha cuantificado la influencia de la posición de instalación (horizontal, vertical o inclinada) en la curva de error de los micromedidores. En este sentido se ha comprobado que el efecto de la posición de instalación sobre la curva de error es más acentuado a caudales bajos, donde su comportamiento es más susceptible de verse afectado. A estos caudales el par motriz del agua es reducido por lo que cualquier alteración en el momento resistente de la turbina cambia significativamente el punto de equilibrio, y consecuentemente la magnitud del error.

Por otro lado se ha comprobado cómo el desgaste de elementos mecánicos del contador altera el momento resistente de la turbina acusándose dicha variación principalmente en el rango inferior de caudales. No obstante, en algunos casos el efecto del mayor rozamiento de las piezas móviles puede extenderse a todo el rango.

La calidad del agua es otra variable que afecta muy negativamente a los instrumentos de medida llegando incluso, en ocasiones, a bloquear totalmente el medidor. Por ejemplo, las deposiciones moderadas de cal en el interior del cuerpo de un contador 0 el aire dentro de la tubería son fenómenos habituales que producen, generalmente, sobrecontaje del volumen consumido por el usuario, afectando prácticamente por igual a todos los caudales. No obstante a largo plazo, puede llegar a bloquearse totalmente la turbina.

Se ha observado en los ensayos de la curva de error en detalle, para diferentes modelos nuevos de una misma tecnología, un comportamiento muy variable a caudales bajos. La repetibilidad encontrada, incluso, para un mismo aparato es significativamente inferior en esta franja de medida. Esta conclusión tiene efectos muy importantes a la hora de diseñar los procedimientos de ensayo de los contadores, por ser, precisamente en este rango de caudales donde interesa caracterizar de la mejor forma posible el comportamiento de los mismos.

Otra de las conclusiones que se pueden extraer de los resultados de los ensayos en detalle es la evolución de la curva de error con el caudal en el rango inferior. En estas curvas en detalle se aprecia que, en los contadores de clase $\mathrm{C}$ de chorro único, el error decrece rápidamente desde el caudal de arranque, pasando de un error cercano al -70\% a dicho caudal a un error de $-5 \%$ en aproximadamente $6 \mathrm{l} / \mathrm{h}$. El incremento del caudal necesario para obtener esta variación del error en clase $B$ es mayor, de aproximadamente $10 \mathrm{l} / \mathrm{h}$.

Otro punto clave que ha consumido un tiempo de estudio significativo es la determinación de la evolución de la curva de error de los contadores en el tiempo. Como se ha comentado, el deterioro de la curva produce errores sistemáticos que 
evolucionan en el tiempo y que es necesario conocer para poder corregirlos. El problema radica en que esta evolución es variable y depende de las condiciones de funcionamiento en campo del instrumento. Parámetros como una instalación inadecuada, la circulación de aguas de gran dureza que produzcan deposiciones calcáreas o un dimensionado incorrecto puede acelerar el proceso natural de deterioro del instrumento.

Determinar el ritmo de deterioro es relativamente sencillo. Simplemente, se debe conocer el estado de la curva de error a varios caudales en diferentes periodos de tiempo, por ejemplo, cuando el contador sale de fábrica y en intervalos de tiempo de dos o tres años.

Pero, el verdadero provecho de conocer la evolución de la curva de error en el tiempo debe aplicarse de forma global para el conjunto de micromedidores de un parque y poder estimar entre otras cosas su error promedio y su frecuencia de renovación óptima. De esta manera, en esta Tesis doctoral se han investigado seis parques de contadores de agua domésticos de diferentes abastecimientos. De estos estudios se extraen diversas conclusiones que pueden mejorar la gestión del parque de contadores:

o Como primera conclusión se evidencia la necesidad de seleccionar adecuadamente los caudales de ensayo, especialmente, la zona de caudales bajos.

o Necesidad de establecer criterios para cada nivel de deterioro. Por ejemplo, la presente Tesis doctoral ha definido como contador parado a los individuos que tienen un error de -100\% a todos los caudales de ensayo, y contador deteriorado cuando su error a 30 y $120 \mathrm{l} / \mathrm{h}$ es $-100 \%$, es decir no contabiliza consumos a estos caudales pero si a caudales superiores. Por último, contador en servicio se ha considerado el que funciona a un caudal de $120 \mathrm{l} / \mathrm{h}$. A la hora de calcular el error global es importante no mezclar los diferentes niveles de deterioro para no sesgar los resultados, debiéndose trabajar con cada grupo por separado.

o Es interesante realizar una comparativa entre modelos de un mismo abastecimiento y entre abastecimientos en los que esté instalado un mismo modelo para justificar qué variables pueden haber afectado en cada caso al ritmo de deterioro de su curva de error. Por ejemplo, en uno de los abastecimientos estudiados se observó que la calidad del agua afectaba negativamente a un determinado modelo. En este caso particular, se producía la obturación del circuito de regulación del contador, montado en paralelo, haciendo que la velocidad de impacto del agua a un determinado caudal fuese más alta y se produjesen errores positivos. En otros abastecimientos, donde la calidad del agua era mejor el comportamiento de este contador era mucho más estable en el tiempo.

o Otra conclusión que cabe destacar la importancia de un muestreo adecuado. En el estudio se aprecia que algunas de las muestras de contadores retirados, seleccionadas por los abastecimientos colaboradores, estaban sesgadas posiblemente por estar compuestas por contadores de los que se tenía sospecha de su mal funcionamiento. Por tanto, conviene resaltar que la muestra se debe seleccionar aleatoriamente para cada uno de los subgrupos extrayendo un número de individuos adecuado para obtener resultados significativos de la población.

o No conviene instalar un único modelo, sino tener cierta variedad en el parque. Se han encontrado partidas de instrumentos en mal estado de una misma marca o modelo que han tenido que ser renovados a los dos años de servicio por un mal diseño.

o En general, se ha comprobado que los contadores de chorro único tienden al subcontaje, salvo determinados modelos con características constructivas particulares. No obstante, también, se ha detectado que incrustaciones en el cuerpo del contador pueden provocar errores positivos en primera instancia, aunque finalmente, al cabo de cierto tiempo, lleguen a bloquear la turbina. 
o Es frecuente que con el tiempo, los contadores de chorro múltiple presenten a caudales superiores a $120 \mathrm{l} / \mathrm{h}$ errores positivos. El motivo se encuentra en el sistema utilizado para la regulación de la curva de error.

o La medición a largo plazo en contadores volumétricos de pistón rotativo, siempre tiende al subcontaje. Esta tecnología es muy sensible a cualquier impureza que contenga el agua dificultando el giro excéntrico del pistón y provocando fugas entre el pistón y la pared de la cámara. En cambio, con aguas de alta calidad y limpias presentan muy buenos resultados ya que no tienen el freno inicial de vencer la inercia de una turbina, mostrando caudales de arranque bajos, incluso menores que $1 / / h$.

Respecto al estudio de los contadores de mediano y gran calibre, la presente Tesis propone un seguimiento individualizado de los mismos. Estos instrumentos utilizados mayoritariamente en usos no domésticos registran mensualmente volúmenes de agua elevados, donde un error de medida relativamente pequeño puede provocar pérdidas económicas de gran magnitud. Los parámetros que pueden afectar a las características de su curva de error son, fundamentalmente, la distorsión en el perfil de velocidades a la entrada del instrumento, el dimensionado inadecuado y la calidad del agua.

Profundizando en el primer parámetro, se realizaron una serie de ensayos en laboratorio con diferentes elementos perturbadores del flujo de agua, cuantificando su incidencia sobre diversas tecnologías. De estos resultados se puede destacar los siguientes aspectos:

o La medición de un contador Woltman de eje horizontal se ve afectada cuando la distorsión del perfil de velocidades la genera una válvula de compuerta prácticamente cerrada (75\%) instalada aguas arriba del contador sin mantener tramos rectos de tubería. Según los resultados experimentales obtenidos, una distancia entre elementos ligeramente superior a tres diámetros es suficiente para moderar el flujo y conseguir una precisión aceptable. A su vez, la distorsión provocada por una válvula de mariposa aguas arriba a más de tres diámetros con diferentes aperturas o por una válvula reductora aguas abajo del contador no resultó determinante en la curva de error. Se observa, en cambio, que cuando el agua circula en sentido inverso, se pueden generar errores superiores a $\pm 10 \%$ sobre la medida de referencia, dependiendo de las características constructivas del instrumento.

o Los resultados obtenidos con el Woltman de eje vertical fueron muy positivos. La influencia de las perturbaciones sobre su error de medición es inapreciable debido a sus características constructivas especiales. En este instrumento un flujo distorsionado a la entrada no incide directamente sobre la turbina sino que sufre cambios de dirección en el interior del contador hasta llegar al elemento móvil, atenuando su influencia. Como en el Woltman de eje horizontal, sentidos inversos del flujo de agua generan errores de aproximadamente $\pm 7 \%$, aunque, en cualquier caso, depende del diseño de cada modelo.

o Los contadores de chorro único de gran calibre ensayados han demostrado que las perturbaciones del flujo no afectan a su curva de error significativamente. Las características constructivas de este contador, con un convergente en la entrada de la cámara de medición, regulariza los perfiles distorsionados no produciéndose ninguna alteración en la curva de error.

o El contador tangencial, teóricamente, por su construcción interna y disposición del elemento sensor es muy sensible a las alteraciones del flujo. El ensayo con una válvula de compuerta instalada aguas arriba del instrumento, sin mantener tramos rectos, desplaza la curva de error al $-5 \%$ de error cuando se encuentra 
totalmente abierta hasta alcanzar un -30\% con un cierre de la válvula del 75\%. La instalación de tres diámetros de tramos rectos reduce el error en torno al $15 \%$. La válvula de mariposa afecta al funcionamiento del instrumento en menor grado llegando a provocar a tres diámetros entre elementos, un error de -10\%, pudiéndose prácticamente eliminar cuando se mantienen seis diámetros aguas arriba del contador. No obstante, en este caso cabe señalar que la orientación de la lenteja de la válvula juega un papel crucial en el error de medición del contador. De este modo, si la válvula se encuentra parcialmente cerrada y la lenteja orienta el flujo hacia la turbina, los errores que se producen tienen signo positivo. Al contrario si la lenteja orienta el chorro de agua saliente de la válvula parcialmente cerrada hacia la zona inferior, los errores adoptan signo negativo.

Otras perturbaciones del flujo también afectan el correcto funcionamiento del instrumento. Así pues, la disposición cerca de un codo, una te y una reducción puede generar errores de hasta el 10\% dependiendo de la configuración de estos elementos.

Por último, este instrumento instalado en sentido inverso del flujo produce errores positivos de $+10 \%$, mientras que no presenta errores cuando se gira $90^{\circ}$ (turbina en un lateral).

o El contador proporcional, fundamentalmente diseñado para aguas sucias, tuvo un comportamiento bastante irregular ante la distorsión causada por una válvula de compuerta, mientras que la válvula de mariposa prácticamente no perturbó su curva de error. Además, se comprobó que la instalación incorrecta del filtro de entrada al contador influía muy negativamente en la curva de error.

Al igual que ocurre con los contadores de pequeño calibre la calidad del agua es otro parámetro que puede causar problemas, sobre todo, a aquellos instrumentos con partes móviles internas que pueden desgastarse $u$ obturarse al cabo de cierto tiempo. A su vez el dimensionado del instrumento es fundamental para un funcionamiento estable y longevo. En este sentido, los instrumentos utilizados en agua de riego deben estar preparados para soportar este inconveniente. Uno de los ensayos de certificación dentro del proyecto de norma prEN 14268 incluye una prueba de resistencia del instrumento al impacto de unas bolas de densidad variables y tamaño igual al 10\% del diámetro nominal de medidor.

\subsubsection{CAPITULO 4}

Comprobada la influencia de un perfil de velocidades distorsionado sobre la curva de error de diferentes tipos de macromedidores, durante el Capítulo 4 se desarrolla un método de análisis numérico, basado en técnicas de Computational Fluid Dynamics, que evalúa cualitativamente, sin necesidad de ensayos en laboratorio, cómo afectan a la curva de error ciertas distorsiones en el flujo. Estudios previos, realizados en el extranjero, aplican estas técnicas para evaluar el funcionamiento de otras tecnologías de medición, en concreto se aplicaron en el análisis del error de medición de un caudalímetro de inserción instalado aguas abajo de una perturbación.

El método presentado permite contrastar las recomendaciones facilitadas por los fabricantes sobre la necesidad de determinadas longitudes de tramos rectos para cada uno de los instrumentos analizados. En particular se simula el funcionamiento de tres instrumentos, un contador Woltman de eje horizontal, que se compara con los resultados experimentales, un caudalímetro electromagnético y uno de ultrasonidos de tiempo de tránsito.

Las simulaciones muestran resultados interesantes. Por un lado, se ha comprobado que las alteraciones en el flujo de agua afectan de forma diferente a cada uno de los instrumentos de medida, por lo que resulta crucial conocer perfectamente el principio de funcionamiento de cada aparato para poder predecir su respuesta en condiciones de trabajo no ideales. Por otro lado, es importante tener en cuenta el tipo de distorsión que genera cada elemento hidráulico. Como se ha comprobado durante los ensayos en laboratorio los resultados obtenidos para cada distorsión fueron muy diferentes. De esta forma, no 
es comparable la distorsión producida por una válvula de compuerta con la de una válvula de mariposa, esto se aprecia perfectamente en cualquiera de los gráficos de salida del análisis numérico.

Como conclusión importante de este capítulo, se observa a partir de las simulaciones que no son necesarias longitudes elevadas, superiores a diez diámetros, para reducir la influencia de las distorsiones en un contador Woltman de eje horizontal. Una longitud entre tres y cinco diámetros de tramos permite obtener resultados similares al de referencia, es decir, con un perfil de velocidades plenamente desarrollado. Por otro lado se ha comprobado que tal y como recomiendan los fabricantes, el caudalímetro electromagnético necesita una distancia mínima de cinco diámetros para acotar los errores dentro de un rango el $\pm 1 \%$.

Finalmente, se ha comprobado que los caudalímetros de ultrasonidos son los más sensibles a las distorsiones del flujo. Requieren al menos seis diámetros de tubería recta aguas arriba del caudalímetro para conseguir una medición aceptable del caudal circulante. Esta afirmación es válida siempre y cuando la perturbación no sea importante y provenga de un solo elemento como una válvula o un codo. En cambio, la respuesta del aparato de medida exige unas longitudes en tramos rectos mucho mayores ante distorsiones más acentuadas, como la provocada por una válvula de regulación o la combinación de dos codos en diferentes planos.

\subsection{APORTACIONES A LA GESTIÓN DE LOS SISTEMAS DE MEDICIÓN}

Tras una primera parte de la Tesis doctoral centrada en el estudio del comportamiento de los medidores de caudal y contadores de agua, esta segunda parte aborda aspectos que ayudan a mejorar la gestión global de estos sistemas. Se presentan estrategias aplicables a la gestión tanto de los contadores domésticos, micromedidores, como de instrumentos de mayor calibre, instalados en las conducciones del sistema o en usuarios con mayor demanda de agua.

Durante el desarrollo de la Tesis doctoral, se han observado carencias importantes en la gestión realizada por las empresas de abastecimiento urbano y las comunidades de regantes, de los instrumentos de medida. Cabe señalar que la medición en las redes de riego todavía no está suficientemente implantada como para, ni siquiera, proponer acciones de mejora en su gestión. En muchos casos en las redes de riego, simplemente plantear la instalación de contadores de agua homologados, de cualquier tipo, representa una mejora sustancial respecto a la situación actual.

A continuación se resumen las principales estrategias de mejora de los sistemas de medición propuestas en la Tesis doctoral para mejorar el control del agua que circula por las redes de distribución.

\subsubsection{CAPITULO 5}

El Capítulo 5 estudió y comparó diferentes metodologías propuestas anteriormente en la bibliografía para el cálculo del error global de medición de parque de contadores. Se proponen ciertas mejoras que reducen la incertidumbre en la estimación de dicho error global. Este error, como se ha comentado durante el epígrafe anterior, se refiere al volumen de agua no contabilizado durante un periodo de tiempo largo, de días y meses, en el que los contadores funcionan en unas condiciones de caudal muy variables, por lo que la estimación de dicho volumen no es inmediata. El cálculo del error global de un contador, y más aún el del parque de contadores, requiere una metodología adecuada que pondere la estimación de la curva de error del contador en todo su rango de funcionamiento con los caudales de consumo, también estimados, del usuario o usuarios, lo que se denomina patrón de consumo.

En una primera parte del capítulo se aborda la elección adecuada de los caudales de ensayo de un contador de agua para reproducir de la manera más fiel posible su curva de error real en todo el rango de caudales. Tras el estudio en 
profundidad de curvas de error detalladas de diferentes modelos de contador frente a curvas de error reconstruidas (linealización de la curva) mediante ensayos en laboratorio a caudales de 30, 120, 750 y $1500 \mathrm{l} / \mathrm{h}$ es posible concluir que el ensayo a un caudal de aproximadamente de $50 \mathrm{l} / \mathrm{h}$ reduce la incertidumbre en la estimación del error global de medición para los contadores de Clase B, al mejorarse sustancialmente la reconstrucción de la curva. Para los contadores de Clase C el ensayo a un caudal de $15 \mathrm{l} / \mathrm{h}$ permite reproducir de forma más aproximada su curva de error.

Además, ciertas metodologías no consideran el caudal de arranque. La determinación, por ensayo o estimación, de este caudal de arranque delimita el funcionamiento del instrumento en el rango inferior de medida. Volúmenes de agua consumidos por debajo de éste deben incluirse en su totalidad como volumen no registrado. En la presente Tesis doctoral se propone un método eficaz para estimar el caudal de arranque a partir del ensayo del error a $30 \mathrm{l} / \mathrm{h}$, 0 un caudal bajo alternativo. Asimismo, se constata que el error aproximado, cuando la turbina de un contador de chorro único empieza a moverse es de aproximadamente el - $70 \%$.

Con respecto a al volumen de agua que se consume en cada rango de caudal, es decir, el patrón de consumo del usuario, es fundamental establecer rangos de caudal estrechos en la zona donde el instrumento tiene peor funcionamiento. Por ejemplo, definir de manera detallada el consumo que se produce por debajo de $100 \mathrm{l} / \mathrm{h}$ ponderándolo con la estimación del error en dicho rango mejora significativamente el cálculo del error global. Es importante tener en cuenta que no conviene fijar rangos de caudal demasiado amplios, ya que si el error en dicho rango tiene variaciones importantes se puede estimar de forma imprecisa el error promedio en el mismo. Por ejemplo, el rango propuesto por Allender (1996) como medio incluye todo el consumo producido entre 0,25 a $2 \mathrm{gpm}(56,8-454,2 \mathrm{l} / \mathrm{h})$ en el que se supone el contador registra el consumo con un error igual al que tiene al caudal superior de dicho rango $(2 \mathrm{gpm})$. Este criterio no tiene en cuenta las posibles variaciones de la curva de error en la franja de caudales considerada.

Finalmente, tras el amplio estudio llevado a cabo en diversas poblaciones con condiciones de consumo y entornos muy diferentes se ha propuesto una clasificación de los patrones de consumo, y otra clasificación de los ritmos de deterioro en función de los ensayos de más de 1000 contadores de agua. Ambas categorizaciones, facilitan información típica sobre dichos parámetros, y permiten agilizar la estimación de error global de medición atendiendo al criterio del técnico encargado y en función de las características específicas del abastecimiento, tanto de las instalaciones como de los propios instrumentos.

\subsubsection{CAPITULO 6}

El Capítulo 6 propone una guía práctica de diferentes estrategias que pueden aplicarse para gestionar correctamente el sistema de medición de caudal de una red de distribución y aumentar tanto su eficacia como su eficiencia. El capítulo se subdivide en dos partes, una primera aborda tácticas de gestión enfocadas a los micromedidores, y una segunda desarrolla diferentes estrategias de actuación aplicables a la gestión de los macromedidores.

El desarrollo de la presente Tesis doctoral ha permitido constatar que actualmente no existe un control generalizado sobre las partidas de contadores adquiridas por las empresas de abastecimiento. De hecho, existe un grupo de trabajo de contadores en AEAS (Asociación Española de Abastecimiento de Agua), que está en proceso de elaboración de un "Pliego de recepción de contadores". El problema está en que no todos los fabricantes de contadores suministran la misma calidad, además, en ocasiones, existen lotes que pueden verse afectados tras su verificación durante el transporte o posterior manipulación.

La Tesis propone un método de control estadístico de calidad a la recepción que analiza los lotes de contadores nuevos y ayuda en la toma de decisiones en cuanto a la aceptabilidad de dicha partida. Concretamente, este trabajo considera adecuado el muestreo por variables, técnica definida en la norma internacional ISO-3951. Mediante el ensayo de una muestra de instrumentos a caudales característicos como el mínimo, transición y máximo, y fijando un nivel de aceptación 
acordado entre comprador y vendedor, se establece si la partida es aceptada o rechazada, y cual es su estado metrológico inicial.

Un segundo epígrafe analiza los costes que supone el uso de medidores de agua, y calcula el periodo óptimo de renovación de los mismos para obtener el máximo beneficio desde un punto de vista económico. Para ello, es necesario evaluar todos los costes asociados con la utilización del instrumento y buscar su mínimo.

La segunda parte de este capítulo aborda el dimensionado de instrumentos de medida de caudal, especialmente contadores de agua. Como se ha visto durante toda la Tesis doctoral, el error de estos instrumentos de medición es dependiente del caudal demandado por el consumidor. Por tanto, una adecuada elección de la capacidad de caudal del instrumento parte por ajustar al máximo su caudal nominal a las condiciones de funcionamiento de la instalación. En el caso de los contadores de agua, un infradimensionado implica que por el instrumento circulan caudales excesivamente altos para su capacidad máxima de funcionamiento, lo que puede dañar en un periodo corto de tiempo sus elementos internos, deteriorando su curva de error. Por el contrario, un contador está sobredimensionado cuando su rango de funcionamiento habitual se encuentra en la zona inferior del rango de medida donde los errores de medición son más elevados, y consecuentemente, los volúmenes de agua que quedan sin registrar son significativos. Este apartado expone técnicas, algunas de ellas desarrolladas en la bibliografía, que ayudan a dimensionar un instrumento y se realizan ciertas puntualizaciones que es conveniente considerar.

Por otra parte, en numerosas ocasiones, estos instrumentos de gran calibre se encuentran instalados en lugares de difícil accesibilidad. Esto dificulta cualquier labor encaminada a mejorar la calidad de sus medidas ya que los costes de renovación o calibración en laboratorio pueden llegar a ser muy elevados. Consecuentemente, es importante encontrar métodos alternativos que permitan verificar su estado metrológico, y las condiciones de funcionamiento de los medidores, sin necesidad de desinstalarlos ni de interrumpir el suministro de agua durante largos periodos de tiempo. Evidentemente, este chequeo o verificación in situ, no es comparable con una calibración en laboratorio pero permite determinar con cierto grado de confianza el estado metrológico del instrumento.

El último apartado plantea el seguimiento de los sistemas de macromedición evaluando la instalación, el tipo de medidor y considerando los factores que pueden afectar a su correcto funcionamiento para establecer un criterio sobre las condiciones en las que puede estar trabajando el medidor. Tras este estudio previo se proponen prácticas para verificar su estado metrológico con un grado de confianza establecido por la empresa y se exponen los inconvenientes que pueden surgir durante cada procedimiento. Finalmente, mediante un cruce adecuado de la información se podría conocer qué variables han podido influir en mayor grado en el desgaste de los aparatos.

\subsubsection{CAPITULO 7}

La finalidad principal de los instrumentos de medida, y consecuentemente uno de los objetivos finales de esta Tesis, es convertir los datos en información útil para el técnico que se encarga de la gestión de la red. Es decir, saber aprovechar las medidas de caudal para el control y mejor gestión del abastecimiento. Durante el Capítulo 7 se manejan las medidas de caudal de los macromedidores de control de sectores y redes, aplicándoles una técnica estadística novedosa en este campo, el análisis por componentes principales.

Este capítulo aporta una metodología que condensa la información recibida en el telemando para crear modelos de funcionamiento típico de la red estableciendo márgenes de variabilidad que permiten detectar de forma rápida cualquier incidencia o perturbación producida en al red que no responda a las condiciones operativas normales del sistema.

Del análisis de las medidas de caudal se extraen parámetros sensibles en la detección de anomalías, como T² Hotelling 0 la distancia al modelo, con los que se establecen los límites de control de los caudales inyectados a la red de distribución. 
Se ha realizado, también, un análisis de sensibilidad de esta técnica estadística en la que se abordan ambos métodos de detección y donde se reflejan unos porcentajes de acierto elevados con respecto a los métodos tradicionales en el reconocimiento de incidencias. Mientras que el método $\mathrm{T}^{2}$ Hotelling mejora su eficacia cuando la fuga se inicia durante las primeras horas del modelo, el método DMOD se muestra más eficaz si la fuga aparece en las horas finales del mismo. Por otro lado, se demostró que debido a la menor variabilidad de los consumos nocturnos, el método $T^{2}$ Hotelling revelaba un mayor porcentaje de acierto en dicho modelo, para un caudal de fuga similar, en comparación con el de mañana o de tarde.

Para concluir el método propuesto es de gran ayuda en la detección de anomalías o incidencias en la red. No obstante, estos modelos generados deberán ser actualizados periódicamente para preservar la eficacia del método y reproducir correctamente nuevas tendencias de consumo en la red.

\subsection{DESARROLLOS FUTUROS}

La presente Tesis doctoral deja muchas puertas abiertas para la investigación y mejora de las líneas propuestas. La primera parte aborda el comportamiento de los medidores. En este sentido, se han estudiado en profundidad los contadores domésticos, su evolución en el tiempo y los parámetros que afectan a su comportamiento en viviendas domésticas. La imposibilidad de obtener medidas en campo en instrumentos de mayor calibre 0 incluso mediciones de los consumos de grandes consumidores de agua, como hospitales, colegios, centros comerciales, etcétera, ha impedido el estudio del error global de medición generado por este tipo de aparatos y de la evolución que sufre su curva de error a lo largo de los años.

Otra propuesta para el futuro consistiría en fijar unas reglas de dimensionado relacionando el calibre del instrumento con el volumen medio de agua consumido. Para ello, conviene muestrear diferentes tipos de consumidores y extraer levantamientos del perfil de velocidades de cada uno. Por ejemplo, sería interesante medir los consumos de una muestra de hospitales o colegios para analizar el volumen que consumen a cada rango de caudales. A partir de este patrón de consumo, de igual forma que se realiza para medidores domésticos, es posible asignar al volumen promedio diario consumido el calibre de contador más adecuado y establecer tablas de dimensionado útiles.

Otro tipo de tecnología poco estudiada durante la Tesis son los contadores electrónicos y las posibles prestaciones que proporcionan. Como se comenta, los contadores electrónicos son capaces de almacenar datos que muchas veces no se utilizan, quizá porque no se dispone de tiempo suficiente para su análisis o porque no se conocen las metodologías adecuadas para convertirlos en información útil. Por ejemplo, hay contadores que dan el numero de arranques, el tiempo funcionando, los caudales de consumo, etc... y ayudarían a gestionar mejor los contadores y dar explicaciones a los usuarios en caso de algún tipo de incidencia. El desarrollo de técnicas que permitan utilizar toda la información suministrada por este tipo de contadores electrónicos es una interesante línea de investigación futura, habida cuenta de la implantación de esta nueva tecnología.

En referencia a la segunda parte de la Tesis, la gestión de los sistemas de medición comprende numerosos frentes. Durante la Tesis se han recabado algunos de ellas, pero quedan pendientes otras técnicas que pueden ser muy útiles en un futuro. Por ejemplo, el desarrollo de técnicas estadísticas que permitan gestionar los contadores eficientemente desde un sistema de información comercial que a su vez estuviese relacionado con un sistema de información geográfica. Esto permite agrupar toda la información del abastecimiento y utilizarla para establecer las causas de los errores de medida que se producen 0 , incluso, analizar el deterioro de los instrumentos a lo largo del las sucesivas facturaciones.

La depuración de la técnica estadística de análisis por componentes principales aplicada a caudales inyectados puede permitir obtener tiempo de detección de fallos más cortos. En este caso, posiblemente la generación de modelos estadísticos que definan el comportamiento de la red cada hora reduciría el nivel de fugas. Además, sería interesante implementar un software que refrescase los modelos de análisis de componentes principales cada cierto tiempo. 
La investigación realizada en la presente Tesis doctoral ha sido parcialmente financiada por el Ministerio de Ciencia y Tecnología y los Fondos FEDER en el marco del Proyecto de investigación "Propuestas metodológicas para el cálculo de la vida útil de los contadores de agua" (DPI2000-0657). 